\title{
Development of High Volume Fly Ash and/ or Slag Modified Concrete and Geopolymer Concrete as Sustainable Construction Materials
}

Soumya Sundar Chowdhury

West Virginia University

Follow this and additional works at: https://researchrepository.wvu.edu/etd

\section{Recommended Citation}

Chowdhury, Soumya Sundar, "Development of High Volume Fly Ash and/ or Slag Modified Concrete and Geopolymer Concrete as Sustainable Construction Materials" (2011). Graduate Theses, Dissertations, and Problem Reports. 4705.

https://researchrepository.wvu.edu/etd/4705

This Thesis is protected by copyright and/or related rights. It has been brought to you by the The Research Repository @ WVU with permission from the rights-holder(s). You are free to use this Thesis in any way that is permitted by the copyright and related rights legislation that applies to your use. For other uses you must obtain permission from the rights-holder(s) directly, unless additional rights are indicated by a Creative Commons license in the record and/ or on the work itself. This Thesis has been accepted for inclusion in WVU Graduate Theses, Dissertations, and Problem Reports collection by an authorized administrator of The Research Repository @ WVU. For more information, please contact researchrepository@mail.wvu.edu. 


\title{
Development of High Volume Fly Ash and/ or Slag Modified Concrete and Geopolymer Concrete as Sustainable Construction Materials
}

\author{
by \\ Soumya Sundar Chowdhury \\ Thesis submitted to the \\ College of Engineering and Mineral Resources \\ at \\ West Virginia University \\ in partial fulfillment of the requirements \\ for the degree of \\ Master of Science \\ in \\ Civil and Environmental Engineering \\ Julio F. Davalos, Ph.D., Chair \\ Indrajit Ray, Ph.D., Co-Chair \\ An Chen, Ph.D., P.E. \\ Radhey Sharma, Ph.D. \\ Department of Civil and Environmental Engineering
}

Morgantown, West Virginia

2011

Keywords: High Volume Fly Ash Concrete; Supplementary Cementitious Concrete; Geopolymer; Geopolymer Concrete; Curing temperature; Isothermal Calorimeter; Environmental impact; Leaching, Durability; Shrinkage; Life Cycle Analysis 


\title{
Abstract
}

\section{Development of High Volume Fly Ash and/ or Slag Modified Concrete and Geopolymer Concrete as Sustainable Construction Materials}

\author{
Soumya Sundar Chowdhury
}

\begin{abstract}
Although cement constitutes only about $10 \%$ to $15 \%$ of the total weight of concrete, it accounts for $6 \%$ of global $\mathrm{CO}_{2}$ emissions. The other emissions from cement plants are: particulate matter, $\mathrm{CO}, \mathrm{NO}_{\mathrm{x}}, \mathrm{SO}_{\mathrm{x}}$, total hydrocarbon, and the major wastes are cement kiln dust and water. Unfortunately cement is also an energy intensive material as 1 metric tonne of cement requires 1 million MJ of energy. Therefore, a large reduction in cement content in concrete by replacing it with other cementitious materials can make concrete a greener and sustainable material. Industrial by-products such as fly ash and ground granulated blast furnace slag (slag) are routinely used as cement replacement materials; but the replacement typically does not exceed $40 \%$ (by mass of cement). Also, recently fly ash produced from coal-fired power plants has been proposed to be declared as a hazardous waste under Resource Conservation and Recovery Act (RCRA) of Environmental Protection Agency (EPA), restricting its disposal as landfill. Considering all these factors, we produced and evaluated a number of high-strength and durable concretes by replacing cement by large volumes of fly ash from $40 \%$ to $70 \%$; and also a group of concretes using $100 \%$ fly ash, $100 \%$ slag, and 50\% fly ash $+50 \%$ slag (no portland cement) all with geopolymer binder. The objective of this study is to evaluate the effects of the beneficial use of including $40 \%$ to $100 \%$ fly ash and/or slag to produce sustainable, green, and durable concretes.

This study included evaluations of compressive strengths from 3 days to 90 days; and durability parameters such as freeze-thaw, free shrinkage, and rapid chloride permeability. Isothermal calorimetry test was conducted to characterize the early hydration reaction of these materials up to 96 hours per ASTM C 1679-09. Leaching tests were performed according to EPA TCLP 1311 on pure fly ash, pure slag, sand, limestone, crushed concretes containing fly ash and/or slag, geopolymer concretes containing fly ash and/or slag at to examine the effectiveness of containment of the heavy metal ions present in fly ash and/or slag within these concretes. The Ecological Toxicity potential was calculated and compared among different concretes. Finally, BEES 4.0 software was used to conduct the life-cycle cost (LCC), life-cycle assessment (LCA) of these concrete products.

Results showed that properly designed high volume fly ash and/or slag modified concretes and geopolymer modified concretes can produce high-strength and durable materials. The leaching tests showed that these concretes also can effectively contain the toxic heavy metal ions within their structures. The LCC and LCA results indicated that concrete products containing high volume fly ash and/or slag as replacement of cement are much more sustainable, green, and energy-efficient compared to concrete without cement replacement.
\end{abstract}




\section{Acknowledgement}

I wish to express my sincere gratitude to my advisor Dr. Julio F. Davalos for providing me the opportunity to work in this interesting project. I am deeply grateful to have him as my teacher as well as advisor. His magnificent ideas, along with his whole-hearted support guided me through the two years of my M.S. program at West Virginia University. I am grateful to him for providing me the opportunity to work with him.

I would like to thank Dr. Indrajit Ray, my co-advisor of this thesis. Without his advice and support it would not have been possible to complete this project. He was always available when I needed help from him to answer my questions, no matter what time it was. Under his supervision in the laboratory, it became much easier for me to conduct research without much previous experience. Thanks to his technical expertise and excellent advice. Now, I consider myself an expert performing many tests on concrete. Thanks to him. I consider Dr. Ray my friend, philosopher, and guide.

I would like to express my sincere gratitude to Dr. An Chen and Dr. Radhey Sharma who provided sincere support to complete my work.

I would also like to thank Dr. Xinchao Wei, Dr. William Ravenscroft, and Dr. Karen Buzby for their valuable suggestions on the analysis of samples. I would like to thank Mr. Kenneth Stewart of NRCCE for leaching tests.

I gratefully acknowledge my fellow graduate students who were always supported me, and also made my work in the office a pleasure. Working in the laboratory or in the office, it would have been hard without their support. I would also like to specially thank my friend Adam Burnley and two other student workers who helped me to conduct the laboratory tests.

I am grateful to all the friends I met while I was far away from home, because they made my work easy. I consider them like my family and I wish all the best for them.

I dedicate this work to my parents Late Jayanta Chowdhury and Suptima Choudhury, and to my all relatives those always supported me throughout my presence here. They made every effort to make me feel confident and bring up the best in me. 


\section{Table of Contents}

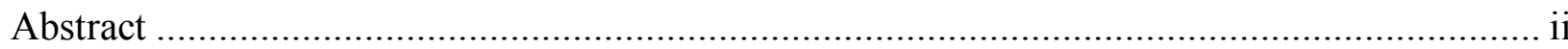

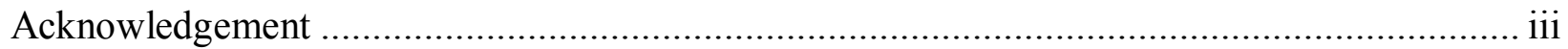

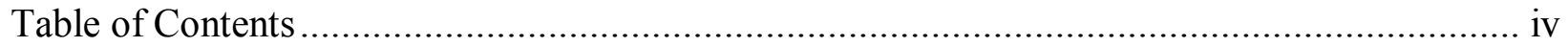

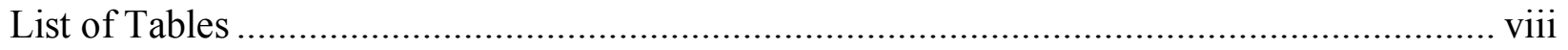

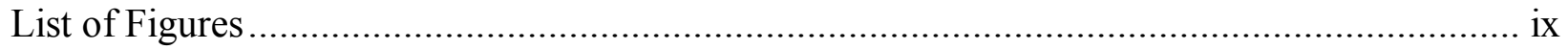

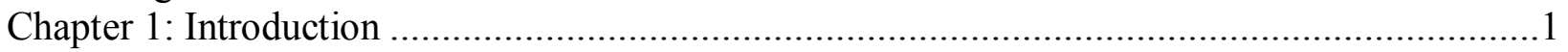

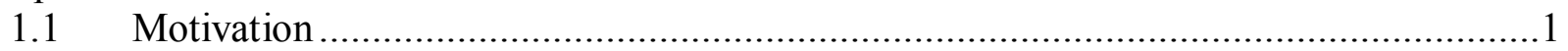

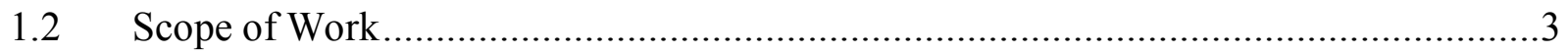

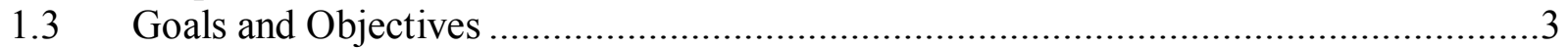

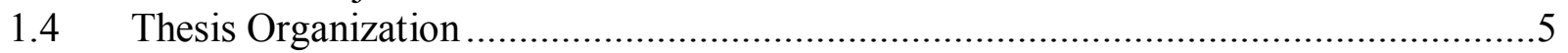

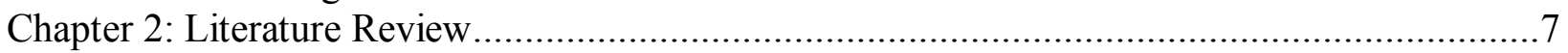

2.1 Review of Concrete with High Volume Fly Ash and Other Mineral Admixtures ...........7

2.1.1 Fresh and Hardened Properties ..........................................................................

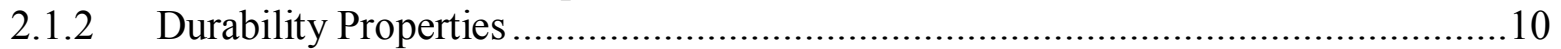

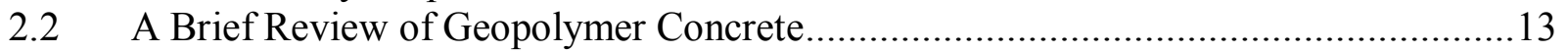

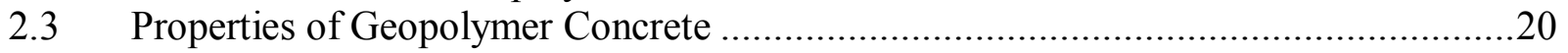

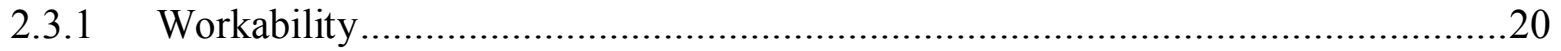

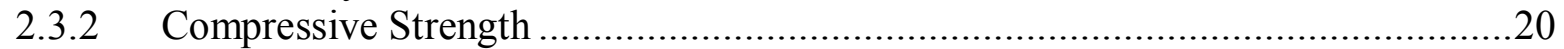

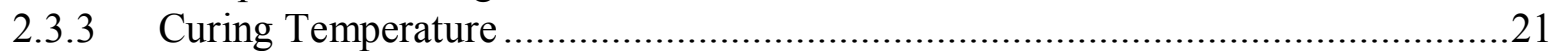

2.4 Sustainable Aspect of Concrete with High Volume of Fly ash and/or slag.................21

Chapter 3: Experimental Program for High Volume Fly Ash and/or Slag Modified Concrete ....26

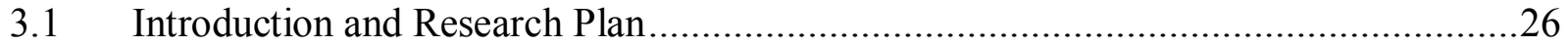

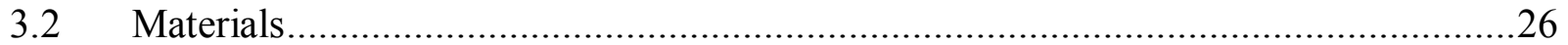

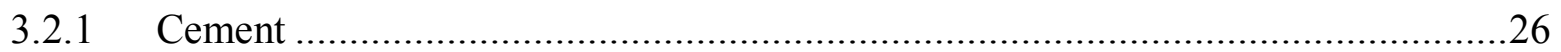

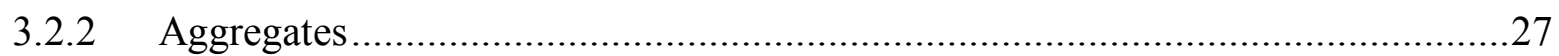

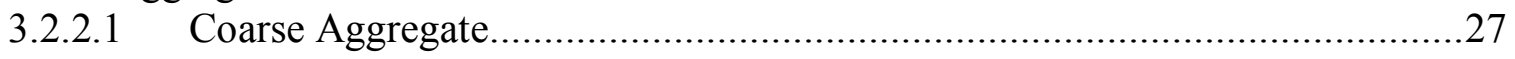

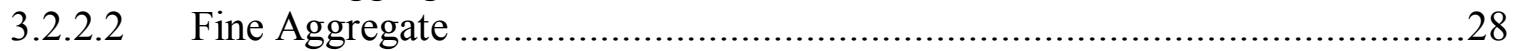

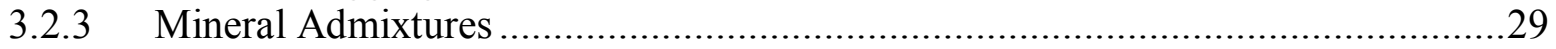

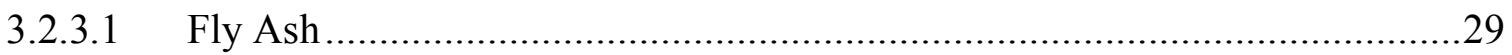

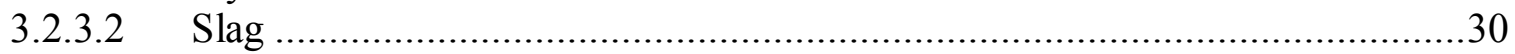

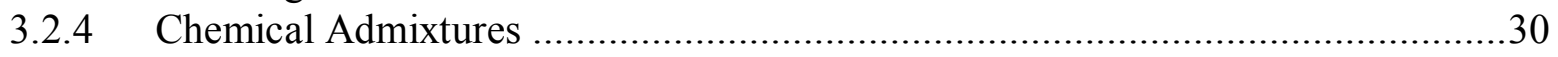

3.2.4.1 High Range Water Reducing Admixture ....................................................31

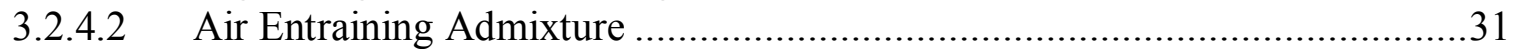

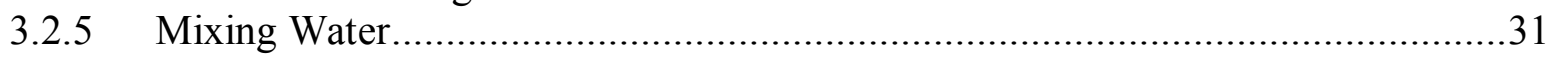

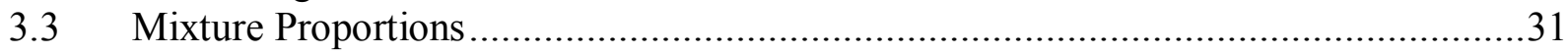

3.4 Testing Procedures of High Volume high volume fly ash and/or slag modified concrete 33

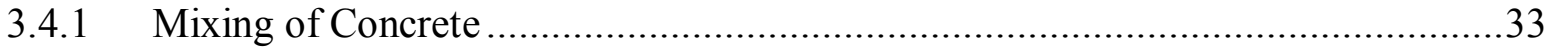

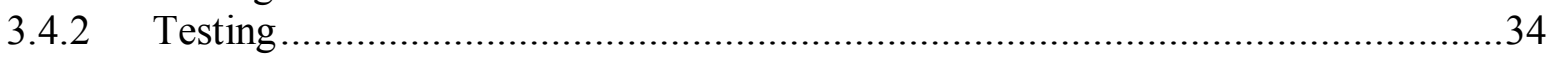

3.4.2.1 Compressive Strength Development ……….............................................. 34

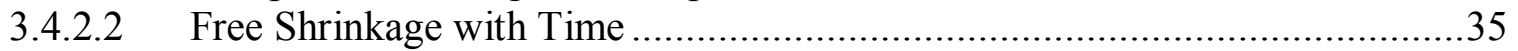

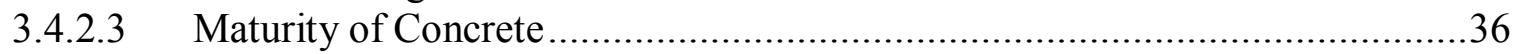

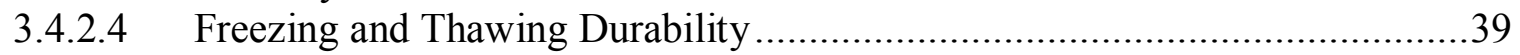

3.4.2.5 Rapid Chloride Penetration for Resistance .................................................... 41 


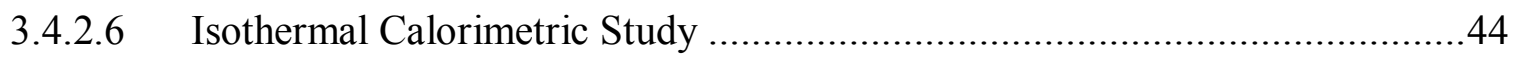

Chapter 4: Discussion on Test Results of High volume Fly Ash and/or Slag Modified Concrete 47

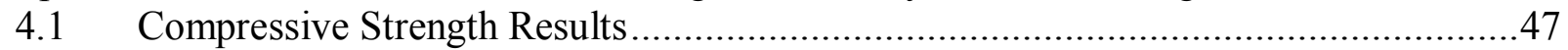

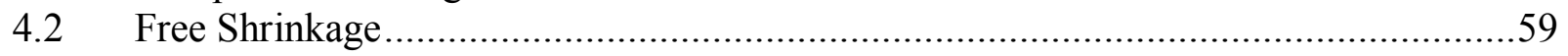

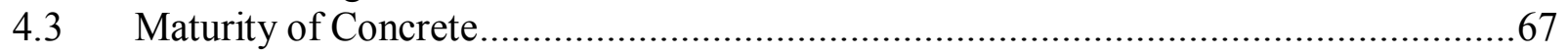

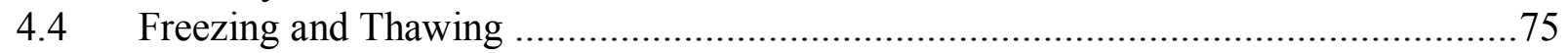

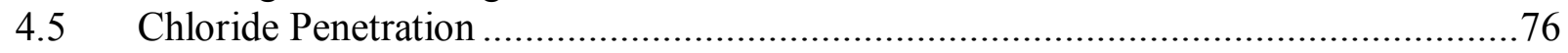

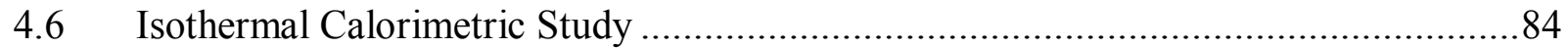

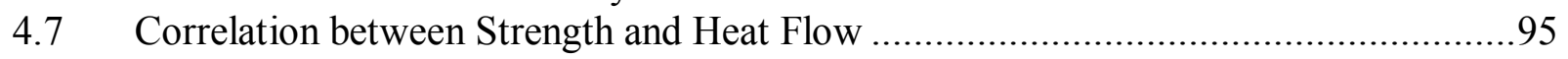

Chapter 5: Experimental Program for Geopolymer Concrete ………....................................... 103

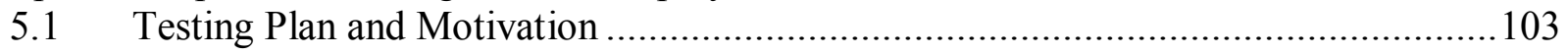

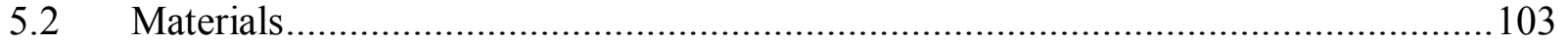

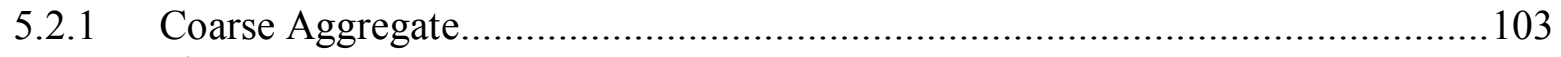

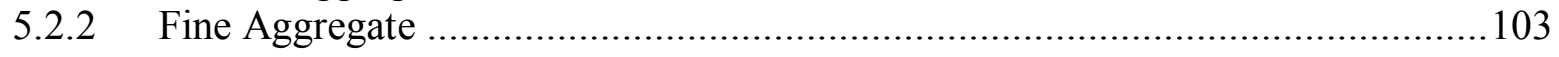

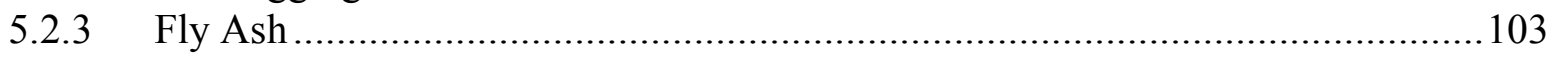

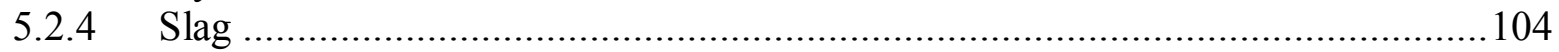

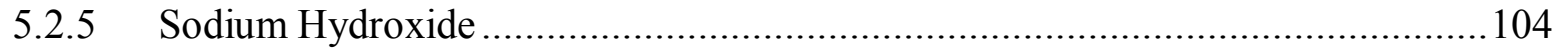

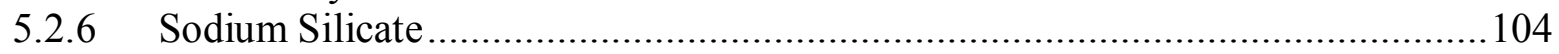

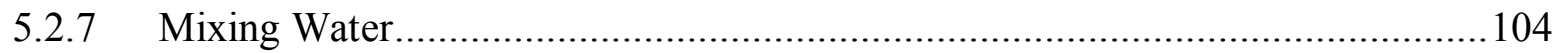

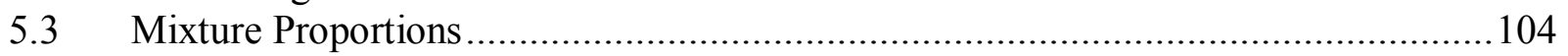

5.4 Testing Procedures for Geopolymer Concrete ……................................................. 107

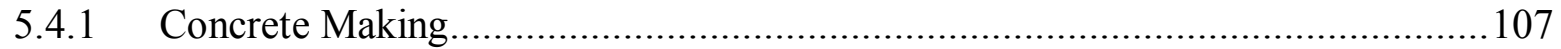

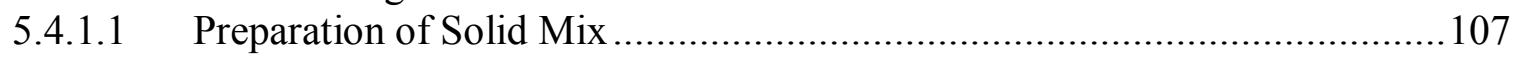

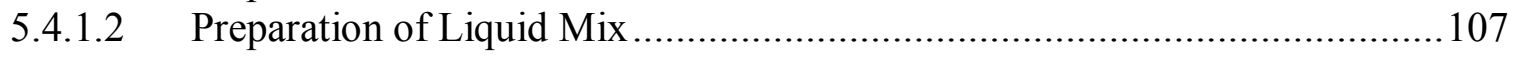

5.4.1.3 Mixing of Solid and Liquid Mix................................................................107

5.4.1.4 Curing Temperature ............................................................................... 107

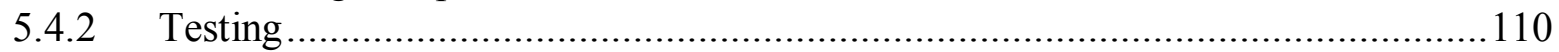

5.4.2.1 Compressive Strength Development .......................................................110

5.5 Discussion on Test Results of Geopolymer Concrete ................................................111

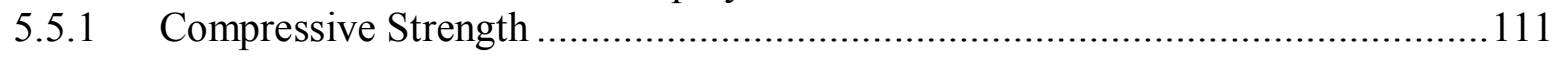

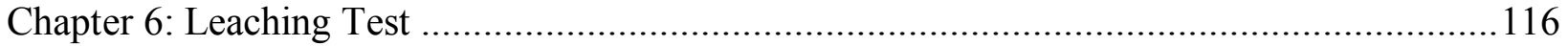

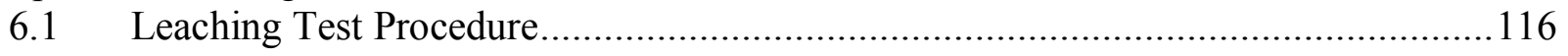

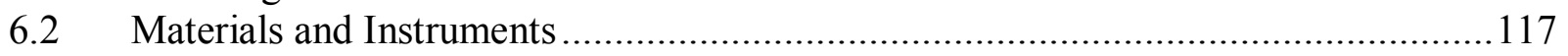

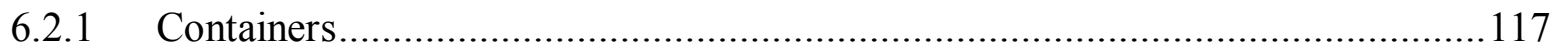

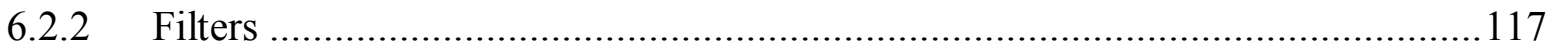

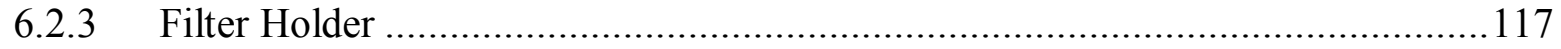

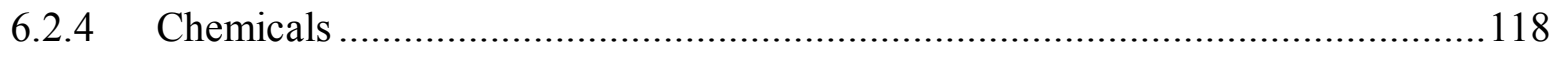

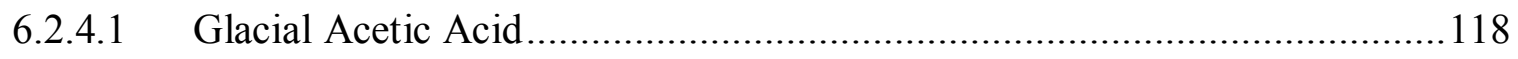

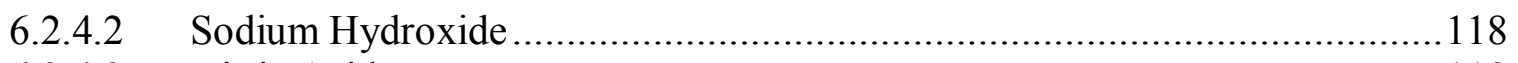

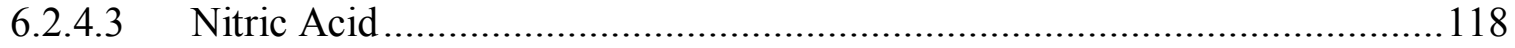

6.3 Leaching Test Results and Discussion................................................................

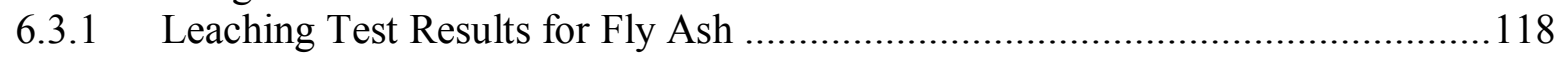

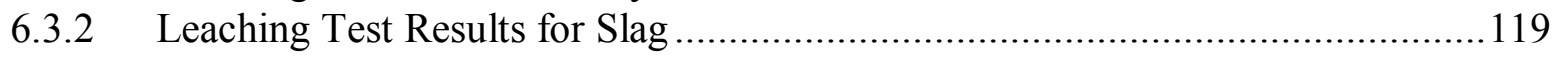

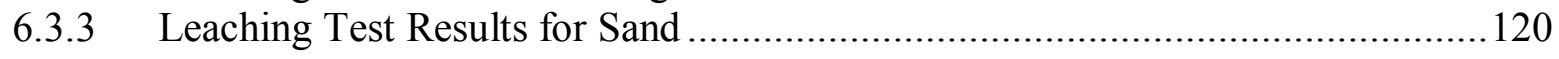

6.3.4 Leaching Test Results for Lime Stone ........................................................... 121

6.3.5 Leaching Test Results for Control Mix.......................................................... 122 
6.3.6 Leaching Test Results for High Volume Fly ash and/or Slag Concrete ...............123

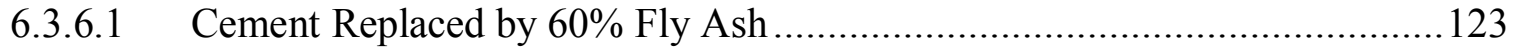

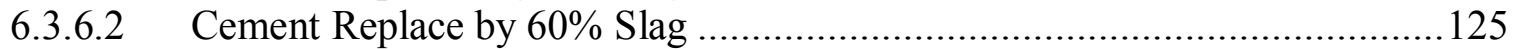

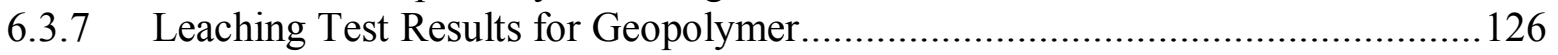

6.3.7.1 Geopolymer Binder with 100\% Fly Ash...................................................126

6.3.7.2 Geopolymer Binder with 100\% Slag ……............................................... 128

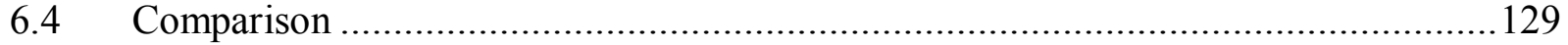

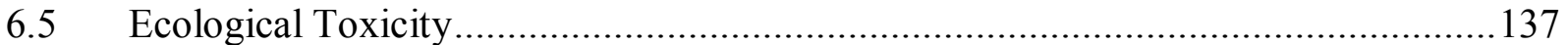

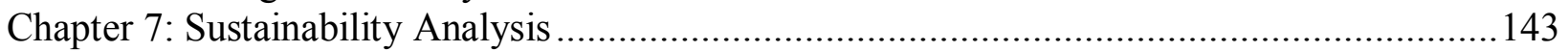

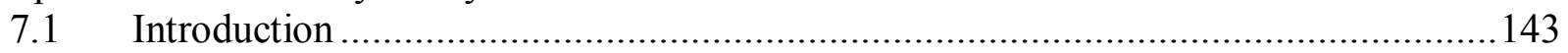

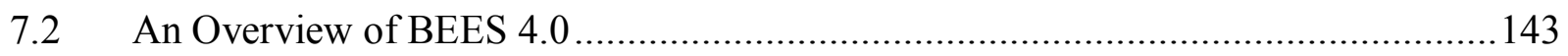

7.2.1 Economic Performance (Source NIST: BEES 4.0) .......................................... 144

7.2.2 Environmental Performance (Source NIST: BEES 4.0) ....................................147

7.2.2.1 Acidification Potential (Source NIST: BEES 4.0) ......................................149

7.2.2.2 Ecological Toxicity (Source NIST: BEES 4.0) ........................................... 151

7.2.2.3 Global warming (Source NIST: BEES 4.0) ................................................. 153

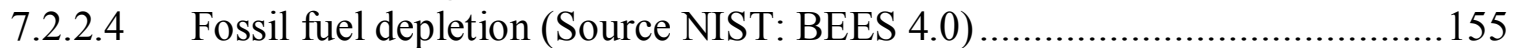

7.2.2.5 Human health (Source NIST: BEES 4.0) .................................................. 157

7.2.2.6 Eutrophication (Source NIST: BEES 4.0) ..............................................160

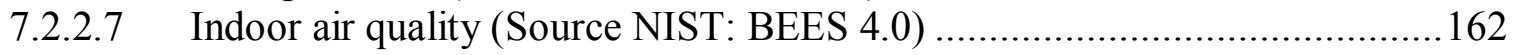

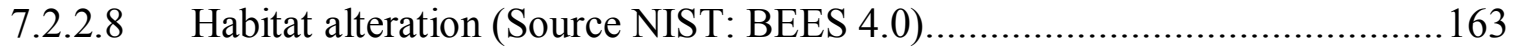

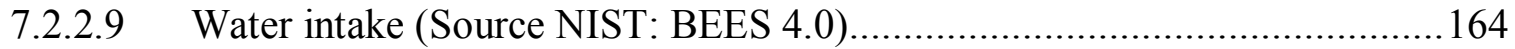

7.2.2.10 Criteria air pollutants (Source NIST: BEES 4.0) .......................................... 166

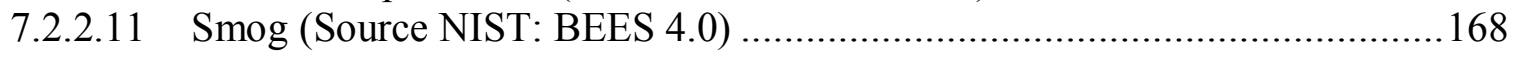

7.2.2.12 Ozone depletion (Source NIST: BEES 4.0) …........................................ 170

7.2.3 Overall Performance (Source NIST: BEES 4.0) ……..................................... 172

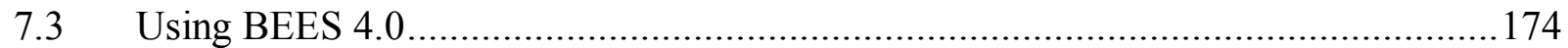

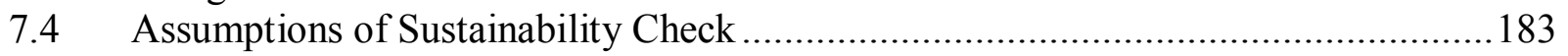

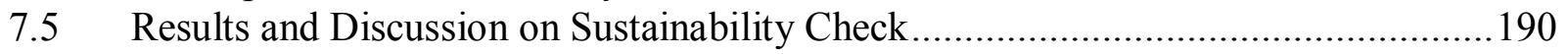

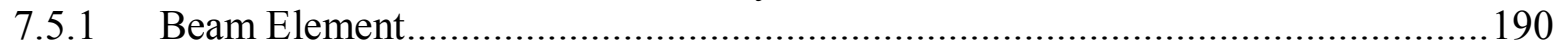

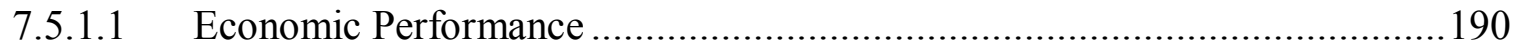

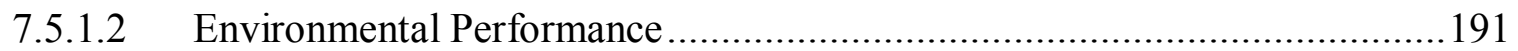

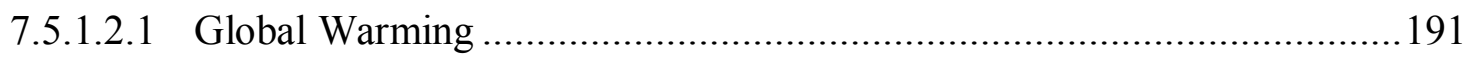

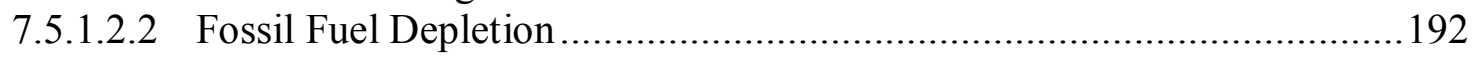

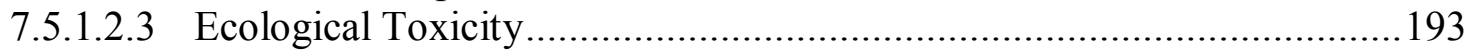

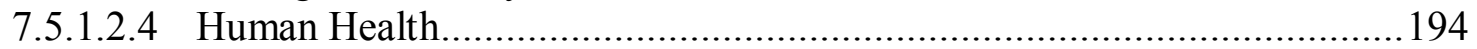

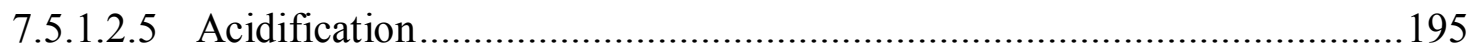

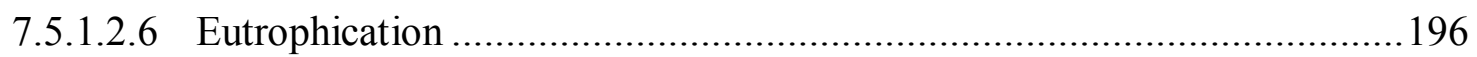

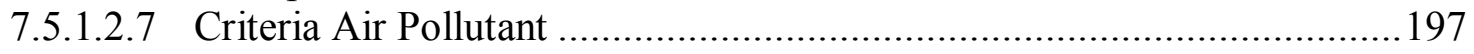

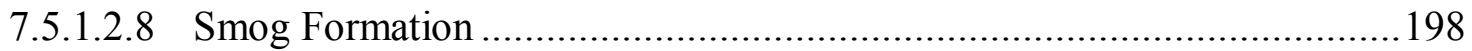

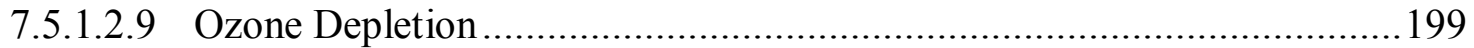

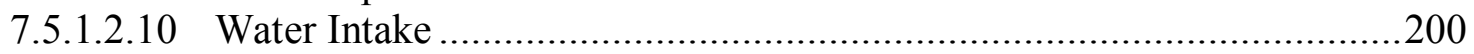

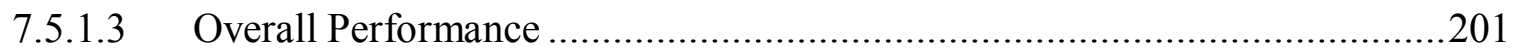

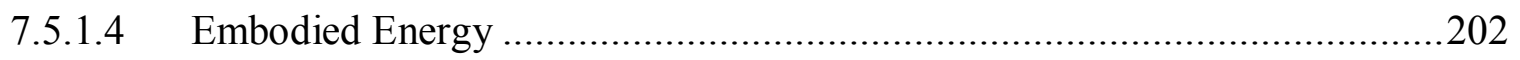

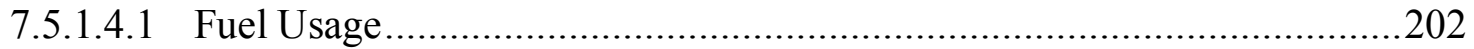

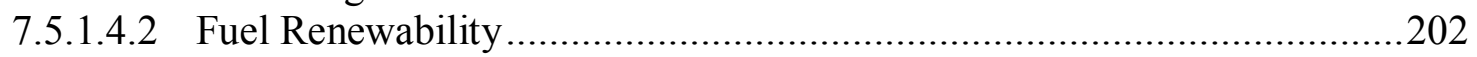




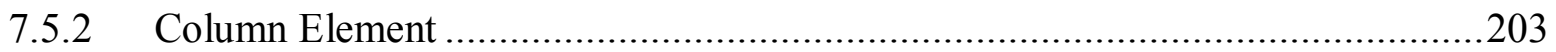

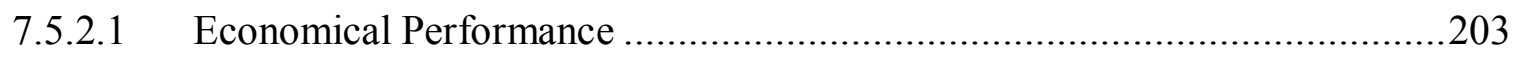

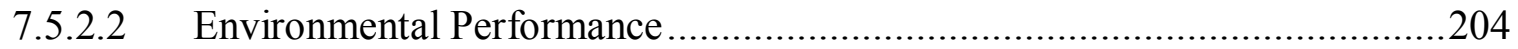

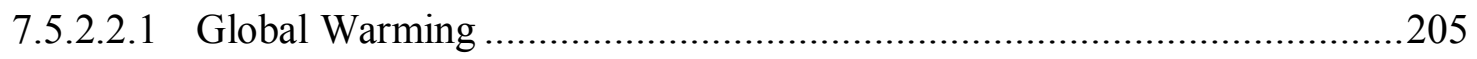

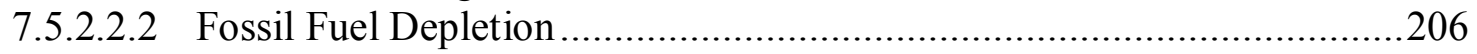

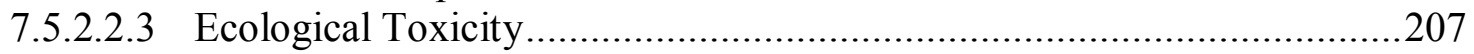

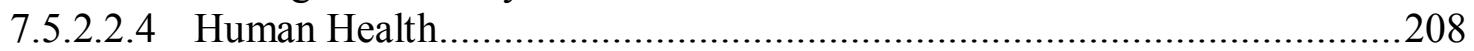

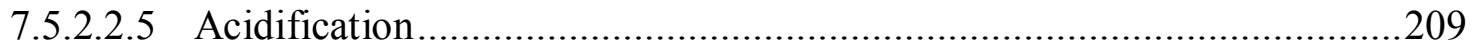

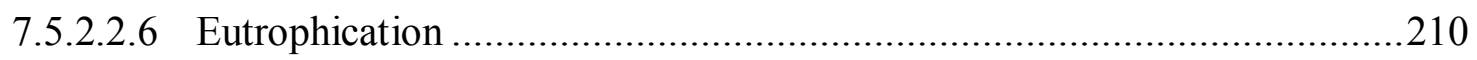

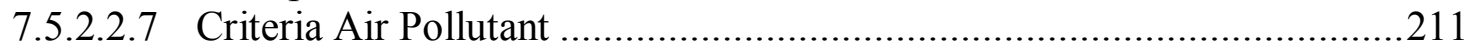

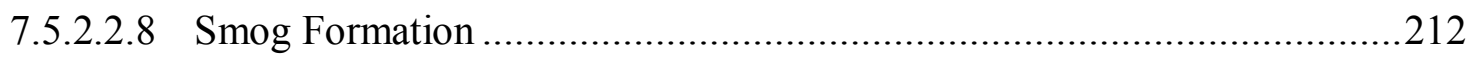

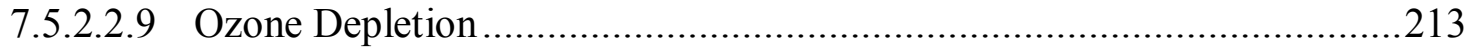

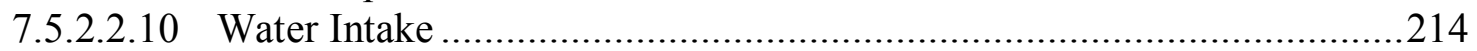

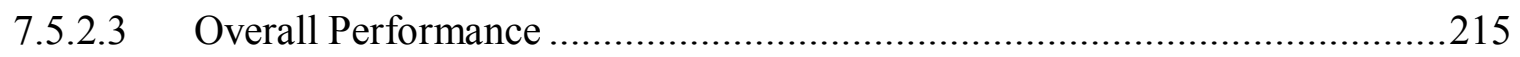

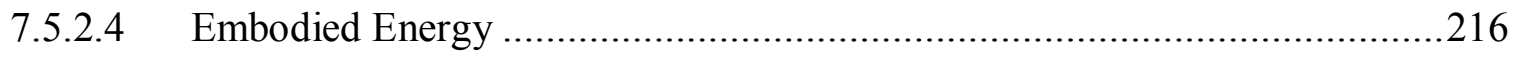

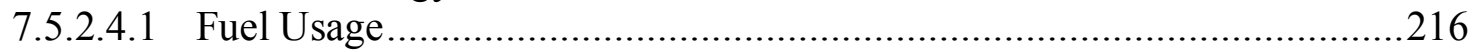

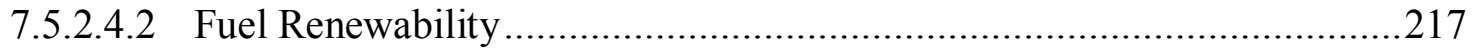

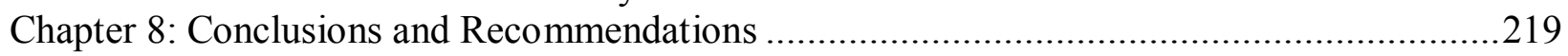

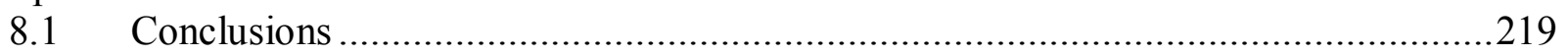

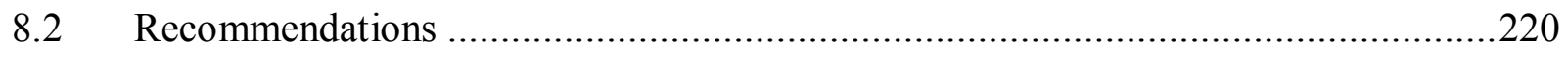

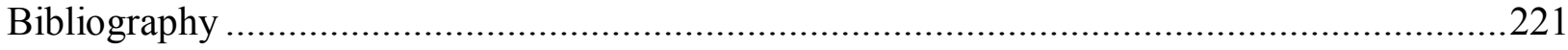




\section{List of Tables}

Table 3.1 Basic Physical Properties of Type I portland cement Used....................................26

Table 3.2 Compound Composition of Type I portland Cement Used. .....................................27

Table 3.3 Properties of Coarse Aggregates ...................................................................27

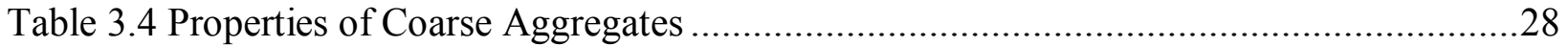

Table 3.5 Properties of fine aggregates ...........................................................................28

Table 3.6 Sieve analysis for natural river sand ...............................................................29

Table 3.7 Basic Properties of Fly Ash................................................................................29

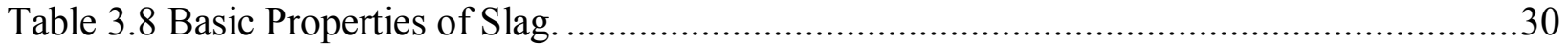

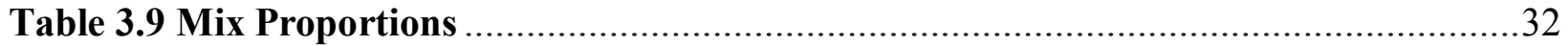

Table 4.1 Strength Maturity Equation FA40(0.3) ................................................6

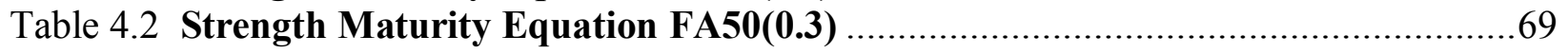

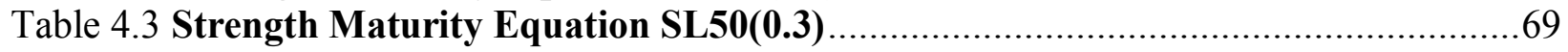

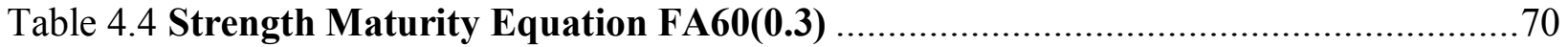

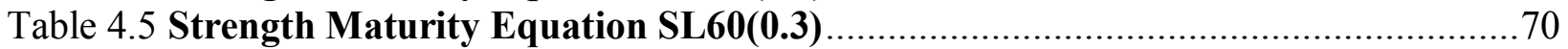

Table 4.6 Strength Maturity Equation FA35+SL35(0.3) ............................................ 71

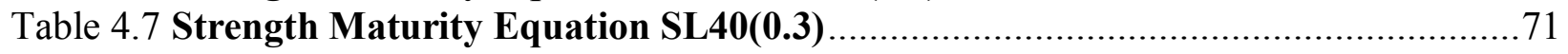

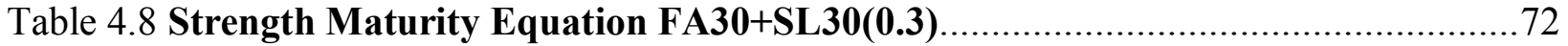

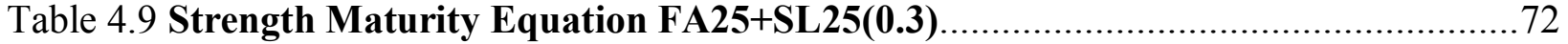

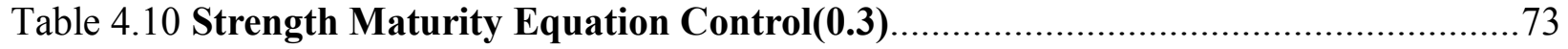

Table 4.11 Strength Maturity Equation Control(0.25)............................................... 73

Table 4.12 Strength Maturity Equation FA35+SL35(0.25) ......................................... 74

Table 4.13 Strength Maturity Equation SL60(0.25) .................................................. 74

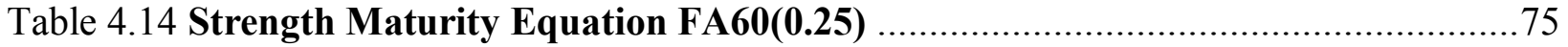

Table 5.1 Mix Proportions for Geopolymer....................................................... 106

Table 5.2 Sample Mix Proportions Calculation for Geopolymer.................................. 106

Table 6.1 Results for Identified Hazardous Metals in Constituent ................................ 131

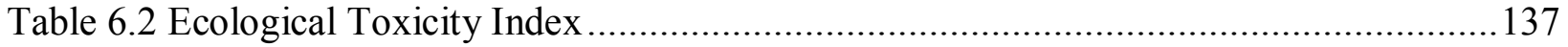




\section{List of Figures}

Figure 2-1Structure of Geopolymer (Source: Davidovits) ............................................... 19

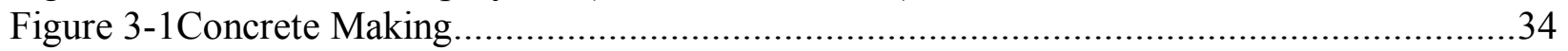

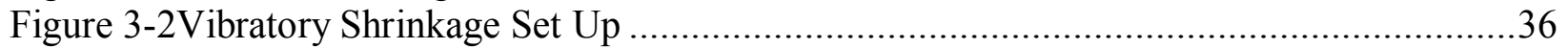

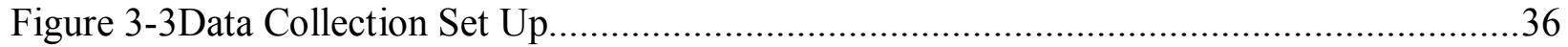

Figure 3-4 Conditioning and Testing Samples for RCPT ..................................................43

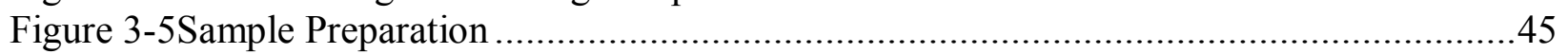

Figure 3-6Placing of Samples...................................................................................4 46

Figure 4-1 Comparison of Compressive Strength of FA40 and SL40 (1 MPa=145psi)............47

Figure 4-2Comparison of Compressive Strength of FA50 and SL50 (1 MPa=145psi).............48

Figure 4-3Comparison of Compressive Strength of FA60 and SL60 (1 MPa=145psi).............49

Figure 4-4Comparison of Compressive Strength of Concrete with Increasing Fly Ash

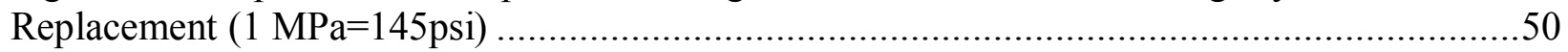

Figure 4-5Comparison of Compressive Strength of Concrete with Increasing Slag Replacement

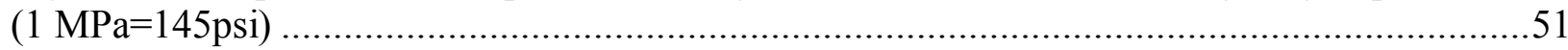

Figure 4-6 Comparison of Compressive Strength when the Combined Replacement is 50 \% (1

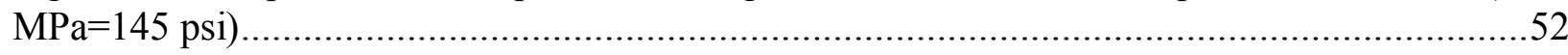

Figure 4-7 Comparison of Compressive Strength when the Combined Replacement is $60 \%$ (1

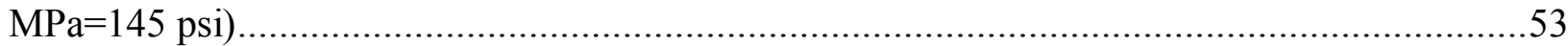

Figure 4-8 Comparison of Compressive Strength with Increasing Combined Replacement (1

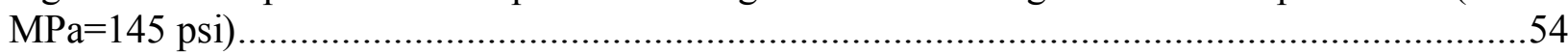

Figure 4-9 Comparison of Compressive Strength with Decreasing w/cm where $60 \%$ Cement Is

Replaced by Fly Ash $(1 \mathrm{MPa}=145$ psi) .........................................................................55

Figure 4-10 Comparison of Compressive Strength with Decreasing w/cm where $60 \%$ Cement Is

Replaced by Slag (1 MPa=145 psi) ............................................................56

Figure 4-11 Comparison of Compressive Strength with Decreasing w/cm where $60 \%$ Cement Is

Replaced by Fly Ash or Slag (1 MPa=145 psi) ..................................................5

Figure 4-12 Comparison of Compressive Strength with Decreasing w/cm where $70 \%$ Cement Is

Replaced by Fly Ash and Slag Combined (1 MPa=145 psi) .............................................58

Figure 4-13 Comparison of Drying Shrinkage of FA40 and SL40 .......................................59

Figure 4-14 Comparison of Drying Shrinkage of FA50 and SL50 ....................................60

Figure 4-15 Comparison of Drying Shrinkage of FA60 and SL60 .....................................60

Figure 4-16 Comparison of Drying Shrinkage of Concrete with Increasing Fly Ash Replacement

Figure 4-17 Comparison of Drying Shrinkage of Concrete with Increasing Slag Replacement ..62

Figure 4-18 Comparison of Drying Shrinkage when the Combined Replacement Is 50 \% ........62

Figure 4-19 Comparison of Drying Shrinkage when the Combined Replacement Is $60 \%$........63

Figure 4-20 Comparison of Drying Shrinkage with Increasing Combined Replacement ...........64

Figure 4-21 Comparison of Drying Shrinkage with Decreasing w/cm where $60 \%$ Cement Is

Replaced by Fly Ash ...............................................................................................64

Figure 4-22 Comparison of Drying Shrinkage with Decreasing w/cm where $60 \%$ Cement Is

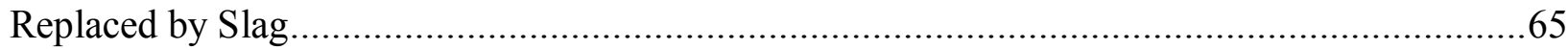


Figure 4-23 Comparison of Drying Shrinkage with Deecreasing w/cm where $60 \%$ Cement Is

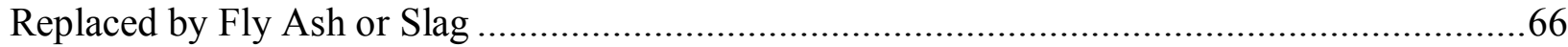

Figure 4-24 Comparison of Drying Shrinkage with Decreasing w/cm where $70 \%$ Cement Is

Replaced by Fly Ash and Slag Combined ....................................................................66

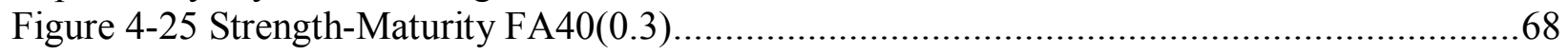

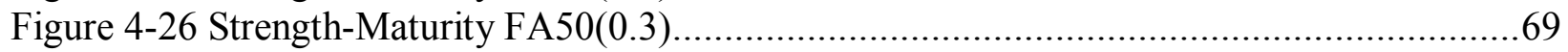

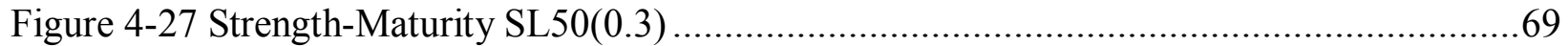

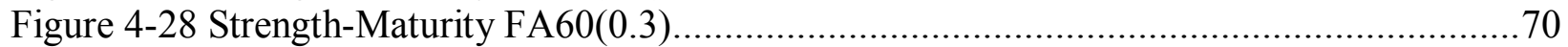

Figure 4-29 Strength-Maturity SL60(0.3) ....................................................................... 70

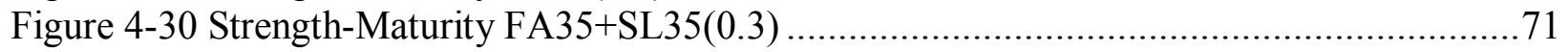

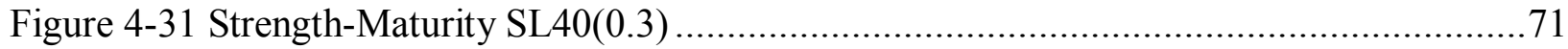

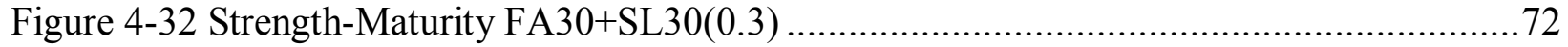

Figure 4-33 Strength-Maturity FA25+SL25(0.3) ......................................................... 72

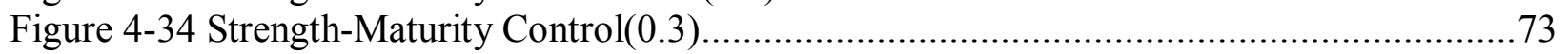

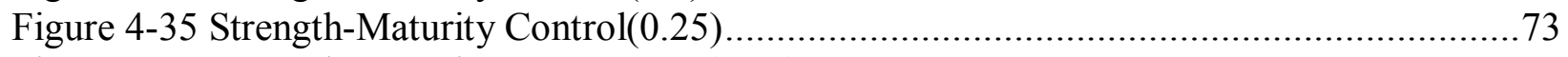

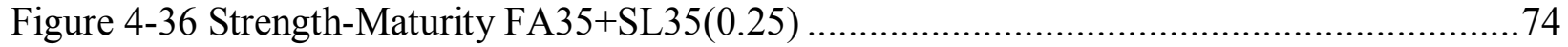

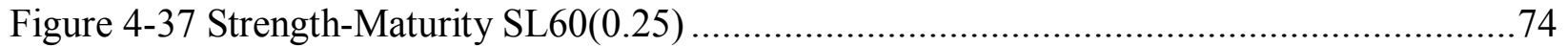

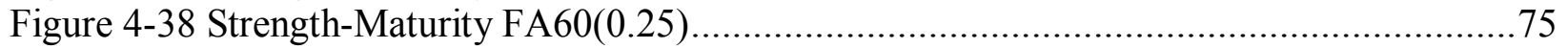

Figure 4-39 Comparison of Charge Passed in FA40 and SL40 .............................................77

Figure 4-40 Comparison of Charge Passed in FA50 and SL50 ..........................................77

Figure 4-41 Comparison of Charge Passed in FA60 and SL60 .........................................78

Figure 4-42 Comparison of Charge Passed in Concrete with Increasing Fly Ash Replacement ..78

Figure 4-43 Comparison of Charge Passed in Concrete with Increasing Slag Replacement.......79

Figure 4-44 Comparison of Charge Passed when the Combined Replacement is $50 \%$..............80

Figure 4-45 Comparison of Charge Passed when the Combined Replacement is 60 \%.............80

Figure 4-46 Comparison of Charge Passed with Increasing Combined Replacement ................81

Figure 4-47 Comparison of Charge Passed with Decreasing w/cm Where $60 \%$ Cement Is

Replaced by Fly Ash ............................................................................................... 82

Figure 4-48 Comparison of Charge Passed with Decreasing w/cm Where $60 \%$ Cement Is

Replaced by Slag .............................................................................................. 82

Figure 4-49 Comparison of Charge Passed with Decreasing w/cm Where $60 \%$ Cement Is

Replaced by Fly Ash or Slag ...................................................................................8 83

Figure 4-50 Comparison of Charge Passed with Decreasing w/cm Where $70 \%$ Cement Is

Replaced by Fly Ash and Slag Combined ............................................................ 84

Figure 4-51 Isothermal Calorimeter Study of FA40 and SL40 …......................................85

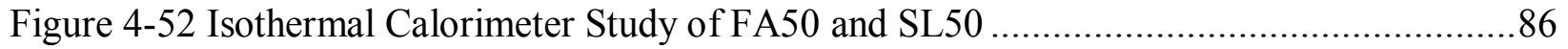

Figure 4-53 Isothermal Calorimeter Study of FA60 and SL60 .........................................8 87

Figure 4-54 Isothermal Calorimeter Study of Concrete with Increasing Fly Ash Replacement...88

Figure 4-55 Isothermal Calorimeter Study of Concrete with Increasing Slag Replacement ........89

Figure 4-56 Isothermal Calorimeter Study of Concrete When the Combined Replacement Is

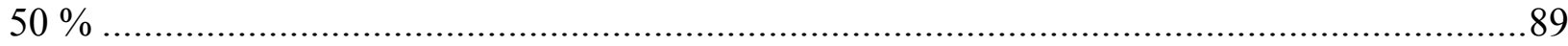

Figure 4-57 Isothermal Calorimeter Study of Concrete When the Combined Replacement Is

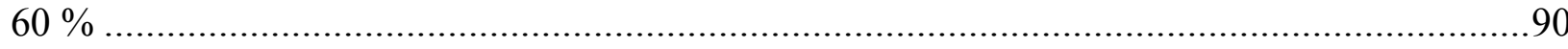

Figure 4-58 Isothermal Calorimeter Study of Concrete with Increasing Combined Replacement 
Figure 4-59 Isothermal Calorimeter Study of Concrete with Decreasing w/cm Where $60 \%$

Cement Is Replaced by Fly Ash ...................................................................................92

Figure 4-60 Isothermal Calorimeter Study of Concrete with Decreasing w/cm Where 60 \% Cement Is Replaced by Slag .........................................................................................

Figure 4-61 Isothermal Calorimeter Study of Concrete with Decreasing w/cm Where $60 \%$

Cement Is Replaced by Fly Ash or Slag ..............................................................................94

Figure 4-62 Isothermal Calorimeter Study of Concrete with Decreasing w/cm Where $70 \%$

Cement Is Replaced by Fly Ash and Slag Combined ..........................................................95

Figure 4-63 Heat Flow and Early Age Strength Correlation Study of FA40 and SL40 ...............96

Figure 4-64 Heat Flow and Early Age Strength Correlation Study of FA50 and SL50 ...............96

Figure 4-65 Heat Flow and Early Age Strength Correlation Study of FA60 and SL60 ...............97

Figure 4-66 Heat Flow and Early Age Strength Correlation Study of Concrete with Increasing Fly Ash Replacement ..................................................................................................

Figure 4-67 Heat Flow and Early Age Strength Correlation Study of Concrete with Increasing

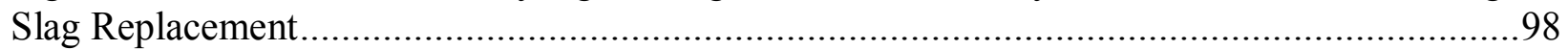

Figure 4-68 Heat Flow and Early Age Strength Correlation Study of Concrete When the

Combined Replacement Is 50 \% .....................................................................................98

Figure 4-69 Heat Flow and Early Age Strength Correlation Study of Concrete When the Combined Replacement Is 60 \%............................................................................................99

Figure 4-70 Heat Flow and Early Age Strength Correlation Study of Concrete with Increasing

Combined Replacement ……………….......................................................................99

Figure 4-71 Heat Flow and Early Age Strength Correlation Study of Concrete with Decreasing w/cm Where 60 \% Cement Is Replaced by Fly Ash............................................................ 100 Figure 4-72 Heat Flow and Early Age Strength Correlation Study of Concrete with Decreasing w/cm Where 60 \% Cement Is Replaced by Slag ...................................................................100

Figure 4-73 Heat Flow and Early Age Strength Correlation Study of Concrete with Decreasing w/cm Where 60 \% Cement Is Replaced by Fly Ash or Slag...................................................... 101 Figure 4-74 Heat Flow and Early Age Strength Correlation Study of Concrete with Decreasing w/cm Where 70 \% Cement Is Replaced by Fly Ash and Slag Combined ................................ 102

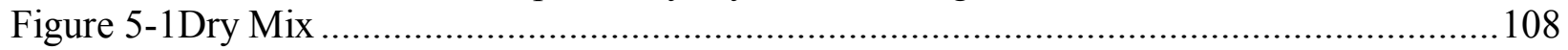

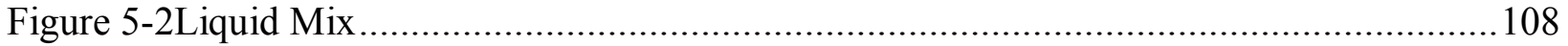

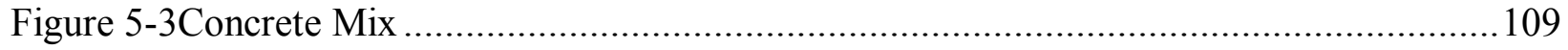

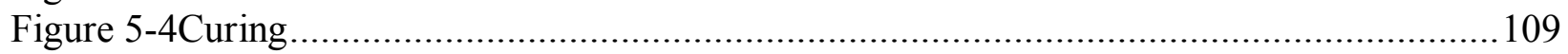

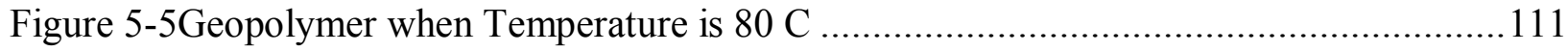

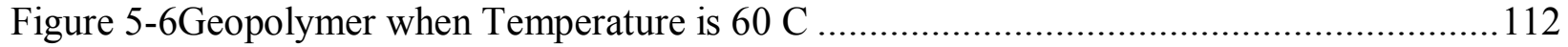

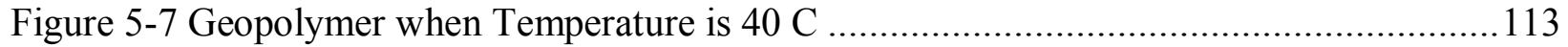

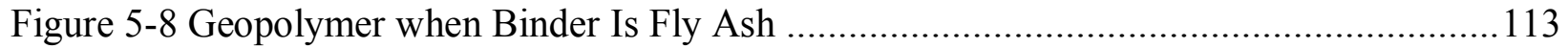

Figure 5-9 Geopolymer when Binder Is Fly Ash and Slag Combined ....................................114

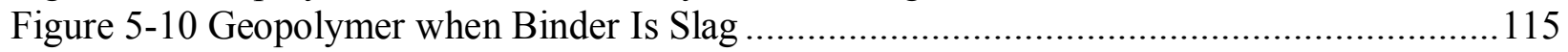

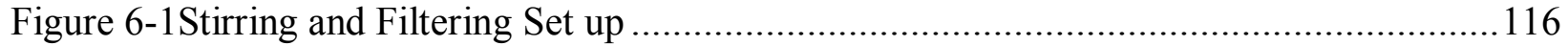

Figure 6-2 Comparison of Fly Ash and Concrete Containing 60\% and 100\% Fly Ash, pH 2.88

Figure 6-3 Comparison of Fly Ash and Concrete Containing 60\% and 100\% Fly Ash, pH 4.93

Figure 6-4, Comparison of Slag and Concrete Containing 60\% and 100\% Slag, pH 2.88.........133

Figure 6-5 Comparison of Slag and Concrete Containing 60\% and 100\% Slag, pH 4.93 ..........133 
Figure 6-6 Comparison of Control Mix and Concrete Containing 60\% and 100\% Fly Ash, pH 2.88

Figure 6-7 Comparison of Control Mix and Concrete Containing 60\% and 100\% Fly Ash, pH 4.93

Figure 6-8 Comparison of Control Mix and Concrete Containing 60\% and 100\% Slag, pH 2.88

Figure 6-9 Comparison of Control Mix and Concrete Containing 60\% and 100\% Slag, pH 4.93

Figure 6-10 Toxicity of Fly Ash and Concrete Containing 60\% and 100\% Fly Ash, pH 2.88... 138

Figure 6-11 Toxicity of Fly Ash and Concrete Containing 60\% and 100\% Fly Ash, pH 4.93 ... 138

Figure 6-12 Toxicity of Fly Ash and Concrete Containing 60\% and 100\% Slag, pH 2.88 ....... 139

Figure 6-13 Toxicity of Fly Ash and Concrete Containing 60\% and 100\% Slag, pH 4.93 ....... 139

Figure 6-14 Toxicity of Control and Concrete Containing 60\% and 100\% Fly Ash, pH $2.88 \ldots 140$

Figure 6-15 Toxicity of Control and Concrete Containing 60\% and 100\% Fly Ash, pH $4.93 \ldots 141$

Figure 6-16 Toxicity of Control and Concrete Containing 60\% and 100\% Slag, pH 2.88........ 141

Figure 6-17 Toxicity of Control and Concrete Containing 60\% and 100\% Slag, pH 4.93 ........ 142

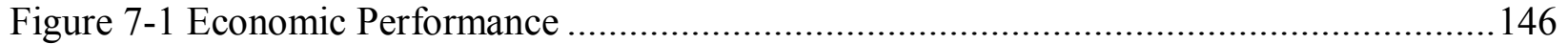

Figure 7-2Environmental Performance ...................................................................... 148

Figure 7-3Acidification Potential ............................................................................. 150

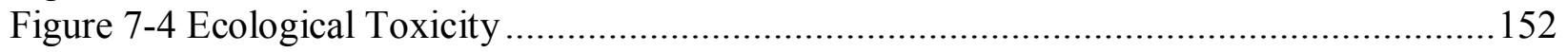

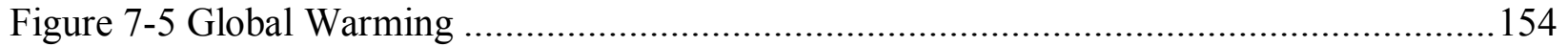

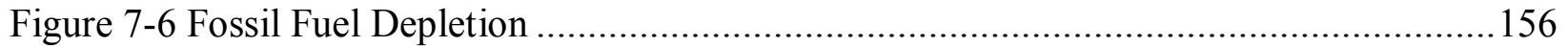

Figure 7-7 Human Health Noncancer ........................................................................ 158

Figure 7-8 Human Health Cancer .................................................................................. 159

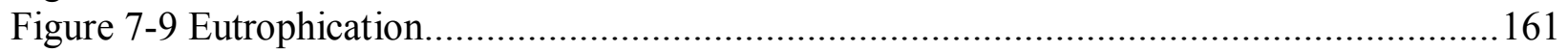

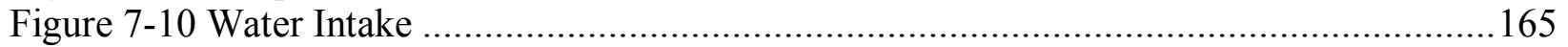

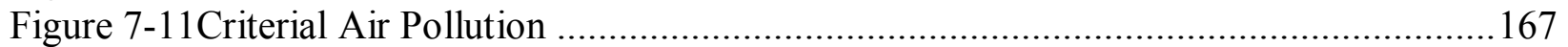

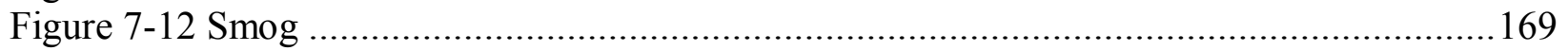

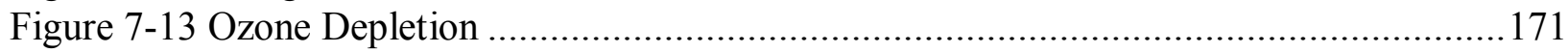

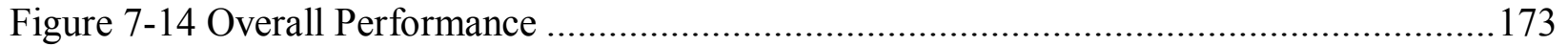

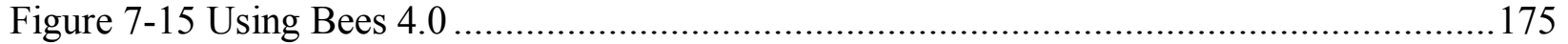

Figure 7-16 Choosing Major Group Element .................................................................. 177

Figure 7-17 Choosing Group Element ....................................................................... 178

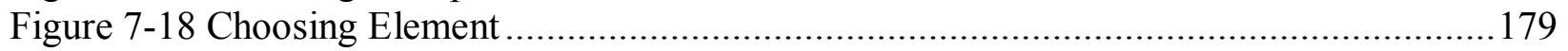

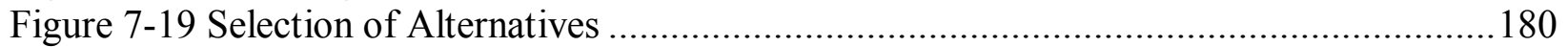

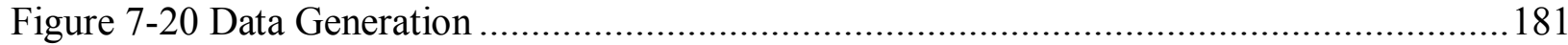

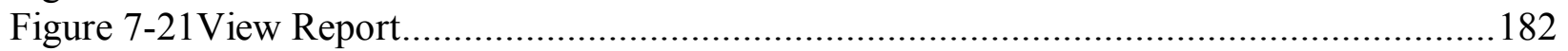

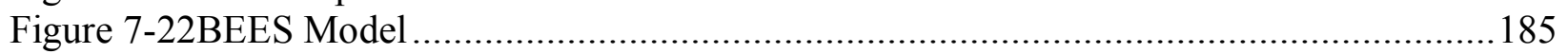

Figure 7-23 Unit Process ......................................................................................... 186

Figure 7-24 Portland Cement Production (NIST : BEES 4.0) ............................................ 189

Figure 7-25 Economic Performance (Beam) .................................................................. 190

Figure 7-26 Environmental Performances (Beam) ............................................................ 191

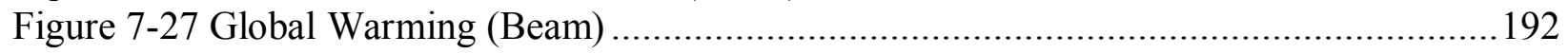

Figure 7-28 Fossil Fuel Depletion (Beam) ................................................................... 193

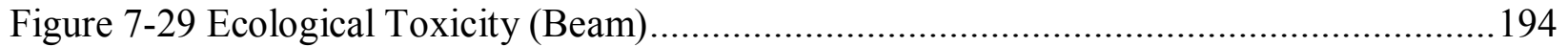

Figure 7-30 Human Health (Beam) ................................................................................. 195 


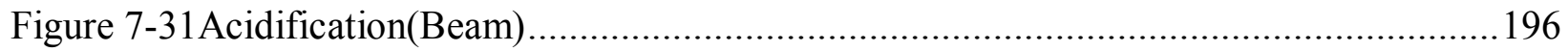

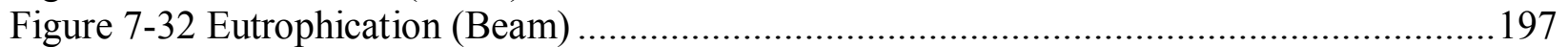

Figure 7-33 Criteria Air Pollutant (Beam) ...................................................................... 198

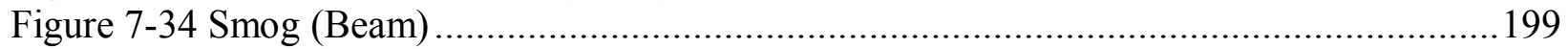

Figure 7-35Ozone Depletion (Beam) ....................................................................200

Figure 7-36 Water Intake (Beam) ............................................................................201

Figure 7-37 Overall Performance (Beam) ...............................................................201

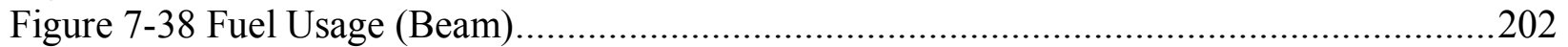

Figure 7-39 Fuel Renewability (Beam) .......................................................................203

Figure 7-40 Economic Performance (Column) .........................................................204

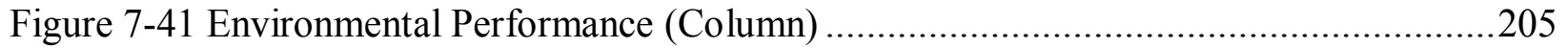

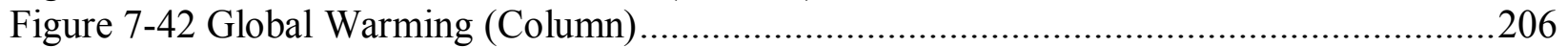

Figure 7-43 Fossil Fuel Depletion (Column) ...................................................................2207

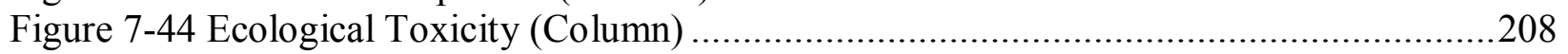

Figure 7-45 Human Health (Column) ...........................................................................209

Figure 7-46Acidification (Column) .....................................................................2 210

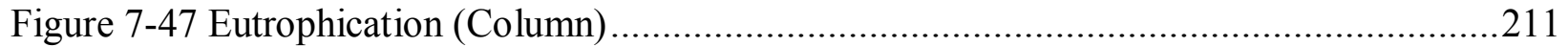

Figure 7-48 Criteria Air Pollutant (Column) ...................................................................2 212

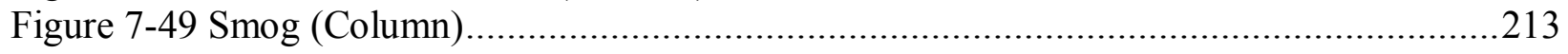

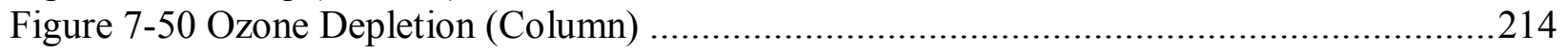

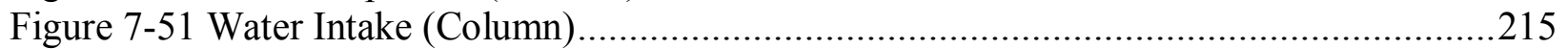

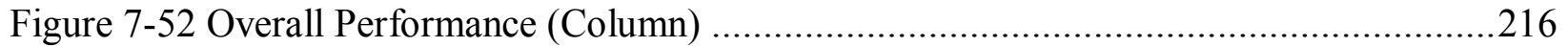

Figure 7-53 Fuel Usage (Column) ...................................................................2 217

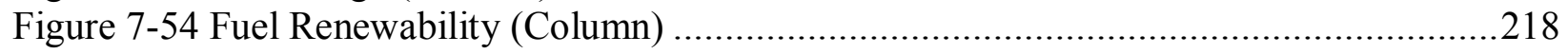




\section{Chapter 1: Introduction}

\subsection{Motivation}

Green Concrete opened a new page in the era of sustainable environmentally friendly development. The green movement is a great way to better our current products and spawn innovation for new creations. In many parts of the world, extreme weather patterns have been occurring with greater frequency. Many people believe the phenomenon is associated with high emission rate of greenhouse gases, primarily carbon dioxide (Mehta, 2005). The environmental carbon-di-oxide $\left(\mathrm{CO}_{2}\right)$ concentration has increased from 280 370 parts per million mainly during the industrial age (Dunn, 2001 and Mehta, 1999). Portland cement is an extremely versatile building material that is used extensively all over the world. Unfortunately, significant environmental problem rises from the process of manufacturing of portland cement. Worldwide this account for production of $5 \%$ of the total carbon dioxide produced by mankind adding the greenhouse gas equivalent to 330 million cars driving 12500 miles per year (Mehta, 1999 and Green Resource Center, 2004). Some building health experts have raised concerns about the presence of trace heavy metals in fly ash. Most of the researchers claim that hazardous metals are kept locked into the paste matrix, preventing their release. EPA suggests hazardous elements are less likely to come out through the denser less permeable structure of fly ash concrete (Green Resource Center, 2004).

Concrete is almost a mandatory part of construction these days, especially in seismically active regions. Unfortunately concrete production causes lot of problems for our environment.

The production of portland cement, the glue that usually binds concrete together, puts about one ton of carbon dioxide into the atmosphere for every ton of cement produced. ( $50 \%$ from the fuel used to heat the raw limestone and half from the chemical reaction that calcifies the limestone) Worldwide, the production of portland cement alone accounts for $6-8 \%$ of the human-generated carbon dioxide. Many scientists are alarmed by dramatic increases in atmospheric $\mathrm{CO}_{2}$ and the resultant greenhouse effect.

Fly ash is a waste product generated by coal burning power plants. It is generally either land filled or, where lack of regulations permit, it is just billowing out of smoke stakes into the 
atmosphere. Fly ash can pollute groundwater with heavy metals and in the air becomes particulate solution or smoke.

Fortunately, fly ash can be used as a replacement of portland cement in concrete to improve its fresh, hardened, and durability properties.

Concrete industry is the largest consumer of virgin materials such as sand, gravel, crushed rock, and water. Portland cement is consumed at a rate of 1.6 billon metric ton. Large amount of materials is wasted when structures deteriorates or fail prematurely (Mehta, 1997). Nations can achieve a tenfold increase in their resource productivity through $90 \%$ reduction in the use of energy and materials (Hawkens, Lovins and Lovins, 1999). Resource productivity can be increased by enhancement of durability of concrete, which is of course the long term sustainability solution. Industrial ecology can be practiced by using the waste product of its own. Reportedly over 1 billion tons of construction and demolition waste is generated every year. Cost effective technologies are available to recycle most of the waste as partial replacement for the coarse aggregate for the fresh concrete. Similarly industrial waste water and non-potable water can substitute mixing water until and unless proven harmful by testing. Portland cement blended with fly ash from coal fired power plants and ground granulated blast furnace slag from iron industry provides excellent industrial ecology. This approach offers a holistic solution for reducing environmental impact of several industries. The construction industry already started using 15 20\% fly ash in mixes or 30 40\% slag in concrete. Three countries USA, China and India, which consume the largest amount of cement also produces over 500 million tons of fly ash every year.

The United States imported over 15 million tons of portland cement in 2003. If this cement had been replaced with fly ash, the trade deficit would have been reduced by at least 1 billion dollars (Mehta, 2005). It is expensive to retrofit coal-burning power plants to keep the fly ash away from entering the atmosphere. So perhaps the economic incentive is to sell the fly ash that is captured, which could fund the installation of this equipment (Mehta, 2005).

Geopolymer concrete is an alkali activated alumino-silicate compound form alumina and silica rich industrial wastes like fly ash and/or slag (Duxson et al., 2007), which can completely replace portland cement as binder. Geopolymer also shows the immobilization of heavy metals present in industrial waste products (Olanrewaju, 2009) by encapsulation. 
A greener alternative, geopolymer concrete fits into an emerging class of concrete materials that utilize 'fly ash', one of the most abundant industrial by-products on earth, as a substitute for portland cement. Researchers believe the Geopolymer concrete's greatest appeal could be its life cycle greenhouse gas reduction potential; as much as $90 \%$ when compared with ordinary portland cement concrete.

Geopolymer concrete has a number of benefits. The first is it has the potential to substantially curb $\mathrm{CO}_{2}$ emissions. It can also produce a more durable infrastructure capable of lasting hundreds of years, instead of tens. And by utilizing the fly ash, it can conserve hundreds of thousands of acres currently used for disposal of coal combustion products, and protect our water ways from fly ash 'contamination', too.

\subsection{Scope of Work}

Significant amount of research work have been done to address different aspects of high volume fly ash and/or slag modified concrete. Geopolymer had been a source of interest for many of the researchers around the world. Environmental concerns had been one of the driving forces of many of those research works. However no systematic studies have been conducted to develop high performance concrete by replacing portland cement with high volume fly ash and/or slag and subsequently evaluating their engineering properties and environmental effects when fly ash is contained within concrete. Recently fly ash produced from coal-fired power plants has been proposed to be declared as a hazardous waste under Resource Conservation and Recovery Act (RCRA) of Environmental Protection Agency (EPA), restricting its disposal as landfill. In our research we studied engineering properties and subsequent environmental effects of containment of fly ash and/or slag through an extensive leaching test of high volume fly ash and/or slag modified concrete to provide complete information about using large volume of fly ash and/or slag in concrete as building material. No proper quantitative trustworthy sustainability analysis is done the worth of using high volume fly ash and/or slag as replacement of portland cement.

\subsection{Goals and Objectives}


The goal of this research is to develop high volume fly ash and/or slag modified concrete and geopolymer concrete as sustainable construction materials. The study will benefit the concrete and construction industry by helping them to select eco-friendly and economically viable sustainable and green materials as building and infrastructure products.

The objectives of this study are as follows:

(1) Characterize the fresh and hardened properties of high volume fly ash and/or slag modified concrete;

(2) Develop and evaluate the geopolymer concrete;

(3) Study the leaching effects of fly ash and/or slag contained within these portland and geopolymer concrete matrix; and

(4) Compare the overall, environmental, and economic performance scores of various modified and controlled concrete to be manufactured as potential building products by using the software BEES 4.0 (Building for Environmental and Economic Sustainability) developed by National Institutes of Standards and Technology (NIST).

To fulfill the above objectives the work is divided into following four tasks. Each task is explained as follows:

Task-1

- To review the published literatures, reports, and state-of-the art information on high volume fly ash and/or slag modified concrete.

- To develop and evaluate the fresh, hardened and durability properties of concrete mixes using 40 to $70 \%$ of fly ash and/or slag in different combinations as replacement of portland cement with water to cementitious materials (w-cm) ratios of 0.3 and 0.25 .

- To study the hydration characteristics of high volume fly ash and/or slag modified to correlate with the early-age strength development.

Task-2

- To review extensively the published literatures, reports and state-of-the art information about geopolymer concrete. 
- To review literature of curing condition, time and temperature of geopolymer and geopolymer concrete.

- To prepare concrete mixes using $100 \%$ fly ash, $100 \%$ slag, and a combination of $50 \%$ fly ash and $50 \%$ slag as solid binder of geopolymer concrete.

Task-3

- To review extensively the published literatures, reports and state-of-the art information on leaching of hazardous ions from industrial by product.

- To conduct leaching tests of fly ash and slag.

- To study the leaching tests of fly ash and slag contained within portland cement concrete and geopolymer matrix using Environmental Protection Agency (EPA)'s TCLP test

Task-4

- To review the published literatures, reports and state-of-the art information on sustainable construction practices.

- To conduct sustainability analysis of above mentioned concrete mixes with help of commercially available software, developed by National Institute of Science and Technology (NIST)

\subsection{Thesis Organization}

This thesis is organized into eight chapters as follows: Chapter 1 describes the introduction to high volume fly ash and/or slag modified concrete and geopolymer, motivation for the research, objectives of the research, scope of the work and the organization of the thesis. In chapter 2, a detailed literature review is conducted on engineering and durability properties of high volume fly ash and/or slag modified concrete, history and findings of fly ash and/or slag based geopolymer concrete. Chapter 3 describes about the materials, casting procedures and different types of tests performed for high volume fly ash and/or slag modified concrete. Chapter 4 describes results of laboratory test results of high volume fly ash and/or slag modified concrete. Chapter 5 discusses about the experimental program and test results fly ash and/or slag based geopolymer modified concrete. Chapter 6 explains leaching test and results on high volume fly ash and/or slag modified concrete. Chapter 7 explains the sustainable aspect of high volume fly 
ash and/or slag modified concrete. Finally, chapter 8 draws conclusions from the performed research and the future recommendations are made based on the present study. 


\section{Chapter 2: Literature Review}

\subsection{Review of Concrete with High Volume Fly Ash and Other Mineral Admixtures}

High strength concrete of late 1970s is now referred as high performance concrete, because it is found that it has many other attributes in addition to high compressive strength (Aitcin, 2003). ACI defines HPC as a special concrete, where one or more character can be enhanced by means of material selection and mix proportions, which refers to family of high tech concrete products whose properties have been tailored to meet specific engineering needs like improved workability, high early strength, high toughness, and durability. ACI does define durability is the mandatory factor for high performance concrete. Brittleness in concrete leads to cracking and premature deterioration of high performance concrete structures in order to achieve high early strength. Field experiments shows foregoing high strength concrete structures are prone to variety of cracking problems. Large thermal contraction due to high portland cement content, huge amount of autogenous shrinkage due to low w/cm, and a high drying shrinkage due to high cement paste to aggregate ratio are some of the reasons (Mehta and Burrows, 2001 and Krauss and Rogalla, 1996). High volume fly ash concrete mitigates most of these problems by improving durability properties (Atis, 2003).

\subsubsection{Fresh and Hardened Properties}

Replacing portland cement with fly ash can reduce the exothermic reaction between cement and water (Bremner and Thomas, 2004). Because of the slower pozzolanic reaction, partial replacement of portland cement with fly ash results in a release of heat over a longer period of time. Therefore, the concrete temperature remains lower because heat is dissipated as it is produced (Joshi and Lohtia, 1997). It has been estimated that the contribution of fly ash to early age heat generation ranges from $15-30 \%$ of that of an equivalent mass of portland cement (Berry and Malhotra, 1986). Although most low calcium fly ashes (Class F) will reduce the rate of temperature rise when used as portland cement replacement, while high calcium fly ashes (Class C) do not always reduce heat evolution because of their self cementitious properties (Joshi and 
Lohtia, 1997). In general, the rate of heat evolution is equivalent to the rate of strength development. Some high calcium ashes react very rapidly with water, generating excessive heat rather than reducing the heat of hydration (Berry and Malhotra, 1986). Temperature rise in concrete depends upon the following factors: rate of heat generated by hydration and pozzolanic reactions, rate of heat loss and the thermal properties of the concrete and surrounding environment, and the size of the concrete member (Joshi and Lohtia, 1997). A substantial reduction in maximum temperature allows casting of large sections without exceeding a maximum temperature differential of $40^{\circ} \mathrm{C}$ (Bremner and Thomas, 2004). For example, in a large concrete block made with high volume fly ash and/or slag modified concrete, the maximum temperature reached in the middle of the block was $54^{0} \mathrm{C}$. In this case the concrete placement temperature was $19^{\circ} \mathrm{C}$, resulting in only a $35^{\circ} \mathrm{C}$ differential between the interior and exterior of the concrete block. The same size block was also cast using only ASTM Type I portland cement. The maximum temperature reached in the middle of this block was $83^{\circ} \mathrm{C}$. In this particular case the concrete placement temperature was $18^{\circ} \mathrm{C}$, resulting in a temperature differential of $65^{\circ} \mathrm{C}$ between the interior and exterior of the concrete block. In this example, the total amount of cementitious material by weight was the same for the two blocks (Malhotra and Mehta, 2002).

The major problem of using high volume of fly ash concrete is slower early strength generation due to less cementitious properties (Obla and Martin, 2003). Low heat generation can affect the timely formwork removal process. As the hydration reaction remains really slow due less embodied energy. Specialized approach like heat insulation during construction should be taken into consideration. On the other hand high volume fly ash and/or slag modified concrete shows reduce internal temperature and improved workability (Mindess, Young and Darwin, 2004). Improved workability is the result of spherical shaped fly ash particles (Haque, Langan and Ward, 1984). Fly ash having very high amount of carbon content requires higher dosage of airentraining admixtures (Crouch, Hewiit, and Byard, 2007 and Bilodeau and Malhotra, 2000 and Hill and Folliard, 2006).

Both the strength at a given age and the rate of strength gain of fly ash concrete are affected by the characteristics of the fly ash (properties, chemical composition, particle size, reactivity), the cement with which it is used, the proportions of each used in the concrete, the temperature and other curing conditions, as well as the presence of other additives (Hobbs, 1983; Berry and Malhotra, 1986; ACI Committee 232, 2003). Although concrete mixtures containing fly ash tend 
to gain strength at a slower rate than concrete without fly ash, the long-term strength is usually higher (Bremner and Thomas, 2004). After the rate of strength gain of hydraulic cement slows, the continued pozzolanic activity of fly ash provides strength gain at later ages if the concrete is kept moist; therefore, concrete containing fly ash with equivalent or lower strength at early ages may have equivalent or higher strength at later ages than concrete without fly ash as long as the concrete is moist cured or exposed to sufficient quantities of moisture during service. The strength gain will continue with time and results in higher later-age strength than can be achieved by using additional cement (Berry and Malhotra, 1986; ACI Committee 232, 2003). However, by using accelerators, activators, water reducers, or by changing the mixture proportions, equivalent 3 or 7-day strength may be achieved (ACI Committee 232, 2003). High calcium fly ashes (Class C) will show a more rapid strength gain at early ages than concrete made with a lower calcium fly ash (Class F) because Class $\mathrm{C}$ ashes often exhibit a higher rate of reaction at early ages than Class F ashes (Bremner and Thomas, 2004; Smith et al., 1982; ACI Committee 232, 2003). However, Class $\mathrm{F}$ ashes will contribute to greater long-term strength gain of concrete than Class $\mathrm{C}$ ashes in spite of its slower rate of strength development at early age. Because of its fineness and pozzolanic activity, fly ash in concrete improves the quality of cement paste and the microstructure of the transition zone between the binder matrix and the aggregate. As a result of the continual process of pore refinement, due to the inclusion of fly ash hydration products in concrete, a gain in strength development with curing is achieved (Joshi and Lohtia, 1997). It should be noted that elevated temperature curing is very beneficial to early strength and subsequent future strength gain of fly ash concrete because of the higher activation energy required for pozzolanic reactions (ACI Committee 232, 2003).

With respect to high volume fly ash and/or slag modified concrete, there is concern within the industry that the low early strength is a potential problem. However, many studies have been conducted regarding this issue and the findings are positive. Siddique (2003) reports that replacement of cement with $40 \%, 45 \%$, and $50 \%$ fly ash content reduces the compressive strength of concrete at 28 days, but there is a continuous and significant improvement of strength beyond 28 days when compared to conventional portland cement concrete. He also stated that the strength of concrete with $40 \%, 45 \%$, and $50 \%$ fly ash content, even at 28 days is sufficient for use in reinforced concrete construction (Siddique, 2003). CANMET has performed studies to investigate the typical strength development of high volume fly ash concrete and have shown 
one-day strengths of approximately $8 \mathrm{MPa}, 28$-day strength of approximately $35 \mathrm{MPa}$, and 91day strengths of approximately $45 \mathrm{MPa}$. However, it must be noted that strength values will differ depending on the materials and proportions used. CANMET also reports that high volume fly ash and/or slag modified concrete can be used for high strength concrete applications since field studies have been conducted on high volume fly ash and/or slag modified concrete and strengths ranged from 35 to $50 \mathrm{MPa}$ at 28 days, and from 50 to $70 \mathrm{MPa}$ at 90 days (Bilodeau et al., 2001; Langley and Leaman, 1998).

\subsubsection{Durability Properties}

For enhancing the durability of concrete, larger amounts of fly ash e. g. in the order of $25 \%$ to $60 \%$ should be used in portland cement concrete. Such a concrete with high volumes of fly ash in it is called High volume fly Ash Concrete. From theoretical consideration and practical experience it is determined that $50 \%$ or more cement replacement by fly ash, it is possible to produce sustainable, high performance concrete mixtures that show higher workability, higher ultimate strength and high durability, Malhotra (1999). However, it is worth mentioning here that for achieving the above discussed properties, the use of superplasticizers (water reducing agents) is almost inevitable in high volume fly ash concrete. With superplasticizers, concrete with as low as $0.2 \mathrm{w} / \mathrm{cm}$ is possible with good workability and strength as high as $83 \mathrm{MPa}$ is possible at test age of 28 days (ACI-211-1993). The maximum strength reported with fly ash and superplasticizer is about $60 \mathrm{MPa}$, Swamy (1985). The use of high volumes of fly ash in concrete to achieve HSC at both early and later ages has been reported by Malhotra (1986). The fact that use of high volume fly ash along with superplasticizer in concrete exhibits good workability and high early strength is emphasized by Raju (1991). Kohubu (1968) provided a major breakthrough in using fly ash in concrete as it was the first comprehensive study of its own kind. Bhanumathidas and Kalidas (2002) focused on inclusion of complementary cementitious materials such as fly ash, slag, silica fume and rice husk on durability aspect of concrete in the light of revised IS-456-2000 (IS: Indian Standard Code). Malhotra and Ramezanianpur (1994) made a comparison in properties of concrete with varying percentages of fly ash in concrete. As per ASTM C 595 (1994), fly ash can be blended with cement to produce blended cement. It defined two blended cements - one with less than 15\% pozzolan and other with $15 \%-40 \%$ 
pozzolan. ASTM C311 (1994) recommends that fly ash to be used in concrete should be monitored by a quality assurance program. Halstead and Woodrow (1986) explained the uses of fly ash in concrete with special reference to time of setting, bleeding, heat of hydration and pumpability. Mehta (1983) explained the use of cementitious byproducts as mineral admixtures for concrete. Helmuth (1987) described that the use fly ash in concrete has increased in last 20 years. However, less than $20 \%$ of the fly ash collected was used in cement and concrete industry. It is explained that one can safely use fly ash in concrete in pavements for economic and ecological benefits. Adams (1988) encourages the use of fly ash in concrete pavements. The price of fly ash concrete is less than the price of mixes with ordinary cement and fly ash concrete is also given preference as it is technically more appropriate. Aitcin and Mehta (1990) described the guidelines for using high performance concrete. ACI 211 (1996) recommends fly ash replacement in cement between 15\% 35\%. Mehta (2001) refers to concrete technology for sustainable development with the aim to reduce greenhouse gas emissions by cement industry. Malhotra and Mehta (2002) described high volume fly Ash Concrete with larger replacement of fly ash (>30\%) in cement as a beneficial practice for sustainable, durable and economic concrete. Bhattacharjee et al (2002) have enlightened the areas in which fly ash usage has potential in India. He pointed out that despite quite optimistic levels of utilization of fly ash in India; only less than $25 \%$ of the total fly ash produced is being utilized. Atis (2002) studied the abrasion resistance of high volume fly ash concrete. His analysis of results showed that abrasion resistance increased as compressive strength increased. Siddique (2004) carried out experimental investigations on class $\mathrm{F}$ fly ash concrete with three percentages of replacement e.g., 40\%, 45\% and $50 \%$. He concluded that partial replacement of cement by fly ash in concrete results in decrease in compressive strength, Split tensile strength, modulus of elasticity and abrasion resistance at 28 days of age. All the properties of hardened concrete; show significant improvement at 90 days and thereafter.

Sujjavanich et al (2005) investigated the effect of high volumes of fly ash in concrete on steel corrosion and chloride penetration. They concluded that high volume fly ash/or slag concrete has lower chloride permeability and has a tendency to minimize or cause no corrosion risk. Sengul (2005) studied the effect of partial replacement ( $0 \%$ to $70 \%)$ of cement by fly ash in concrete on its compressive strength, brittleness index and chloride penetration. He reported that high volume fly ash concrete has decreased compressive strength at 28 days, better strength at later ages i.e. 
56 and 120 days; increased brittleness index and better resistance to chloride ions penetration. Mullick (2006) has traced the development of high performance concrete in India and its adoption in practice for infrastructure and water resources projects. Naik (2007) reviewed some of the experimental studies in the laboratory to analyze the suitability of utilization of a particular type of fly ash sample with the aim to reduce environmental degradation being caused by disposal of high volumes of fly ash in landfills. Sukhvarsh et al (2007) reported that increase of fly ash content from $30 \%$ to $45 \%$ increased the durability of concrete without loss of compressive and flexural strength. Kumar et al (2007) studied the suitability of superplasticized high volume fly ash concrete for pavements. He concluded that high volume fly ash concrete with $50 \%-60 \%$ fly ash can be designed to meet the strength and workability requirement of concrete pavements. Yazic (2008) has compared self-compacting concrete with fly ash $30 \%$ to $60 \%$ as cement replacement and $10 \%$ silica fumes as cement replacement in addition to other similar concretes. He reported that addition of $10 \%$ silica fume positively affected both, the fresh and hardened properties of high performance high volume fly ash concrete. Vengata (2009) has reported that addition of fly ash in high volumes considerably decreases the permeability of concrete even though the strength of fly ash concrete at 28 days is not encouraging.

Mehta (2004) has reviewed the theory and construction practice of concrete mixture with more than $50 \%$ fly ash. He has discussed the mechanisms of incorporating high volumes of fly ash in concrete for reducing water demand, improving workability, minimizing thermal and drying shrinkage and enhancing durability. The present study for which this literature has been collected is aimed at analyzing the use of fly ash in high performance concrete for pavements in India.

Plastic shrinkage occurs on the surface of freshly mixed concrete soon after it has been placed, while it is being finished or shortly thereafter. Plastic shrinkage occurs when environmental conditions produce rapid evaporation of moisture from the concrete surface. These cracks occur when water evaporates from the surface faster than it can give rise to the surface during the bleeding process. This creates rapid drying shrinkage and tensile stresses in the surface that often result in short, irregular cracks (Cement Association of Canada, 2003). Plastic shrinkage is a potential problem of high volume fly ash concrete. The amount of bleed water available for evaporation of high volume fly ash concrete is very low because of its low unit water content, and therefore it is recommended that moist curing of high volume fly ash concrete be started as 
soon as the concrete is poured to limit the amount of evaporable water and reduce plastic shrinkage. (Malhotra and Mehta, 2002; Langley and Leaman, 1998).

The permeability of high volume fly ash and/or slag modified concrete is very low. The estimated permeability (hydraulic conductivity) of high volume fly ash and/or slag modified concrete is less than $10-13 \mathrm{~m} / \mathrm{s}$. As a comparison, normal portland cement concrete with a w/cm of 0.40, would have an estimated permeability of 10-12 m/s (Malhotra and Mehta, 2002). In general, the resistance of a reinforced concrete structure to corrosion, alkali aggregate expansion, sulfate and other forms of chemical attack depends on the water tightness of the concrete. high volume fly ash and/or slag modified concrete when properly cured is 15 able to provide excellent water-tightness and durability (Mehta, 2004). The use of fly ash in concrete decreases the required water and this combined with the production of additional cementitious compounds leads to a low porosity and discontinuous pore structure which reduces the permeability of the concrete (Estakhri and Saylak, 2004 and Malhotra and Mehta, 2002). It is worth re-emphasizing that the permeability of high volume fly ash and/or slag modified concrete is greatly influenced by curing.

\subsection{A Brief Review of Geopolymer Concrete}

This presents a historical background about important events in the field of alkali-activated binders (Roy, 1999). The development of alkali-activated binders had a major contribution in the 1940s with the work of Purdon in 1940. That author used blast furnace slag activated with sodium hydroxide. According to him, the process was developed in two steps. During the first one, liberation of silica aluminium and calcium hydroxide took place. After that, the formation of silica and alumina hydrates would happen as well as the regeneration of the alkali solution.

Also Malinowsky (2003) had investigated ancient constructions repaired with ordinary portland cement, having noticed that the repairing material was disintegrated just after 10 years, showing its low durability when compared with the repaired structures. Several authors had reported the existence of almost $40 \%$ of analcime zeolites in the composition of mortars found in Jericho in the valley of the Jordan river and also in Tel-Ramad Siria, as old as 7000 B.C. Other researchers

had analyzed Roman mortars having also found the presence of analcime (Langton and Roy, 1984, 1989). Campbell and Folk showed that the durability of ancient binders was due to its high 
level of amorphous zeolitic compounds. Also Granizo (1999) thinks that the presence of zeolitic compounds in several ancient binders suggests they are the final stable phase of a long term conversion of the primary phases to zeolite-like materials. A large part of the investigations about alkali-activated binders is related to the activation of blast furnace slag, known as "Alkalislag cement" or "Alkali-activated slag cement". Blast furnace slag is a by-product of iron production industry, having a high content of calcium which is due to the use of calcium carbonate in the calcination operations. Being a low performance cementitious material, it can achieve high compression strength when an alkaline activator is used. Shi and Day (2001) mentioned that the alkali-activation with $\mathrm{Na}_{2} \mathrm{O} . \mathrm{nSiO}_{3}$ led to a compression strength of $160 \mathrm{MPa}$ after 90 days curing at room temperature. However, Glukhovsky (1980) had already made crucial investigations about the activation of blast furnace slag: (a) identifying hydration products as being composed by calcium silicate hydrates and calcium and sodium aluminosilicate hydrates and (b) noticing that clay minerals when submitted to alkali-activation formed aluminium silicate hydrates (zeolite). The same author (1981) classified the alkaline activators in six groups, where $\mathrm{M}$ is an alkali ion:

- Alkalis, MOH.

- Weak acid salts, $\mathrm{M}_{2} \mathrm{CO}_{3}, \mathrm{M}_{2} \mathrm{SO}_{3}, \mathrm{M}_{3} \mathrm{PO}_{4}, \mathrm{MF}$.

- Silicates, $\mathrm{M}_{2} \mathrm{O} . \mathrm{nSiO}_{3}$.

- Aluminates, $\mathrm{M}_{2} \mathrm{O} \cdot \mathrm{nAl}_{2} \mathrm{O}_{3}$.

- Aluminosilicates, $\mathrm{M}_{2} \mathrm{O}$. $\mathrm{Al}_{2} \mathrm{O}_{3}$. (2-6) $\mathrm{SiO}_{2}$.

- Strong acid salts, $\mathrm{M}_{2} \mathrm{SO}_{4}$.

Investigations in the field of alkali activation had an exponential increase after the research results of the french author Dr. Davidovits who developed and patented binders obtained from the alkali-activation of metakaolin, and coined the term "Geopolymer" in 1978. According to that author, the new binder is generated by an adjustment of the process used by the Roman and the Egyptians. Davidovits even suggests that the pyramids were not been made with natural stone but were made of man-made binders instead. Based on chemical and mineralogical studies he stated that the pyramid blocks were made of a mixture, with limestone sand, calcium hydroxide, sodium carbonate and water. According to his investigations, pyramid blocks were not made of calcium fossilized layers as it happens in natural stones, but oriented in a random manner as in an artificial binder. XRD diffraction patterns of pyramid specimens indicate that 
$\left(\mathrm{CaCO}_{3}\right)$ is the major crystalline phase. However, an amorphous material composed of aluminosilicates and a zeolite like material $\left(\mathrm{Na}_{2} \mathrm{O} \cdot \mathrm{Al}_{2} \mathrm{O} 3.4 \mathrm{SiO}_{2} \cdot 2 \mathrm{H}_{2} \mathrm{O}\right)$ were also found (Davidovits, 1987). For the chemical designation of the geopolymer, Davidovits suggests the name "polysialates", in which Sialate is an abbreviation for aluminosilicate oxide. The sialate network is composed of tetrahedral anions $\left(\mathrm{SiO}_{4}\right)^{4-}$ and $\left(\mathrm{AlO}_{4}\right)^{5-}$ sharing the oxygen, which need positive ions such as $\left(\mathrm{Na}^{+}, \mathrm{K}^{+}, \mathrm{Li}^{+}, \mathrm{Ca}^{2+}, \mathrm{Na}^{+}, \mathrm{Ba}^{2+}, \mathrm{NH}^{\mathrm{b}}, \mathrm{H}^{3} \mathrm{O}^{+}\right)$to compensate the electric charge of $\mathrm{Al}^{3+}$ in tetrahedral coordination (after dehydroxilation the aluminium changes from coordination 6 (octahedral) to coordination 4 (tetrahedral)). The polysialate has the following empiric formulae: $\mathrm{M}_{\mathrm{n}}\left\{-\left(\mathrm{SiO}_{2}\right)_{\mathrm{z}}-\mathrm{AlO}_{2}\right\} \mathrm{n}, \mathrm{wH}_{2} \mathrm{O}$ where $\mathrm{n}$ is the degree of polymerization, $\mathrm{z}$ is 1,2 or 3, and $\mathrm{M}$ is an alkali cation, such as potassium or sodium, generating different types of polysialates. According to Davidovits, geopolymers are polymers because they transform, polymerize and harden at low temperature and also because they are inorganic, hard and stable at high temperature and also non inflammable.

Although these new binders have been named as alkaline cements or alkali-activated cements, this name was not universally accepted, because of the conflict with similar product named portland cement. This binder was overwhelmingly the only one from the last century, thus, becoming known as the cement. In fact, portland cement also hardens in a alkaline environment. The same happens with the pozzolanic reaction, which means that the designation alkaline cement is not very accurate. Davidovits even calls portland cement as alkali-activated calcium silicates (1994).

Over the last few years that author has argued that the designation alkali-activated binders is confusing and may wrongly influence civil engineers. It makes them think it could generate alkali-silica reactions, suggesting other names such as geopolymer cement, geopolymeric cementitious compounds, eco-cements or polysialates (Davidovits, 2005). However, although there is some ambiguity of the name alkali-activated cement; it is not easy to accept the reason related to the fact that it may mislead engineers about the alkali-silica reaction. Besides, it is not granted that all alkali-activated binders are really geopolymers, nor even clear why some authors mentioned the pozzolanic reaction as being a geopolymeric one (Davidovits, 1993). The fact that alkali-activated binders could be considered pozzolanic cements is also raised by other authors (Buchwald, Kaps and Hohmann 2003 and Pinto, 2004). According to Palomo, in a conference about geopolymers that took place in 2004 (UTAD-Portugal), the name "Geopolymer" is above 
all a commercial designation and, therefore, should not be used. In fact, the name portland cement is also a commercial name which is due to the color of the limestone rock from the Dorchester region in England, named as portland (Neville 1997). So it is not very accurate the use of the name portland cement in other parts of the world as it is the case. That is so due to the importance of the material patented by Aspdin, much more than to any resemblance related to the raw materials used to make portland cement. Even before the patent of Aspdin (1824), Parker (1796) had already patented binders named as roman cements or natural cements (Varas, Buego and Fort, 2005), using conditions very similar to the one, which is later involved in the production of portland cement and, despite that, the work of that author is almost unknown and very rarely mentioned. So it is believed that the general rule is to use the name alkali-activated binders, and the name geopolymer should only be used when the matrix is formed. However for all practical application the term geopolymer is well accepted.

The exact reaction mechanism which explains the setting and hardening of alkali-activated binders is not yet quite understood, although it is thought to be dependent on the prime material as well as on the alkaline activator. According to Glukhovsky (2003), the mechanism of alkaliactivation is composed of conjoined reactions of destruction- condensation, that include the destruction of the prime material into low stable structural units, their interaction with coagulation structures and the creation of condensation structures. The first steps consist of a breakdown of the covalent bonds $\mathrm{Si}-\mathrm{O}-\mathrm{Si}$ and $\mathrm{Al}-\mathrm{O}-\mathrm{Si}$, which happens when the $\mathrm{pH}$ of the alkaline solution rises, so those groups are transformed in a colloid phase.

Then an accumulation of the destroyed products occurs, which interacts among them to form a coagulated structure, leading in a third phase to the generation of a condensed structure. Other authors also agree that the majority of the proposed mechanisms indicate an initial phase of silica dissolution, followed by the phases of transportation and polycondensation (Davidovits, 1988 and Jaarsveld et al, 1998). However, those phases occur almost simultaneously, preventing their analysis in an individual mode (Palamo, Grutzek and Balnco, 1999). Granizo (2000) studied the alkali-activation of metakaolin having reported different reactions when the alkaline activator is made just of sodium hydroxide or if it also contains waterglass. In the first case, after the dissolution phase an induction period follows, when the destroyed products start to accumulate. In the second case, after a fast dissolution phase a fast polycondensation reaction follows right away. According to Palomo et al., (2001) two models of alkali-activation could be established; 
the first one is the case of the activation of blast furnace slag $(\mathrm{Si}+\mathrm{Ca})$ with a mild alkaline solution, having $\mathrm{CSH}$ as the main reaction products. In the second model of alkali activation ( $\mathrm{Si}$ $+\mathrm{Al}$ ), the general example is the alkali-activation of metakaolin with medium to high alkaline solutions. The final product is characterized by a polymeric model and high mechanical strength. The former model has similarities with the zeolite formation process. Thus, it can be concluded that the activation of metakaolin gives rise to an amorphous polymer just like a zeolite. The alkali activation of fly ashes takes place through an exothermic process of dissolution, during which the breakdown of the covalent bonds $\mathrm{Si}-\mathrm{O}-\mathrm{Si}$ and $\mathrm{Al}-\mathrm{O}-\mathrm{Al}$ occurs. The products generated due to the destruction of fly ash start to accumulate for a period and finally a condensation of the produced structure in a poorly ordered structure with a high mechanical strength. Other authors (Jarsveld and Deventer, 1999) believe that the nucleation mechanism involves the ordering of the water molecules by the alkali cations. The lower dimension cations are fitter than the higher dimension ones. However, in less ordered systems, higher condensations levels have been noticed, as it can be the case of mixtures with more water percentage and less cations to order it, resulting in a higher condensation structure. Alonso and Palomo performed heat evolution tests over sodium hydroxide alkali-activated metakaolin, having identified several phase peaks. A first one due to the dissolution of metakaolin, followed by an induction period with a low heat release and, finally, a third exothermic peak related to the final structure formation and influenced by the concentration of the alkaline activator.

According to Jaarsveld et al., (2001) the geopolymer formation follows the same process of zeolites: (a) dissolution due to the hydroxide ions $\mathrm{OH}$; (b) Orientation of the dissolved species; (c) condensation and hardening of the structure in a geopolymeric system.

Krizan and Zivanovic (2005) analyzed the heat release in alkali-activated blast furnace slag, and have noticed that the hydration process was influenced by the sodium content and the silica modulus (Ms). The higher $\mathrm{Na}_{2} \mathrm{O}$ and $\mathrm{Ms}$ were related to higher hydration levels. According to these authors, the process begins with a destruction of the slag bonds $\mathrm{Ca}-\mathrm{O}, \mathrm{Mg}-\mathrm{O}, \mathrm{Si}-\mathrm{O}-\mathrm{Si}$, $\mathrm{Al}-\mathrm{O}-\mathrm{Al}$ and $\mathrm{Al}-\mathrm{O}-\mathrm{Si}$, related to the initial peaks, and then a second family of peaks occurs due to the formation of a $\mathrm{Si}-\mathrm{Al}$ layer all over the surface of slag grains and, finally, the formation of the hydration products. For Lee and Deventer (2001) one of the differences between the ordinary portland cement binders and the alkali-activated ones is that in the first case it uses water with an initial neutral $\mathrm{pH}$ that slowly turns alkaline (12-13) as the hydration process undergoes a series 
of non-hydrated particles and several types of crystalline CSH gel. In the former case, strong alkali solutions are needed to start the dissolution process. In order to achieve good physical and chemical properties in the final product, it is necessary to add soluble silica (sodium silicate) but, as the initial $\mathrm{pH}$ is high, that prevents the coagulation and polymerization of the silicate.

When the $\mathrm{pH}$ goes to less than 14 due to the dissolution of the prime materials, condensation occurs very quickly. Then a group of reactions of polysialatization, coagulation, colloid formation and hardening occurs in a final product of undissolved aluminosilicate species in an amorphous aluminosilicate structure.

$\mathrm{Xu}$ et al. (2001) studied mixtures of kaolin, sodium and potassium feldspars activated with water glass, and reported that the geopolymerization is a three step process: dissolution of kaolin and feldspars forming a gel, condensation of the gel with the polymerization of Al and Si in threedimensional structures in which the alkali metals compensate the electric charge of the aluminium. During the geopolymerization water acts as a reagent and also as a reaction process. The dissolution phase of $\mathrm{Al}-\mathrm{Si}$ uses water, but the polymerization releases water. According to Fernandez-Jimenez et al. (2005) when the fly ashes are added to the alkaline solution, a dissolution process of the $\mathrm{Al}$ and Si occurs. Then the higher molecules condense in a gel (polymerization and nucleation) and the alkali attack opens the spheres exposing small spheres on the inside which will be also dissolved until the spheres, became almost dissolved with the formation of reaction products inside and outside the sphere. The activation of fly ashes is a process that may be considered as a zeolitization in which the last phase does not occur, since the experimental conditions lead to very fast dissolution and condensation reactions but a lower one when the hardening take place (Palamo et al., 2004).

For Criado et al., (2003) the activation of fly ashes is a process very different from the portland cement hydration, but resembling the chemical principles involved in the formation of several types of zeolites with an alkaline aluminosilicate as the main reaction product. This reaction product involves the tetrahedral coordination of silica and aluminum in polymeric chains in which the $\mathrm{Al}^{3+}$ replace the $\mathrm{Si}^{4+}$, with the negative electric charge being compensated by alkali cations. During the alkali attack of the aluminosilicate material, an initial nucleation phase takes place where the aluminosilicate species are dissolved. When the nuclei reach a critical size, they start to crystallize, but this is a very slow process so it may only be complete after a long time. 
Other authors studied the activation of metakaolin pastes and confirmed that the initial phase formed during the geopolymerization is later transformed to a second, more ordered phase. They noticed however that increasing $\mathrm{SiO}_{2} / \mathrm{AlO}_{3}$ ratio generally decreases the initial rate of reaction (Provis and Deventer, 2007). This presents a simplified model of the reaction processes involved in the geopolymerization of metakaolin (Provis et al., 2005). However, Deventer et al. suggests that it may also apply for other aluminosilicate raw materials. Those authors show how the presence of calcium and iron influences fly ash geopolymerization kinetics, by providing extra nucleation sites (2007).

$$
\begin{aligned}
& \text { Poly(sialate) } \\
& \text { Si:Al=1 }(- \text { Si-O-Al-O-) }
\end{aligned}
$$

Poly(sialate-siloxo)

Si:Al=2 (-Si-O-Al-O-Si-O-)
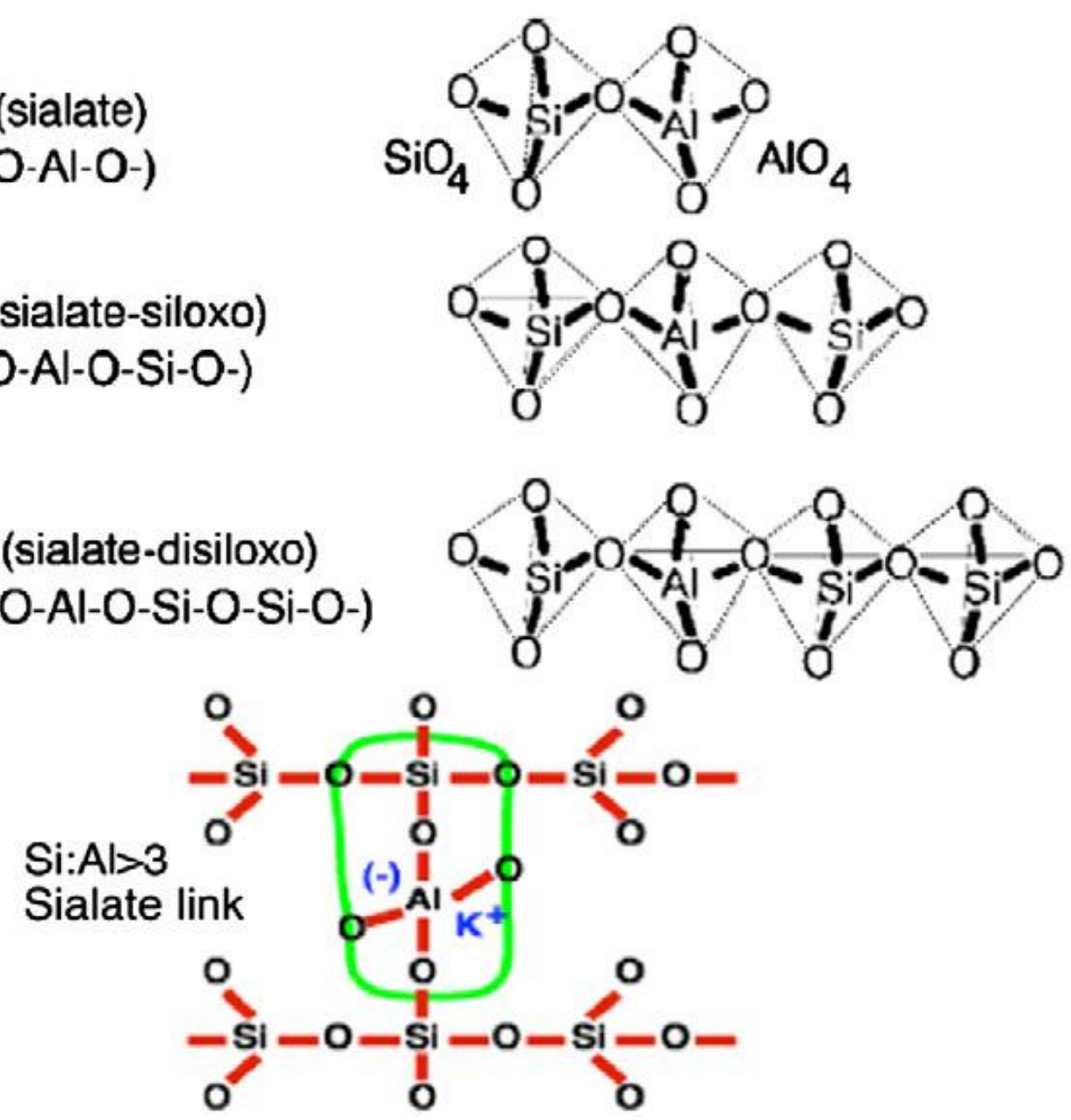

Figure 2-1Structure of Geopolymer (Source: Davidovits) 


\subsection{Properties of Geopolymer Concrete}

\subsubsection{Workability}

Water also play important role in geopolymer concrete as much as normal concrete. The used of water in geopolymer is to improve the workability, but it will increase the porosity in concrete due to the evaporation of water during curing process at elevated temperature (Sathia et al., 2008). Chindaprasirt et al. (2007) discovered an increase in sodium hydroxide and sodium silicate concentration will reduce the flow of mortar. The workable flow of geopolymer mortar was in the range of $110 \mathrm{~mm} \pm 5 \mathrm{~mm}$ to $135 \mathrm{~mm} \pm 5 \%$.

To improve the workability of mortar, superplasticiser or extra water can be added. However, the use of superplasticiser had an adverse effect on the strength of geopolymer. As such, extra water gives higher strength than addition of superplasticiser.

\subsubsection{Compressive Strength}

Compressive strength is an essential property for all concrete where it also depends on curing time and curing temperature. When the curing time and temperature increase, the compressive strength also increases. With curing temperature in range of 60 to $90^{\circ} \mathrm{C}$, within time in 24 to 72 $\mathrm{h}$, the compressive strength of concrete can be obtained about $40 \mathrm{~N} / \mathrm{mm}^{2}$ to $50 \mathrm{~N} / \mathrm{mm}^{2}$ (Chanh et al., 2008). In addition, the compressive strength of geopolymers also mainly depended on the content of fly ash fine particles (smaller than $43 \mu \mathrm{m}$ ). The compressive strength was increase when the finest of fly ash increase. Hence the nature and the concentration of the activators were dominant factors in the reaction of alkali activation. The highest compressive strength was obtained using a solution of sodium silicate as an activator $\left(n=1.5 ; 10 \% \mathrm{Na}_{2} \mathrm{O}\right)$. Sodium silicate is the most suitable as alkaline activator because it contains dissolved and partially polymerized silicon which reacts easily, incorporates into the reaction products and significantly contributes to improving the mortar characteristics (Komljenovi'c et al., 2010). 


\subsubsection{Curing Temperature}

Setting time of geopolymer depend on many factors such as composition of alkaline solution and ratio of alkaline liquid to fly ash by mass. However, the curing temperature is the most important factor for geopolymer. As the curing temperature increases, the setting time of concrete decreases (Chanh et al., 2008). During curing process, the geopolymer concrete experience polymerization process. Due to the increasing of temperature, polymerization become more rapid and the concrete can gain $70 \%$ of its strength within 3 to $4 \mathrm{~h}$ of curing (Kong and Sanjayan, 2008).

Unlike portland cement concrete geopolymer concrete is not cured with water, instead it requires heat (Rangan, 2007). The nature of these concretes depends on the source material, curing temperature and activating alkali solution (Duxson et al., 2007). The problem remains though by means of high energy consumption for heat curing and infeasibility of heat curing. High material cost also can be a constraint.

\subsection{Sustainable Aspect of Concrete with High Volume of Fly ash and/or slag}

As used in everyday speech, sustain means to support or to keep a process going, and the goal of sustainability is that life on the planet can be sustained for the foreseeable future. There are three components of sustainability: environment, economy, and society. To meet its goal, sustainable development must provide that these three components remain healthy and balanced. Furthermore, it must do so simultaneously and throughout the entire planet, both now and in the future. At the moment, the environment is probably the most important component, and an engineer or architect uses sustainability to mean having no net negative impact on the environment. Thus the term sustainable has come to be synonymous with environmentally sound or friendly and "green."

The environmental component has our attention now because deterioration of our environment is driving the current worldwide focus on sustainable development. We could cite countless examples of environmental deterioration, and all are important. 
Probably the most troubling for the long-term health of the planet and for the goal of sustainability are the climate changes resulting from the thinning of the ozone layer and the progressive decline in biodiversity resulting from loss of habitat. Both of these changes are a direct result of human development. The economic component is given less attention in the developed countries of the world, but is equally essential to the goal of sustainable development. There is poverty throughout the planet, and the global inequities in consumption of resources are staggering. Economic sustainability and environmental sustainability are closely linked.

Concrete is manufactured from aggregates (rock and sand), hydraulic cement, and water. It usually contains a small amount of some chemical admixture, and (at least in the USA) it often contains a mineral admixture replacing some portion of the cement. A typical concrete formulation contains a large amount of coarse and fine aggregate, a moderate amount of cement and water, and a small amount of admixture. Most of these constituents are themselves manufactured products, byproducts, or materials extracted by mining. In order to assess the environmental impact of concrete manufacture, it is necessary to consider the impact of each separate constituent.

The aggregates are usually obtained by mining. The coarse and fine aggregates are usually mined separately. Occasionally aggregate is obtained as a by-product of some other process (e.g., slag or recycled concrete). Aggregates may be crushed and may be washed. They are usually separated into various size fractions and reconstituted so as to satisfy the grading requirements. They may need to be dried. A modest amount of energy is involved in all these processes. The principal wastes are dust and water, neither of which is especially damaging to the environment. The dust may be used in some other process or may be disposed in a landfill. The hydraulic cement may be straight portland cement or a mixture of portland cement and some proportion of a supplemental cementing material such as fly ash and/or slag. Portland cement is usually manufactured by heating a mixture of limestone and shale in a kiln to a high temperature (approximately $1500^{\circ} \mathrm{C}$ ), then intergrading the resulting clinker with gypsum to form a fine powder. Thus it is not surprising that the portland cement has a rather high embodied energy. The reaction between limestone and shale to produce clinker produces CO2. Furthermore, the fuel used in the kiln and the electricity in the grinding mills themselves produces some amount of gaseous waste, principally $\mathrm{CO}_{2}$ and $\mathrm{CO}$. These gases are nontoxic and are released to the atmosphere, where they contribute to global warming. Supplemental cementing materials, as 
noted above, may also be used as mineral admixtures in concrete. These are byproducts of other manufacturing processes and as such are taken to have minimal embodied energy.

The water in concrete is normally ordinary tap water with no further processing.

Thus it has very little embodied energy and no waste. It is only an environmental issue in locations where the water is already not sufficient for basic needs. Concrete is usually manufactured by combining and mixing these constituents in large batches in a ready-mixed concrete plant and hauling the mixture to the construction site in a truck. These processes (moving materials, mixing them, and hauling the concrete) require modest amounts of energy and produce small amounts of waste. Dust, unused concrete, and wash water contaminated with concrete are the principal waste, and the latter two wastes may be at least partially reclaimed and reused.

Concrete used in structural applications normally includes some amount of reinforcing steel, and in some applications this steel is pre-stressed. Pre-stressed concrete is often precast. Precast concrete is manufactured at a plant and heated to accelerate the early hydration reactions and allow rapid removal from formwork.

The origin, properties, and use of low levels of fly ash in concrete are now generally well established and accepted in the construction industry. However sustainability is the driving force behind the trend to higher fly ash replacement levels. For example in Canada, the Canadian Green Building Council has introduced a program that promotes the development and implementation of green building practices. This program is referred to as LEED (Leadership in Energy and Environmental Design). LEED is based on a point system such that points are earned for environmentally friendly actions taken during the building process. Projects are then LEED certified according to the following LEED Green Building Certification Levels:

- $\quad$ LEED Certified 26-32 points

- $\quad$ LEED Silver 33-38 points

- $\quad$ LEED Gold 39-51 points

- $\quad$ LEED Platinum 52-70 points

The LEED program is broken down into six point categories with a maximum number of points being 70:

- Sustainable Sites 14 points

- Water Efficiency 5 points 
- Energy and Atmosphere 17 points

- Materials and Resources 14 points

- Indoor Environmental Quality 15 points

- Innovation and Design Process Points 5 points

Concrete as a building material is very effective in earning LEED points. The maximum number of LEED points a project can receive through use of concrete is 23 points; 5 points through Sustainable Sites, up to 10 points through Energy and Atmosphere, 7 points through Materials and Resources, and 1 point through Innovative and Design Process. However, although 23 points are available through concrete, 6 of these points would be very difficult if not impossible to earn unless concrete contained low to high levels of supplementary cementing materials. For example, Materials and Resources

Credits 4.1 and 4.2 (Recycled Content) are only achieved with concrete if the concrete 6 building is built with 25 and $40 \%$ of the portland cement replaced with fly ash (or ground granulated blast furnace slag), respectively. Other examples where higher levels of fly ash replacement may be necessary to obtain maximum LEED points with concrete are:

Credit 5.1 (Regional Materials, 10\% Extracted and Manufactured Regionally)

Credit 5.2 (Regional Materials, 20\% Extracted and Manufactured Regionally)

Credit 8 (Durable Building)

Credit 2 (LEED Accredited Professional, Innovation and Design).

Although LEED certification for private buildings is still not mandatory and probably won't be in the near future, support for green buildings has increased over the last number of years in order to achieve a more environmentally friendly image. For example, Mountain Equipment Coop (MEC), a Canadian company that specializes in outdoor adventure products has recently built stores in Ottawa and Montreal that are LEED certified and insist all new MEC stores will be LEED certified. This is just one company's attempt to promote sustainability and environmentalism. Many cities and government agencies require LEED certification for new public buildings. For example, City of Vancouver, Alberta Infrastructure, City of Calgary, Manitoba Hydro, Public Works and Government Services Canada, and BC Buildings Corporation all require new public buildings to be LEED certified (Cement Association of Canada, 2005). Sustainability, durability, and economy are the paramount reasons for the use of high volume fly ash concrete instead of conventional portland cement concrete. As can be seen 
from the comparison below, high volume fly ash and/or slag modified concrete is more environmentally friendly and has more desirable technical properties then conventional concrete (Green Resource Center, 2004) 


\section{Chapter 3: Experimental Program for High Volume Fly Ash and/or Slag Modified Concrete}

\subsection{Introduction and Research Plan}

This chapter describes the materials and the mixture proportions for different concrete mixtures containing high volume fly ash and/or slag concrete.

\subsection{Materials}

The materials used in this study were selected on the basis of its local availability and continuous supply the after discussions with concrete, aggregate and materials suppliers. The representative aggregates were selected based on the approved list of aggregates provided by WVDOH.

\subsubsection{Cement}

For this specific testing commercially available Type I portland cement, which conforms the ASTM C 150 (Standard Specification for portland cement) was used. The basic physical properties and compound composition of cement are presented in Table 3.1 and 3.2 respectively.

Table 3.1 Basic Physical Properties of Type I portland cement Used.

\begin{tabular}{|c|c|c|c|}
\hline \multirow{2}{*}{ Specific Gravity } & \multirow{2}{*}{ Fineness } & \multicolumn{2}{|c|}{ Setting time } \\
\cline { 3 - 4 } & & Initial (min.) & Final (min.) \\
\hline 3.15 & $320 \mathrm{~m}^{2} / \mathrm{kg}\left(1561 \mathrm{ft}^{2} / \mathrm{lb}\right)$ & 90 & 260 \\
\hline
\end{tabular}


Table 3.2 Compound Composition of Type I portland Cement Used.

\begin{tabular}{|c|c|}
\hline Compounds & percentage by mass \\
\hline Tricalcium Silicate $\left(\mathrm{C}_{3} \mathrm{~S}\right)$ & 49.0 \\
\hline Dicalcium Silicate $\left(\mathrm{C}_{2} \mathrm{~S}\right)$ & 25.0 \\
\hline Tricalcium Aluminate $\left(\mathrm{C}_{3} \mathrm{~F}\right)$ & 12.0 \\
\hline Tetracalcium Aluminoferrite $\left(\mathrm{C}_{4} \mathrm{AF}\right)$ & 8.0 \\
\hline Calcium Sulfate $\left(\mathrm{CSH}_{2}\right)$ & 2.2 \\
\hline Calcium Oxide $(\mathrm{CaO})$ & 0.8 \\
\hline Magnesium Oxide $(\mathrm{MgO})$ & 2.0 \\
\hline Others & 1.0 \\
\hline
\end{tabular}

\subsubsection{Aggregates}

The Aggregates used in this study are described below.

\subsubsection{Coarse Aggregate}

One type of graded coarse aggregates was used in this study conform the ASTM C 33 (Standard Specification for Concrete Aggregates). The properties and sieve Analysis described in Table 3.3 (a) for crushed \#8 limestone with a maximum size of $9.5 \mathrm{~mm}$ (3/8 in) and Table 3.3 (b) sieve analysis of \#8 limestone aggregate.

Table 3.3 Properties of Coarse Aggregates

\begin{tabular}{|c|c|}
\hline Properties & Value \\
\hline Absorption (\%) & 0.53 \\
\hline SSD Specific Gravity & 2.69 \\
\hline Bulk Specific Gravity & 2.68 \\
\hline Apparent Specific Gravity & 2.719 \\
\hline
\end{tabular}


Table 3.4 Properties of Coarse Aggregates

\begin{tabular}{|c|l|c|c|c|c|}
\hline \multicolumn{2}{|c|}{ Sieve Size } & $\begin{array}{c}\text { Wt. } \\
\text { retained }\end{array}$ & $\begin{array}{c}\text { Amount } \\
\text { Retained }\end{array}$ & $\begin{array}{c}\text { Cumulative } \\
\text { amount } \\
\text { retained }\end{array}$ & $\begin{array}{c}\text { Cumulative } \\
\text { amount } \\
\text { Passing }\end{array}$ \\
\cline { 3 - 6 } & $\mathbf{( g m . )}$ & $\mathbf{( w t . ~ \% ) ~}$ & $\mathbf{( \% )}$ & $\mathbf{( \% )}$ \\
\hline $12.5 \mathrm{~mm}$ & $3 / 4$ & 0.00 & 0.00 & 0.00 & 100.00 \\
\hline $9.5 \mathrm{~mm}$ & $3 / 8 "$ & 4.50 & 0.41 & 0.41 & 91.26 \\
\hline $4.75 \mathrm{~mm}$ & No. 4 & 127.20 & 11.45 & 11.46 & 88.14 \\
\hline $2.36 \mathrm{~mm}$ & No. 8 & 827.20 & 74.47 & 86.33 & 13.67 \\
\hline $1.18 \mathrm{~mm}$ & No. 16 & 140.60 & 12.76 & 98.98 & 1.02 \\
\hline
\end{tabular}

$\left(1 \mathrm{~mm}=0.039\right.$ in., $1 \mathrm{gm}=2.205 \times 10^{-3} \mathrm{lb}, 1 \mu \mathrm{m}=3.937 \times 10^{-5}$ in $)$

\subsubsection{Fine Aggregate}

One type of fine aggregate (sand) conforming to ASTM C 33 (Standard Specification for Concrete Aggregates) was used in this study. The fine aggregates were Natural Sand provided by Arrow Concrete and with the following properties and sieve analysis.

Table 3.5 Properties of fine aggregates

\begin{tabular}{|c|c|}
\hline \multicolumn{2}{|c|}{ Source and Basic Properties } \\
\hline Facility Source & Arrow Concrete \\
\hline Type & Natural river sand \\
\hline SSD Specific Gravity & 2.61 \\
\hline Bulk Specific Gravity & 2.59 \\
\hline Apparent Specific Gravity & 2.65 \\
\hline Absorption & $1.0 \%$ \\
\hline
\end{tabular}


Table 3.6 Sieve analysis for natural river sand

\begin{tabular}{|l|c|c|c|c|c|}
\hline \multirow{2}{*}{ Sieve Size } & $\begin{array}{c}\text { Wt. } \\
\text { retained }\end{array}$ & $\begin{array}{c}\text { Amount } \\
\text { Retained }\end{array}$ & $\begin{array}{c}\text { Cumulative } \\
\text { amount } \\
\text { retained }\end{array}$ & $\begin{array}{c}\text { Cumulative } \\
\text { amount } \\
\text { Passing }\end{array}$ \\
\cline { 3 - 6 } & (gm.) & (wt. \%) & (\%) & (\%) \\
\hline $9.5 \mathrm{~mm}$ & $3 / 8$ " & 0.00 & 0.00 & 0.00 & 100.00 \\
\hline $4.75 \mathrm{~mm}$ & No. 4 & 25.50 & 4.98 & 4.98 & 95.02 \\
\hline $2.36 \mathrm{~mm}$ & No. 8 & 58.30 & 11.39 & 16.37 & 83.63 \\
\hline $1.18 \mathrm{~mm}$ & No. 16 & 55.10 & 10.76 & 27.13 & 72.87 \\
\hline $600 \mu \mathrm{m}$ & No. 30 & 90.80 & 17.74 & 44.87 & 55.13 \\
\hline $300 \mu \mathrm{m}$ & No. 50 & 217.30 & 42.45 & 87.32 & 12.68 \\
\hline $75 \mu \mathrm{m}$ & & 60.30 & 11.78 & 99.10 & 0.90 \\
\hline \multicolumn{2}{|c|}{$\left(1 \mathrm{~mm}=0.039\right.$ in., $\left.1 \mathrm{gm}=2.205 \times 10^{-3} \mathrm{lb}, 1 \mu \mathrm{m}=3.937 \times 10^{-5} \mathrm{in}\right)$} \\
\hline
\end{tabular}

\subsubsection{Mineral Admixtures}

Two kinds of mineral admixtures were used for this study. The properties are described below.

\subsubsection{Fly Ash}

Class F fly Ash (Fly Ash) is one of the residues generated in combustion of coal. It is finer than cement and consists of glassy-spherical particles. The Class F fly ash from Hatfield Power station, PA was used in this study, supplied by Arrow Concrete. The fly ash conforms to ASTM C 618. The basic properties of fly ash are presented in Table 3.6.

Table 3.7 Basic Properties of Fly Ash.

\begin{tabular}{|c|c|}
\hline Specific Gravity & 2.47 \\
\hline Specific Surface $\left(\mathrm{m}^{2} / \mathrm{kg}\right)$ & 496 \\
\hline Loss of ignition, $\%$ & 3.00 \\
\hline $\mathrm{SiO}_{2}, \%$ & 49.34 \\
\hline $\mathrm{Al}_{2} \mathrm{O}_{3}, \%$ & 22.73 \\
\hline $\mathrm{CaO}, \%$ & 3.09 \\
\hline $\mathrm{MgO}, \%$ & 1.06 \\
\hline $\mathrm{SO}_{3}, \%$ & 0.156 \\
\hline $\mathrm{Na}_{2} \mathrm{O}, \%$ & 0.57 \\
\hline $\mathrm{K}_{2} \mathrm{O}, \%$ & - \\
\hline $\mathrm{Fe}_{2} \mathrm{O}_{3}, \%$ & - \\
\hline$\left(1 \mathrm{~m}^{2} / \mathrm{kg}=703.07 \mathrm{in}^{2} / \mathrm{lb}\right)$ \\
\hline
\end{tabular}

$\left(1 \mathrm{~m}^{2} / \mathrm{kg}=703.07 \mathrm{in}^{2} / \mathrm{lb}\right)$ 


\subsubsection{Slag}

Ground granulated blast-furnace slag (Slag), is defined as a finely ground glassy granular material made from iron blast-furnace slag when it is rapidly chilled. The commercially available ground granulated blast-furnace slag (Slag) of grade 100 was used conformed to ASTM C 989 (Standard Specification for G.G.B.F Slag for Use in Concrete and Mortars). The basic properties of the slag provided by Arrow Concrete Company are presented in the following table.

Table 3.8 Basic Properties of Slag.

\begin{tabular}{|c|c|}
\hline Specific Gravity & 2.88 \\
\hline Specific Surface $\left(\mathrm{m}^{2} / \mathrm{kg}\right)$ & 581 \\
\hline Loss of ignition, $\%$ & 0.00 \\
\hline $\mathrm{SiO}_{2}, \%$ & 36.00 \\
\hline $\mathrm{Al}_{2} \mathrm{O}_{3}, \%$ & 12.00 \\
\hline $\mathrm{CaO}, \%$ & 42.00 \\
\hline $\mathrm{MgO}, \%$ & 6.00 \\
\hline $\mathrm{SO}_{3}, \%$ & 0.20 \\
\hline $\mathrm{Na}_{2} \mathrm{O}+0_{0} 685 \mathrm{~K}_{2} \mathrm{O} \%$ & 0.74 \\
\hline Other Oxides $\%$ & 1.8 \\
\hline $\mathrm{Fe}_{2} \mathrm{O}_{3}, \%$ & 1.2 \\
\hline Appearance & White Powder \\
\hline Odor & No Distinct odor \\
\hline Physical State & Solid (powder) \\
\hline pH Value (in water) & 10.5 to 12.7 \\
\hline Solubility in water, $\%$ & Slightly $(0.1$ to 1.0$)$ \\
\hline Melting Point $\left({ }^{\circ} \mathrm{C}\right)$ & $1300-1350$ \\
\hline
\end{tabular}

$$
\left(1 \mathrm{~m}^{2} / \mathrm{kg}=703.07 \mathrm{in}^{2} / \mathrm{lb}\right)
$$

\subsubsection{Chemical Admixtures}

Chemical admixtures manufactured chemicals which are added to the concrete before or during mixing and are used to give special properties to fresh or hardened concrete. For this project two kinds of chemical admixtures were used. 


\subsubsection{High Range Water Reducing Admixture}

It is a special class of water-reducer admixture also known as superplasticizer depending on its application. It reduces the water content in a given concrete mix between 12 to $30 \%$. Glenium 3030 NS high-range water reducing admixture (HRWRA) type A/F conforming the ASTM C 494 was used for this study and it was provided by BASF.

\subsubsection{Air Entraining Admixture}

Air Entraining is a liquid chemical added during mixing of concrete to produce microscopic air bubbles known as entrained air. The commercial air-entraining admixture used for this study conforming the ASTM C 260 (Standard Specification for Air-Entraining Admixtures for Concrete) and the material was provided by BASF.

\subsubsection{Mixing Water}

The mixing water used in this study was tap water from the Morgantown city water supply and was assumed to have a density of $100 \mathrm{Kg} / \mathrm{m}^{3}\left(169 \mathrm{lb} / \mathrm{yd}^{3}\right)$.

\subsection{Mixture Proportions}

Mixture proportions are prepared in accordance with ACI 211.1. The most common method used in North America is that established by ACI Recommended Practice 211.1. The process is followed as, at the beginning the job parameters - aggregate properties, maximum aggregate size, slump, w/cm, admixtures, determined, then calculation of batch weight is done. At first the $\mathrm{w} / \mathrm{cmn}$ is determined. Water/ cementitious ratio $(\mathrm{w} / \mathrm{cm})$ theory states that for a given combination of materials and as long as workable consistency is obtained, the strength of concrete at a given age depends on the $\mathrm{w} / \mathrm{cm}$ as lower the $\mathrm{w} / \mathrm{cm}$, the higher the concrete strength. Whereas strength depends on the w/cm, economy depends on the percentage of aggregate presence that would still give a workable mix. The aim of the designer should always be to get concrete mixtures of optimum strength at minimum cement content and acceptable workability. Amount of air and 
water is decided using the table 3.2 of ACI 211.1. Although minimum of $175 \mathrm{~kg}$ of water is recommended, only $150 \mathrm{~kg}$ and $125 \mathrm{~kg}$ of water were considered for addition, for two different concrete with different water ratio. This modification was required for high volume fly ash and high volume slag concrete. The mix design is done for moderate environmental condition so the air void ration is considered $5.5 \%$ by volume. $\mathrm{W} / \mathrm{cm}$ is then selected using table 3.3 of ACI 211.1. Presence of large amount of pozzolans may affect the strength so $\mathrm{w} / \mathrm{cm}$ is selected as 0.3 and 0.25 respectively. Cement content is decided by multiplying amount of water to be added with the w/cm. Shrinkage increase due to high volume of finer material restricts the use of cementitious material less than $408 \mathrm{~kg} / \mathrm{m}^{3}$. Here we used $500 \mathrm{~kg}$ for the research purpose to ensure the quality. Amount of course aggregate is chosen using the table 3.4 of ACI 211.1, and amount of fine aggregate is calculated using volume batching method and table 3.5 of ACI 211.1. The mix design table is provided below.

Table 3.9 Mix Proportions

\begin{tabular}{|c|c|c|c|c|c|c|c|c|c|c|}
\hline & & & & & Cement & Fly ash & Slag & $\mathbf{C A}$ & Water & $\mathbf{F A}$ \\
\hline Name & Cement \% & Fly Ash \% & Slag \% & $\mathbf{w} / \mathbf{c m}$ & Kg & Kg & $\mathbf{K g}$ & Kg & $\mathbf{K g}$ & Kg \\
\hline FA40 (0.3) & 60 & 40 & $\mathbf{0}$ & 0.3 & 300 & 200 & $\mathbf{0}$ & 982 & 150 & 703 \\
\hline FA50 (0.3) & 50 & 50 & $\mathbf{0}$ & 0.3 & 250 & 250 & $\mathbf{0}$ & 982 & 150 & 685 \\
\hline SL50 (0.3) & 50 & $\mathbf{0}$ & 50 & 0.3 & 250 & $\mathbf{0}$ & 250 & 982 & 150 & 748 \\
\hline FA60 $(0.3)$ & 40 & 60 & $\mathbf{0}$ & 0.3 & 200 & 300 & $\mathbf{0}$ & 982 & 150 & 667 \\
\hline SL60 (0.3) & 40 & $\mathbf{0}$ & 60 & 0.3 & 200 & $\mathbf{0}$ & 300 & 982 & 150 & 743 \\
\hline FA35+SL35 (0.3) & 30 & 35 & 35 & 0.3 & 150 & 175 & 175 & 982 & 150 & 694 \\
\hline SL40 (0.3) & 60 & $\mathbf{0}$ & 40 & 0.3 & 300 & $\mathbf{0}$ & 200 & 982 & 150 & 753 \\
\hline FA30+SL30 (0.3) & 40 & 30 & 30 & 0.3 & 200 & 150 & 150 & 982 & 150 & 705 \\
\hline FA25+SL25 (0.3) & 50 & 25 & 25 & 0.3 & 250 & 125 & 125 & 982 & 150 & 717 \\
\hline Control (0.3) & 100 & $\mathbf{0}$ & $\mathbf{0}$ & 0.3 & 500 & $\mathbf{0}$ & $\mathbf{0}$ & 982 & 150 & 774 \\
\hline Control (0.25) & 100 & $\mathbf{0}$ & $\mathbf{0}$ & 0.25 & 500 & $\mathbf{0}$ & $\mathbf{0}$ & 982 & 125 & 839 \\
\hline FA35+SL35 (0.25) & 30 & 35 & 35 & 0.25 & 150 & 175 & 175 & 982 & 125 & 759 \\
\hline SL60 (0.25) & 40 & $\mathbf{0}$ & 60 & 0.25 & 200 & $\mathbf{0}$ & 300 & 982 & 125 & 808 \\
\hline FA60 (0.25) & 40 & 60 & $\mathbf{0}$ & 0.25 & 200 & 300 & $\mathbf{0}$ & 982 & 125 & 732 \\
\hline
\end{tabular}

CA: Coarse Aggregate; FA: Fine Aggregate

HRWRA (High Range Water Reducing Admixture): $3000 \mathrm{ml}-5850 \mathrm{ml}$

AEA (Air Entraining Admixture): $250 \mathrm{ml}$ 


\subsection{Testing Procedures of High Volume high volume fly ash and/or slag modified concrete}

\subsubsection{Mixing of Concrete}

As the w/cm can have significant influence on the strength and hydration of high volume fly ash and/or slag modified concrete mixes, the moisture content of aggregates were maintained strictly and surface moisture quantities were subtracted from the total water quantity to keep the w/cm constant. Variable dosage of HRWRA was used to get workable yet stable mixtures. For mixing, a non-tilting horizontal axis variable speed laboratory mix was used. All the mixing was completed within 15 20 minutes.

Mixing procedures were based on guidelines and sequences recommended by industry experts and established literatures. The detailed mixing sequences are listed as follows,

- Batched the material by weight

- Added the AEA to the fine aggregate

- Added the coarse aggregates, and 3/4 of the mixing water

- Added the fine aggregate to mixer, and mixed it for another 2 minutes;

- Added cement and fly ash and/or slag or both as the case may be in one third quantities each time and rotated the mixer for some time. The procedure was repeated for three times

- $1 / 3$ rd of HRWRA was added to the remaining water, and stirred

- The solution (water + HRWRA) was added to the mixture and rotated for couple of minutes

- Added the remaining HRWRA, if required and mixed for about 3 4 minutes

- Rotated the mixer until the concrete become workable 


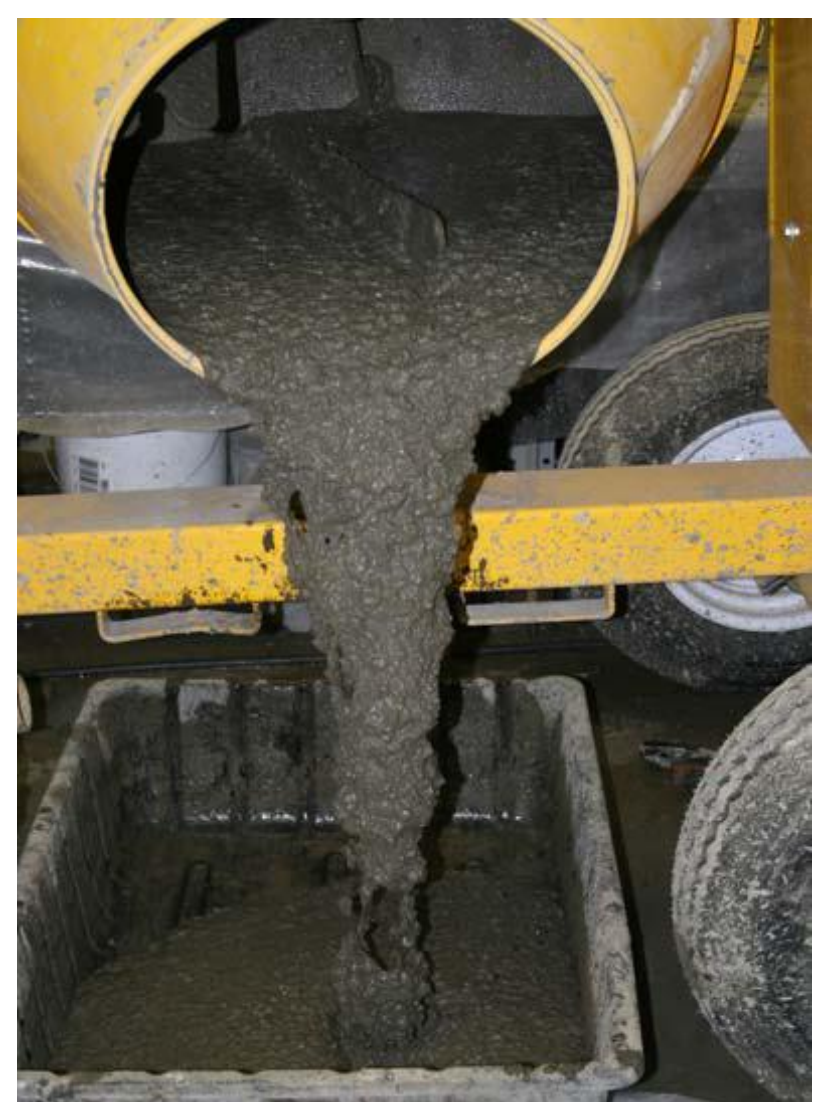

Figure 3-1Concrete Making

\subsubsection{Testing}

Testing procedures for the concrete materials and process is described.

\subsubsection{Compressive Strength Development}

Compressive strength is the single most important property of concrete evaluation. Compressive strength was measured as per ASTM C 31.

The compressive strength test was conducted at different ages with the purpose of monitoring the strength development of HPC with time. Early age strength is a guide for finishing and curing, and later strength is a measure of long-term performance. Values of compressive strength will depend on the size and shape of the specimen, batching, mixing procedures, methods of sampling, molding, age, temperature, and moisture conditions during curing. 
Cylinder specimens of $100 \mathrm{~mm}$ (4 in) X 200mm ( 8 in) dimension were prepared for compression testing. High volume fly ash and/or slag modified concrete samples are tested for 3 days, 7 days, 28 days, 56 days and 90 days respectively.

\subsubsection{Free Shrinkage with Time}

Free shrinkage test was conducted as per ASTM C 157. For each of the high volume fly ash and/or slag modified concrete mix, three $76.2 \mathrm{~mm} \times 76.2 \mathrm{~mm} \times 311.2 \mathrm{~mm}$ ( 3 in $\times 3$ in x $11.75 \mathrm{in}$ ) prisms were cast. After one day curing under wet burlap, the prisms were de-molded and kept in an environmental chamber at a temperature of $23 \mathrm{C}(73 \mathrm{~F})$ and relative humidity of $50 \%$. The onset of drying after one day was selected to capture shrinkage from early age.

Strain measurements were performed by embedding vibrating wire strain gauges (VWSG) of gauge length $100 \mathrm{~mm}(4 \mathrm{in})$ in the center of the molds. The main reason for using the VWSG was to eliminate human error in recording the strains through the length comparator and due to its high sensitivity. Vibrating wire principle is used in this type of strain gauges. A length of steel wire is tensioned between two end blocks that are embedded in concrete. Strain changes of the concrete mass results in relative movement of the end blocks, which in turn causes tension in the steel wire. This tension is measured by plucking the wire and the resonant frequency is measured by using an electro-magnetic coil. The other advantages of this type of strain gauges are excellent long term stability, maximum resistance to the effects of moisture and suitable for transmission over long ranges. The VWSG was suspended in the center of the prism mold using metal ties connected to the rigid part of the mold within the free shrinkage specimens. The specimens were de-molded after 24 hours of casting and left dry in the humidity chamber in order to measure the shrinkage. The VWSG was connected to a data logger which recorded strains for every 2 seconds until 90 days after casting. Figure 3-2 shows the molds for free shrinkage with the VWSG. Figure 3-3 specimens along with the data acquisition system for the shrinkage test. 


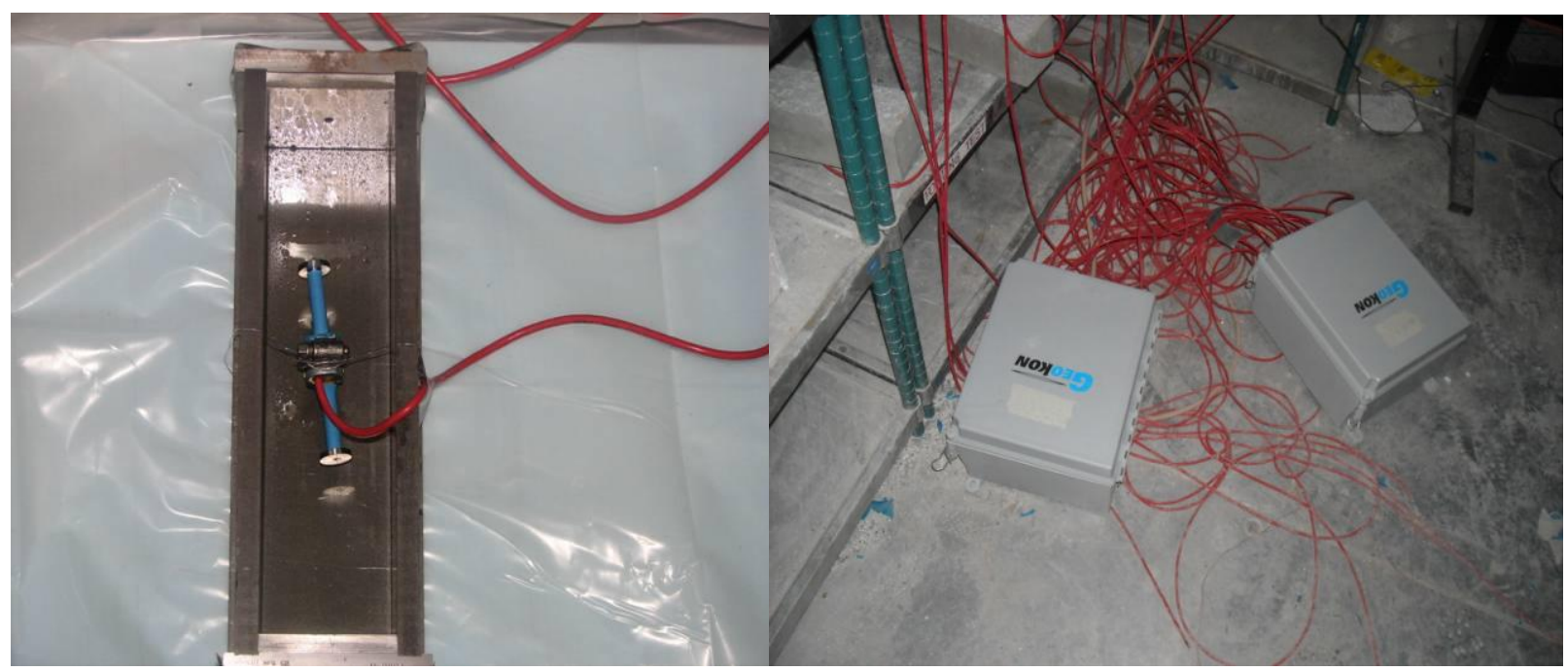

Figure 3-2Vibratory Shrinkage Set Up

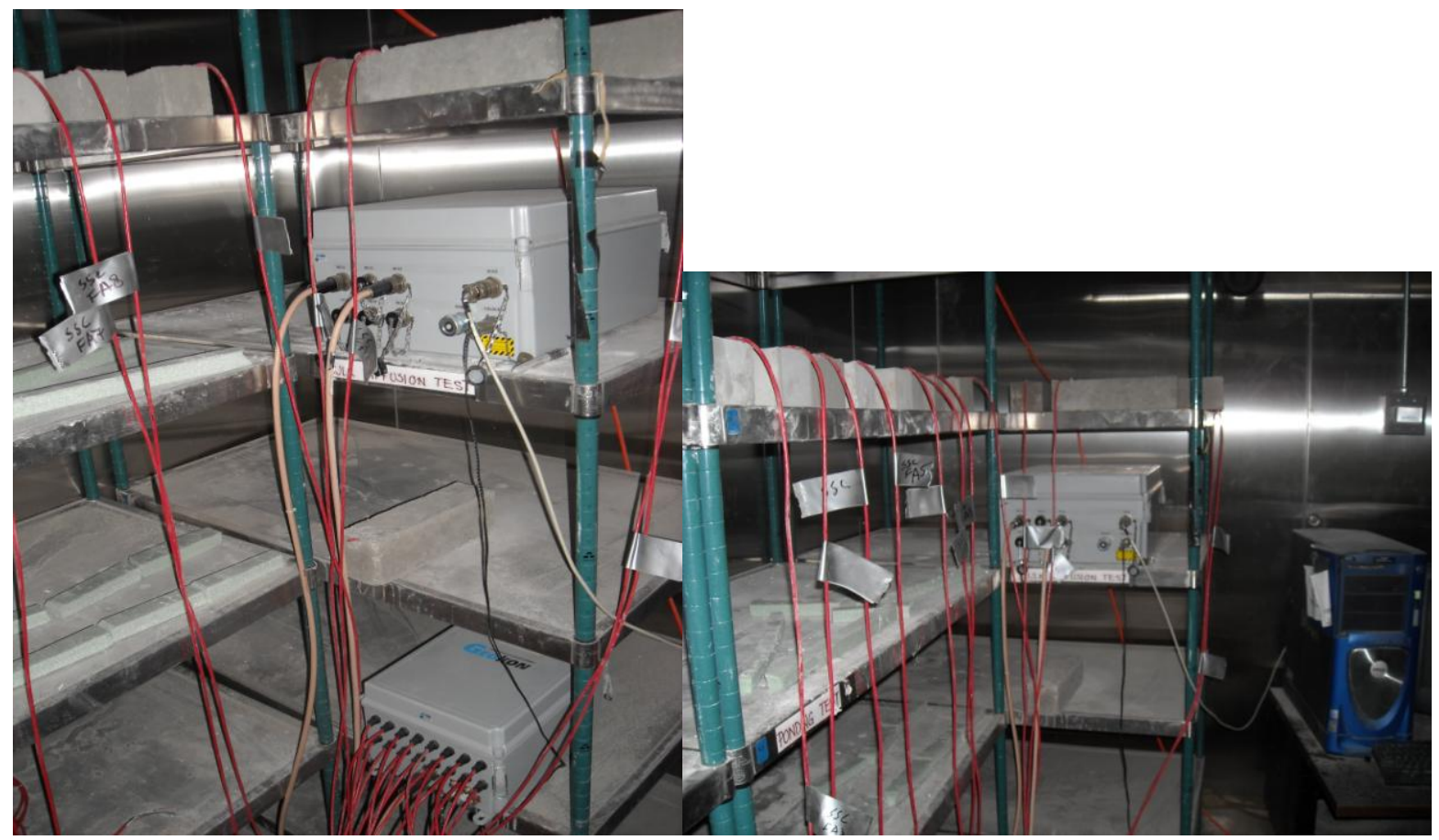

Figure 3-3Data Collection Set Up

\subsubsection{Maturity of Concrete}

This practice provides a procedure for estimating concrete strength by means of the maturity method. This method is a technique for estimating concrete strength based on the assumption that samples of a given concrete mixtures reach equal strength if they have equal values of a 
maturity index, that is an indicator of maturity calculated from the temperature history of the cementitious mixture by using a maturity function (ASTM C 1074).

Compressive strength is the most important property for the evaluation of concrete mixtures, as all material and design specifications are closely related to this parameter. In this work the strength evolution of concrete was monitored to establish what the strength development of high volume fly ash and/or slag concrete mixes as replacement of portland cement with large quantity of fly ash and/or slag tend to affect the strength development particularly at early age. The maturity method provides an easy and efficient approach for making determinations of in-place concrete strength during construction.

Applying the method leads to the knowledge of know when external loads as post-tension and live loads could be applied, and an earlier determination of when formwork can be removed, resulting in a faster construction and significant cost savings. Using concrete maturity in combination with, or instead of, testing different specimens such as cylinders to measure concrete strength can improve quality control, because the Maturity method is based on data obtained from the real structure.

Three steps are required to carry out the Maturity method: 1) Development of the maturity calibration curve for the specific mix; 2) Estimation of the in-situ strength of the concrete using the maturity index calculated from the recorded temperature history; 3) Verification of the strength-maturity relationship.

This practice has some limitations; like that it is important that the concrete must be maintained in a condition that permits the cement hydration. Also the maturity method does not take into account the effects of early-age concrete temperature on the long-term strength, and it is needed to have other indications of the potential strength of the concrete mixtures.

In the ASTM C 1074 two functions for computing the maturity index from the measure temperature history of the concrete are described, one is the temperature time factor and the other 
one uses the equivalent age. In our study the temperature-time factor was used determine the maturity, which is based o Nurse-Saul function.

Due to the kind of maturity loggers and the temperature reader used in this project and because the Nurse-Saul function is more commonly used by various states highways agencies in the United States, it was opted to use in this project the maturity function described in the ASTM C 1074 as temperature-time factor function:

$M(t)=\sum(T a-T o) \Delta t$

\section{1}

Where

$\mathrm{M}(\mathrm{t}) \quad=$ Temperature-time factor at age $\mathrm{t}$. degree-days or degree-hours.

$\Delta \mathrm{t}=$ Time interval, days or hours.

Ta $=$ Average concrete temperature during time interval, $\Delta \mathrm{t},{ }^{\circ} \mathrm{C}$

To $=$ Temperature subtracted from measure concrete temperature (recommended value $0{ }^{\circ} \mathrm{C}$ $\left.=32^{\circ} \mathrm{F}\right)$.

An important variable in the equation is the datum temperature that is the temperature at which concrete strength gain ceases, therefore the time periods during the concrete is below this point do not contribute to strength gain. Recommended values for the datum temperature are provided in ASTM C 1074. The datum temperature is affected by parameters such as cement fineness, particle size distribution, w/cm, cement composition, admixtures, and initial temperature.

The datum temperatures assumed for this project after recommendations from Engius (Maturity loggers manufacturer) and discussion with the advisory panel was of $0^{\circ} \mathrm{C}\left(32^{\circ} \mathrm{F}\right)$ for all the concrete mixtures.

In these project two cylindrical specimens 152 x $304 \mathrm{~mm}(6 \times 12 \mathrm{in})$ was used for each type of concrete mix. Maturity values are correlated to strength on different point. 


\subsubsection{Freezing and Thawing Durability}

Concrete is vulnerable to damage under repeated cycles of freezing and towing because it is a porous material that contains moisture. For mixes with w/cmm higher that 0.24 is required the addition of air entrained admixtures to be able to resist this freezing and thawing cycles taking into account that a decrease in the $\mathrm{w} / \mathrm{cmm}$ ratio improves the ability of concrete to resist cycles of freeze and thawing. To achieve a stable air-void system in high performance concrete, quantities of air-entraining agent may be higher than the quantities used for conventional concretes. However, because high strength concrete has a low $\mathrm{w} / \mathrm{cmm}$ ratio, there is not much freezable water so lower air contents may prove satisfactory resistance to freeze and thawing, which is important because there is approximately a 5\% loss of total strength for each $1 \%$ of air content increased (Mindess et.al. 2003).

The microscopic air bubbles created by the air entrained provide chambers for the water to enter and thus relieve the hydraulic pressure. When the concrete contains saturated aggregate hydraulic pressure can also be generated within the aggregates, but good quality paste will prevent most aggregate particles from becoming saturated. The bubbles create a system called the air-void system which is fundamental because it accommodates the small amounts of excess water that may be expelled from aggregates, thus protecting the concrete from freeze-thaw damage, making the concrete in this way more durable (Kosmatka et.al, 2006).

Three specimens were cast at the laboratory for each concrete mix, then after 28 days of curing the samples were placed in thawing water to begin the testing cycles. The specimens were removed from the apparatus in thawed condition at 30 cycle interval. As per the standard, the maximum interval can be 36 cycle. After removal, the fundamental transverse frequency and the mass were measured and returned back to the apparatus for following cycles.

- Molded beam specimens should be cured for 14 days prior to testing.

- Then bring the specimens to a temperature within $-1 \mathrm{C}$ and $+2 \mathrm{C}$ of the target thaw temperature that will be used in the freeze-thaw cycle and test for fundamental transverse frequency, determine the mass and average length and cross section dimensions of the concrete specimen. 
- Start the test by placing the specimens in the water containers and run the apparatus for no more than 36 cycles and then test for fundamental transverse frequency and the mass.

- Change the water in the container and place the specimen in a different position in the apparatus, then run the test again until, it has been subjected to 300 cycles or until its relative dynamic modulus of elasticity reaches $60 \%$ of the initial modulus.

- Whenever the specimens are tested for modulus of elasticity is important to make notes of its visual appearance and to make comments of any defect.

Note: when the sequence of freezing and thawing cycles on, must not be interrupted, when it is stored in frozen condition.

The Relative dynamic modulus of elasticity $(\mathrm{Pc})$ is calculated as follows:

$$
P_{c}=\left(n_{1}^{2} / n^{2}\right) x 100
$$

\section{2}

Where:

$\mathrm{n} \quad=$ fundamental transverse frequency at 0 cycles of freezing and thawing.

$\mathrm{n}_{1} \quad=$ fundamental transverse frequency after c cycles of freezing and thawing.

The durability factor (DF) is calculated as follows:

$$
D F=P N / M
$$

\section{3}

Where:

$\mathrm{P} \quad=$ relative dynamic modulus of elasticity at $\mathrm{N}$ cycles, $\%$.

$\mathrm{N} \quad=$ number of cycles at which $\mathrm{P}$ reaches the specified minimum value for discontinuing the test or the specified number of cycles at which the exposure is to be terminated, whichever is less.

$\mathrm{M}=$ specified number of cycles at which the exposure is to be terminated. 
Two prism specimens of $75 \mathrm{~mm}$ (3 in) X $100 \mathrm{~mm}$ (4 in) X $405 \mathrm{~mm}$ (16 in) of each concrete mix were prepared for freezing and thawing test in this project.

\subsubsection{Rapid Chloride Penetration for Resistance}

The problem of chloride attack arises usually when chloride ions ingress from outside. This can be caused by application of de-icing salts in bridge decks during winter season. Ingress of chloride ion takes place by none-steady state diffusion. The protective passive layer on the surface of embedded steel consists of gama- $\mathrm{Fe}_{2} \mathrm{O}_{3}$ that tightly adheres to the steel, which protects the steel to be intact. However, this layer can be destroyed with the presence of chloride ion. This is one the major problem nowadays for the concrete bridge decks and girders in USA.

This practice covers the laboratory evaluation of the electrical conductance of concrete samples to provide a rapid indication of their resistance to chloride ion penetration. This test method is suitable for evaluation of materials and material proportions for design purposes and research and development.

This test method consist of monitoring the amount of electrical current passed through $51 \mathrm{~mm}$ (2-in) thick slices of $102 \mathrm{~mm}$ (4-in) nominal diameter from the top of cylinders during 6-h period.

The total charge passed (coulombs) from this test method must be used with caution, especially in applications such as quality control and acceptance testing.

The rapid chloride permeability test of disc specimens cut from laboratory cured specimens and cored specimens was conducted in accordance with ASTM C 1202 (Standard Test Method for Electrical Indication of Concrete's Ability to Resist Chloride Ion Penetration). The specimens were conditioned and then tested following the next steps:

Conditioning is done by, 
- Vigorously a liter or more of tap water was boiled in a large sealable container, and allowed to cool to ambient temperature.

- Since the diameter of the core specimens was slightly larger than $102 \mathrm{~mm}$ (4-in) it was needed to grind the specimens until the required diameter was obtained. Then the specimens were place on a suitable support while coating to ensure complete coating of sides (for coating was used 100\% silicon sealant). Allowing curing of the coating for 24 .

- After curing the specimens are placed in vacuum desiccators. Both end faces of specimen must be exposed. The desiccators were sealed and vacuum pump is started to reduce internal pressure to less than $1 \mathrm{~mm} \mathrm{Hg}$ and then maintain at that level for 3 hours.

- With the vacuum pump still working sufficient water is drained into beaker or container to cover specimen (do not allow air to enter desiccators). And the vacuum pump is allowed to run for one more hour and then the pump is turned off and the air is allowed to re-enter the desiccators.

- The specimens are soaked under water (the water used before) for $18 \pm 2 \mathrm{~h}$.

Procedures for the test are,

- The specimens are removed from water, and then placed on cells sealing around specimen-cell boundary with $100 \%$ silicone sealant (no leaking is allowed).

- After the silicone has cured for $24 \mathrm{~h}$ the cell containing the top surface of the specimen is filled with $3.0 \% \mathrm{NaCl}$ solution. (That side of the cell will be connected to the negative terminal of the power supply) and the other side of the cell (Which will be connected to the positive terminal of the power supply) was filled with $0.3 \mathrm{~N}$ $\mathrm{NaOH}$ solutions.

- Finally the power supply is turned on and set to $60.0 \pm 0.1 \mathrm{~V}$. and the readings were taken for every $5 \mathrm{~min}$ for the first $60 \mathrm{~min}$ and the every $30 \mathrm{~min}$ until $360 \mathrm{~min}(6 \mathrm{~h})$. Temperatures of the specimen, applied voltage cell, and solution shall be 20 to $25^{\circ} \mathrm{C}$ ( 68 to $77^{\circ} \mathrm{F}$ ) at the time the test is initiated, that is, when the power supply is turned on. 
During the test, the temperature of the solution should not be allowed to exceed $190{ }^{\circ} \mathrm{F}\left(90^{\circ} \mathrm{C}\right)$ in order to avoid damage to the cell and to avoid boiling of the solution.
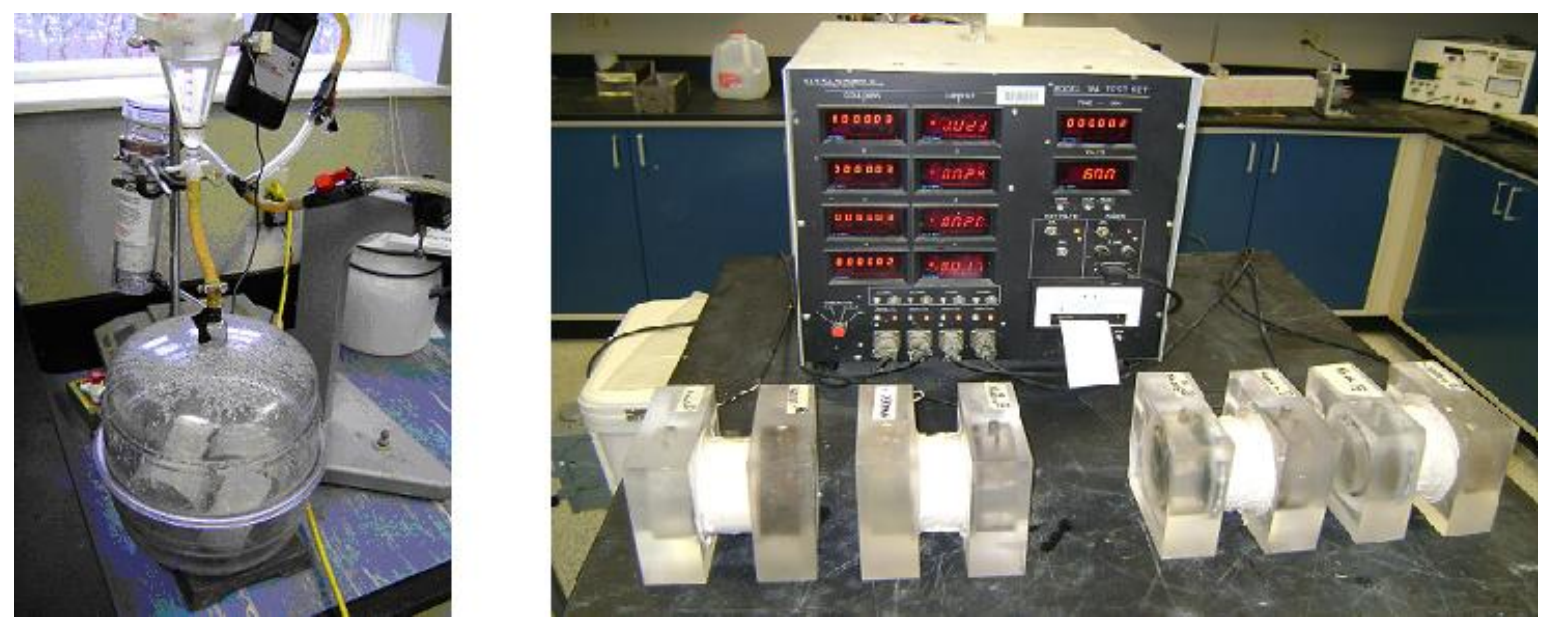

Figure 3-4 Conditioning and Testing Samples for RCPT

To obtain the ampere-seconds or coulombs of charge passed during the 6-hours test period is needed to integrate the area underneath the curve obtained from plotting the current (in amperes) versus time (in seconds). But in this case was used an automatic data processing equipment to perform the integration during the test and to display the coulomb value. This total charge passed is a measure of the electrical conductance of the concrete during the period of the test.

To obtain a manual value of the charge the following formula based on the trapezoidal rule, can be used to perform the integration (ASTM C 1202).

$Q=900\left(I_{0}+2 I_{30}+2 I_{60}+\ldots .+2 I_{300}+2 I_{330}+I_{360}\right)$

Where:

Q $\quad=$ Charge passed (coulombs)

Io $\quad=$ Current (amperes) immediately after voltage is applied

It $=$ Current (amperes) at time $\mathrm{t}$ after voltage is applied.

Cylinder specimens of $100 \mathrm{~mm}$ (4 in) X 200mm (8 in) dimension are prepared for rapid chloride penetration testing. Rapid chloride penetration tests are performed on 56 days samples. 


\subsubsection{Isothermal Calorimetric Study}

Thermal power curves are used to evaluate the isothermal hydration kinetics (ASTM C 1679) of the combined mixture of different materials during the early period after being mixed with water. These isothermal power curves, or hydration profiles, may provide indications relative to setting characteristics, compatibility of different materials, sulfate balance and early strength development. The isothermal hydration profiles can also be used to evaluate the effects of compositions, proportions, and time of addition of materials as well as curing temperature Special care must be used in evaluating extended retardation with paste specimens, which have been shown to overestimate the retardation of some mixtures containing cement, fly ash, and other mineral admixtures.

This procedure can be used to measure the effect of chemical admixtures on the cement hydration profile. In many cases, the addition of chemical admixture changes the kinetics of cement hydration.

Although this technique has been used historically to understand issues related to setting and slump loss, it must be emphasized that isothermal calorimeter results cannot predict concrete performance definitely, either positively or negatively. Extensive verification in concrete at planned dosages and temperatures, and at higher dosages, is needed. Isothermal calorimeter is an effective tool to identify sensitivities, so that concrete testing can be efficiently planned and performed.

This practice provides a means of assessing the relative hydration performance of various test mixtures compared with control mixtures that are prepared in a similar manner.

The procedure and apparatus can be used to monitor the thermal power from pastes and mortars alone or in combination with chemical admixtures. 
The isothermal calorimeter described here can be used to measure the thermal power and heat of hydration of mortars prepared independently or obtained by wet sieving from concrete in accordance with practice.

About 6.5 grams of paste for each mix with ' $0.3 \mathrm{w} / \mathrm{cm}$ ', and 6.25 grams of paste for mix with ' $0.25 \mathrm{w} / \mathrm{cm}$ ' is prepared for the test. After the paste was prepared it was poured in a plastic container, which has $3 / 4$ inch of diameter. The containers were sealed and inserted in the calorimeter. A hook was attached to each of them for convenience. TAM-Air instrument was used for recording the data. It was kept in room temperature, which is $25 \mathrm{C}(72 \mathrm{~F})$. Figure 3.5 describes the preparation of sample for the test. Figure 3.6 shows the placing the specimens inside the machine. The data was collected for 96 hours.

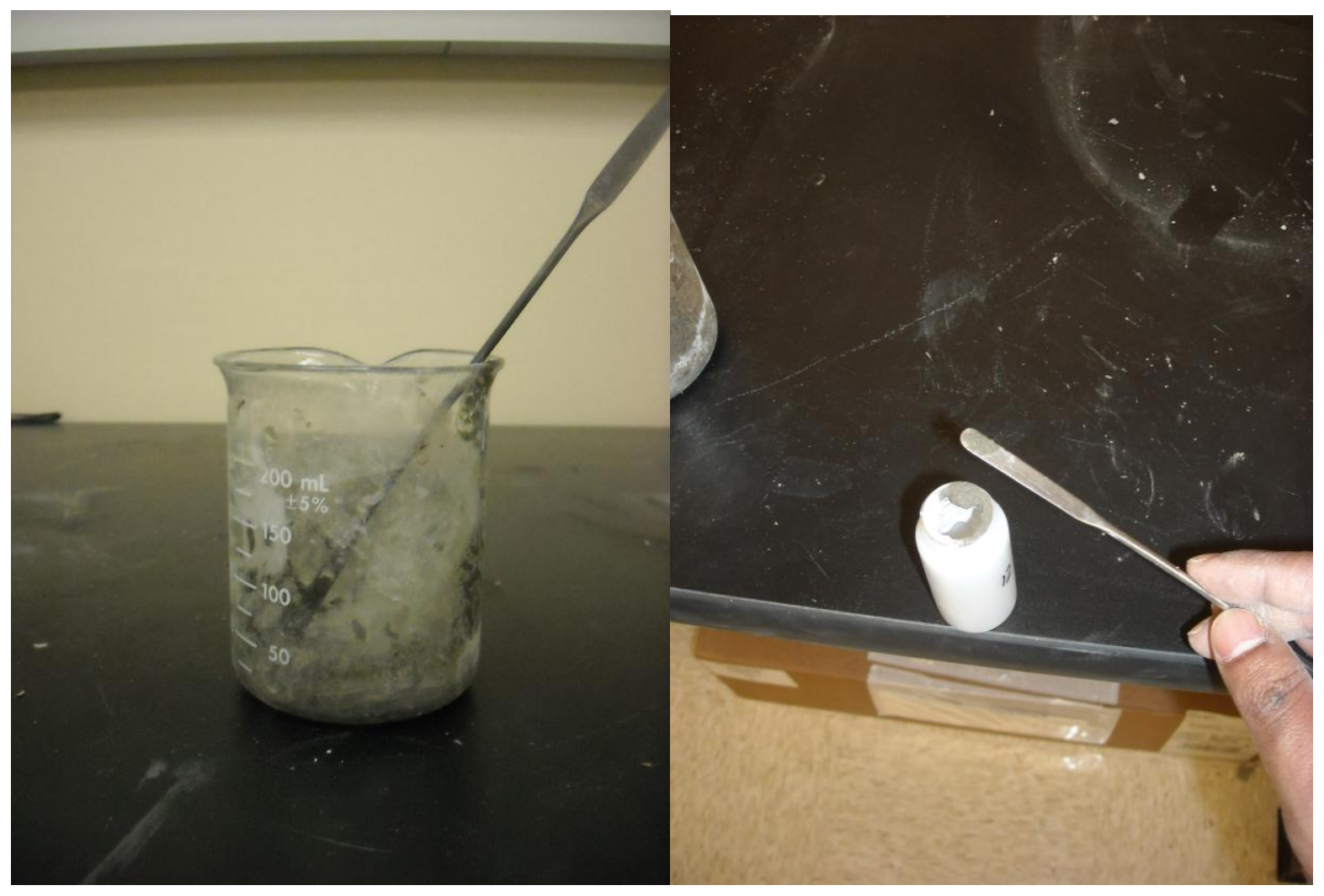

Figure 3-5Sample Preparation 


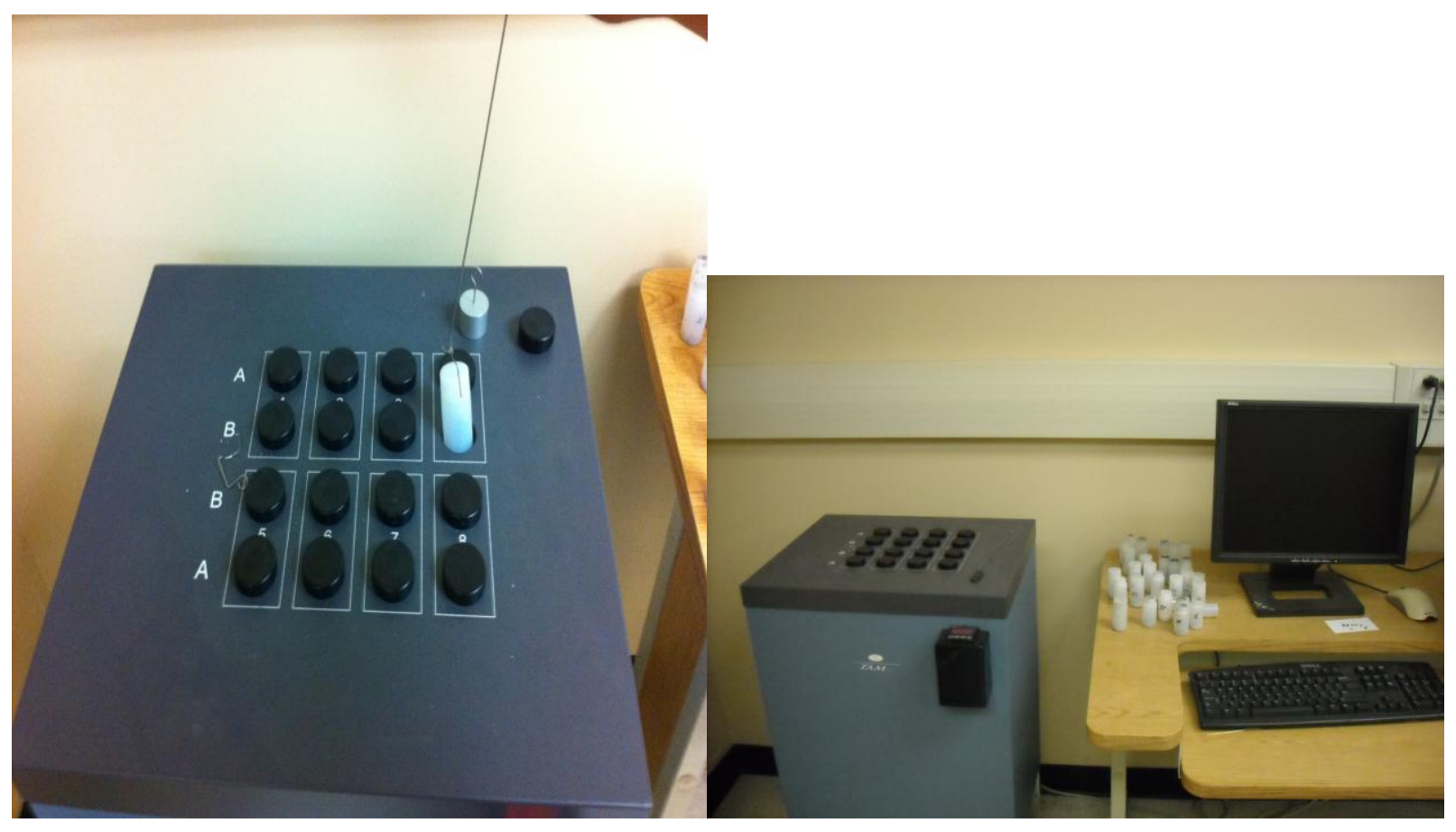

Figure 3-6Placing of Samples 


\section{Chapter 4: Discussion on Test Results of High volume Fly Ash and/or Slag Modified Concrete}

\subsection{Compressive Strength Results}

Compressive Strength is the single most important property of concrete. The obtained results from compressive strength test are presented here. The strength obtained at different ages of concrete is plotted against time to obtain strength development.

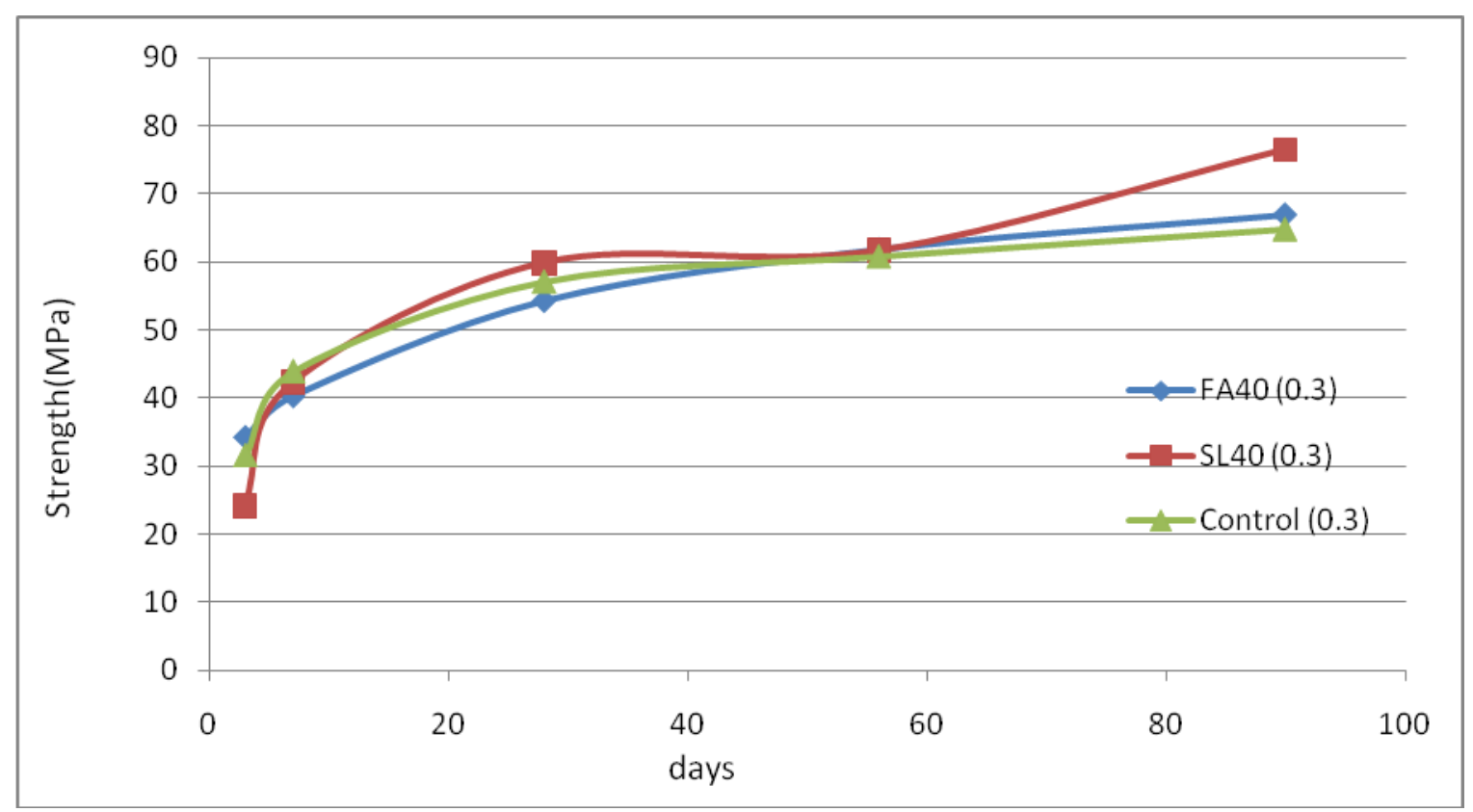

Figure 4-1 Comparison of Compressive Strength of FA40 and SL40 (1 MPa=145psi)

In Figure 4.1 the concrete with $40 \%$ cement replacement is compared with the control concrete samples up to 90 days. Concrete where slag had replaced cement shows the least least strength after 3 days which means slag modified concrete is the least ealy age strength. Fly ash modified concrete shows almost same strength generation like control concrete but slows down due to low hydration rate where slag modified concrete picks up after 7 days age. After 28 days slag modified concrete become the strongest concrete where as fly ash modified concrete shows the least strength. Till 56 days no more strength generation is observed for slag modified concrete. 
After 90 days fly ash modified concrete shows more strength than control mix, when the replacement is $40 \%$. In nutshell slag modified concrete, where $50 \%$ cement is replaced by slag, has the lowest early age strength which shows a steep increase in strength generation after 7 days, where as fly ash modified concrete, where 50\% cement is replaced by fly ash, has moderate early age strength but also it has consistent but slow strength generation. Control concrete almost shows no strength generation after 28 days, where as fly ash modified concrete keeps on becoming stronger till 90 days.

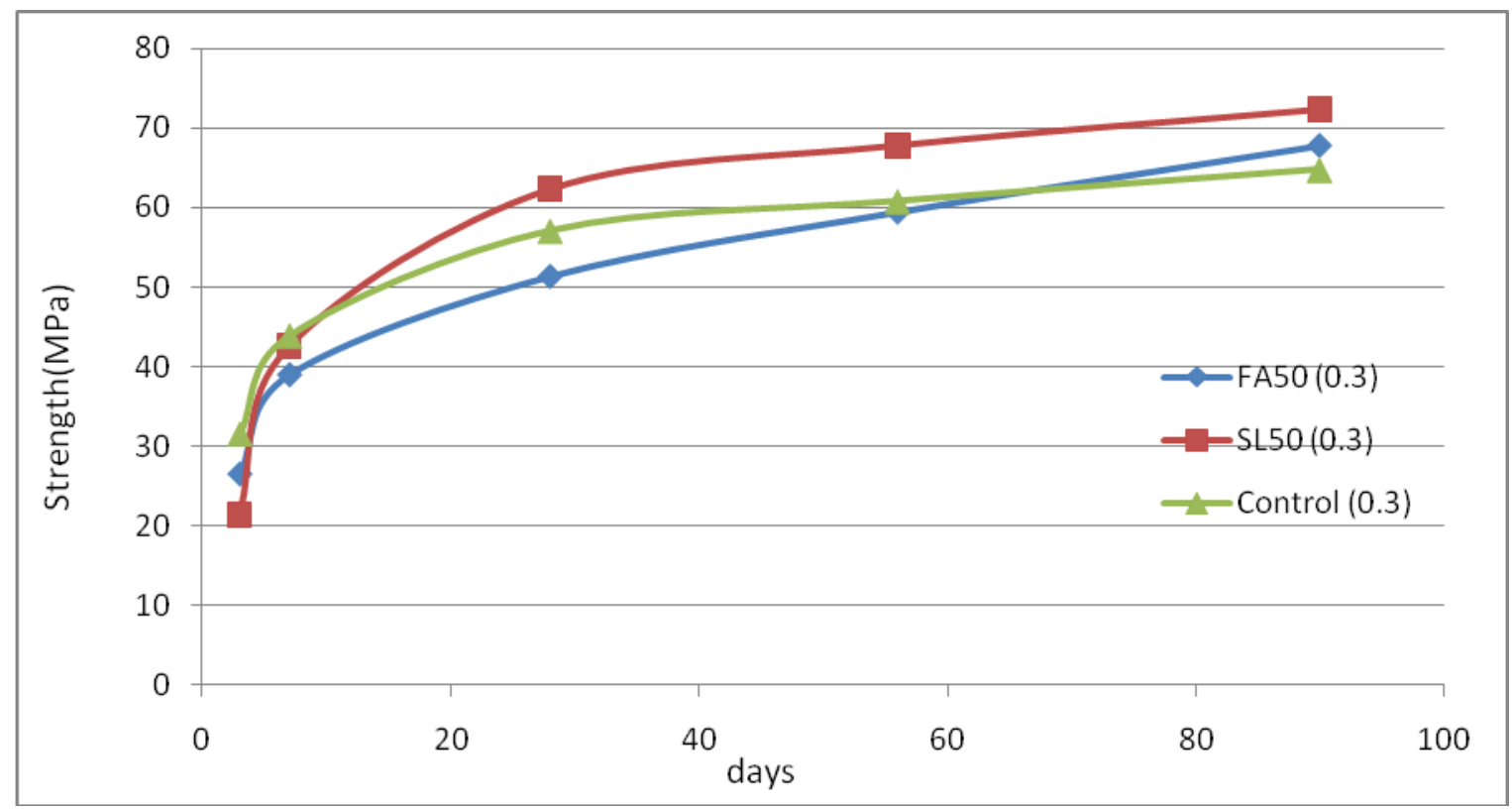

Figure 4-2Comparison of Compressive Strength of FA50 and SL50 (1 MPa=145psi)

In Figure 4.2 the concretes with $50 \%$ cement replacement is compared with the control concrete samples up to 90 days. Concrete where slag had replaced cement shows the least least strength after 3 days which means slag modified concrete is the least ealy age strength. Fly ash modified concrete shows almost same strength generation like control concrete but slows down due to low hydration rate where slag modified concrete picks up after 7 days age. After 28 days slag modified concrete becomes the strongest concrete where as fly ash modified concrete shows the least strength. After 90 days fly ash modified concrete shows more strength than control mix, when the replacement is $50 \%$. In the nutshell slag modified concrete, where $50 \%$ cement is replaced by slag, has the lowest early age strength which shows a steep increase in strength generation after 7 days though hardly shows any further improvement after 28 days, but still shows more strength than concontrol mix and fly ash modified concrete after 90 days. Fly ash 
modified concrete, where $50 \%$ cement is replaced by fly ash has moderate early age strength but also it has consistent but slow strength generation. Control concrete almost shows no strength generation after 28 days, where as fly ash modified concrete keeps on becoming stronger till 90 days.

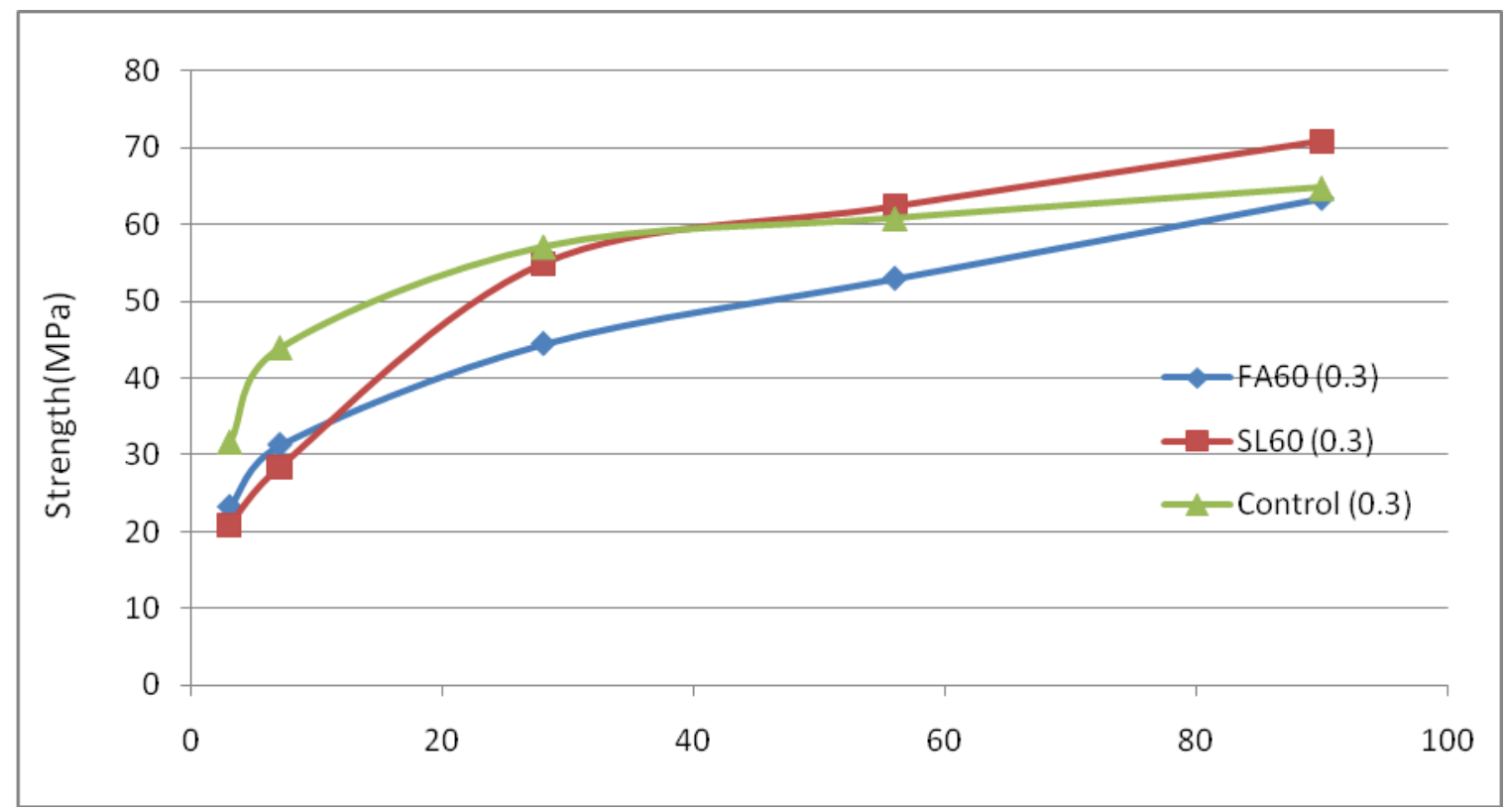

Figure 4-3Comparison of Compressive Strength of FA60 and SL60 (1 MPa=145psi)

In Figure 4.3 the concretes with $60 \%$ cement replacement is compared with the control concrete samples up to 90 days. Concrete where slag had replaced cement shows the least least strength after 3 days which means slag modified concrete is the least ealy age strength. Fly ash modified concrete shows almost same strength generation like control concrete but slows down due to low hydration rate where slag modified concrete picks up after 7 days age. After 28 days slag modified concrete become the strongest concrete where as fly ash modified concrete shows the least strength. After 90 days fly ash modified concrete shows same strength as of control mix, when the replacement is $60 \%$. In nutshell slag modified concrete, where $60 \%$ cement is replaced by slag, has the lowest early age strength which shows a steep increase in strength generation after 7 days though hardly shows any further improvement after 28 days, but still shows more strength than concontrol mix and fly ash modified concrete after 90 days. Fly ash modified concrete, where $60 \%$ cement is replaced by fly ash has moderate early age strength but also it has consistent but slow strength generation. Control concrete almost shows no strength 
generation after 28 days, where as fly ash modified concrete keeps on becoming stronger till 90 days.

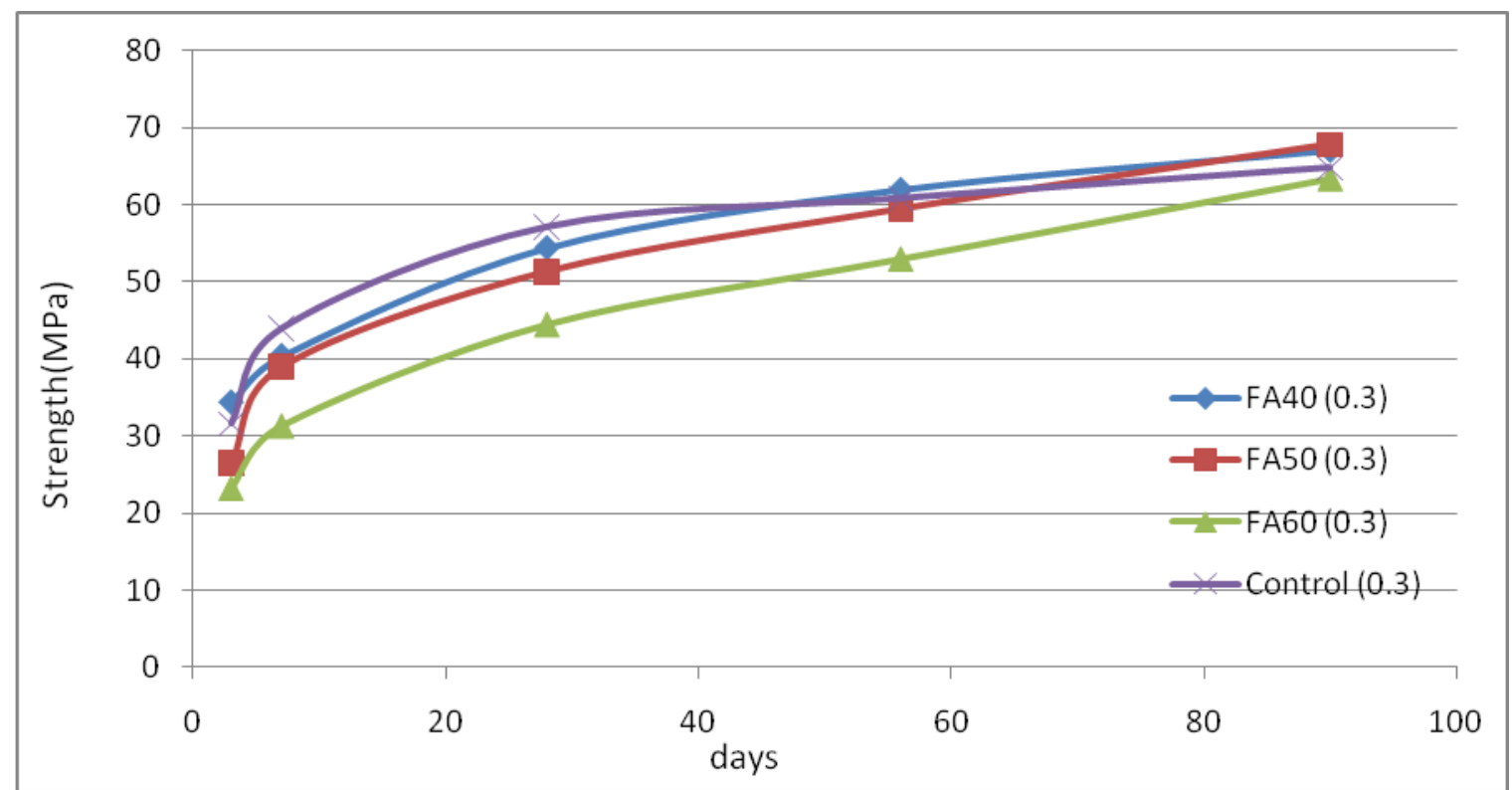

Figure 4-4Comparison of Compressive Strength of Concrete with Increasing Fly Ash Replacement (1 MPa=145psi)

Figure 4.4 shows a comparison between the concretes with increasing fly ash replacement. As percentage of fly ash increases as replacement early age strength decreases as we know lower hydration due to increased amount of pozzolanic material is responsible for these changes. Control mix shows a little improvement after 28 days where as strength kept increasing up to 90 days for all the fly ash modified concrete with $40 \%, 50 \%$, and $60 \%$ respectively. Initial rise in strength after 3days has been steeper for fly ash modified concretes with lesser replacement. In fact steepness of the curve in between the results obtained from 3 days to 7 days period decreases as the replacement increases, where as consistency of steepness after 7 days up to 90 days decreases with decrease in replacemnt, confirming the process of slower hydration reaction rate for the concrete with higher pozzolanic replacement. Fly ash modified concrete with $40 \%$ replacement gained $66 \%$ more strength from 7 days to 90 days interval, where as fly ash modified concrete with $50 \%$ replacemnt and $60 \%$ replacemnt have gained $74 \%$ and $103 \%$ respectively, clearly showing the effect of increasing slowness in hydration, therefore slower strength generation with increasing fly ash content 


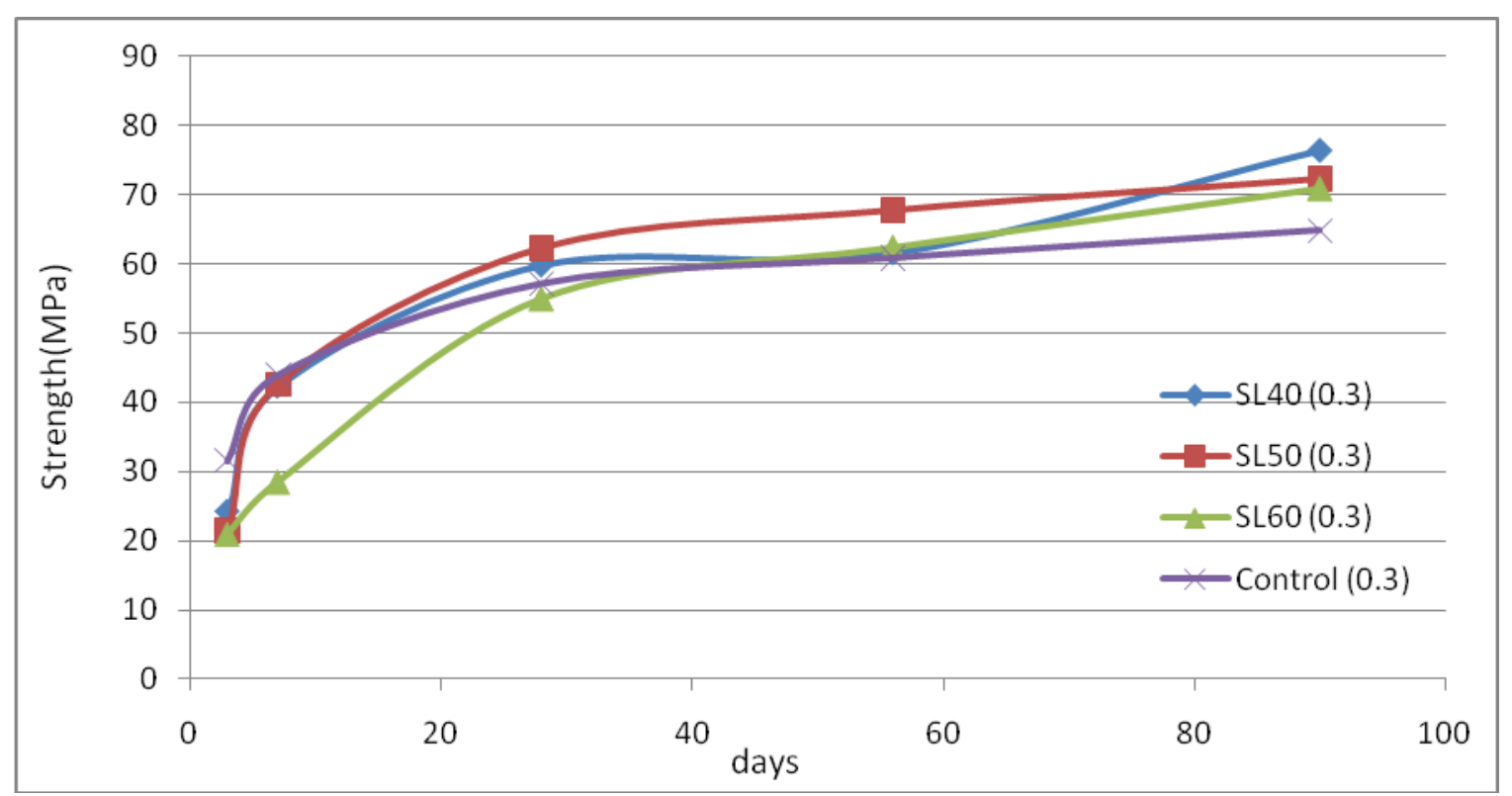

Figure 4-5Comparison of Compressive Strength of Concrete with Increasing Slag Replacement $(1 \mathrm{MPa}=145 \mathrm{psi})$

Figure 4.5 shows a comparison between the concretes with increasing slag replacement. As percentage of slag increases as replacement early age strength decreases as we know lower hydration due to increased amount of pozzolanic material is responsible for these changes. Control mix shows a little improvement after 28 days where as all the slag modified concrete with $40 \%, 50 \%$, and $60 \%$ replacement respectively shows the same trend. Control mix shows moderate rise is strength after 3 days with high early strength, where as slag modified concrete shows steep increase after showing very low initial strength genearation after 3 days. Initial rise in strength after 3days has been steeper for slag modified concretes with lesser replacement. In fact steepness of the curve in between the results obtained from 3 days to 28 days period decreases as the replacement increases, where as consistency of steepness after 28 days up to 90 days decreases with decrease in replacement, confirming the process of slower hydration reaction rate for the concrete with higher pozzolanic replacement. Slag modified concrete with $40 \%$ replacement gained $150 \%$ more strength from 3 days to 28 days interval, where as slag modified concrete with $50 \%$ replacemnt and $60 \%$ replacemnt have gained $195 \%$ and $161 \%$ respectively, clearly showing the effect of increasing slowness in hydration, therefore slower strength generation with increasing slag content. 


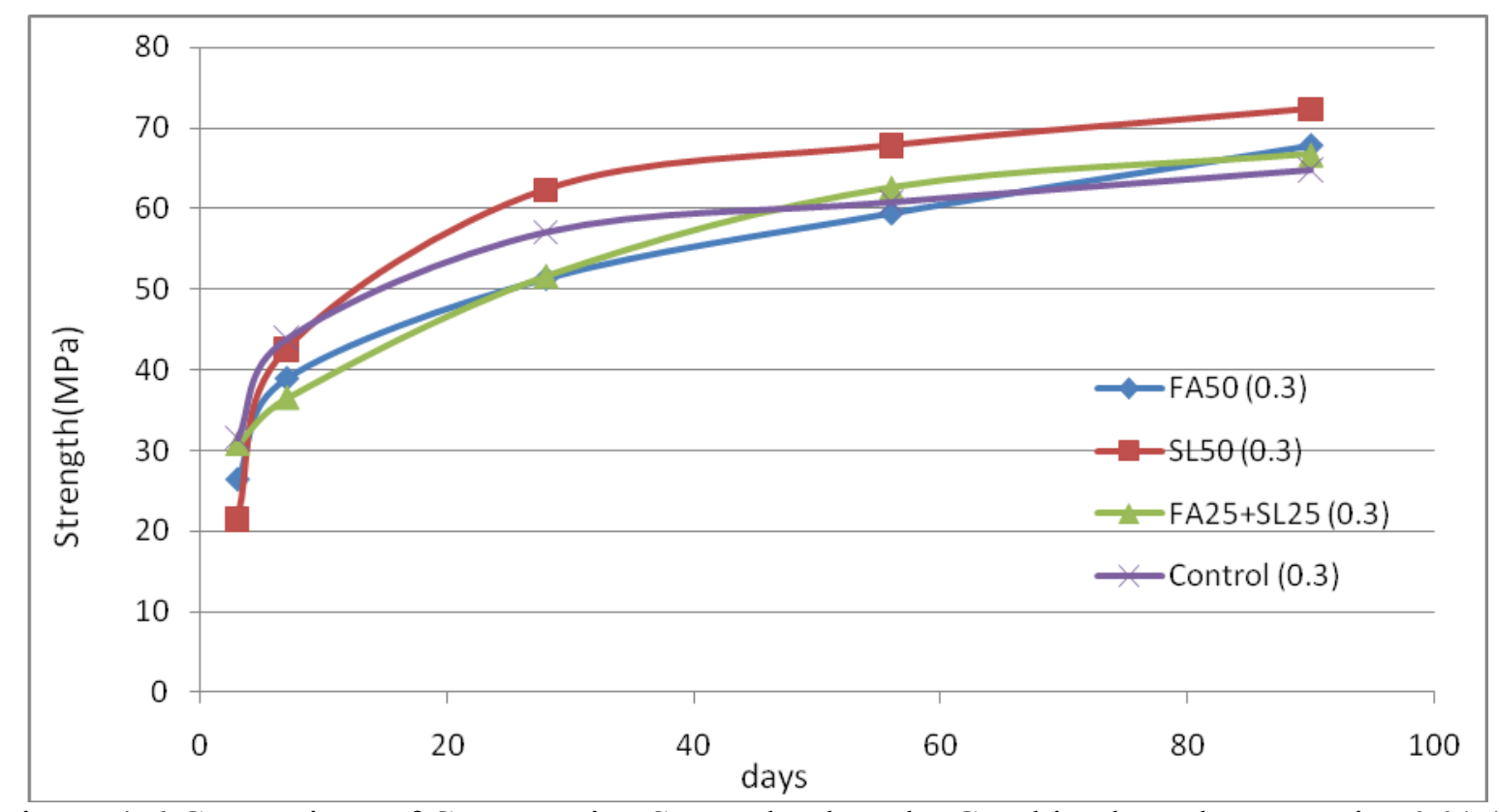

Figure 4-6 Comparison of Compressive Strength when the Combined Replacement is 50 \% (1 $\mathrm{MPa}=145 \mathrm{psi})$

Figure 4.6 explains the effect of concretes where the cement replacement touches $50 \%$ either totally by slag, fly ash or combination of both. We have already studied the effect of fly ash modified concrete or slag modified concrete where the replacement touches $50 \%$. Combination of fly ash and/or slag provides some interesting effect on concrete strength. The early strength was found to be close to control mix. Control mix showed virtually no improvement after 28 days, slag modified concrete showed sudden increase in strength after 3 days, and fly ash modified concrete showed a gradual consistent increase in strength up to 90 days, whereas combination slag and fly ash as replacement showed steep increase in strength up to 56 days, though at the end of 90 days it remained less stronger than fly ash modified concrete and slag modified concrete. It showed more strength than control mix after 56 days, though 28 days strength was much less than the control concrete mixes. 


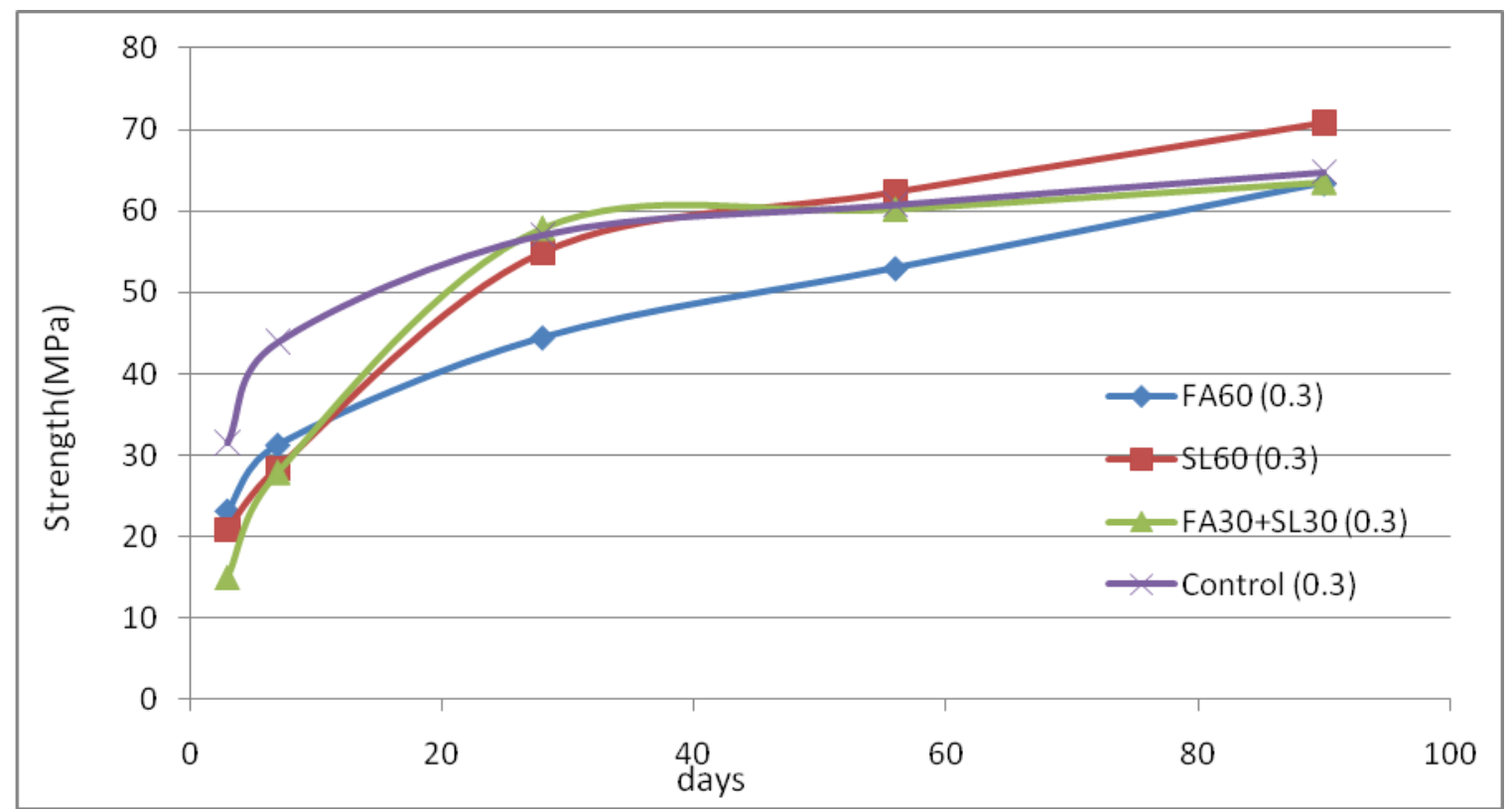

Figure 4-7 Comparison of Compressive Strength when the Combined Replacement is 60 \% (1 $\mathrm{MPa}=145$ psi)

Figure 4.7 explains the effect of concretes where the cement replacement touches $60 \%$ either totally by slag, fly ash or combination of both. We have already studied the effect of fly ash modified concrete or slag modified concrete where the replacement touches $60 \%$. Combination of fly ash and/or slag provides some interesting effect on concrete strength. The early strength was found to be lower than fly ash modified concrete and slag modified concrete. Control mix showed virtually no improvement after 28 days, slag modified concrete showed sudden increase in strength after 3 days and kept on increasing until 90 days, and fly ash modified concrete showed a gradual consistent increase in strength up to 90 days, whereas combination slag and fly ash as replacement showed steep increase in strength up to 28 days, though at the end of 90 days it remained less stronger than fly ash modified concrete and slag modified concrete. It showed as much as strength as control mix after 28 days, though 3 days strength was much less than the control concrete mixes.

Figure 4.8 explains the condition where replacement of cement increases by the combination of fly ash and/or slag in fly ash and/or slag modified concrete. Where the replacement is $50 \%$ shows a gradual steady increase thoughout the 90 days of curing period. Concrete with $60 \%$ replacement shows steeper rise in strength till 28 


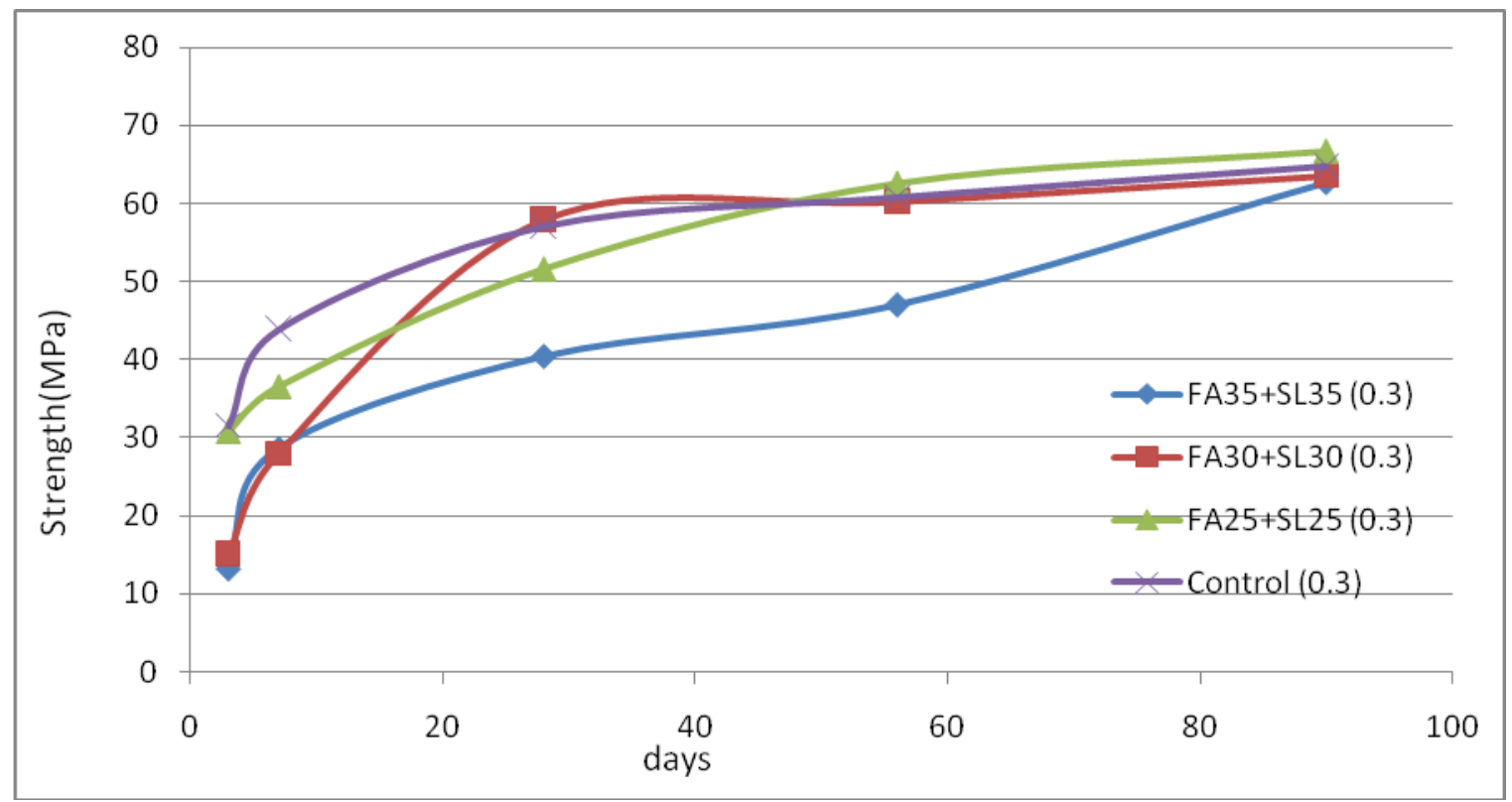

Figure 4-8 Comparison of Compressive Strength with Increasing Combined Replacement (1 $\mathrm{MPa}=145 \mathrm{psi})$

days period, where the initial strength gain is for this concrete is really low after 3 days. The initial strength gain is very similar for the concrete where $70 \%$ cement is replaced with combined replacement of fly ash and/or slag is used. Evidently concrete with maximum replacement has slower initial srength generation due to lack calcium oxide, but steady increase of strength through 90 days period ensures as much as strength of control mix, where as control mix shows a liitle sign of increase in strength after 28 days period. Concrete with $70 \%$ combined replacement showed increase of strength from 28 days period to 90 days period is $58 \%$, where as concrete with $60 \%$ replacement showed a increase of $11 \%$ and concrete with $50 \%$ replacemnt showed a increase of $29 \%$ respectively in between 28 days to 90 days period.

Figure 4.9 explains compressive strength with decreasing w/cm where $60 \%$ cement is replaced by fly ash. Generally when the $w / \mathrm{cm}$ decreases the strength increases. The same feature is evident with the control mix, decrease in w/cm increased the strength in big way. Concrete with $60 \%$ fly ash as cement replacement shows less strength when w/cm is decreased. Early strength of concrete with $60 \%$ fly ash as cement replacement remained lowest where as strength after 90 days were also remained one the lowest among all. 


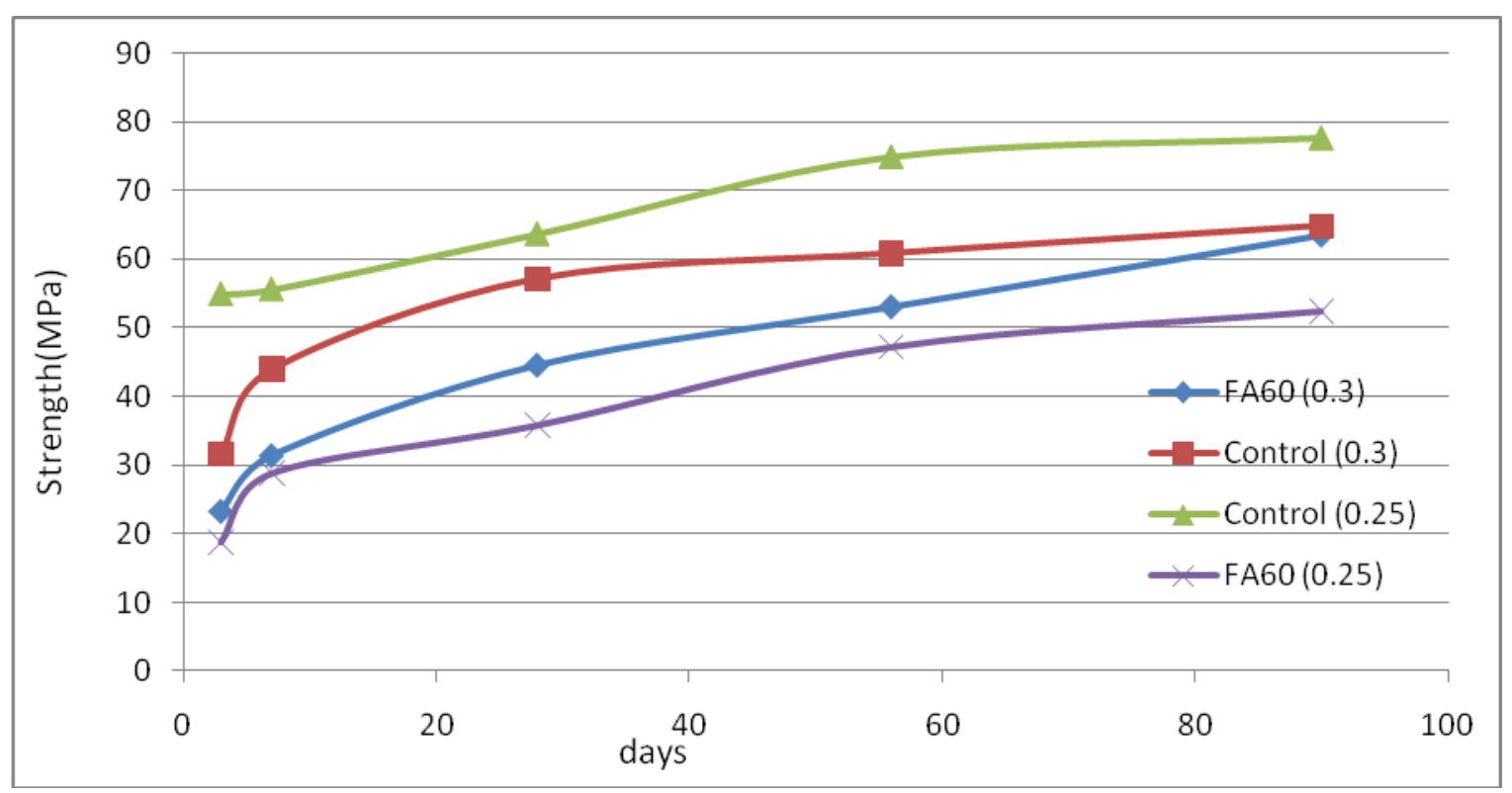

Figure 4-9 Comparison of Compressive Strength with Decreasing w/cm where $60 \%$ Cement Is Replaced by Fly Ash ( $1 \mathrm{MPa}=145$ psi)

Lower hydration reaction due to less availability of calcium ions may lead to the less strength generation. For cement concrete unhydrated cement particles lead to the strength of concrete may be because of the higher density. Concrete with $60 \%$ fly ash as cement replacement, may lack the strength, when remained unhydrated, while w/cm decreases, may not achieve the same strength because of the low density of fly ash particles and high presence of fly ash particles. The amount of filler materials like sand, which contributes to the strength significantly also can be a reason behind this.

Figure 4.10 explains compressive strength with decreasing w/cm where $60 \%$ cement is replaced by slag. Generally when the w/cm decreases the strength increases. The same feature is evident with the control mix, decrease in w/cm increased the strength in big way. Concrete with $60 \%$ slag as cement replacement shows less strength initially, but in the later stage increases significantly, when w/cm is decreased. Early strength of concrete with $60 \%$ slag as cement replacement remained lowest where as strength after 90 days were remained high significantly.

Slag acts as week cement so in the initial stage the stregth is much lower but once the reaction takes place, the strength increases rapidly. Concrete with $60 \%$ slag as cement replacement shows less strength in the initially but later one it behave as normal cement concrete. 


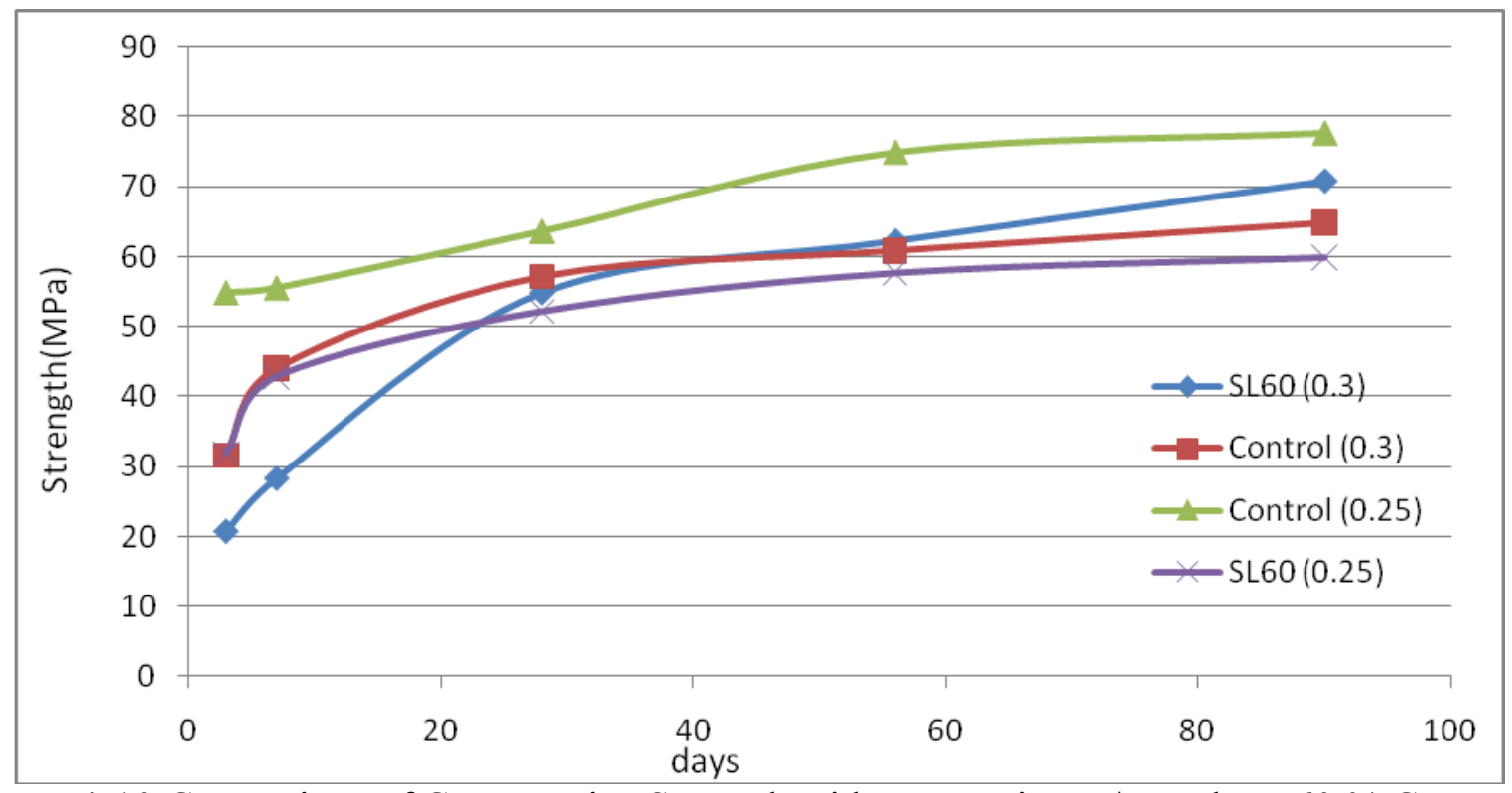

Figure 4-10 Comparison of Compressive Strength with Decreasing w/cm where $60 \%$ Cement Is Replaced by Slag (1 MPa=145 psi)

For cement concrete unhydrated cement particles lead to the strength of concrete may be because of the higher density. Strength of concrete with $60 \%$ slag as cement replacement, does not increase as much control mix when remained unhydrated, while w/cm decreases, because of the low density of slag particles and high presence of slag particles. The amount of filler materials like sand, which contributes to the strength significantly also can be a reason behind this.

Figure 4.11 explains compressive strength with decreasing $\mathrm{w} / \mathrm{cm}$ where $60 \%$ cement is replaced by fly ash and/or slag. Generally when the w/cm decreases the strength increases. The same feature is evident with the control mix, decrease in $\mathrm{w} / \mathrm{cm}$ increased the strength in big way. Early strength of concrete with $60 \%$ fly ash as cement replacement remained lowest where as strength after 90 days were also remained one the lowest among all, where as early strength of concrete with $60 \%$ slag as cement replacement remained lower where as strength after 90 days were remained high significantly.

Slag acts as week cement so in the initial stage the stregth is much lower but once the reaction takes place, the strength increases rapidly. Concrete with $60 \%$ slag as cement replacement shows less strength in the initially but later one it behave as normal cement concrete. 


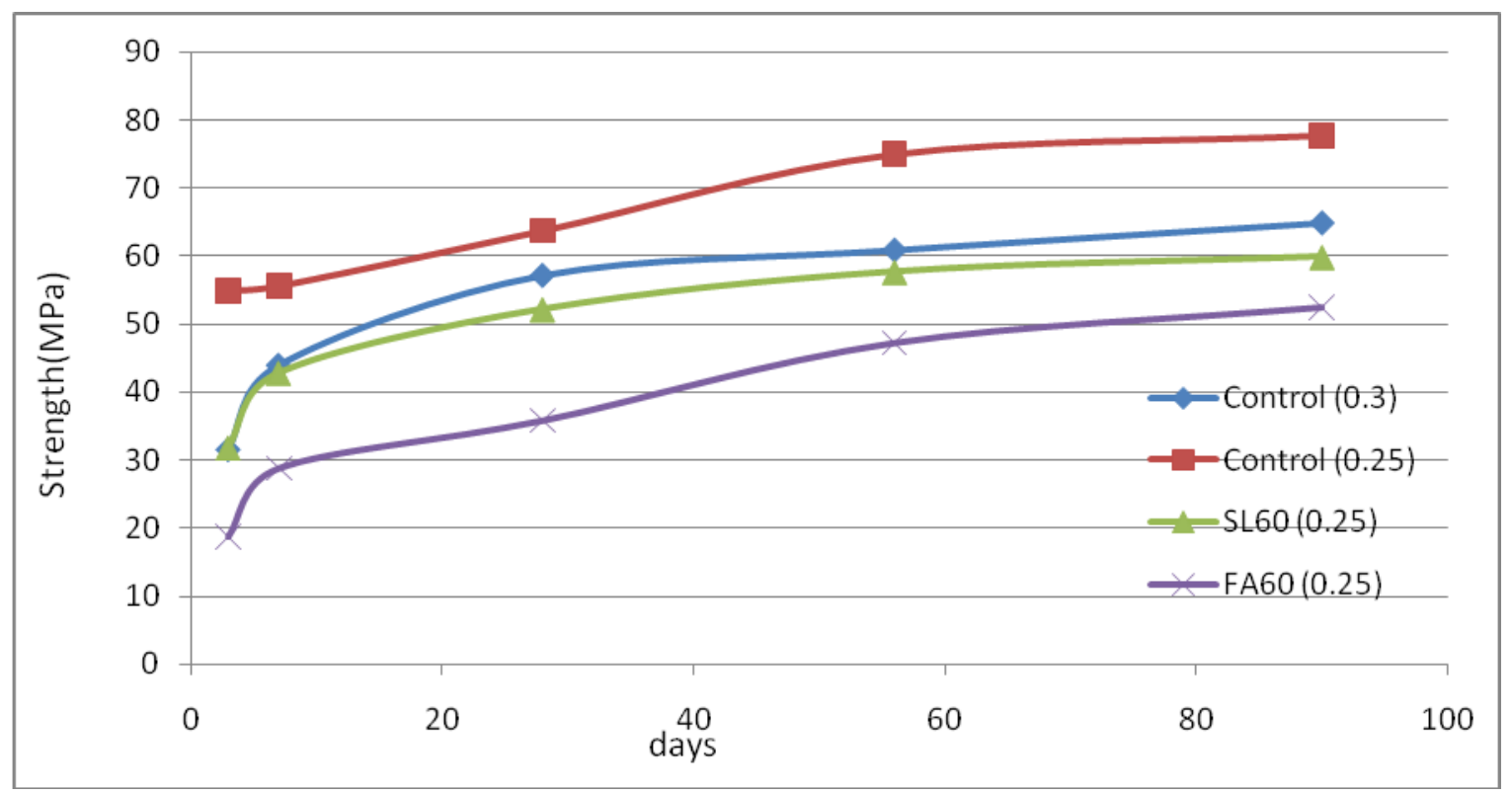

Figure 4-11 Comparison of Compressive Strength with Decreasing w/cm where $60 \%$ Cement Is Replaced by Fly Ash or Slag (1 MPa=145 psi)

For cement concrete unhydrated cement particles lead to the strength of concrete may be because of the higher density. Strength of concrete with $60 \%$ slag or as cement replacement, does not increase as much control mix when remained unhydrated, while $\mathrm{w} / \mathrm{cm}$ decreases, because of the low density of slag particles and high presence of slag particles. Concrete with $60 \%$ fly ash as cement replacement, showed really low strength, when remained unhydrated, while w/cm decreases, because of the low density of fly ash particles and high presence of fly ash particles. The amount of filler materials like sand, which contributes to the strength significantly also can be a reason behind this.

Figure 4.12 explains compressive strength with decreasing $\mathrm{w} / \mathrm{cm}$ where $70 \%$ cement is replaced by slag. Generally when the w/cm decreases the strength increases. The same feature is evident with the control mix, decrease in w/cm increased the strength in big way. Concrete with $70 \%$ fly ash and/or slag as cement replacement shows higher strength initially, and also in the later stage increases significantly, when $\mathrm{w} / \mathrm{cm}$ is decreased. Early strength of concrete with $70 \%$ fly ash and/or slag as cement replacement remained higher where as strength after 90 days were remained high significantly. 


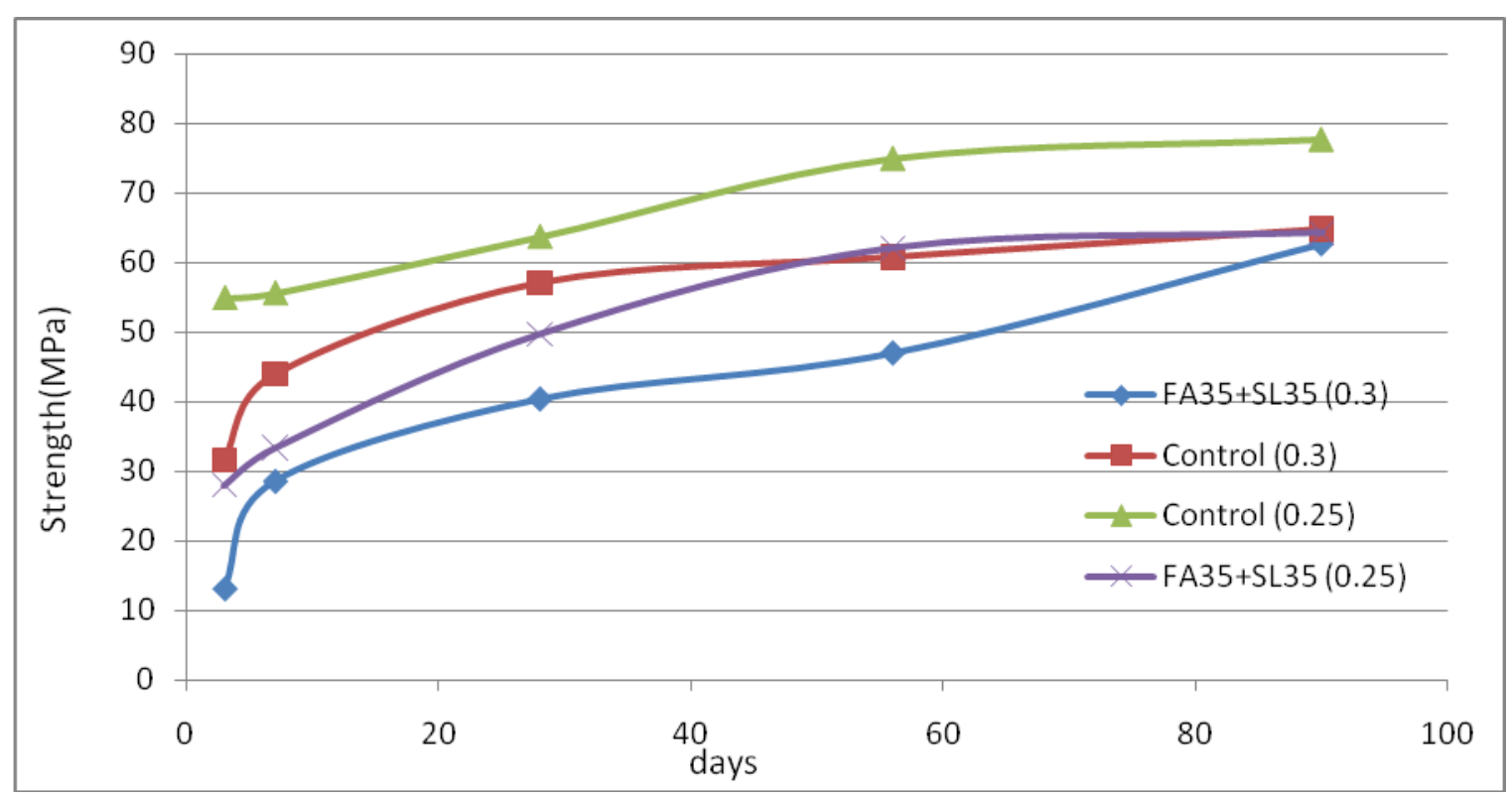

Figure 4-12 Comparison of Compressive Strength with Decreasing w/cm where $70 \%$ Cement Is Replaced by Fly Ash and Slag Combined (1 MPa=145 psi)

Slag acts as week cement so in the initial stage the stregth is much lower but once the reaction takes place, the strength increases rapidly. Concrete with $70 \%$ fly ash and/or slag as cement replacement shows higher strength in the initially and also later on, almost behave as normal cement concrete.

For cement concrete unhydrated cement particles lead to the strength of concrete may be because of the higher density. Strength of concrete with $70 \%$ fly ash and/or slag as cement replacement, does not increase as much control mix when remained unhydrated, while w/cm decreases, because of the low density of slag particles and high presence of slag particles. The amount of filler materials like sand, which contributes to the strength significantly also can be a reason behind this.

The strength of all concrete mix showed good strength (more than $50 \mathrm{MPa}$ ) after 90 days of curing, which means, strength generation is likely to slower than usual concrete in use. Formwork removal maybe an issue in this case, but accelerated curing may help the early removal of formwork. It can be used for precast concrete effectively. Mass concrete casting can be done in higher pace as risk of thermal cracking reduces due to less hydration heat generation. 


\subsection{Free Shrinkage}

Drying shrinkage is one of the identified problems for concrete durability as decrease in volume leads to cracking especially around the rebar in reinforced concrete structures. From the measured drying shrinkage, the data was collected for every 2 seconds. However the hourly data was used after data reduction from the onset up to 90 days. These shrinkage data was plotted against the days to show the comparison between different concrete mixes.

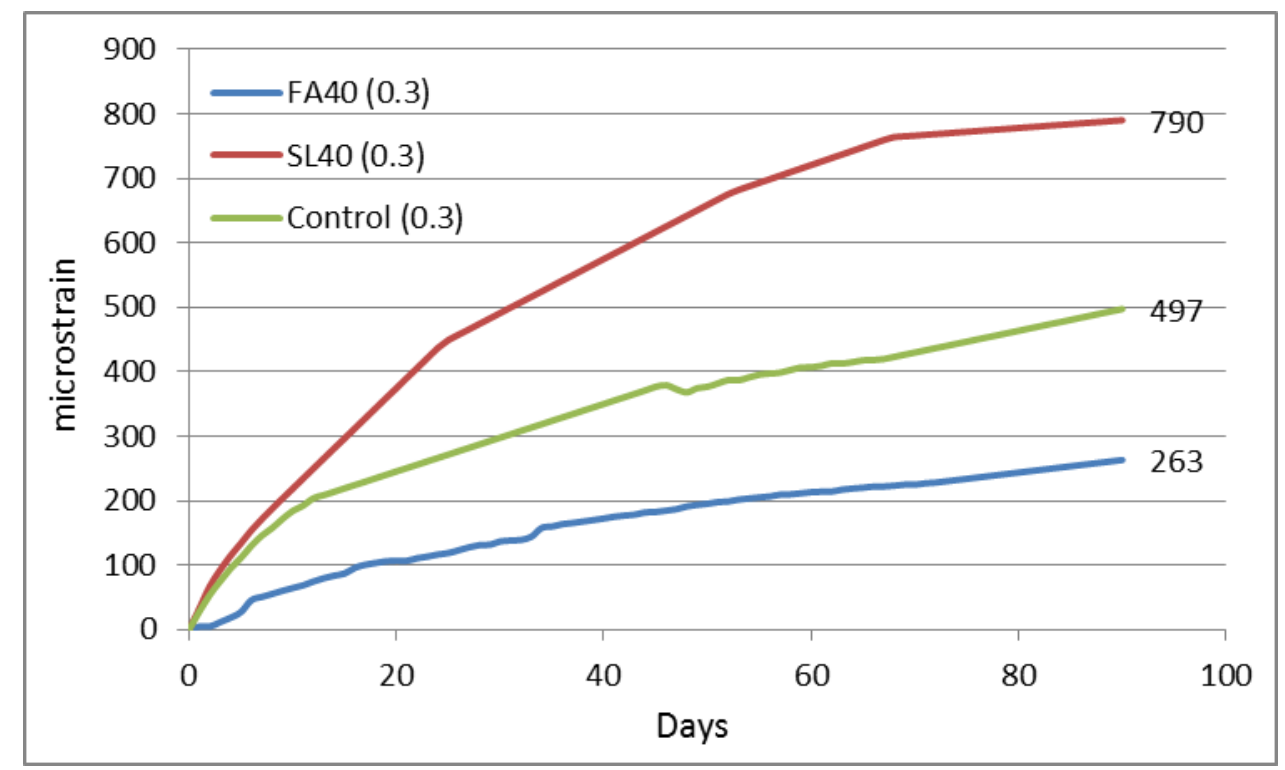

Figure 4-13 Comparison of Drying Shrinkage of FA40 and SL40

In Figure 4.13 the drying shrinkage of concretes with $40 \%$ cement replacement is compared with the control concrete samples up to 90 days. Concrete with $40 \%$ fly ash as cement replacement had the least drying shrinkage among all, while Concrete with $40 \%$ slag as cement replacement had the most drying shrinkage, control mix had moderate drying shrinkage. Coarser fly ash particles acted as better filler material, which lead to more compact material, which in turn allowed less drying shrikage. 


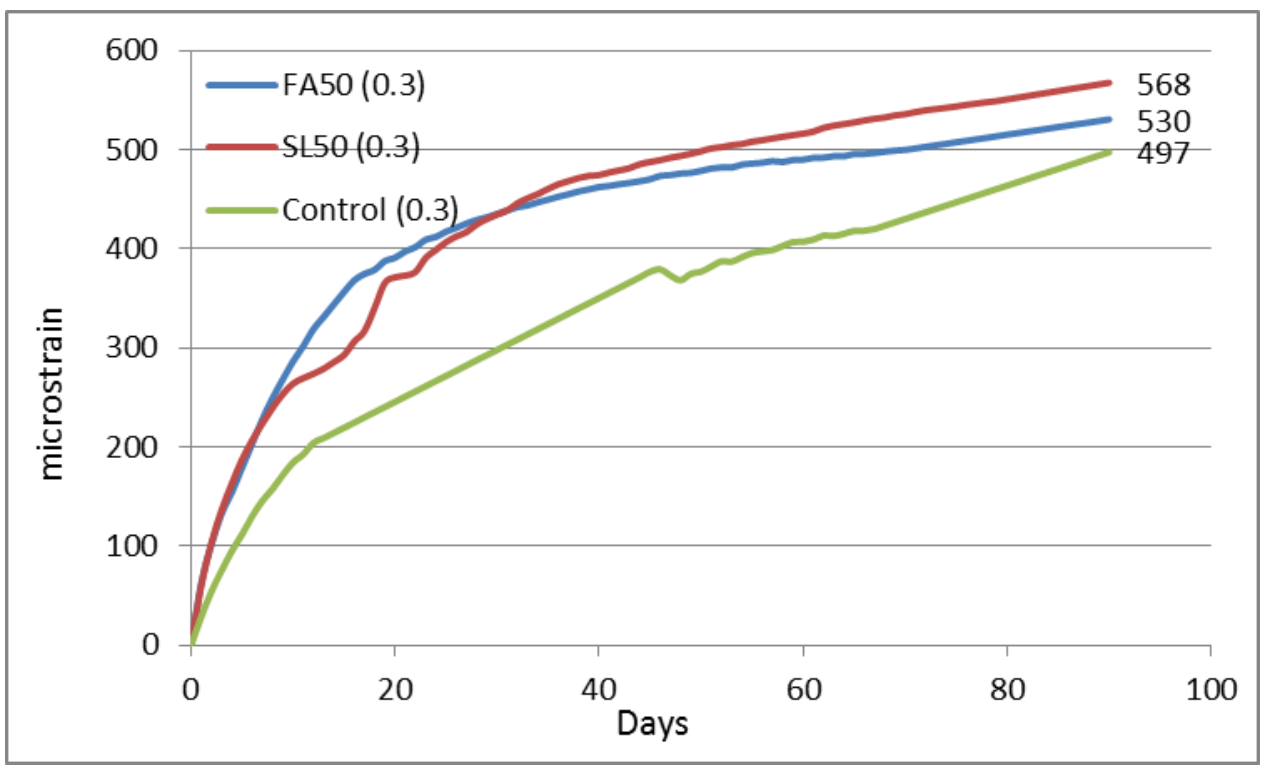

Figure 4-14 Comparison of Drying Shrinkage of FA50 and SL50

In Figure 4.14 the drying shrinkage of concretes with $50 \%$ cement replacement is compared with the control concrete samples up to 90 days. Concrete with $50 \%$ fly ash as cement replacement had the lesser drying shrinkage, while Concrete with $50 \%$ slag as cement replacement had the most drying shrinkage, control mix had least drying shrinkage. Coarser fly ash particles acted as better filler material, which lead to more compact material, which in turn allowed less drying shrikage.

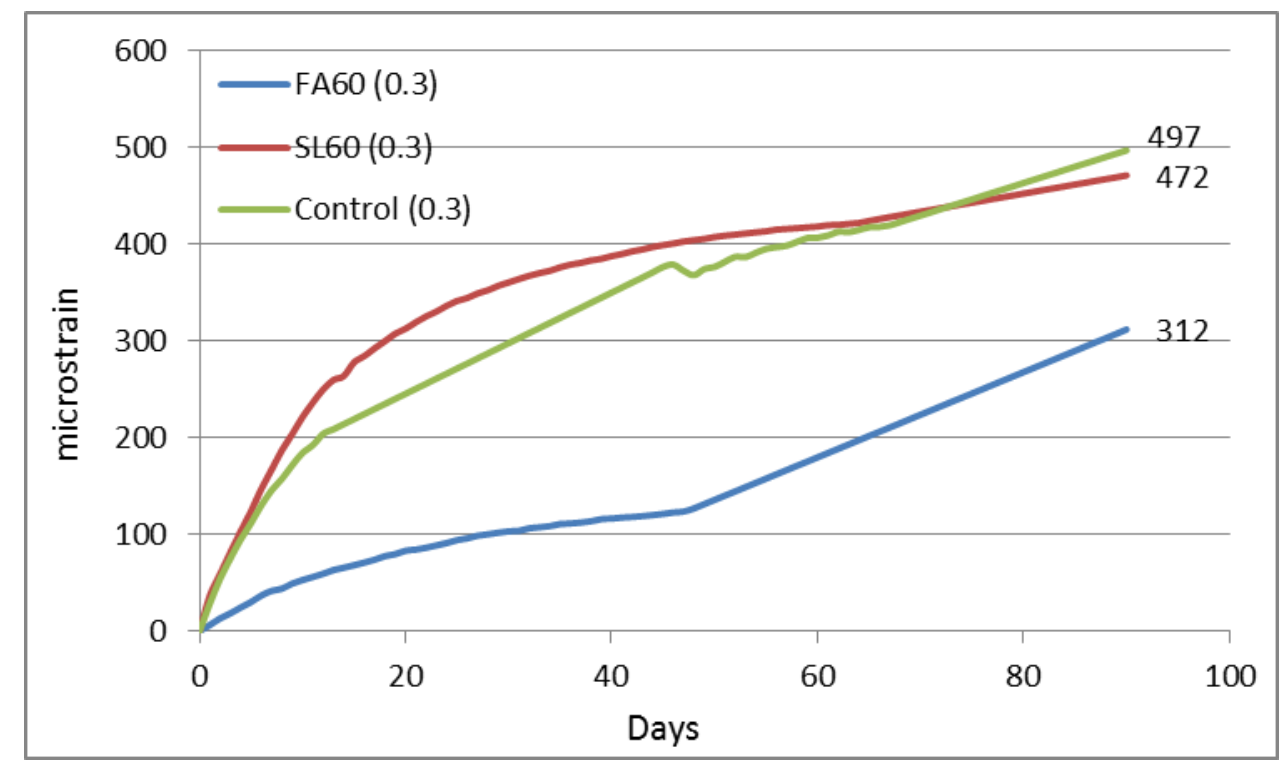

Figure 4-15 Comparison of Drying Shrinkage of FA60 and SL60

In Figure 4.15 the drying shrinkage of concretes with $60 \%$ cement replacement is compared with the control concrete samples up to 90 days. Concrete with $60 \%$ fly ash as cement 
replacement had the least drying shrinkage among all, while Concrete with $60 \%$ slag as cement replacement had the more drying shrinkage, control mix had most drying shrinkage. Coarser fly ash particles acted as better filler material, which lead to more compact material, which in turn allowed less drying shrikage.

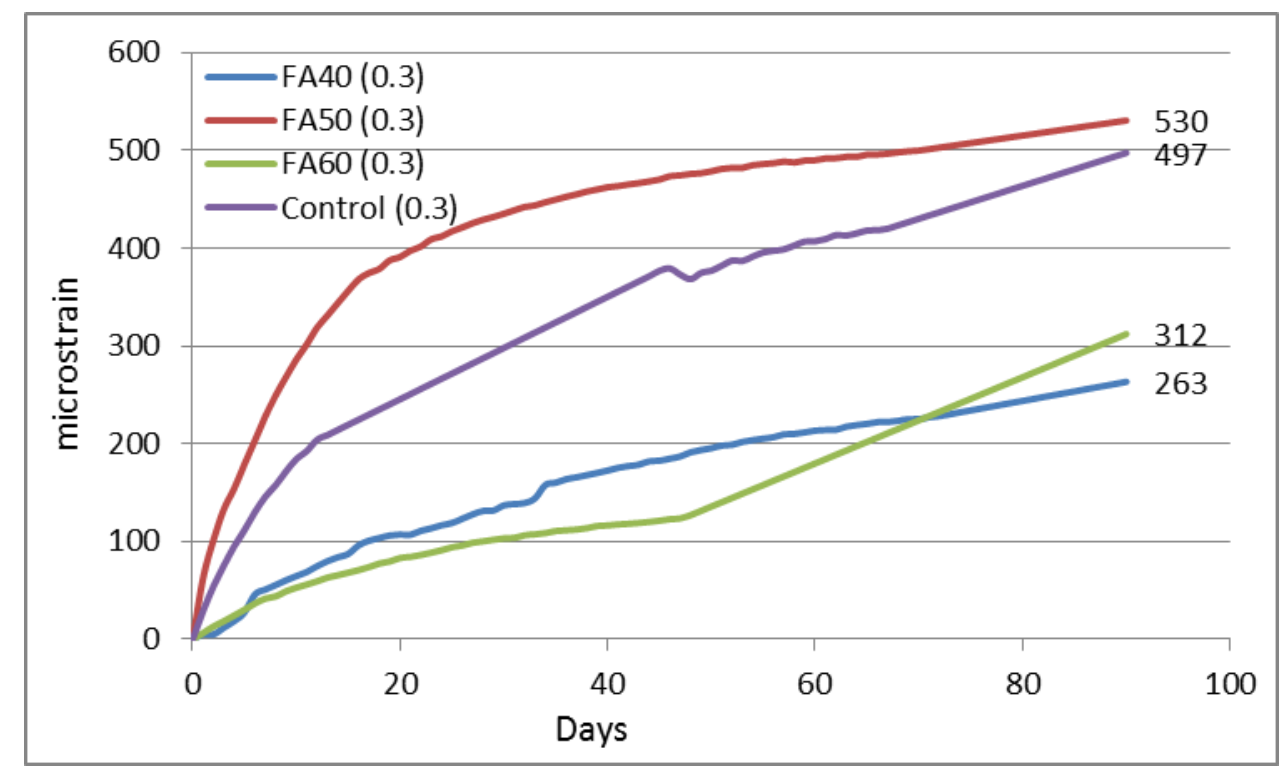

Figure 4-16 Comparison of Drying Shrinkage of Concrete with Increasing Fly Ash Replacement

In Figure 4.16 the drying shrinkage of concretes with increasing fly ash replacement is compared. Concrete with $40 \%$ fly ash as cement replacement and Concrete with $60 \%$ fly ash as cement replacement had the less drying shrinkage among all, while Concrete with $50 \%$ fly ash as cement replacement had the most drying shrinkage, control mix had moderate drying shrinkage. Coarser fly ash particles acted as better filler material, which lead to more compact material, which in turn allowed less drying shrikage, though Concrete with $50 \%$ fly ash as cement replacement remained the exeption may be due to human error. 


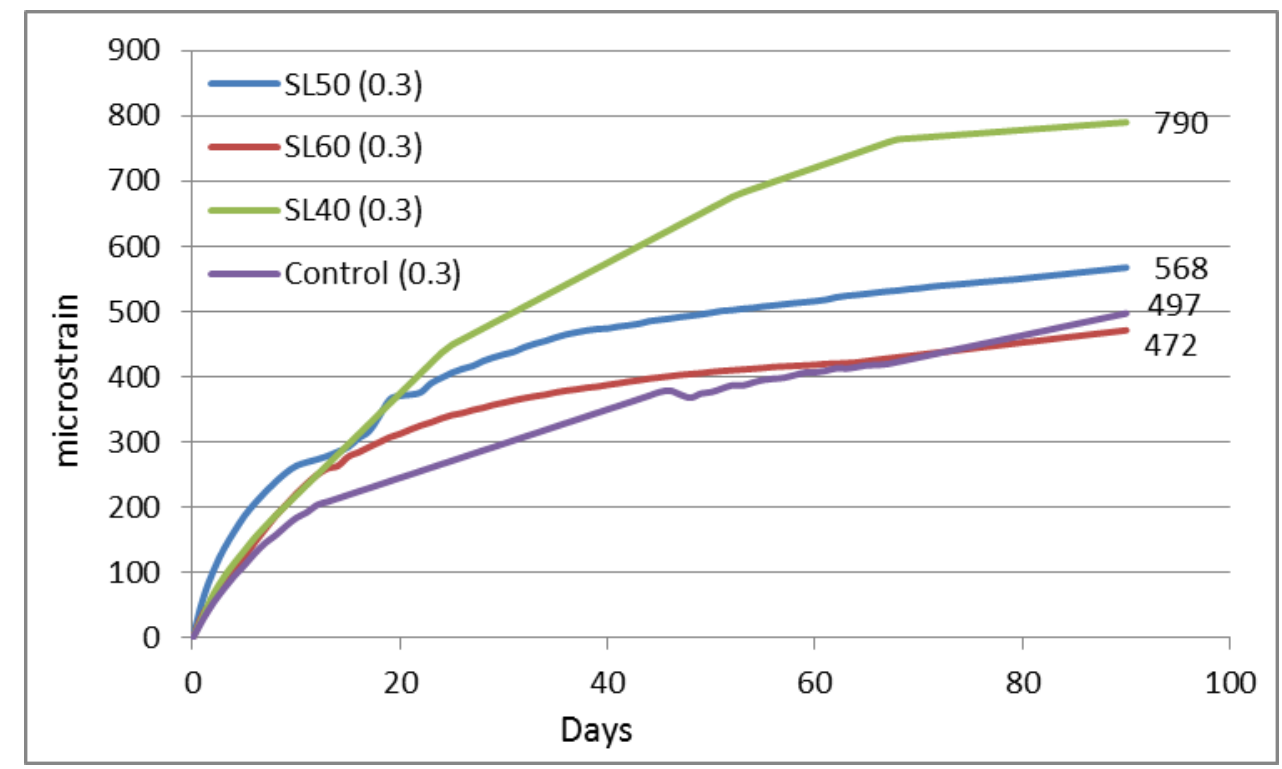

Figure 4-17 Comparison of Drying Shrinkage of Concrete with Increasing Slag Replacement

In Figure 4.17 the drying shrinkage of concretes with increasing slag replacement is compared. Concrete with $60 \%$ slag as cement replacement had the least drying shrinkage among all, while concrete with $50 \%$ slag as cement replacement had the more drying shrinkage, and concrete with $40 \%$ slag as cement replacement had the most drying shrinkage, where as control mix had almost as much as concrete with $60 \%$ slag as cement replacement drying shrinkage. Drying shrinkage reduced as the amount of slag increases.

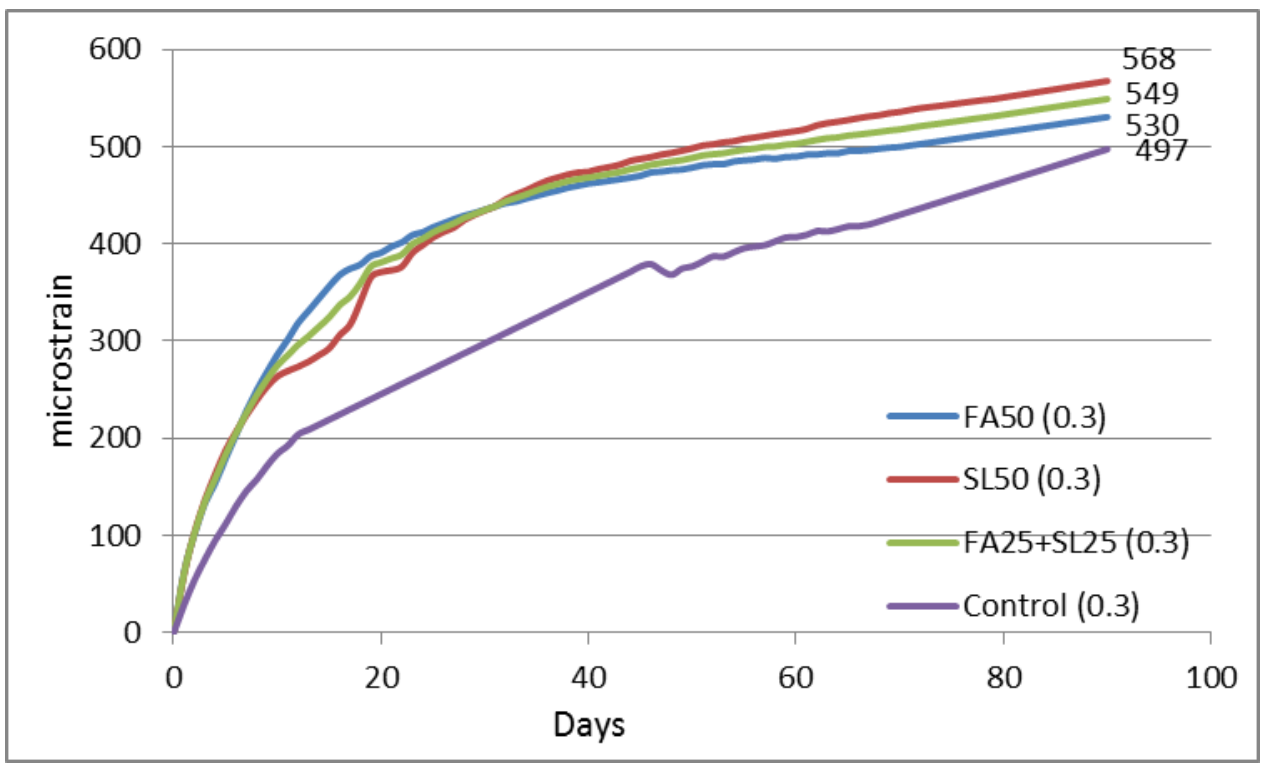

Figure 4-18 Comparison of Drying Shrinkage when the Combined Replacement Is $50 \%$ 
In Figure 4.18 the drying shrinkage of concretes with $50 \%$ combined cement replacement is compared with the control concrete samples up to 90 days. Concrete with $50 \%$ fly ash as cement replacement had the lesser drying shrinkage, while Concrete with $50 \%$ slag as cement replacement had the most drying shrinkage, concrete with $50 \%$ combined cement replacement is just in between, where as control mix had least drying shrinkage. Coarser fly ash particles acted as better filler material, which lead to more compact material, which in turn allowed less drying shrikage.

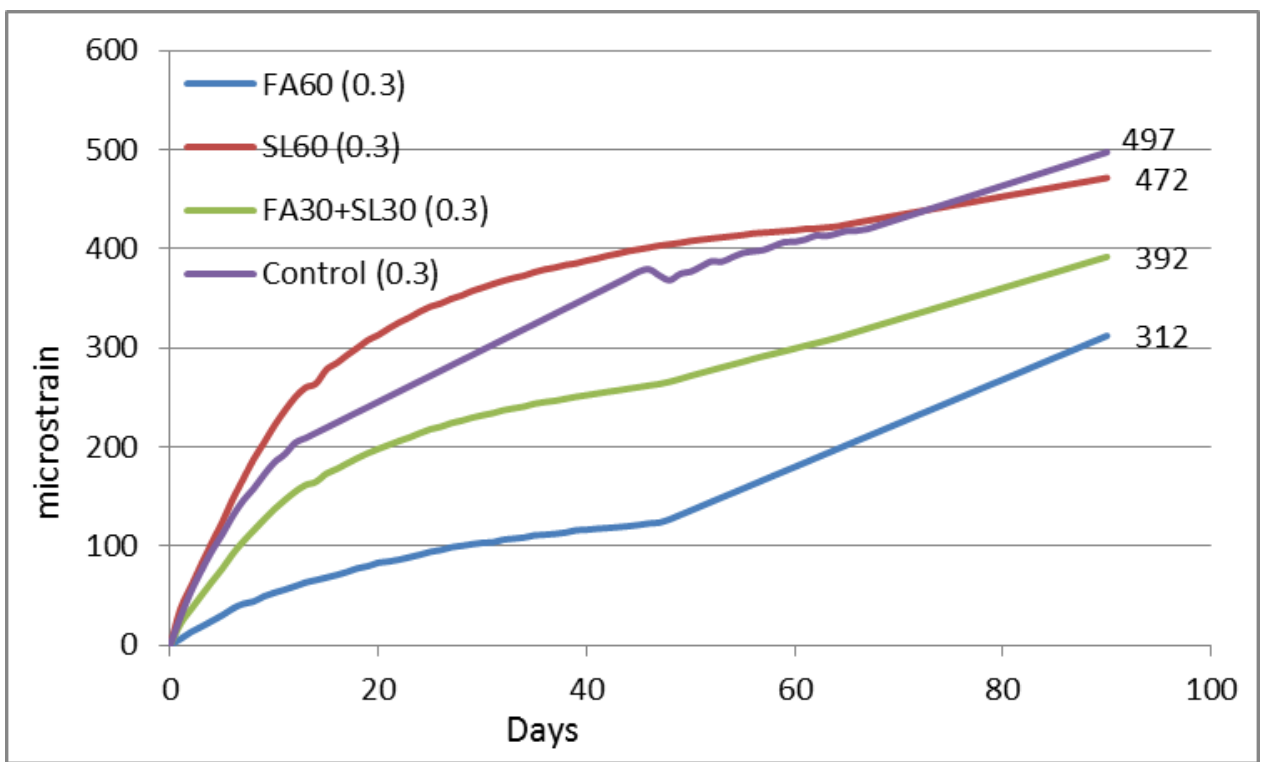

Figure 4-19 Comparison of Drying Shrinkage when the Combined Replacement Is $60 \%$

In Figure 4.19 the drying shrinkage of concretes with $60 \%$ combined cement replacement is compared with the control concrete samples up to 90 days. Concrete with $60 \%$ fly ash as cement replacement had the least drying shrinkage among all, while Concrete with $60 \%$ slag as cement replacement had the more drying shrinkage, concrete with $60 \%$ combined cement replacement is just in between, where as control mix had most drying shrinkage. Coarser fly ash particles acted as better filler material, which lead to more compact material, which in turn allowed less drying shrikage. 


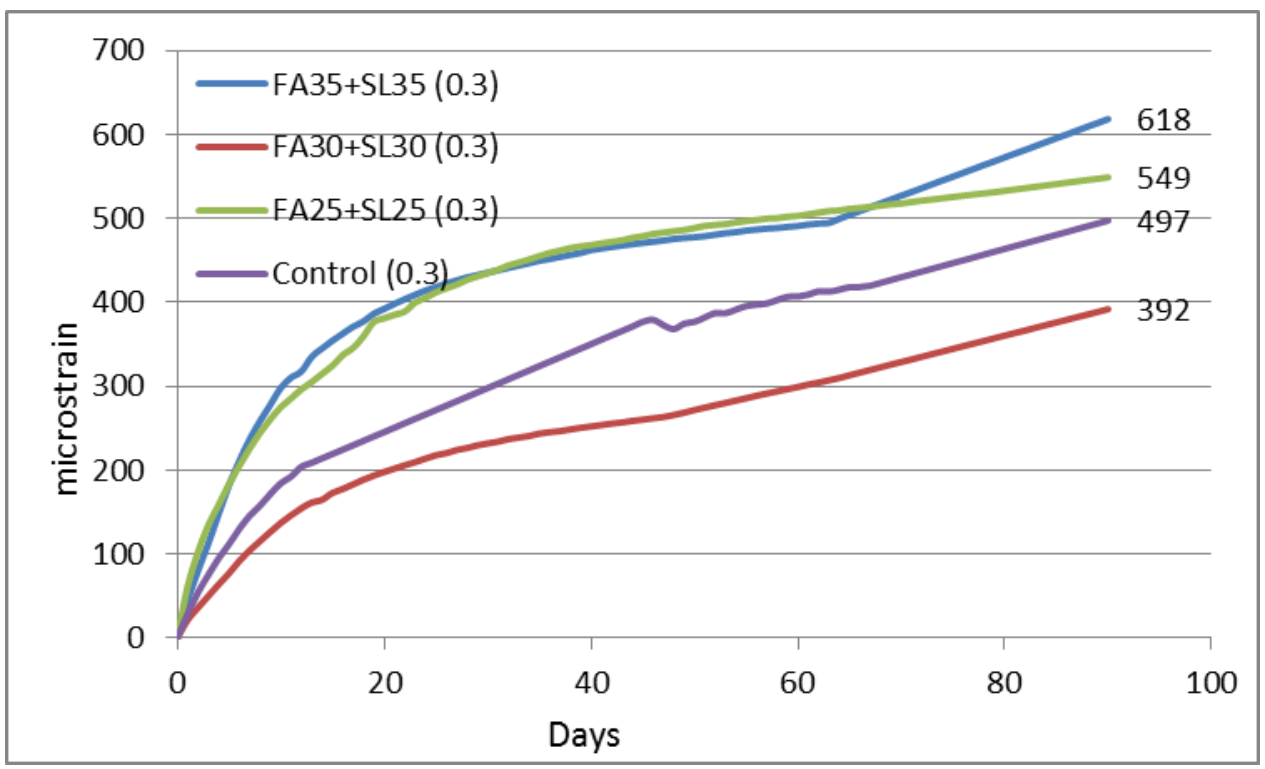

Figure 4-20 Comparison of Drying Shrinkage with Increasing Combined Replacement

Figure 4.20 explains the comparison of drying shrinkage with increasing combined replacement. Concrete with $70 \%$ combined replacement had the most drying shrinkage where as concrete with $50 \%$ combined replacement had the least drying shrinkage. Control mix showed moderate drying shrinkage compared to the other mixes.

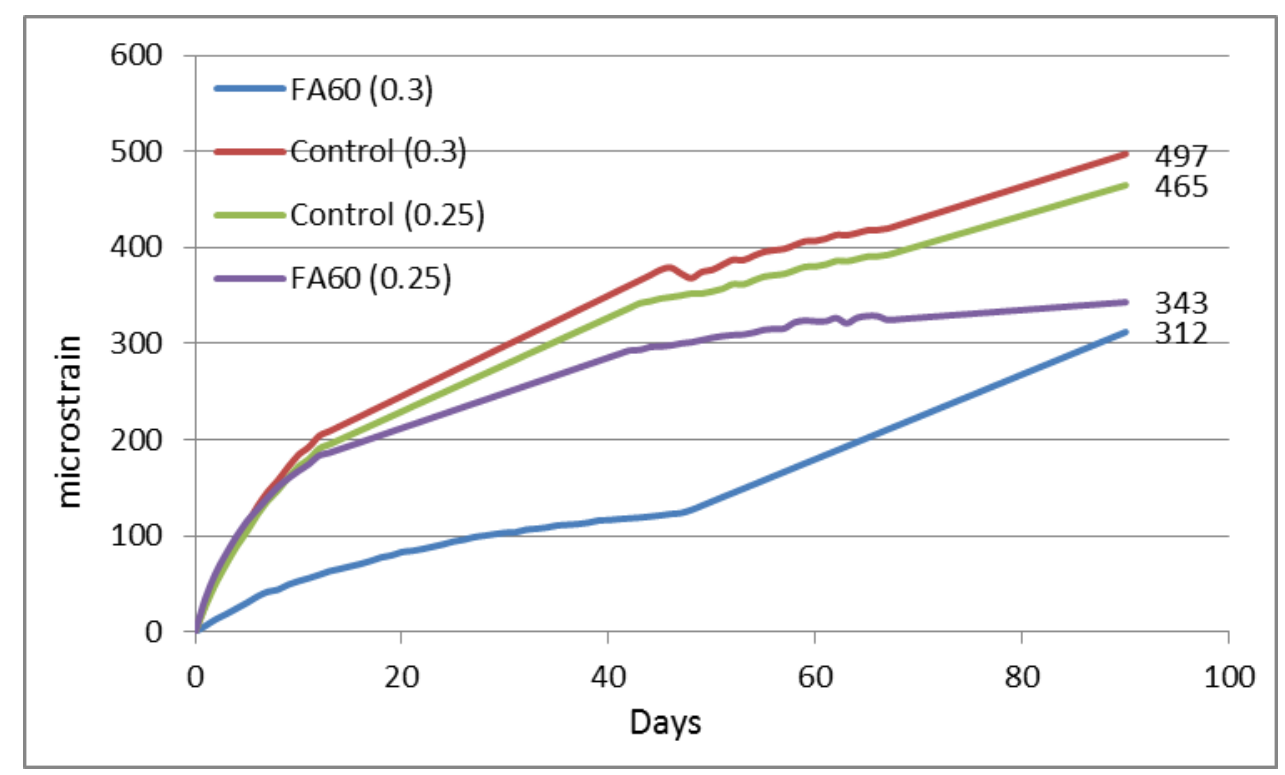

Figure 4-21 Comparison of Drying Shrinkage with Decreasing w/cm where $60 \%$ Cement Is Replaced by Fly Ash

In Figure 4.21 comparison of drying shrinkage with decreasing w/cm where $60 \%$ cement is replaced by fly ash is explained. Concrete with $60 \%$ fly ash as cement replacement showed 
more drying shrikage, when water to cemnt ratio was decreased. Control mix also showed less drying shrinkage when the w/cm was brought down from 0.3 to 0.25 At the end of 90 days concrete with $60 \%$ fly ash as cement replacement, showd least drying shrinkage.

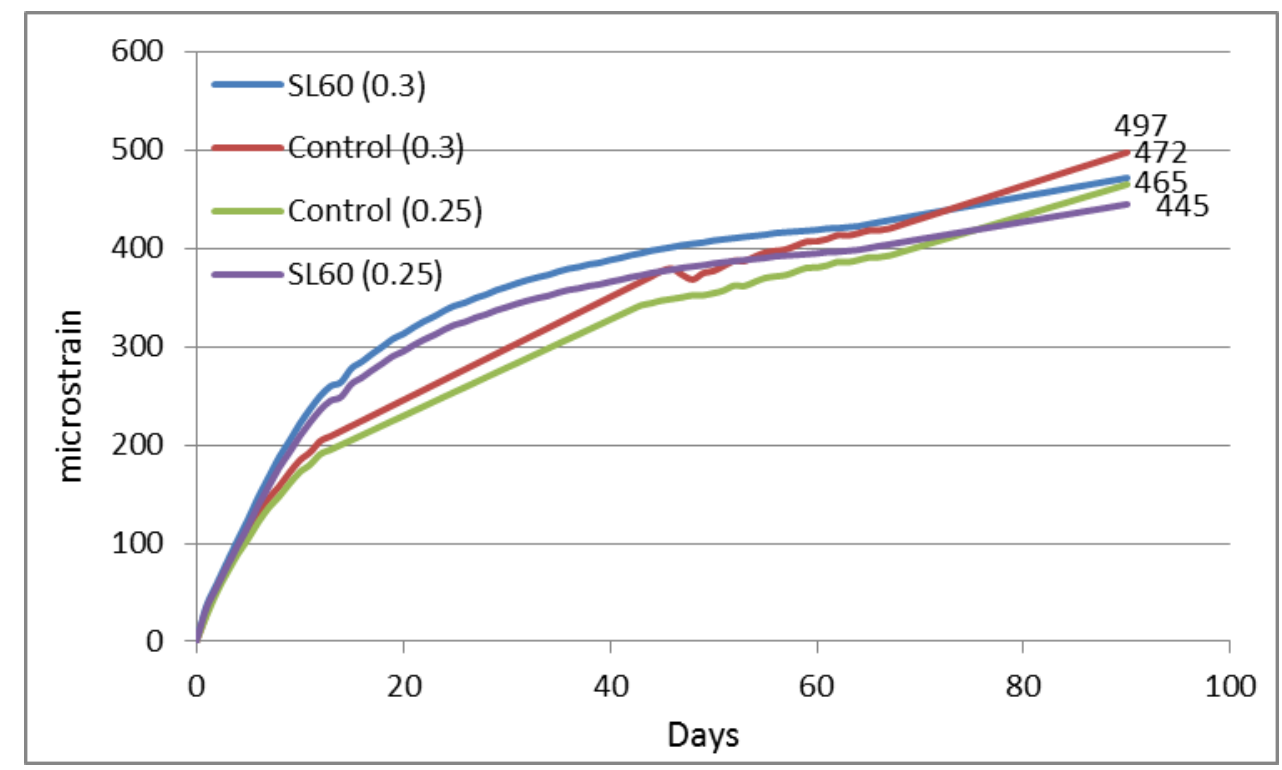

Figure 4-22 Comparison of Drying Shrinkage with Decreasing w/cm where $60 \%$ Cement Is Replaced by Slag

In Figure 4.22 comparison of drying shrinkage with decreasing w/cm where $60 \%$ cement is replaced by slag is explained. Concrete with $60 \%$ slag as cement replacement showed lesser drying shrikage, when w/cm was decreased. Control mix also showed less drying shrinkage when the w/cm was brought down from 0.3 to 0.25 , though the values at the end of 90 days are so close that it is hard draw a conclusion. 


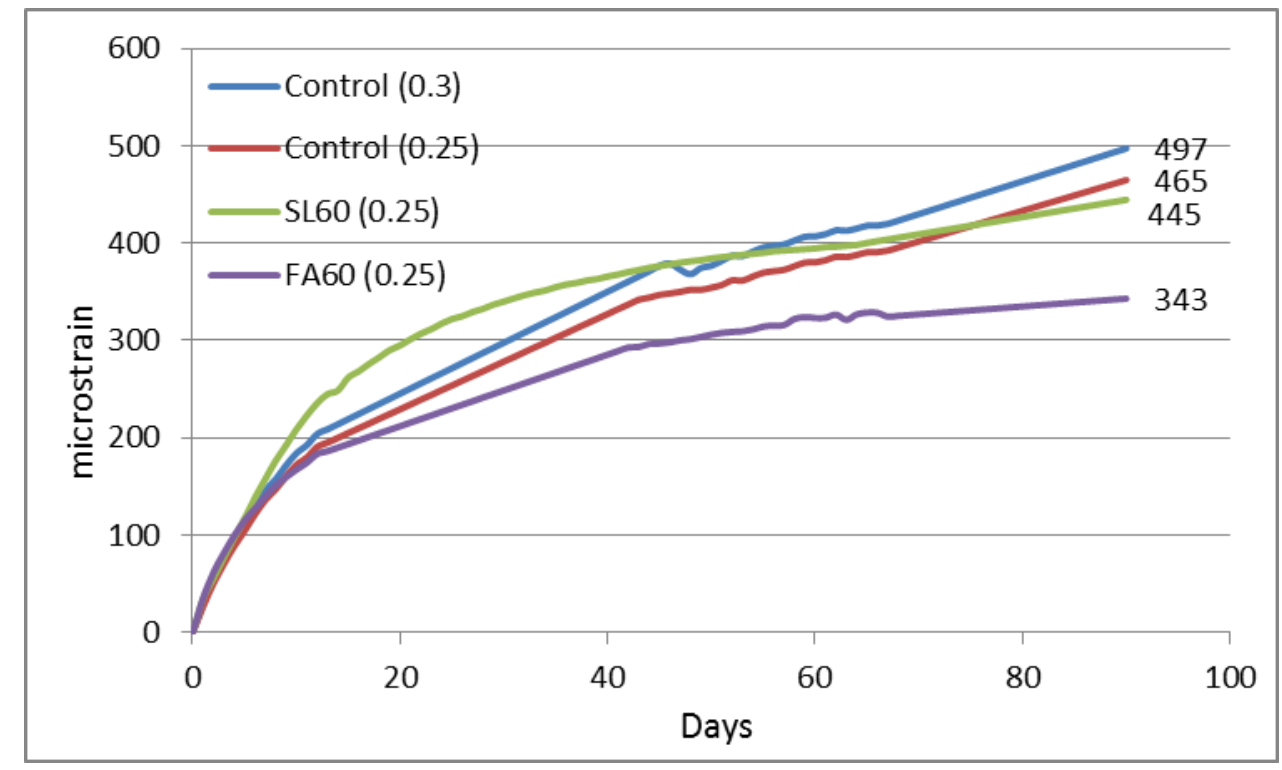

Figure 4-23 Comparison of Drying Shrinkage with Deecreasing w/cm where $60 \%$ Cement Is Replaced by Fly Ash or Slag

In Figure 4.23 comparison of drying shrinkage with decreasing w/cm where $60 \%$ cement is replaced by fly ash and/or slag is explained. Concrete with $60 \%$ fly ash as cement replacement showed least drying shrikage, when w/cm was decreased, though drying shrinkage of concrete with $60 \%$ slag as cement replacement was more. Control mix also showed less drying shrinkage when the w/cm was brought down from 0.3 to 0.25 .

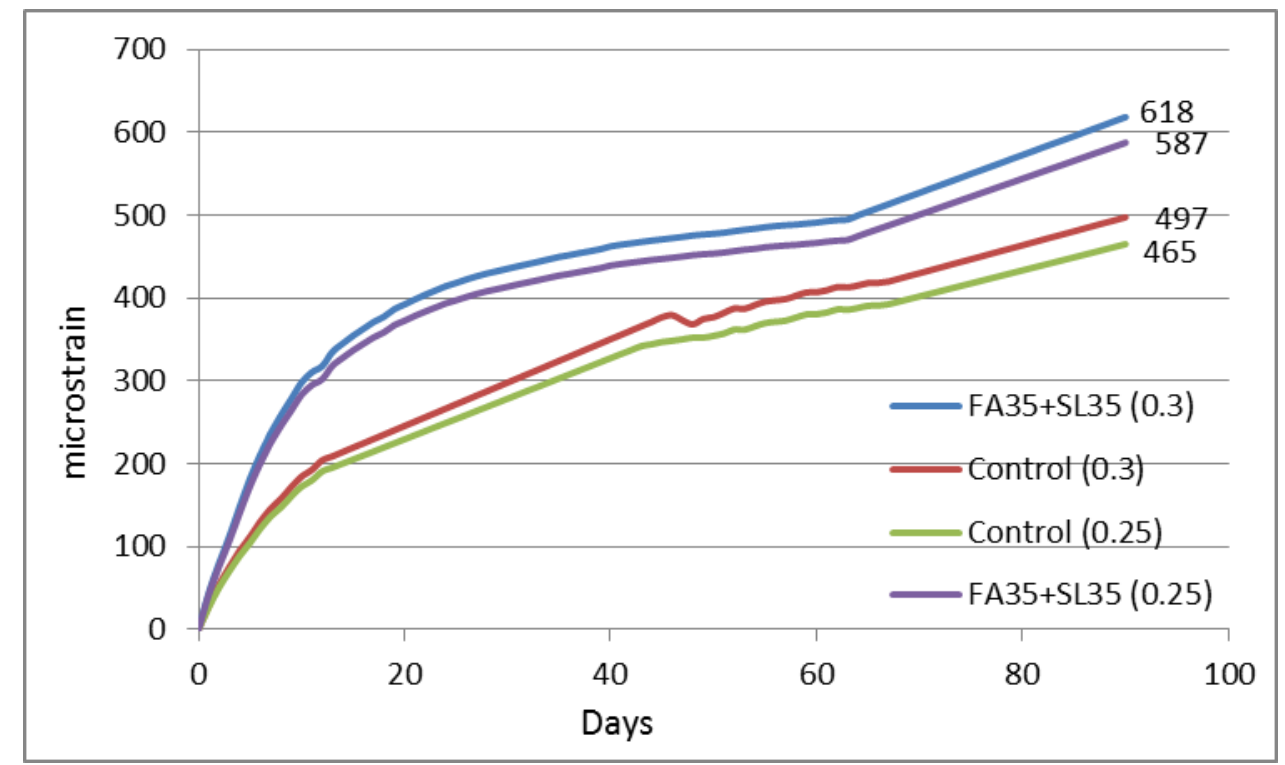

Figure 4-24 Comparison of Drying Shrinkage with Decreasing w/cm where $70 \%$ Cement Is Replaced by Fly Ash and Slag Combined 
In Figure 4.24 comparison of drying shrinkage with decreasing w/cm where $70 \%$ cement is replaced by fly ash and/or slag combined is explained. Concrete with $70 \%$ combined cement replacement showed lesser drying shrikage, when w/cm was decreased. Control mix also showed less drying shrinkage when the w/cm was brought down from 0.3 to 0.25 .

Drying shrinkage of high volume fly ash concrete is much less compared to high volume slag modified concrete and control concrete. Infact shrinkage reduces as the fly ash content increased. As the figure 4.25 showed slag modified concrete showed more shrinkage compared control mixes though with increase in replacement the shrinkage decreased. However the combination of fly ash and/or slag concrete failed to show any kind of good correlation betweeen the percentage replacement and shrinkage also remained in higher side, though much less than 800 microstrain.

\subsection{Maturity of Concrete}

Cylindrical specimens were tested for compressive strength at 3, 7, 28, 56 and 90 days in accordance with test method ASTM C 39 and the average maturity index was recorded for the instrumented specimens at the same ages, but for the development of the maturity calibration curve only the data until 56 days was used following the ASTM 1074.

The resulting curve from plotting the average compressive strength as function of the average value of the maturity index is the Strength-Maturity relationship, which can be use for estimating the strength of the concrete mixtures cured under other temperature conditions.

The correlation curve was generated according to the Nurse-Saul Material Function. The graphs of the natural logarithms curve adequately fit the data as shown by the $\mathrm{R}^{2}$ values.

Due to the way that the cylindrical specimens were cured under controlled conditions in the laboratory, it was almost assured that the maturity reached in 3, 7, 28 and 56 days is close from one concrete mix to the other. But even when the maturity is the pretty much the same for the fourteen mixes studied, the compressive strength is not, and then is why it is important to create 
the Strength-Maturity relationship curve and to find the Strength-Maturity equation for each single concrete mix.

The Strength-Maturity can be written in the form proposed by Plowman (Mindess et al. 2005). Strength-Maturity equations can be used to predict the strength of this fourteen concrete mixes as function of the maturity index.

$$
Y=b^{*} \operatorname{Ln}(x)+a
$$

Where

Y : Compressive strength

$\mathrm{x} \quad$ : Maturity index at any time $\mathrm{t}$.

$\mathrm{a}, \mathrm{b}$ : Are functions of the proportions and the materials used in the concrete mix, (these values have no physical meaning).

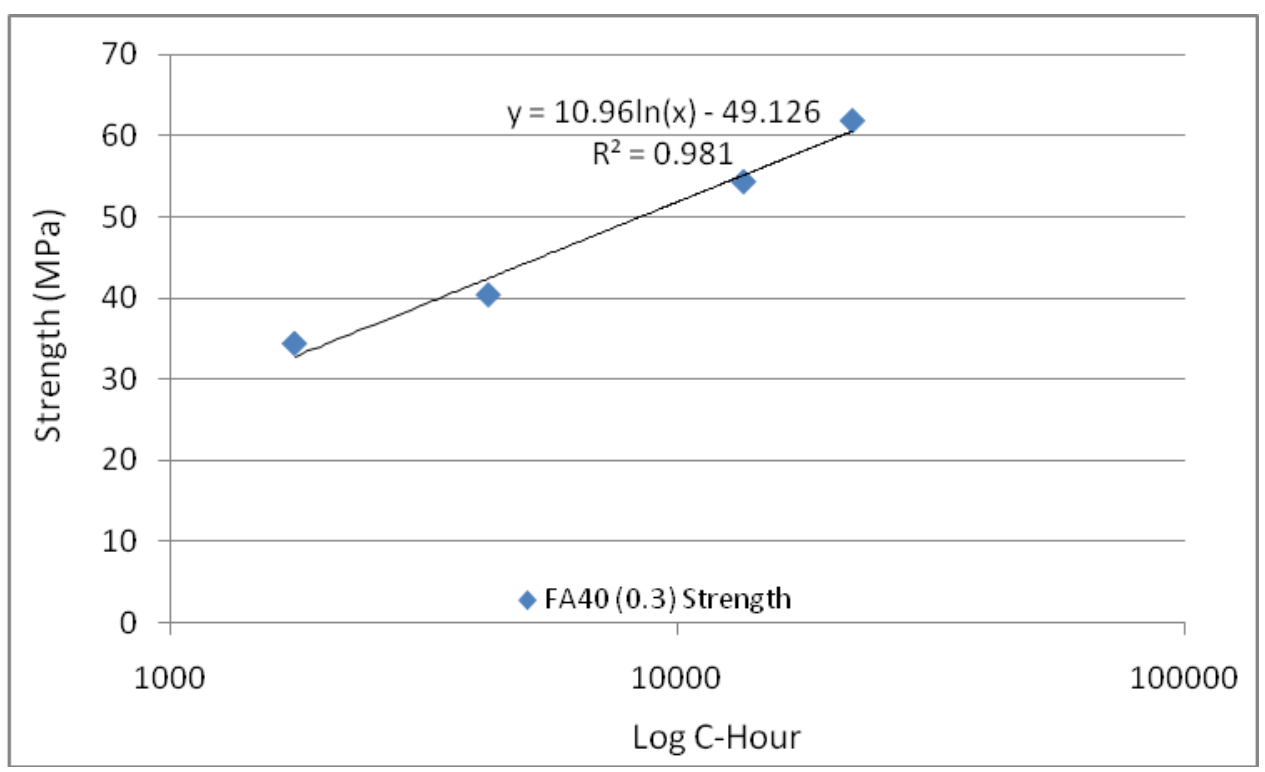

Figure 4-25 Strength-Maturity FA40(0.3)

Table 4.1 Strength Maturity Equation FA40(0.3)

\begin{tabular}{|l|l|c|c|}
\hline $\mathbf{a}$ & $\mathbf{b}$ & $\mathbf{Y}=\mathbf{b} \mathbf{x} \operatorname{Ln}(\mathbf{x})+\mathbf{a}$ & $\mathbf{R}^{2}$ \\
\hline-49.126 & 10.96 & $\mathrm{Y}=10.96 * \operatorname{Ln}(\mathrm{x})-49.126$ & 0.981 \\
\hline
\end{tabular}




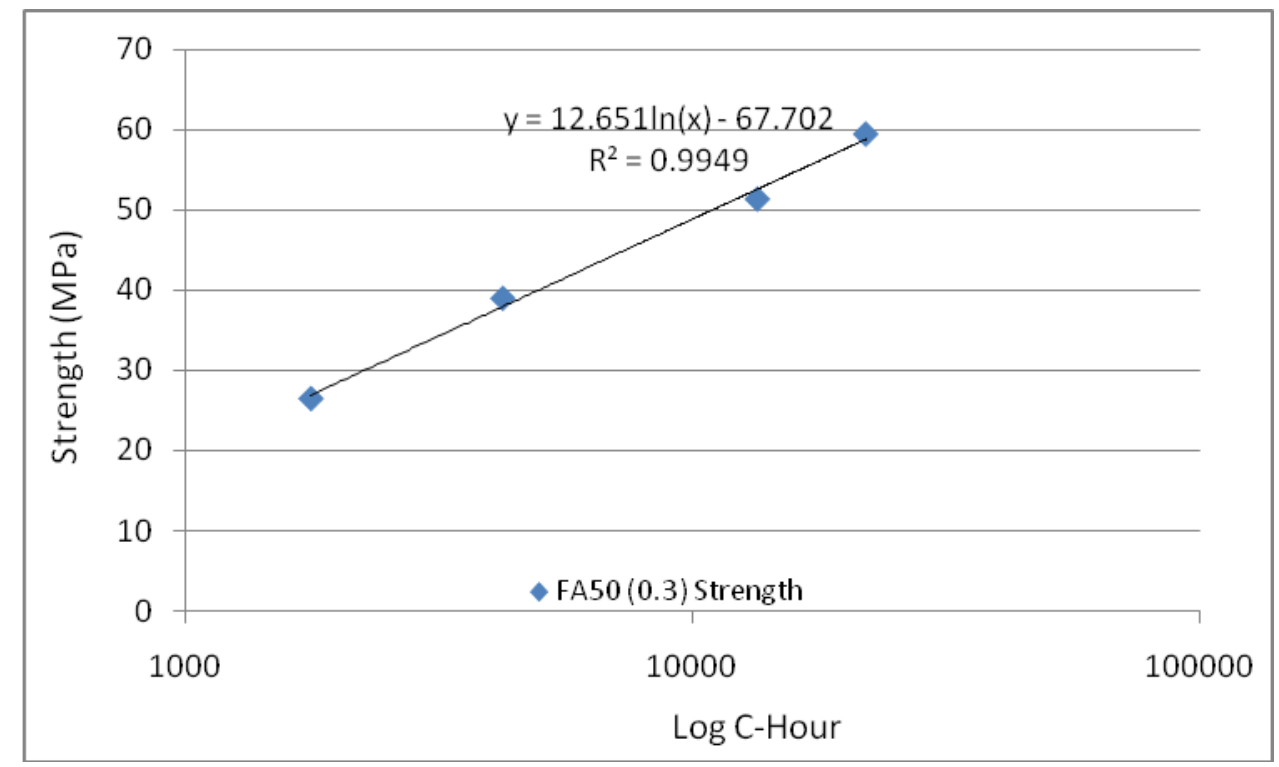

Figure 4-26 Strength-Maturity FA50(0.3)

Table 4.2 Strength Maturity Equation FA50(0.3)

\begin{tabular}{|l|l|l|c|}
\hline $\mathbf{a}$ & $\mathbf{b}$ & $\mathbf{Y}=\mathbf{b} \mathbf{x} \mathbf{L n}(\mathbf{x})+\mathbf{a}$ & $\mathbf{R}^{\mathbf{2}}$ \\
\hline-67.702 & 12.651 & $\mathrm{Y}=12.651^{*} \operatorname{Ln}(\mathrm{x})-67.702$ & 0.9949 \\
\hline
\end{tabular}

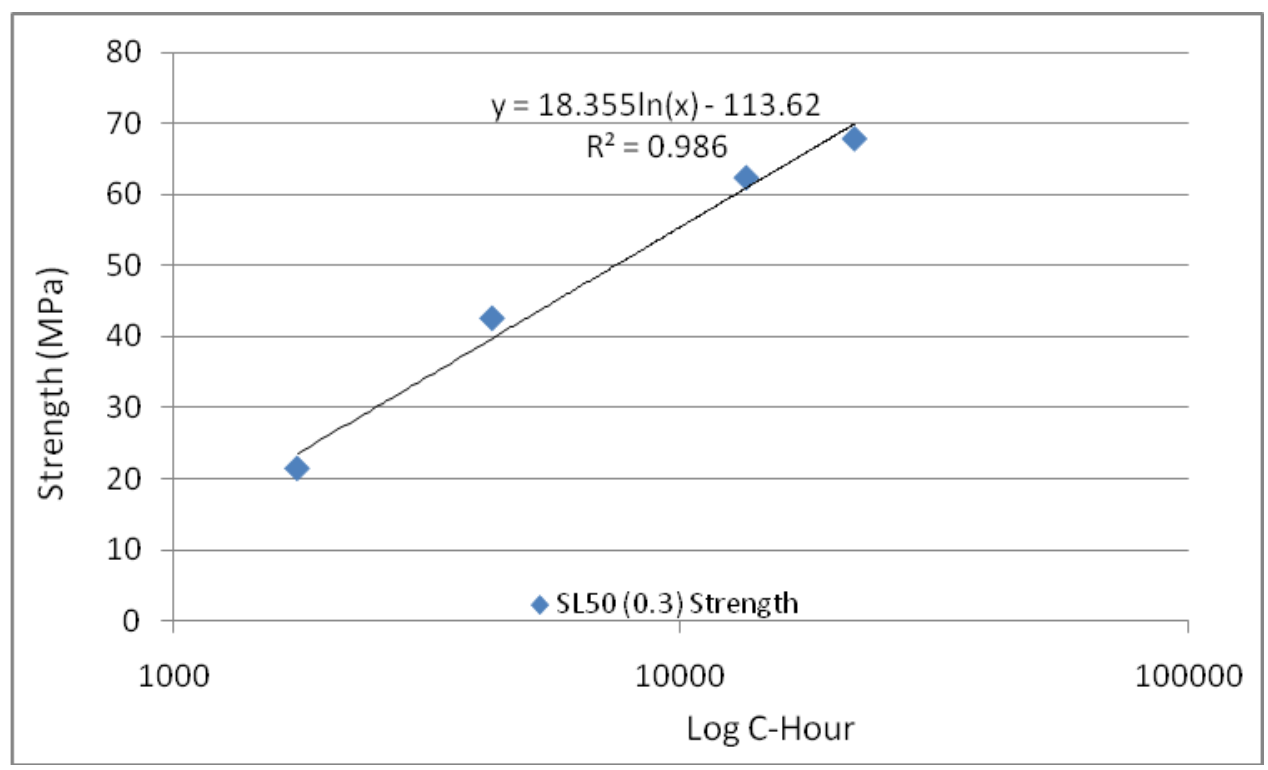

Figure 4-27 Strength-Maturity SL50(0.3)

Table 4.3 Strength Maturity Equation SL50(0.3)

\begin{tabular}{|l|l|l|l|}
\hline $\mathbf{a}$ & $\mathbf{b}$ & $\mathbf{Y}=\mathbf{b} \mathbf{x} \operatorname{Ln}(\mathbf{x})+\mathbf{a}$ & $\mathbf{R}^{\mathbf{2}}$ \\
\hline-113.62 & 18.355 & $\mathrm{Y}=18.355^{*} \operatorname{Ln}(\mathrm{x})-113.62$ & 0.986 \\
\hline
\end{tabular}




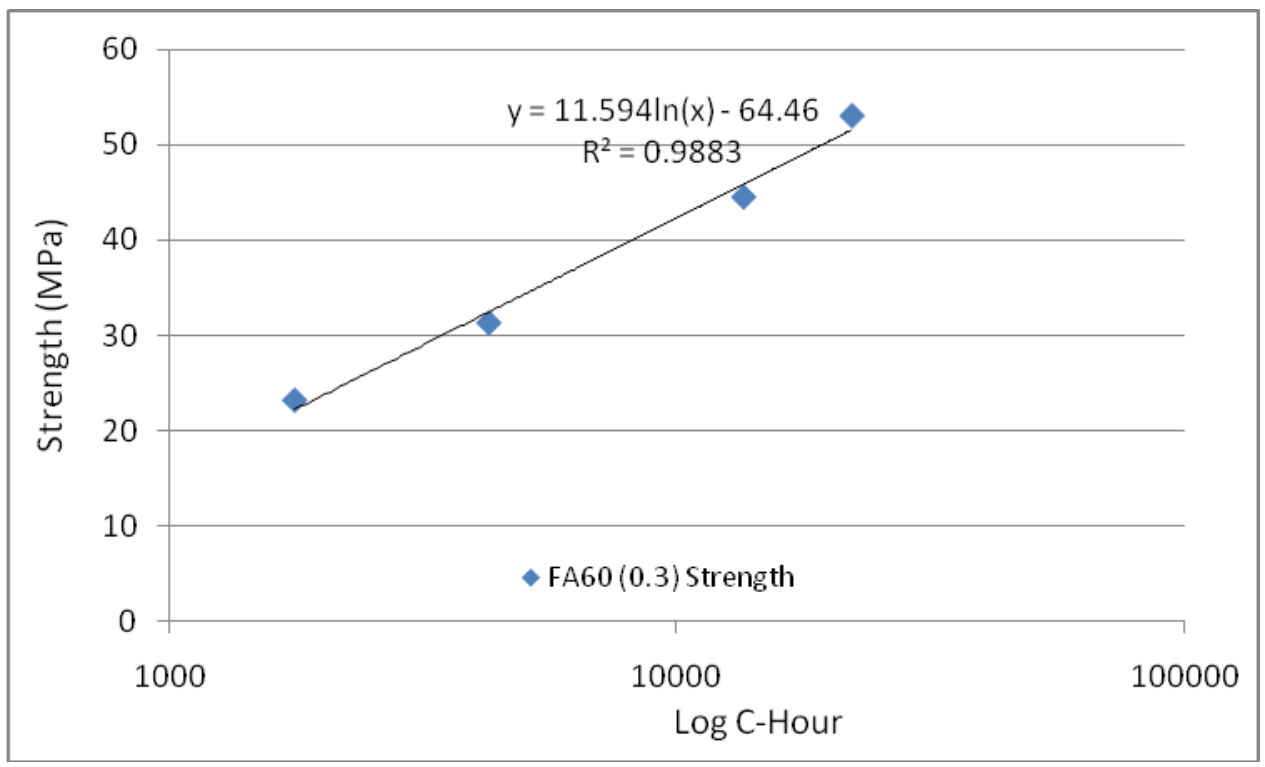

Figure 4-28 Strength-Maturity FA60(0.3)

Table 4.4 Strength Maturity Equation FA60(0.3)

\begin{tabular}{|c|l|l|c|}
\hline \multicolumn{1}{|c|}{$\mathbf{a}$} & $\mathbf{b}$ & $\mathbf{Y}=\mathbf{b} \mathbf{x} \operatorname{Ln}(\mathbf{x})+\mathbf{a}$ & $\mathbf{R}^{\mathbf{2}}$ \\
\hline-64.46 & 11.59 & $\mathrm{Y}=11.59{ }^{*} \operatorname{Ln}(\mathrm{x})-64.46$ & 0.9883 \\
\hline
\end{tabular}

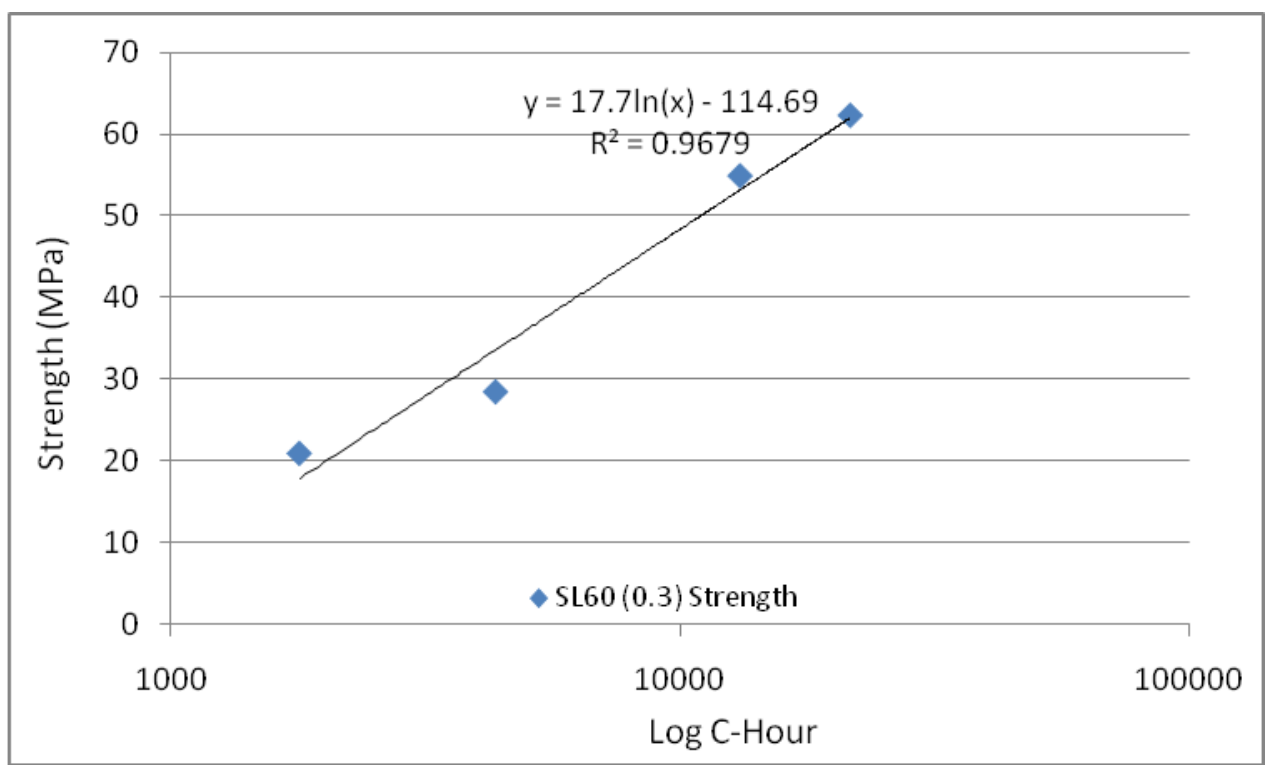

Figure 4-29 Strength-Maturity SL60(0.3)

Table 4.5 Strength Maturity Equation SL60(0.3)

\begin{tabular}{|l|c|c|c|}
\hline $\mathbf{a}$ & $\mathbf{b}$ & $\mathbf{Y}=\mathbf{b} \mathbf{x} \operatorname{Ln}(\mathbf{x})+\mathbf{a}$ & $\mathbf{R}^{\mathbf{2}}$ \\
\hline-114.69 & 17.7 & $\mathrm{Y}=17.7^{*} \operatorname{Ln}(\mathrm{x})-114.69$ & 0.9679 \\
\hline
\end{tabular}




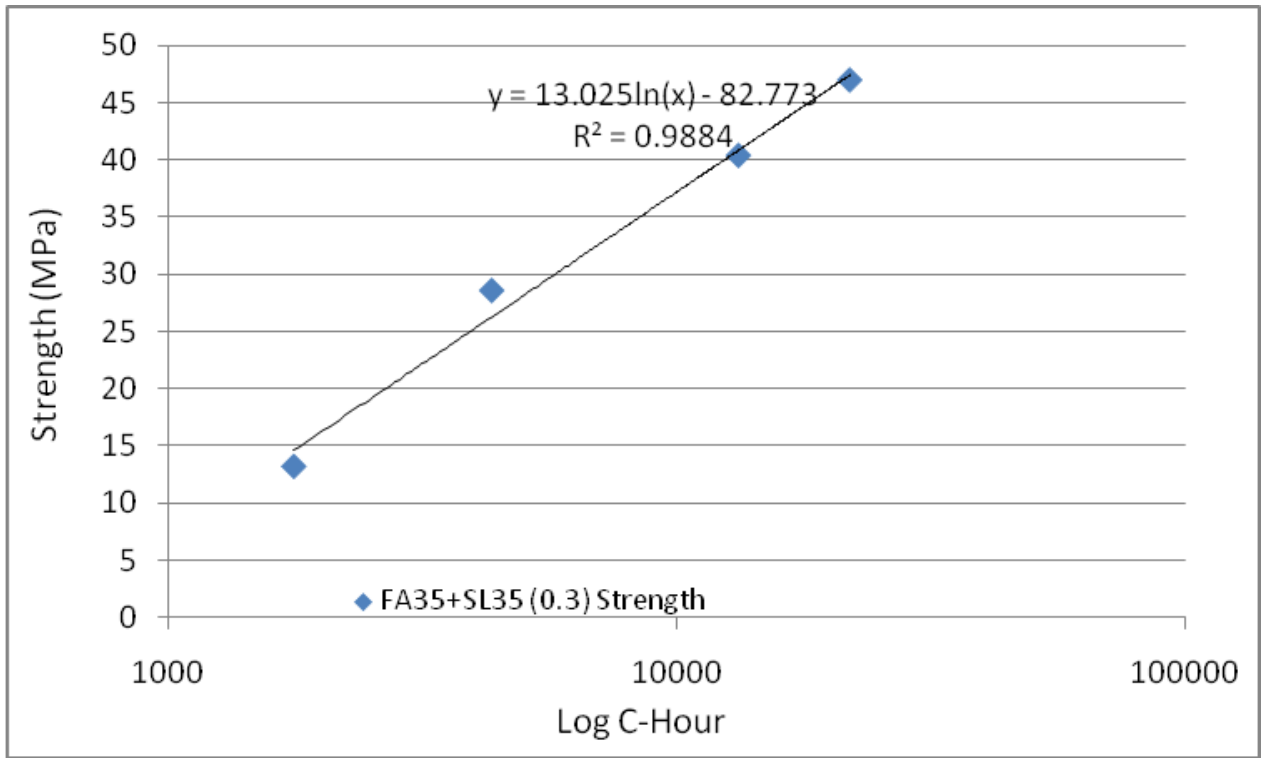

Figure 4-30 Strength-Maturity FA35+SL35(0.3)

Table 4.6 Strength Maturity Equation FA35+SL35(0.3)

\begin{tabular}{|l|l|l|c|}
\hline $\mathbf{a}$ & $\mathbf{b}$ & $\mathbf{Y}=\mathbf{b} \mathbf{x} \mathbf{L n}(\mathbf{x})+\mathbf{a}$ & $\mathbf{R}^{\mathbf{2}}$ \\
\hline-82.773 & 13.025 & $\mathrm{Y}=13.025{ }^{*} \operatorname{Ln}(\mathrm{x})-82.773$ & 0.9884 \\
\hline
\end{tabular}

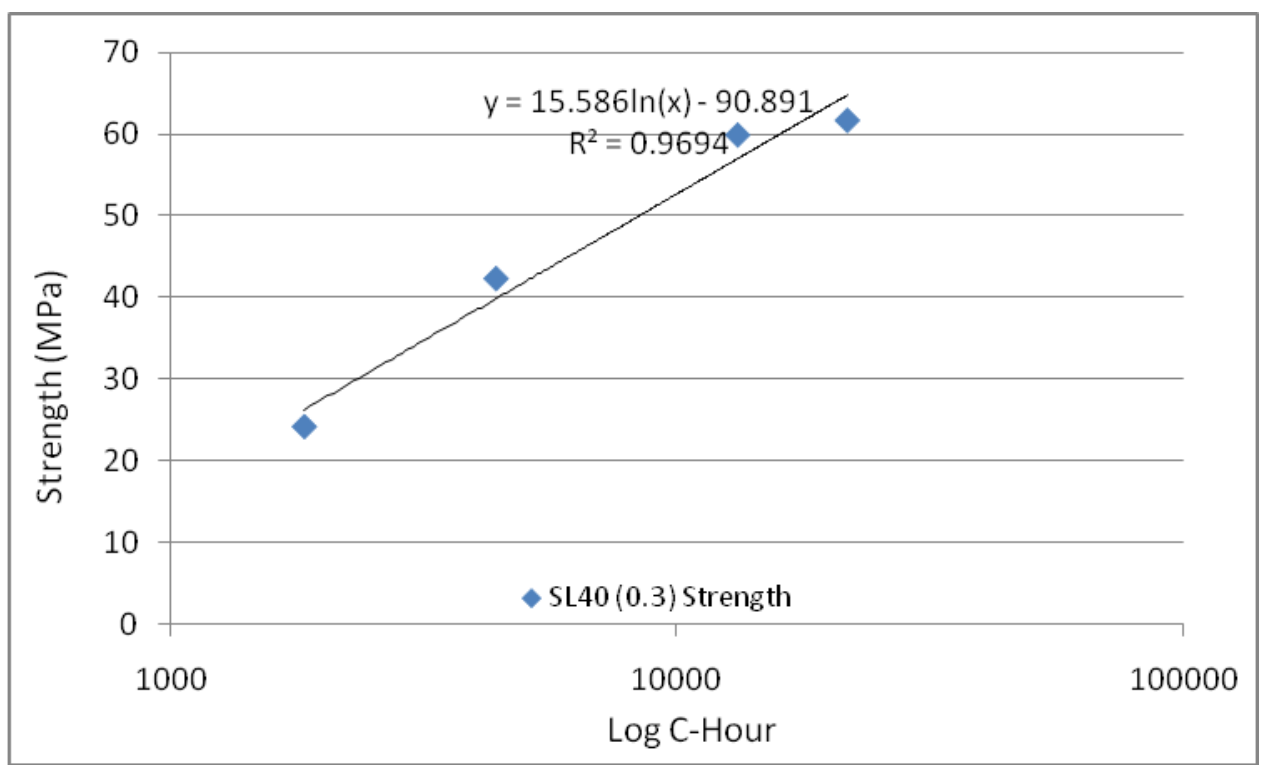

Figure 4-31 Strength-Maturity SL40(0.3)

Table 4.7 Strength Maturity Equation SL40(0.3)

\begin{tabular}{|l|l|l|c|}
\hline $\mathbf{a}$ & $\mathbf{b}$ & $\mathbf{Y ~ = b ~ x ~} \mathbf{L n}(\mathbf{x})+\mathbf{a}$ & $\mathbf{R}^{\mathbf{2}}$ \\
\hline-90.891 & 15.586 & $\mathrm{Y}=15.586^{*} \operatorname{Ln}(\mathrm{x})-90.891$ & 0.9694 \\
\hline
\end{tabular}




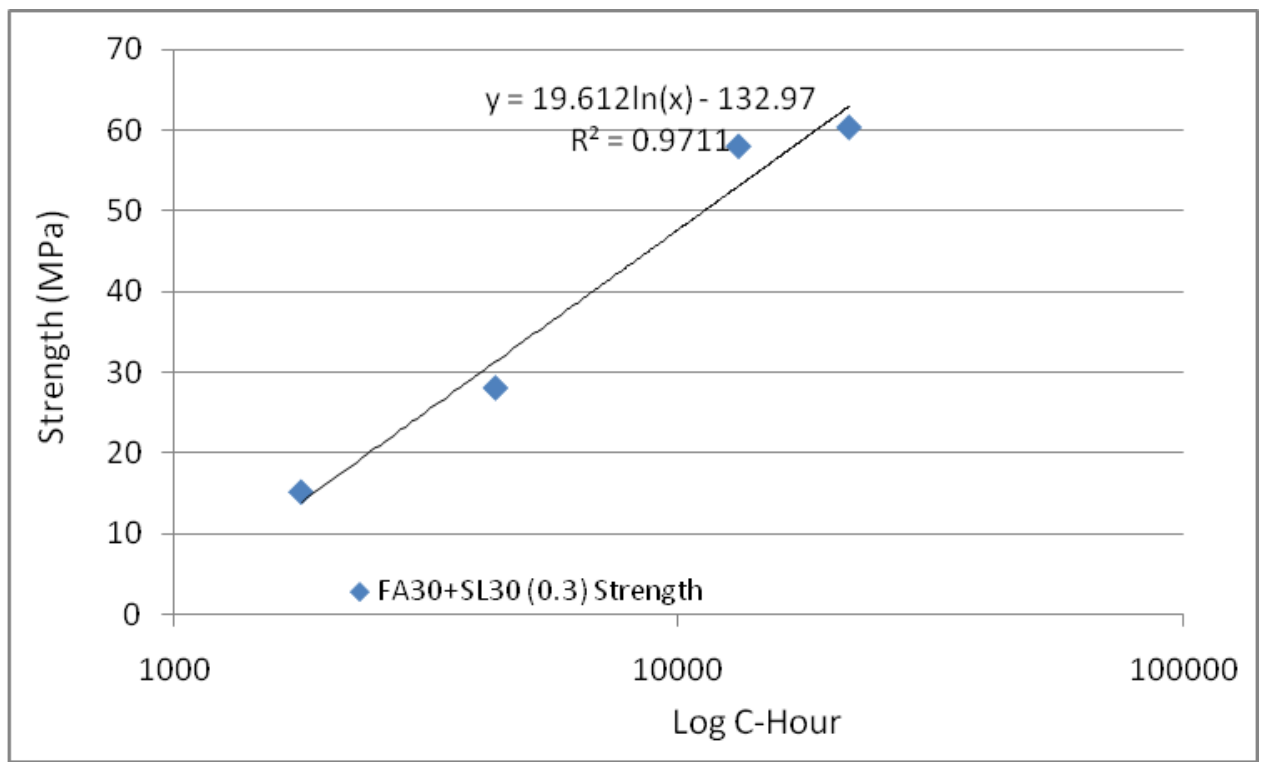

Figure 4-32 Strength-Maturity FA30+SL30(0.3)

Table 4.8 Strength Maturity Equation FA30+SL30(0.3)

\begin{tabular}{|l|l|l|c|}
\hline $\mathbf{a}$ & $\mathbf{b}$ & $\mathbf{Y}=\mathbf{b} \mathbf{x} \mathbf{L n}(\mathbf{x})+\mathbf{a}$ & $\mathbf{R}^{\mathbf{2}}$ \\
\hline-132.97 & 19.612 & $\mathrm{Y}=19.61{ }^{*} \operatorname{Ln}(\mathrm{x})-132 . .97$ & 0.9711 \\
\hline
\end{tabular}

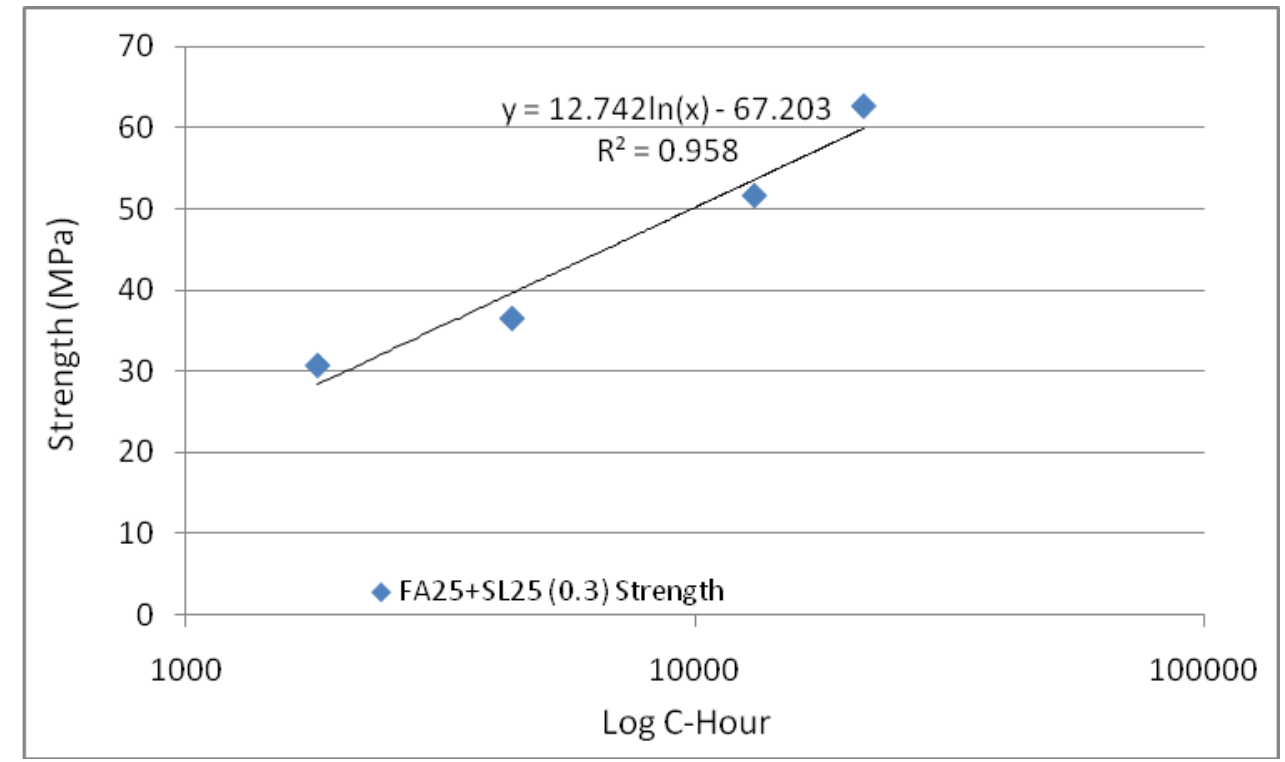

Figure 4-33 Strength-Maturity FA25+SL25(0.3)

Table 4.9 Strength Maturity Equation FA25+SL25(0.3)

\begin{tabular}{|l|l|l|l|}
\hline $\mathbf{a}$ & $\mathbf{b}$ & $\mathbf{Y}=\mathbf{b} \mathbf{x} \operatorname{Ln}(\mathbf{x})+\mathbf{a}$ & $\mathbf{R}^{\mathbf{2}}$ \\
\hline-67.203 & 12.742 & $\mathrm{Y}=12.742{ }^{*} \operatorname{Ln}(\mathrm{x})-67.203$ & 0.958 \\
\hline
\end{tabular}




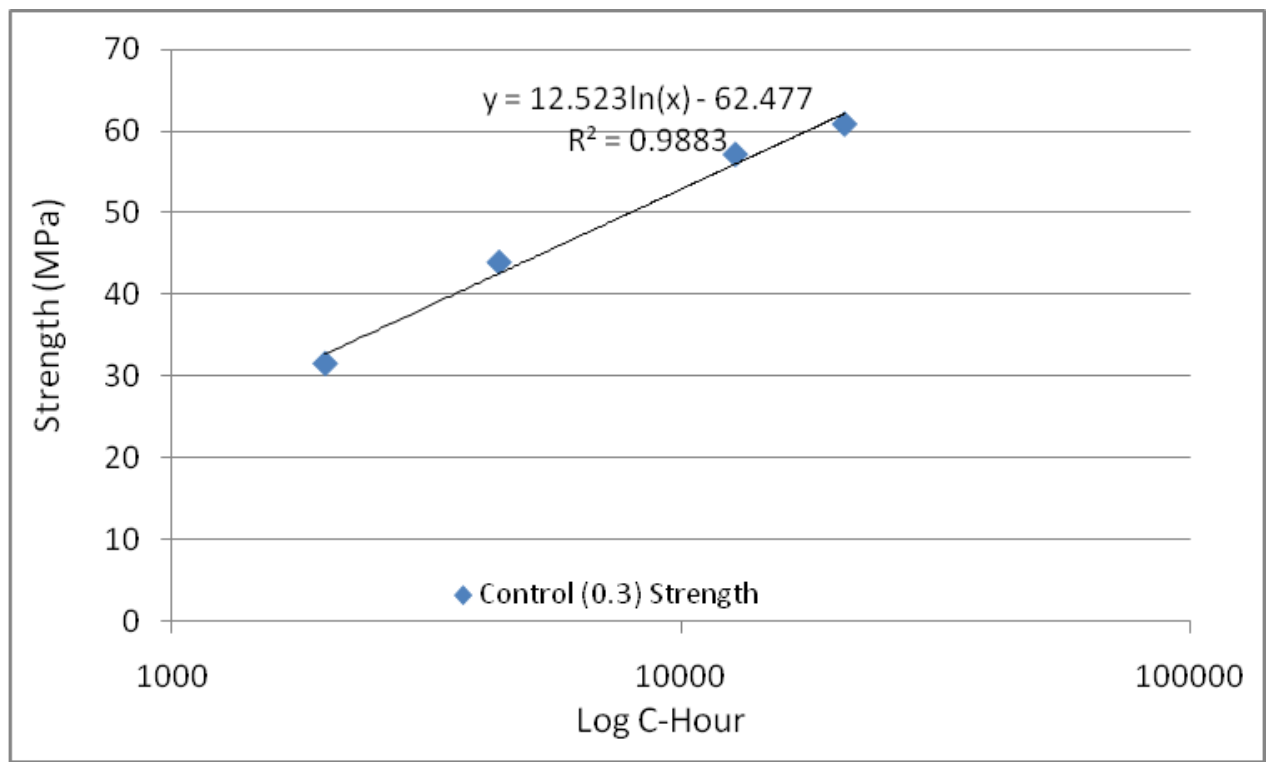

Figure 4-34 Strength-Maturity Control(0.3)

Table 4.10 Strength Maturity Equation Control(0.3)

\begin{tabular}{|l|l|l|c|}
\hline $\mathbf{a}$ & $\mathbf{b}$ & $\mathbf{Y}=\mathbf{b} \mathbf{x} \mathbf{L n}(\mathbf{x})+\mathbf{a}$ & $\mathbf{R}^{\mathbf{2}}$ \\
\hline-62.477 & 12.523 & $\mathrm{Y}=12.523{ }^{*} \operatorname{Ln}(\mathrm{x})-62.477$ & 0.9883 \\
\hline
\end{tabular}

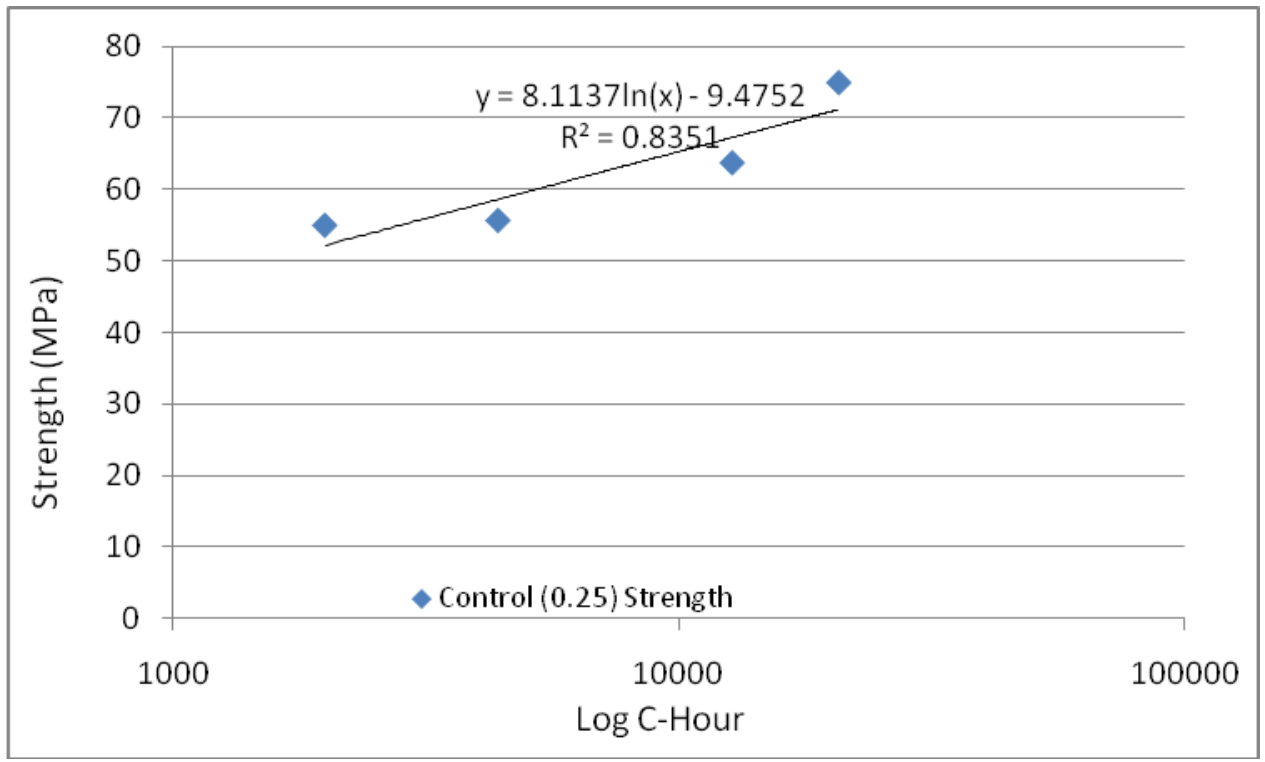

Figure 4-35 Strength-Maturity Control(0.25)

Table 4.11 Strength Maturity Equation Control(0.25)

\begin{tabular}{|l|l|l|l|}
\hline $\mathbf{a}$ & $\mathbf{b}$ & $\mathbf{Y}=\mathbf{b} \mathbf{x} \operatorname{Ln}(\mathbf{x})+\mathbf{a}$ & $\mathbf{R}^{\mathbf{2}}$ \\
\hline-9.4752 & 8.1137 & $\mathrm{Y}=8.1137^{*} \operatorname{Ln}(\mathrm{x})-9.4752$ & 0.8351 \\
\hline
\end{tabular}




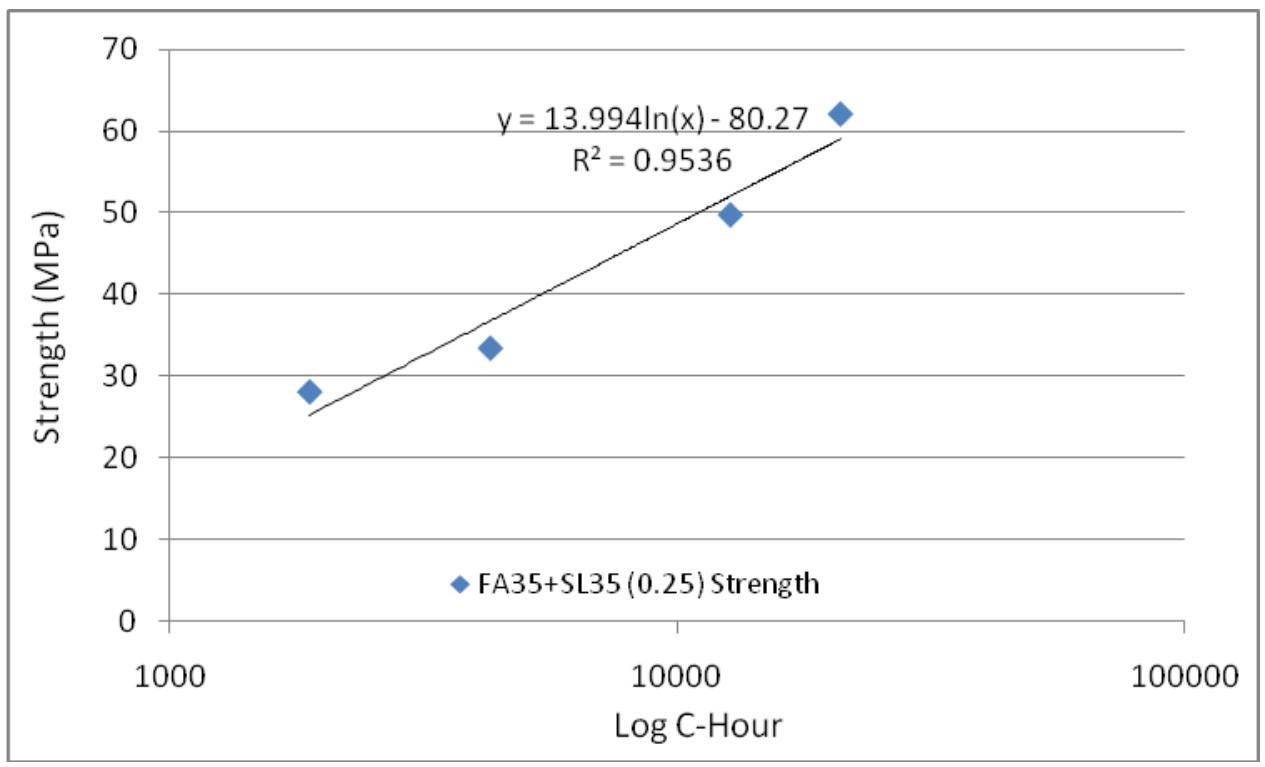

Figure 4-36 Strength-Maturity FA35+SL35(0.25)

Table 4.12 Strength Maturity Equation FA35+SL35(0.25)

\begin{tabular}{|c|l|l|c|}
\hline \multicolumn{1}{|c|}{$\mathbf{a}$} & $\mathbf{b}$ & $\mathbf{Y}=\mathbf{b} \mathbf{x} \operatorname{Ln}(\mathbf{x})+\mathbf{a}$ & $\mathbf{R}^{\mathbf{2}}$ \\
\hline-80.27 & 13.99 & $\mathrm{Y}=13.99{ }^{*} \operatorname{Ln}(\mathrm{x})-80.27$ & 0.9536 \\
\hline
\end{tabular}

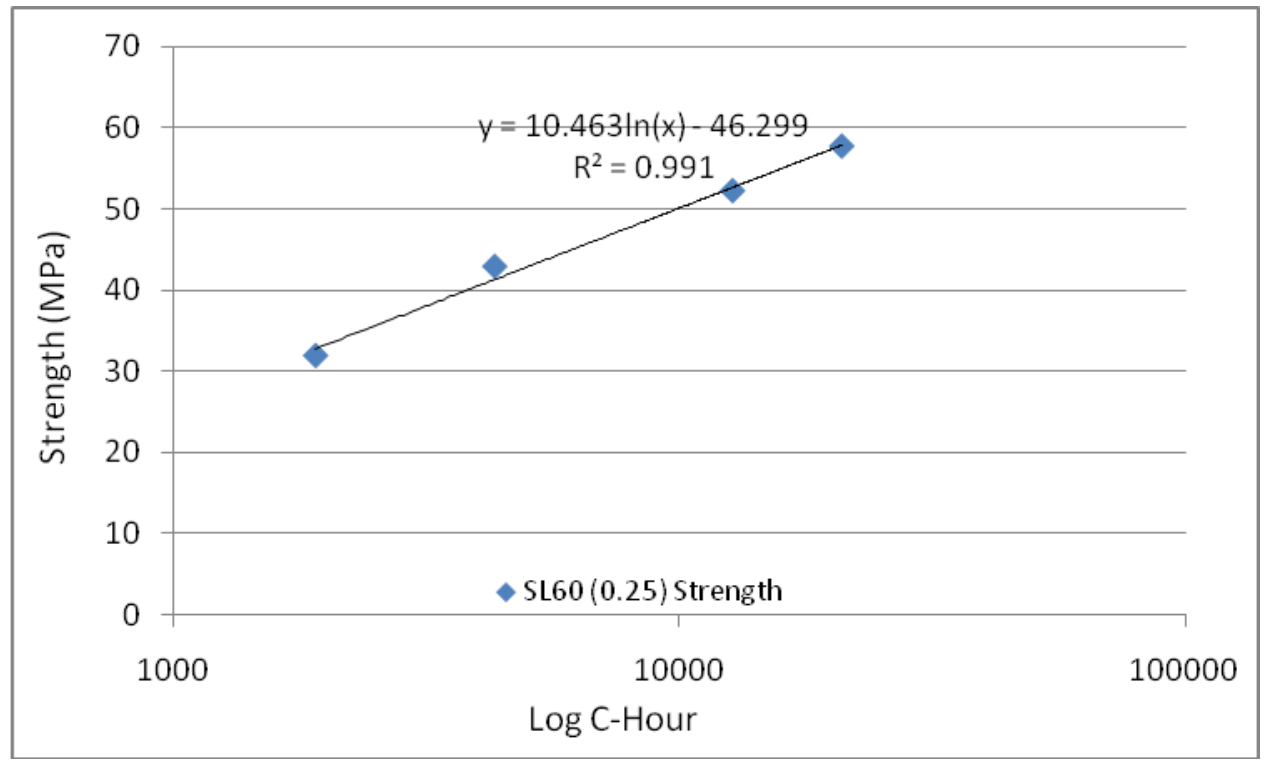

Figure 4-37 Strength-Maturity SL60(0.25)

Table 4.13 Strength Maturity Equation SL60(0.25)

\begin{tabular}{|l|l|l|l|}
\hline $\mathbf{a}$ & $\mathbf{b}$ & $\mathbf{Y}=\mathbf{b} \mathbf{x} \operatorname{Ln}(\mathbf{x})+\mathbf{a}$ & $\mathbf{R}^{\mathbf{2}}$ \\
\hline-46.299 & 10.463 & $\mathrm{Y}=10.463^{*} \operatorname{Ln}(\mathrm{x})-46.299$ & 0.991 \\
\hline
\end{tabular}




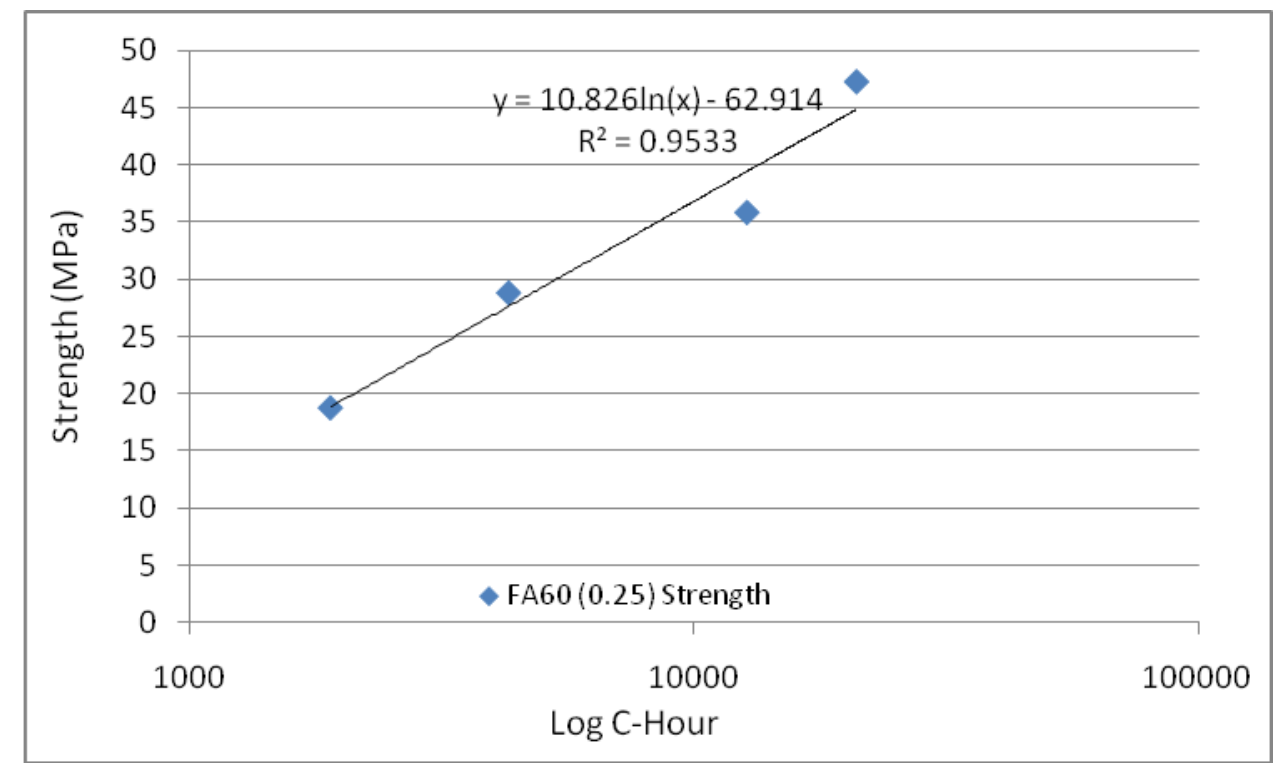

Figure 4-38 Strength-Maturity FA60(0.25)

Table 4.14 Strength Maturity Equation FA60(0.25)

\begin{tabular}{|l|l|l|c|}
\hline $\mathbf{a}$ & $\mathbf{b}$ & $\mathbf{Y}=\mathbf{b} \mathbf{x} \mathbf{L n}(\mathbf{x})+\mathbf{a}$ & $\mathbf{R}^{\mathbf{2}}$ \\
\hline-62.914 & 10.826 & $\mathrm{Y}=10.826{ }^{*} \operatorname{Ln}(\mathrm{x})-62.914$ & 0.9533 \\
\hline
\end{tabular}

As the combination of high volume fly ash and/or slag concrete is used with $\mathrm{w} / \mathrm{cm}$ as 0.3 the correlation showed is over $95 \%$ for all the concrete. As the $\mathrm{w} / \mathrm{cm}$ is decreased to 0.25 the control mix did not show a good correlation between strength and the maturity as the correlation value drops to $83 \%$. The high volume slag and high volume fly ash modified concrete showed a good correlation.

\subsection{Freezing and Thawing}

Freezing and thawing test for all the concrete with high volume fly ash, high volume slag, or combination of both showed good consistency after 300 hundered cycles. For all the concrete more than $95 \%$ consistency is showed Table 4.15 
Table 4.15 Durability Factor for High volume fly ash and/or slag modified concrete

\begin{tabular}{|r|c|c|c|}
\hline \multirow{2}{*}{ Name } & After 0 cycles & After 300 cycles & Durability \\
& Factor \\
& Modulus of Elasticity & Modulus of Elasticity & \\
\hline FA40 (0.3) & KHz & $\mathrm{KHz}$ & \\
\hline FA50 (0.3) & 5.149 & 5.255 & 0.96 \\
\hline SL50 (0.3) & 5.157 & 5.345 & 0.95 \\
\hline FA60 (0.3) & 5.035 & 5.342 & 0.93 \\
\hline SL60 (0.3) & 5.096 & 5.121 & 0.97 \\
\hline FA35+SL35 (0.3) & 5.145 & 5.292 & 0.93 \\
\hline SL40 (0.3) & 5.256 & 5.087 & 1.02 \\
\hline FA30+SL30 (0.3) & 5.278 & 5.252 & 1.00 \\
\hline FA25+SL25 (0.3) & 5.54 & 5.241 & 1.01 \\
\hline Control (0.3) & 5.321 & 5.282 & 1.10 \\
\hline Control (0.25) & 5.235 & 5.346 & 0.99 \\
\hline FA35+SL35 (0.25) & 5.215 & 5.284 & 0.98 \\
\hline SL60 (0.25) & 5.189 & 5.145 & 1.03 \\
\hline FA60 (0.25) & 5.197 & 5.274 & 0.97 \\
\hline
\end{tabular}

\subsection{Chloride Penetration}

Chloride penetration is one of the identified problems for concrete durability, as increase in porosity leads to corrosion of the rebar in reinforced concrete structures. Also, corrosion of concrete makes it more brittle. From the measured chloride data of every 30 minutes seconds till 6 hours plotted against the minutes to show the comparison between different concrete mixes. 


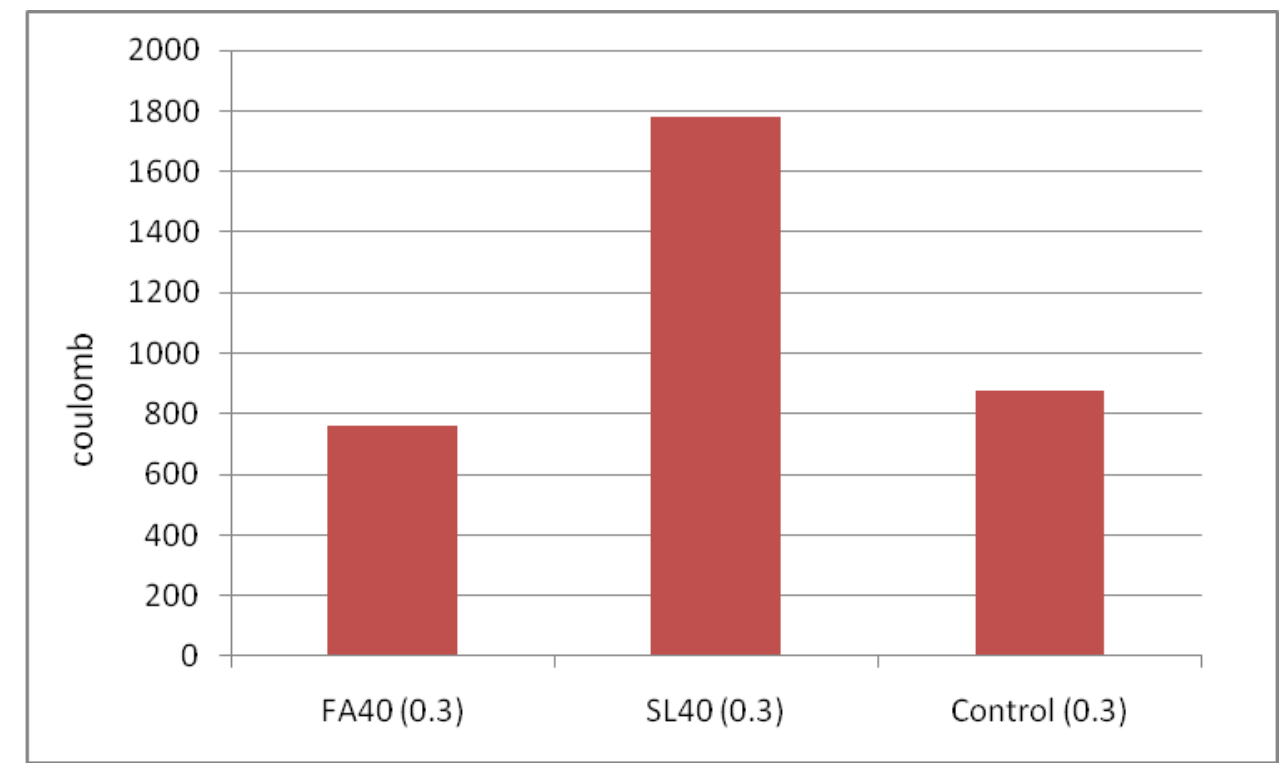

Figure 4-39 Comparison of Charge Passed in FA40 and SL40

In Figure 4.39 the charge passed in concretes with $40 \%$ cement replacement is compared with the control concrete samples up to 6 hours. Concrete with $40 \%$ fly ash as cement replacement had the least porosity among all, while Concrete with $40 \%$ slag as cement replacement had the most porosity, control mix had moderate porosity. Coarser fly ash particles acted as better filler material, which lead to more compact material, which in turn allowed less porosity.

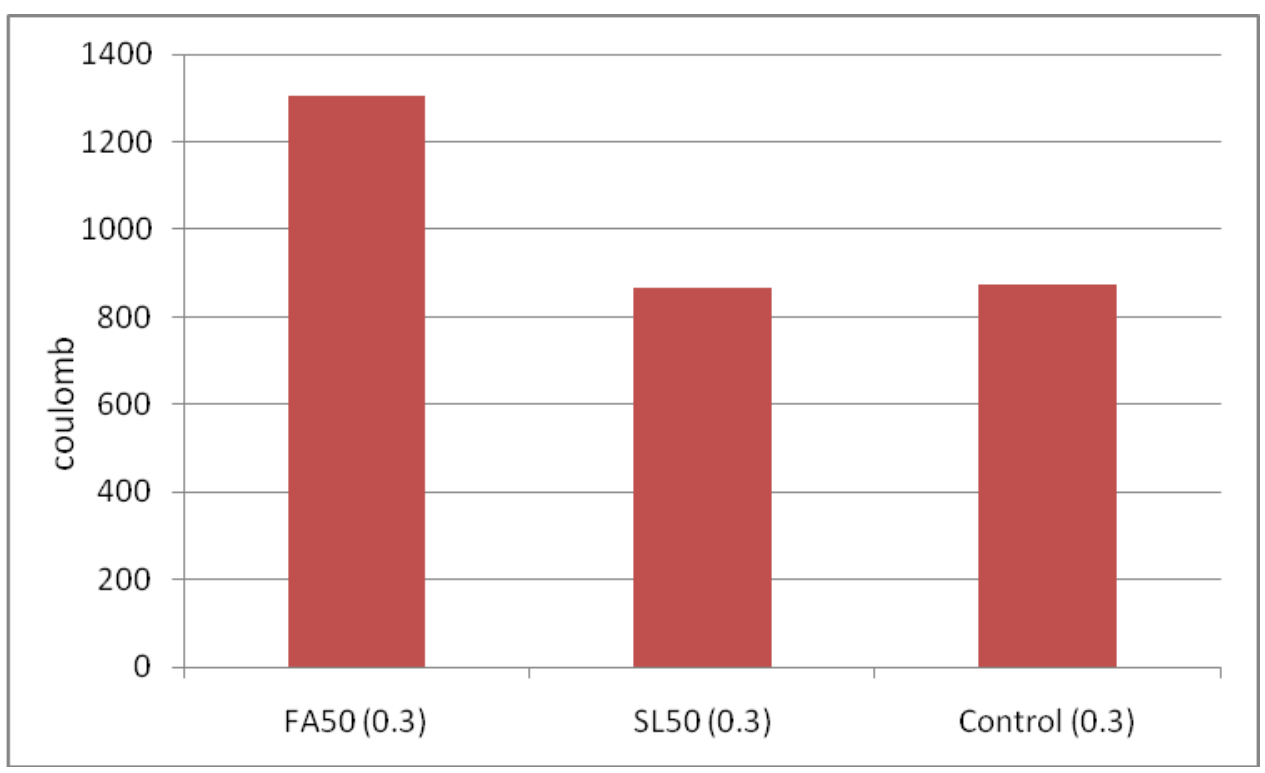

Figure 4-40 Comparison of Charge Passed in FA50 and SL50 
In Figure 4.40 the charge passed in concretes with $50 \%$ cement replacement is compared with the control concrete samples up to 6 hours. Concrete with $50 \%$ fly ash as cement replacement had the most porosity, while Concrete with $50 \%$ slag as cement replacement had the least porosity, control mix had moderate porosity.

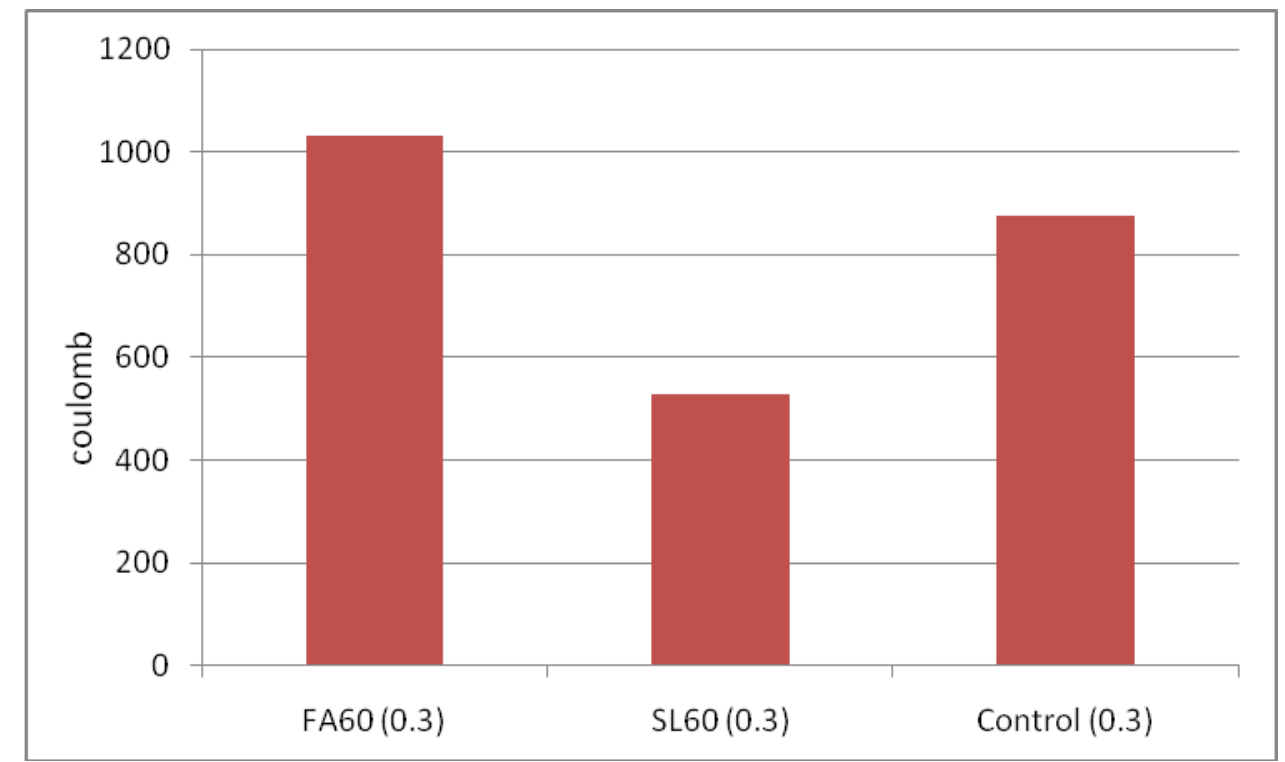

Figure 4-41 Comparison of Charge Passed in FA60 and SL60

In Figure 4.41 the charge passed in concretes with $60 \%$ cement replacement is compared with the control concrete samples up to 6 hours. Concrete with $60 \%$ fly ash as cement replacement had the most porosity among all, while Concrete with $60 \%$ slag as cement replacement had the least porosity, control mix had moderate porosity.

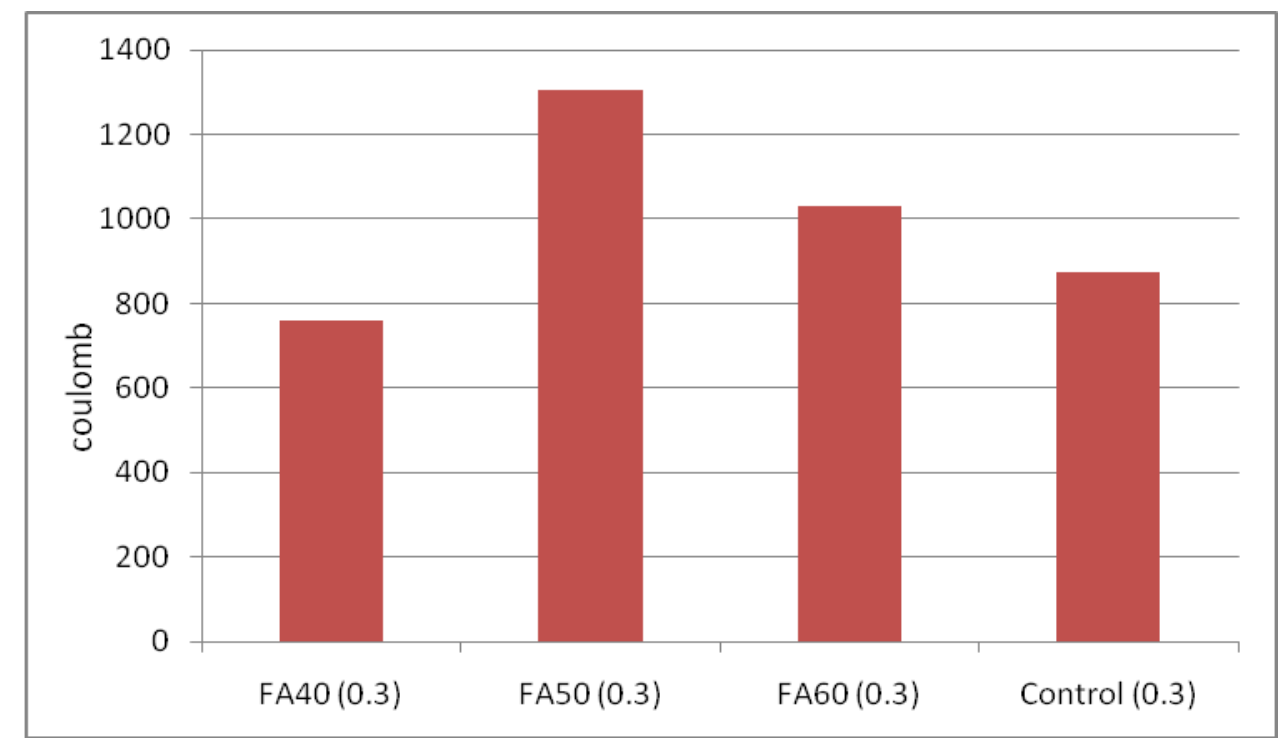

Figure 4-42 Comparison of Charge Passed in Concrete with Increasing Fly Ash Replacement 
In Figure 4.42 the charge passed in concretes with increasing fly ash replacement is compared. Concrete with $40 \%$ fly ash as cement replacement and Concrete with $60 \%$ fly ash as cement replacement had the less porosity among all, while Concrete with $50 \%$ fly ash as cement replacement had the most porosity, control mix had moderate porosity.

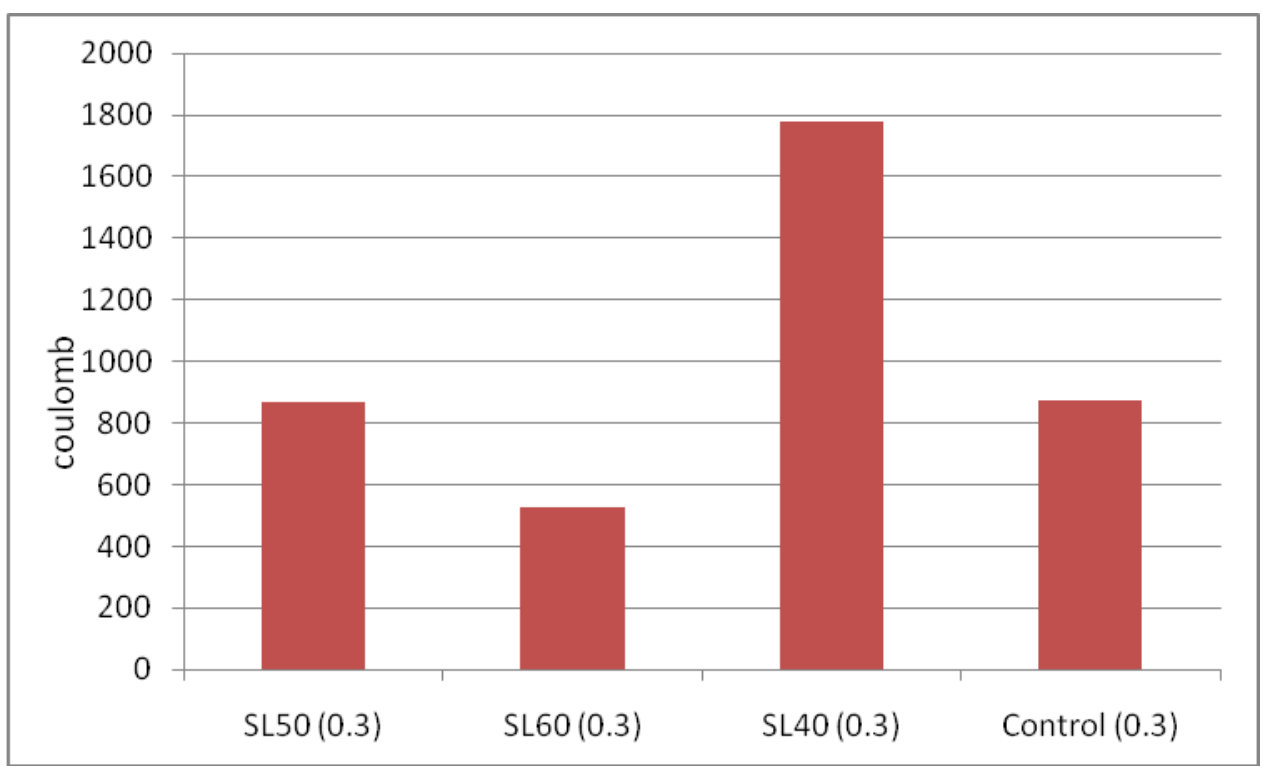

Figure 4-43 Comparison of Charge Passed in Concrete with Increasing Slag Replacement

In Figure 4.43 the charge passed in concretes with increasing slag replacement is compared. Concrete with $60 \%$ slag as cement replacement had the least porosity among all, while concrete with $50 \%$ slag as cement replacement had the more porosity, and concrete with $40 \%$ slag as cement replacement had the most porosity, where as control mix had almost as much as concrete with $60 \%$ slag as cement replacement porosity. porosity reduces as the amount of slag increases. 


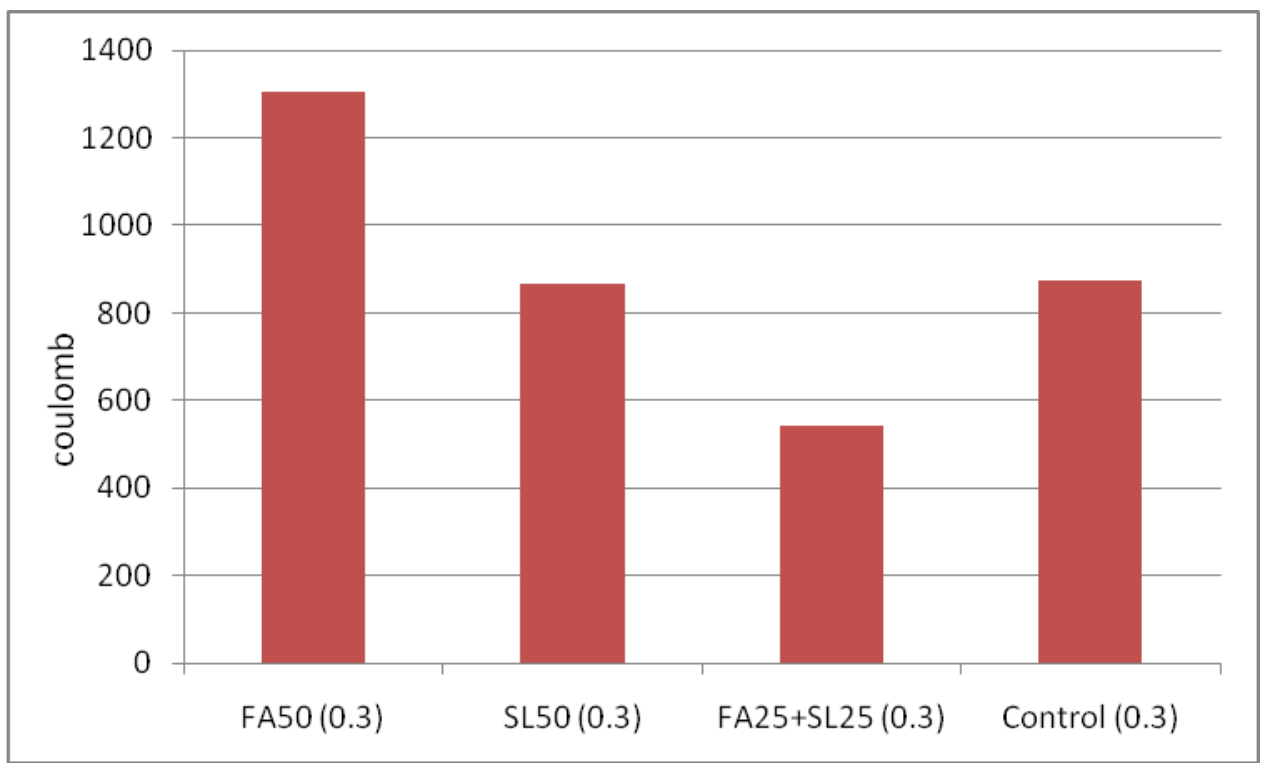

Figure 4-44 Comparison of Charge Passed when the Combined Replacement is 50 \%

In Figure 4.44 the charge passed in concretes with $50 \%$ combined cement replacement is compared with the control concrete samples up to 90 days. Concrete with $50 \%$ fly ash as cement replacement had the lesser porosity, while Concrete with $50 \%$ slag as cement replacement had the most porosity, concrete with $50 \%$ combined cement replacement is just in between, where as control mix had least porosity.

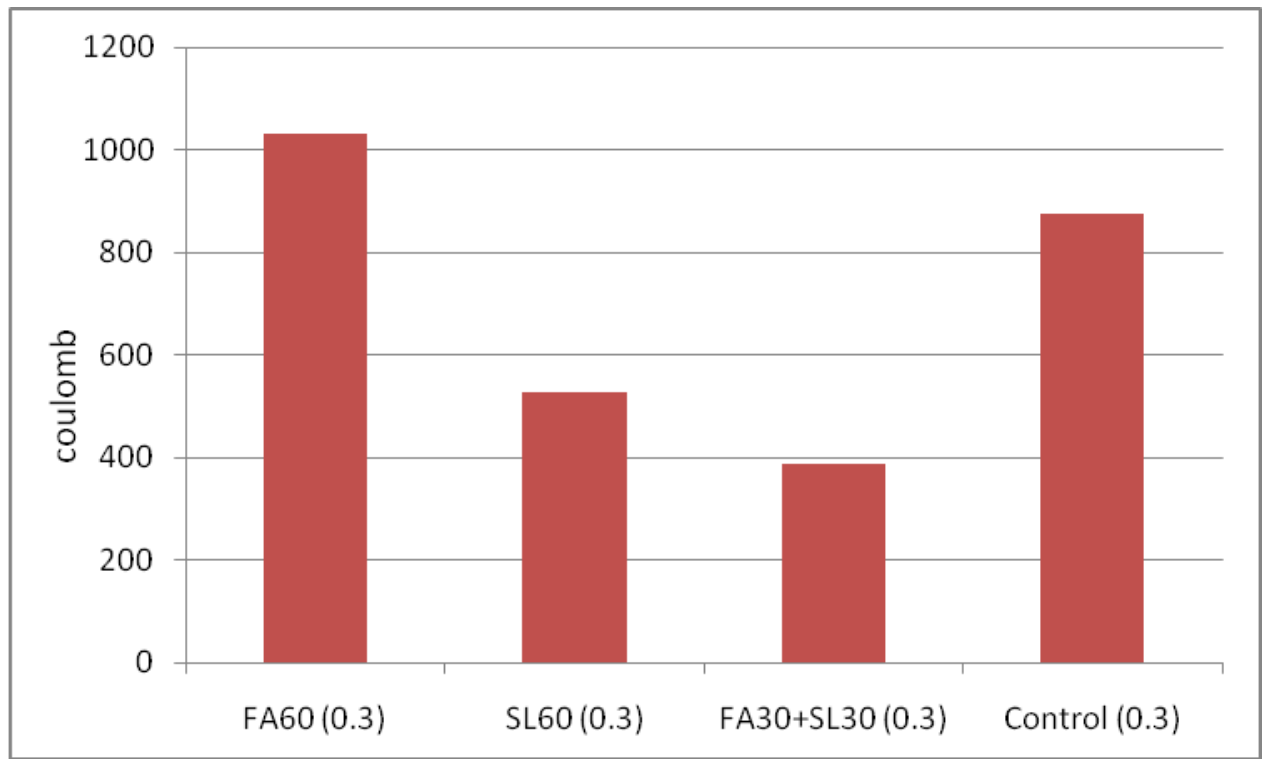

Figure 4-45 Comparison of Charge Passed when the Combined Replacement is $60 \%$ 
In Figure 4.45 the charge passed in concretes with $60 \%$ combined cement replacement is compared with the control concrete samples up to 90 days. Concrete with $60 \%$ fly ash as cement replacement had the least porosity among all, while Concrete with $60 \%$ slag as cement replacement had the more porosity, concrete with $60 \%$ combined cement replacement is just in between, where as control mix had most porosity.

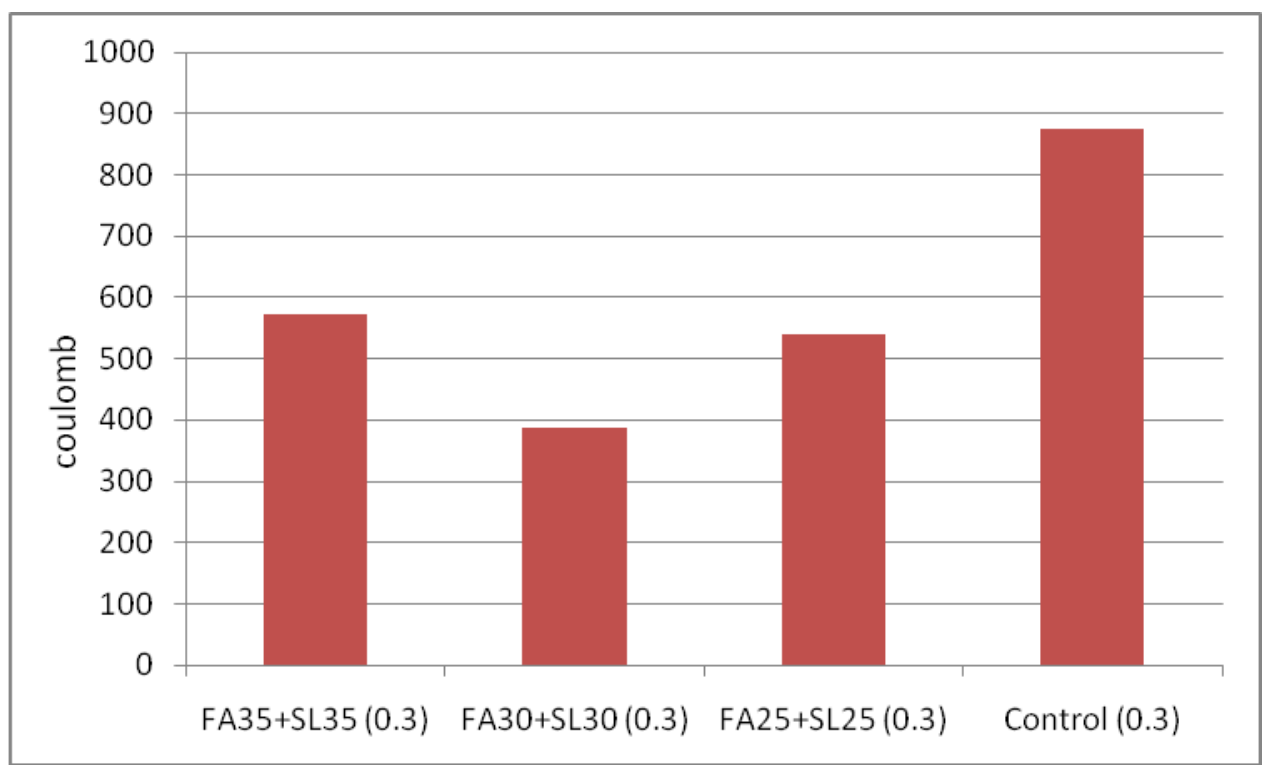

Figure 4-46 Comparison of Charge Passed with Increasing Combined Replacement

Figure 4.46 explains the comparison of porosity with increasing combined replacement. Concrete with $70 \%$ combined replacement had the most porosity where as concrete with $50 \%$ combined replacement had the least drying shrinkage. Control mix showed moderate porosity compared to the other mixes. 


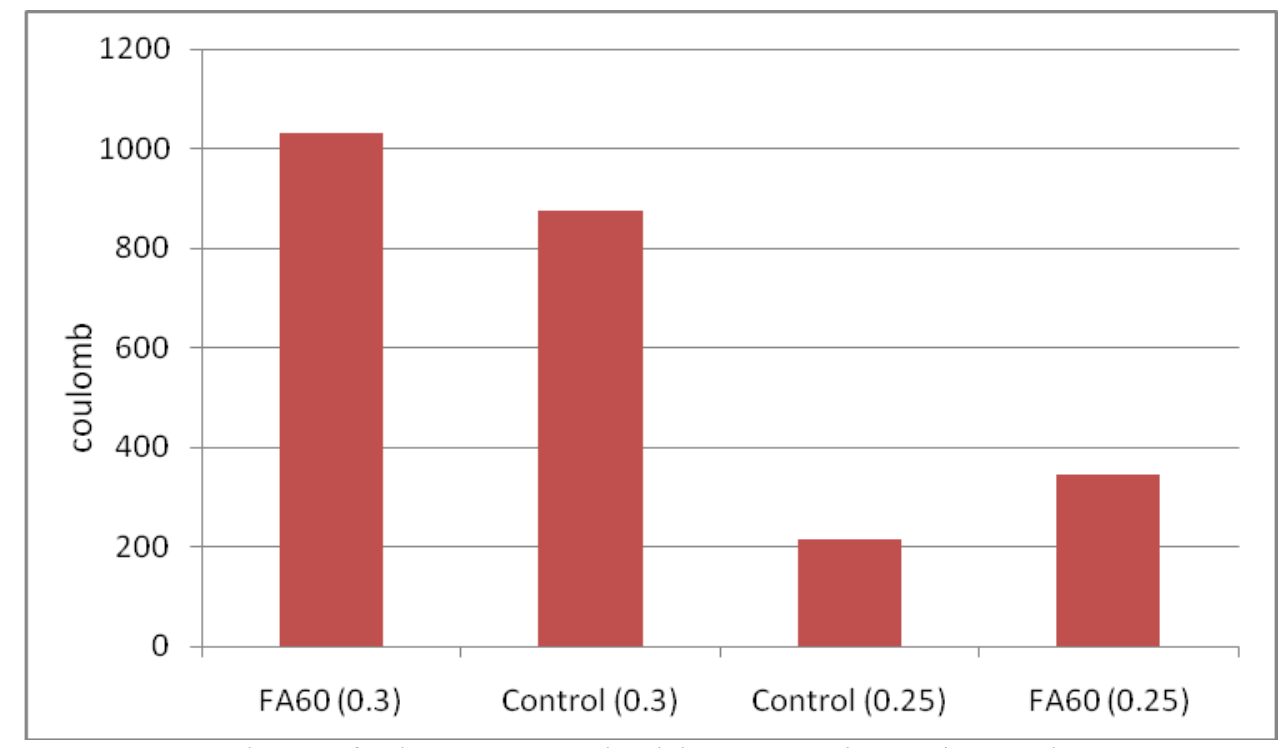

Figure 4-47 Comparison of Charge Passed with Decreasing w/cm Where $60 \%$ Cement Is Replaced by Fly Ash

In Figure 4.47 comparison of porosity with decreasing w/cm where $60 \%$ cement is replaced by fly ash is explained. Concrete with $60 \%$ fly ash as cement replacement showed more porosity, when water to cemnt ratio was decreased. Control mix also showed less porosity when the w/cm was brought down from 0.3 to 0.25 At the end of 6 hours concrete with $60 \%$ fly ash as cement replacement, showd least drying shrinkage.

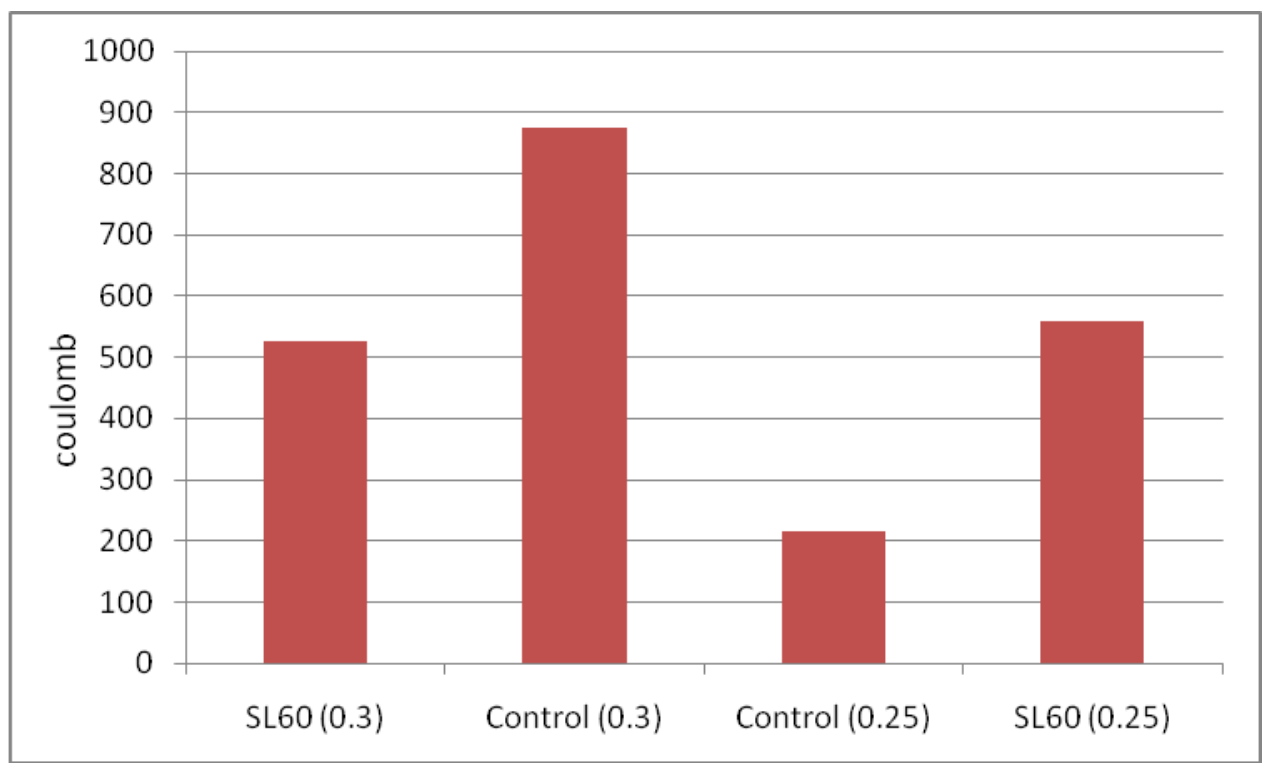

Figure 4-48 Comparison of Charge Passed with Decreasing w/cm Where $60 \%$ Cement Is Replaced by Slag 
In Figure 4.48 comparison of porosity with decreasing w/cm where $60 \%$ cement is replaced by slag is explained. Concrete with $60 \%$ slag as cement replacement showed lesser porosity, when $\mathrm{w} / \mathrm{cm}$ was decreased. Control mix also showed less porosity when the $\mathrm{w} / \mathrm{cm}$ was brought down from 0.3 to 0.25 , though the values at the end of 90 days are so close that it is hard draw a conclusion.

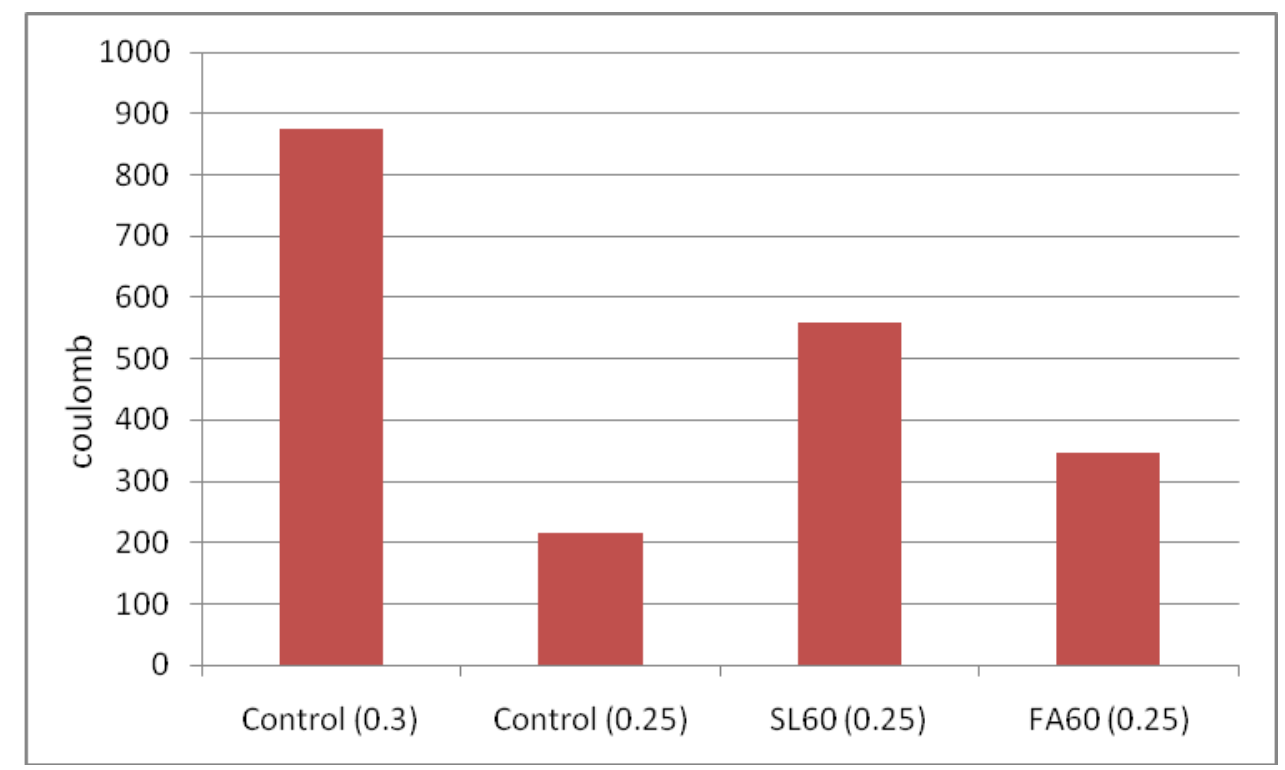

Figure 4-49 Comparison of Charge Passed with Decreasing w/cm Where $60 \%$ Cement Is Replaced by Fly Ash or Slag

In Figure 4.49 comparison of porosity with decreasing w/cm where $60 \%$ cement is replaced by fly ash and/or slag is explained. Concrete with $60 \%$ fly ash as cement replacement showed least porosity, when w/cm was decreased, though porosity of concrete with $60 \%$ slag as cement replacement was more. Control mix also showed less porosity when the w/cm was brought down from 0.3 to 0.25 . 


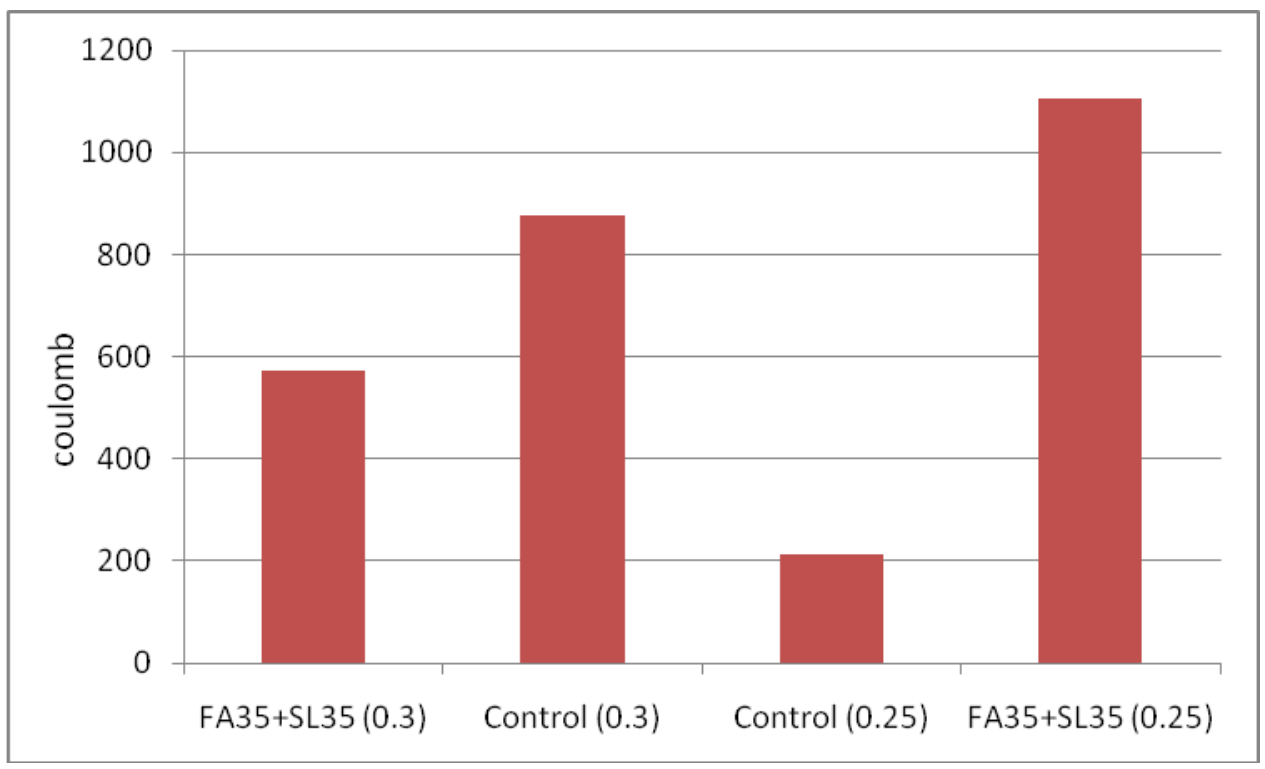

Figure 4-50 Comparison of Charge Passed with Decreasing w/cm Where $70 \%$ Cement Is Replaced by Fly Ash and Slag Combined

In Figure 4.50 comparison of porosity with decreasing w/cm where $70 \%$ cement is replaced by fly ash and/or slag combined is explained. Concrete with $70 \%$ combined cement replacement showed lesser porosity, when w/cm was decreased. Control mix also showed less porosity when the $\mathrm{w} / \mathrm{cm}$ was brought down from 0.3 to 0.25 .

Chloride pentraition for all the high volume fly ash and/or slag modified concrete has been really low kept up with Class H high performance concrete classified by West Virginia, USA. Most of the concrete specimens showed very low permeability ( $<1000$ coulombs) according to ASTM C 1202. Very few showed low peremeability (between 1000 coulombs -2000 coulombs)

\subsection{Isothermal Calorimetric Study}

The cement replacement in cement paste is reflected by the heat of hydration reaction. The isothermal calorimeter study showed us the heat generation due to hydration reaction inside the cement paste. Normalized heat flow is plotted against time to get the view of hydration reaction as heat evolution is directly proportional rate of reaction and strength generation. 


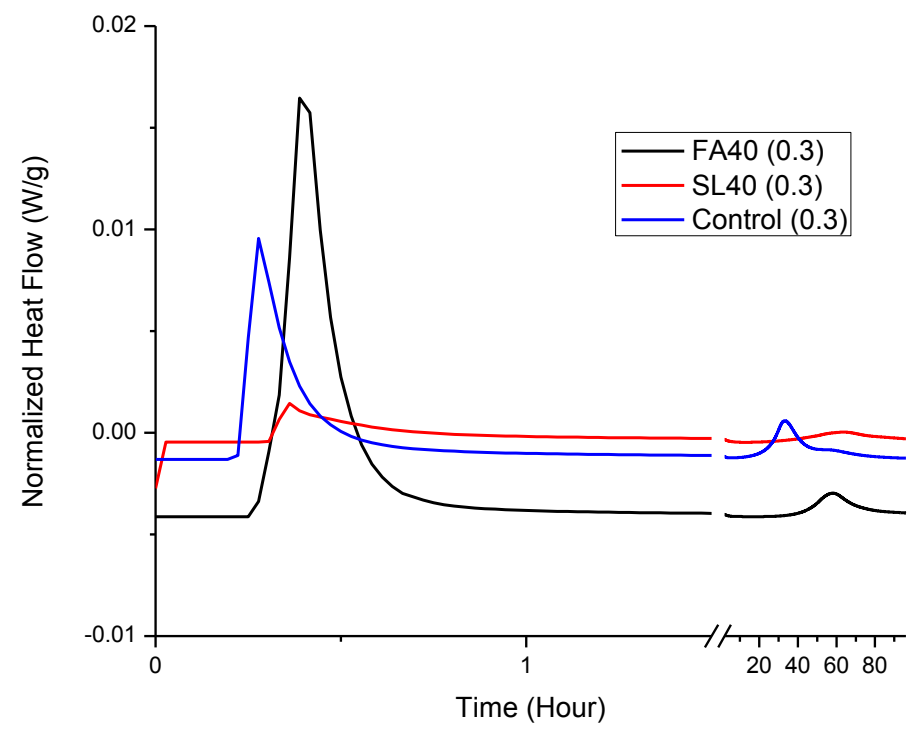

Figure 4-51 Isothermal Calorimeter Study of FA40 and SL40

In Figure 4. 51 the cement paste with $40 \%$ cement replacement is compared with the control cement paste samples up to 96 hours. cement paste where slag had replaced cement shows the least hydration heat on peak which means slag modified cement paste has the least hydration heat. Fly ash modified cement paste shows less hydration heat generation than control cement paste at the peak. 


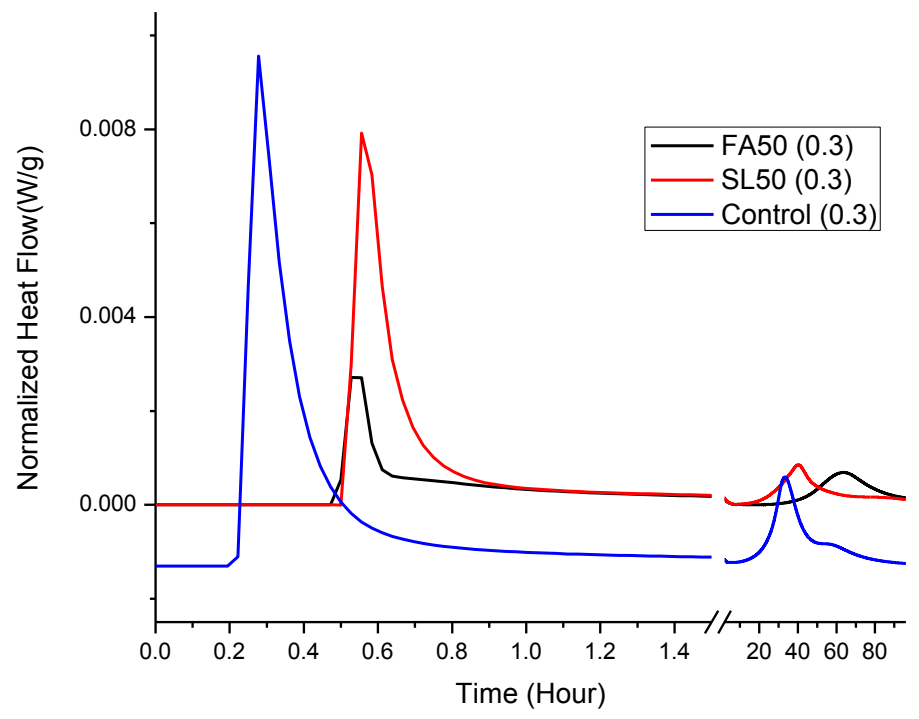

Figure 4-52 Isothermal Calorimeter Study of FA50 and SL50

In Figure 4.52 the cement paste with $50 \%$ cement replacement is compared with the control cement paste samples up to 96 hours. cement paste where slag had replaced cement shows the least hydration heat on peak which means slag modified cement paste has the least hydration heat. Fly ash modified cement paste shows greater hydration heat generation than control cement paste at the peak. 


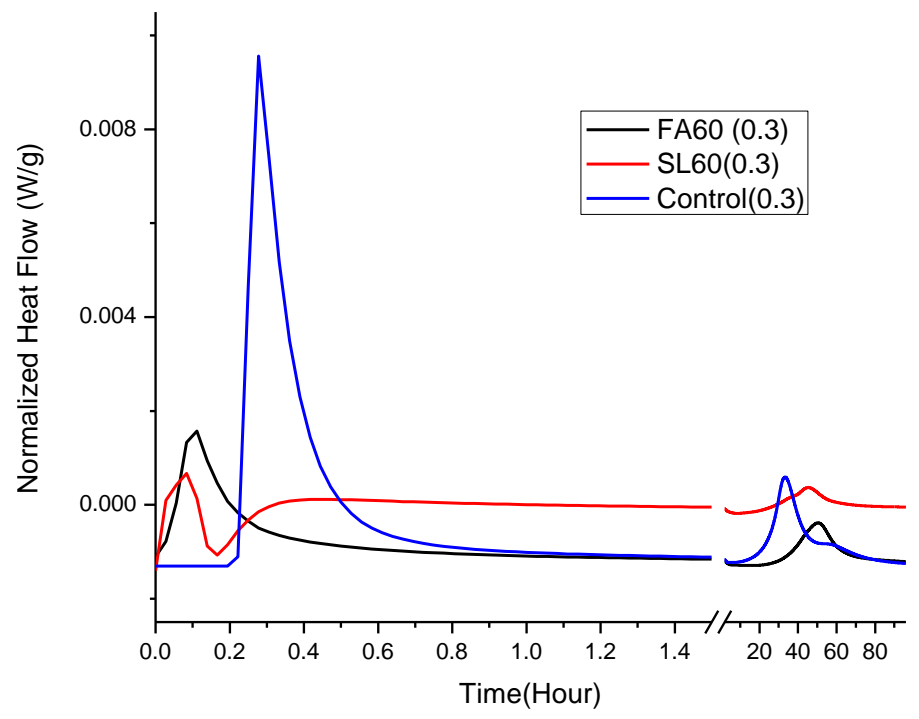

Figure 4-53 Isothermal Calorimeter Study of FA60 and SL60

In Figure 4. 53 the cement paste with $60 \%$ cement replacement is compared with the control cement paste samples up to 96 hours. cement paste where slag had replaced cement shows the least hydration heat on peak which means slag modified cement paste has the least hydration heat. Fly ash modified cement paste shows much much greater hydration heat generation than control cement paste at the peak. 


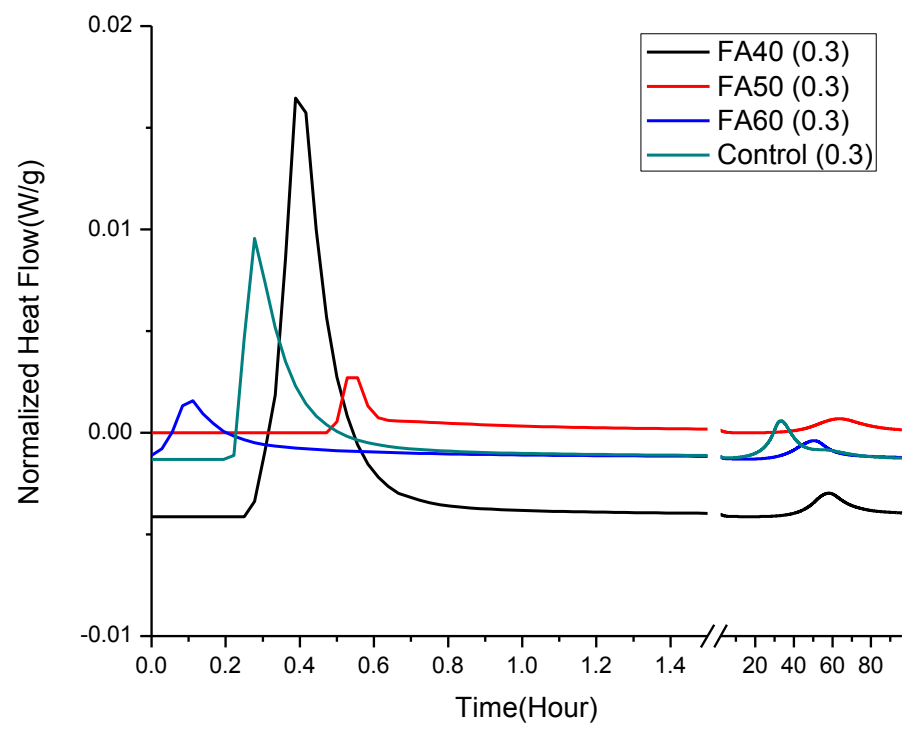

Figure 4-54 Isothermal Calorimeter Study of Concrete with Increasing Fly Ash Replacement

Figure 4.54 shows a comparison between the cement paste with increasing fly ash replacement. As percentage of fly ash increases as replacement hydration heat flow peak decreases as we know lower hydration due to increased amount of pozzolanic material is responsible for these changes. 


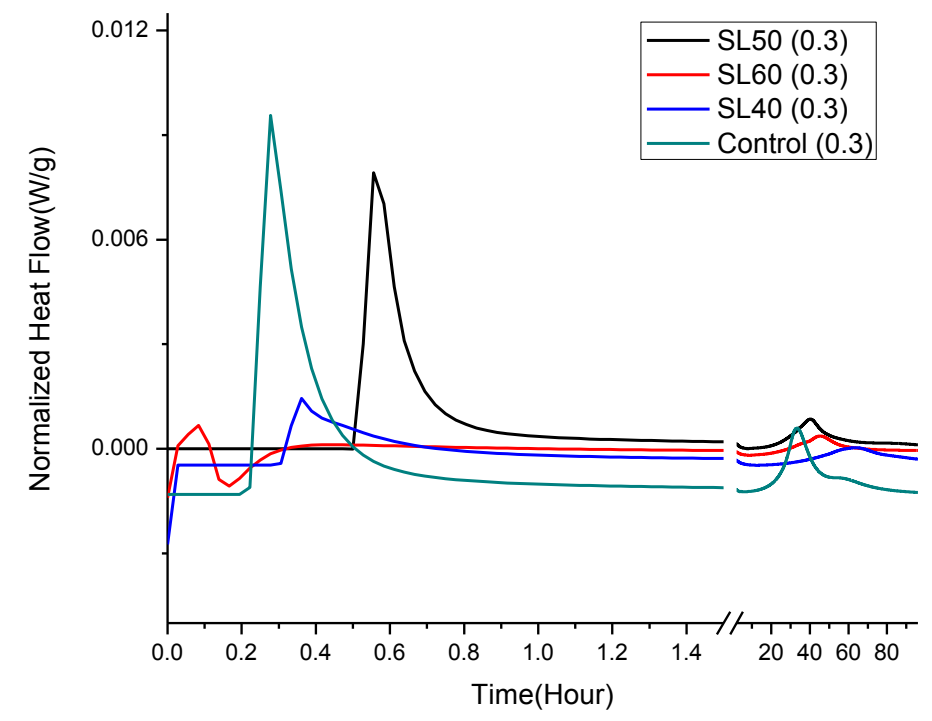

Figure 4-55 Isothermal Calorimeter Study of Concrete with Increasing Slag Replacement

Figure 4.55 shows a comparison between the cement paste with increasing slag replacement. Cement paste with $50 \%$ replacement showed bigger peak than cement paste with $60 \%$ replacement and $40 \%$ replacement but less than cement paste of control mix. Cement paste with $40 \%$ replacement showed least peak.

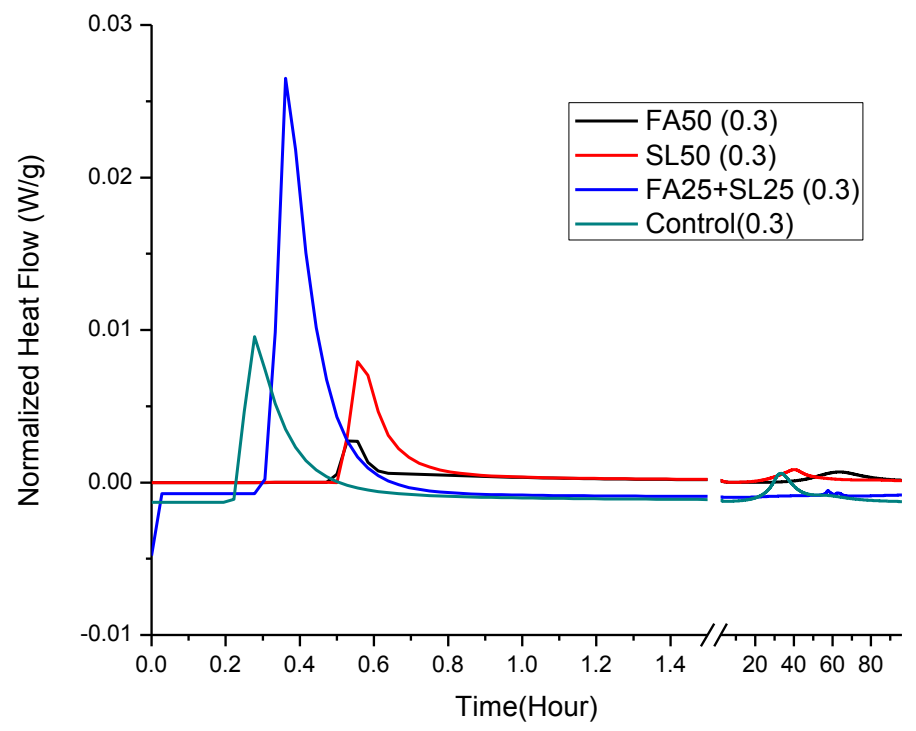

Figure 4-56 Isothermal Calorimeter Study of Concrete When the Combined Replacement Is $50 \%$ 
Figure 4.56 explains the effect of cement paste where the cement replacement touches $50 \%$ either totally by slag, fly ash or combination of both. We have already studied the effect of fly ash modified concrete or slag modified concrete where the replacement touches $50 \%$. Combination of fly ash and/or slag provides some interesting effect on cement paste hydration heat. Hydration heat flow peak is the most for combination among all the cement paste.

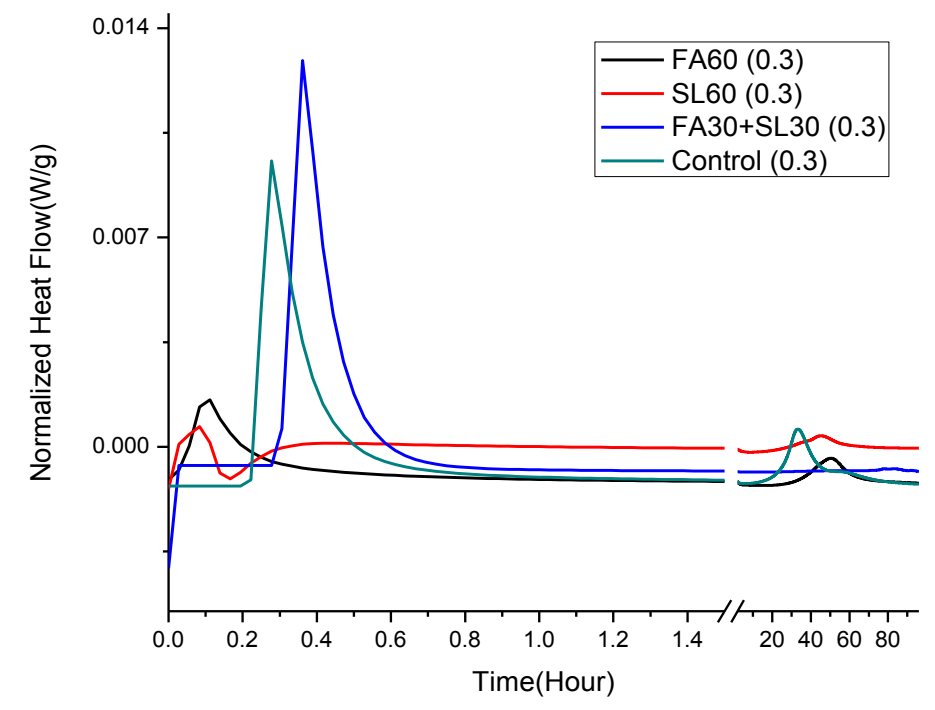

Figure 4-57 Isothermal Calorimeter Study of Concrete When the Combined Replacement Is $60 \%$

Figure 4.57 explains the effect of cement paste where the cement replacement touches $60 \%$ either totally by slag, fly ash or combination of both. We have already studied the effect of fly ash modified concrete or slag modified concrete cement paste where the replacement touches 60 $\%$. Combination of fly ash and/or slag provides some interesting effect on concrete strength. Combination of fly ash and/or slag provides some interesting effect on cement paste hydration heat. Hydration heat flow peak is the most for combination among all the cement paste. 


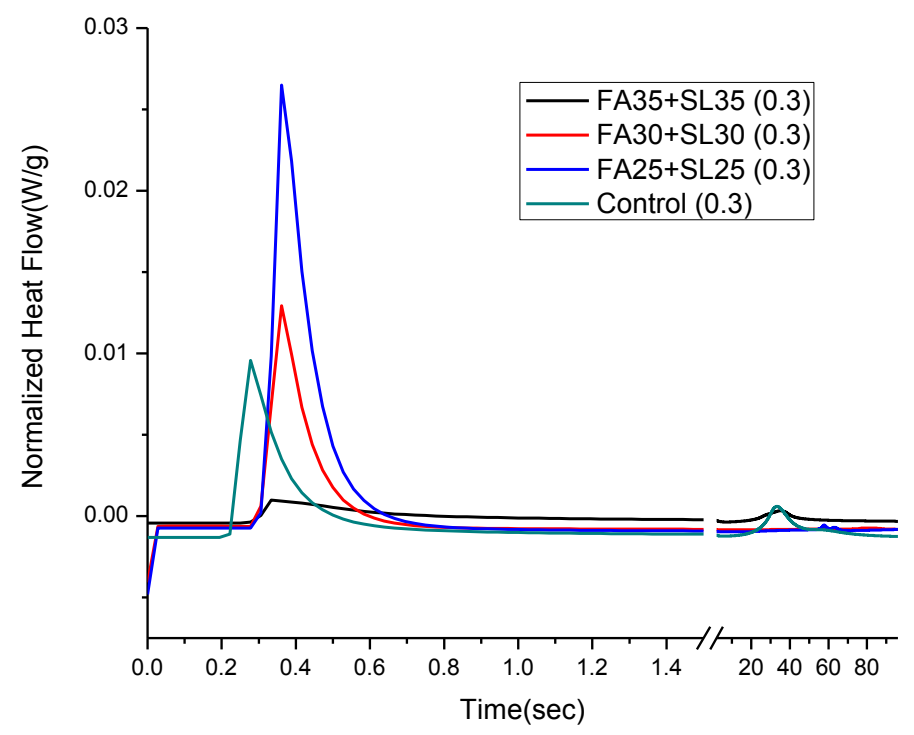

Figure 4-58 Isothermal Calorimeter Study of Concrete with Increasing Combined Replacement

Figure 4.58 explains the condition where replacement of cement increases by the combination of fly ash and/or slag in fly ash and/or slag modified concrete. Where the replacement is $50 \%$ showed highest peak during 96 hours of testing period. Cement paste with $60 \%$ replacement showed higher flow peak than cement paste of control mix. Cement paste where $70 \%$ cement is replaced with combined replacement of fly ash and/or slag is used showed the least peak value. Evidently concrete with maximum replacement has slower hydration reation generation due to lack calcium oxide. 


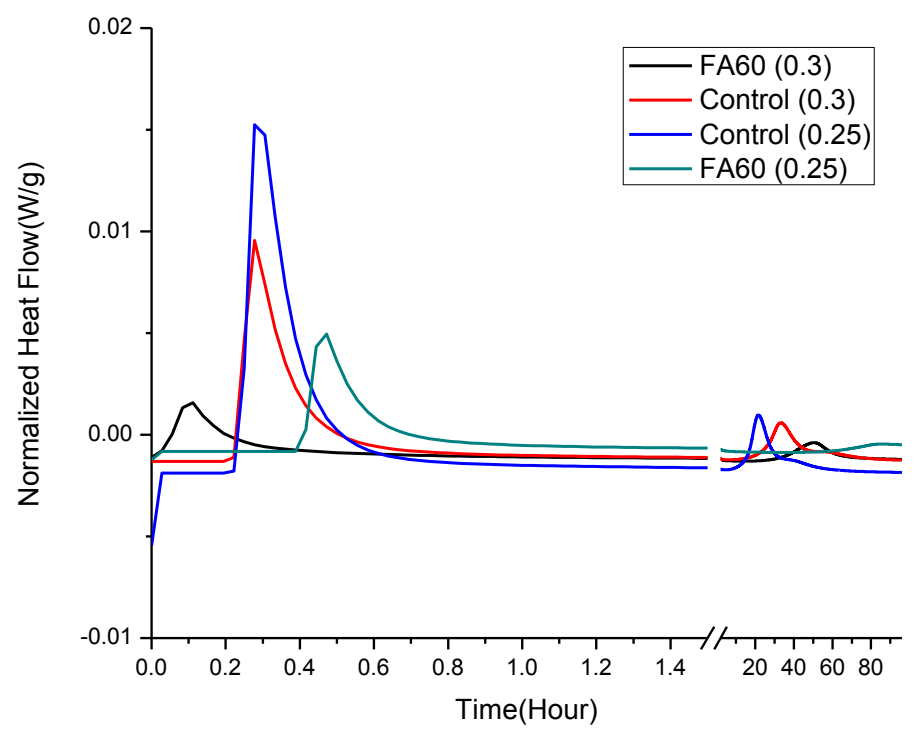

Figure 4-59 Isothermal Calorimeter Study of Concrete with Decreasing w/cm Where $60 \%$ Cement Is Replaced by Fly Ash

Figure 4.59 explains hydration heat generation of cement paste with decreasing w/cm where 60 $\%$ cement is replaced by fly ash. Generally when the w/cm decreases the hydration heat generation increases. The same feature is evident with the control mix, decrease in $w / c m$ increased the hydration heat generation in big way. Cement paste with $60 \%$ fly ash as cement replacement showed less hydration heat geneartion flow peak when $\mathrm{w} / \mathrm{cm}$ is decreased. 


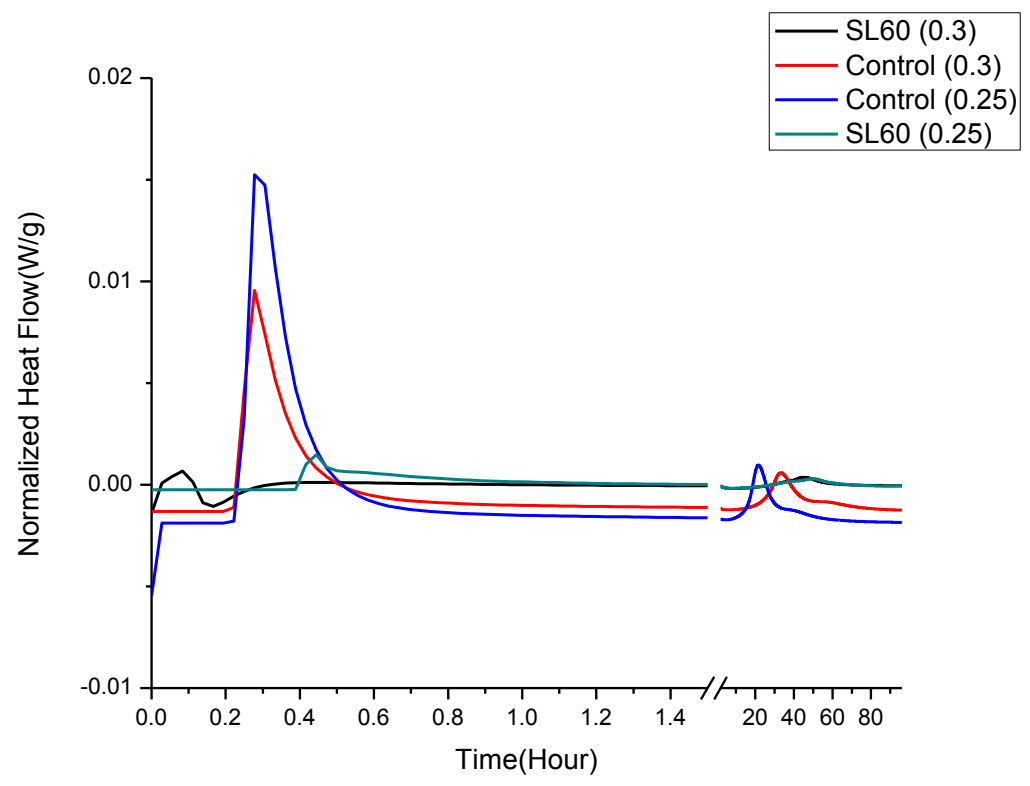

Figure 4-60 Isothermal Calorimeter Study of Concrete with Decreasing w/cm Where $60 \%$ Cement Is Replaced by Slag

Figure 4.60 explains hydration heat generation of cement paste with decreasing w/cm where 60 $\%$ cement is replaced by slag. Generally when the w/cm decreases the hydration heat generation increases. The same feature is evident with the control mix, decrease in $\mathrm{w} / \mathrm{cm}$ increased the hydration heat generation in big way. Cement paste with $60 \%$ slag as cement replacement showed similar hydration heat generation flow peak when w/cm is decreased but different time. 


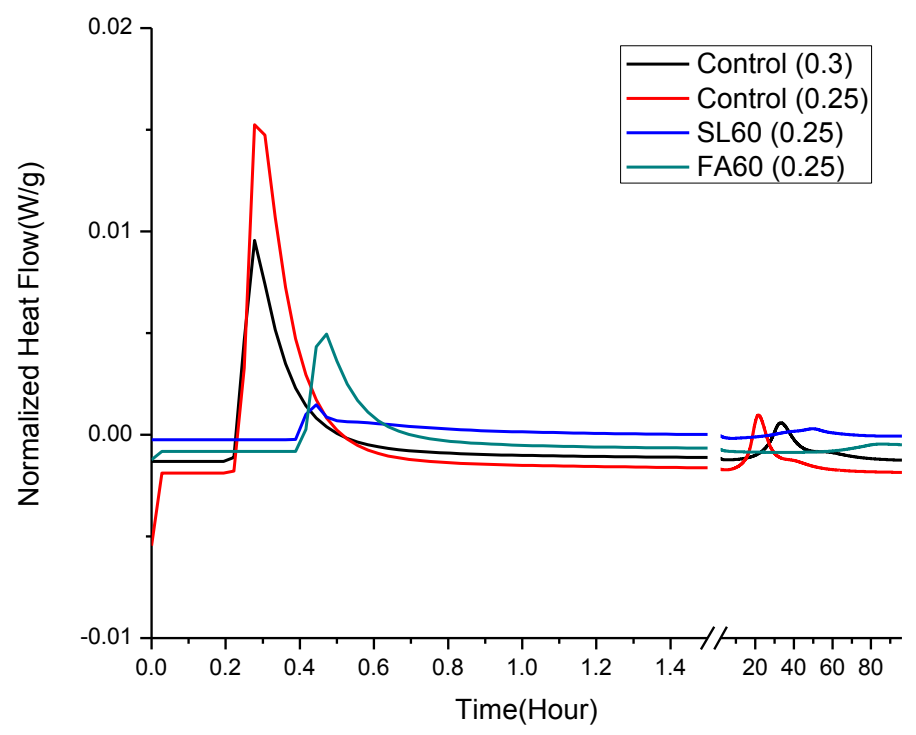

Figure 4-61 Isothermal Calorimeter Study of Concrete with Decreasing w/cm Where $60 \%$ Cement Is Replaced by Fly Ash or Slag

Figure 4.61 explains hydration heat generation of cement paste with decreasing w/cm where 60 $\%$ cement is replaced by fly ash and/or slag. Generally when the w/cm decreases the strength increases. The same feature is evident with the control mix, decrease in $\mathrm{w} / \mathrm{cm}$ increased the strength in big way. Cement paste with $60 \%$ fly ash as cement replacement showed higher flow peak than cement paste with $60 \%$ slag as cement replacement. 


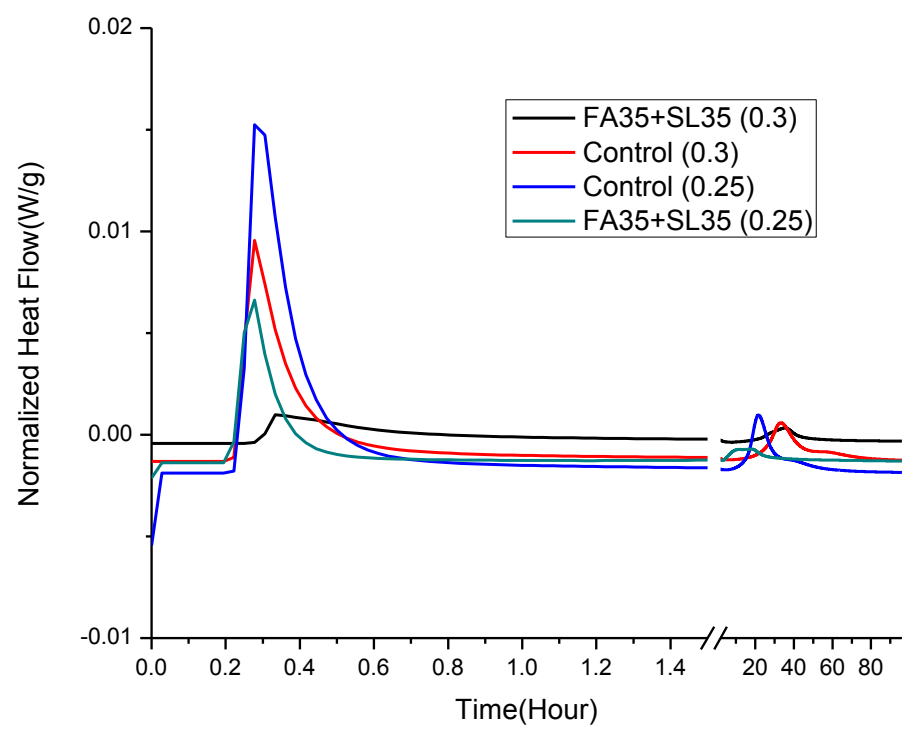

Figure 4-62 Isothermal Calorimeter Study of Concrete with Decreasing w/cm Where $70 \%$ Cement Is Replaced by Fly Ash and Slag Combined

Figure 4.62 explains hydration heat generation of cement paste with decreasing w/cm where 70 $\%$ cement is replaced by slag. Generally when the $\mathrm{w} / \mathrm{cm}$ decreases the strength increases. The same feature is evident with the control mix, decrease in w/cm increased the strength in big way. The same thing happened to cement paste with $70 \%$ fly ash and/or slag as cement replacement.

\subsection{Correlation between Strength and Heat Flow}

The cement replacement in cement paste is reflected by the heat of hydration reaction. We measured heat of hydration until 96 hours, that's why 3 days strength is compared with heat flow. 

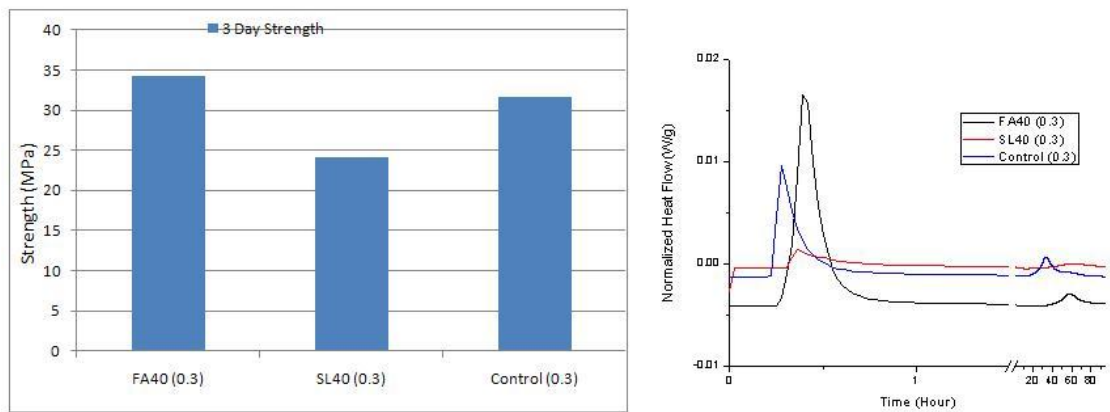

Figure 4-63 Heat Flow and Early Age Strength Correlation Study of FA40 and SL40

In Figure 4.63 the cement paste with $40 \%$ cement replacement is compared with the control cement paste samples up to 96 hours. cement paste where slag had replaced cement shows the least hydration heat on peak which means slag modified cement paste has the least hydration heat. Fly ash modified cement paste shows less hydration heat generation than control cement paste at the peak. 3 days strength of concrete mixes showed the same.
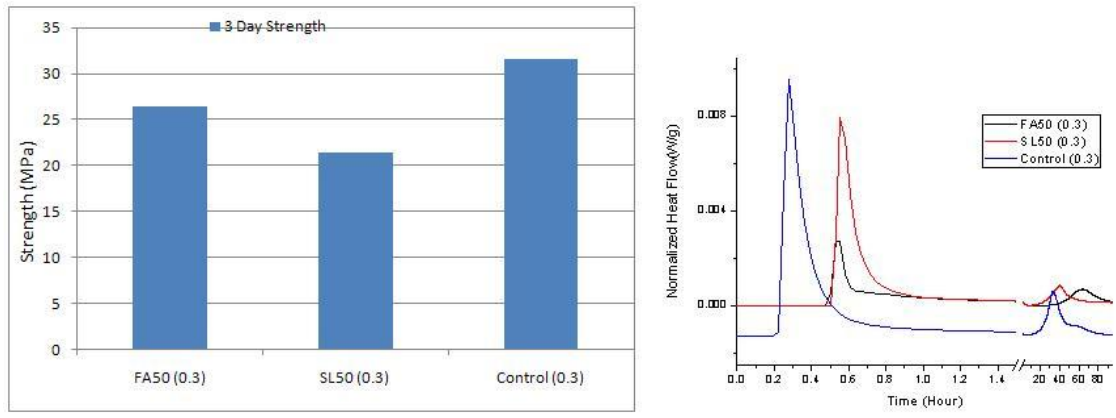

Figure 4-64 Heat Flow and Early Age Strength Correlation Study of FA50 and SL50

In Figure 4.64 the cement paste with $50 \%$ cement replacement is compared with the control cement paste samples up to 96 hours. cement paste where slag had replaced cement shows the least hydration heat on peak which means slag modified cement paste has the least hydration heat. Fly ash modified cement paste shows greater hydration heat generation than control cement paste at the peak. 3 days strength of concrete mixes showed almost the same, though control mix showed higher 3 day strength than concrete with $50 \%$ cement replacement. 

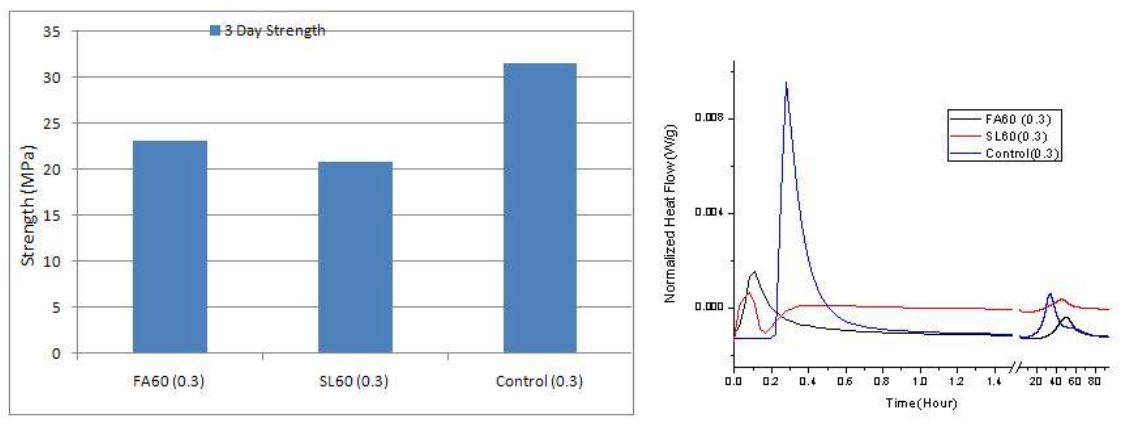

Figure 4-65 Heat Flow and Early Age Strength Correlation Study of FA60 and SL60

In Figure 4.65 the cement paste with $60 \%$ cement replacement is compared with the control cement paste samples up to 96 hours. cement paste where slag had replaced cement shows the least hydration heat on peak which means slag modified cement paste has the least hydration heat. Fly ash modified cement paste shows much much greater hydration heat generation than control cement paste at the peak. 3 days strength of concrete mixes did not show the same, because control mix showed much higher 3 day strength than concrete with $60 \%$ cement replacement.
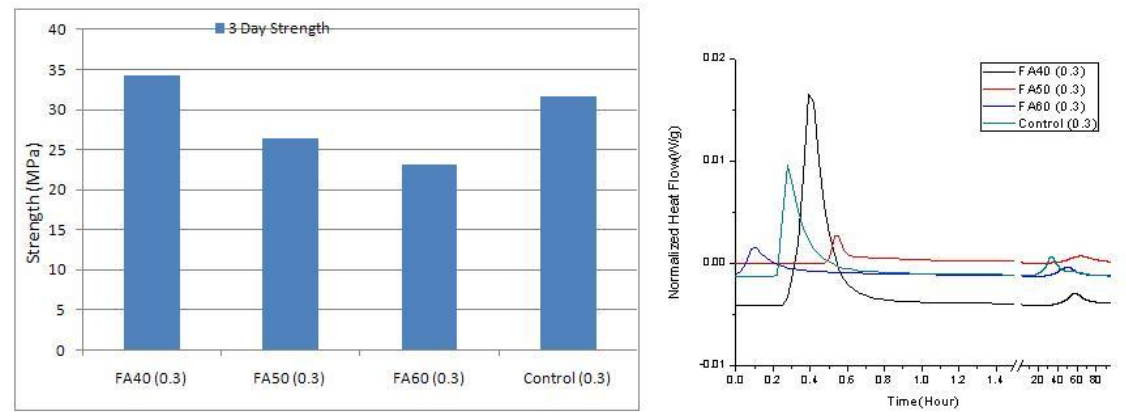

Figure 4-66 Heat Flow and Early Age Strength Correlation Study of Concrete with Increasing Fly Ash Replacement

Figure 4.66 shows a comparison between the cement paste with increasing fly ash replacement. As percentage of fly ash increases as replacement hydration heat flow peak decreases as we know lower hydration due to increased amount of pozzolanic material is responsible for these changes. 3 days strength of concrete mixes showed almost the same, though control mix showed higher 3 day strength than concrete with $50 \%$ cement replacement. 

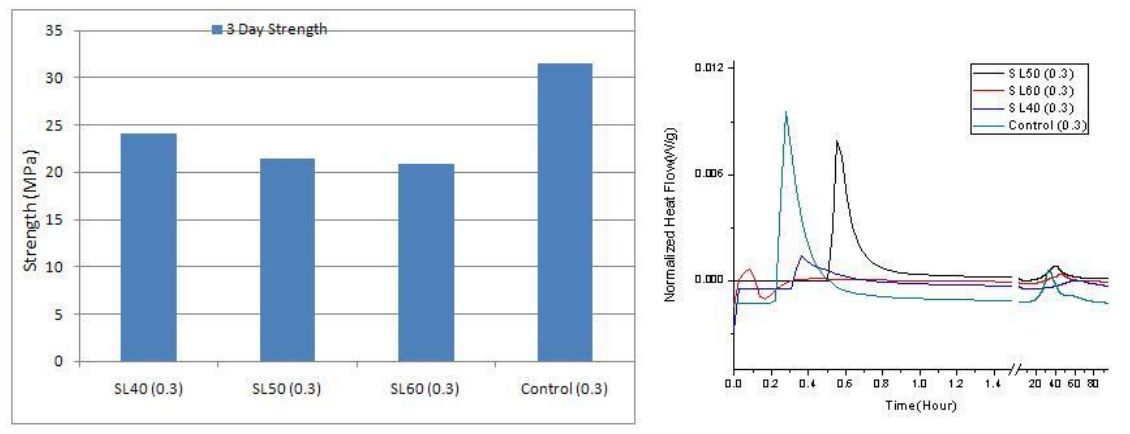

Figure 4-67 Heat Flow and Early Age Strength Correlation Study of Concrete with Increasing

Slag Replacement

Figure 4.67 shows a comparison between the cement paste with increasing slag replacement. Cement paste with $50 \%$ replacement showed bigger peak than cement paste with $60 \%$ replacement and $40 \%$ replacement but less than cement paste of control mix. Cement paste with $40 \%$ replacement showed least peak. 3 days strength of concrete mixes decreased with the increase in pozzolanic material.
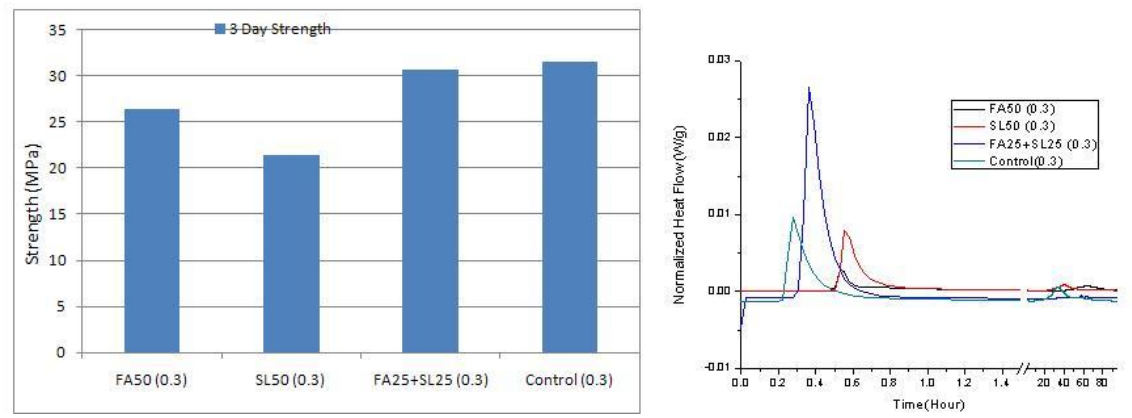

Figure 4-68 Heat Flow and Early Age Strength Correlation Study of Concrete When the Combined Replacement Is $50 \%$

Figure 4.68 explains the effect of cement paste where the cement replacement touches $50 \%$ either totally by slag, fly ash or combination of both. We have already studied the effect of fly ash modified concrete or slag modified concrete where the replacement touches $50 \%$. Combination of fly ash and/or slag provides some interesting effect on cement paste hydration heat. Hydration heat flow peak is the most for combination among all the cement paste. 3 days 
strength of concrete mixes showed almost the same, though control mix showed higher 3 day strength than concrete with $50 \%$ fly ash as cement replacement, whereas control mix showed almost same 3 day strength than concrete with $50 \%$ fly ash and/or slag combination as cement replacement.
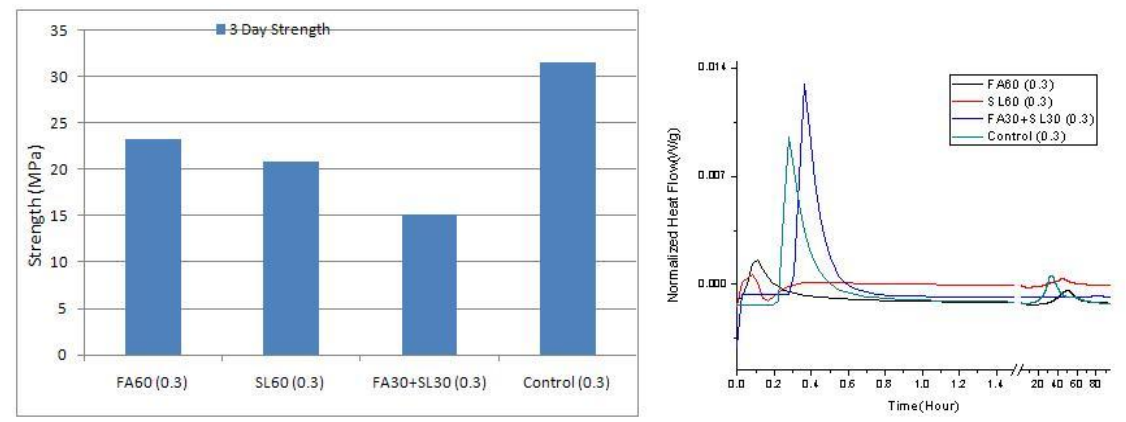

Figure 4-69 Heat Flow and Early Age Strength Correlation Study of Concrete When the Combined Replacement Is $60 \%$

Figure 4.69 explains the effect of cement paste where the cement replacement touches $60 \%$ either totally by slag, fly ash or combination of both. We have already studied the effect of fly ash modified concrete or slag modified concrete cement paste where the replacement touches 60 $\%$. Combination of fly ash and/or slag provides some interesting effect on concrete strength. Combination of fly ash and/or slag provides some interesting effect on cement paste hydration heat. Hydration heat flow peak is the most for combination among all the cement paste. 3 days strength did not provide the same, because strength of concrete with $60 \%$ fly ash and/or slag as combined replacement showed least strength.
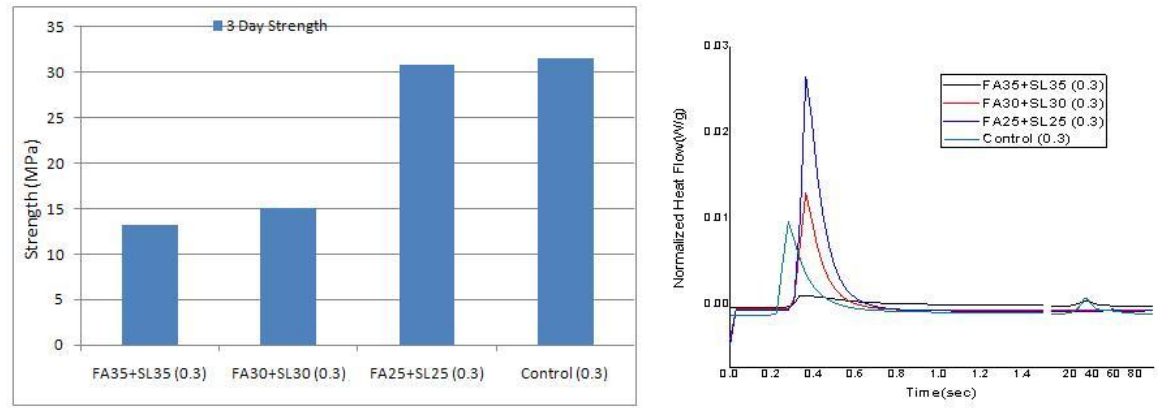

Figure 4-70 Heat Flow and Early Age Strength Correlation Study of Concrete with Increasing Combined Replacement 
Figure 4.70 explains the condition where replacement of cement increases by the combination of fly ash and/or slag in fly ash and/or slag modified concrete. Where the replacement is $50 \%$ showed highest peak during 96 hours of testing period. Cement paste with $60 \%$ replacement showed higher flow peak than cement paste of control mix. Cement paste where $70 \%$ cement is replaced with combined replacement of fly ash and/or slag is used showed the least peak value. Evidently concrete with maximum replacement has slower hydration reation generation due to lack of calcium oxide. The 3 days strength exacly reflected the same.
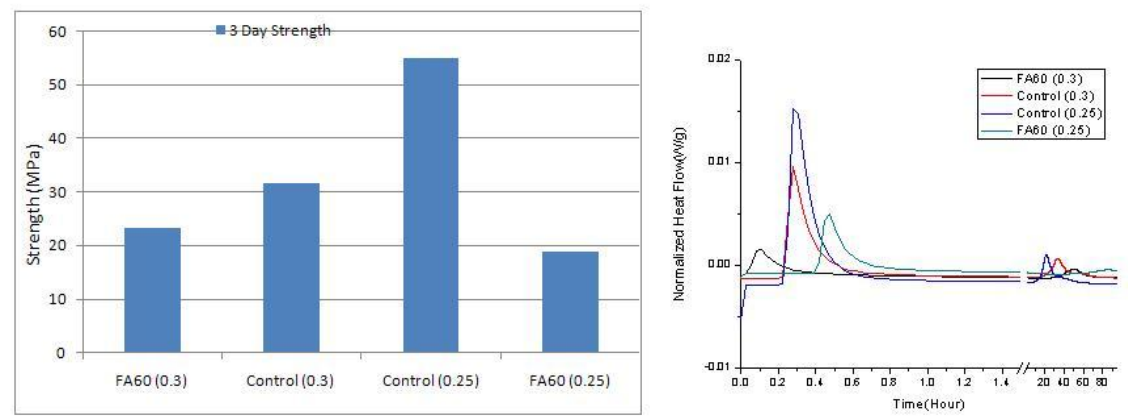

Figure 4-71 Heat Flow and Early Age Strength Correlation Study of Concrete with Decreasing w/cm Where 60 \% Cement Is Replaced by Fly Ash

Figure 4.71 explains hydration heat generation of cement paste with decreasing w/cm where 60 $\%$ cement is replaced by fly ash. Generally when the $\mathrm{w} / \mathrm{cm}$ decreases the hydration heat generation increases. The same feature is evident with the control mix, decrease in w/cm increased the hydration heat generation in big way. Cement paste with $60 \%$ fly ash as cement replacement showed less hydration heat geneartion flow peak when $\mathrm{w} / \mathrm{cm}$ is decreased. The 3 days strength exactly reflected the same.
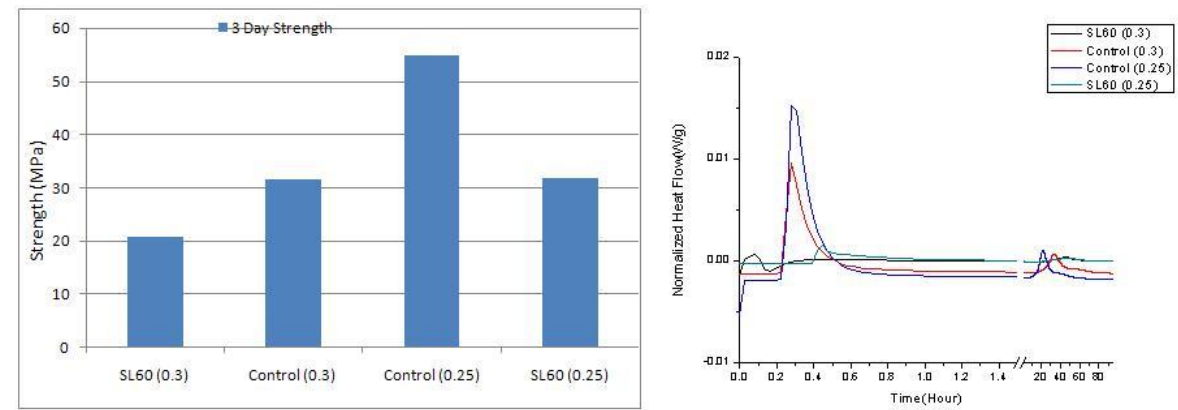

Figure 4-72 Heat Flow and Early Age Strength Correlation Study of Concrete with Decreasing w/cm Where $60 \%$ Cement Is Replaced by Slag 
Figure 4.72 explains hydration heat generation of cement paste with decreasing $\mathrm{w} / \mathrm{cm}$ where 60 $\%$ cement is replaced by slag. Generally when the w/cm decreases the hydration heat generation increases. The same feature is evident with the control mix, decrease in $\mathrm{w} / \mathrm{cm}$ increased the hydration heat generation in big way. Cement paste with $60 \%$ slag as cement replacement showed similar hydration heat generation flow peak when $\mathrm{w} / \mathrm{cm}$ is decreased but different time. The 3 days strength did not exactly reflects the same. 3 days strength of concrete with slag as 60 $\%$ replacement and $0.25 \mathrm{w} / \mathrm{cm}$ showed higher strength.
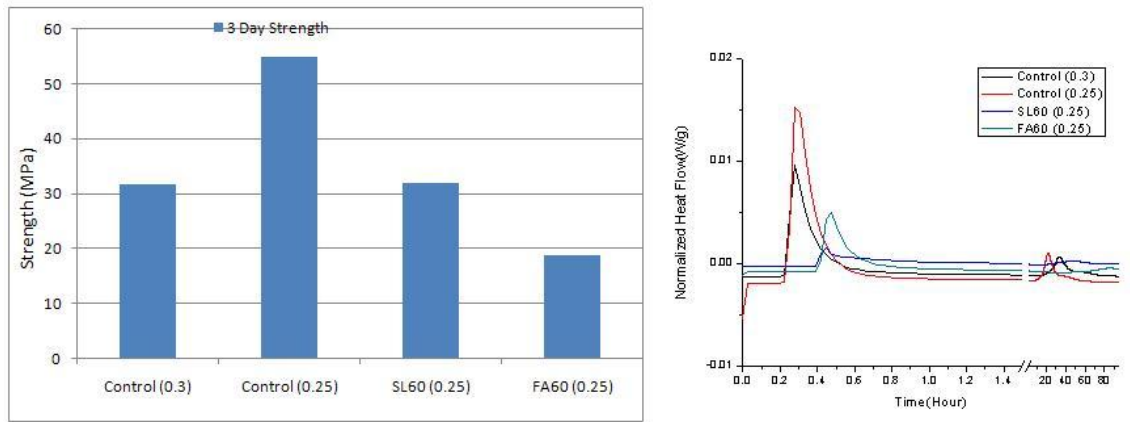

Figure 4-73 Heat Flow and Early Age Strength Correlation Study of Concrete with Decreasing w/cm Where $60 \%$ Cement Is Replaced by Fly Ash or Slag

Figure 4.73 explains hydration heat generation of cement paste with decreasing $\mathrm{w} / \mathrm{cm}$ where 60 $\%$ cement is replaced by fly ash and/or slag. Generally when the w/cm decreases the strength increases. The same feature is evident with the control mix, decrease in $\mathrm{w} / \mathrm{cm}$ increased the strength in big way. Cement paste with $60 \%$ fly ash as cement replacement showed higher flow peak than cement paste with $60 \%$ slag as cement replacement. 3 days strength gave the picture other than 3 days strength of concrete with slag as $60 \%$ replacement and $0.25 \mathrm{w} / \mathrm{cm}$ showed higher strength than concrete with fly ash as $60 \%$ replacement and $0.25 \mathrm{w} / \mathrm{cm}$. 

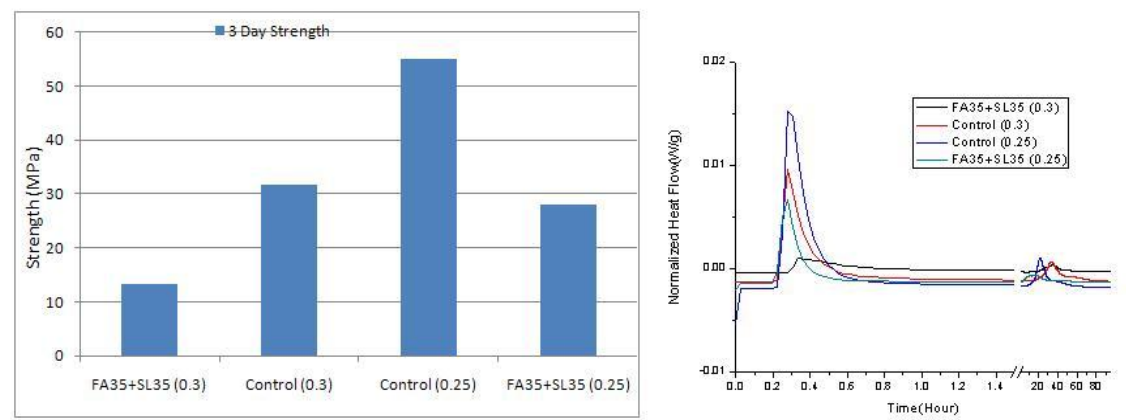

Figure 4-74 Heat Flow and Early Age Strength Correlation Study of Concrete with Decreasing w/cm Where $70 \%$ Cement Is Replaced by Fly Ash and Slag Combined

Figure 4.74 explains hydration heat generation of cement paste with decreasing w/cm where 70 $\%$ cement is replaced by slag. Generally when the $\mathrm{w} / \mathrm{cm}$ decreases the strength increases. The same feature is evident with the control mix, decrease in w/cm increased the strength in big way. The same thing happened to cement paste with $70 \%$ fly ash and/or slag as cement replacement. The 3 days strength showed exactly the same.

These graph actually gave good correlation between 3 days strength and hydration heat geneartion. 


\section{Chapter 5: Experimental Program for Geopolymer Concrete}

\subsection{Testing Plan and Motivation}

\subsection{Materials}

\subsubsection{Coarse Aggregate}

One type of graded coarse aggregates was used in this study conforms to the ASTM C 33 (Standard Specification for Concrete Aggregates). The properties and sieve analysis described in Table 3.3 and Table 3.4 for crushed number 8 Limestone with a maximum size of $9.5 \mathrm{~mm} \mathrm{(3/8}$ in) provided by Arrow Concrete.

\subsubsection{Fine Aggregate}

One type of fine aggregate (sand) conforming the ASTM C 33 (Standard Specification for Concrete Aggregates) was used in this study. The fine aggregates were Natural Sand provided by Arrow Concrete and with the following properties and sieve analysis. The values are provided in Table 3.5 and Table 3.6.

\subsubsection{Fly Ash}

Class F fly Ash (Fly Ash) is one of the residues generated in combustion of coal. It is finer than cement and consists of glassy-spherical particles. The Class F fly ash from Arrow Concrete station was used in this study, which considers ASTM C 618. The basic properties of fly ash are presented in Table 3.7. 


\subsubsection{Slag}

Ground granulated blast-furnace slag (Slag), is defined as a finely ground glassy granular material made from iron blast-furnace slag when it is rapidly chilled. On this project was used commercial grade 100 ground granulated blast-furnace slag (Slag) conforming the ASTM C 989 (Standard Specification for G.G.B.F Slag for Use in Concrete and Mortars). The basic properties of the slag provided by Arrow Concrete are presented in the Table 3.8.

\subsubsection{Sodium Hydroxide}

Sodium Hydroxide beads supplied by Essential Depot had been used. The beads were used because it is easier to dissolve beads in any other dissolving liquid than tablets. The beads were more than $98 \%$ pure.

\subsubsection{Sodium Silicate}

Sodium silicate used for this research was supplied by Columbia Chemicals. The sodium silicate was $40 \%$ concentrated industrial grade sodium poly-silicate. Silicon Oxide $\left(\mathrm{SiO}_{2}\right)$ to Sodium Oxide $\left(\mathrm{Na}_{2} \mathrm{O}\right)$ ratio was 3.22

\subsubsection{Mixing Water}

The mixing water used in this study was tap water from the Morgantown city water supply and was assumed to have a density of $100 \mathrm{Kg} / \mathrm{m}^{3}\left(169 \mathrm{lb} / \mathrm{yd}^{3}\right)$.

\subsection{Mixture Proportions}

The primary difference between geopolymer concrete and portland cement concrete is the binder. The silicon and aluminum oxides in the low-calcium fly ash and/or slag reacts with the alkaline liquid to form the geopolymer paste that binds the loose coarse aggregates, fine aggregates, and other un-reacted materials together to form the geopolymer concrete. As in the case of portland cement concrete, the coarse and fine aggregates occupy about 75 to $80 \%$ of the 
mass of geopolymer concrete. The influence of aggregates, such as grading, angularity and strength, are considered to be the same as in the case of portland cement concrete (Lloyd and Rangan, 2009). Therefore, this component of geopolymer concrete mixtures can be designed using the tools currently available for portland cement concrete.

Studies have been carried out on fly ash-based geopolymer concrete. The compressive strength and the workability of geopolymer concrete are influenced by the proportions and properties of the constituent materials that make the geopolymer paste. Research results (Hardjito and Rangan, 2005) have shown the following:

- Higher concentration (in terms of molar) of sodium hydroxide solution results in higher compressive strength of geopolymer concrete.

- Higher ratio of sodium silicate solution-to-sodium hydroxide solution ratio by mass, results in higher compressive strength of geopolymer concrete.

- The slump value of the fresh geopolymer concrete increases when the water content of the mixture increases. High range water reducing admixture may assist in improving workability.

- As the $\mathrm{H}_{2} \mathrm{O}$-to- $\mathrm{Na}_{2} \mathrm{O}$ molar ratio increases, the compressive strength of geopolymer concrete decreases.

As can be seen from the above, the interaction of various parameters on the compressive strength and the workability of geopolymer concrete is complex. In order to assist the design of lowcalcium fly ash-based geopolymer concrete mixtures, a single parameter called ,water-togeopolymer solids ratio " by mass was devised. In this parameter, the total mass of water is the sum of the mass of water contained in the sodium silicate solution, the mass of water used in the making of the sodium hydroxide solution, and the mass of extra water, if any, present in the mixture. The mass of geopolymer solids is the sum of the mass of fly ash, the mass of sodium hydroxide solids used to make the sodium hydroxide solution, and the mass of solids in the sodium silicate solution (i.e. the mass of $\mathrm{Na}_{2} \mathrm{O}$ and $\mathrm{SiO}_{2}$ ).

Mix proportions had been designed keeping all the above things in mind. $400 \mathrm{~kg} / \mathrm{m}^{3}$ solid binder had been considered keeping in mind it is lower than $407 \mathrm{~kg} / \mathrm{m}^{3}$. Total aggregate is considered as $77.5 \%$ of total mass. Sodium Hydroxide and Sodium Silicate is adjusted accordingly so that the $\mathrm{SiO}_{2} / \mathrm{Na}_{2} \mathrm{O}$ in the liquid mix remain 1. The details provided in Table 5.1 and Table 5.2. 
Table 5.1 Mix Proportions for Geopolymer

\begin{tabular}{|c|c|c|c|c|c|c|c|c|c|c|c|}
\hline & curing & percentage & & & Slag & fly ash & CA & FA & $\mathrm{Na}\left(\mathrm{SiO}_{2}\right)_{\mathbf{x}}$ & $\mathrm{NaOH}$ & water \\
\hline Designation & temp & Fly Ash & Slag & $\mathrm{L} / \mathrm{S}$ & $\mathrm{kg}$ & $\mathrm{kg}$ & $\mathrm{kg}$ & $\mathrm{kg}$ & $\mathrm{kg}$ & $\mathrm{kg}$ & $\mathrm{kg}$ \\
\hline IP-FA & $80 \mathrm{C}$ & 100 & 0 & 0.3 & 0 & 400 & 1209 & 651 & 156 & 43 & 58 \\
\hline IP-FA & $60 \mathrm{C}$ & 100 & 0 & 0.3 & 0 & 400 & 1209 & 651 & 156 & 43 & 58 \\
\hline IP-FA & $40 \mathrm{C}$ & 100 & 0 & 0.3 & 0 & 400 & 1209 & 651 & 156 & 43 & 58 \\
\hline IP-FA+SL & $80 \mathrm{C}$ & 50 & 50 & 0.3 & 200 & 200 & 1209 & 651 & 156 & 43 & 58 \\
\hline IP-FA+SL & $60 \mathrm{C}$ & 50 & 50 & 0.3 & 200 & 200 & 1209 & 651 & 156 & 43 & 58 \\
\hline IP-FA+SL & $40 \mathrm{C}$ & 50 & 50 & 03 & 200 & 200 & 1209 & 651 & 156 & 43 & 58 \\
\hline IP-SL & $80 \mathrm{C}$ & 0 & 100 & 0.3 & 400 & 0 & 1209 & 651 & 156 & 43 & 58 \\
\hline IP-SL & $60 \mathrm{C}$ & 0 & 100 & 0.3 & 400 & 0 & 1209 & 651 & 156 & 43 & 58 \\
\hline IP-SL & $40 \mathrm{C}$ & 0 & 100 & 0.3 & 400 & 0 & 1209 & 651 & 156 & 43 & 58 \\
\hline
\end{tabular}

Table 5.2 Sample Mix Proportions Calculation for Geopolymer

\begin{tabular}{|l|r|l|r|}
\hline mass of concrete $\left(\mathrm{kg} / \mathrm{m}^{3}\right)$ & 2400 & specification of sodium silicate & \\
\hline mass of aggregate $\left(\mathrm{kg} / \mathrm{m}^{3}\right)$ & 1860 & silicate to sodium oxide ratio(needed) & 1 \\
\hline mass of sand $\left(\mathrm{kg} / \mathrm{m}^{3}\right)$ & 651 & water content & $60 \%$ \\
\hline mass of coarse aggregate $(3 / 8 \mathrm{in})\left(\mathrm{kg} / \mathrm{m}^{3}\right)$ & 1209 & sodium oxide & $40 \%$ \\
\hline alkaline liquid to powder ratio & 0.35 & & \\
\hline mass of binder $\left(\mathrm{kg} / \mathrm{m}^{3}\right)$ & 540 & Fly Ash & $100 \%$ \\
\hline mass of powder & 400 & Slag & $0 \%$ \\
\hline mass of alkaline liquid & 156 & & \\
\hline & & solid sodium silicate & 62.4 \\
\hline & & water in sodium silicate & 93.6 \\
\hline sodium silicate & 156 & solid sodium hydroxide & 43.06 \\
\hline super plasticizer $(\mathrm{mL})$ & 4680 & total solid & 505.5 \\
\hline & & total water & 93.6 \\
\hline Slag & 200 & water to solid ratio (needed) & 0.30 \\
\hline fly ash & 200 & water to be added & 58.0 \\
\hline
\end{tabular}




\subsection{Testing Procedures for Geopolymer Concrete}

\subsubsection{Concrete Making}

Geopolymer concrete making procedure is described below.

\subsubsection{Preparation of Solid Mix}

Solid Mix is prepared first. At the beginning sand, lime stone and fly ash and/or slag or both mixed properly to ensure best quality. The details are shown in Figure 5-1.

\subsubsection{Preparation of Liquid Mix}

The water, Sodium Silicate and Sodium Hydroxide are mixed properly to prepare a proper blend. The details are provided in Figure 5-2.

\subsubsection{Mixing of Solid and Liquid Mix}

The liquid mix is added to solid mix to prepare a cohesive mix. As the geopolymer concrete, tends to set very rapidly, so very small quantity of concrete is batched. So no mixer machine is used. So the liquid and dry mix is mixed very carefully, to avoid any kind of chemical burn. The mix is prepared very rapidly to ensure the time for workability. The Figure 5-3 shows the mixing of dry mix and liquid mix.

\subsubsection{Curing Temperature}

The specimens are cured after 24 hours of casting. Those samples are cured in 3 different temperatures; $40 \mathrm{C}, 60,80 \mathrm{C}$ respectively for 24 hours in oven. The curing can be seen in Figure $5-4$ 


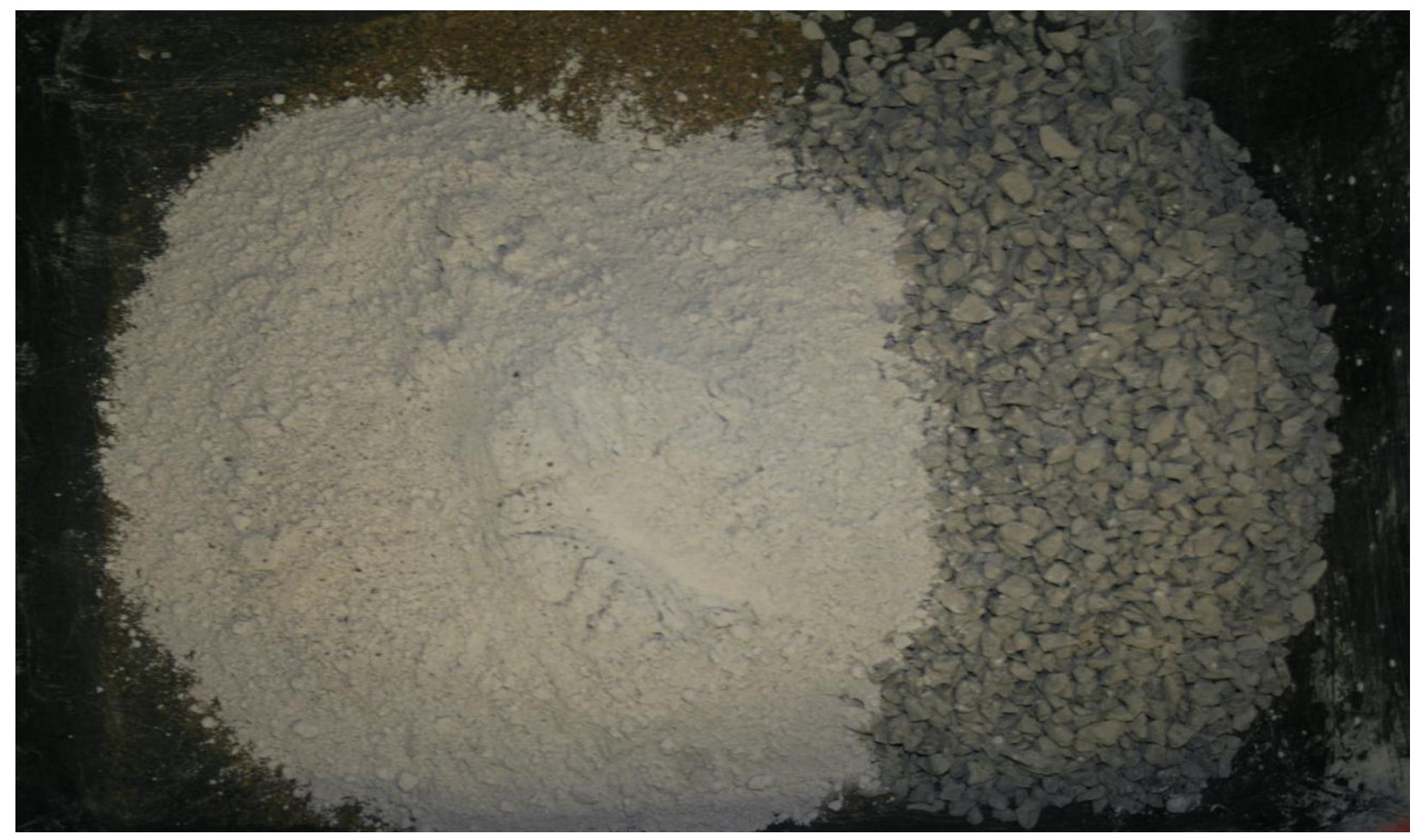

Figure 5-1Dry Mix

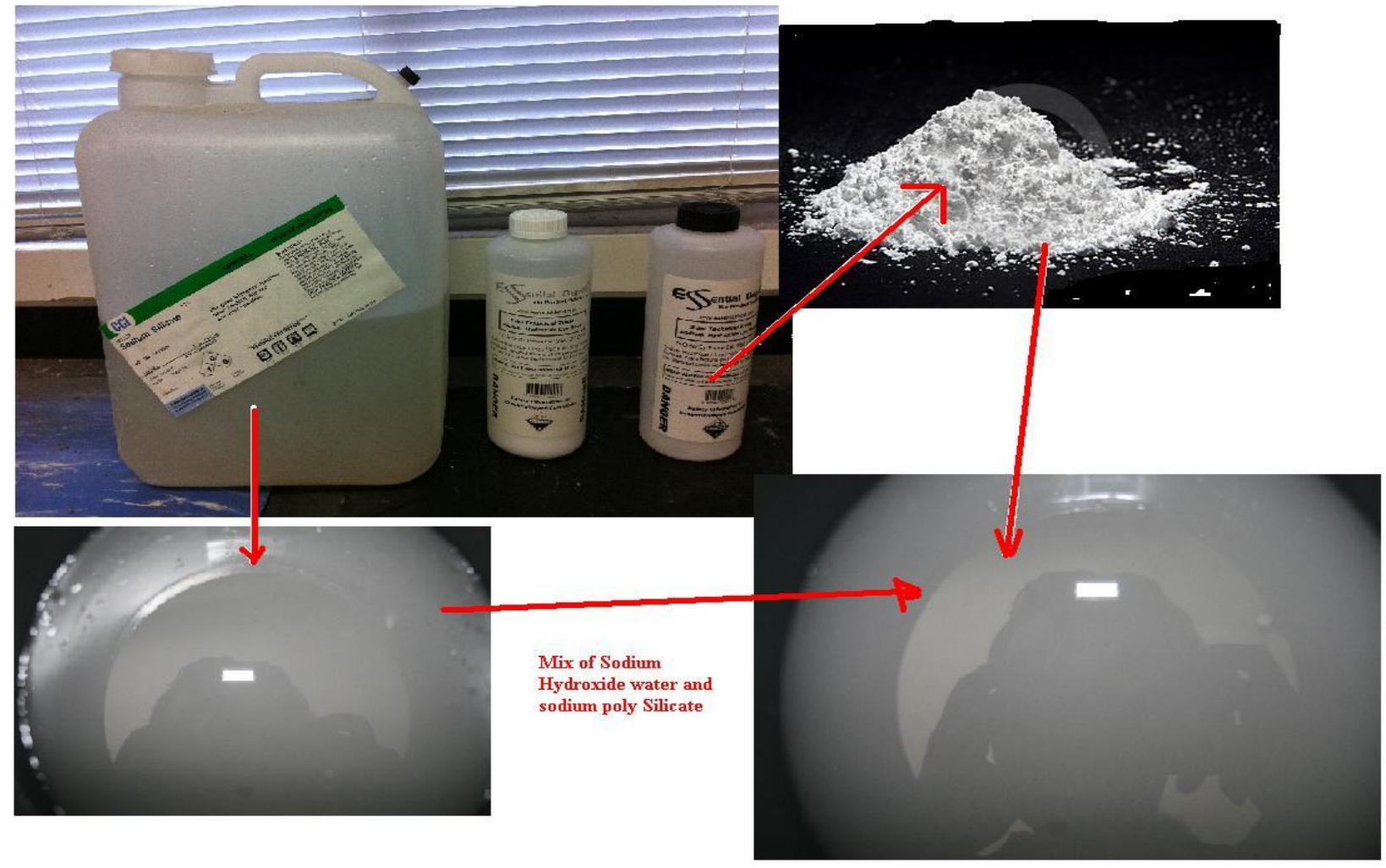

Figure 5-2Liquid Mix 


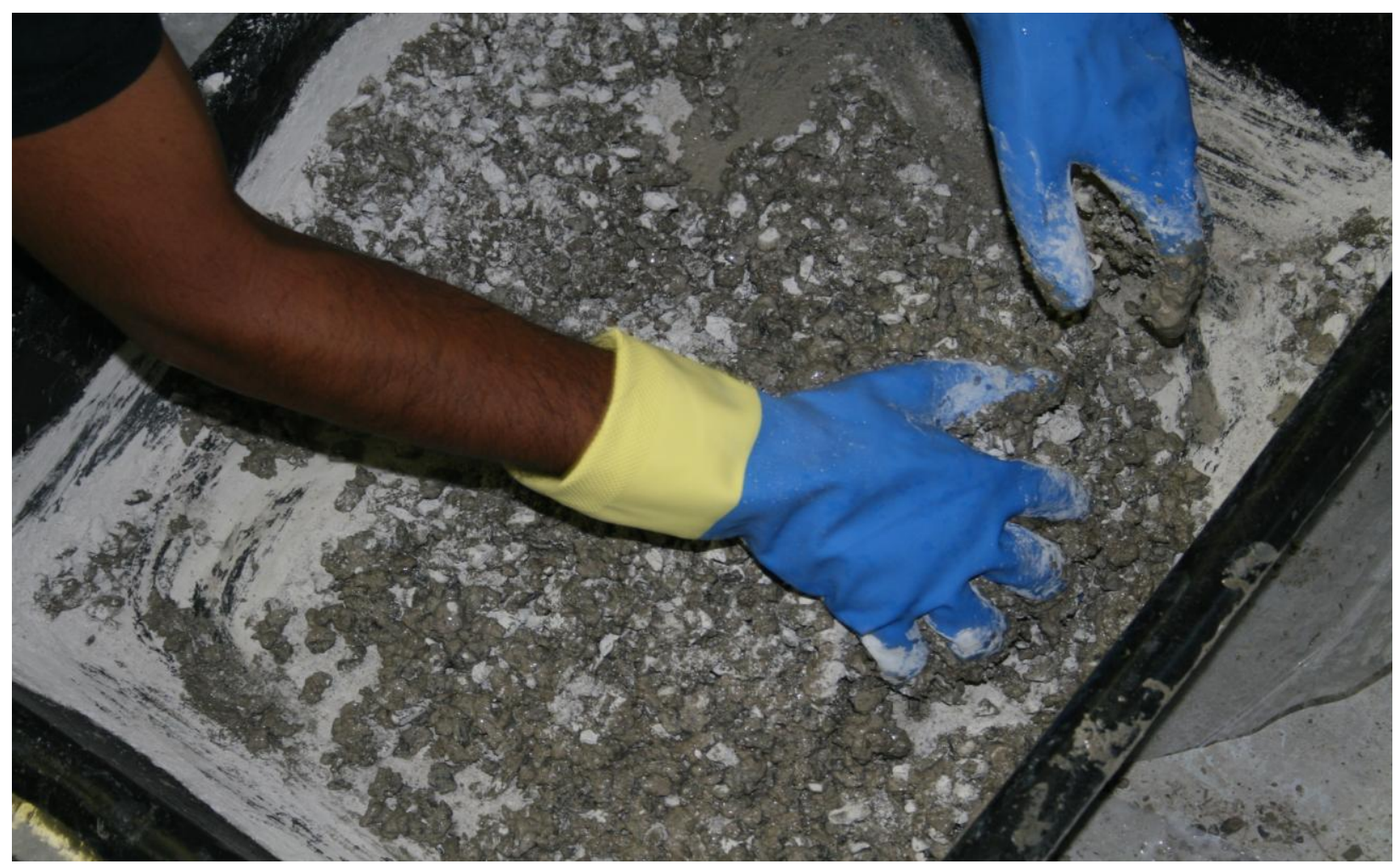

Figure 5-3Concrete Mix

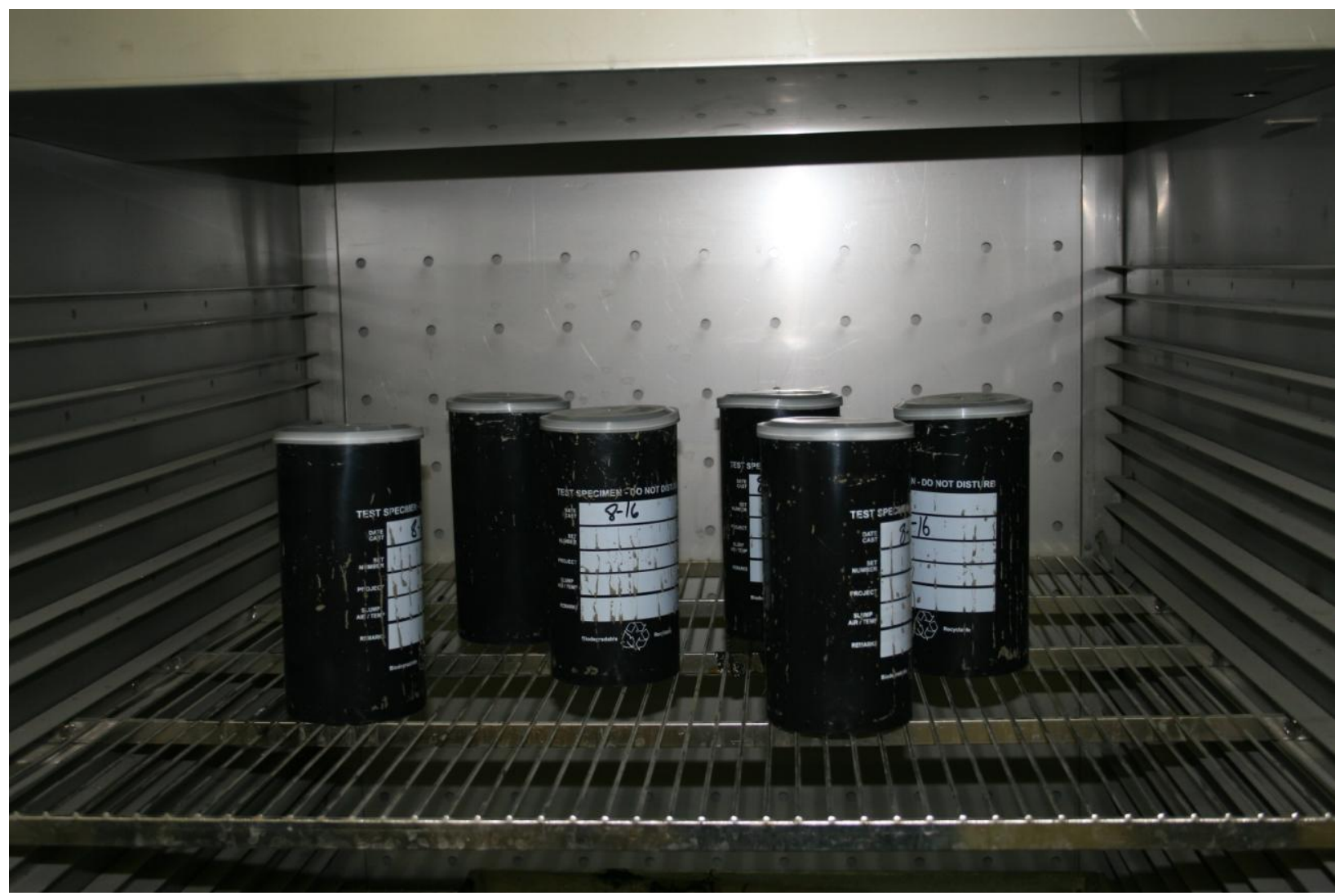

Figure 5-4Curing 


\subsubsection{Testing}

The specimens are tested for their physical properties.

\subsubsection{Compressive Strength Development}

Sampling the concrete delivered to a project is important to test if the concrete meets the requirements of the job specification and for quality control. For testing the concrete, cylindrical and prisms specimens are cast with the requirements of ASTM C 31.

If the specimens are made and standard cured, the resulting strength test data when the specimens are tested are able to be used for acceptance testing for a specified compressive strength, and for checking adequacy of mixture proportions for strength and quality control. If the specimens are made and field cured, the data are used for determination of whether the structure is capable of being put in service, comparison with test results from various in-placed methods (as the Maturity method), checking adequacy of curing and determining the time for formwork removal. In conclusion the results of the test are used as basis for quality control of concrete proportioning, mixing, and placing operations; determination of compliance with specifications; control for evaluating effectiveness of admixtures; and similar uses.

Compressive strength is the single most important property of concrete evaluation. For 28-day design strength the WVDOH specifies $27.58 \mathrm{MPa}$ (4000 psi) for deck concrete.

The compressive strength test was conducted at different ages for two types of curing and also for core samples with the purpose of monitoring the strength development of HPC with time. Early age strength is a guide for finishing and curing, and later strength is a measure of long-term performance. Values of compressive strength will depend on the size and shape of the specimen, batching, mixing procedures, methods of sampling, molding, age, temperature, and moisture conditions during curing. 
Cylinder specimens of $100 \mathrm{~mm}$ (4 in) X 200mm (8 in) dimension are prepared for compression testing. High volume fly ash and/or slag modified concrete samples are tested for 7 days, 28 days, respectively keeping in mind not much residual strength increase is predicted after curing.

\subsection{Discussion on Test Results of Geopolymer Concrete}

The results obtained all the tests mentioned before is analyzed and discussed in the following articles.

\subsubsection{Compressive Strength}

Compressive Strength is the most important physical property of concrete. In many ways compressive strength predicts the behavior of concrete in gross. The obtained results from compressive strength test are presented here. The strength obtained at different ages of concrete with different composition were plotted in a bar diagram form to compare it to each other.

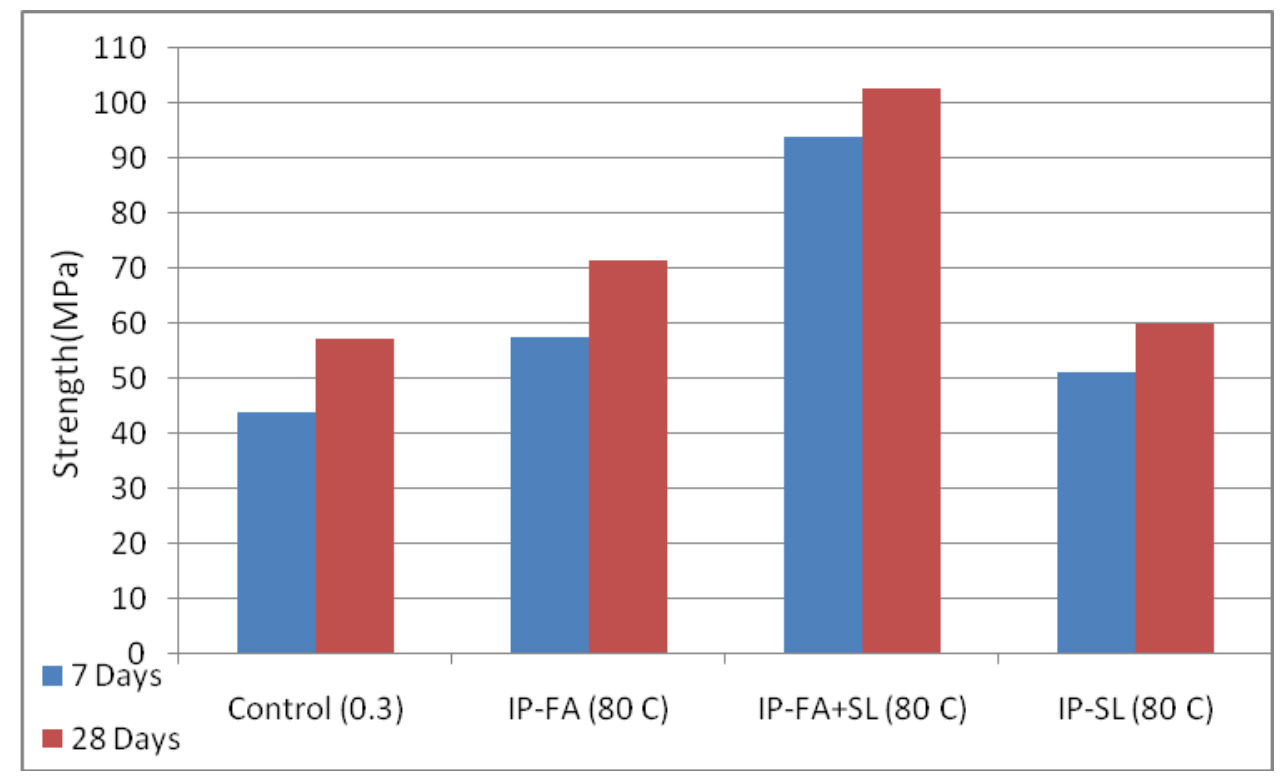

Figure 5-5Geopolymer when Temperature is $80 \mathrm{C}$

In Figure 5.6 Three different geopolymer cured at $80^{\circ} \mathrm{C}$ is compared with control concrete mix up to 28 days. Very little residual strength generation is observed after 7 days. Geopolymer made with fly ash and/or slag combination as solid binder is the highest among all, where as 
geopolymer made with slag as solid binder showed the least strength among geopolymers though more than control mix.

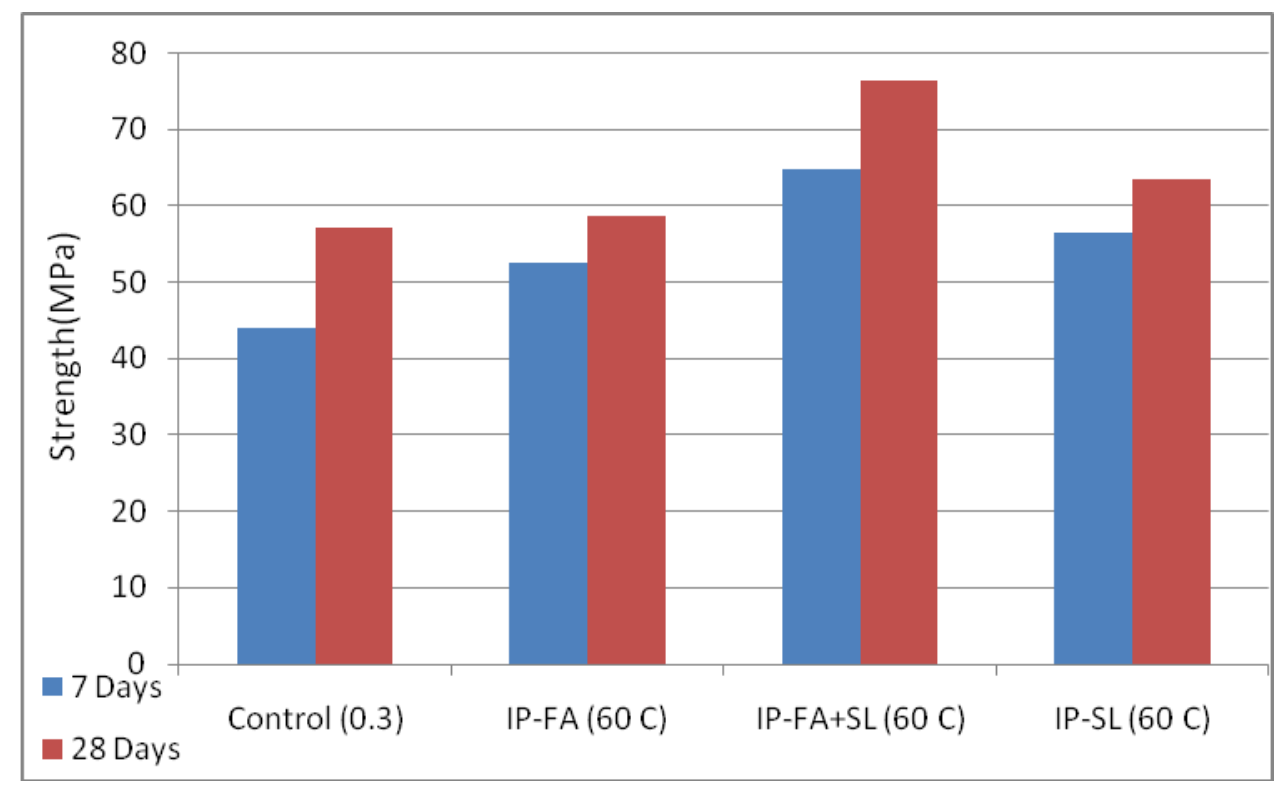

Figure 5-6Geopolymer when Temperature is $60 \mathrm{C}$

In Figure 5. 7Three different geopolymer cured at $60^{\circ} \mathrm{C}$ is compared with control concrete mix up to 28 days. Very little residual strength generation is observed after 7 days. Geopolymer made with fly ash and/or slag combination as solid binder is the highest among all, where as geopolymer made with fly ash as solid binder showed the least strength among geopolymers though more than control mix. 


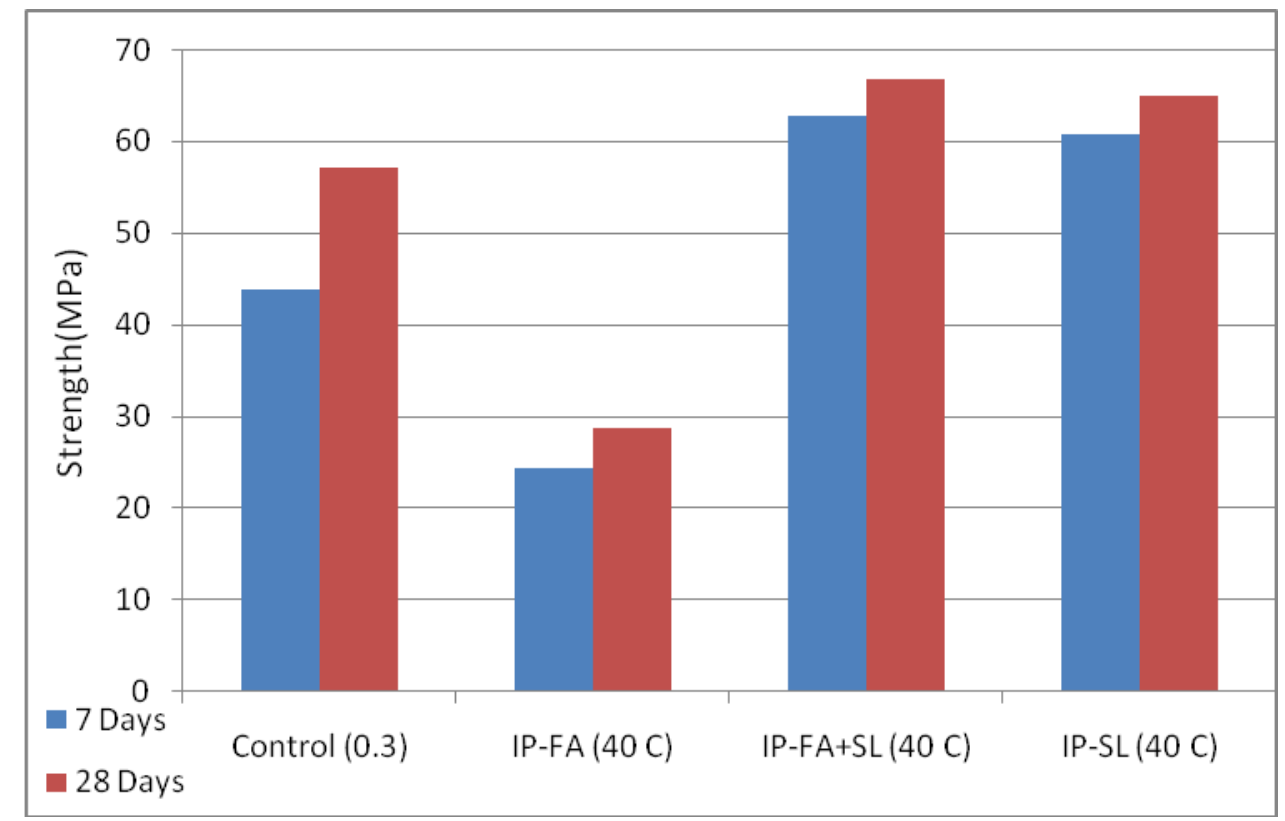

Figure 5-7 Geopolymer when Temperature is $40 \mathrm{C}$

In Figure 5.8 Three different geopolymer cured at $40^{\circ} \mathrm{C}$ is compared with control concrete mix up to 28 days. Very little residual strength generation is observed after 7 days. Geopolymer made with fly ash and/or slag combination as solid binder is the highest among all, where as geopolymer made with fly ash as solid binder showed the least strength among geopolymers even less than control mix.

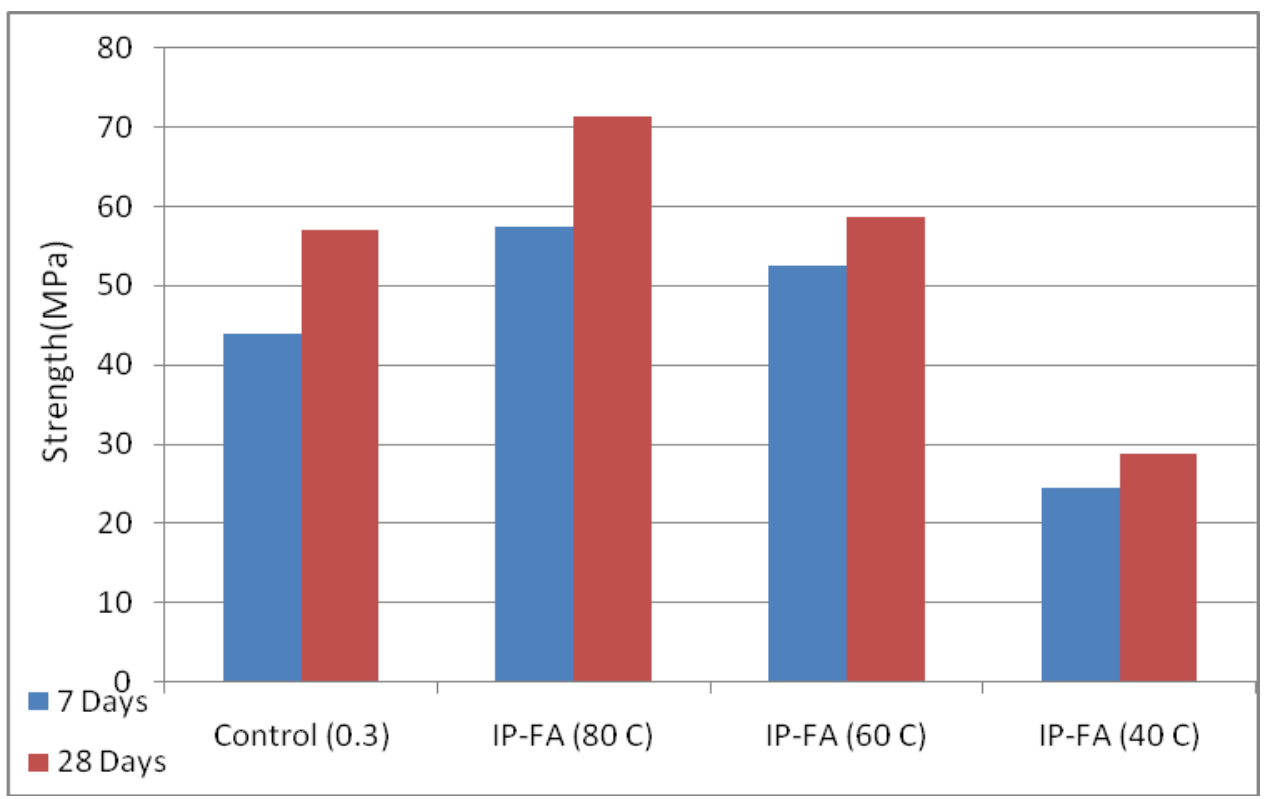

Figure 5-8 Geopolymer when Binder Is Fly Ash 
In Figure 5.9 geopolymer made with fly ash as solid binder cured at different temparature is compared with control concrete mix up to 28 days. Very little residual strength generation is observed after 7 days. Strength increased as the temperature increased.

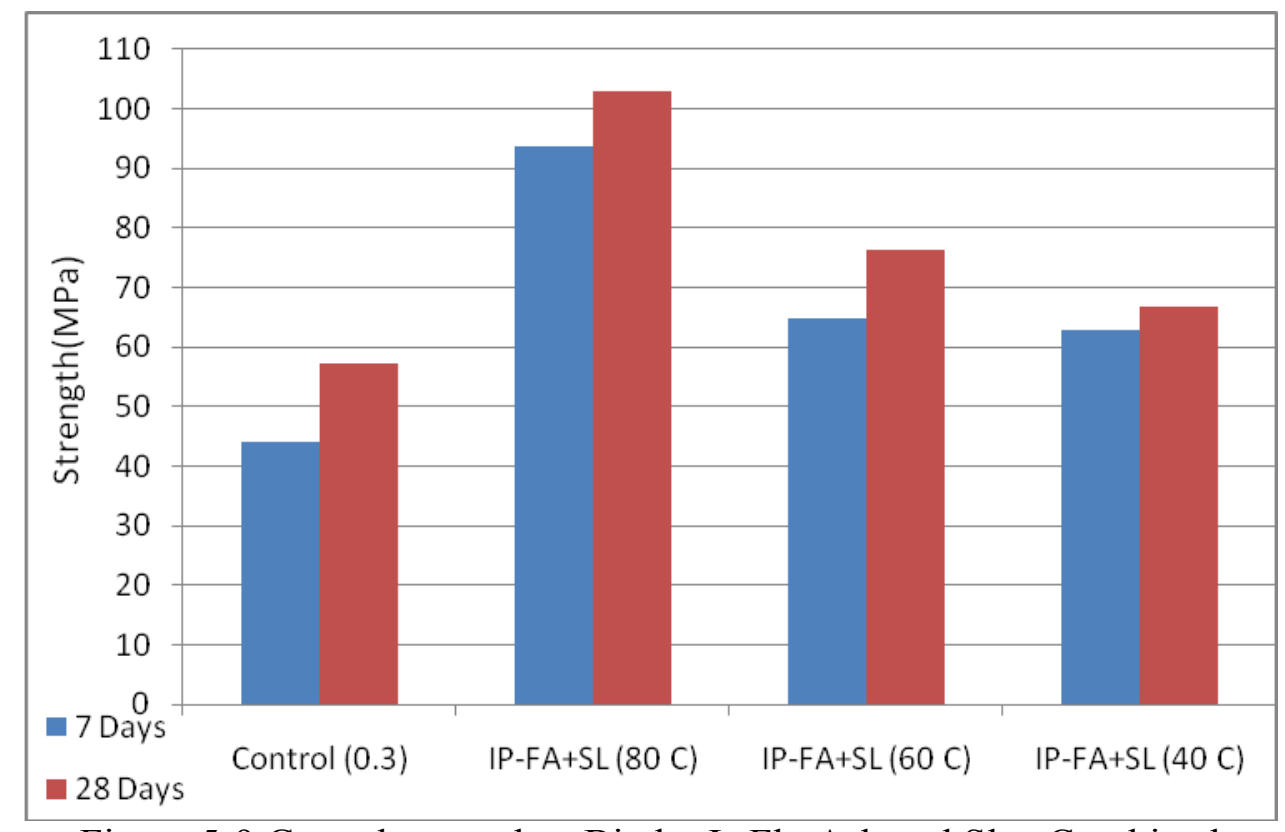

Figure 5-9 Geopolymer when Binder Is Fly Ash and Slag Combined

In Figure 5.10 geopolymer made with fly ash and/or slag combined as solid binder cured at different temparature is compared with control concrete mix up to 28 days. Very little residual strength generation is observed after 7 days. Strength increased as the temperature increased. 


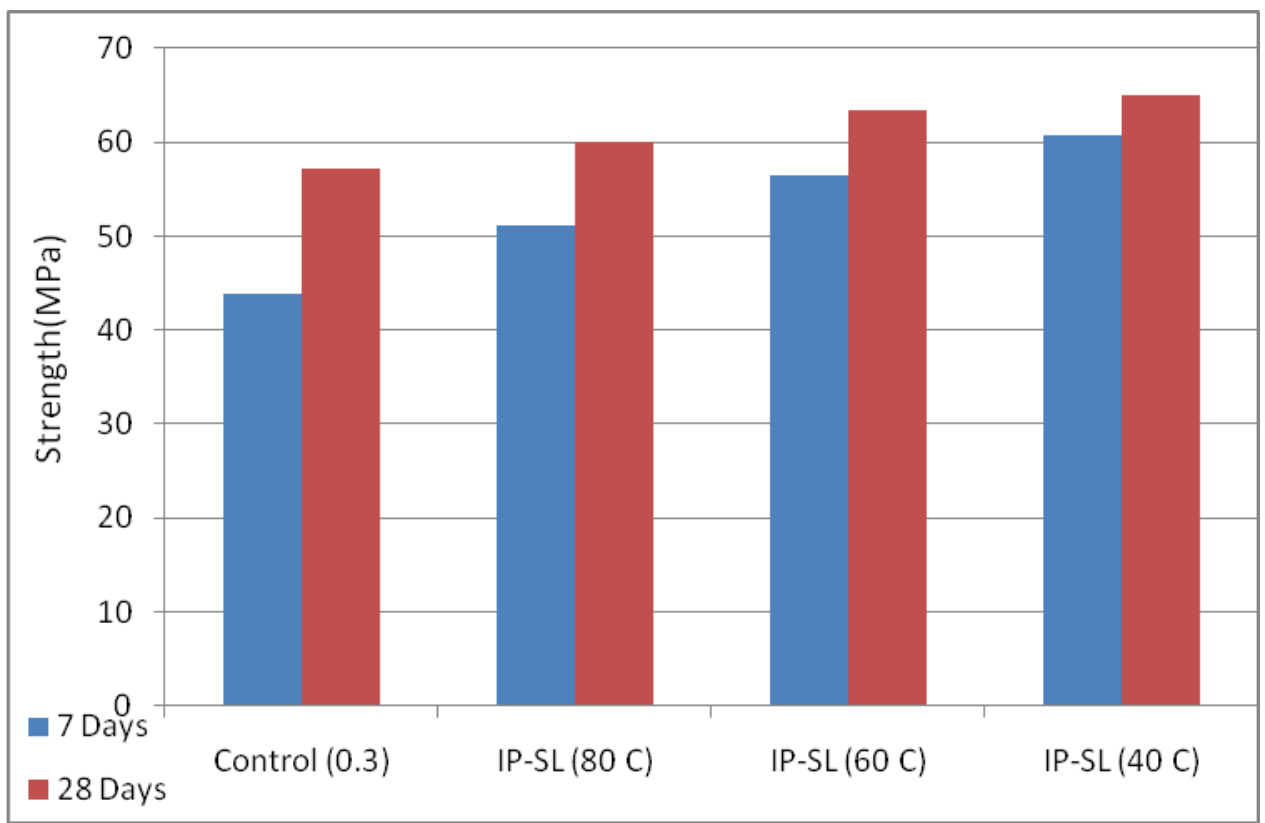

Figure 5-10 Geopolymer when Binder Is Slag

In Figure 5.11 geopolymer made with slag as solid binder cured at different temparature is compared with control concrete mix up to 28 days. Very little residual strength generation is observed after 7 days. Strength decreased as the temperature increased. 


\section{Chapter 6: Leaching Test}

\subsection{Leaching Test Procedure}

The tests were performed following US EPA TCLP 1311 for hazardous wastes. Two different extraction fluid of $\mathrm{pH} 2.88$ and 4.93 is prepared using glacial acetic acid and sodium hydroxide (laboratory grade) following the process described in EPA TCLP 1311.

Extraction fluid can be made in two ways. For the first case $5.7 \mathrm{~mL}$ glacial $\left(\mathrm{CH}_{3}\right)_{2} \mathrm{CHOOH}$ is added to $500 \mathrm{~mL}$ of reagent water. Then $64.3 \mathrm{~mL}$ of $1 \mathrm{~N} \mathrm{NaOH}$ is added, and diluted to a volume of 1 liter. When correctly prepared, the $\mathrm{pH}$ of this fluid will be $4.93+0.05$. In the second case $5.7 \mathrm{~mL}$ glacial $\left(\mathrm{CH}_{3}\right)_{2} \mathrm{CHOOH}$ is added to $1 \mathrm{~L}$ of reagent water. When correctly prepared, the $\mathrm{pH}$ of this fluid will be $2.88+0.05$ (5.7).

The $50 \mathrm{gm}$ of each sample is poured in $500 \mathrm{ml}$ of extraction fluid to ensure liquid to solid ratio of $10 \mathrm{ml} / \mathrm{gm}$. Poly-tetra-fluoro-ethylene (PTFE) containers are used to avoid the reaction with the container. The enclosed air tight containers are then shaken in a vertical shaker for 18 hours. Then the leached water sample is collected by filtration through filter of 0.7 micron pore size. Nitric acid is poured in the water sample to reduce its $\mathrm{pH}$ to less than 2 to produce an aliquot to avoid the precipitation of metallic ions from the solution. Then the solutions are tested for hazardous metals and non metals presence.

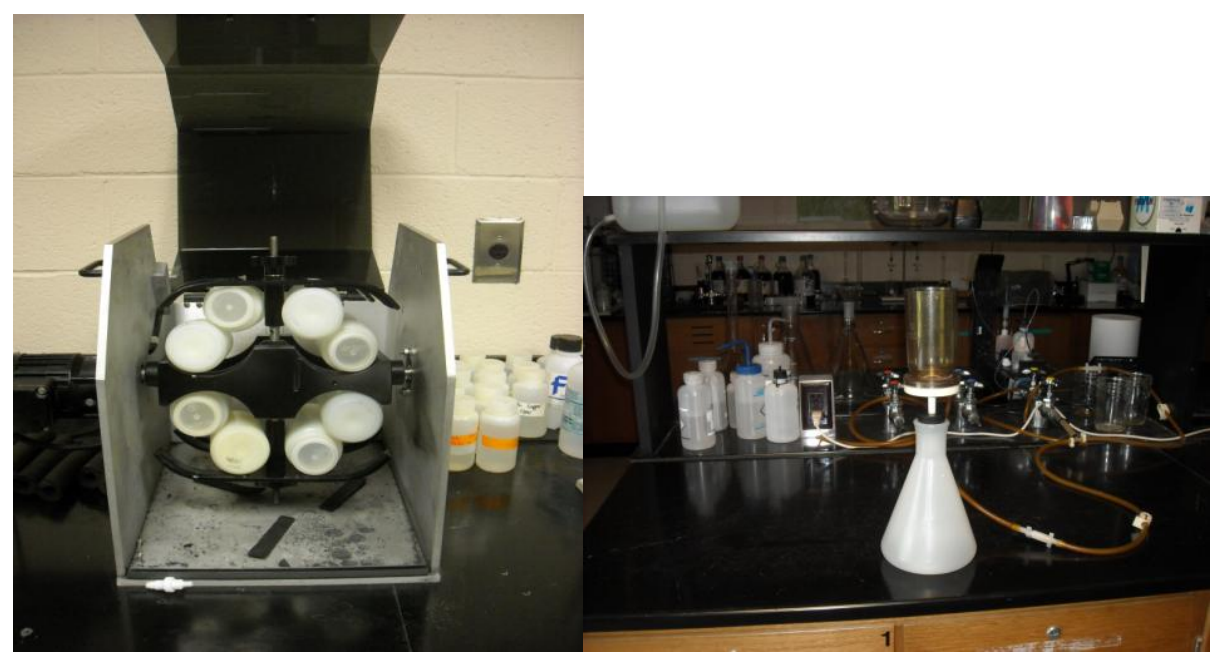

Figure 6-1Stirring and Filtering Set up 


\subsection{Materials and Instruments}

Materials used for this test are described below.

\subsubsection{Containers}

Bottle Extraction Vessel: When the waste is being evaluated using the nonvolatile extraction, a jar with sufficient capacity to hold the sample and the extraction fluid is needed. Headspace is allowed in this vessel. The extraction bottles may be constructed from various materials, depending on the analytes to be analyzed and the nature of the waste. It is recommended that borosilicate glass bottles be used instead of other types of glass, especially when inorganic compounds are of concern.

\subsubsection{Filters}

For materials of construction extraction vessels and filtration devices were made of inert materials which will not leach or absorb waste components. Glass, poly-tetra-fluoro-ethylene (PTFE), were used when evaluating the mobility of both organic and inorganic components. Devices made of high density polyethylene (HDPE), polypropylene (PP), or polyvinyl chloride (PVC) may be used only when evaluating the mobility of metals. Borosilicate glass bottles are recommended for use over other types of glass bottles, especially when inorganic compounds are of concern.

Filters were made of borosilicate glass fiber, shall contain no binder materials, and shall have an effective pore size of 0.6 to $0.8 \mu \mathrm{m}$, or equivalent. Pre-filters must not be used. When evaluating the mobility of metals, filters were acid-washed prior to use by rinsing with 1Normal nitric acid followed by three consecutive rinses with de-ionized distilled water (a minimum of 1 Liter per rinse is recommended). Glass fiber filters are fragile and should be handled with care.

\subsubsection{Filter Holder}

Filter holder capable of supporting a glass fiber filter and able to withstand the pressure needed to accomplish separation may be used. Suitable filter holders range from simple vacuum units to 
relatively complex systems capable of exerting pressures of up to 50 psi or more. The type of filter holder used depends on the properties of the material to be filtered. These devices had a minimum internal volume of $300 \mathrm{~mL}$ and be equipped to accommodate a minimum filter size of $47 \mathrm{~mm}$ (filter holders having an internal capacity of $1.5 \mathrm{~L}$ or greater, and equipped to accommodate a $142 \mathrm{~mm}$ diameter filter, are recommended). Wastes should be filtered using positive pressure filtration.

\subsubsection{Chemicals}

Three different laboratory grade chemicals has been used to avoid contamination and least human error.

\subsubsection{Glacial Acetic Acid}

Laboratory grade Glacial Acetic acid provided by Fisher Scientific were used for these test. .

\subsubsection{Sodium Hydroxide}

Sodium hydroxide tablet, which had more than 98 \% purity; supplied by Fisher Scientific is used for the purpose of producing $1 \mathrm{~N}$ solution which is later used for the tests.

\subsubsection{Nitric Acid}

Laboratory grade concentrated Nitric acid is used provided by Fisher scientific. Almost $70 \%$ concentrated nitric acid is diluted to produce $1 \mathrm{~N}$ solution which is used for the tests.

\subsection{Leaching Test Results and Discussion}

The test results are described below.

\subsubsection{Leaching Test Results for Fly Ash}

The result shows fly ash leached approximately $0.272 \mathrm{mg} / \mathrm{L}$ Silver (Ag), $0.19 \mathrm{mg} / \mathrm{L}$ Aluminum (Al), $6.02 \mathrm{mg} / \mathrm{L}$ Boron (B), $0.4699 \mathrm{mg} / \mathrm{L}$ Barium (Ba), $2133.15 \mathrm{mg} / \mathrm{L}$ Calcium (Ca), $0.34 \mathrm{mg} / \mathrm{L}$ Chromium (Cr), $0.411 \mathrm{mg} / \mathrm{L}$ Iron (Fe), $0.0001 \mathrm{mg} / \mathrm{L}$ Mercury (Hg), 0.48 mg/L Magnesium (Mg), 
$0.103 \mathrm{mg} / \mathrm{L}$ Manganese (Mn), $0.281 \mathrm{mg} / \mathrm{L}$ Molybdenum (Mo), $0.029 \mathrm{mg} / \mathrm{L}$ Nickel (Ni), 0.051 $\mathrm{mg} / \mathrm{L}$ Lead (Pb), $345.55 \mathrm{mg} / \mathrm{L}$ Sulfur (S), $0.038 \mathrm{mg} / \mathrm{L}$ Antimony (Sb), $0.055 \mathrm{mg} / \mathrm{L}$ Selenium (Se), $0.302 \mathrm{mg} / \mathrm{L}$ Tin (Sn), $4.08 \mathrm{mg} / \mathrm{L}$ Strontium (Sr), $0.07 \mathrm{mg} / \mathrm{L}$ Titanium (Ti), 0.221 mg/L Vanadium (V), $0.299 \mathrm{mg} / \mathrm{L}$ Zinc (Zn) while extraction fluid's $\mathrm{pH}$ was 2.88, whereas leaching of Arsenic (As), Beryllium (Be), Cadmium (Cd), Cobalt (Co), Copper (Cu), Phosphorus (P), Thallium (Tl), remain under the detection limit.

fly ash leached approximately $0.12 \mathrm{mg} / \mathrm{L}$ Aluminum (Al), $1.195 \mathrm{mg} / \mathrm{L}$ Boron (B), $0.5337 \mathrm{mg} / \mathrm{L}$ Barium (Ba), 1140.9 mg/L Calcium (Ca), $0.27 \mathrm{mg} / \mathrm{L}$ Chromium (Cr), 0.078 mg/L Iron (Fe), 0.12 mg/L Magnesium (Mg), 0.474 mg/L Molybdenum (Mo), 327.27 mg/L Sulfur (S), 0.055 mg/L Antimony (Sb), $0.036 \mathrm{mg} / \mathrm{L}$ Selenium (Se), $0.156 \mathrm{mg} / \mathrm{L}$ Tin (Sn), $4.4 \mathrm{mg} / \mathrm{L}$ Strontium (Sr), Thallium (Tl), $0.023 \mathrm{mg} / \mathrm{L}$ Vanadium (V), while extraction fluid's $\mathrm{pH}$ was 4.93, whereas leaching of Silver (Ag), Arsenic (As), Beryllium (Be), Cadmium (Cd), Cobalt (Co), Copper $(\mathrm{Cu})$, Mercury (Hg), Manganese (Mn), Nickel (Ni), Phosphorus (P), Lead (Pb), Titanium (Ti), Thallium (Tl), Zinc $(\mathrm{Zn})$ remain under the detection limit.

Leaching of Silver (Ag), Aluminum (Al), Boron (B), Calcium (Ca), Chromium (Cr), Iron (Fe), Mercury (Hg), Magnesium (Mg), Manganese (Mn), Nickel (Ni), Lead (Pb), Sulfur (S), Selenium (Se), Tin (Sn), Titanium (Ti), Vanadium (V), Zinc (Zn) increased with decreasing pH, whereas leaching of Barium (Ba), Molybdenum (Mo), Antimony (Sb), Strontium (Sr) decreased with the decrease of $\mathrm{pH}$.

\subsubsection{Leaching Test Results for Slag}

The result shows slag leached approximately $27.344 \mathrm{mg} / \mathrm{L}$ Silver (Ag), $46.19 \mathrm{mg} / \mathrm{L}$ Aluminum (Al), 43.955 mg/L Arsenic (As), 40.88 mg/L Boron (B), 1.495 mg/L Barium (Ba), 0.912 mg/L Beryllium (Be), $1932.42 \mathrm{mg} / \mathrm{L}$ Calcium (Ca), $1.31 \mathrm{mg} / \mathrm{L}$ Cadmium (Cd), $3.68 \mathrm{mg} / \mathrm{L}$ Cobalt (Co), $3.64 \mathrm{mg} / \mathrm{L}$ Chromium (Cr), $21.25 \mathrm{mg} / \mathrm{L}$ Copper $(\mathrm{Cu}), 7.98 \mathrm{mg} / \mathrm{L}$ Iron $(\mathrm{Fe}), 1.45 \mathrm{mg} / \mathrm{L}$ Magnesium (Mg), 11.26 mg/L Manganese (Mn), 7.73 mg/L Molybdenum (Mo), $11.81 \mathrm{mg} / \mathrm{L}$ Nickel (Ni), 48.29 mg/L Phosphorus (P), $65.11 \mathrm{mg} / \mathrm{L}$ Lead (Pb), $64228.7 \mathrm{mg} / \mathrm{L}$ Sulfur (S), 46.66 mg/L Antimony (Sb), 133.24 mg/L Selenium (Se), 136.35 mg/L Tin (Sn), 5.04 mg/L Strontium (Sr), $10.91 \mathrm{mg} / \mathrm{L}$ Titanium (Ti), $5.88 \mathrm{mg} / \mathrm{L}$ Thallium (Tl), $7.95 \mathrm{mg} / \mathrm{L}$ Vanadium (V), $4.55 \mathrm{mg} / \mathrm{L}$ Zinc (Zn) while extraction fluid's $\mathrm{pH}$ was 2.88, whereas leaching of Mercury $(\mathrm{Hg})$ remain under the detection limit. 
Slag leached approximately $22.339 \mathrm{mg} / \mathrm{L}$ Silver (Ag), $30.663 \mathrm{mg} / \mathrm{L}$ Aluminum (Al), $0.998 \mathrm{mg} / \mathrm{L}$ Arsenic (As), $21.647 \mathrm{mg} / \mathrm{L}$ Boron (B), $1.198 \mathrm{mg} / \mathrm{L}$ Barium (Ba), $0.566 \mathrm{mg} / \mathrm{L}$ Beryllium (Be), $955.79 \mathrm{mg} / \mathrm{L}$ Calcium (Ca), $1.08 \mathrm{mg} / \mathrm{L}$ Cadmium (Cd), 3.24mg/L Cobalt (Co), $3.62 \mathrm{mg} / \mathrm{L}$ Chromium (Cr), 12.84mg/L Copper $(\mathrm{Cu}), 3.97 \mathrm{mg} / \mathrm{L}$ Iron $(\mathrm{Fe})$, Mercury $(\mathrm{Hg}), 0.26 \mathrm{mg} / \mathrm{L}$ Magnesium (Mg), $6.61 \mathrm{mg} / \mathrm{L}$ Manganese (Mn), $5.09 \mathrm{mg} / \mathrm{L}$ Molybdenum (Mo), $3.43 \mathrm{mg} / \mathrm{L}$ Nickel (Ni), 43.41mg/L Phosphorus (P), $45.43 \mathrm{mg} / \mathrm{L}$ Lead (Pb), $30430.1 \mathrm{mg} / \mathrm{L}$ Sulfur (S), $33.39 \mathrm{mg} / \mathrm{L}$ Antimony (Sb), $75.27 \mathrm{mg} / \mathrm{L}$ Selenium (Se), $75.44 \mathrm{mg} / \mathrm{L}$ Tin (Sn), $4.1 \mathrm{mg} / \mathrm{L}$ Strontium (Sr), 7.92 $\mathrm{mg} / \mathrm{L}$ Titanium (Ti), $9.5 \mathrm{mg} / \mathrm{L}$ Thallium (Tl), $6.68 \mathrm{mg} / \mathrm{L}$ Vanadium (V), $2.12 \mathrm{mg} / \mathrm{L}$ Zinc (Zn) while extraction fluid's $\mathrm{pH}$ was 2.88 , whereas leaching of Mercury $(\mathrm{Hg})$ remain under the detection limit.

Leaching of Silver (Ag), Aluminum (Al), Arsenic (As), Boron (B), Barium (Ba), Beryllium (Be), Calcium (Ca), Cadmium (Cd), Cobalt (Co), Chromium (Cr), Copper ( $\mathrm{Cu}$ ), Iron ( $\mathrm{Fe})$, Magnesium $(\mathrm{Mg})$, Manganese (Mn), Molybdenum (Mo), Nickel (Ni), Phosphorus (P), Lead (Pb), Sulfur (S), Antimony (Sb), Selenium (Se), Tin (Sn), Strontium (Sr), Titanium (Ti), Vanadium (V), Zinc ( $\mathrm{Zn})$ increased with decreasing $\mathrm{pH}$, whereas leaching of Thallium (Tl), decreased with the decrease of $\mathrm{pH}$.

\subsubsection{Leaching Test Results for Sand}

The result shows fly ash leached approximately $0.272 \mathrm{mg} / \mathrm{L}$ Silver $(\mathrm{Ag}), 0.19 \mathrm{mg} / \mathrm{L}$ Aluminum (Al), Arsenic (As), $6.02 \mathrm{mg} / \mathrm{L}$ Boron (B), $0.4699 \mathrm{mg} / \mathrm{L}$ Barium (Ba), Beryllium (Be), 2133.15 $\mathrm{mg} / \mathrm{L}$ Calcium (Ca), Cadmium (Cd), Cobalt (Co), $0.34 \mathrm{mg} / \mathrm{L}$ Chromium (Cr), Copper $(\mathrm{Cu})$, $0.411 \mathrm{mg} / \mathrm{L}$ Iron $(\mathrm{Fe}), 0.0001 \mathrm{mg} / \mathrm{L}$ Mercury $(\mathrm{Hg}), 0.48 \mathrm{mg} / \mathrm{L}$ Magnesium $(\mathrm{Mg}), 0.103 \mathrm{mg} / \mathrm{L}$ Manganese (Mn), $0.281 \mathrm{mg} / \mathrm{L}$ Molybdenum (Mo), $0.029 \mathrm{mg} / \mathrm{L}$ Nickel (Ni), Phosphorus (P), $0.051 \mathrm{mg} / \mathrm{L}$ Lead $(\mathrm{Pb}), 345.55 \mathrm{mg} / \mathrm{L}$ Sulfur $(\mathrm{S}), 0.038 \mathrm{mg} / \mathrm{L}$ Antimony $(\mathrm{Sb}), 0.055 \mathrm{mg} / \mathrm{L}$ Selenium (Se), $0.302 \mathrm{mg} / \mathrm{L}$ Tin $(\mathrm{Sn}), 4.08 \mathrm{mg} / \mathrm{L}$ Strontium $(\mathrm{Sr}), 0.07 \mathrm{mg} / \mathrm{L}$ Titanium (Ti), Thallium (Tl), $0.221 \mathrm{mg} / \mathrm{L}$ Vanadium (V), $0.299 \mathrm{mg} / \mathrm{L}$ Zinc (Zn) while extraction fluid's pH was 2.88, whereas leaching of Silver (Ag), Aluminum (Al), Arsenic (As), Boron (B), Barium (Ba), Beryllium (Be), Calcium (Ca), Cadmium (Cd), Cobalt (Co), Chromium (Cr), Copper (Cu), Iron (Fe), Mercury (Hg), Magnesium (Mg), Manganese (Mn), Molybdenum (Mo), Nickel (Ni), Phosphorus (P), Lead ( $\mathrm{Pb}$ ), Sulfur (S), Antimony (Sb), Selenium (Se), Tin (Sn), Strontium ( $\mathrm{Sr}$ ), Titanium (Ti), Thallium (Tl), Vanadium (V), Zinc (Zn) remain under the detection limit. 
fly ash leached approximately $0.272 \mathrm{mg} / \mathrm{L}$ Silver (Ag), $0.19 \mathrm{mg} / \mathrm{L}$ Aluminum (Al), Arsenic (As), $6.02 \mathrm{mg} / \mathrm{L}$ Boron (B), $0.4699 \mathrm{mg} / \mathrm{L}$ Barium (Ba), Beryllium (Be), $2133.15 \mathrm{mg} / \mathrm{L}$ Calcium (Ca), Cadmium (Cd), Cobalt (Co), $0.34 \mathrm{mg} / \mathrm{L}$ Chromium (Cr), Copper $(\mathrm{Cu}), 0.411 \mathrm{mg} / \mathrm{L}$ Iron $(\mathrm{Fe})$, $0.0001 \mathrm{mg} / \mathrm{L}$ Mercury (Hg), $0.48 \mathrm{mg} / \mathrm{L}$ Magnesium $(\mathrm{Mg}), 0.103 \mathrm{mg} / \mathrm{L}$ Manganese (Mn), 0.281 $\mathrm{mg} / \mathrm{L}$ Molybdenum (Mo), $0.029 \mathrm{mg} / \mathrm{L}$ Nickel (Ni), Phosphorus (P), $0.051 \mathrm{mg} / \mathrm{L} \mathrm{Lead} \mathrm{(Pb),}$ $345.55 \mathrm{mg} / \mathrm{L}$ Sulfur (S), $0.038 \mathrm{mg} / \mathrm{L}$ Antimony (Sb), $0.055 \mathrm{mg} / \mathrm{L}$ Selenium (Se), $0.302 \mathrm{mg} / \mathrm{L}$ Tin (Sn), $4.08 \mathrm{mg} / \mathrm{L}$ Strontium (Sr), $0.07 \mathrm{mg} / \mathrm{L}$ Titanium (Ti), Thallium (Tl), $0.221 \mathrm{mg} / \mathrm{L}$ Vanadium (V), $0.299 \mathrm{mg} / \mathrm{L}$ Zinc (Zn) while extraction fluid's $\mathrm{pH}$ was 2.88, whereas leaching of Silver (Ag), Aluminum (Al), Arsenic (As), Boron (B), Barium (Ba), Beryllium (Be), Calcium (Ca), Cadmium (Cd), Cobalt (Co), Chromium (Cr), Copper ( $\mathrm{Cu}$ ), Iron ( $\mathrm{Fe}$ ), Mercury (Hg), Magnesium (Mg), Manganese (Mn), Molybdenum (Mo), Nickel (Ni), Phosphorus (P), Lead (Pb), Sulfur (S), Antimony (Sb), Selenium (Se), Tin (Sn), Strontium (Sr), Titanium (Ti), Thallium (T1), Vanadium (V), Zinc (Zn) remain under the detection limit.

Leaching of Silver (Ag), Aluminum (Al), Arsenic (As), Boron (B), Barium (Ba), Beryllium (Be), Calcium (Ca), Cadmium (Cd), Cobalt (Co), Chromium (Cr), Copper ( $\mathrm{Cu})$, Iron ( $\mathrm{Fe})$, Mercury (Hg), Magnesium (Mg), Manganese (Mn), Molybdenum (Mo), Nickel (Ni), Phosphorus (P), Lead ( $\mathrm{Pb}$ ), Sulfur (S), Antimony (Sb), Selenium (Se), Tin (Sn), Strontium (Sr), Titanium (Ti), Thallium ( $\mathrm{Tl})$, Vanadium $(\mathrm{V})$, Zinc $(\mathrm{Zn})$ increased with decreasing $\mathrm{pH}$, whereas leaching of Silver (Ag), Aluminum (Al), Arsenic (As), Boron (B), Barium (Ba), Beryllium (Be), Calcium (Ca), Cadmium (Cd), Cobalt (Co), Chromium ( $\mathrm{Cr})$, Copper $(\mathrm{Cu})$, Iron ( $\mathrm{Fe})$, Mercury $(\mathrm{Hg})$, Magnesium (Mg), Manganese (Mn), Molybdenum (Mo), Nickel (Ni), Phosphorus (P), Lead $(\mathrm{Pb})$, Sulfur (S), Antimony (Sb), Selenium (Se), Tin (Sn), Strontium (Sr), Titanium (Ti), Thallium (Tl), Vanadium (V), Zinc (Zn) decreased with the decrease of $\mathrm{pH}$.

\subsubsection{Leaching Test Results for Lime Stone}

The result shows lime stone leached approximately $0.27 \mathrm{mg} / \mathrm{L}$ Aluminum (Al), $0.126 \mathrm{mg} / \mathrm{L}$ Boron (B), $0.346 \mathrm{mg} / \mathrm{L}$ Barium (Ba), $2373.08 \mathrm{mg} / \mathrm{L}$ Calcium (Ca), $0.55 \mathrm{mg} / \mathrm{L}$ Iron (Fe), 37.54 $\mathrm{mg} / \mathrm{L}$ Magnesium (Mg), $0.55 \mathrm{mg} / \mathrm{L}$ Manganese (Mn), $28.67 \mathrm{mg} / \mathrm{L}$ Sulfur $(\mathrm{S}), 3.16 \mathrm{mg} / \mathrm{L}$ Strontium (Sr), 0.063 Thallium (Tl), $0.024 \mathrm{mg} / \mathrm{L}$ Vanadium (V), while extraction fluid's $\mathrm{pH}$ was 2.88, whereas leaching of Silver (Ag), Arsenic (As), Beryllium (Be), Cadmium (Cd), Cobalt (Co), Chromium (Cr), Copper (Cu), Mercury (Hg), Molybdenum (Mo), Nickel (Ni), Phosphorus 
$(\mathrm{P})$, Lead $(\mathrm{Pb})$, Antimony $(\mathrm{Sb})$, Selenium $(\mathrm{Se})$, Tin $(\mathrm{Sn})$, Titanium (Ti), Zinc ( $\mathrm{Zn})$ remained under the detection limit.

Lime stone leached approximately $0.45 \mathrm{mg} / \mathrm{L}$ Aluminum (Al), $0.113 \mathrm{mg} / \mathrm{L}$ Boron (B), 0.322 $\mathrm{mg} / \mathrm{L}$ Barium (Ba), $774.75 \mathrm{mg} / \mathrm{L}$ Calcium $(\mathrm{Ca}), 0.07 \mathrm{mg} / \mathrm{L}$ Iron $(\mathrm{Fe}), 18.82 \mathrm{mg} / \mathrm{L}$ Magnesium (Mg), $0.05 \mathrm{mg} / \mathrm{L}$ Manganese (Mn), $6.16 \mathrm{mg} / \mathrm{L}$ Sulfur (S), $0.037 \mathrm{mg} / \mathrm{L}$ Antimony (Sb), $1.99 \mathrm{mg} / \mathrm{L}$ Strontium (Sr), 0.04 Thallium (Tl), while extraction fluid's $\mathrm{pH}$ was 4.93, whereas leaching of Silver (Ag), Arsenic (As), Beryllium (Be), Cadmium (Cd), Cobalt (Co), Chromium (Cr), Copper $(\mathrm{Cu})$, Mercury (Hg), Molybdenum (Mo), Nickel (Ni), Phosphorus (P), Lead (Pb), Selenium (Se), Tin (Sn), Titanium (Ti), Vanadium (V), Zinc (Zn) remained under the detection limit.

Leaching of Boron (B), Barium (Ba), Calcium (Ca), Magnesium (Mg), Manganese (Mn), Sulfur (S), Strontium ( $\mathrm{Sr}$ ), Thallium ( $\mathrm{Tl}$ ), increased with decreasing $\mathrm{pH}$, whereas leaching of Aluminum (Al), Iron (Fe), Antimony ( $\mathrm{Sb}$ ), Vanadium (V), decreased with the decrease of $\mathrm{pH}$.

\subsubsection{Leaching Test Results for Control Mix}

The result showed Control Mix with w/cm 0.3 of nominal grain size $4.75 \mathrm{~mm}$ leached approximately $0.05 \mathrm{mg} / \mathrm{L}$ Silver (Ag), $0.08 \mathrm{mg} / \mathrm{L}$ Aluminum (Al), $6.02 \mathrm{mg} / \mathrm{L}$ Boron (B), 0.267 mg/L Barium (Ba), 1581.39 mg/L Calcium (Ca), 0.079 mg/L Chromium (Cr), 1.66 mg/L Magnesium (Mg), $0.053 \mathrm{mg} / \mathrm{L}$ Molybdenum (Mo), $39.97 \mathrm{mg} / \mathrm{L}$ Sulfur (S), $0.055 \mathrm{mg} / \mathrm{L}$ Tin (Sn), $3.75 \mathrm{mg} / \mathrm{L}$ Strontium (Sr), $0.023 \mathrm{mg} / \mathrm{L}$ Thallium (Tl), $0.03 \mathrm{mg} / \mathrm{L}$ Vanadium (V), while extraction fluid's pH was 2.88, whereas leaching of Arsenic (As), Beryllium (Be), Cadmium (Cd), Cobalt $(\mathrm{Co})$, Copper $(\mathrm{Cu})$, Iron $(\mathrm{Fe})$, Manganese $(\mathrm{Mn})$, Nickel $(\mathrm{Ni})$, Lead $(\mathrm{Pb})$, Phosphorus $(\mathrm{P})$, Antimony (Sb), Selenium (Se), Tin (Sn), Strontium (Sr), Titanium (Ti), Thallium (Tl), Zinc (Zn) remain under the detection limit.

Control Mix with w/cm 0.3 of nominal grain size $4.75 \mathrm{~mm}$ leached approximately $1.07 \mathrm{mg} / \mathrm{L}$ Aluminum (Al), $0.054 \mathrm{mg} / \mathrm{L}$ Boron (B), $0.311 \mathrm{mg} / \mathrm{L}$ Barium (Ba), $705.33 \mathrm{mg} / \mathrm{L}$ Calcium (Ca), $0.056 \mathrm{mg} / \mathrm{L}$ Chromium (Cr), $0.02 \mathrm{mg} / \mathrm{L}$ Iron (Fe), $0.106 \mathrm{mg} / \mathrm{L}$ Magnesium $(\mathrm{Mg}), 0.048 \mathrm{mg} / \mathrm{L}$ Lead (Pb), $14.74 \mathrm{mg} / \mathrm{L}$ Sulfur (S), $0.037 \mathrm{mg} / \mathrm{L}$ Antimony (Sb), $0.44 \mathrm{mg} / \mathrm{L}$ Tin (Sn), $2.53 \mathrm{mg} / \mathrm{L}$ Strontium (Sr), while extraction fluid's pH was 4.93, whereas leaching of Silver (Ag), Arsenic (As), Beryllium (Be), Cadmium (Cd), Cobalt (Co), Copper ( $\mathrm{Cu}$ ), Manganese (Mn), Molybdenum (Mo), Nickel (Ni), Phosphorus (P), Selenium (Se), Titanium (Ti), Thallium (Tl), Vanadium (V), Zinc $(\mathrm{Zn})$ remain under the detection limit. 
Leaching of Aluminum (Al), Boron (B), Calcium (Ca), Chromium (Cr), Mercury ( $\mathrm{Hg}$ ), Magnesium (Mg), Molybdenum (Mo), Sulfur (S), Tin (Sn), Strontium (Sr), Thallium (Tl), Vanadium (V), increased with decreasing $\mathrm{pH}$, whereas leaching of Silver (Ag), Barium (Ba), Iron ( $\mathrm{Fe})$, Lead ( $\mathrm{Pb}$ ), Antimony ( $\mathrm{Sb})$, decreased with the decrease of $\mathrm{pH}$.

\subsubsection{Leaching Test Results for High Volume Fly ash and/or Slag Concrete}

Among all the high volume fly ash slag modified concrete mixes, only two of were selected for this test keeping in mind the maximum contamination can be possible by the concrete, which had most amount of fly ash and/or slag. It was important to see the effect of immobilization of fly ash and/or slag separately so concrete mix, where $70 \%$ cement is replaced by slag and fly ash.

\subsubsection{Cement Replaced by 60\% Fly Ash}

The result shows Concrete with $60 \%$ as fly ash replacement leached approximately $0.056 \mathrm{mg} / \mathrm{L}$ Silver (Ag), $0.21 \mathrm{mg} / \mathrm{L}$ Aluminum (Al), $2.232 \mathrm{mg} / \mathrm{L}$ Boron (B), $0.731 \mathrm{mg} / \mathrm{L}$ Barium (Ba), $1979.05 \mathrm{mg} / \mathrm{L}$ Calcium (Ca), $0.031 \mathrm{mg} / \mathrm{L}$ Chromium (Cr), $0.22 \mathrm{mg} / \mathrm{L}$ Iron $(\mathrm{Fe}), 44.77 \mathrm{mg} / \mathrm{L}$ Magnesium (Mg), 0.0.25 mg/L Manganese (Mn), $0.07 \mathrm{mg} / \mathrm{L}$ Molybdenum (Mo), $0.08 \mathrm{mg} / \mathrm{L}$ Nickel (Ni), $66.24 \mathrm{mg} / \mathrm{L}$ Sulfur (S), $0.058 \mathrm{mg} / \mathrm{L}$ Selenium (Se), $5.48 \mathrm{mg} / \mathrm{L}$ Strontium (Sr), $0.018 \mathrm{mg} / \mathrm{L}$ Titanium (Ti), $0.065 \mathrm{mg} / \mathrm{L}$ Thallium (Tl), $0.03 \mathrm{mg} / \mathrm{L}$ Vanadium (V), $0.038 \mathrm{mg} / \mathrm{L}$ Zinc ( $\mathrm{Zn})$ while extraction fluid's pH was 2.88 and average grain size was $4.75 \mathrm{~mm}$, whereas leaching of Arsenic (As), Beryllium (Be), Cadmium (Cd), Cobalt (Co), Copper (Cu), Phosphorus $(\mathrm{P})$, Lead $(\mathrm{Pb})$, Antimony $(\mathrm{Sb})$, Tin $(\mathrm{Sn})$ remain under the detection limit.

Concrete with $60 \%$ as fly ash replacement leached approximately $0.37 \mathrm{mg} / \mathrm{L}$ Aluminum (Al), $0.722 \mathrm{mg} / \mathrm{L}$ Boron (B), $0.330 \mathrm{mg} / \mathrm{L}$ Barium (Ba), $766.47 \mathrm{mg} / \mathrm{L}$ Calcium (Ca), $0.041 \mathrm{mg} / \mathrm{L}$ Chromium (Cr), $0.41 \mathrm{mg} / \mathrm{L}$ Magnesium (Mg), $0.07 \mathrm{mg} / \mathrm{L}$ Molybdenum (Mo), $40.53 \mathrm{mg} / \mathrm{L}$ Sulfur (S), $3.38 \mathrm{mg} / \mathrm{L}$ Strontium (Sr), $0.053 \mathrm{mg} / \mathrm{L}$ Thallium (Tl), $0.04 \mathrm{mg} / \mathrm{L}$ Vanadium (V), while extraction fluid's pH was 4.93 and average grain size was $4.75 \mathrm{~mm}$, whereas leaching of Arsenic (As), Beryllium (Be), Cadmium (Cd), Cobalt (Co), Copper ( $\mathrm{Cu})$, Phosphorus (P), Lead ( $\mathrm{Pb}$ ), 
Antimony (Sb), Tin ( $\mathrm{Sn})$, Silver (Ag), Iron (Fe), Manganese (Mn), Nickel (Ni), Selenium (Se), Titanium (Ti), Zinc (Zn) remain under the detection limit.

The result shows Concrete with $60 \%$ as fly ash replacement leached approximately $0.047 \mathrm{mg} / \mathrm{L}$ Silver (Ag), $3.809 \mathrm{mg} / \mathrm{L}$ Boron (B), $0.479 \mathrm{mg} / \mathrm{L}$ Barium (Ba), $2101.52 \mathrm{mg} / \mathrm{L}$ Calcium (Ca), $0.021 \mathrm{mg} / \mathrm{L}$ Cobalt (Co), $0.02 \mathrm{mg} / \mathrm{L}$ Copper $(\mathrm{Cu}), 0.64 \mathrm{mg} / \mathrm{L}$ Iron $(\mathrm{Fe}), 77.18 \mathrm{mg} / \mathrm{L}$ Magnesium (Mg), $0.64 \mathrm{mg} / \mathrm{L}$ Manganese (Mn), $0.13 \mathrm{mg} / \mathrm{L}$ Molybdenum (Mo), $0.17 \mathrm{mg} / \mathrm{L}$ Nickel (Ni), 0.051 $\mathrm{mg} / \mathrm{L} \mathrm{Lead} \mathrm{(Pb),} 134.62 \mathrm{mg} / \mathrm{L}$ Sulfur (S), $4.75 \mathrm{mg} / \mathrm{L}$ Strontium (Sr), $0.09 \mathrm{mg} / \mathrm{L}$ Thallium (Tl), $0.04 \mathrm{mg} / \mathrm{L}$ Vanadium $(\mathrm{V}), 0.21 \mathrm{mg} / \mathrm{L}$ Zinc (Zn) while extraction fluid's pH was 2.88 and average grain size was 300 micron, whereas leaching of Aluminum (Al), Arsenic (As), Beryllium (Be), Cadmium (Cd), Chromium (Cr), Phosphorus (P), Antimony (Sb), Selenium (Se), Tin (Sn), Titanium (Ti) remain under the detection limit.

Concrete with $60 \%$ as fly ash replacement leached approximately $1.753 \mathrm{mg} / \mathrm{L}$ Boron (B), 0.204 mg/L Barium (Ba), $744.58 \mathrm{mg} / \mathrm{L}$ Calcium (Ca), $0.055 \mathrm{mg} / \mathrm{L}$ Chromium (Cr), $16.56 \mathrm{mg} / \mathrm{L}$ Magnesium (Mg), $0.13 \mathrm{mg} / \mathrm{L}$ Molybdenum (Mo), $114.61 \mathrm{mg} / \mathrm{L}$ Sulfur (S), $0.073 \mathrm{mg} / \mathrm{L}$ Tin (Sn), $2.72 \mathrm{mg} / \mathrm{L}$ Strontium (Sr), $0.09 \mathrm{mg} / \mathrm{L}$ Thallium (Tl), $0.07 \mathrm{mg} / \mathrm{L}$ Vanadium (V), while extraction fluid's $\mathrm{pH}$ was 4.93 and average grain size was 300 micron, whereas leaching of Silver (Ag), Aluminum (Al), Arsenic (As), Beryllium (Be), Cadmium (Cd), Cobalt (Co), Copper (Cu), Iron (Fe), Manganese (Mn), Nickel (Ni), Phosphorus (P), Lead (Pb), Antimony (Sb), Selenium (Se), Titanium (Ti), Zinc (Zn) remain under the detection limit.

Leaching of Silver (Ag), Boron (B), Barium (Ba), Calcium (Ca), Cobalt (Co), Copper (Cu), Iron $(\mathrm{Fe})$, Magnesium (Mg), Manganese (Mn), Molybdenum (Mo), Nickel (Ni), Sulfur (S), Strontium (Sr), Zinc ( $\mathrm{Zn})$ increased with decreasing $\mathrm{pH}$, whereas leaching of Aluminum (Al), Chromium (Cr), Tin (Sn), Vanadium (V) decreased with the decrease of $\mathrm{pH}$.

Leaching of Boron (B), Calcium (Ca), Cobalt (Co), Copper (Cu), Iron (Fe), Magnesium ( $\mathrm{Mg}$ ), Manganese (Mn), Molybdenum (Mo), Sulfur (S), Tin (Sn), Thallium (Tl), Vanadium (V), increased with decreasing size, whereas leaching of Silver (Ag), Aluminum (Al), Barium (Ba), Chromium (Cr), Nickel (Ni), Phosphorus (P), Lead (Pb), Sulfur (S), Antimony (Sb), Selenium (Se), Strontium ( $\mathrm{Sr}$ ), Titanium (Ti), Zinc ( $\mathrm{Zn}$ ) decreased with the decrease of size. 


\subsubsection{Cement Replace by $60 \%$ Slag}

The result shows Concrete with $60 \%$ as slag replacement leached approximately $1.32 \mathrm{mg} / \mathrm{L}$ Silver (Ag), 0.575 mg/L Boron (B), 1.166 mg/L Barium (Ba), 2192.03 mg/L Calcium (Ca), 0.09 mg/L Iron (Fe), 109.54 mg/L Magnesium (Mg), 1.45 mg/L Manganese (Mn), 0.082 mg/L Nickel (Ni), $125.99 \mathrm{mg} / \mathrm{L}$ Sulfur (S), $5.53 \mathrm{mg} / \mathrm{L}$ Strontium (Sr), $0.045 \mathrm{mg} / \mathrm{L}$ Thallium (Tl), 0.026 mg/L Vanadium (V), while extraction fluid's $\mathrm{pH}$ was 2.88 and average grain size was $4.75 \mathrm{~mm}$, whereas leaching of Aluminum (Al), Arsenic (As), Beryllium (Be), Cadmium (Cd), Cobalt (Co), Chromium (Cr), Copper (Cu), Molybdenum (Mo), Phosphorus (P), Lead (Pb), Antimony (Sb), Selenium (Se), Tin (Sn), Titanium (Ti), Zinc (Zn) remain under the detection limit.

Concrete with $60 \%$ as slag replacement leached approximately $0.2 \mathrm{mg} / \mathrm{L}$ Silver (Ag), Aluminum (Al), Arsenic (As), $0.242 \mathrm{mg} / \mathrm{L}$ Boron (B), $0.432 \mathrm{mg} / \mathrm{L}$ Barium (Ba), $769.35 \mathrm{mg} / \mathrm{L}$ Calcium (Ca), $0.013 \mathrm{mg} / \mathrm{L}$ Chromium (Cr), $0.12 \mathrm{mg} / \mathrm{L}$ Iron (Fe), $8.53 \mathrm{mg} / \mathrm{L}$ Magnesium (Mg), $0.38 \mathrm{mg} / \mathrm{L} \mathrm{Lead}$ $(\mathrm{Pb}), 59.87 \mathrm{mg} / \mathrm{L}$ Sulfur (S), $2.99 \mathrm{mg} / \mathrm{L}$ Strontium (Sr), $0.078 \mathrm{mg} / \mathrm{L}$ Thallium (Tl), 0.028 mg/L Vanadium (V) while extraction fluid's $\mathrm{pH}$ was 4.93 and average grain size was $4.75 \mathrm{~mm}$, whereas leaching of Aluminum (Al), Arsenic (As), Beryllium (Be), Cadmium (Cd), Cobalt (Co), Copper (Cu), Molybdenum (Mo), Manganese (Mn), Nickel (Ni), Phosphorus (P), Antimony $(\mathrm{Sb})$, Selenium $(\mathrm{Se})$, Tin $(\mathrm{Sn})$, Titanium $(\mathrm{Ti})$, Zinc $(\mathrm{Zn})$ remain under the detection limit.

The result shows Concrete with $60 \%$ as slag replacement leached approximately $0.39 \mathrm{mg} / \mathrm{L}$ Silver (Ag), $0.359 \mathrm{mg} / \mathrm{L}$ Boron (B), $0.714 \mathrm{mg} / \mathrm{L}$ Barium (Ba), $1828.27 \mathrm{mg} / \mathrm{L}$ Calcium (Ca), $0.015 \mathrm{mg} / \mathrm{L}$ Chromium (Cr), $0.03 \mathrm{mg} / \mathrm{L}$ Iron (Fe), $73.06 \mathrm{mg} / \mathrm{L}$ Magnesium $(\mathrm{Mg}), 0.09 \mathrm{mg} / \mathrm{L}$ Manganese (Mn), $0.019788 \mathrm{mg} / \mathrm{L}$ Nickel (Ni), $275.82 \mathrm{mg} / \mathrm{L}$ Sulfur (S), $5.15 \mathrm{mg} / \mathrm{L}$ Strontium (Sr), $0.067 \mathrm{mg} / \mathrm{L}$ Thallium (Tl), $0.024 \mathrm{mg} / \mathrm{L}$ Vanadium (V), while extraction fluid's pH was 2.88 and average grain size was 300 micron, whereas leaching of Aluminum (Al), Arsenic (As), Beryllium (Be), Cadmium (Cd), Cobalt (Co), Copper (Cu), Molybdenum (Mo), Phosphorus (P), Lead $(\mathrm{Pb})$, Antimony (Sb), Selenium (Se), Tin (Sn), Titanium (Ti), Zinc (Zn) remain under the detection limit.

Concrete with $60 \%$ as slag replacement leached approximately $0.05 \mathrm{mg} / \mathrm{L}$ Silver (Ag), 0.231 mg/L Boron (B), 0.314 mg/L Barium (Ba), $715.64 \mathrm{mg} / \mathrm{L}$ Calcium (Ca), 0.044 mg/L Chromium (Cr), $2.59 \mathrm{mg} / \mathrm{L}$ Magnesium (Mg), $0.051 \mathrm{mg} / \mathrm{L}$ Selenium (Se), $294.26 \mathrm{mg} / \mathrm{L}$ Sulfur (S), 2.67 $\mathrm{mg} / \mathrm{L}$ Strontium (Sr), $0.035 \mathrm{mg} / \mathrm{L}$ Thallium (Tl), $0.033 \mathrm{mg} / \mathrm{L}$ Vanadium (V) while extraction 
fluid's pH was 4.93 and average grain size was 300 micron, whereas leaching of Aluminum (Al), Arsenic (As), Beryllium (Be), Cadmium (Cd), Cobalt (Co), Copper (Cu), Molybdenum (Mo), Iron (Fe), Manganese (Mn), Nickel (Ni), Phosphorus (P), Lead (Pb), Antimony (Sb), Tin (Sn), Titanium (Ti), Zinc $(\mathrm{Zn})$ remain under the detection limit.

Leaching of Silver (Ag), Boron (B), Barium (Ba), Beryllium (Be), Calcium (Ca), Iron (Fe), Magnesium (Mg), Manganese (Mn), Nickel (Ni), Sulfur (S), Strontium (Sr), Thallium (Tl), increased with decreasing $\mathrm{pH}$, whereas leaching of Chromium $(\mathrm{Cr})$, Lead $(\mathrm{Pb})$, Selenium $(\mathrm{Se})$, Vanadium (V) decreased with the decrease of $\mathrm{pH}$.

Leaching of Chromium (Cr), Selenium (Se) increased with decreasing size, whereas leaching of Silver (Ag), Boron (B), Barium (Ba), Beryllium (Be), Calcium (Ca), Iron (Fe), Mercury (Hg), Magnesium (Mg), Manganese (Mn), Nickel (Ni), Lead (Pb), Strontium (Sr), Vanadium (V) decreased with the decrease of size.

Leaching Sulfur (S) decreased when the size was bigger as the $\mathrm{pH}$ increased, but leaching of Sulfur (S) increased as the $\mathrm{pH}$ increased, when the size was smaller. Leaching Thallium (Tl) increased when the size was bigger as the $\mathrm{pH}$ increased, but leaching of Thallium (Tl) decreased as the $\mathrm{pH}$ increased, when the size was smaller.

\subsubsection{Leaching Test Results for Geopolymer}

Among the entire geopolymer modified concrete mixes, only two of were selected for this test keeping in mind the maximum polymerization can be possible by the concrete, which had highest curing temperature. It was important to see the effect of immobilization of fly ash and/or slag separately so concrete mix prepared with combined mix of slag and fly was not taken into consideration.

\subsubsection{Geopolymer Binder with 100\% Fly Ash}

The result shows fly ash based geopolymer concrete leached approximately $0.589 \mathrm{mg} / \mathrm{L}$ Arsenic (As), $9.160 \mathrm{mg} / \mathrm{L}$ Boron (B), $0.146 \mathrm{mg} / \mathrm{L}$ Barium (Ba), $831.83 \mathrm{mg} / \mathrm{L}$ Calcium (Ca), $0.077 \mathrm{mg} / \mathrm{L}$ Iron (Fe), $25.58 \mathrm{mg} / \mathrm{L}$ Magnesium (Mg), $0.077 \mathrm{mg} / \mathrm{L}$ Manganese (Mn), $0.29 \mathrm{mg} / \mathrm{L}$ Molybdenum (Mo), $0.08 \mathrm{mg} / \mathrm{L}$ Nickel (Ni), $1.47 \mathrm{mg} / \mathrm{L}$ Phosphorus (P), $170.71 \mathrm{mg} / \mathrm{L} \quad$ Sulfur (S), 0.13 mg/L Selenium (Se), $3.86 \mathrm{mg} / \mathrm{L}$ Strontium (Sr), $0.052 \mathrm{mg} / \mathrm{L}$ Thallium (T1), $1.03 \mathrm{mg} / \mathrm{L}$ Vanadium 
(V), while extraction fluid's $\mathrm{pH}$ was 2.88 and average grain size was $4.75 \mathrm{~mm}$, whereas leaching of Silver (Ag), Aluminum (Al), Beryllium (Be), Cadmium (Cd), Cobalt (Co), Chromium (Cr), Copper $(\mathrm{Cu})$, Lead $(\mathrm{Pb})$, Antimony $(\mathrm{Sb}), \quad$ Tin $(\mathrm{Sn})$, Titanium $(\mathrm{Ti})$, Zinc $(\mathrm{Zn})$ remain under the detection limit.

Fly ash based geopolymer concrete leached approximately $0.050 \mathrm{mg} / \mathrm{L}$ Aluminum (Al), 1.404 $\mathrm{mg} / \mathrm{L}$ Arsenic (As), $6.253 \mathrm{mg} / \mathrm{L}$ Boron (B), $0.032 \mathrm{mg} / \mathrm{L}$ Barium (Ba), $69 \mathrm{mg} / \mathrm{L}$ Calcium (Ca), $4.24 \mathrm{mg} / \mathrm{L}$ Magnesium (Mg), $0.28 \mathrm{mg} / \mathrm{L}$ Molybdenum (Mo), $0.04 \mathrm{mg} / \mathrm{L}$ Nickel (Ni), $1.24 \mathrm{mg} / \mathrm{L}$ Phosphorus (P), $0.051 \mathrm{mg} / \mathrm{L}$ Lead $(\mathrm{Pb}), 162.38 \mathrm{mg} / \mathrm{L}$ Sulfur $(\mathrm{S}), 0.13 \mathrm{mg} / \mathrm{L}$ Selenium $(\mathrm{Se})$, $0.54 \mathrm{mg} / \mathrm{L}$ Strontium (Sr), $0.051 \mathrm{mg} / \mathrm{L}$ Thallium (Tl), $2.15 \mathrm{mg} / \mathrm{L}$ Vanadium (V), while extraction fluid's pH was 4.93 and average grain size was $4.75 \mathrm{~mm}$, whereas leaching of Silver (Ag), Beryllium (Be), Zinc (Zn) Manganese (Mn), Antimony (Sb), Tin (Sn), Titanium (Ti), Cadmium (Cd), Cobalt $(\mathrm{Co})$, Chromium $(\mathrm{Cr})$, Copper $(\mathrm{Cu})$, Iron $(\mathrm{Fe})$ remain under the detection limit.

The result shows fly ash based geopolymer concrete leached approximately $0.036 \mathrm{mg} / \mathrm{L}$ Aluminum (Al), 0.656b mg/L Arsenic (As), $14.263 \mathrm{mg} / \mathrm{L}$ Boron (B), $0.082 \mathrm{mg} / \mathrm{L}$ Barium (Ba), $91 \mathrm{mg} / \mathrm{L}$ Calcium (Ca), $\quad 0.017 \mathrm{mg} / \mathrm{L}$ Chromium (Cr), $0.016 \mathrm{mg} / \mathrm{L}$ Iron $(\mathrm{Fe}), 28.34 \mathrm{mg} / \mathrm{L}$ Magnesium (Mg), 0.46 mg/L Molybdenum (Mo), 0.06 mg/L Nickel (Ni), 0.31 mg/L Phosphorus (P), $246.29 \mathrm{mg} / \mathrm{L}$ Sulfur (S), $0.18 \mathrm{mg} / \mathrm{L}$ Selenium (Se), $2.60 \mathrm{mg} / \mathrm{L}$ Strontium (Sr), $1.20 \mathrm{mg} / \mathrm{L}$ Vanadium (V), while extraction fluid's pH was 2.88 and average grain size was 300 micron, whereas leaching of Silver (Ag), Beryllium (Be), Cadmium $(\mathrm{Cd})$, Cobalt $(\mathrm{Co})$, Copper $(\mathrm{Cu})$, Manganese (Mn), Lead ( $\mathrm{Pb})$, Antimony (Sb), Tin (Sn), Titanium (Ti), Thallium (Tl), Zinc (Zn) remain under the detection limit.

Fly ash based geopolymer concrete leached approximately $0.094 \mathrm{mg} / \mathrm{L}$ Aluminum (Al), 2.734 $\mathrm{mg} / \mathrm{L}$ Arsenic (As), $11.55 \mathrm{mg} / \mathrm{L}$ Boron (B), $373.1 \mathrm{mg} / \mathrm{L}$ Calcium (Ca), Cadmium (Cd), Cobalt (Co), $0.051 \mathrm{mg} / \mathrm{L}$ Chromium (Cr), $0.61 \mathrm{mg} / \mathrm{L}$ Magnesium (Mg), $0.50 \mathrm{mg} / \mathrm{L}$ Molybdenum (Mo), $0.08 \mathrm{mg} / \mathrm{L}$ Nickel (Ni), $5.39 \mathrm{mg} / \mathrm{L}$ Phosphorus (P), $0.034 \mathrm{mg} / \mathrm{L}$ Lead $(\mathrm{Pb}), 281.03 \mathrm{mg} / \mathrm{L} \mathrm{Sulfur}$ (S), $0.38 \mathrm{mg} / \mathrm{L}$ Selenium (Se), $0.07 \mathrm{mg} / \mathrm{L}$ Strontium (Sr), $4.93 \mathrm{mg} / \mathrm{L}$ Vanadium (V), while extraction fluid's pH was 4.93 and average grain size was 300 micron, whereas leaching of Silver (Ag), Barium (Ba), Beryllium (Be), Copper (Cu), Iron (Fe), Manganese (Mn), Antimony $(\mathrm{Sb})$, Tin $(\mathrm{Sn})$, Titanium $(\mathrm{Ti})$, Thallium $(\mathrm{Tl})$, Zinc $(\mathrm{Zn})$ remain under the detection limit. 
Leaching of Boron (B), Barium (Ba), Iron (Fe), Magnesium (Mg), Manganese (Mn), Selenium (Se), Strontium (Sr), Thallium (Tl), increased with decreasing $\mathrm{pH}$, whereas leaching of Aluminum (Al), Arsenic (As), Calcium (Ca), Molybdenum (Mo), Nickel (Ni), Phosphorus (P), Lead $(\mathrm{Pb})$, Antimony (Sb), Vanadium (V), decreased with the decrease of $\mathrm{pH}$.

Leaching of Aluminum (Al), Arsenic (As), Boron (B), Chromium (Cr), Magnesium (Mg), Selenium (Se), Vanadium (V) increased with decreasing size, whereas leaching of Barium (Ba), Iron (Fe), Manganese ( $\mathrm{Mn})$, Lead $(\mathrm{Pb})$, Strontium (Sr), and Thallium (Tl) decreased with the decrease of size.

Inference could not be drawn from leaching study results of Calcium (Ca), Molybdenum (Mo), Nickel (Ni), Phosphorus (P), Sulfur (S) because of their erratic behavior.

\subsubsection{Geopolymer Binder with 100\% Slag}

The result shows slag based geopolymer concrete leached approximately $0.051 \mathrm{mg} / \mathrm{L}$ Silver (Ag), $0.385 \mathrm{mg} / \mathrm{L}$ Boron (B), $0.283 \mathrm{mg} / \mathrm{L}$ Barium (Ba), 518.1 mg/L Calcium (Ca), $5.21 \mathrm{mg} / \mathrm{L}$ Magnesium (Mg), 0.06 mg/L Molybdenum (Mo), 0.05 mg/L Nickel (Ni), 807.80 mg/L Sulfur (S), $0.11 \mathrm{mg} / \mathrm{L}$ Selenium (Se), $1.58 \mathrm{mg} / \mathrm{L}$ Strontium (Sr), $0.067 \mathrm{mg} / \mathrm{L}$ Thallium (T1), 0.05 mg/L Vanadium (V), while extraction fluid's $\mathrm{pH}$ was 2.88 and average grain size was $4.75 \mathrm{~mm}$, whereas leaching of Aluminum (Al), Arsenic (As), Beryllium (Be), Cadmium (Cd), Cobalt (Co), Chromium (Cr), Copper (Cu), Iron (Fe), Manganese (Mn), Phosphorus (P), Lead (Pb), Antimony $(\mathrm{Sb})$, Tin $(\mathrm{Sn})$, Titanium (Ti), Zinc (Zn) remain under the detection limit.

Slag based geopolymer concrete leached approximately $0.297 \mathrm{mg} / \mathrm{L}$ Silver $(\mathrm{Ag}), 0.081 \mathrm{mg} / \mathrm{L}$ Aluminum (Al), 0.057mg/L Arsenic (As), $0.384 \mathrm{mg} / \mathrm{L}$ Boron (B), $0.031 \mathrm{mg} / \mathrm{L}$ Barium (Ba), $29371 \mathrm{mg} / \mathrm{L}$ Calcium (Ca), 0.16 mg/L Magnesium (Mg), Molybdenum (Mo), 0.18 mg/L Nickel (Ni), $0.052 \mathrm{mg} / \mathrm{L} \mathrm{Lead} \mathrm{(Pb),} 745.06 \mathrm{mg} / \mathrm{L}$ Sulfur (S), $0.2 \mathrm{mg} / \mathrm{L}$ Strontium (Sr), $0.062 \mathrm{mg} / \mathrm{L}$ Thallium (Tl), $0.11 \mathrm{mg} / \mathrm{L}$ Vanadium (V), while extraction fluid's $\mathrm{pH}$ was 4.93 and average grain size was $4.75 \mathrm{~mm}$, whereas leaching of Beryllium (Be), Cadmium (Cd), Cobalt (Co), Chromium $(\mathrm{Cr})$, Copper $(\mathrm{Cu})$, Iron (Fe), Manganese (Mn), Phosphorus (P), Antimony (Sb), Selenium (Se), Tin (Sn), Titanium (Ti), Zinc (Zn) remain under the detection limit.

The result shows slag based geopolymer concrete leached approximately $0.14 \mathrm{mg} / \mathrm{L} \mathrm{Silver}(\mathrm{Ag})$, Aluminum (Al), Arsenic (As), $0.342 \mathrm{mg} / \mathrm{L}$ Boron (B), 0.161 mg/L Barium (Ba), $257.15 \mathrm{mg} / \mathrm{L}$ Calcium (Ca), 1.24 mg/L Magnesium (Mg), 0.04 mg/L Nickel (Ni), 0.06 mg/L Lead (Pb), 963.63 
$\mathrm{mg} / \mathrm{L}$ Sulfur (S), $0.049 \mathrm{mg} / \mathrm{L}$ Selenium (Se), $1.12 \mathrm{mg} / \mathrm{L}$ Strontium (Sr), $0.085 \mathrm{mg} / \mathrm{L}$ Thallium (Tl), $0.06 \mathrm{mg} / \mathrm{L}$ Vanadium (V), while extraction fluid's $\mathrm{pH}$ was 2.88 and average grain size was 300 micron, whereas leaching of Beryllium (Be), Cadmium (Cd), Cobalt (Co), Chromium (Cr), Copper ( $\mathrm{Cu}$ ), Iron ( $\mathrm{Fe})$, Manganese (Mn), Molybdenum (Mo), Phosphorus (P), Antimony ( $\mathrm{Sb}$ ), Tin (Sn), Titanium (Ti), Zinc (Zn) remain under the detection limit.

Slag based geopolymer concrete leached approximately $0.076 \mathrm{mg} / \mathrm{L}$ Arsenic (As), $0.749 \mathrm{mg} / \mathrm{L}$ Boron (B), $0.017 \mathrm{mg} / \mathrm{L}$ Barium (Ba), $5.69 \mathrm{mg} / \mathrm{L}$ Calcium (Ca), $0.05 \mathrm{mg} / \mathrm{L}$ Molybdenum (Mo), $0.20 \mathrm{mg} / \mathrm{L}$ Nickel (Ni), $0.040 \mathrm{mg} / \mathrm{L}$ Lead $(\mathrm{Pb}), 881.01 \mathrm{mg} / \mathrm{L}$ Sulfur (S), $0.05 \mathrm{mg} / \mathrm{L}$ Strontium $(\mathrm{Sr}), 0.34 \mathrm{mg} / \mathrm{L}$ Vanadium $(\mathrm{V})$ while extraction fluid's $\mathrm{pH}$ was 4.93 and average grain size was 300 micron, whereas leaching of Silver (Ag), Aluminum (Al), Beryllium (Be), Cadmium (Cd), Cobalt $(\mathrm{Co})$, Chromium $(\mathrm{Cr})$, Copper $(\mathrm{Cu})$, Iron $(\mathrm{Fe})$, Magnesium $(\mathrm{Mg})$, Manganese $(\mathrm{Mn})$, Phosphorus (P), Antimony (Sb), Selenium (Se), Tin (Sn), Titanium (Ti), Thallium (Tl), Zinc $(\mathrm{Zn})$ remain under the detection limit.

Leaching of Silver (Ag), Barium (Ba), Calcium (Ca), Magnesium (Mg), Lead (Pb), Sulfur (S), Selenium (Se), Strontium (Sr), Thallium (Tl) increased with decreasing $\mathrm{pH}$, whereas leaching of Aluminum (Al), Arsenic (As), Boron (B), Molybdenum (Mo), Nickel (Ni), Vanadium (V) decreased with the decrease of $\mathrm{pH}$.

Leaching of Silver (Ag), Arsenic (As), Boron (B), Nickel (Ni), Lead (Pb), Sulfur (S), Selenium (Se), Thallium (Tl), Vanadium (V), increased with decreasing size, whereas leaching of Aluminum (Al), Barium (Ba), Calcium (Ca), Magnesium (Mg), Molybdenum (Mo), and Strontium (Sr) decreased with the decrease of size.

\subsection{Comparison}

The Tools for Reduction and Assessment of other Chemical Impacts (TRACI) by EPA was followed for environmental impact analysis. The result showed in Table 6.1, apart from limestone fly ash, slag, sand shows traces of Chromium in it, which increases with the lesser $\mathrm{pH}$ value of extraction fluid. The leached sample from fly ash shows presence of Chromium which is little more than the limit for drinking water set by EPA. The leached samples from slag shows much higher presence of chromium ions than the drinking water limits though it's sufficiently lower 
than the limit for hazardous waste set by EPA. Sand has more chromium ions present than even limit set by EPA for hazardous waste.

Presence of Cadmium is in fly ash as well as in limestone is really low, but presence of cadmium in slag is higher than that of hazardous wastes prescribed by EPA, which increases with the decrease in $\mathrm{pH}$ value of extraction fluid. Presence of Cadmium is really high in sand. But with higher $\mathrm{pH}$ value of extraction fluid it falls below the limit for hazardous waste, which means in less acidic condition the sand will be less intimidating.

Presence of Arsenic also really high in slag and sand and also those values are much higher than the limit for hazardous waste. With increase in $\mathrm{pH}$ of extraction fluid the presence of Arsenic in leached sample from the slag falls below the hazardous limit, but the presence of Arsenic in leached sample from sand remain significantly higher than that of hazardous limit, though it decreases within increase in $\mathrm{pH}$ value of extraction fluid.

Presence of Lead in leached samples from fly ash is trace in amount though little higher than that of drinking water limit but it falls with the increase in $\mathrm{pH}$ of extraction fluid. The presence of Lead in slag and sand decreases with increase in $\mathrm{pH}$ of extraction fluid, it is significantly higher than that of hazardous limit.

Limit of presence of Nickel in drinking water is not provided by EPA, but it is prescribed by California Department of Health Hazards. Presence of nickel in leached water sample from sand and slag is really high, which decreases with increase in $\mathrm{pH}$ of extraction fluid. For fly ash it's little higher than that of drinking water limit.

Mercury in all the samples is found in trace amount so no further testing for the presence of mercury in concrete sample is done. 
Table 6.1 Results for Identified Hazardous Metals in Constituent

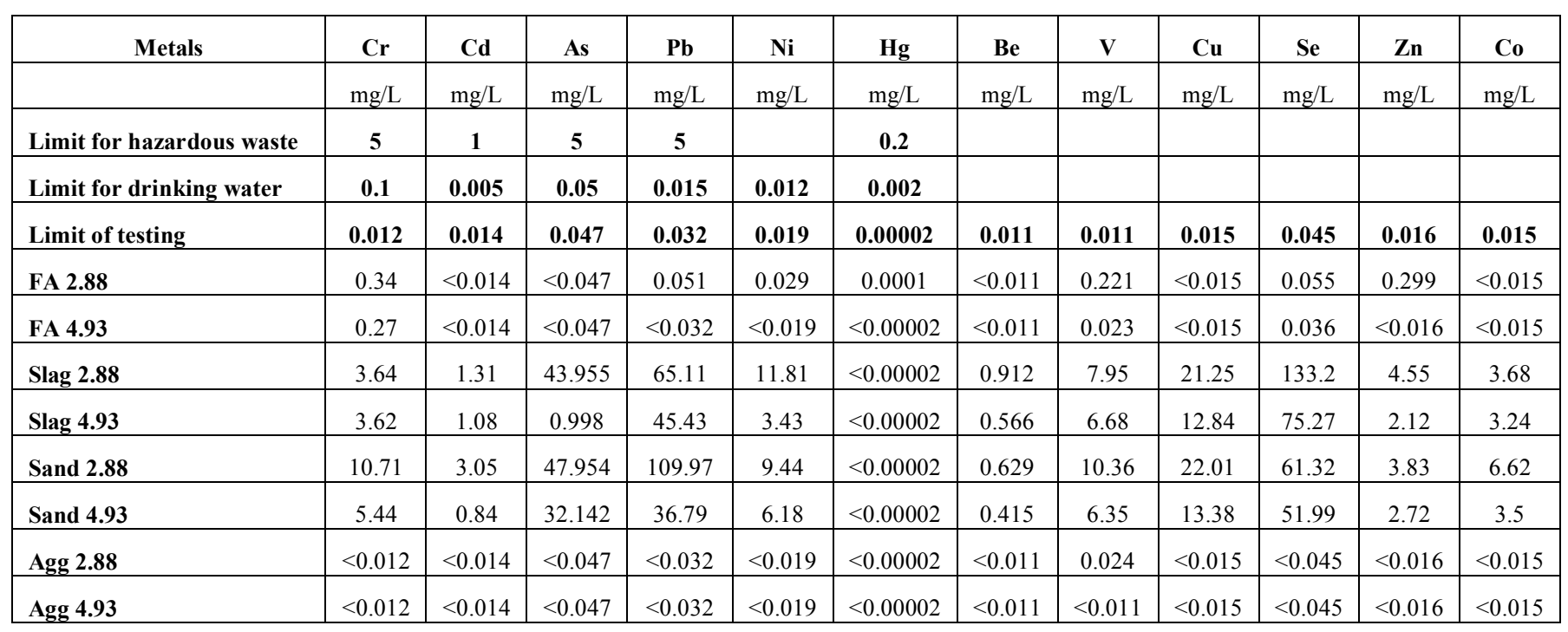

There is no direct method available to measure the total amount of containment. So two indirect method has been used to measure the containment. As fly ash and/or slag particles are less than 300 micron in size according to particle size. So less than 300 micron samples are collected from 28 days crushed samples and compared with the fly ash and/or slag respectively. Another indirect method used here is fly ash based or slag concrete samples are compared with control mix to show that not much or next to nothing leaching of the hazardous ion is observed.

The figure 6.1 shows how greatly the chromium ion is arrested in the concrete by means of high volume fly ash concrete, though little bit of inconsistency is showed by the presence of Arsenic but those are mainly because of other constituent materials like sand which contains high amount of Arsenic. 
pH: 2.88, Size: 300 micron

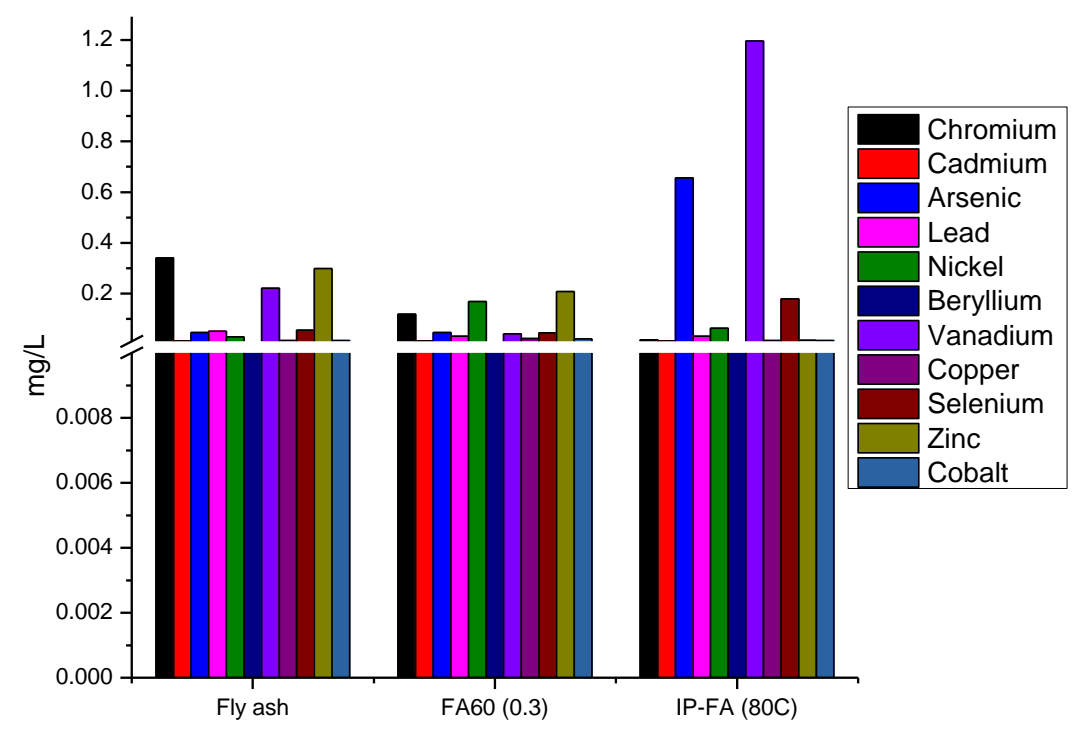

Figure 6-2 Comparison of Fly Ash and Concrete Containing 60\% and 100\% Fly Ash, pH 2.88

The figure 6.2 shows apart from Arsenic all the element shows great consistency. Again presence of less chromium proves the worth of these concrete.

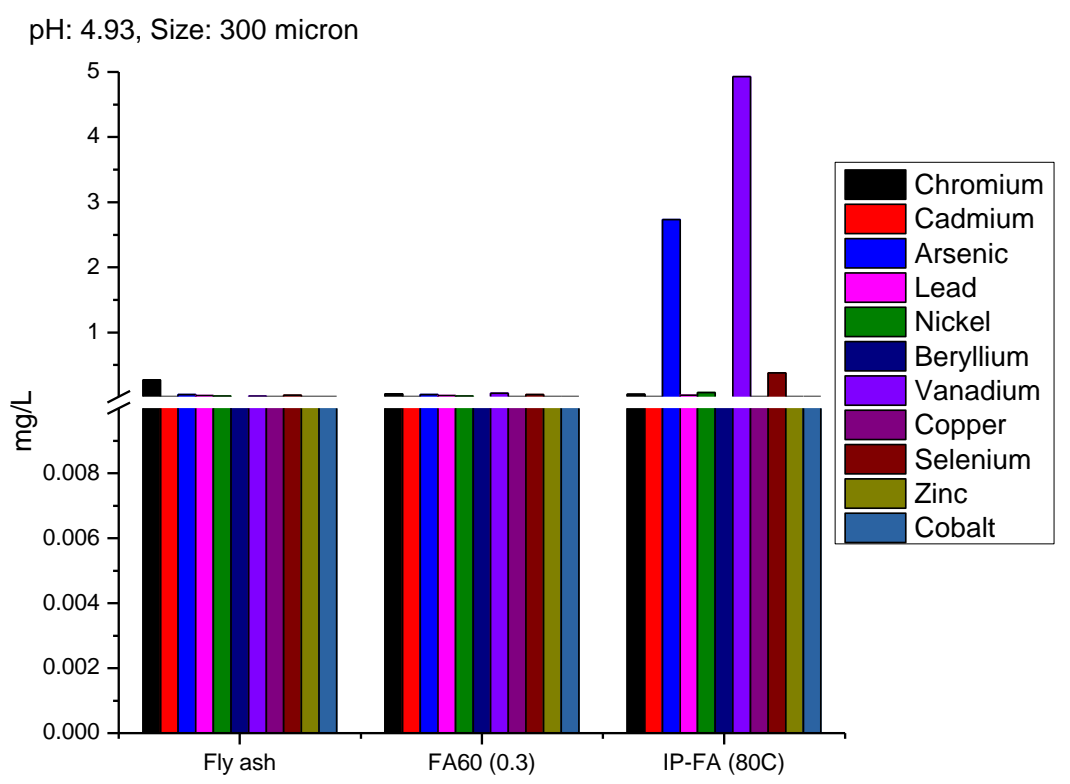

Figure 6-3 Comparison of Fly Ash and Concrete Containing 60\% and 100\% Fly Ash, pH 4.93 Less presence of all the element in slag modified concrete than just as material slag indirectly proves the containment of hazardous elements by means of producing concrete. 
$\mathrm{pH}:$ 2.88, Size: 300 micron

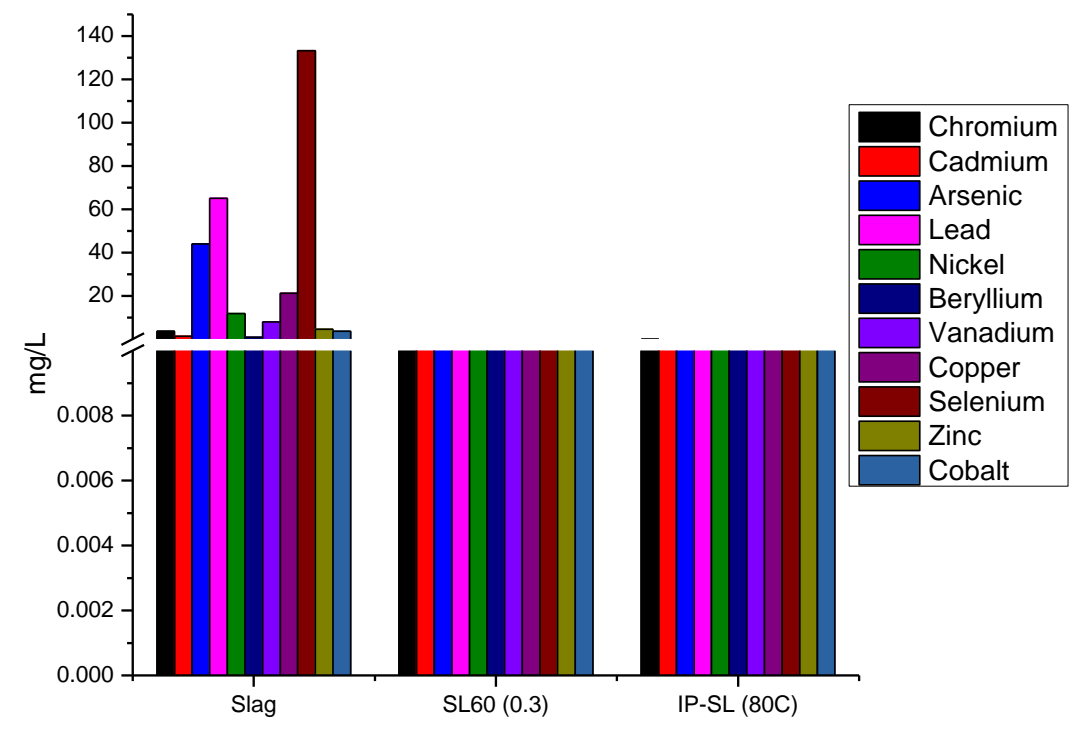

Figure 6-4, Comparison of Slag and Concrete Containing 60\% and 100\% Slag, pH 2.88

Just like the previous graph lesser presence of all the element in slag modified concrete than just as material slag indirectly proves the containment of hazardous elements by means of producing concrete.

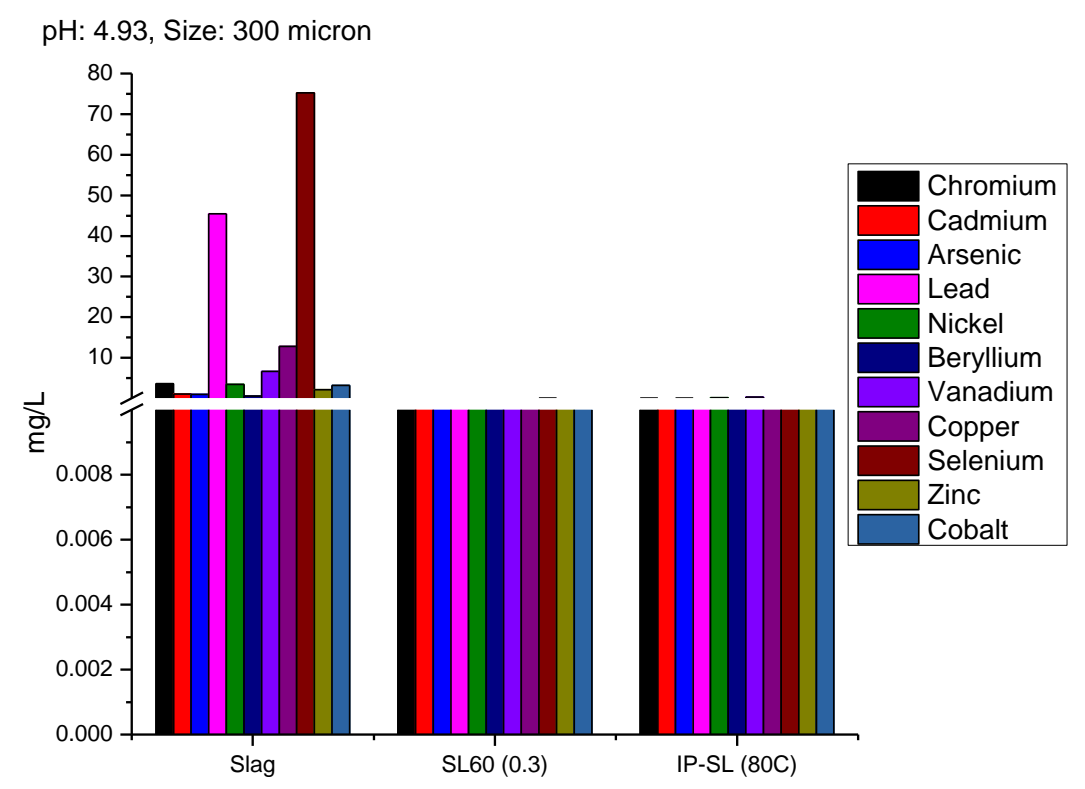

Figure 6-5 Comparison of Slag and Concrete Containing 60\% and 100\% Slag, pH 4.93 
The normal concrete leaches almost same amount of elements as compare to fly ash modified concrete, which indirectly satisfies our cause, though high leaching of Arsenic from the geopolymer does not satisfy our expectations.

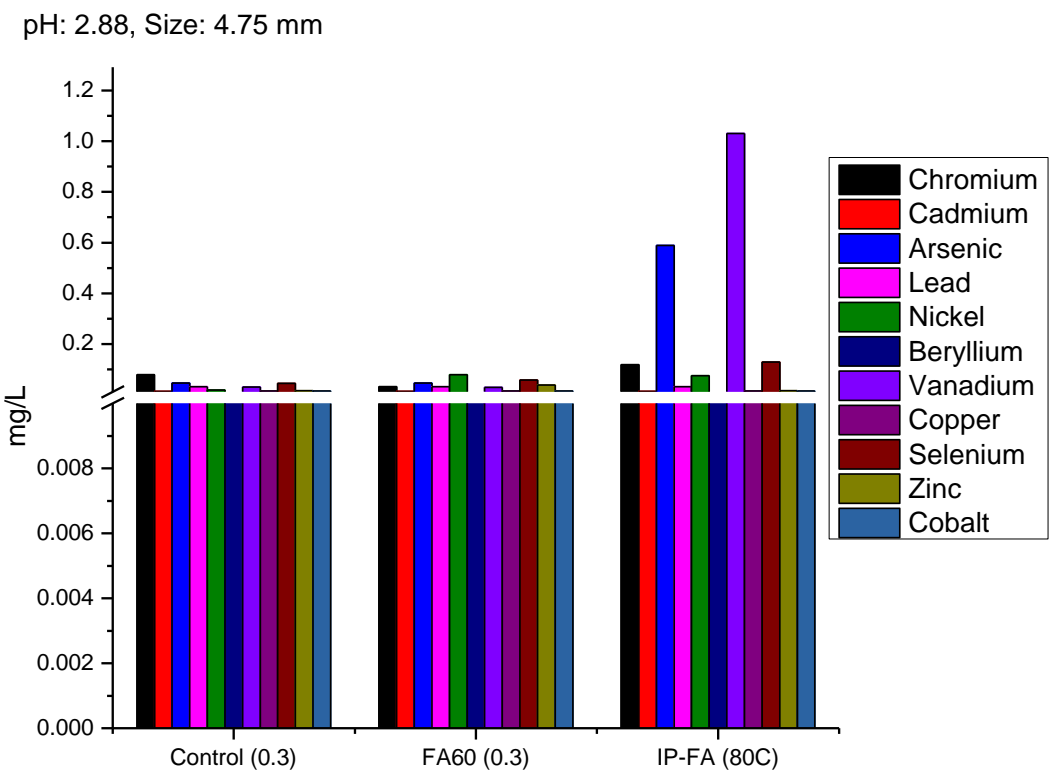

Figure 6-6 Comparison of Control Mix and Concrete Containing 60\% and 100\% Fly Ash, pH 2.88

The normal concrete leaches almost same amount of elements as compare to fly ash modified concrete, though high leaching of Arsenic from the geopolymer does not satisfy our expectations even at higher $\mathrm{pH}$ of extraction fluid. 
pH: 4.93, Size: $4.75 \mathrm{~mm}$

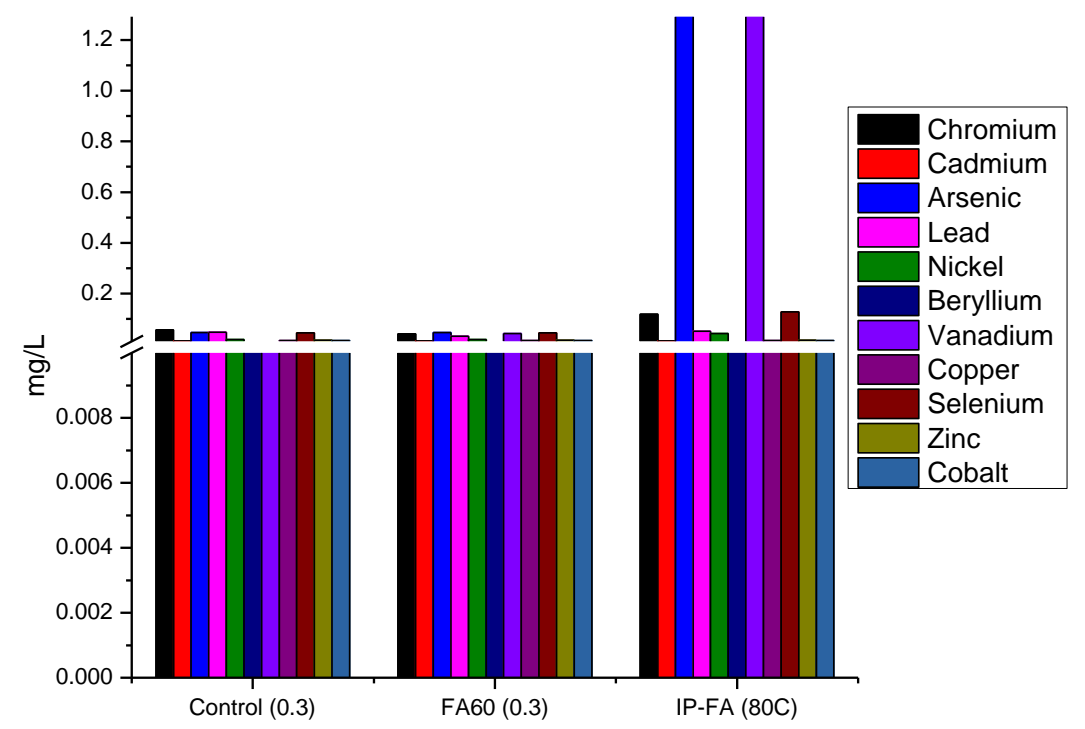

Figure 6-7 Comparison of Control Mix and Concrete Containing 60\% and 100\% Fly Ash, $\mathrm{pH}$ 4.93

The normal concrete leaches almost same amount of elements as compare to slag modified concrete, which indirectly satisfies our cause. Even arsenic bonds well with concrete.

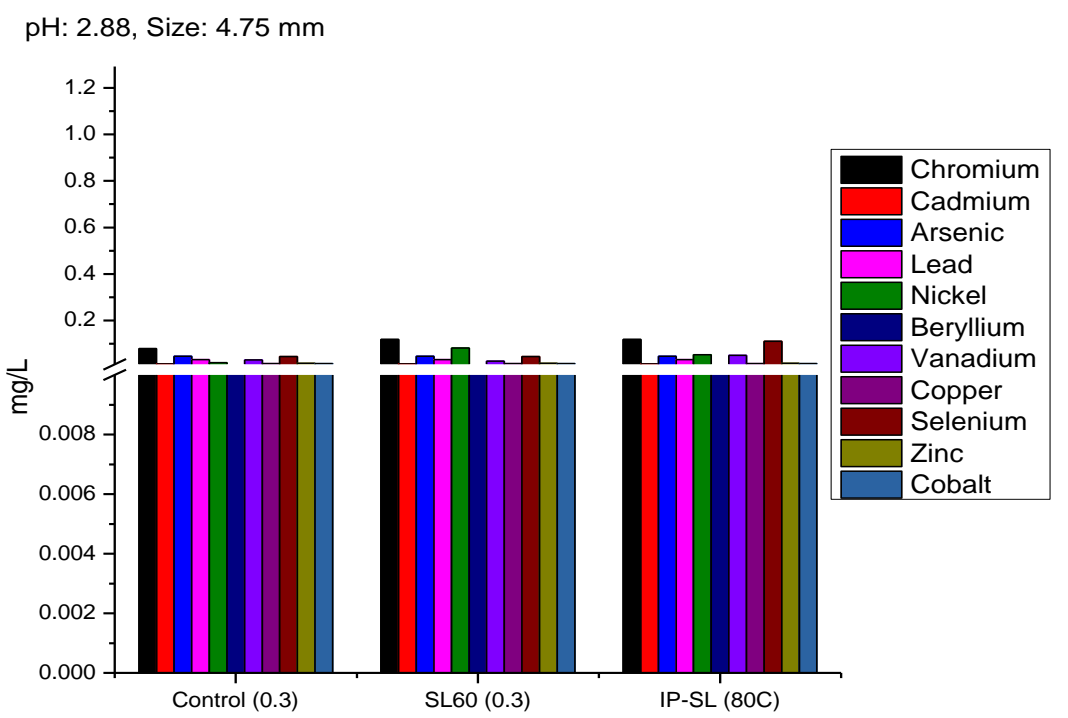

Figure 6-8 Comparison of Control Mix and Concrete Containing 60\% and 100\% Slag, pH 2.88 
The normal concrete leaches almost same amount of elements as compare to slag modified concrete, which indirectly satisfies our cause. Even arsenic bonds well with concrete. This shows a better result in extraction fluid with higher $\mathrm{pH}$.

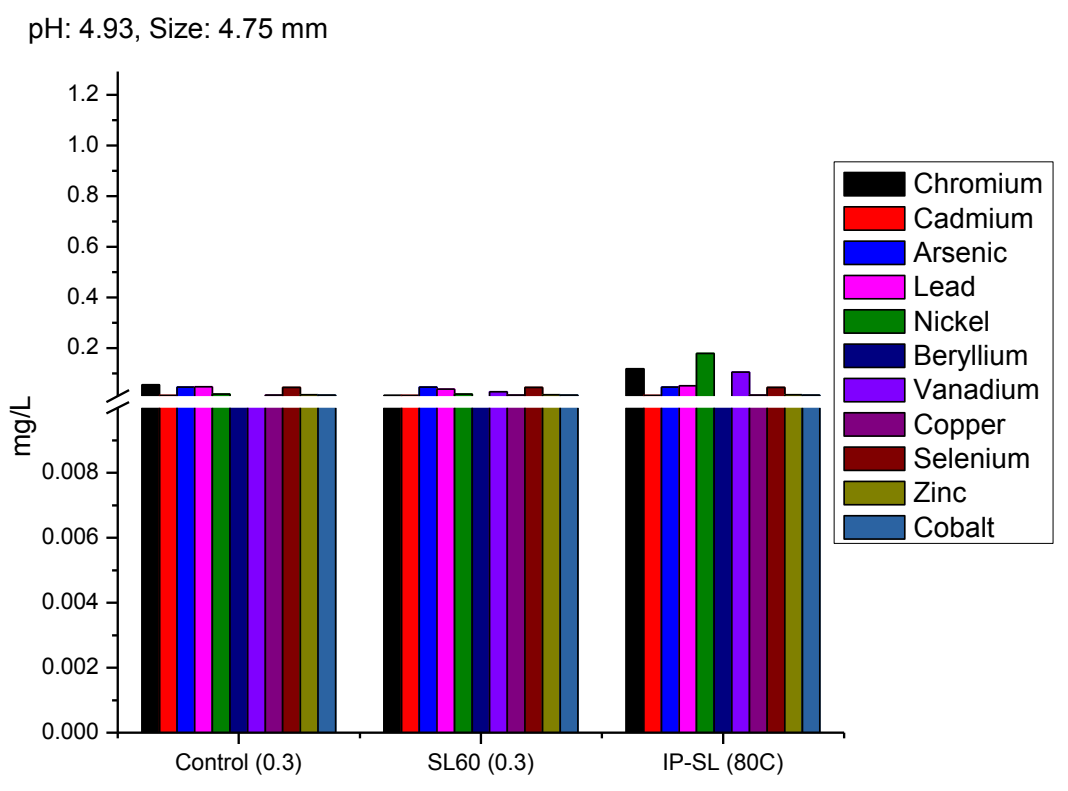

Figure 6-9 Comparison of Control Mix and Concrete Containing 60\% and 100\% Slag, pH 4.93 


\subsection{Ecological Toxicity}

Ecological toxicity is calculated using the Table 6.2 (EPA Ecological Toxicity Index)

Table 6.2 Ecological Toxicity Index

\begin{tabular}{|c|c|}
\hline Flow & 2, 4 Dichlorophenoxy Aectic Acid \\
\hline (a) Dioxins (unspecified) & 2486822.73 \\
\hline (a) Mercury (Hg) & 118758.09 \\
\hline (a) Benzo (g,h,i)perylene $\left(\mathrm{C}_{22} \mathrm{H}_{12}\right)$ & 4948.81 \\
\hline (a) Cadmium (Cd) & 689.74 \\
\hline (a) Benzo(a)anthracene & 412.83 \\
\hline (a) Chromium (Cr VI) & 203.67 \\
\hline (w) Naphthalene $\left(\mathrm{C}_{10} \mathrm{H}_{8}\right)$ & 179.80 \\
\hline (a) Vanadium (V) & 130.37 \\
\hline (a) Benzo(a)pyrene $\left(\mathrm{C}_{20} \mathrm{H}_{12}\right)$ & 109.99 \\
\hline (a) Beryllium (Be) & 106.56 \\
\hline (a) Arsenic (As) & 101.32 \\
\hline (a) Copper (Cu) & 89.46 \\
\hline (w) Vanadium (V3+, V5+) & 81.82 \\
\hline (a) Nickel (Ni) & 64.34 \\
\hline (w) Mercury $(\mathrm{Hg}+, \mathrm{Hg}++)$ & 58.82 \\
\hline (a) Cobalt (Co) & 49.45 \\
\hline (a) Selenium (Se) & 35.07 \\
\hline (a) Fluoranthene & 29.47 \\
\hline (w) Copper (Cu+, $\mathrm{Cu}++)$ & 26.93 \\
\hline (a) Chromium (Cr III, Cr VI) & 24.54 \\
\hline (w) Cadmium (Cd++) & 22.79 \\
\hline (w) Formaldehyde $\left(\mathrm{CH}_{2} \mathrm{O}\right)$ & 22.62 \\
\hline (a) Zinc (Zn) & 18.89 \\
\hline (w) Beryllium (Be) & 16.55 \\
\hline (a) Lead (Pb) & 12.32 \\
\hline
\end{tabular}




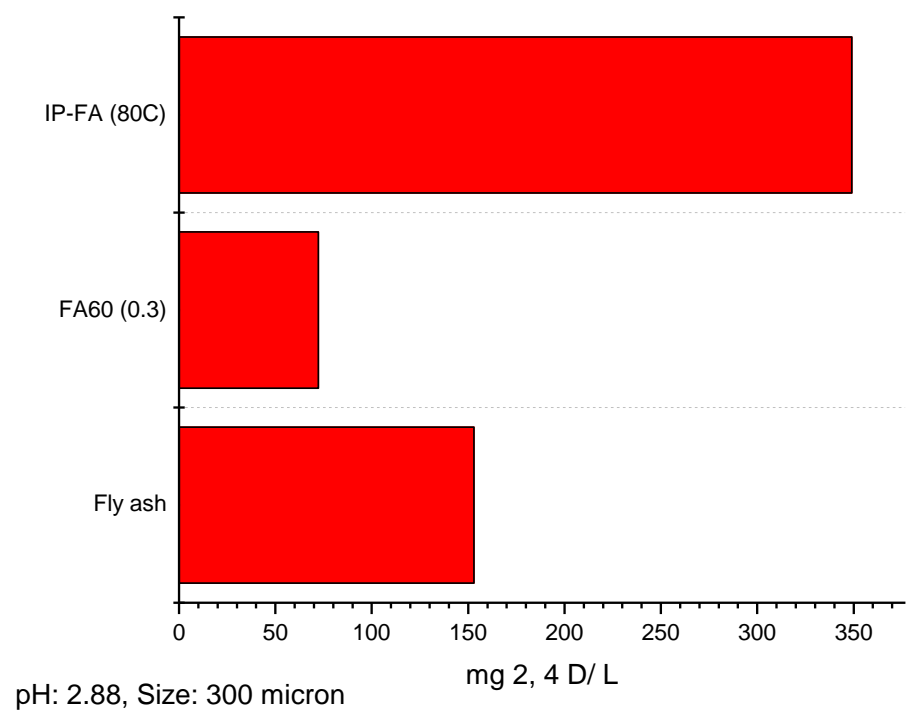

Figure 6-10 Toxicity of Fly Ash and Concrete Containing 60\% and 100\% Fly Ash, pH 2.88

High volume fly ash concrete showed a really good immobilization potential in terms of ecological toxicity compared to fly ash, though geopolymer did not do any good when the $\mathrm{pH}$ is 2.88 .

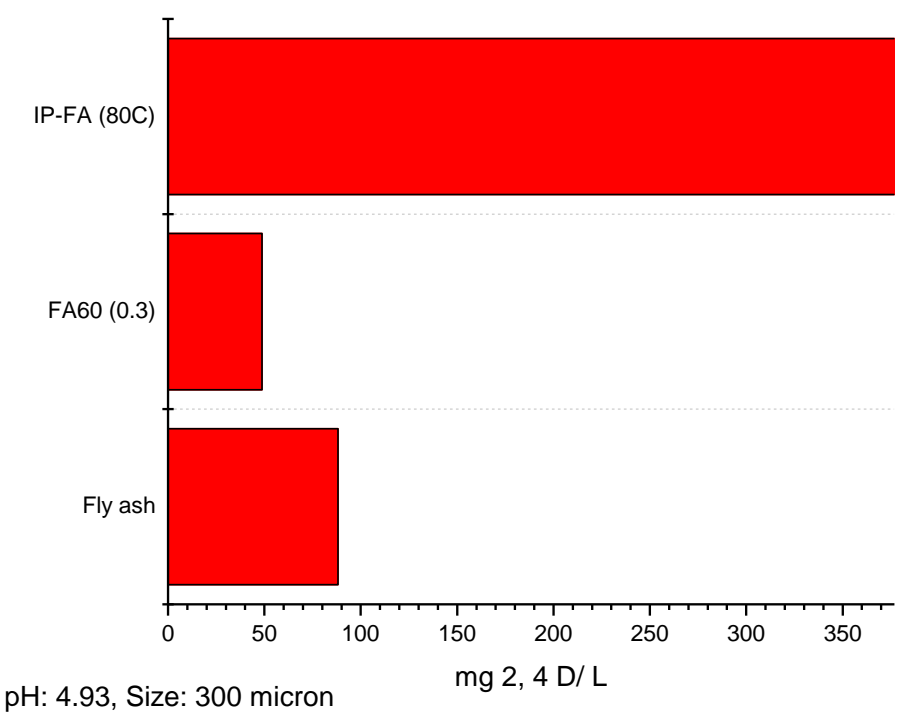

Figure 6-11 Toxicity of Fly Ash and Concrete Containing 60\% and 100\% Fly Ash, pH 4.93 
High volume fly ash concrete showed a really good immobilization potential in terms of ecological toxicity compared to fly ash, though geopolymer did not do any good when the $\mathrm{pH}$ is 4.93.

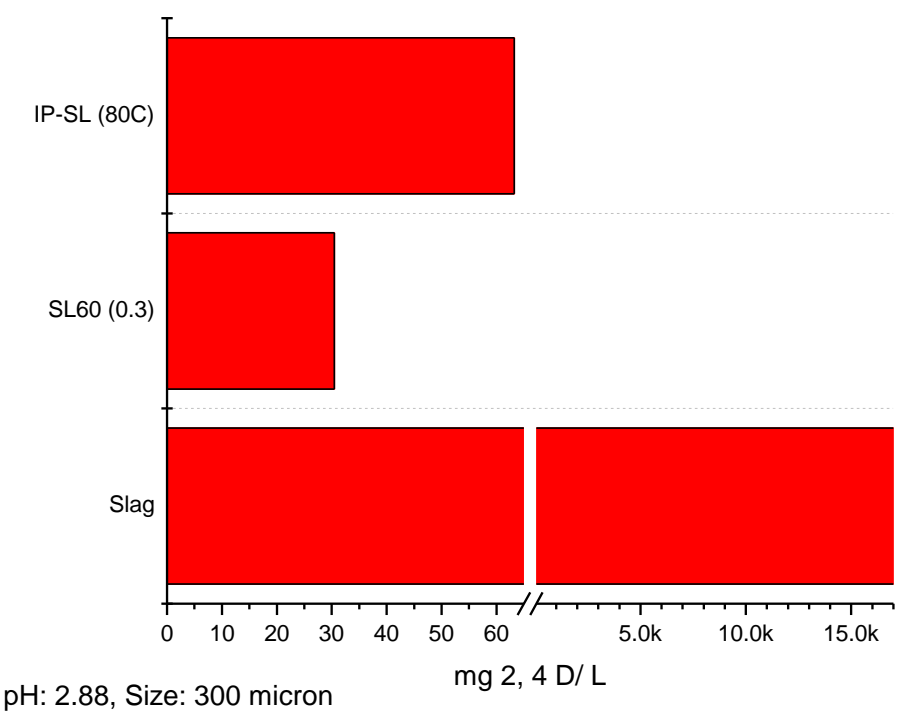

Figure 6-12 Toxicity of Fly Ash and Concrete Containing 60\% and 100\% Slag, pH 2.88

High volume slag concrete showed a really good immobilization potential in terms of ecological toxicity compared to slag, though geopolymer showed great results by means of arresting toxicity potential when the $\mathrm{pH}$ is 2.88 .

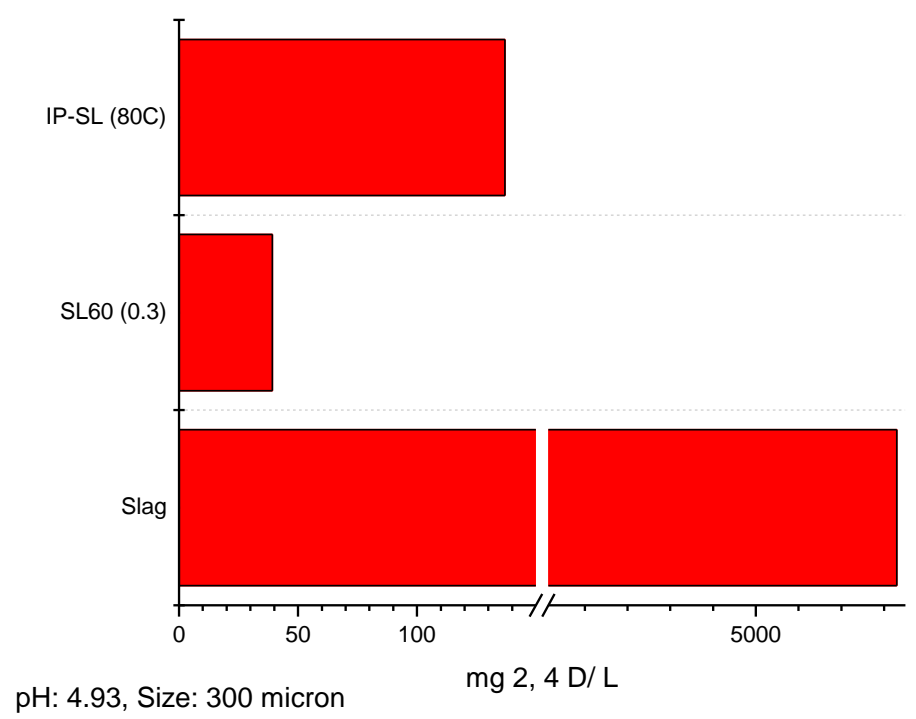

Figure 6-13 Toxicity of Fly Ash and Concrete Containing 60\% and 100\% Slag, pH 4.93 
High volume slag concrete showed a really good immobilization potential in terms of ecological toxicity compared to slag, though geopolymer showed great results by means of arresting toxicity potential when the $\mathrm{pH}$ is 4.93 .

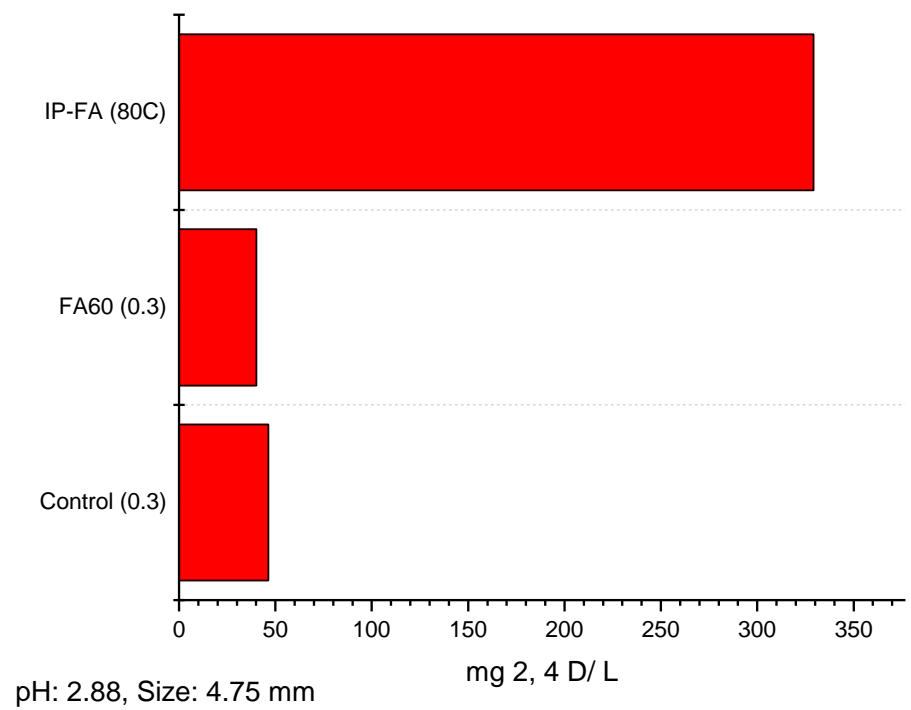

Figure 6-14 Toxicity of Control and Concrete Containing 60\% and 100\% Fly Ash, $\mathrm{pH} 2.88$

High volume fly ash concrete showed a really good immobilization potential in terms of ecological toxicity compared to control concrete, though geopolymer did not do any good when the $\mathrm{pH}$ is 2.88 . 


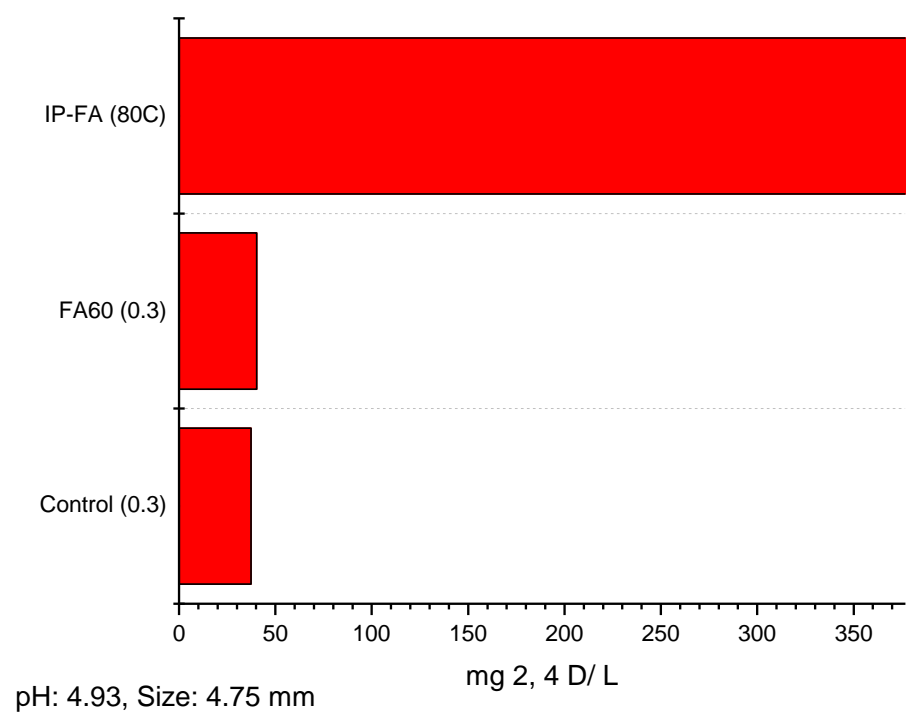

Figure 6-15 Toxicity of Control and Concrete Containing 60\% and 100\% Fly Ash, pH 4.93

High volume fly ash concrete showed a really good immobilization potential in terms of ecological toxicity compared to control concrete, though geopolymer did not do any good when the $\mathrm{pH}$ is 4.93 .

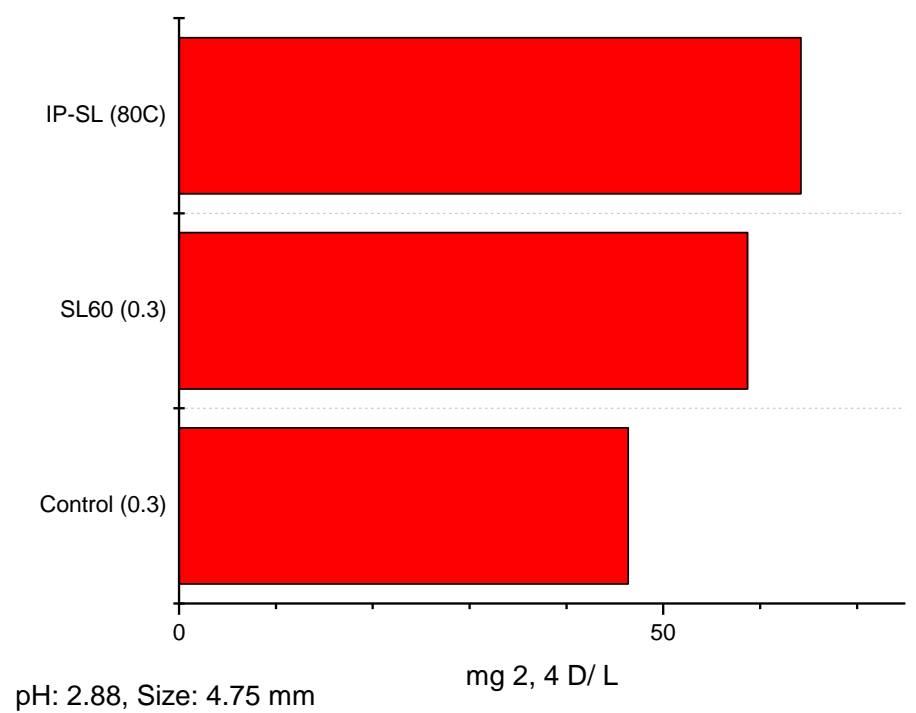

Figure 6-16 Toxicity of Control and Concrete Containing 60\% and 100\% Slag, pH 2.88

High volume slag concrete showed a really good immobilization potential in terms of ecological toxicity compared to control concrete, though geopolymer did not do any good when the $\mathrm{pH}$ is 2.88 . 


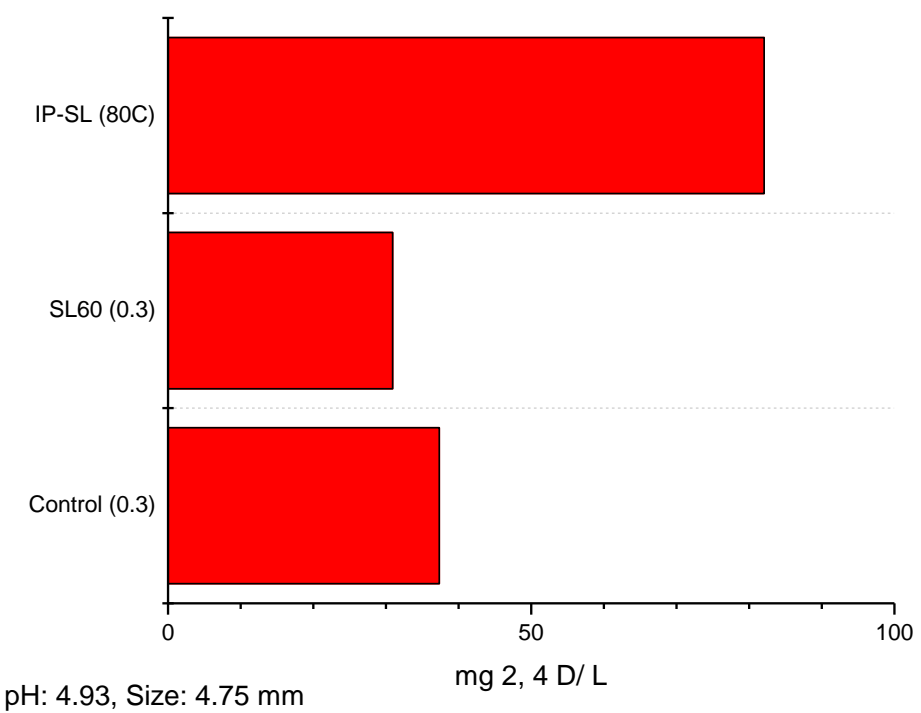

Figure 6-17 Toxicity of Control and Concrete Containing 60\% and 100\% Slag, pH 4.93

High volume slag concrete showed a really good immobilization potential in terms of ecological toxicity compared to control concrete, though geopolymer did not do any good when the $\mathrm{pH}$ is 4.93. 


\section{Chapter 7: Sustainability Analysis}

\subsection{Introduction}

The purpose of this chapter is to describe the computation of sustainability effect of high volume fly ash and/or slag modified concrete. This chapter is presented to show a gross comparison between conventional concrete and high performance high volume fly ash and/or slag modified concrete. Mainly two aspects of sustainability is considered for this work. There is lot of available software in the market. BEES and ATHENA are the most popular among the available software right now. For this purpose NIST recommended BEES 4.0 is used.

\subsection{An Overview of BEES 4.0}

The BEES methodology considers a multidimensional life-cycle approach. It accounts for multiple environmental and economic impacts over the entire life of the building products. Multiple impacts and life-cycle stages are necessary to be considered because the product selection decisions based on single impacts or stages could affect the results. Therefore, for a comprehensive and balanced analysis, a multidimensional life-cycle approach is necessary.

Building products are bought and sold in the marketplace where the cost is the only parameter. Thant is why it is relatively easier to select products based on minimum life-cycle economic impacts. But including the life-cycle environmental impacts in our purchase decisions is a complex procedure. Economic impact does not account for the environmental impacts such as global warming, water pollution and resource depletion. That is, their costs are not reflected in the market prices of the products that generated the impacts. Moreover, even if there were a mandate today to include environmental "costs" in market prices, it would be nearly impossible to do so due to difficulties in assessing these impacts in economic terms. There is no way to put a price on clean air and clean water. The value of human life is not considered either. Economists have debated these questions for decades, without coming up with a comprehensive solution.

Environmental performance cannot be measured on a monetary scale, but it can be quantified using the evolving, multi-disciplinary approach known as environmental life-cycle assessment 
(LCA). The BEES methodology measures environmental performance using an LCA approach, following guidance in the International Organization for Standardization (ISO) 14040 standard for LCA.

- Economic performance is separately measured using the ASTM International standard life-cycle cost (LCC) approach.

- These two performance measures are then synthesized into an overall performance measure using the ASTM standard for Multi-attribute Decision Analysis. For the entire BEES analysis, building products are defined and classified based on UNIFORMAT II, the ASTM standard classification for building elements.

\subsubsection{Economic Performance (Source NIST: BEES 4.0)}

The economic performance calculation of building products is less complex than structuring environmental performance. Economic performance data are readily available. ASTM standard methods for conducting economic performance evaluations are well-established. First cost data are collected from the R.S. Means publication, 2007 Building Construction Cost Data, and industry interviews. Future cost data are based on data published by Whitestone Research in The Whitestone Building Maintenance and Repair Cost Reference 2006-2007 and industry interviews. The most appropriate method for measuring the economic performance of building products is the LCC method. BEES 4.0 follow the ASTM standard method for life-cycle costing of building-related investments.

It is important to clarify the difference between the time periods used to measure environmental performance and economic performance. These time periods are different. For environmental LCA, the time period begins with raw material acquisition and ends with product end-of-life. Economic performance is evaluated over a fixed period (known as the study period) that begins with the purchase and installation of the product and ends at some point in the future that does not necessarily correspond with product's end of life.

Economic performance is evaluated beginning at product purchase and installation because this is when usage costs begin to be incurred, and investment decisions are made based upon livelihood costs. The study period ends at a fixed date in the future. For a private investor, its length is set at the period of product or facility ownership. For society as a whole, the study period length is often taken as the useful life of the longest-lived product alternative. However, 
when alternatives have very long lives, (e.g., more than 50 years), a shorter study period may be selected for three reasons:

- Technological obsolescence becomes an issue

- Data become too uncertain

- The farther in the future, the less important the costs

In the BEES model, economic performance is measured over a 50-year study period. This study period is selected to reflect a reasonable period of time over which to evaluate economic performance for society as a whole. Different products have different useful lives but still the same 50-year period is used to evaluate all products. This is one of the strengths of the LCC method. It accounts for the fact that different products have different useful lives by evaluating them over the same study period.

For consistency, the BEES 4.0 model evaluates the use stage of environmental performance over the same 50-year study period. Product replacements over this 50-year period are accounted for the life cycle inventory analysis, and end-of-life inventory flows are prorated to year 50 for products with lives longer than the 50-year study period.

The LCC method sums over the study period all relevant costs associated with a product. Alternative products for the same function like floor covering can be compared on the basis of their LCCs to determine which is the least cost means of fulfilling that function over the study period. Categories of cost typically include costs for purchase, installation, operation, maintenance, repair, and replacement. A negative cost item is the residual value. The residual value is the product value remaining at the end of the study period. In the BEES 4.0 model, the residual value is computed by prorating the purchase and installation cost over the product life remaining beyond the 50-year period.

Future costs must be expressed in terms consistent with the discount rate used. There are two approaches. First, a real discount rate may be used with constant-dollar costs. Real discount rates reflect that portion of the time value of money attributable to the real earning power of money over time and not to general price inflation. Even if all future costs are expressed in constant dollars, they must be discounted to reflect this portion of the time-value of money. Second, a market discount rate may be used with current-dollar amounts (e.g., actual future prices). Market discount rates reflect the time value of money stemming from both inflation and the real earning power of money over time. When applied properly, both approaches yield the same LCC results. 
The BEES model computes LCCs using constant dollars and a real discount rate. By default, the BEES tool offers a real rate of $2.7 \%$, the 2010 rate mandated by the U.S. Office of Management and Budget for most Federal projects.

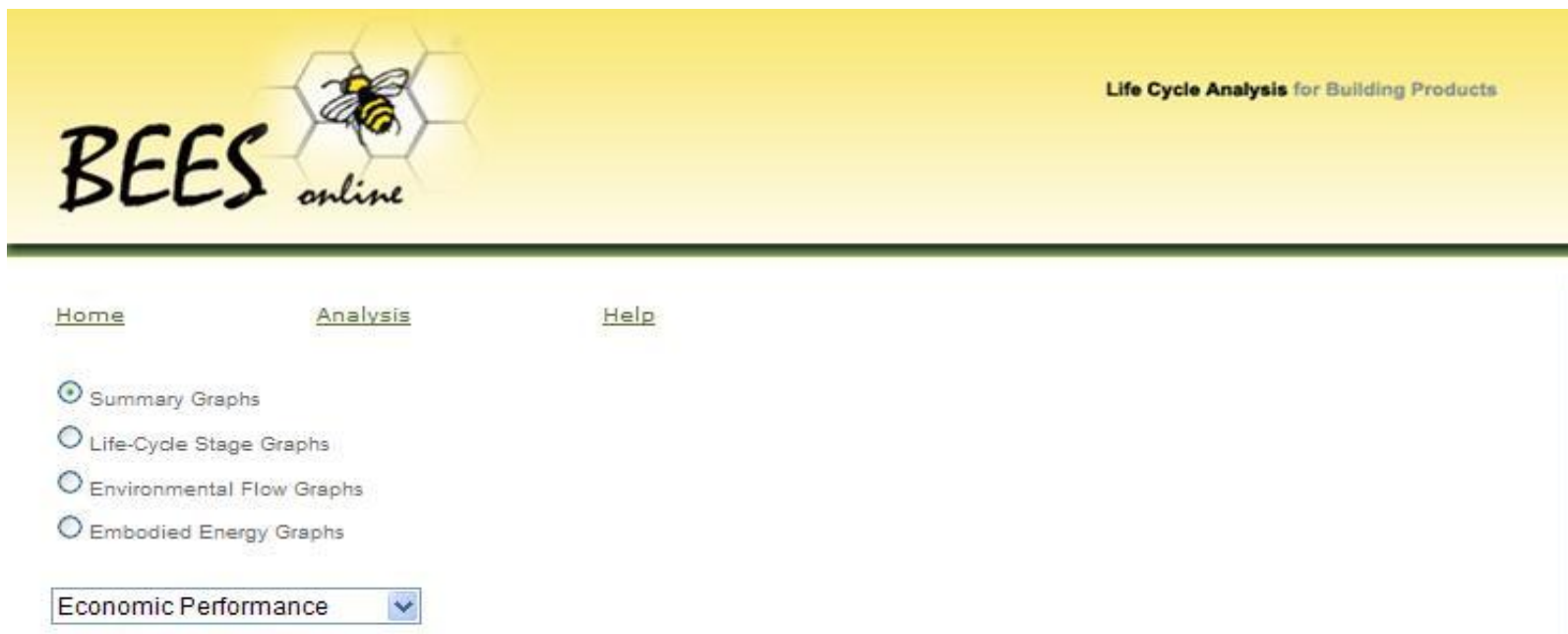

Economic Performance

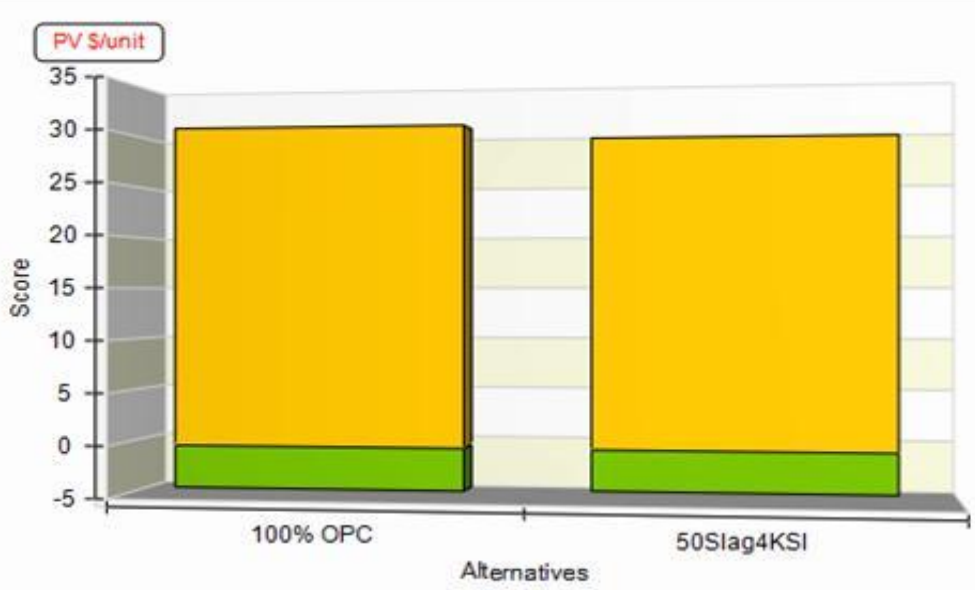

$-\square$ First cost

$-\square$-Future Cost - $2.7 \%$

Category

$100 \%$ OPC

50 Slag $4 \mathrm{KSI}$

\begin{tabular}{|c|c|c|}
\hline Category & $100 \%$ OPC & 50 Slag4KSI \\
\hline First Cost & 30.17 & 28.82 \\
\hline Future Cost - $2.7 \%$ & -3.98 & -3.80 \\
\hline Sum & 26.19 & 25.02 \\
\hline
\end{tabular}

Figure 7-1 Economic Performance 


\subsubsection{Environmental Performance (Source NIST: BEES 4.0)}

"Cradle-to-grave," systems approach is used for environmental life-cycle assessment and for calculating environmental performance. The approach is based on the hypothesis that all stages in the life of a product generate environmental impacts. So all stages must be therefore analyzed including raw materials acquisition, product manufacture, transportation, installation, operation and maintenance, and ultimately recycling and waste management. An analysis excluding any of these stages is limits the results of performance analysis because it ignores the full range of upstream and downstream impacts of stage-specific processes.

The major positives of environmental life-cycle assessment are its comprehensive, multidimensional scope. Many green building organization claims and strategies are now based on a single life-cycle stage or a single environmental impact. A product is claimed to be green simply because it has recycled content, or accused of not being green because it emits volatile organic compounds (VOCs) during its installation and use. These single-attribute claims may be misleading because they ignore the possibility that other life-cycle stages, or other environmental impacts, may yield offsetting impacts. For example, the recycled content product may have high embodied energy content, leading to fossil fuel depletion, global warming, and acid rain impacts during the raw materials acquisition, manufacturing, and transportation life-cycle stages. LCA thus broadens the environmental discussion by accounting for shifts of environmental problems from one life-cycle stage to another, or one environmental medium (land, air, water) to another. The benefit of the LCA approach is in implementing a trade-off analysis to achieve a genuine reduction in overall environmental impact, rather than a simple shift of impact.

The general LCA methodology involves four steps.

The goal and scope definition step spells out the purpose of the study and its breadth and depth.

- The inventory analysis step identifies and quantifies the environmental inputs and outputs associated with a product over its entire life cycle.

- Environmental inputs include water, energy, land, and other resources; outputs include releases to air, land, and water. However, it is not these inputs and outputs, or inventory flows that are of primary interest. We are more interested in their consequences, or impacts on the environment. 
- Impact assessment, characterizes these inventory flows in relation to a set of environmental impacts. For example, the impact assessment step might relate carbon dioxide emissions, a flow, to global warming, an impact.

- The interpretation step combines the environmental impacts in accordance with the goals of the LCA study.

The parameter for the environmental assessment is described below.

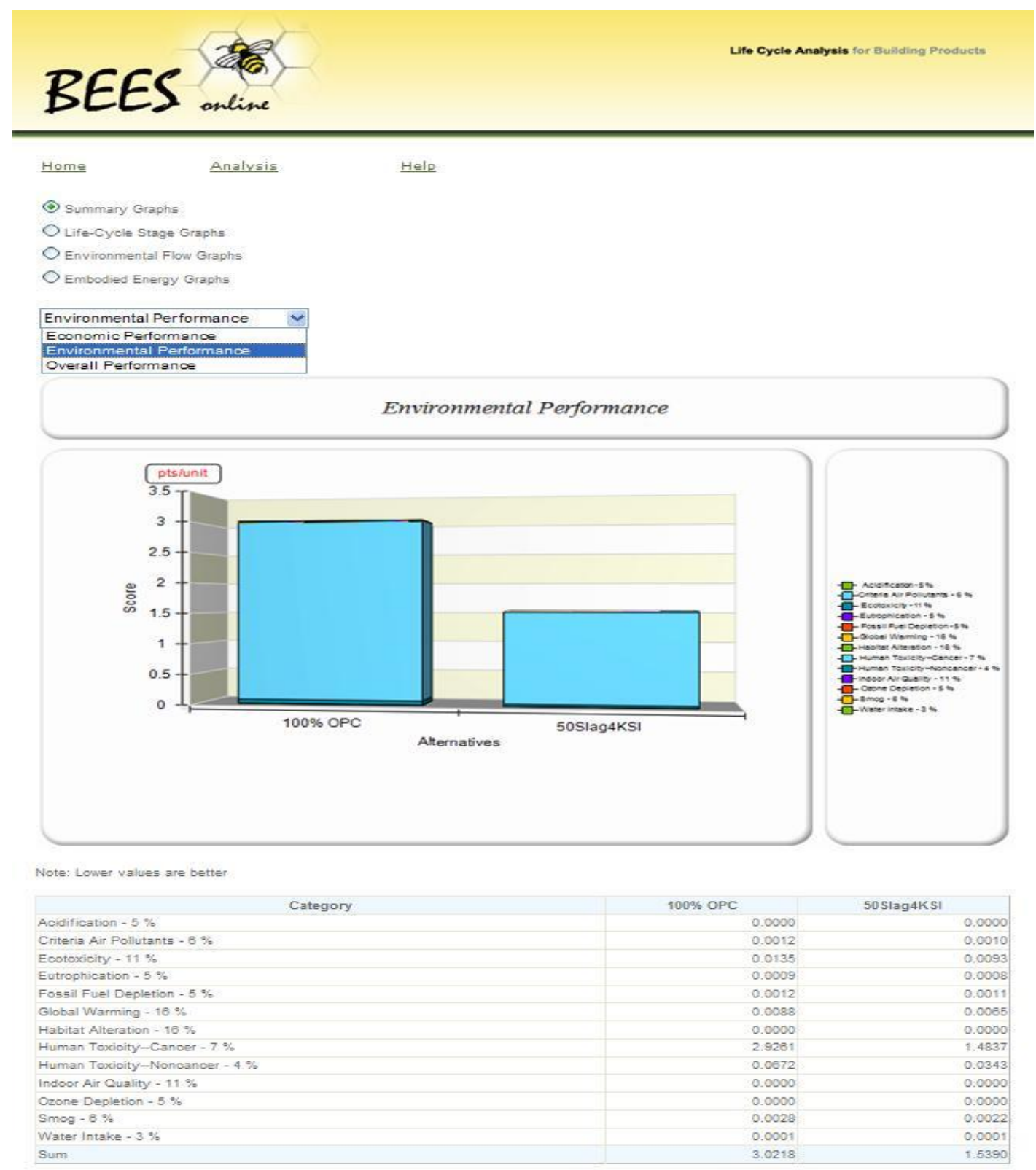

Figure 7-2Environmental Performance 


\subsubsection{Acidification Potential (Source NIST: BEES 4.0)}

Acidifying compounds may be in a fluid state either dissolved in water or as particulate matter. They reach ecosystems through dissolution in rain or wet deposition. Acidification affects trees, soil, buildings, animals, and humans. Sulfur and nitrogen compounds are the two compounds principally involved in acidification. Their principal human sources of this acidification are fossil fuel and biomass combustion. Other compounds, such as hydrogen chloride and ammonia, also contribute to acidification.

Characterization factors for potential acid deposition onto the soil and in water have been developed like those for the global warming potential, with hydrogen ions as the reference substance. These factors permit computation of a single index for potential acidification (in grams of hydrogen ions per functional unit of product), representing the quantity of hydrogen ion emissions with the same potential acidifying effect:

Acidification index $=\Sigma_{\mathrm{i}} \mathrm{mi}_{\mathrm{i}} * \mathrm{AP}$, where

$\mathrm{m}_{\mathrm{i}}=$ mass (in grams) of inventory flow $\mathrm{i}$, and

$\mathrm{AP}_{\mathrm{i}}=$ millimoles of hydrogen ions with the same potential acidifying effect as one gram of inventory flow i 
Summary Graphs

$\odot_{\text {Life-Cycle Stage Graphs }}$

Environmental Flow Graphs

Ombodied Energy Graphs

\section{Acidification}

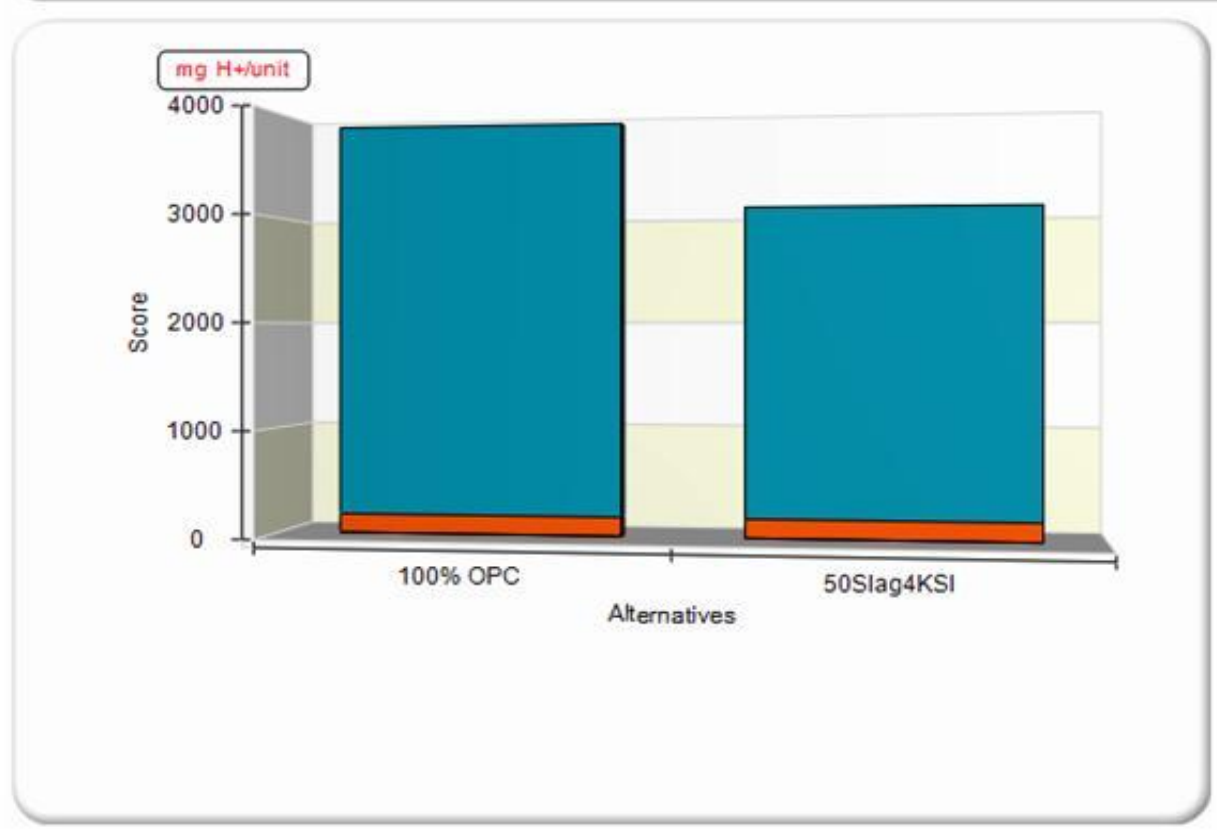

Note: Lower values are better

\begin{tabular}{|c|c|c|}
\hline Category & $100 \%$ OPC & 50 Slag $4 \mathrm{KSI}$ \\
\hline 1. Raw Materials & 3882,4307 & 2890.1734 \\
\hline 2. Manufacturing & 0.0000 & 0.0000 \\
\hline 3. Transportation & 177.9808 & 178.3056 \\
\hline 4. Use & 0.0000 & 0.0000 \\
\hline 5. End of Life & 0.0000 & 0.0000 \\
\hline Sum & 3860.4113 & 3068.4790 \\
\hline
\end{tabular}

Figure 7-3Acidification Potential 


\subsubsection{Ecological Toxicity (Source NIST: BEES 4.0)}

The ecological toxicity impact measures the potential of a chemical released into the environment to harm terrestrial and aquatic ecosystems. An assessment method for this impact was developed for the TRACI set of U.S. impact assessment methods and adopted in BEES. The method involves measuring pollutant concentrations from industrial sources as well as the potential of these pollutants to harm ecosystems.

TRACI characterization factors for potential ecological toxicity use 2, 4-dichlorophenoxy-acetic acid as the reference substance. These factors permit computation of a single index for potential ecological toxicity (in grams of 2, 4-dichlorophenoxy-acetic acid per functional unit of product), representing the quantity of 2, 4-dichlorophenoxy-acetic acid with the same potential for ecological toxicity:

Ecological toxicity index $=\Sigma \mathrm{i}$ mi $\mathrm{x} \mathrm{EPi}$, where

$\mathrm{mi}=$ mass (in grams) of inventory flow $\mathrm{i}$, and

$\mathrm{EPi}=$ grams of 2, 4-dichlorophenoxy-acetic acid with the same ecological toxicity potential as one gram of inventory flow $\mathrm{i}$. 
BEES

Life Cycle Analysis for Bullding Products

Home

Analysis

Help

Summary Graphs

- Life-Cycle Stage Graphs

Environmental Flow Graphs

Embodied Energy Graphs

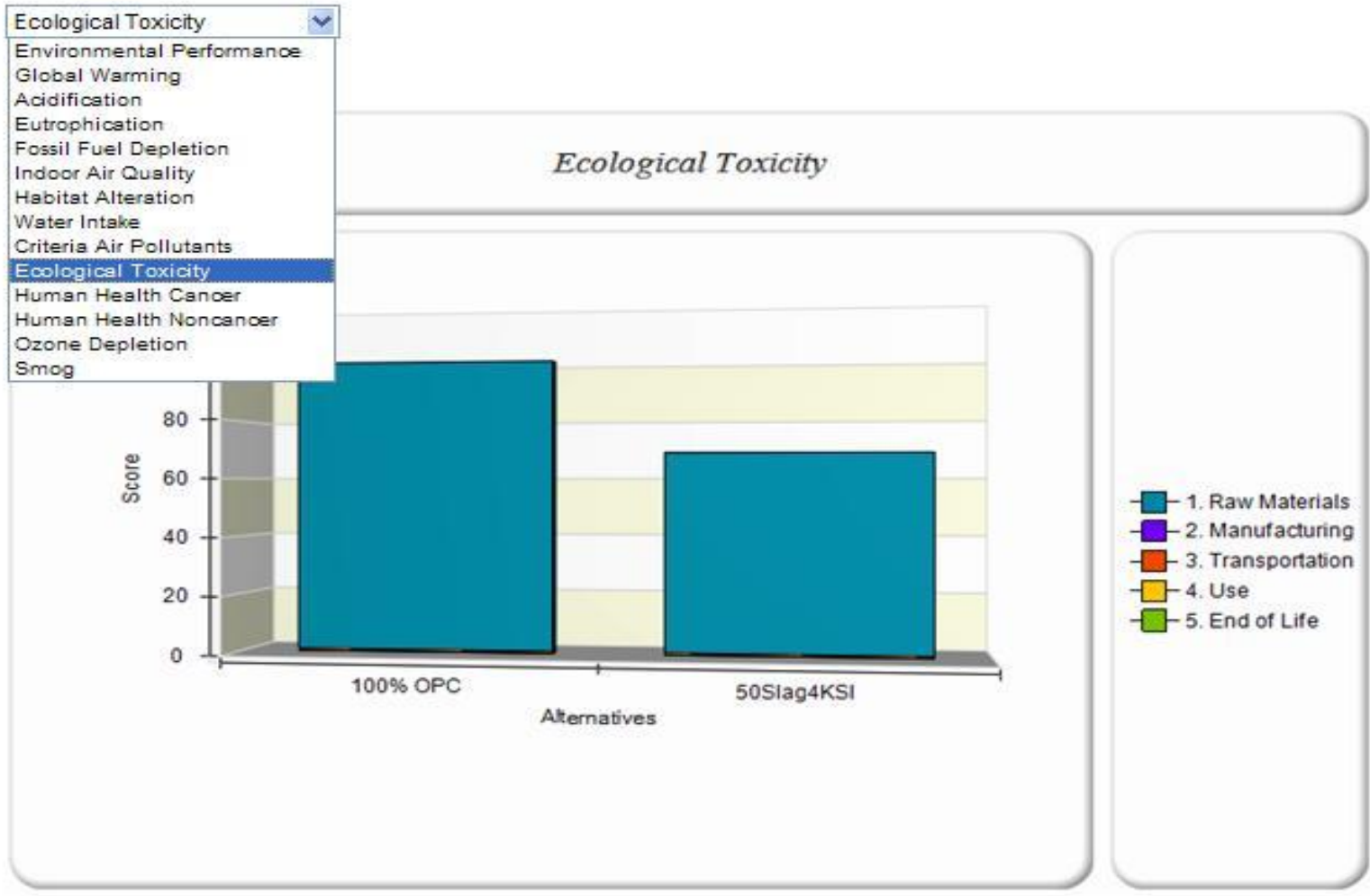

Note: Lower values are better

\begin{tabular}{|c|c|c|}
\hline Category & $100 \%$ OPC & 50 Slag $4 \mathrm{KSI}$ \\
\hline 1. Raw Materials & 99.5940 & 68.0444 \\
\hline 2. Manufacturing & 0.0000 & 0.0000 \\
\hline 3. Transportation & 0.6989 & 0.6997 \\
\hline 4. Use & 0.0000 & 0.0000 \\
\hline 5. End of Life & 0.0000 & 0.0000 \\
\hline Sum & 100.2929 & 88.7441 \\
\hline
\end{tabular}

Figure 7-4 Ecological Toxicity 


\subsubsection{Global warming (Source NIST: BEES 4.0)}

The Earth absorbs radiation from the Sun, mainly at the surface. This energy is then redistributed by the atmosphere and ocean and re-radiated to space at longer wavelengths. Some of the thermal radiation is absorbed by "greenhouse" gases in the atmosphere, principally water vapor, but also carbon dioxide, methane, the chlorofluorocarbons, and ozone. The absorbed energy is re-radiated in all directions, downwards as well as upwards, such that the radiation that is eventually lost to space is from higher, colder levels in the atmosphere.

The result is that the surface loses less heat to space than it would in the absence of the greenhouse gases and consequently stays warmer than it would be otherwise. This phenomenon, which acts rather like a 'blanket' around the Earth, is known as the greenhouse effect.

The greenhouse effect is a natural phenomenon. The environmental issue is the change in the greenhouse effect due to emissions (an increase in the effect) and absorptions (a decrease) attributable to humans. A general increase in temperature can alter atmospheric and oceanic temperatures, which can potentially lead to alteration of circulation and weather patterns. A rise in sea level is also predicted from an increase in temperature due to thermal expansion of the oceans and melting of polar ice sheets.

Global Warming Potentials, or GWPs, have been developed to characterize the change in the greenhouse effect due to emissions and absorptions attributable to humans. LCAs commonly use those GWPs representing a 100- year time horizon. GWPs permit computation of a single index, expressed in grams of carbon dioxide per functional unit of a product, which measures the quantity of carbon dioxide with the same potential for global warming over a 100 -year period:

Global warming index $=\sum \mathrm{i}$ mi x GWPi, where

$\mathrm{mi}=$ mass (in grams) of inventory flow $\mathrm{i}$, and

GWPi $=$ grams of carbon dioxide with the same heat trapping potential over 100 years as one gram of inventory flow i 
BEES

Osummary Graphs

() Life-Cycle Stage Graphs

Environmental Flow Graphs

OEmbodied Energy Graphs

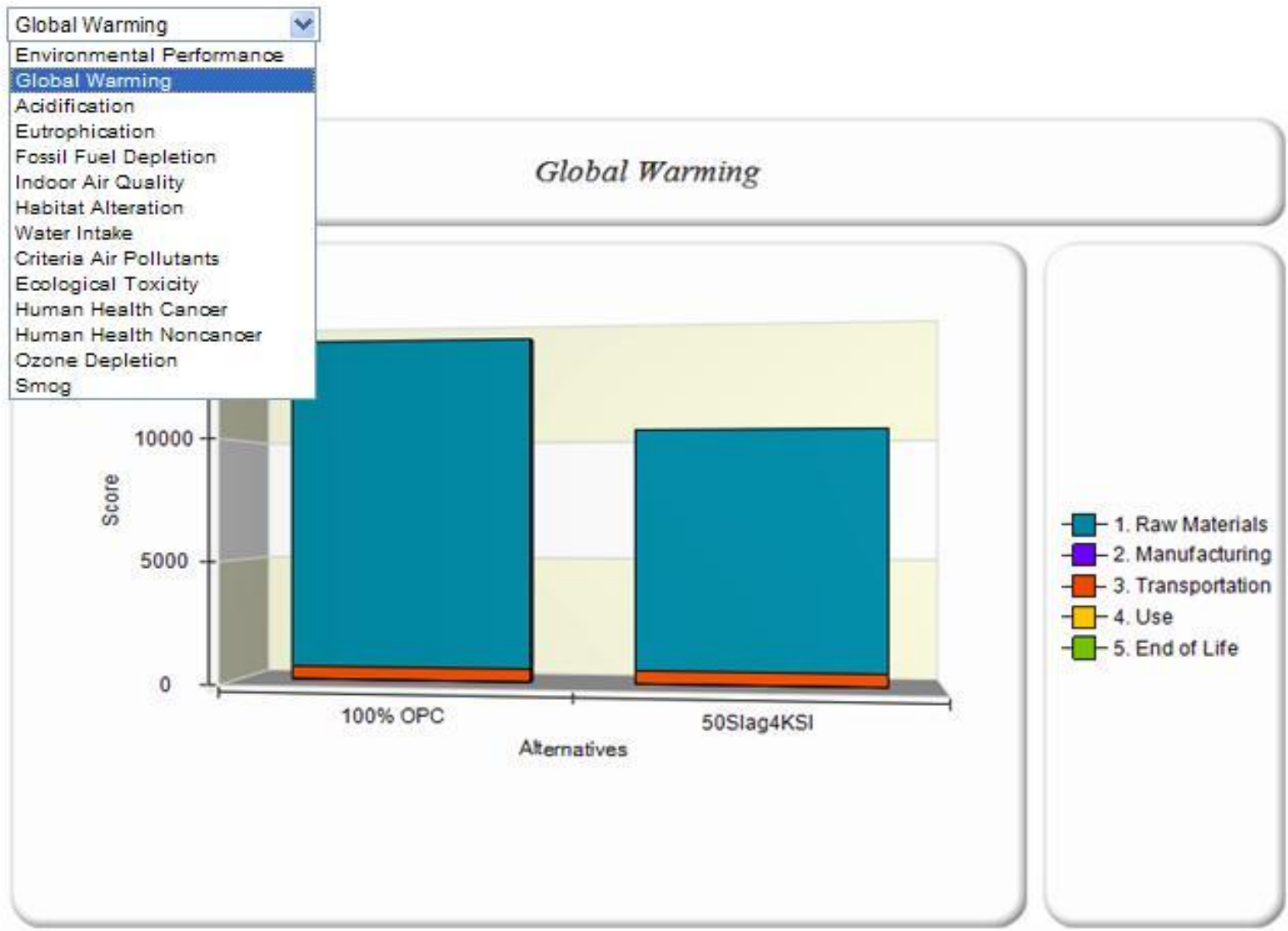

Note: Lower values are better

\begin{tabular}{|c|c|c|}
\hline Category & $100 \%$ OPC & 50 Slag4KSI \\
\hline 1. Raw Materials & 13805.0407 & 9831.1472 \\
\hline 2. Manufacturing & 0.0000 & 0.0000 \\
\hline 3. Transportation & 535.7041 & 534.3975 \\
\hline 4. Use & 0.0000 & 0.0000 \\
\hline 5. End of Life & 0.0000 & 0.0000 \\
\hline Sum & 14140.7448 & 10385.6447 \\
\hline
\end{tabular}

Figure 7-5 Global Warming 


\subsubsection{Fossil fuel depletion (Source NIST: BEES 4.0)}

Some experts believe fossil fuel depletion is fully accounted for in market prices. That is, market price mechanisms are believed to take care of the scarcity issue, price being a measure of the level of depletion of a resource and the value society places on that depletion. However, price is influenced by many factors other than resource supply, such as resource demand and non-perfect markets (e.g., monopolies and subsidies). Furthermore, fossil fuel depletion is at the heart of the sustainability debate.

Fossil fuel depletion is included in the TRACI set of impact assessment methods adopted by BEES 4.0. It is important to recognize that this impact addresses only the depletion aspect of fossil fuel extraction, not the fact that the extraction itself may generate impacts. Extraction impacts, such as methane emissions from coal mining, are addressed in other impacts, such as global warming.

To assess fossil fuel depletion, TRACI follows the approach developed for the Eco-Indicator 99 method, which measures how the amount of energy required to extract a unit of energy for consumption changes over time. Characterization factors have been developed permitting computation of a single index for potential fossil fuel depletion--in surplus megajoules (MJ) per functional unit of product--and assess the surplus energy requirements from the consumption of fossil fuels:

Fossil fuel depletion index $=\Sigma \mathrm{i}$ ci $\mathrm{xP}$, where

$\mathrm{ci}=$ consumption (in $\mathrm{kg}$ ) of fossil fuel $\mathrm{i}$, and

$\mathrm{FPi}=\mathrm{MJ}$ input requirement increase per kilogram of consumption of fossil fuel $\mathrm{i}$ 


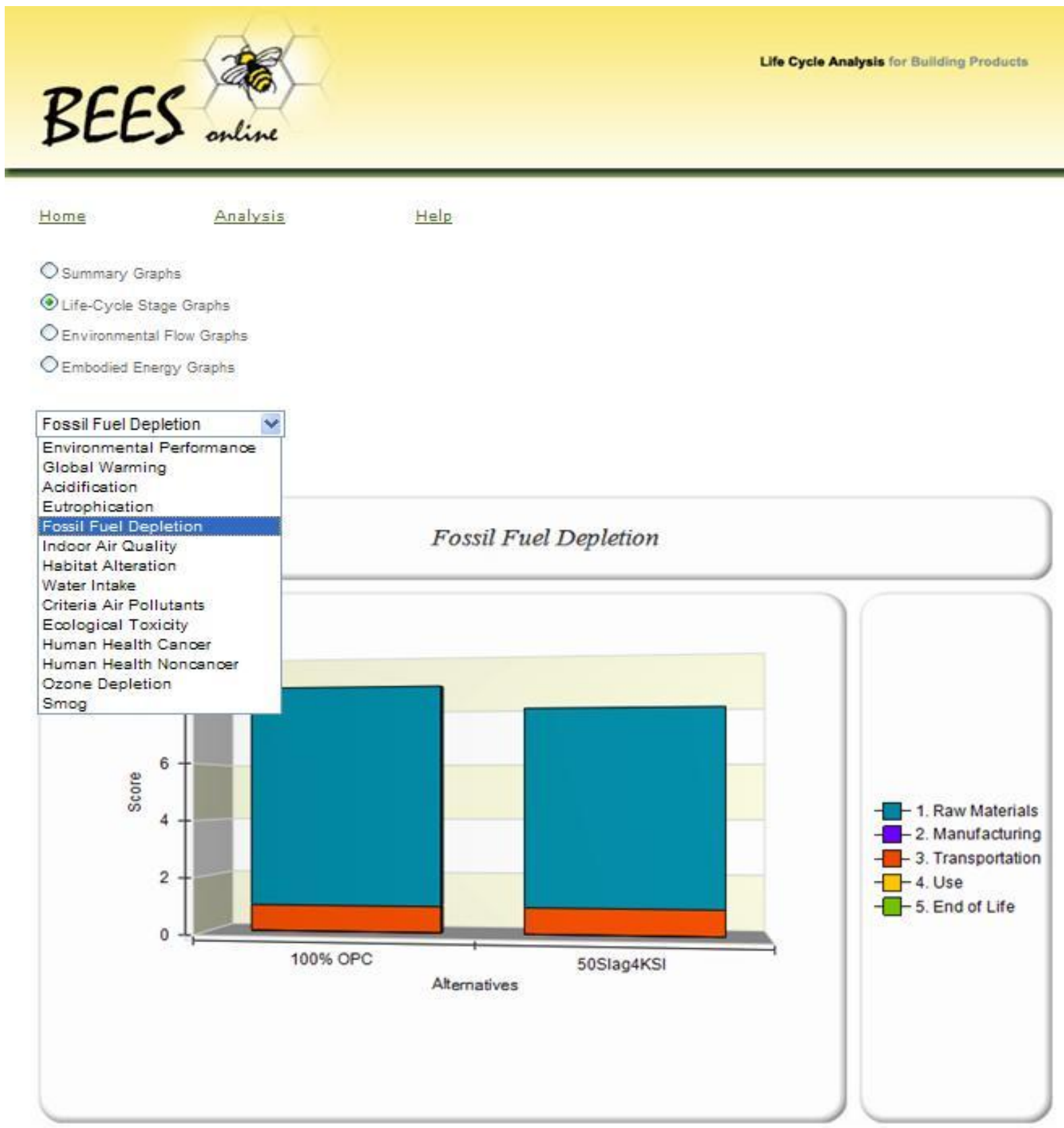

Note: Lower values are better

\begin{tabular}{|c|c|c|}
\hline Category & $100 \%$ OPC & 50 Slag4KSI \\
\hline 1. Raw Materials & 7.8278 & 7.0131 \\
\hline 2. Manufacturing & 0.0000 & 0.0000 \\
\hline 3. Transportation & 0.9308 & 0.9305 \\
\hline 4. Use & 0.0000 & 0.0000 \\
\hline 5. End of Life & 0.0000 & 0.0000 \\
\hline Sum & 8.7584 & 7.9436 \\
\hline
\end{tabular}

Figure 7-6 Fossil Fuel Depletion 


\subsubsection{Human health (Source NIST: BEES 4.0)}

There are many potential human health effects from exposure to industrial and natural substances, ranging from transient irritation to permanent disability and even death. Some substances have a wide range of different effects, and different individuals have widely varying tolerances to different substances. BEES adopts and extends the TRACI 1.0 approach to evaluating human health impacts. Note that this approach does not include occupational health effects.

TRACI developers have computed Toxicity Equivalency Potentials (TEPs), which are characterization factors measuring the relative health concern associated with various chemicals from the perspective of a generic individual in the United States. For cancer effects, the TRACI system's TEPs are expressed in terms of benzene equivalents, while for noncancer health effects they are denominated in toluene equivalents. In order to synthesize all environmental impacts in the next LCA step (interpretation), however, BEES requires a combined measure of cancer and noncancer health effects because three of its four impact importance weight sets are available only at the combined level. The BEES 2.0 Peer Review Team suggested that to address this need, threshold levels for toluene and benzene be obtained from the developers of the TRACI TEPs and be given equal importance in combining cancer and noncancer health effects. 1 Threshold levels were thus obtained and used to develop a ratio converting benzene equivalents to toluene equivalents ( $21000 \mathrm{~kg}$ toluene $/ \mathrm{kg}$ benzene) .2

The "extended" TRACI characterization factors permit computation of a single index for potential human health effects (in grams of toluene per functional unit of product), representing the quantity of toluene with the same potential human health effects:

Human health index $=\Sigma \mathrm{i}$ mi x HPi, where

$\mathrm{mi}=$ mass (in grams) of inventory flow $\mathrm{i}$, and

$\mathrm{HPi}=$ grams of toluene with the same potential human health effects as one gram of inventory flow i. 


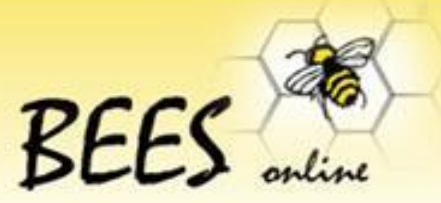

Life Cycle Analysis for Bullding Products

Home

Analysis

Help

OSummary Graphs

(1) Life-Cycle Stage Graphs

Onvironmental Flow Graphs

Embodied Energy Graphs

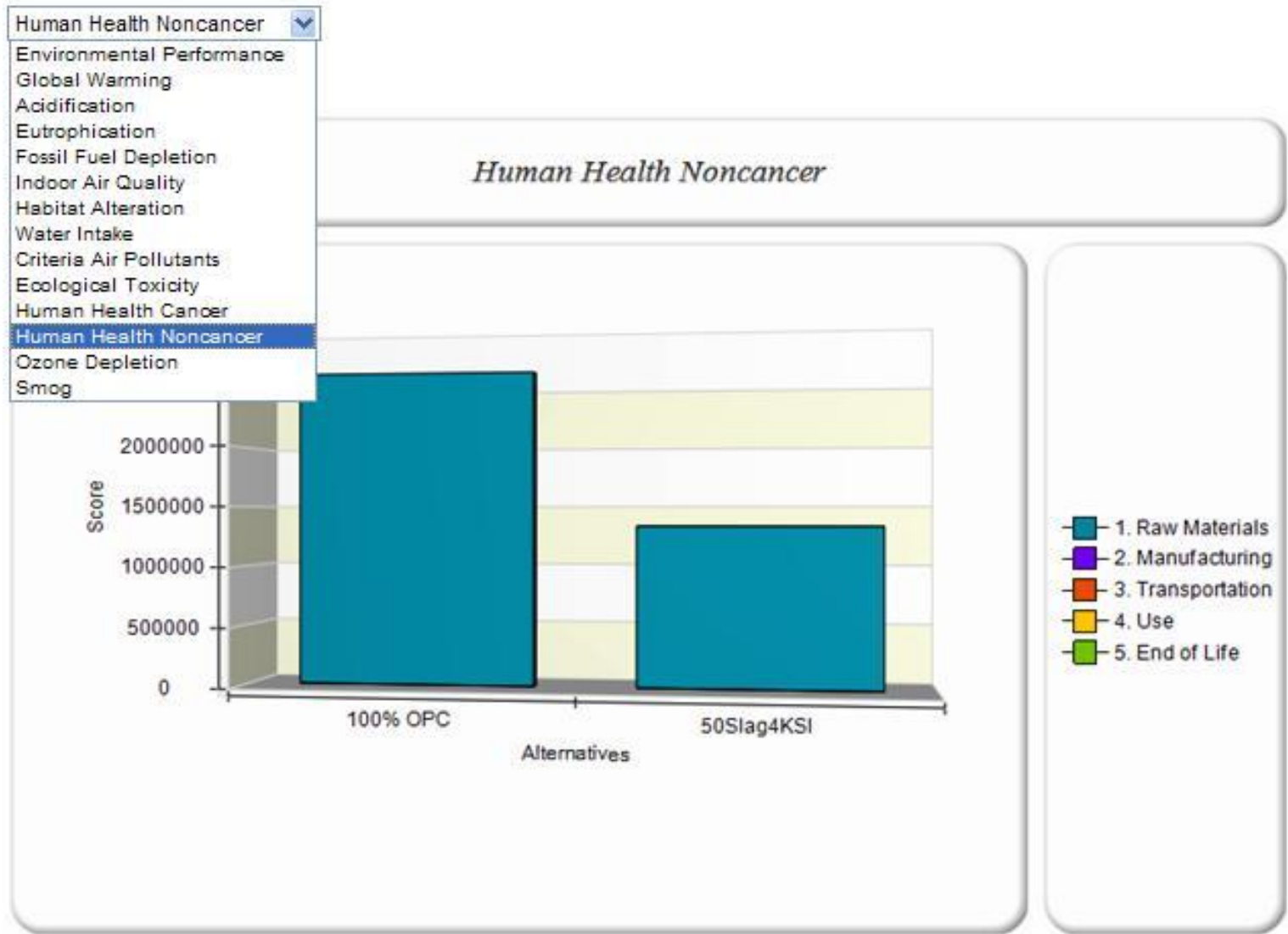

Note: Lower values are better

\begin{tabular}{|c|c|c|}
\hline Category & $100 \%$ OPC & 50 Slag4KSI \\
\hline 1. Raw Materials & 2821888.6104 & 1338873.8937 \\
\hline 2. Manufacturing & 0.0000 & 0.0000 \\
\hline 3. Transportation & 188.0263 & 188.0975 \\
\hline 4. Use & 0.0000 & 0.0000 \\
\hline 5. End of Life & 0.0000 & 0.0000 \\
\hline Sum & 2822056.6367 & 1337041.9912 \\
\hline
\end{tabular}

Figure 7-7 Human Health Noncancer 


\section{BEES}

Home

Help

Osummary Graphs

(-) Life-Cycle Stage Graphs

Environmental Flow Graphs

Embodied Energy Graphs

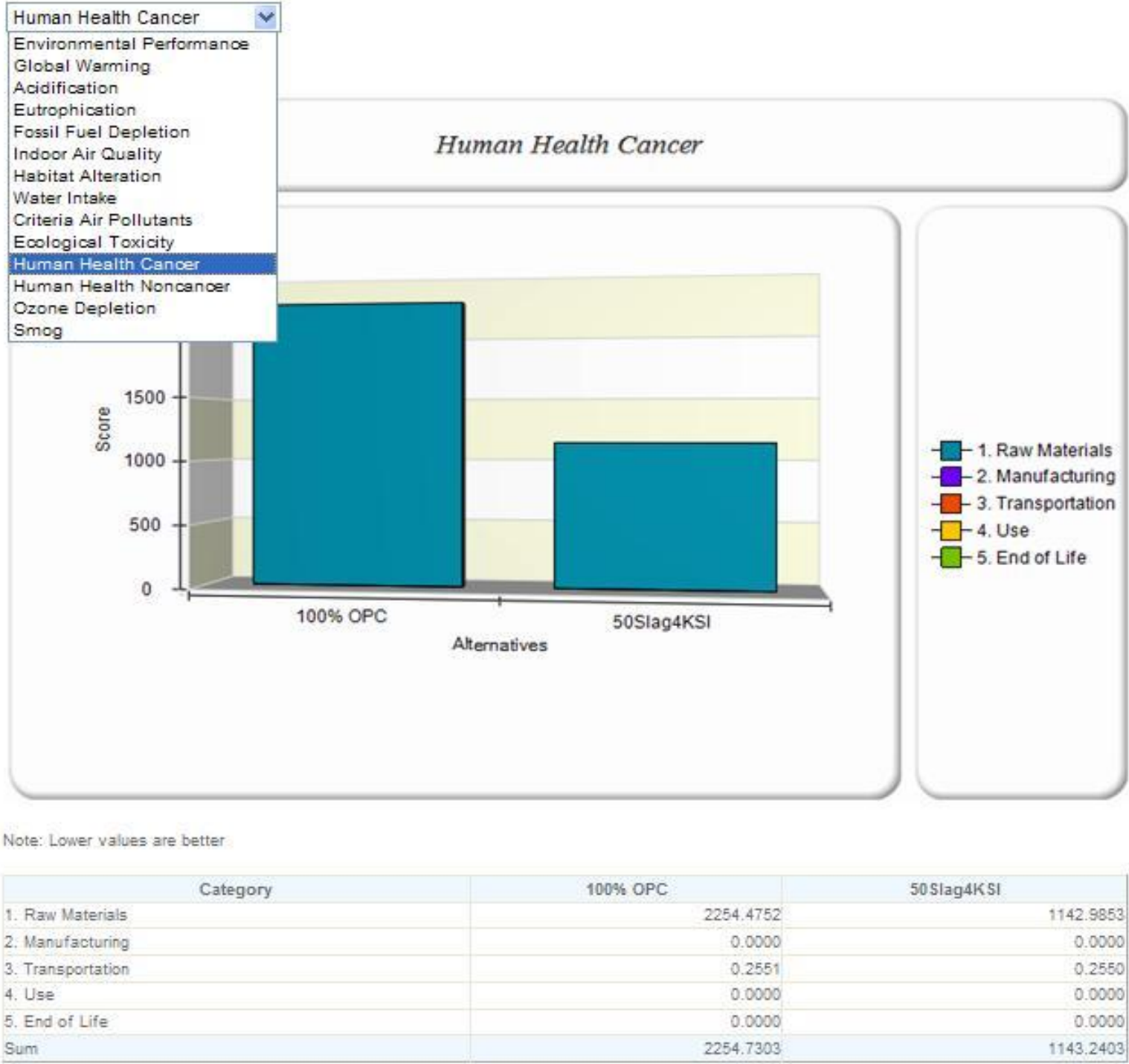

Figure 7-8 Human Health Cancer 


\subsubsection{Eutrophication (Source NIST: BEES 4.0)}

Eutrophication is the addition of mineral nutrients to the soil or water. In both media, the addition of large quantities of mineral nutrients, such as nitrogen and phosphorous, results in generally undesirable shifts in the number of species in ecosystems and a reduction in ecological diversity. In water, it tends to increase algae growth, which can lead to lack of oxygen and therefore death of species like fish.

Characterization factors for potential eutrophication have been developed like those for the global warming potential, with nitrogen as the reference substance. These factors permit computation of a single index for potential eutrophication (in grams of nitrogen per functional unit of product), representing the quantity of nitrogen with the same potential nutrifying effect:

Eutrophication index $=\sum \mathrm{i} \mathrm{mix}_{\mathrm{x}} \mathrm{EP}$, where

$\mathrm{m}_{\mathrm{i}}=$ mass (in grams) of inventory flow $\mathrm{i}$, and

$\mathrm{EP}_{\mathrm{i}}=$ grams of nitrogen with the same potential nutrifying effect as one gram of inventory flow $\mathrm{i}$ 


\section{BEES}

Home

Analysis

Help

Summary Graphs

○ Life-Cycle Stage Graphs

Onvironmental Flow Graphs

Ombodied Energy Graphs

Eutrophication $\vee$

Eutrophication

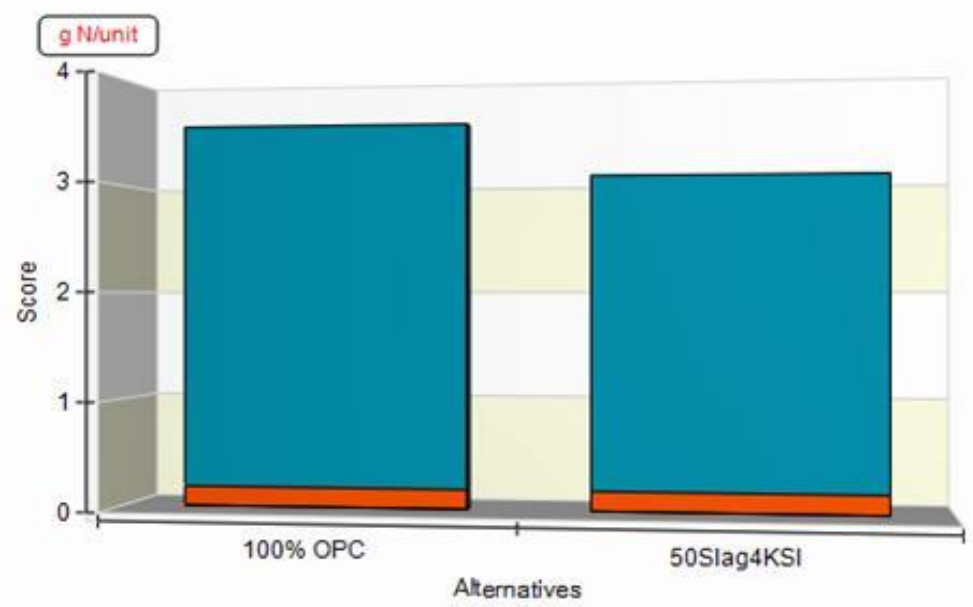

1. Raw Materials

2. Manufacturing

$-\square$ - Transportation

$-\square$ - Use

-5 . End of Life

Note: Lower values are better

\begin{tabular}{|c|c|c|}
\hline Category & $100 \%$ OPC & 50 Slag $4 \mathrm{KSI}$ \\
\hline 1. Raw Materials & 3.3670 & 2.8807 \\
\hline 2. Manufacturing & 0.0000 & 0.0000 \\
\hline 3. Transportation & 0.1809 & 0.1813 \\
\hline 4. Use & 0.0000 & 0.0000 \\
\hline 5. End of Life & 0.0000 & 0.0000 \\
\hline Sum & 3.5479 & 3.0820 \\
\hline
\end{tabular}

Figure 7-9 Eutrophication 


\subsubsection{Indoor air quality (Source NIST: BEES 4.0)}

Indoor air quality impacts are not included in traditional life-cycle impact assessments. Most LCAs conducted to date have been applied to relatively short-lived, non-building products (e.g., paper and plastic bags), for which indoor air quality impacts are not an important issue. However, the indoor air performance of building products is of particular concern to the building community and should be explicitly considered in any building product LCA.

Ideally, characterization factors would be available for indoor air pollutants as they are for other flows such as global warming gases. However, there is little scientific consensus about the relative contributions of pollutants to indoor air performance. In the absence of reliable characterization factors, a product's total volatile organic compound (VOC) emissions are often used as a measure of its indoor air performance. Note that a total VOC measure equally weights the contributions of the individual compounds that make up the measure. Also, reliance on VOC emissions alone may be misleading if other indoor air contaminants, such as particulates, aerosols, and mold, are also present. Finally, total VOC measures are highly dependent on the analytical method used and there is no single analytical method than can measure the entire range of VOCs, rendering the term "total" somewhat misleading.

Indoor air quality is assessed for the following building elements currently covered in BEES: floor coverings, interior wall finishes, chairs, carpet cleaners, glass cleaners, bath and tile cleaner, floor stripper, and adhesive and mastic remover.1 Recognizing the inherent limitations from using total VOCs to assess indoor air quality performance, estimates of total VOC emissions are used as a proxy measure. The total VOC emissions over an initial number of $h$ (e.g., for floor coverings, combined product and adhesive emissions over the first $72 \mathrm{~h}$ ) is multiplied by the number of times over the product category's use period those "initial h" will occur (to account for the possibility of product replacements), to yield an estimate of total VOC emissions per functional unit of product. The result is entered into the life cycle inventory for the product, and used directly to assess the indoor air quality impact. The rationale for this particular approach is that VOC emissions are at issue for a limited period of time after installation. The more installations required then, the greater the indoor air quality impact.

Indoor air quality is discussed in the context of sheathing and insulation products. Sheathing products are often made of wood, which is of concern for its formaldehyde emissions. 
Formaldehyde is thought to affect human health, especially for people with chemical sensitivity. Composite wood products using urea-formaldehyde adhesives have higher formaldehyde emissions than those using phenol-formaldehyde adhesives, and different composite wood products have different levels of emissions. Composite wood products include oriented strand board (OSB) and softwood plywood, both included as sheathing products in BEES. Most OSB is now made using a methylene diphenylisocyanate (MDI) binder, and is modeled as such in BEES. OSB using an MDI binder emits no formaldehyde other than the insignificant amount naturally occurring in the wood itself.2 Softwood plywood also has extremely low indoor formaldehyde emissions because it uses phenol-formaldehyde binders and because it is used primarily on the exterior shell of buildings. 3 Thus, assuming formaldehyde emission is the only significant indoor air concern for wood products, neither of the two composite wood products as modeled in BEES are thought to significantly affect indoor air quality.

Indoor air quality is also an issue for insulation products. The main issues are the health impacts of fibers, hazardous chemicals, and particles released from some insulation products. These releases are the only insulation-related indoor air issues considered in BEES. As a result of its listing by the International Agency for Research on Cancer as a "possible carcinogen," fiberglass products are now required to have cancer warning labels. The fiberglass industry has responded by developing fiberglass products that reduce the amount of loose fibers escaping into the air. For cellulose products, there are claims that fire retardant chemicals and respirable particles are hazardous to human health. Mineral wool is sometimes claimed to emit fibers and chemicals that could be health irritants. For all these products, however, there should be little or no health risks to building occupants if they are installed in accordance with manufacturers' recommendations. Assuming proper installation, then, none of these products as modeled in BEES are thought to significantly affect indoor air quality.

4

All other BEES building elements are primarily exterior elements, or interior elements made of inert materials, for which indoor air quality is not an issue.

\subsubsection{Habitat alteration (Source NIST: BEES 4.0)}

The habitat alteration impact measures the potential for land use by humans to lead to damage of Threatened and Endangered (TandE) Species. In TRACI 1.0, the set of U.S. impact assessment 
methods adopted in BEES, the density of TandE Species is used as a proxy for the degree to which the use of land may lead to undesirable changes in habitats. Note that this approach does not consider the original condition of the land, the extent to which human activity changes the land, or the length of time required to restore the land to its original condition. As impact assessment science continues to evolve, it is hoped that these potentially important factors will become part of the habitat alteration assessment. Future versions of BEES will incorporate improved habitat alteration assessment methods as they become available.

Inventory data are not readily available for habitat alteration assessment across all life cycle stages; the use and end-of-life stages offer the only reliable inventory data for this impact to date. These two stages, though, may be the most important life cycle stages for habitat alteration assessment due to their contributions to landfills. Indeed, an informal evaluation of two interior wall products found that post-consumer landfill use accounted for more than $80 \%$ of the total habitat alteration impact for both products. In BEES, habitat alteration is assessed at the use and end of life stages only, based on the landfilled waste (adjusted for current recycling practices) from product installation, replacement, and end of life. Future versions of BEES will incorporate more life cycle stages as consistent inventory data become available.

Characterization factors have been developed permitting computation of a single index for potential habitat alteration, expressed in TandE Species count per functional unit of product:

Habitat alteration index $=\Sigma \mathrm{i}$ ai $\mathrm{x}$ TED, where

$\mathrm{ai}=$ surface area (in $\mathrm{m} 2$ disrupted) of land use flow $\mathrm{i}$, and TED = U.S. TandE Species density (in TandE Species count per $\mathrm{m}^{2}$ )

\subsubsection{Water intake (Source NIST: BEES 4.0)}

Water resource depletion has not been routinely assessed in LCAs to date, but researchers are beginning to address this issue to account for areas where water is scarce, such as the Western United States. It is important to recognize that this impact addresses only the depletion aspect of water intake, not the fact that activities such as agricultural production and product manufacture may generate water pollution. Water pollution impacts, such as nitrogen runoff from agricultural production, are addressed in other impacts, such as eutrophication. In TRACI 1.0, the set of U.S. impact assessment methods adopted in BEES, the Direct Use of Inventories approach is used to assess water resource depletion. Water intake from cradle to grave is recorded in the BEES life 
cycle inventory for each product (in liters per functional unit), and is used directly to assess this impact.

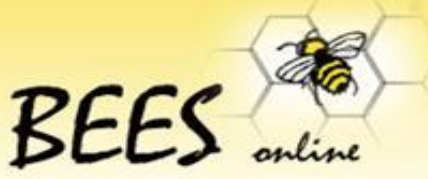

Life Cycle Analysis for Building Products

Home Analysis Help

Summary Graphs

- Life-Cycle Stage Graphs

Environmental Flow Graphs

Embodied Energy Graphs

Water Intake $v$

\section{Water Intake}

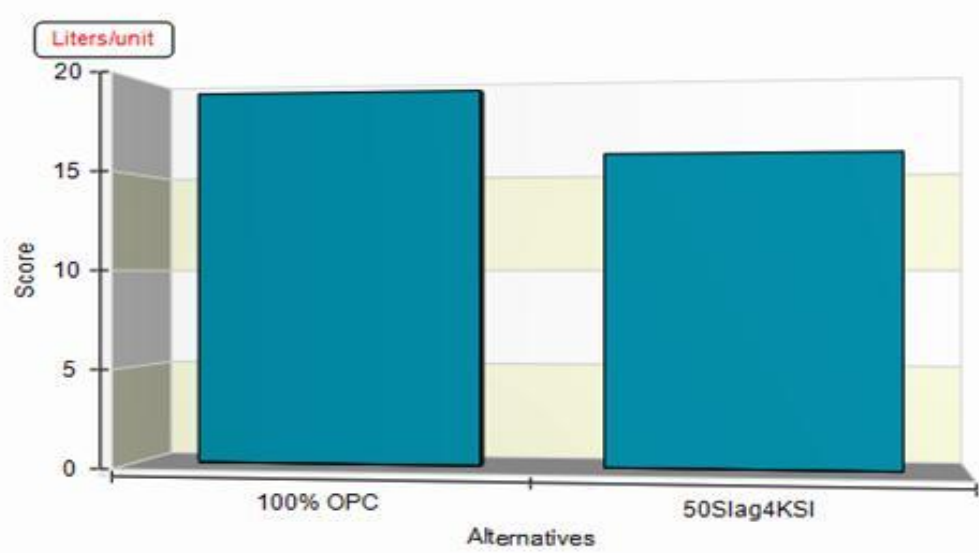

$\square$ 1. Raw Materials

-2. Manufacturing

- - 3. Transportation

$-\square$ - Use

$-\square-5$. End of Life

Note: Lower values are better

\begin{tabular}{|c|c|c|}
\hline Category & $100 \%$ OPC & 50 Slag $4 \mathrm{KSI}$ \\
\hline 1. Raw Materials & 19.2000 & 15.9000 \\
\hline 2. Manufacturing & 0.0000 & 0.0000 \\
\hline 3. Transportation & 0.0000 & 0.0000 \\
\hline 4. Use & 0.0000 & 0.0000 \\
\hline 5. End of Life & 0.0000 & 0.0000 \\
\hline Sum & 19.2000 & 15.9000 \\
\hline
\end{tabular}

Figure 7-10 Water Intake 


\subsubsection{Criteria air pollutants (Source NIST: BEES 4.0)}

- Ozone (ground-level) - A colorless gas that is the major constituent of photochemical smog

- Carbon Monoxide (CO) - An odorless, colorless gas resulting from incomplete fossil fuel combustion.

- Nitrogen Dioxide (NO2) - A brownish gas, belongs to family of reactive gases called oxides of nitrogen (NOx).

- Particulate Matter - Mixture of solid particles and liquid droplets in the air; particles may be visible or microscopic.

- Sulfur Dioxide (SO2) - A colorless gas, odorless at low concentrations, but pungent at very high concentrations.

- Lead - A heavy metal which can cause adverse health effects either through ingestion or direct inhalation. 
Summary Graphs

$\odot_{\text {Life-Cyde Stage Graphs }}$

Environmental Flow Graphs

Embodied Energy Graphs

Criteria Air Pollutants $\checkmark$

Criteria Air Pollutants

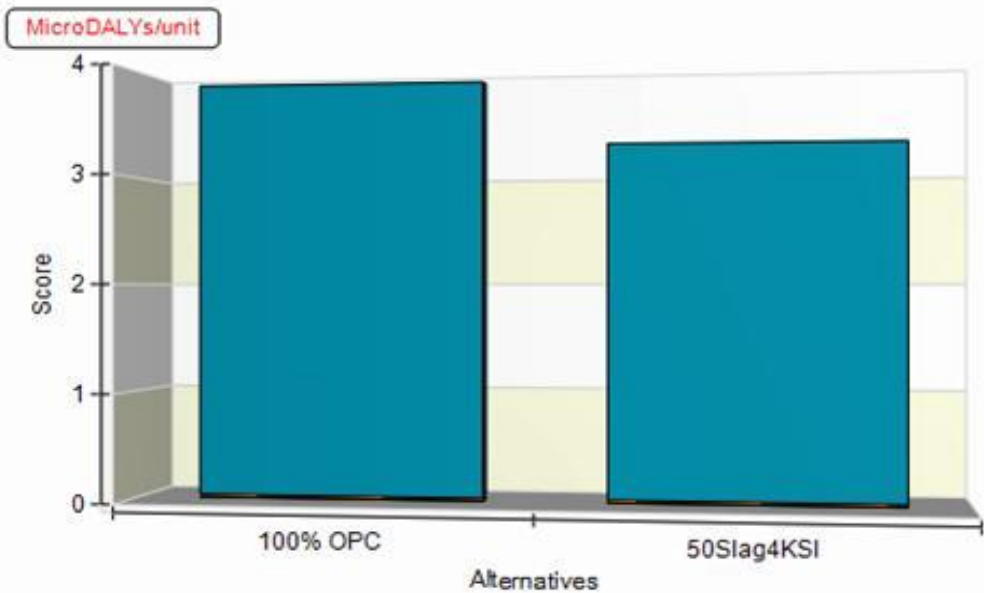

1. Raw Materials

Note: Lower values are better

\begin{tabular}{|c|c|c|}
\hline Category & $100 \%$ OPC & 50 Slag 4 KSI \\
\hline 1. Raw Materials & 3.8407 & 3.2587 \\
\hline 2. Manufacturing & 0.0000 & 0.0000 \\
\hline 3. Transportation & 0.0250 & 0.0251 \\
\hline 4. Use & 0.0000 & 0.0000 \\
\hline 5. End of Life & 0.0000 & 0.0000 \\
\hline Sum & 3.8657 & 3.2838 \\
\hline
\end{tabular}

Figure 7-11Criterial Air Pollution 


\subsubsection{Smog (Source NIST: BEES 4.0)}

Under certain climatic conditions, air emissions from industry and transportation can be trapped at ground level, where they react with sunlight to produce photochemical smog. One of the components of smog is ozone, which is not emitted directly, but rather produced through the interactions of volatile organic compounds (VOCs) and oxides of nitrogen (NOx). Smog leads to harmful impacts on human health and vegetation. In BEES, the smog impact does not account for indoor VOCs that make their way outdoors. Rather, indoor VOCs are evaluated under the BEES Indoor Air Quality impact.

Characterization factors for potential smog formation have been developed for the TRACI set of U.S. impact assessment methods, with nitrogen oxides as the reference substance. These factors permit computation of a single index for potential smog formation (in grams of nitrogen oxides per functional unit of product), representing the quantity of nitrogen oxides with the same potential for smog formation:

$$
\text { Smog index }=\Sigma \mathrm{i} \text { mi x SPi, where }
$$

$\mathrm{mi}=$ mass (in grams) of inventory flow $\mathrm{i}$, and

$\mathrm{SPi}=$ grams of nitrogen oxides with the same potential for smog formation as one gram of inventory flow i 


\section{BEES}

Home

Analysis

Help

Osummary Graphs

$\odot_{\text {Life-Cycle Stage Graphs }}$

Environmental Flow Graphs

Embodied Energy Graphs

Smog v

Smog

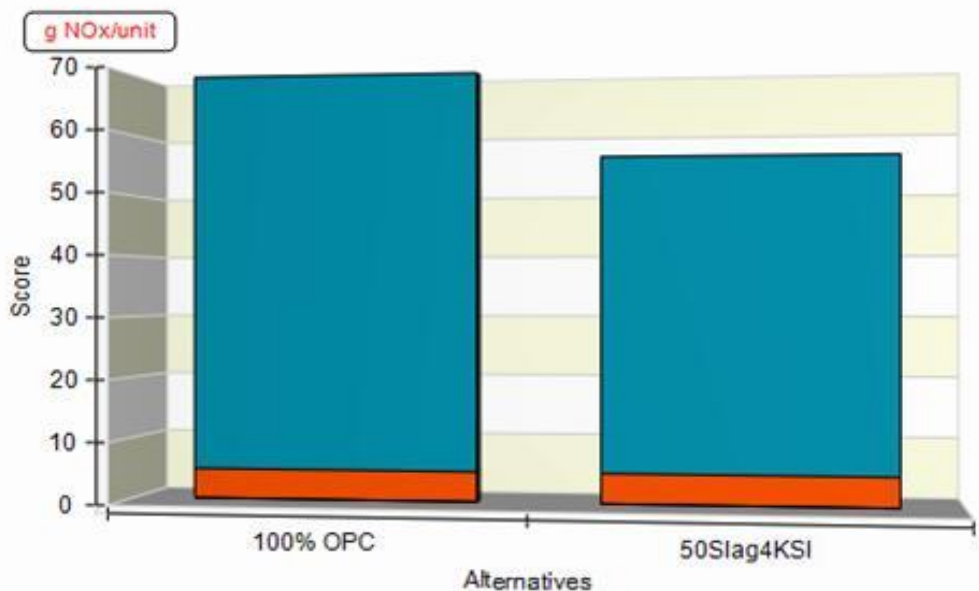

1. Raw Materials

2. Manufacturing

- 3. Transportation

$-\square-4$. Use

$-\square$. End of Life

Note: Lower values are better

\begin{tabular}{|c|c|c|}
\hline Category & $100 \%$ OPC & 50 Slag $4 \mathrm{KSI}$ \\
\hline 1. Raw Materials & 84.7256 & 50.9235 \\
\hline 2. Manufacturing & 0.0000 & 0.0000 \\
\hline 3. Transportation & 4.8733 & 4.8830 \\
\hline 4. Use & 0.0000 & 0.0000 \\
\hline 5. End of Life & 0.0000 & 0.0000 \\
\hline Sum & 69.5989 & 55.8065 \\
\hline
\end{tabular}

Figure 7-12 Smog 


\subsubsection{Ozone depletion (Source NIST: BEES 4.0)}

The ozone layer is present in the stratosphere and acts as a filter absorbing harmful short wave ultraviolet light while allowing longer wavelengths to pass through. A thinning of the ozone layer allows more harmful short wave radiation to reach the Earth's surface, potentially causing changes to ecosystems as flora and fauna have varying abilities to cope with it. There may also be adverse effects on agricultural productivity. Effects on man can include increased skin cancer rates (particularly fatal melanomas) and eye cataracts, as well as suppression of the immune system. Another issue is the uncertain effect on the climate.

Characterization factors for potential ozone depletion are included in the TRACI set of U.S. impact assessment methods, with CFC-11 as the reference substance. These factors permit computation of a single index for potential ozone depletion (in grams of CFC-11 per functional unit of product), representing the quantity of $\mathrm{CFC}-11$ with the same potential for ozone depletion:

Ozone depletion index $=\Sigma \mathrm{i}$ mi x OPi, where

$\mathrm{mi}=$ mass (in $\mathrm{g})$ of inventory flow $\mathrm{i}$, and

$\mathrm{OP} i=$ grams of CFC-11 with the same ozone depletion potential as one gram of inventory flow $\mathrm{i}$ 
BEES

Life Cycle Analysis for Building Products

Home

Analysis

Help

Summary Graphs

$\odot_{\text {Life-Cycle Stage Graphs }}$

Environmental Flow Graphs

Ombodied Energy Graphs

Ozone Depletion

$\checkmark$

\section{Ozone Depletion}

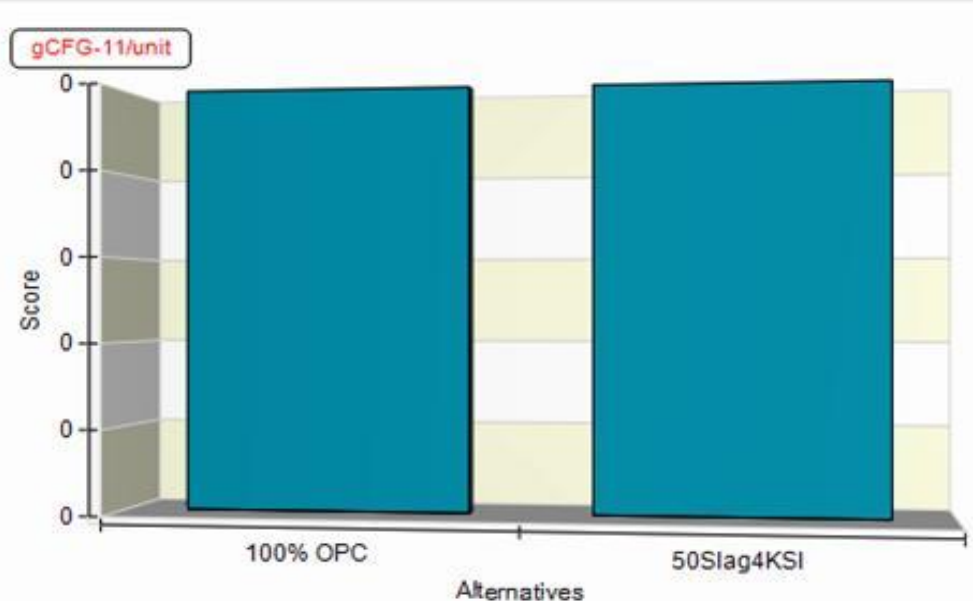

- 2. Manufacturing

$-\square$ 3. Transportation

$-\square$ - Use

-5 . End of Life

Note: Lower values are better

\begin{tabular}{|c|c|c|}
\hline Category & $100 \%$ OPC & 50 Slag4KSI \\
\hline 1. Raw Materials & 0.0001 & 0.0001 \\
\hline 2. Manufacturing & 0.0000 & 0.0000 \\
\hline 3. Transportation & 0.0000 & 0.0000 \\
\hline 4. Use & 0.0000 & 0.0000 \\
\hline 5. End of Life & 0.0000 & 0.0000 \\
\hline Sum & 0.0001 & 0.0001 \\
\hline
\end{tabular}

Figure 7-13 Ozone Depletion 


\subsubsection{Overall Performance (Source NIST: BEES 4.0)}

The BEES overall performance measure synthesizes the environmental and economic results into a single score, as illustrated in the BEES Online Model Graphic help item. Yet the environmental and economic performance scores are denominated in different units. How can these diverse measures of performance be combined into a meaningful measure of overall performance? The most appropriate technique is Multi-attribute Decision Analysis (MADA). MADA problems are characterized by tradeoffs between apples and oranges, as is the case with the BEES environmental and economic performance results. The BEES system follows the ASTM standard for conducting MADA evaluations of building-related investments.

Before combining the environmental and economic performance scores, each is placed on a common scale by dividing by the sum of corresponding scores across all alternatives under analysis. In effect, then, each performance score is rescaled in terms of its share of all scores, and is placed on the same, relative scale from 0 to 100 . Then the two scores are combined into an eco-efficiency score by weighting environmental and economic performance by their relative importance and taking a weighted average. The BEES user specifies the relative importance weights used to combine environmental and economic performance scores and should test the sensitivity of the eco-efficiency scores to different sets of relative importance weights. 
() Summary Graphs

Life-Cycle Stage Graphs

Environmental Flow Graphs

OEmbodied Energy Graphs

\begin{tabular}{l}
\hline Overall Performance \\
\hline Economic Performance \\
Environmental Performance \\
Overall Performance
\end{tabular}

Overall Performance

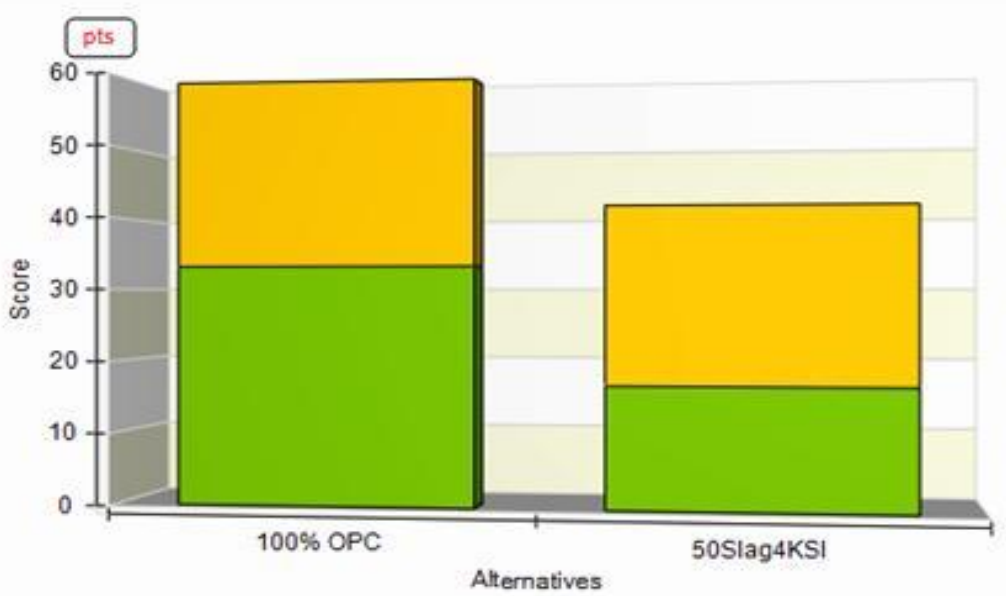

ㅁ- Ecen Peftorm - $500 \%$ $-\square$ - Envinon. Perlorm - $50 \%$

Note: Lower valuas are better

\begin{tabular}{|c|c|c|}
\hline Category & $100 \%$ OPC & 50 Slag $4 \mathrm{KSI}$ \\
\hline Eoon. Perform.-50.0\% & 25.5721 & 24.4279 \\
\hline Environ. Perform, $-50.0 \%$ & 33.1289 & 16.8711 \\
\hline Sum & 58.7010 & 41.2990 \\
\hline
\end{tabular}

Figure 7-14 Overall Performance 


\subsection{Using BEES 4.0}

BEES 4.0 had been used for the study of the sustainability aspect of high volume fly ash and/or slag modified concrete. For this purpose one model beam and one model column is designed using ACI 318-08. The calculations are described below.

$$
\begin{aligned}
& \mathrm{a}:=\mathrm{d}-\sqrt{\mathrm{d}^{2}-2 \frac{|\mathrm{Mu}|}{0.85 \mathrm{fc} \cdot \phi \cdot \mathrm{b}}} \\
& \text { Cmax }:=\frac{\xi \mathrm{cmax} \cdot \mathrm{d}}{\xi \mathrm{cmax}+\xi \mathrm{smin}}
\end{aligned}
$$

$\xi \mathrm{cmax}:=0.003$

$\xi \operatorname{smin}:=0.005$

$\operatorname{amax}:=\beta 1 \mathrm{Cmax}$

$\beta 1:=0.85-0.05 \frac{(\mathrm{fc}-4000)}{1000}$

$0.65 \leq \beta 1 \leq 0.85$

So the section reduction factor is given by the ratio of $\beta_{1}$.

In the same manner for Column,

$P:=0.85 \mathrm{fc} \cdot(\mathrm{Ag}-\mathrm{Ast})+$ Ast $\cdot \mathrm{fy}$

As $\mathrm{A}_{\mathrm{st}}<<\mathrm{A}_{\mathrm{g}}$, so,

$\mathrm{f}_{\mathrm{c}} \infty 1 / \mathrm{A}_{\mathrm{g}}$

So the section reduction factor is calculated by the ratio of compressive strength.

Then the following steps are followed in the BEES 4.0 software to generate the data.

The steps are as follows, 


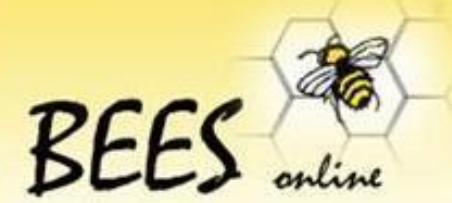

Life Cycle Analysis for Buliding Products

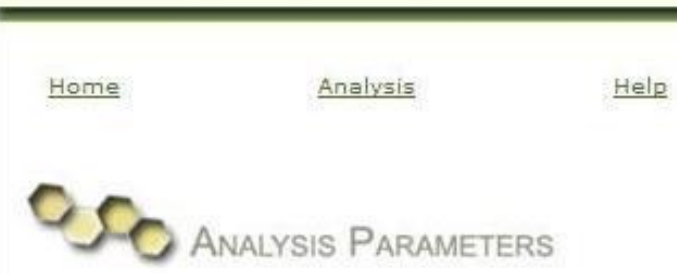

Environmental Impact Category Weights

$\square$ No Weighting

View Predefined Weights

BEES Stakeholder Panel

EPA Science Advisory Board-based

Equal Weights

User-Defined

Eutrophication

Fossil Fuel Depletion

Indoor Air Quality

Habitat Alteration

Water Intake

Criteria Air Pollutants

Smog

Ecotoxicity

Ozone Depletion

Human Health

Sum:

Select No Weighting

for

environmental daims

\section{Performance Weights}

Environmental Performance (96): 50

Economic Performance (1\%): 50

Discount Rate( 96 )(Excluding Inflation): 2.7

Building Element for Comparison

Major Group Element

Building Maintenance

Group Element

Cleaning Products

Individusl Element

Bath and Tile Cleaners

View Product List

Clids the Next button to select product alternatives:

Next

Figure 7-15 Using Bees 4.0

In 1990 and again in 2000, EPA's Science Advisory Board (SAB) developed lists of the relative importance of various environmental impacts to help EPA best allocate its resources. The following criteria were used to develop the lists:

- The spatial scale of the impact 
- The severity of the hazard

- The degree of exposure

- The penalty for being wrong

Ten of the twelve BEES impact categories were included in the SAB lists of relative importance:

- Highest-Risk Problems: global warming, habitat alteration

- High-Risk Problems: indoor air quality, ecological toxicity, human health

- Medium-Risk Problems: ozone depletion, smog, acidification, eutrophication, criteria air pollutants

The SAB did not explicitly consider fossil fuel depletion or water intake as impacts. For this exercise, fossil fuel depletion and water intake are assumed to be relatively medium-risk and low-risk problems, respectively, based on other relative importance lists. 2

Verbal importance rankings, such as "highest risk," may be translated into numerical importance weights by following ASTM standard guidance provided by a Multi-attribute Decision Analysis method known as the Analytic Hierarchy Process (AHP).з The AHP methodologies suggests the following numerical comparison scale:

1 Two impacts contribute equally to the objective (in this case environmental performance)

3 Experience and judgment slightly favor one impact over another

5 Experience and judgment strongly favor one impact over another

7 One impact is favored very strongly over another, its dominance demonstrated in practice

9 The evidence favoring one impact over another is of the highest possible order of affirmation

2,4,6,8 When compromise between values of $1,3,5,7$, and 9 , is needed. 


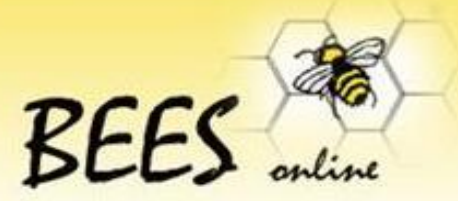

Lifo Cycle Analysis for Buliding Products

Home

Analysis

Help

\section{AnAlysis Parameters}

Environmental Impact Category Weights

$\square$ No Weighting

View Predefined Weights

BEES Stakeholder Panel

Impact

Global Warming

Acidification

Eutrophication

Fossil Fuel Depletion

Indoor Air Quality

Habitat Alteration

Water Intake

Criteria Air Pollutants

Smog

Ecotoxicity

Ozone Depletion

Human Health

Sum:

Select No Weighting

for

environmentsl deims
Performance Weights

Environmental Performance (\%): 50

Economic Performance ( $\%$ ): 50

Discount Rate( $\%$ )/Excluding Inflation): 2.7

Building Element for Comparison

Major Group Element

Building Maintenance

Building Maintenance

Building Repair \& Remodeling

Building Sitework

Equipment \& Furnishings

Interiors

Services

Shell

Substructure

View Product List

Cliok the Next button to select

product alternatives.

Next

Figure 7-16 Choosing Major Group Element

Then major group element is selected. 
BEES

Life Cycle Analysis for Bullding Products

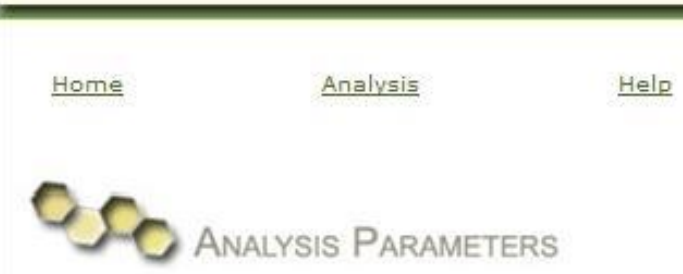

Environmental Impact Category Weights

$\square$ No Weighting

View Predefined Weights

BEES Stakeholder Panel v

Global Warming Impact

Acidification

Eutrophication

Fossil Fuel Depletion

Indoor Air Quality

Habitat Alteration

Water Intake

Criteria Air Pollutants

Smog

Ecotoxicity

Ozone Depletion

Human Health

Sum:

Select No Weighting

for

environmentsl daims

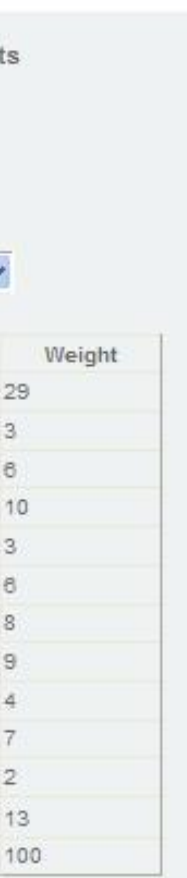

\section{elp}

Performance Weights

Environmental Performance (\%): 50

Economic Performance ( $\%$ ): 50

Discount Rate( 96 )(Excluding Inflation): 2.7

Building Element for Comparison

Major Group Element

Shel

$\checkmark$

Group Element

Exterior Enclosure

Exterior Enclosure

Roofing

Superstructure

View Product List

Clidk the Next button to select

product alternatives.

Next

Figure 7-17 Choosing Group Element

Then group element is selected. 


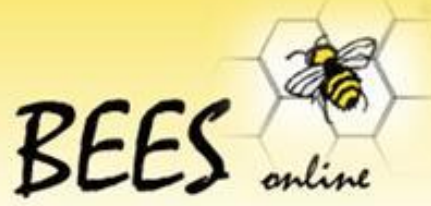

Lifo Cycle Analysis for Bullding Products

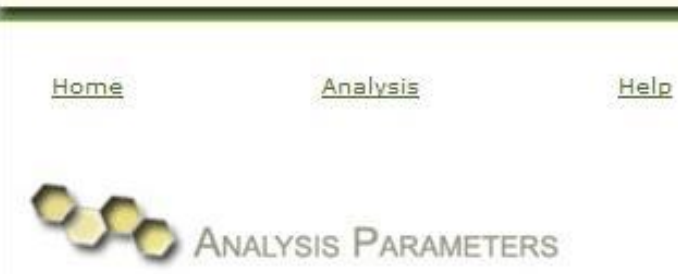

Environmental Impact Category Weights

$\square$ No Weighting

View Predefined Weights

BEES Stakeholder Panel

Impact

Global Warming

Acidification

Eutrophication

Fossil Fuel Depletion

Indoor Air Quality

Habitat Alteration

Water Intake

Criteria Air Pollutants

Smog

Ecotoxicity

Ozone Depletion

Human Health

Sum

Select No Weighting

for

environmental daims

\section{Performance Weights}

Environmental Performance (\%):

Economic Performance (\%): 50

Discount Rate(\%)(Excluding Inflation): 2.7

Building Element for Comparison

Major Group Element

Shell

Group Element

Superstructure

Individual Element

Beams

Beams

Columns

Roof Sheathing

Clidk the Next button to select

product alternatives.

Next

Figure 7-18 Choosing Element

Then individual element is selected. 
BEES

Life Cycle Analysis for Building Products

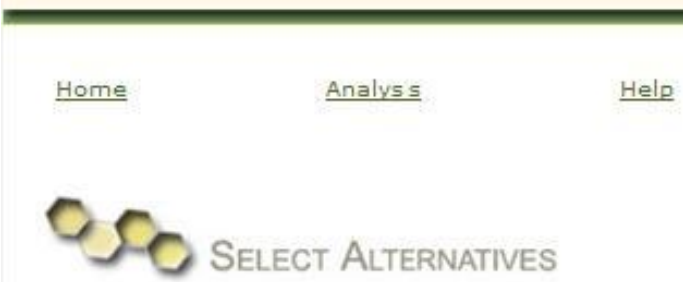

Select Product Altermatives

Update Product Details

Generic $100 \%$ Portland Cement 4KSI

Generic $100 \%$ Portland Cement $5 \mathrm{KSI}$

Generic 15\% Fly Ash Cement 4KSI

Generic 15\% Fly Ash Cement $5 \mathrm{KSI}$

Generic 20\% Fly Ash Cement 4KSI

Generic 20\% Fly Ash Cement 5KSI

Generic 20\% Limestone Cement 4KSI

Generic 20\% Limestone Cement 5KSI

Generic $20 \%$ Slag Cement $4 \mathrm{KSI}$

Generic $20 \%$ Slag Cement $5 \mathrm{KSI}$

Generic 35\% Slag Cement $4 \mathrm{KSI}$

Generic 35\% Slag Cement $5 \mathrm{KSI}$

Generic 5\% Limestone Cement $4 \mathrm{KS}$

Generic 5\% Limestone Cement $5 \mathrm{KSI}$

Generic $50 \%$ Slag Cement $4 \mathrm{KSI}$

\section{View Product Datg}

Generic $100 \%$ Portland Cement 4KSI

Transportation distance from manufacture to use: 50 miles

80 kilometers Update

Select Alternative

Figure 7-19 Selection of Alternatives

Then product alternatives are selected. 
Select Product Altermatives

Generic 35\% Slag Cement 5KSI

Generic 5\% Limestone Cement 4KSI

Generic 5\% Limestone Cement 5KSI

Generic 50\% Slag Cement 4KSI

Generic 50\% Slag Cement 5KSI

Lafarge NewCem Slag Cement $4 \mathrm{KSI}(20 \%)$

Lafarge NewCem Slag Cement $4 \mathrm{KSI}(35 \%)$

Lafarge NewCem Slag Cement $4 \mathrm{KSI}(50 \%)$

Lafarge NewCem Slag Cement 5KSI $(20 \%)$

Lafarge NewCem Slag Cement $5 \mathrm{KSI}(35 \%)$

Lafarge NewCem Slag Cement $5 \mathrm{KSI}(50 \%)$

Lafarge Portland Type I Cement 4KSI

Lafarge Portland Type I Cement 5KSI

Lafarge Silica Fume Cement 4KSI

Lafarge Silica Fume Cement $4 \mathrm{KSI}$
Update Product Details

\section{View Product Data}

Generic 50\% Slag Cement 4KSI

Transportation distance from manufacture to use: 50 miles

80 kilometers Update

\begin{tabular}{|l|l|l|}
\hline & \multicolumn{1}{c|}{ Product } & \multicolumn{1}{c|}{ Distance (miles) } \\
\hline Delete & Generic 100\% Portland Cement 4KSI & 50 \\
\hline Delete & Generic 15\% Fly Ash Cement 4KSI & 50 \\
\hline Delete & Generic 20\% Fly Ash Cement 4KSI & 50 \\
\hline Delete & Generic 20\% Slag Cement 4KSI & 50 \\
\hline Delete & Generic 35\% Slag Cement 4KSI & 50 \\
\hline Delete & Generic 50\% Slag Cement 4KSI & 50 \\
\hline
\end{tabular}

Compute

Figure 7-20 Data Generation

All the product alternatives are selected before computation of data. 
Home Analysis Help

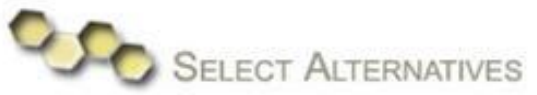

Select Product Altermatives

Generic 35\% Slag Cement 5KSI Generic 5\% Limestone Cement $4 \mathrm{KSI}$

Generic 5\% Limestone Cement 5KSI

Generic $50 \%$ Slag Cement $4 \mathrm{KSI}$

Generic $50 \%$ Slag Cement $5 \mathrm{KSI}$

Lafarge NewCem Slag Cement $4 \mathrm{KSI}(20 \%)$

Lafarge NewCem Slag Cement $4 \mathrm{KSI}(35 \%)$

Lafarge NewCem Slag Cement $4 \mathrm{KSI}(50 \%)$

Lafarge NewCem Slag Cement 5KSI (20\%)

Lafarge NewCem Slag Cement 5 KSI (35\%)

Lafarge NewCem Slag Cement $5 \mathrm{KSI}(50 \%)$

Lafarge Portland Type I Cement 4KSI

Lafarge Portland Type I Cement 5KSI

Lafarge Silica Fume Cement $4 \mathrm{KSI}$

Lafarge Silica Fume Cement $4 \mathrm{KSI}$
Update Product Details

View Product Data

Generic $50 \%$ Slag Cement 4KSI

Transportation distance from manufacture to use: 50 miles

80 kilometers Update

\begin{tabular}{|l|l|l|}
\hline & \multicolumn{1}{c|}{ Product } & \multicolumn{1}{c|}{ Distance (miles) } \\
\hline Delete & Generic 100\% Portland Cement 4KSI & 50 \\
\hline Delete & Generic 15\% Fly Ash Cement 4KSI & 50 \\
\hline Delete & Generic 20\% Fly Ash Cement 4KSI & 50 \\
\hline Delete & Generic 20\% Slag Cement 4KSI & 50 \\
\hline Delete & Generic 35\% Slag Cement 4KSI & 50 \\
\hline Delete & Generic 50\% Slag Cement 4KSI & 50 \\
\hline \hline
\end{tabular}

Figure 7-21View Report

Then view report button is clicked after the computation of data. The results are collected from the table and the graph is saved for future reference. As the BEES 4.0 does not support the 
amount of replacement of cement for high volume fly ash and/or slag modified concrete, so obtained results are modified with different factors to generate data for high volume fly ash and/or slag modified concrete.

\subsection{Assumptions of Sustainability Check}

1. BEES 4.0 are used to select environmentally-preferred, cost effective building products using a science-based and standards-driven performance rating system. This software is used to compare among the various building products to choose how green and sustainable they are.

2. For environmental impact analysis, BEES used 4.0 Tools for Reduction and Assessment of other Chemical Impacts (TRACI) by EPA approach. The ASTM E 2129 (2010) was used for data collection for sustainability assessment of building products and definitions. ASTM E 917 (2005) was used for measuring the life-cycle costs (LCC) of buildings and building systems. The manufacturing data used in BEES for concrete products were taken from the Portland Cement Association's LCA database.

3. The BEES 4.0 software considers both environmental and economic performance in a single performance score to express the overall life-cycle performance. Lower the score better is the performance. The observations are always relative; no absolute values have any significance on our study.

4. The various environmental impacts were done using 'single index' parameter expressed as summation of product of mass of individual inventory flow and its corresponding potential of harmful effect with respect to a standard as prescribed by Tools for Reduction and Assessment of other Chemical Impacts (TRACI) by EPA.

5. BEES life cycle scores Environmental and economic performances are two different attributes of building product performance. The BEES model assumes that competing product alternatives all meet minimum technical performance requirements. However, there may be significant differences in technical performance, such as acoustic or fire performance, which may outweigh environmental and economic considerations. In our case all the concrete products met the minimum criteria for strength and durability requirements. 
6. The economic performance includes the life-cycle cost (sum of first cost and discounted future cost).

7. The environmental performance considers the weighted impact category for the following criteria. The options are provide for four different weighted impact categories. These are: (1) EPA Science Advisory Board; (2) BEES Stakeholder Panel; (3) Equal Weight; and (4) User-defined weight. In our study the EPA Science Advisory Board weight percentages were used. We compared the effect of other weight percentages (say BEES stakeholder, equal weights and user-defined) and found that they have little effect on the relative environmental performance scores (not absolute scores) among different products used by us. It is to be mentioned that with the changes in pattern of life, the weight percentages can vary in future.

The criteria considered for environmental performance are as follows:

- Global warming

- Ecological toxicity

- Fossil fuel depletion

- Human health

- Acidification

- Euthrophication

- Indoor air quality

- Habitat alteration

- Water intake

- Criteria air pollutants

- Smog

- Ozone depletion

The sensitivity of the human health criteria on the result is very high; therefore for even a small weighted percentage of human health, a large magnitude of human health impact is displayed among the entire environmental performance. For example even for $1 \%$ of weighted percentage assigned to human health, we found about $90 \%$ of environmental impact is due to human health. 


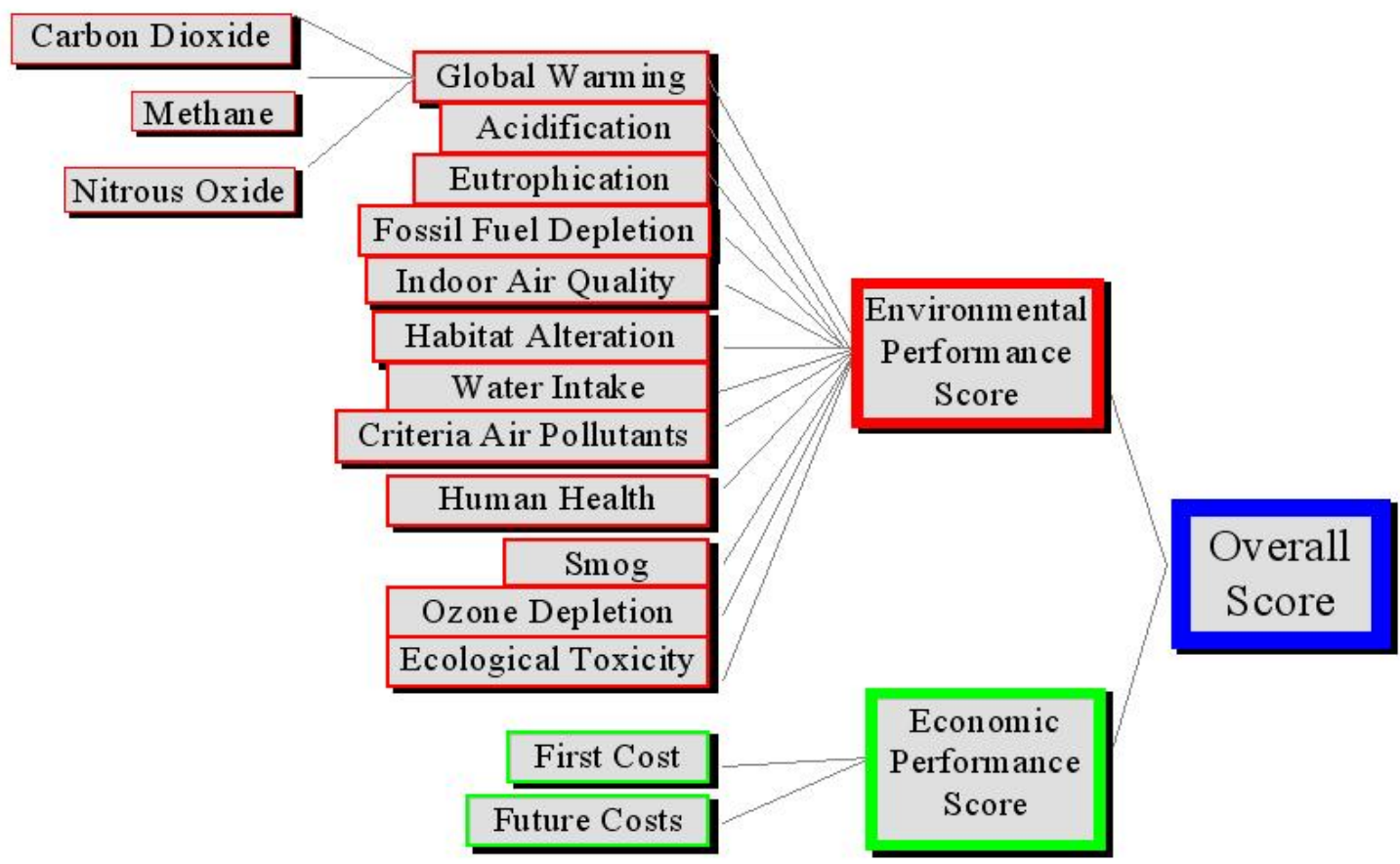

Figure 7-22BEES Model

8. The inventory data for LCA used here are mostly collected data derived from a representative sample of locations believed to statistically describe the typical process across technologies, which is also known as industry-average data. For some products, the unit-process and facility specific data are used. The inventory analysis included the quantifying the inventory flows for a product system. Following figure shows the BEES inventory data category. 


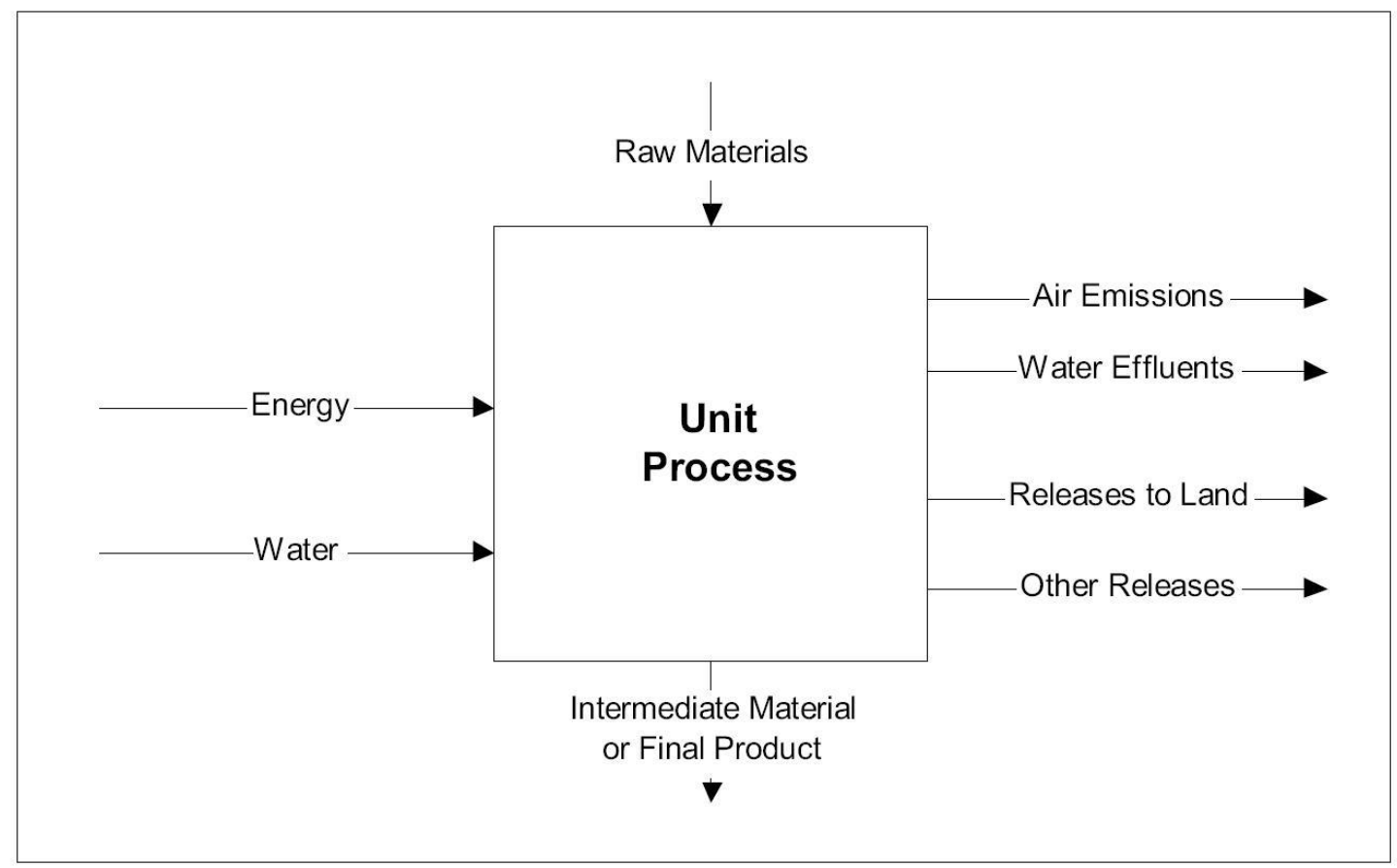

Figure 7-23 Unit Process

9. The sum of economic performance and environmental performance is presented as overall performance. The weight percentage of each of the economic performance and environmental performance are taken as $50 \%$.

10. For environmental performance study in the life-cycle stages of the products, only the following four criteria are explained for brevity. These four criteria are also highly relevant as our study is concerned to find the greener and sustainable concrete materials. Structural shapes and types are not considered in this study.

- Global warming

- Ecological toxicity

- Fossil fuel depletion

- Human health

11. The embodied energy is compared both in terms of its fuel usage (feedstock and fuel energy) and fuel renewability (nonrenewable and renewable).

12. BEES overall performance scores do not represent absolute performance. They represent relative performances among competitive alternatives. Since they are relative performance 
scores, no conclusions may be drawn by comparing overall scores across building elements. So no comparisons are possible between roof and wall or between column and beam.

13. In our case we used BEES 4.0 to compare the performance among various concrete products developed by us such as control concrete (without replacement of cement), concrete with replacement of cement from $40 \%$ to $70 \%$ by fly ash and/or slag by weight of cement. The $\mathrm{w}-\mathrm{cm}$ ratio was accordingly varied to achieve and maintain the high strength. Although our materials can be used in civil infrastructures such as concrete pavements, piers, and foundations; BEES analysis is only capable of analyzing columns, beams, foundations, slabs, roofs, and walls for commercial and residential buildings.

14. In our example we have showed individual element such as column and a beam element. The definition of building elements were taken from ASTM E2129 (2010). The ranking of the elements were done by ASTM UNIFORMAT II classification (2005).

15. In this example to demonstrate the relative advantages and disadvantages of various concretes, we considered two structural elements: a column element and a beam element.

16. Due to very low w-cm ratios, all the concretes with high volume fly ash and/or slag achieved high strength at 28 days. In this example for the comparative studies among alternatives, this effect of enhanced strength was also considered by reducing the sections of structural elements (beam and a column) for a given load bearing capacity. The design was done per ACI 318.

17. Since BEES 4.0 software does not allow more than $50 \%$ of slag and $35 \%$ of fly ash, we added the effects of performance indexes linearly. No interaction or overlapping was considered. For example to achieve $60 \%$ slag, we added the individual benefits of $30 \%$ slag. This is logical as our main purpose is to compare the economic, environmental and energy benefits, those are proportionally increased with the increase of replacement materials, unless the strength or durability is affected. In our case all the replacement had enough strength as well as very good durability.

18. The LCA and LCC are based on generic and manufacture based products. Some of the inventory flows not scientific and tested, were not included in impact assumption. The BEES LCA and LCC approaches produce U.S. average performance results for generic and manufacturer-specific product alternatives. The results do not apply to products sold 
in other countries where manufacturing and agricultural practices, fuel mixes, environmental regulations, transportation distances, and labor and material markets may differ.

19. LCA for building product is relatively new and this is subject to evolutions with time. This method of impact analysis is the state-of art methods, therefore needs to be changed with time.

20. The BEES LCAs do not incorporate uncertainty analysis as required by ISO 14040 (International Organization for Standardization (ISO), Environmental Management- Life Cycle Assessment-Principles and Framework, 2006).

21. It also excludes the uncertainty unaccounted data. Those inventory flows which currently do not have scientifically proven or quantifiable impacts on the environment are excluded, such as mineral extraction and wood harvesting which are qualitatively thought to lead to loss of habitat and an accompanying loss of biodiversity.

22. The economic performance was measured in accordance with ASTM E 917 (2005). The economic performance is measured over a 50- year study period. The study period is not necessarily the life of the building. It is a period based on the way the building will be used or owned. A 50-year study period will avoid the future uncertainties and problem of being obsolete.

23. It is important that for consistency, the BEES model evaluates the use stage of environmental performance over the same 5- year study period. Product replacements over this 50-year period are accounted for in the life cycle inventory analysis and the end-oflife inventory flows are prorated to year 50 for product with lives longer than the 50- year study period.

24. In the economic performance study all the future costs were converted to the present value (base time) by using a discount rate. BEES 4.0 use a real discount rate with constant-dollar costs. Real discount rates reflect that portion of the time value of money attributable to the real earning power of money over time and not to general price inflation.

25. The rate used was $2.7 \%$ which is 2010 rate mandated by U.S. Office of Management and Budget for most Federal Project. 
26. There are inherent limits to comparing product alternatives without reference to the whole building design context. Such comparisons may overlook important environmental and cost interactions among building elements. For example, the useful life of one building element (e.g., floor coverings), which influences both its environmental and economic performance scores, may depend on the selection of related building elements (e.g., subflooring). There is no substitute for good building design.

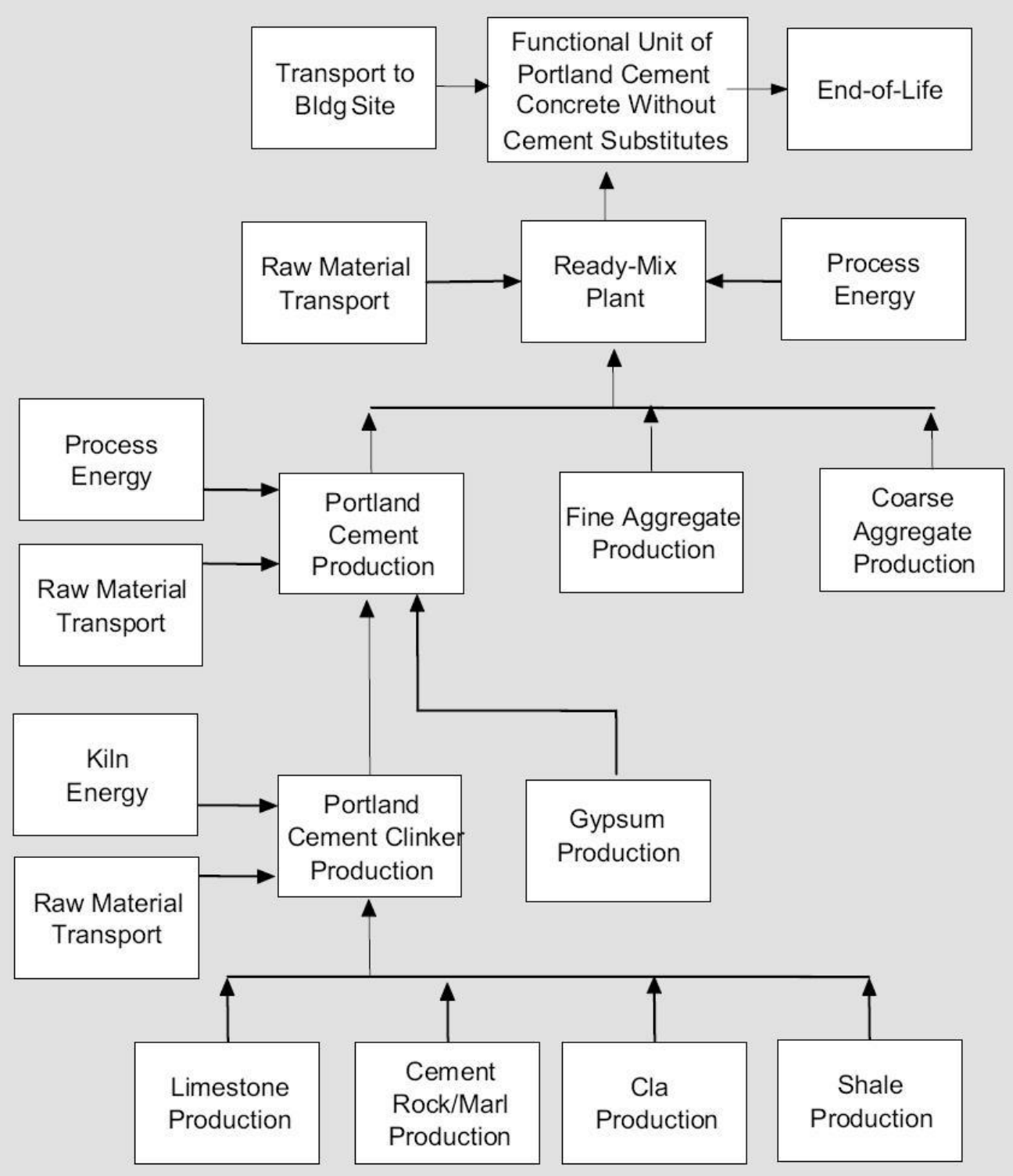

Figure 7-24 Portland Cement Production (NIST : BEES 4.0) 


\subsection{Results and Discussion on Sustainability Check}

The data generated from BEES 4.0 is plotted to get the overview of sustainability of our concrete products.

\subsubsection{Beam Element}

Results of the element beam are described here.

\subsubsection{Economic Performance}

The Economic perfomance performance does not change, when compared with the control mix, but difference with the $100 \%$ OPC (4KSI) is due to the strength factor. In fact the concrete mix, where $70 \%$ cement is replaced by fly ash and/or slag combination, that cost more than control mix, which accounts for high amount of high range water reducing admixture. Concrete mixes with increasing fly ash replacement, showed increase in cost too, where the cost reuduces significantly as the amount of slag in mix increases. Concrete mixes where cement is replaced by the combination of fly ash and/or slag, concrete with $60 \%$ cement replacement showed least price among all.

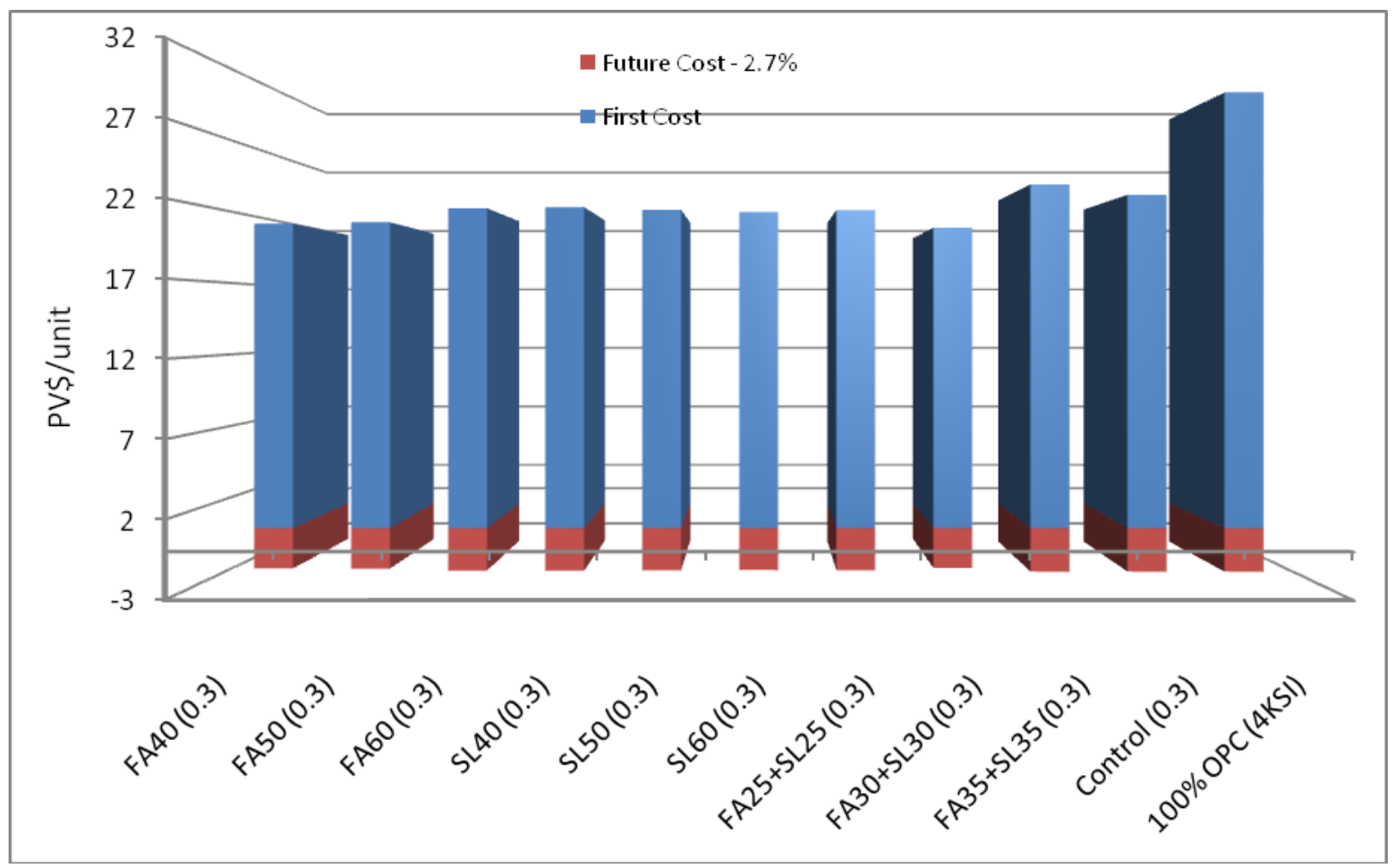

Figure 7-25 Economic Performance (Beam) 


\subsubsection{Environmental Performance}

Environmental performances showed major improvement as there is visible difference with the control mix is observed. As the replacement increases the environmental performance become better.

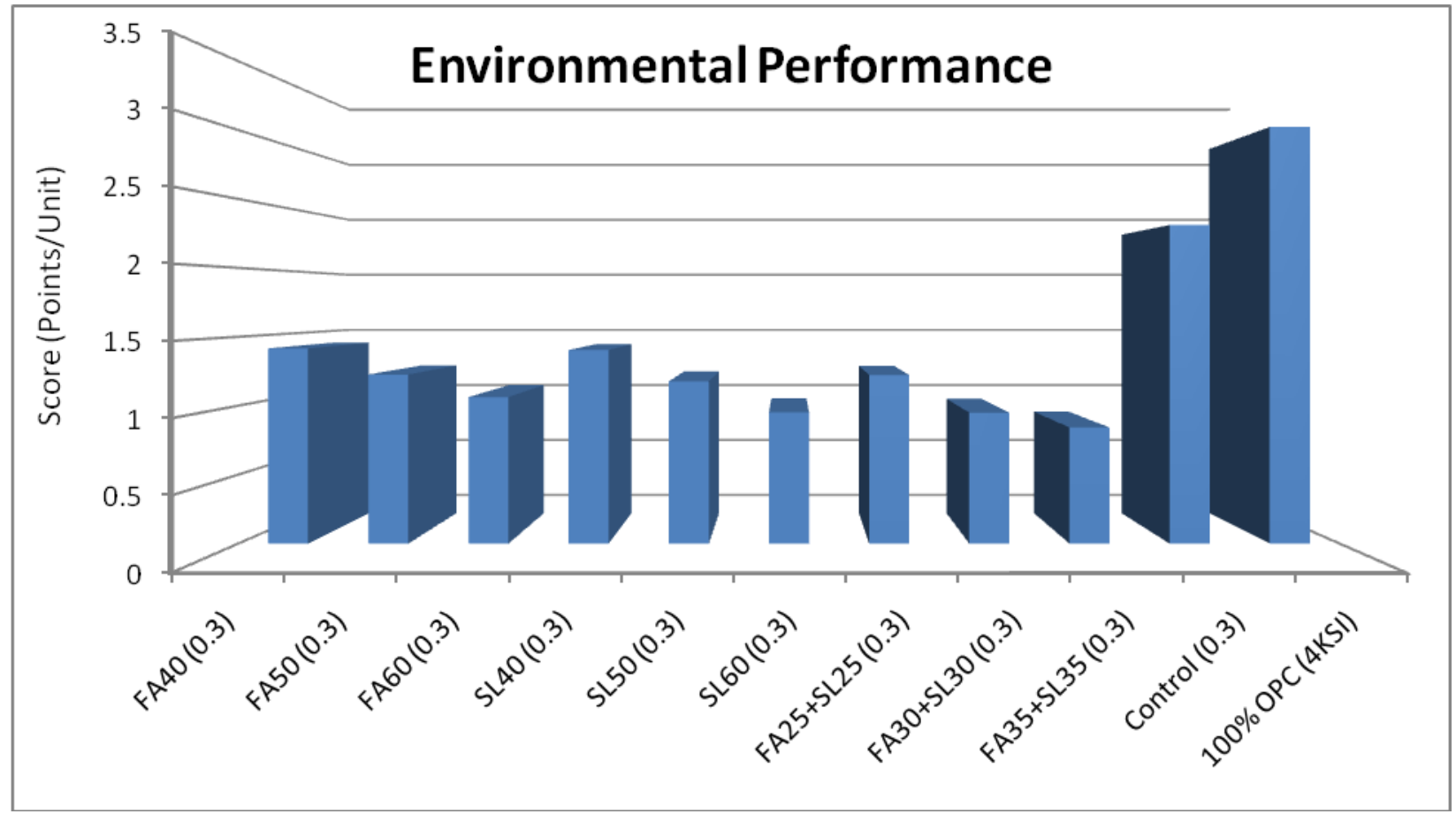

Figure 7-26 Environmental Performances (Beam)

\subsection{Global Warming}

Figure 7.27 showed the global warming potential of our concrete mixes. Global warming potential showed the same trend as the visible difference with control mix. As the replacement increases the potential global warming decreases. 


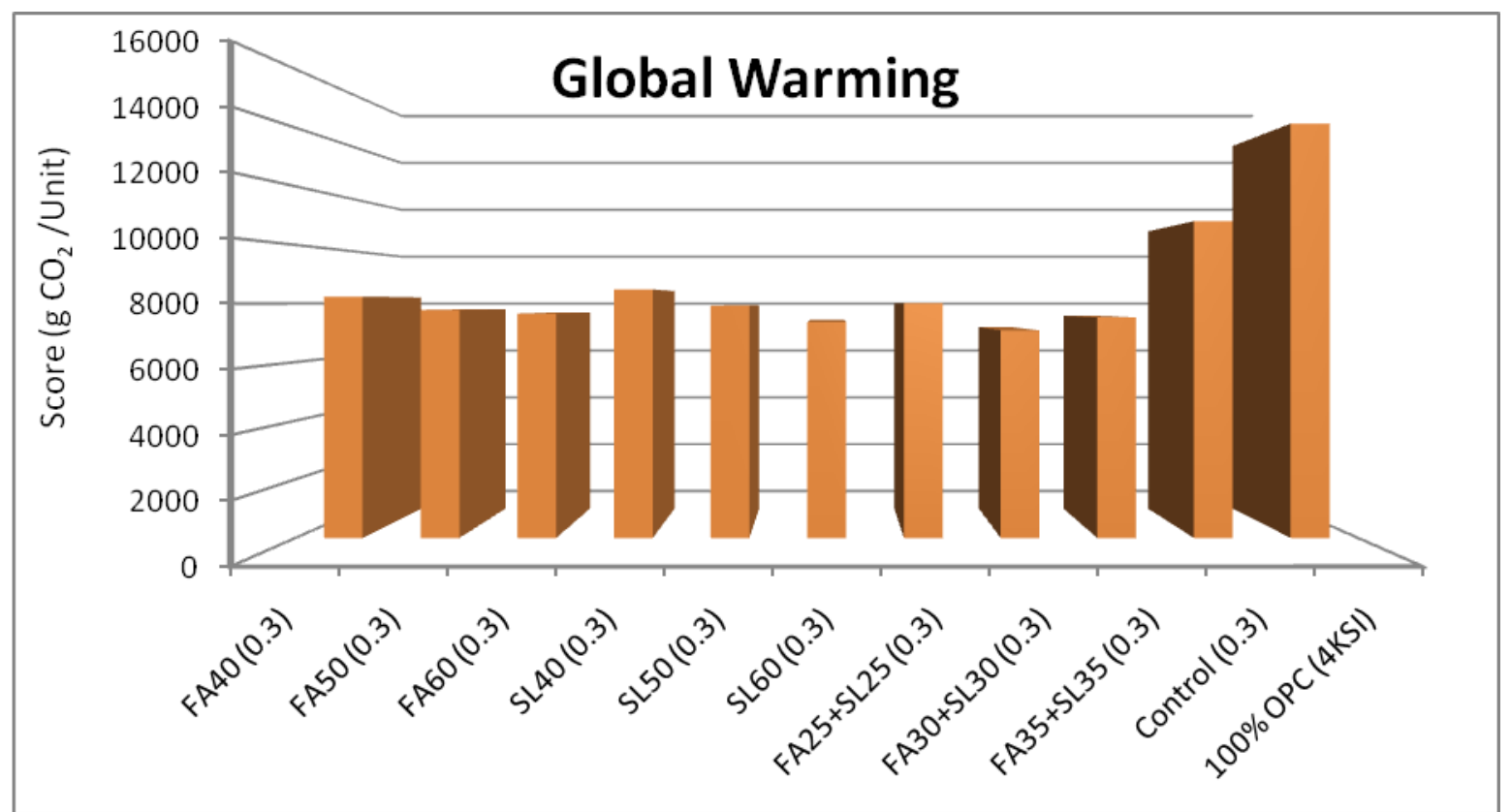

Figure 7-27 Global Warming (Beam)

\subsection{Fossil Fuel Depletion}

The fossil fuel depletion potential does not change, when compared with the control mix, but

difference with the $100 \%$ OPC (4KSI) is due to the strength factor. Concrete mixes with increasing fly ash replacement, showed increase in fossil fuel depletion potential too, where the fossil fuel depletion potential reuduces significantly as the amount of slag in mix increases. Concrete mixes where cement is replaced by the combination of fly ash and/or slag, concrete with $60 \%$ cement replacement showed least fossil fuel depletion potential among all. 


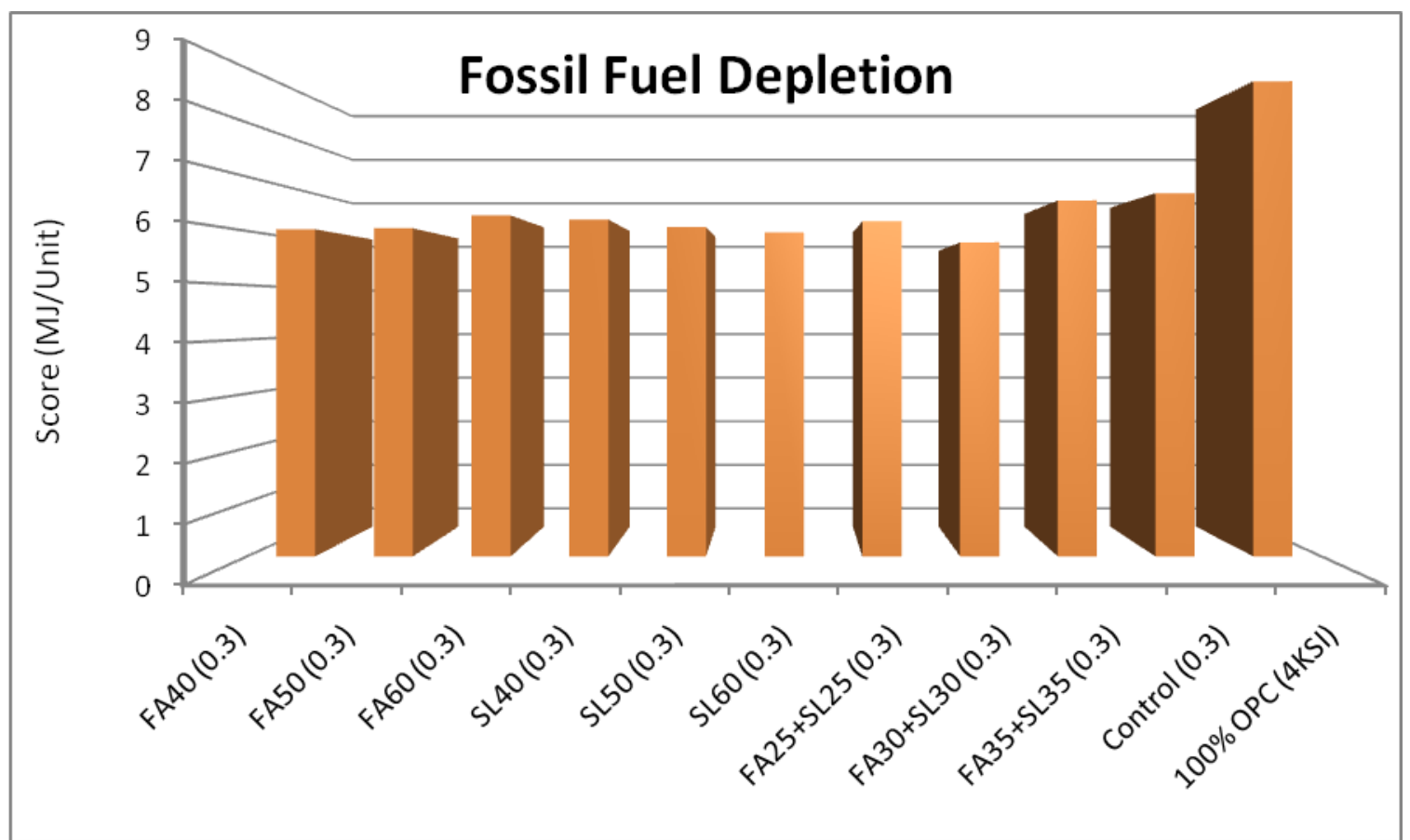

Figure 7-28 Fossil Fuel Depletion (Beam)

\subsection{Ecological Toxicity}

Figure 7.29 showed the ecological toxicity potential of our concrete mixes. Ecological toxicity potential showed the same trend as the visible difference with control mix. As the replacement increases the potential decreases. 


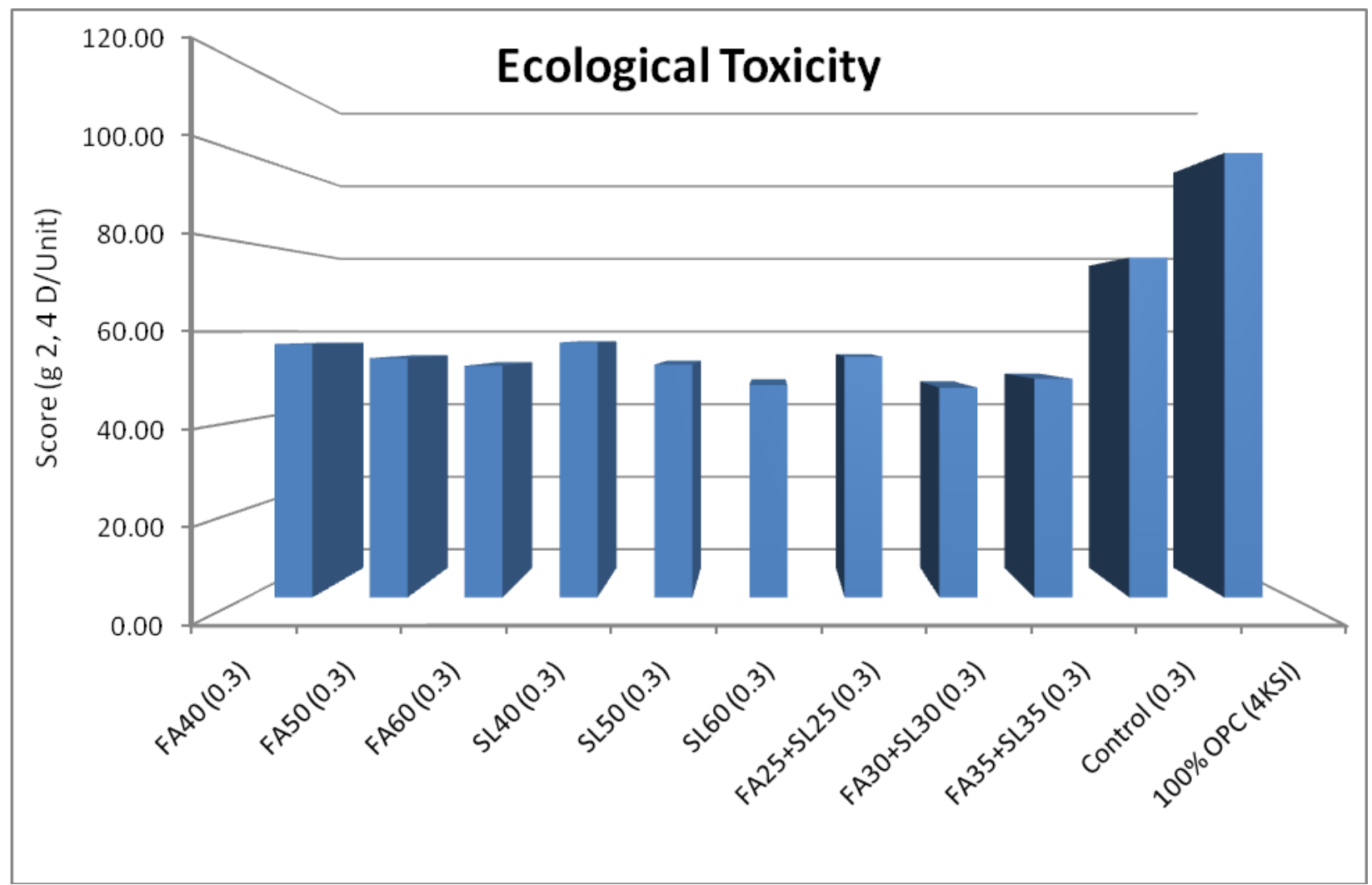

Figure 7-29 Ecological Toxicity (Beam)

\subsection{Human Health}

Human health threat potential showed major improvement as there is visible difference with the control mix is observed. As the replacement increases the human health threat potential become less. 


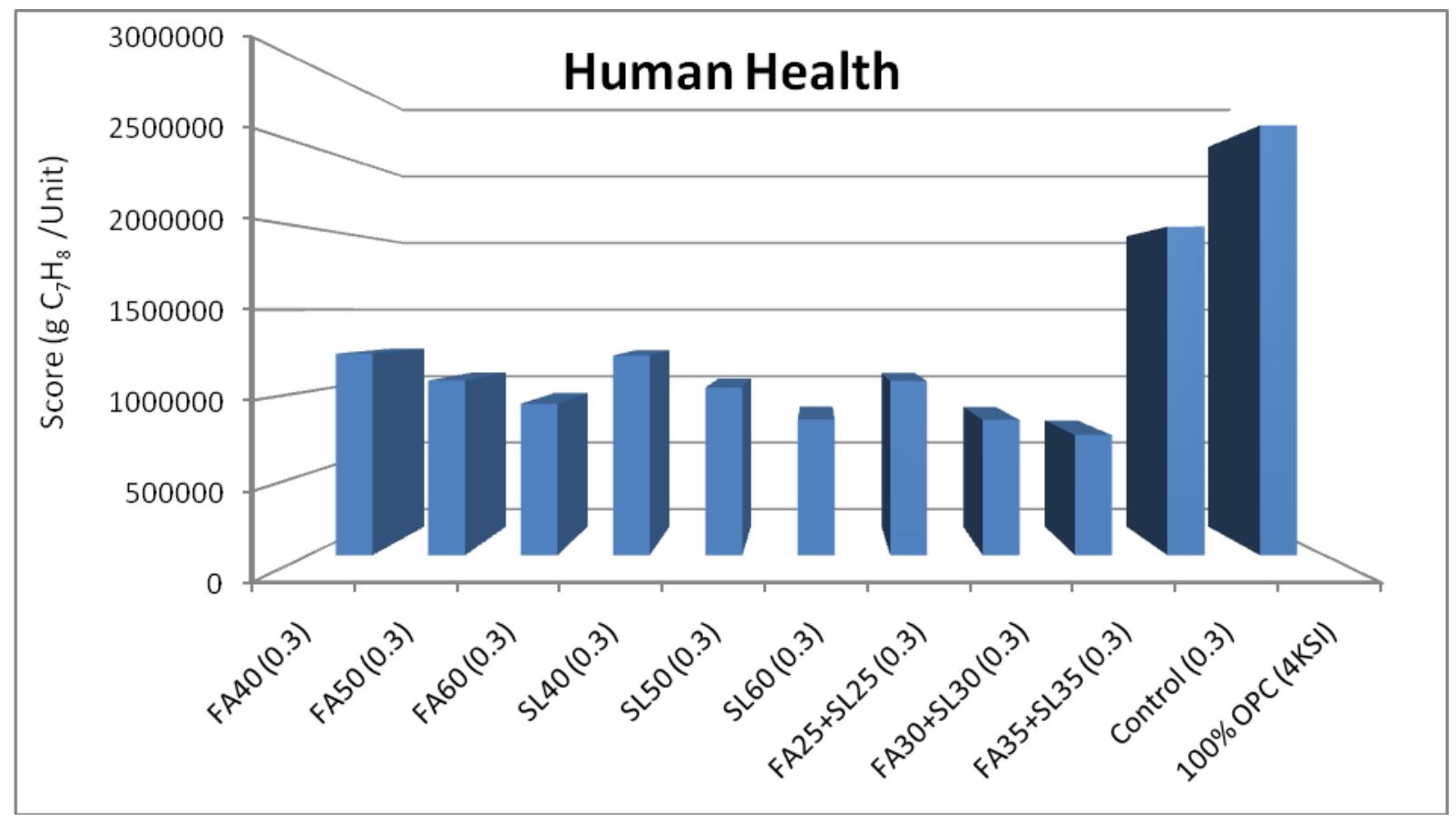

Figure 7-30 Human Health (Beam)

\subsection{Acidification}

The acidification potential does not change, when compared with the control mix, but difference with the $100 \%$ OPC (4KSI) is due to the strength factor. Concrete mixes with increasing fly ash replacement, showed increase in acidification potential too, where the acidification potential reuduces significantly as the amount of slag in mix increases. Concrete mixes where cement is replaced by the combination of fly ash and/or slag, concrete with $60 \%$ cement replacement showed least acidification potential among all. 


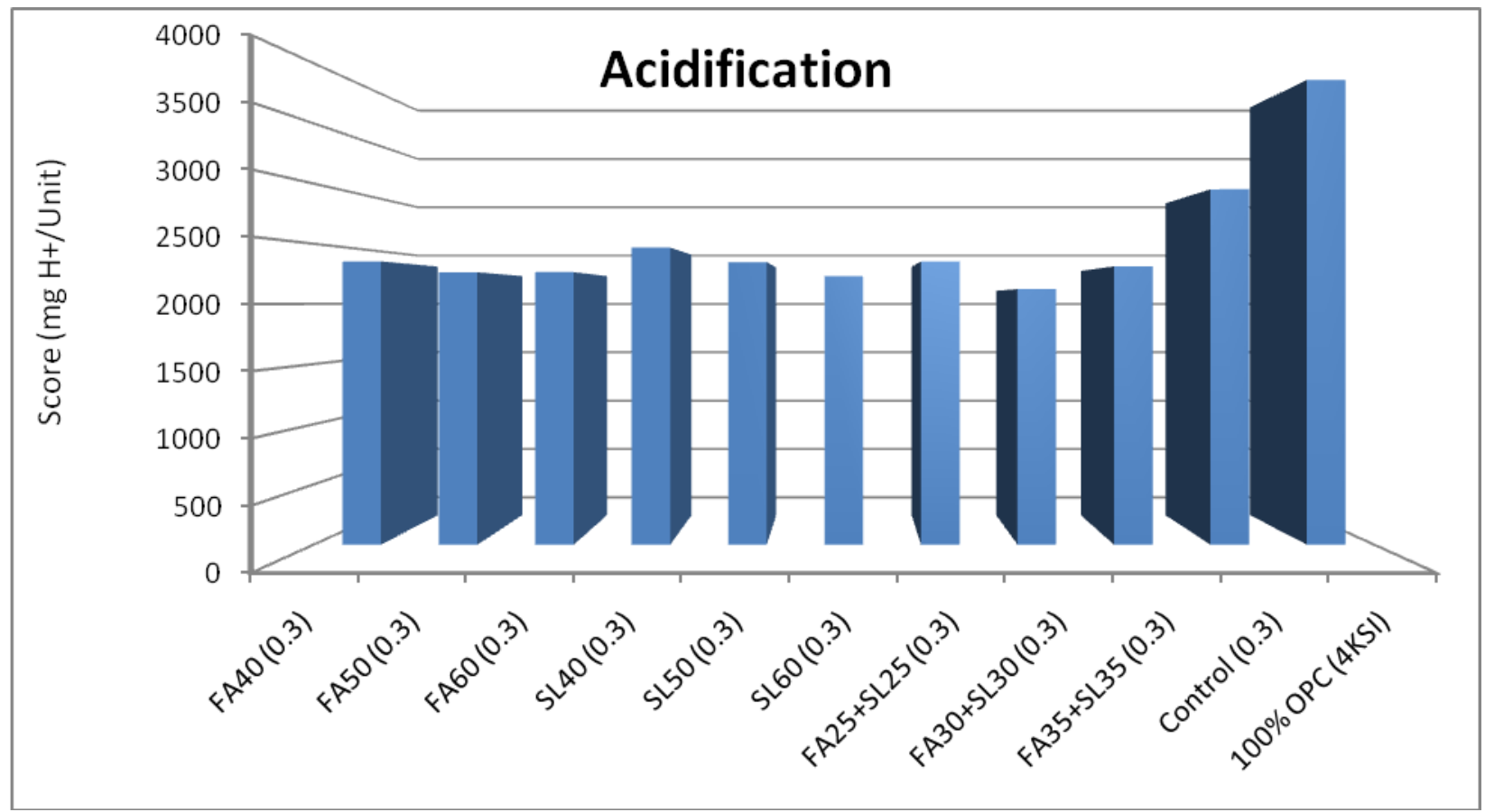

Figure 7-31Acidification(Beam)

\subsection{Eutrophication}

The eutrophication potential does not change, when compared with the control mix, but difference with the $100 \%$ OPC (4KSI) is due to the strength factor. Concrete mixes with increasing fly ash replacement, showed increase in eutrophication potential too, where the eutrophication potential reuduces significantly as the amount of slag in mix increases. Concrete mixes where cement is replaced by the combination of fly ash and/or slag, concrete with $60 \%$ cement replacement showed least eutrophication potential among all. 


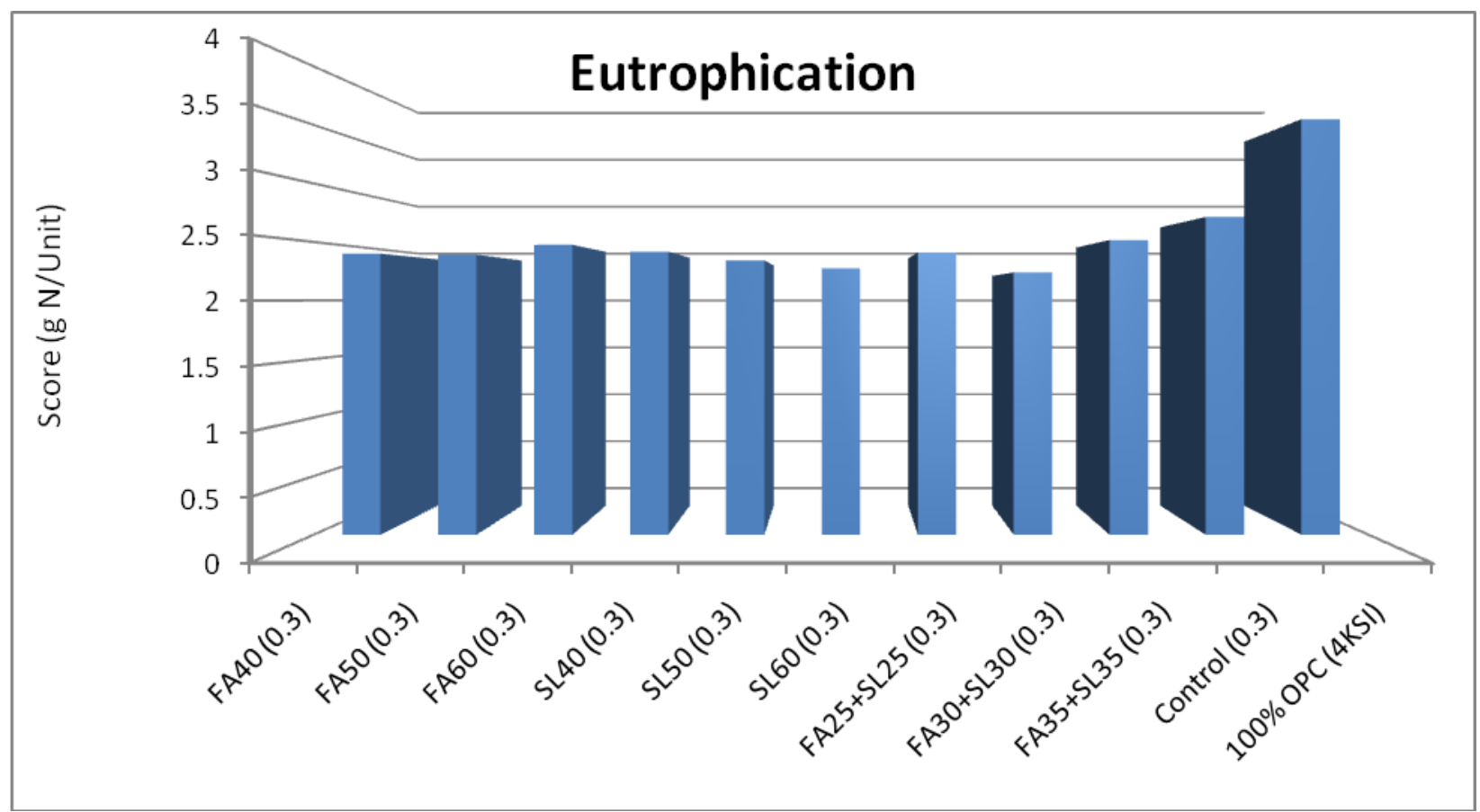

Figure 7-32 Eutrophication (Beam)

\subsection{Criteria Air Pollutant}

The criterial air pollutants does not change, when compared with the control mix, but difference with the $100 \%$ OPC (4KSI) is due to the strength factor. Concrete mixes with increasing fly ash replacement, showed increase in criterial air pollutants too, where the criterial air pollutants reuduces significantly as the amount of slag in mix increases. Concrete mixes where cement is replaced by the combination of fly ash and/or slag, concrete with $60 \%$ cement replacement showed least criterial air pollutants among all. 


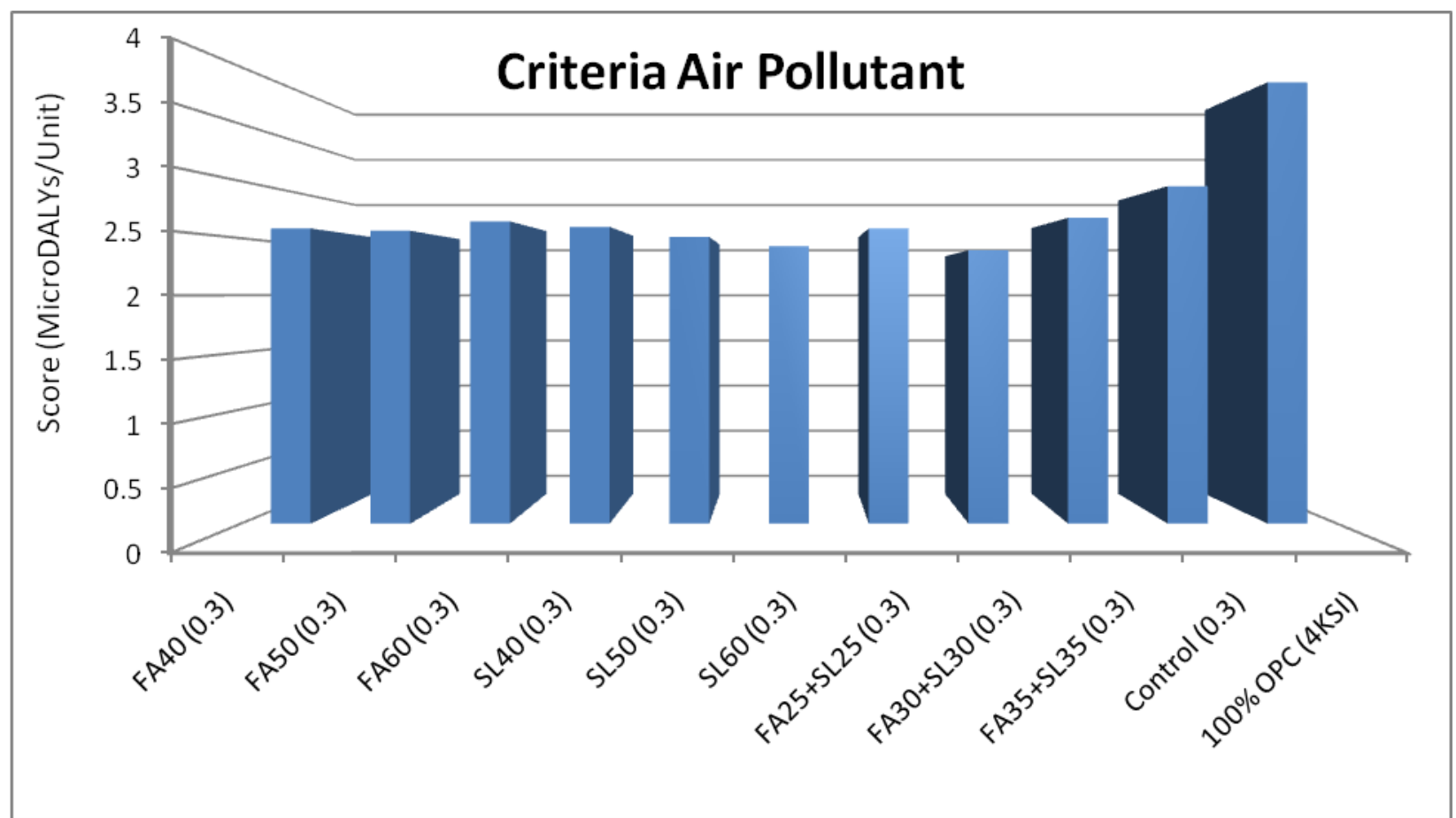

Figure 7-33 Criteria Air Pollutant (Beam)

\subsection{Smog Formation}

The smog formation potential does not change, when compared with the control mix, but difference with the $100 \%$ OPC (4KSI) is due to the strength factor. Concrete mixes with increasing fly ash replacement, showed increase in smog formation potential too, where the smog formation potential reuduces significantly as the amount of slag in mix increases. Concrete mixes where cement is replaced by the combination of fly ash and/or slag, concrete with $60 \%$ cement replacement showed least smog formation potential among all. 


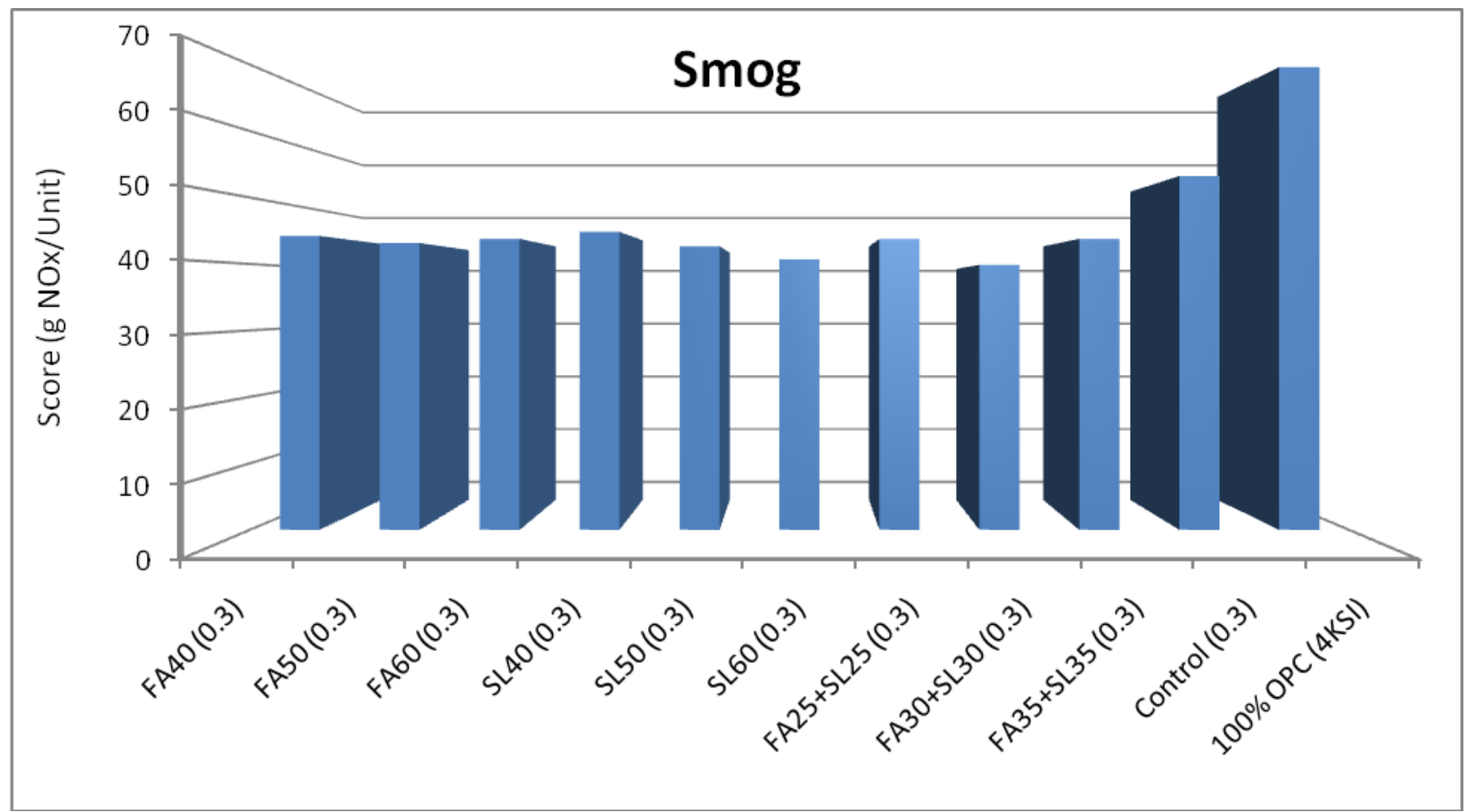

Figure 7-34 Smog (Beam)

\subsection{Ozone Depletion}

The ozone depletion potential does not change, when compared with the control mix, but difference with the $100 \%$ OPC (4KSI) is due to the strength factor. Concrete mixes with increasing fly ash replacement, showed increase in ozone depletion potential too, where the ozone depletion potential reuduces significantly as the amount of slag in mix increases. Concrete mixes where cement is replaced by the combination of fly ash and/or slag, concrete with $60 \%$ cement replacement showed least ozone depletion potential among all. 


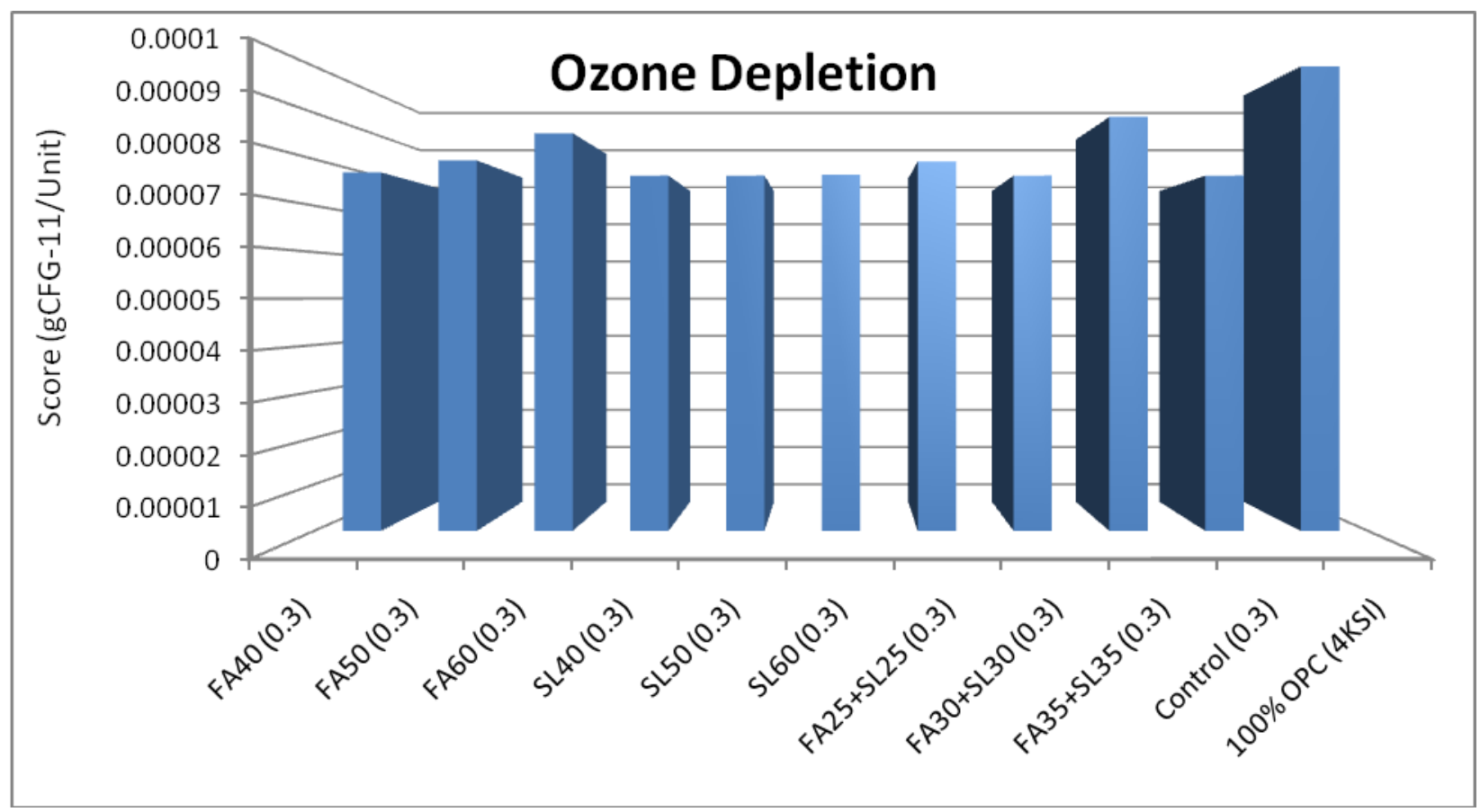

Figure 7-35Ozone Depletion (Beam)

\subsection{Water Intake}

The water intake potential does not change, when compared with the control mix, but difference with the $100 \%$ OPC (4KSI) is due to the strength factor. Concrete mixes with increasing fly ash replacement, showed increase in water intake potential too, where the water intake potential reuduces significantly as the amount of slag in mix increases. Concrete mixes where cement is replaced by the combination of fly ash and/or slag, concrete with $60 \%$ cement replacement showed least water intake potential among all. 


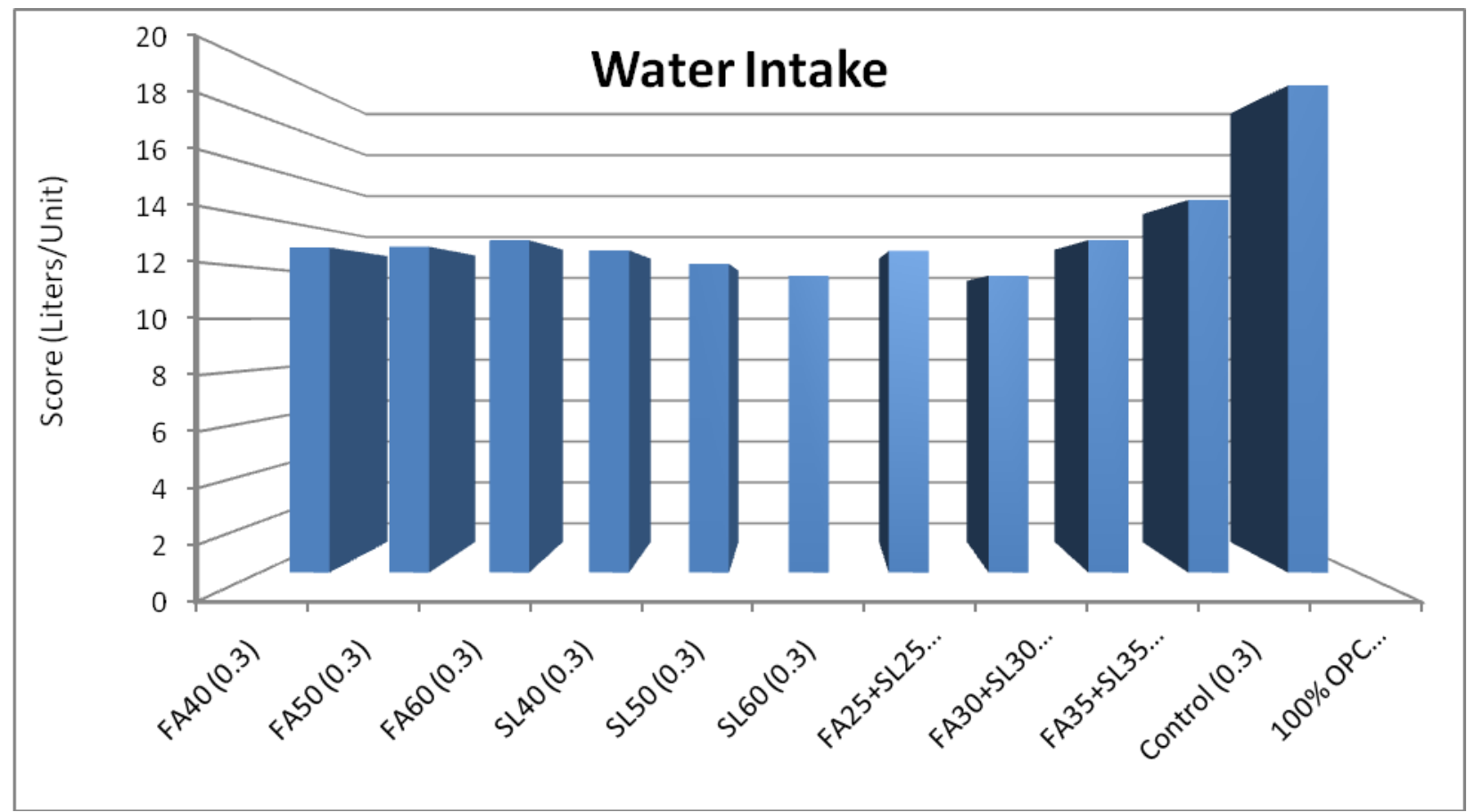

Figure 7-36 Water Intake (Beam)

\subsubsection{Overall Performance}

Figure 7.37 showed the global warming potential of our concrete mixes. Global warming potential showed the same trend as the visible difference with control mix. As the replacement increases the potential decreases.

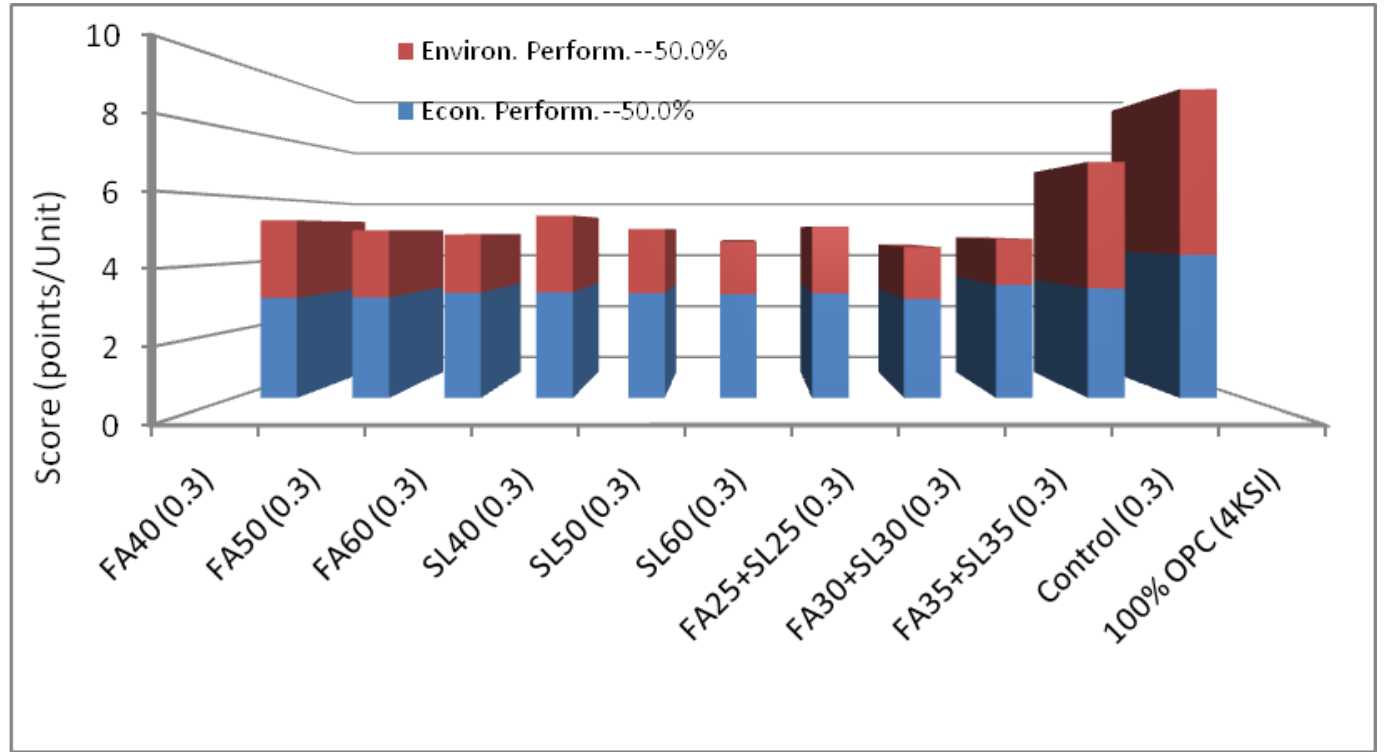

Figure 7-37 Overall Performance (Beam) 


\subsubsection{Embodied Energy}

Embodied energy graphs are presented and discussed below.

\subsection{Fuel Usage}

The fuel usage perfomance does not change, when compared with the control mix, but difference with the $100 \% \mathrm{OPC}(4 \mathrm{KSI})$ is due to the strength factor. In fact the concrete mix, where $70 \%$ cement is replaced by fly ash and/or slag combination. Concrete mixes with increasing fly ash replacement, showed increase in fuel usage perfomance too, where the fuel usage perfomance reuduces significantly as the amount of slag in mix increases. Concrete mixes where cement is replaced by the combination of fly ash and/or slag, concrete with $60 \%$ cement replacement showed best fuel usage perfomance among all.

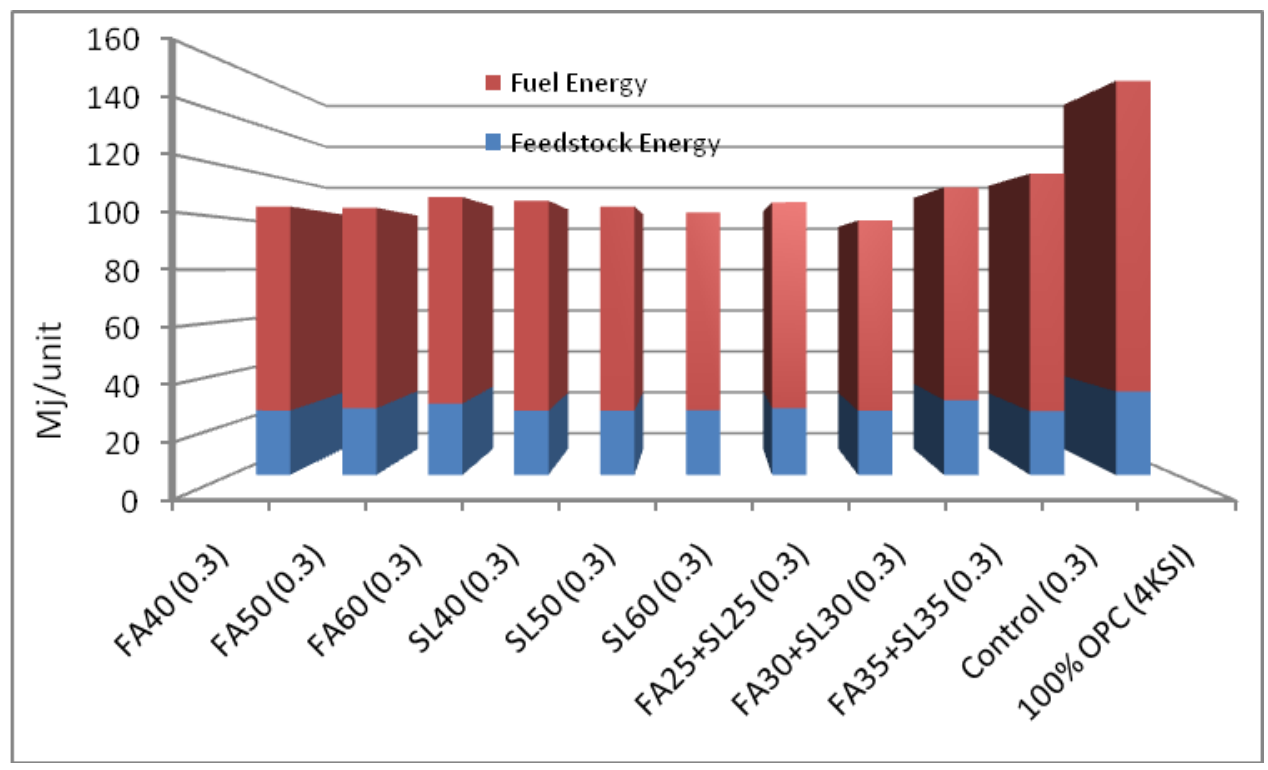

Figure 7-38 Fuel Usage (Beam)

\subsection{Fuel Renewability}

The fuel renewability perfomance does not change, when compared with the control mix, but difference with the $100 \%$ OPC (4KSI) is due to the strength factor. In fact the concrete mix, where $70 \%$ cement is replaced by fly ash and/or slag combination. Concrete mixes with increasing fly ash replacement, showed increase in fuel renewability perfomance too, where the 
fuel renewability perfomance reuduces significantly as the amount of slag in mix increases. Concrete mixes where cement is replaced by the combination of fly ash and/or slag, concrete with $60 \%$ cement replacement showed best fuel renewability perfomance among all.

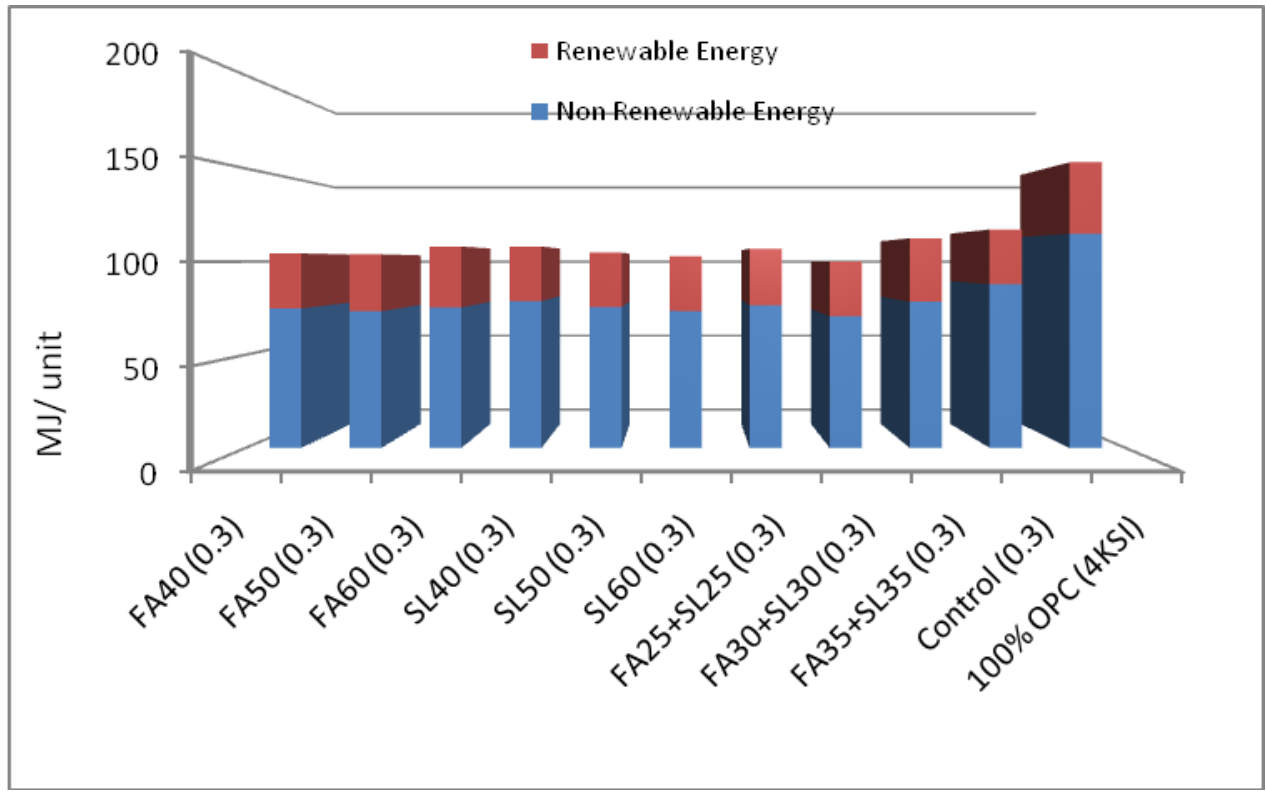

Figure 7-39 Fuel Renewability (Beam)

\subsubsection{Column Element}

\subsubsection{Economical Performance}

The Economic perfomance performance does not change, when compared with the control mix, but difference with the $100 \%$ OPC (4KSI) is due to the strength factor. In fact the concrete mix, where $70 \%$ cement is replaced by fly ash and/or slag combination, that cost more than control mix, which accounts for high amount of high range water reducing admixture. Concrete mixes with increasing fly ash replacement, showed increase in cost too, whereas the cost increases significantly as the amount of slag in mix increases too. Concrete mixes where cement is replaced by the combination of fly ash and/or slag, concrete with $60 \%$ cement replacement showed least price among all. 


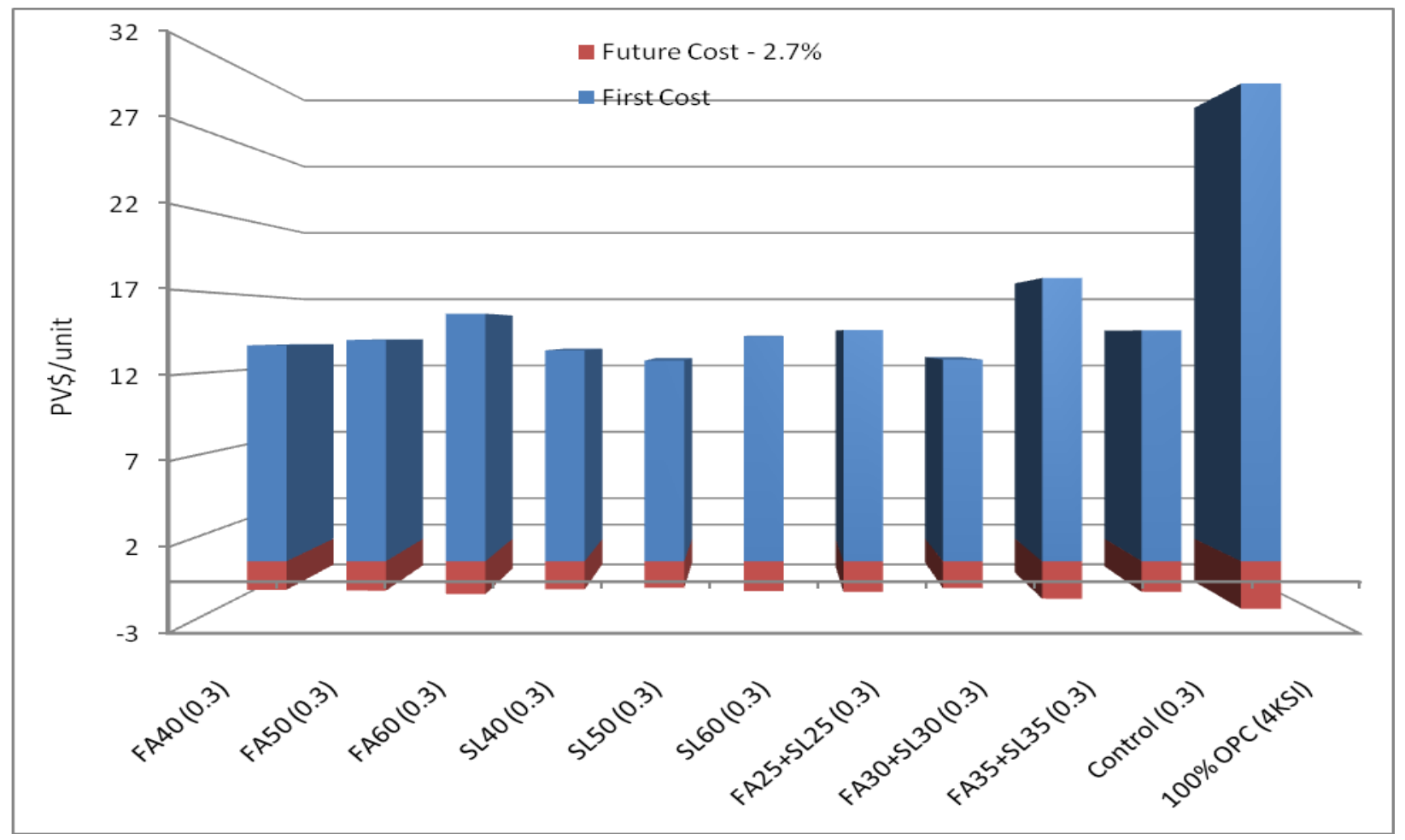

Figure 7-40 Economic Performance (Column)

\subsubsection{Environmental Performance}

Environmental performances showed major improvement as there is visible difference with the control mix is observed. As the replacement increases the environmental performance become better. 


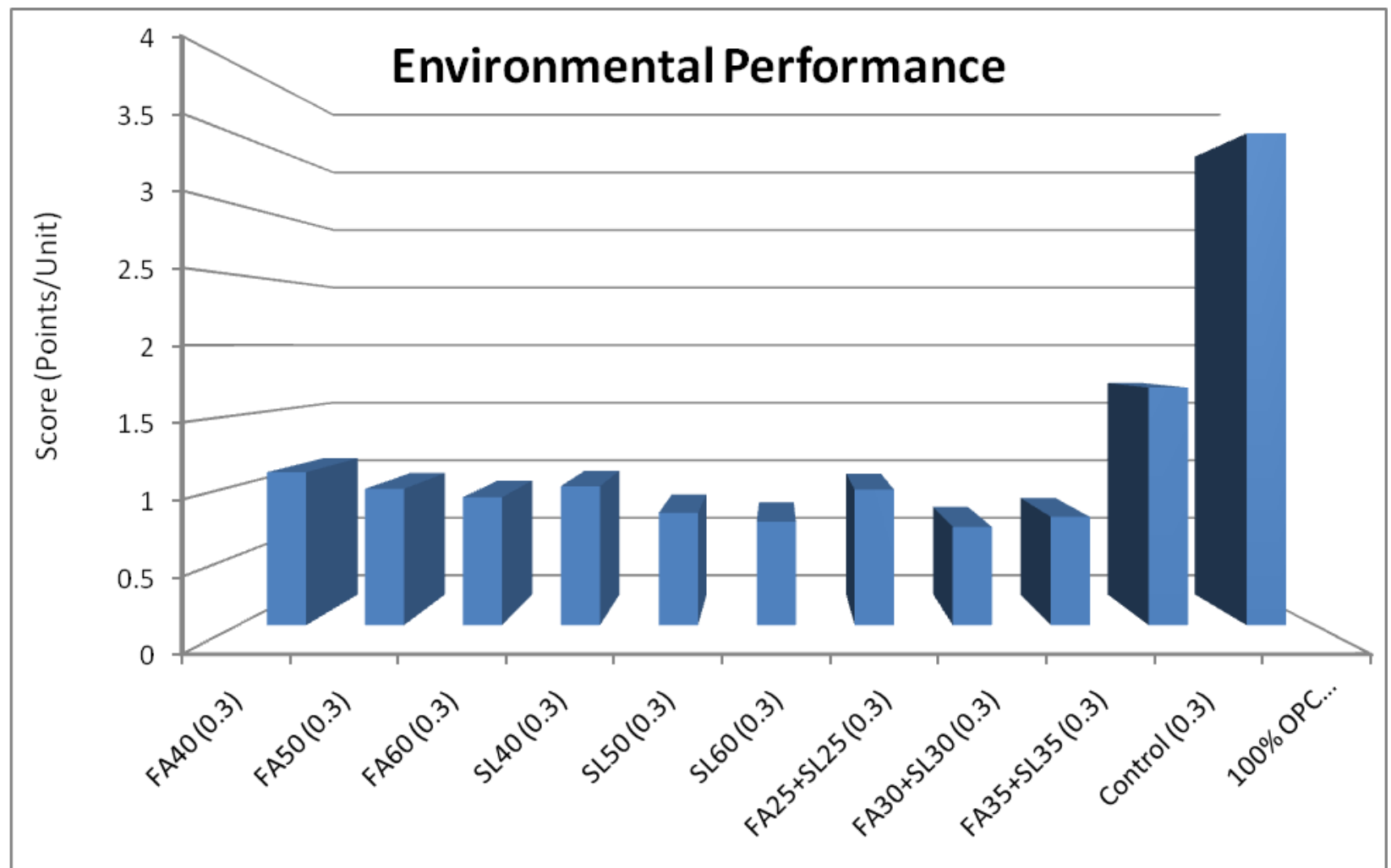

Figure 7-41 Environmental Performance (Column)

\subsection{Global Warming}

Figure 7.42 showed the global warming potential of our concrete mixes. Global warming potential showed the same trend as the visible difference with control mix. As the replacement increases the potential decreases. 


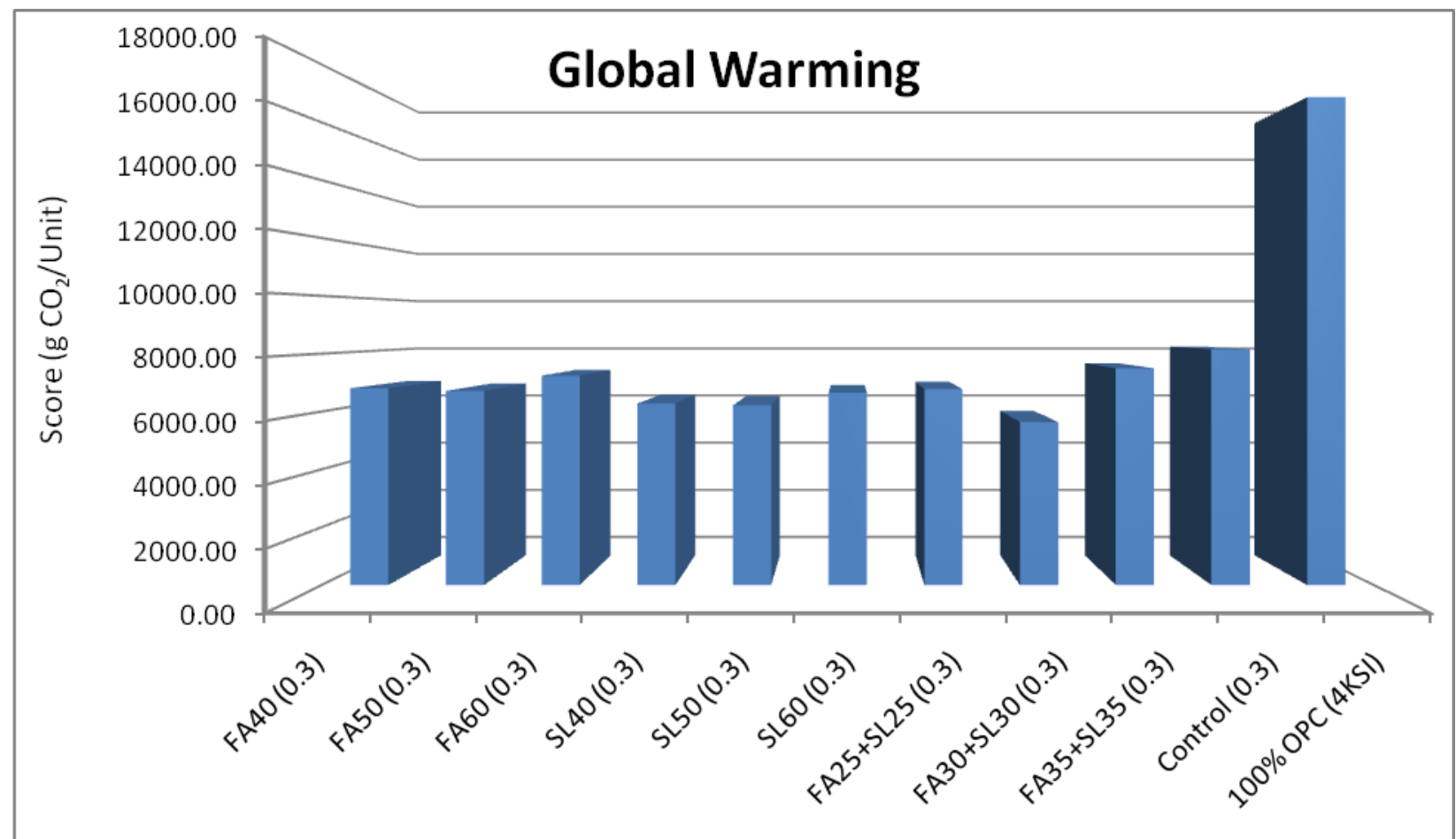

Figure 7-42 Global Warming (Column)

\subsection{Fossil Fuel Depletion}

The fossil fuel depletion potential does not change, when compared with the control mix, but difference with the $100 \%$ OPC (4KSI) is due to the strength factor. Concrete mixes with increasing fly ash replacement, showed increase in fossil fuel depletion potential too, whereas the fossil fuel depletion potential increases significantly as the amount of slag in mix increases too. Concrete mixes where cement is replaced by the combination of fly ash and/or slag, concrete with $60 \%$ cement replacement showed least fossil fuel depletion potential among all. 


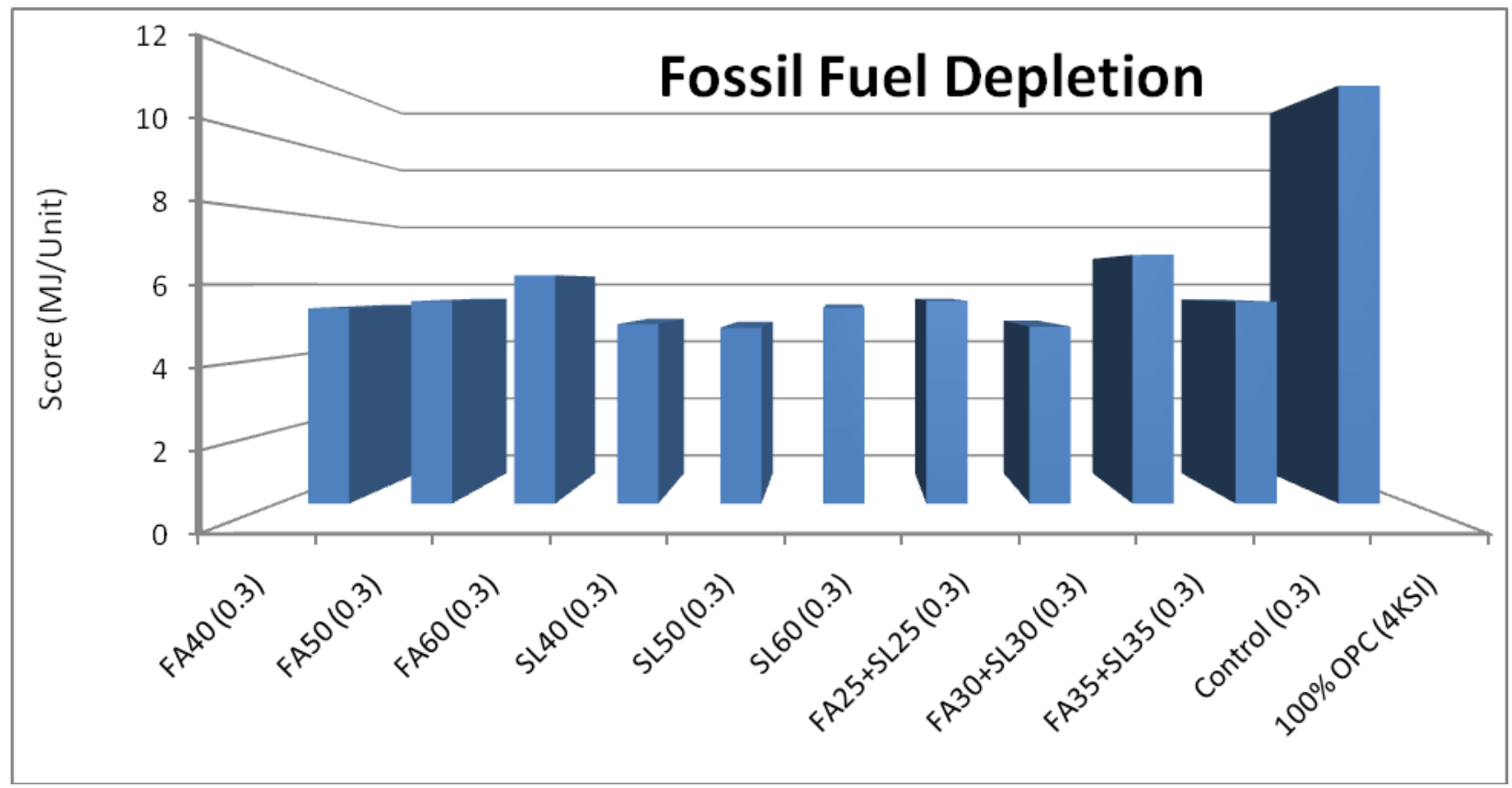

Figure 7-43 Fossil Fuel Depletion (Column)

\subsection{Ecological Toxicity}

Figure 7.44 showed the ecological toxicity potential of our concrete mixes. Ecological toxicity potential showed the same trend as the visible difference with control mix. As the replacement increases the potential decreases. 


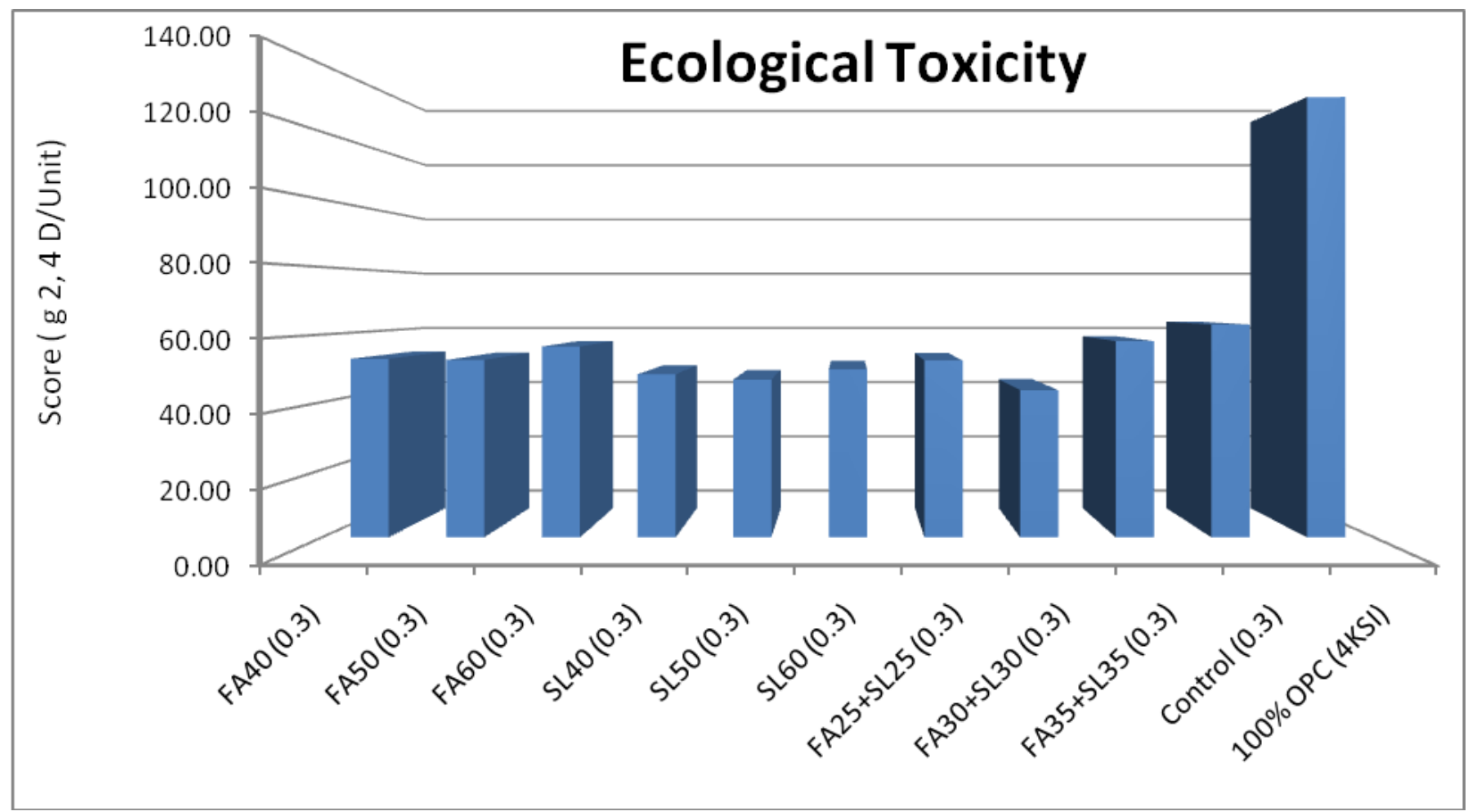

Figure 7-44 Ecological Toxicity (Column)

\subsection{Human Health}

Human health threat potential showed major improvement as there is visible difference with the control mix is observed. As the replacement increases the human health threat potential become less. 


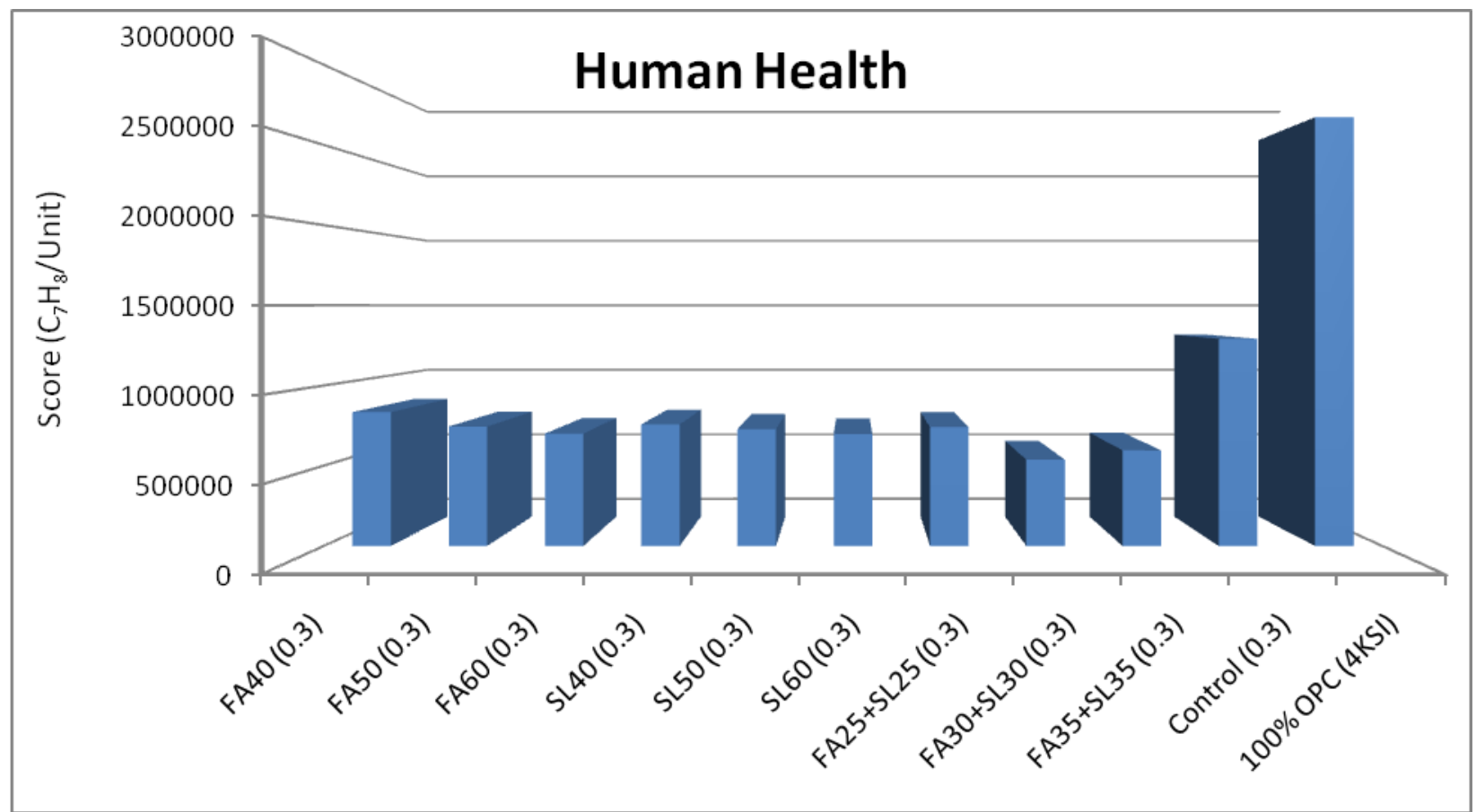

Figure 7-45 Human Health (Column)

\subsection{Acidification}

The acidification potential does not change, when compared with the control mix, but difference with the $100 \%$ OPC (4KSI) is due to the strength factor. Concrete mixes with increasing fly ash replacement, showed increase in acidification potential too, whereas the acidification potential increases significantly as the amount of slag in mix increases too. Concrete mixes where cement is replaced by the combination of fly ash and/or slag, concrete with $60 \%$ cement replacement showed least acidification potential among all. 


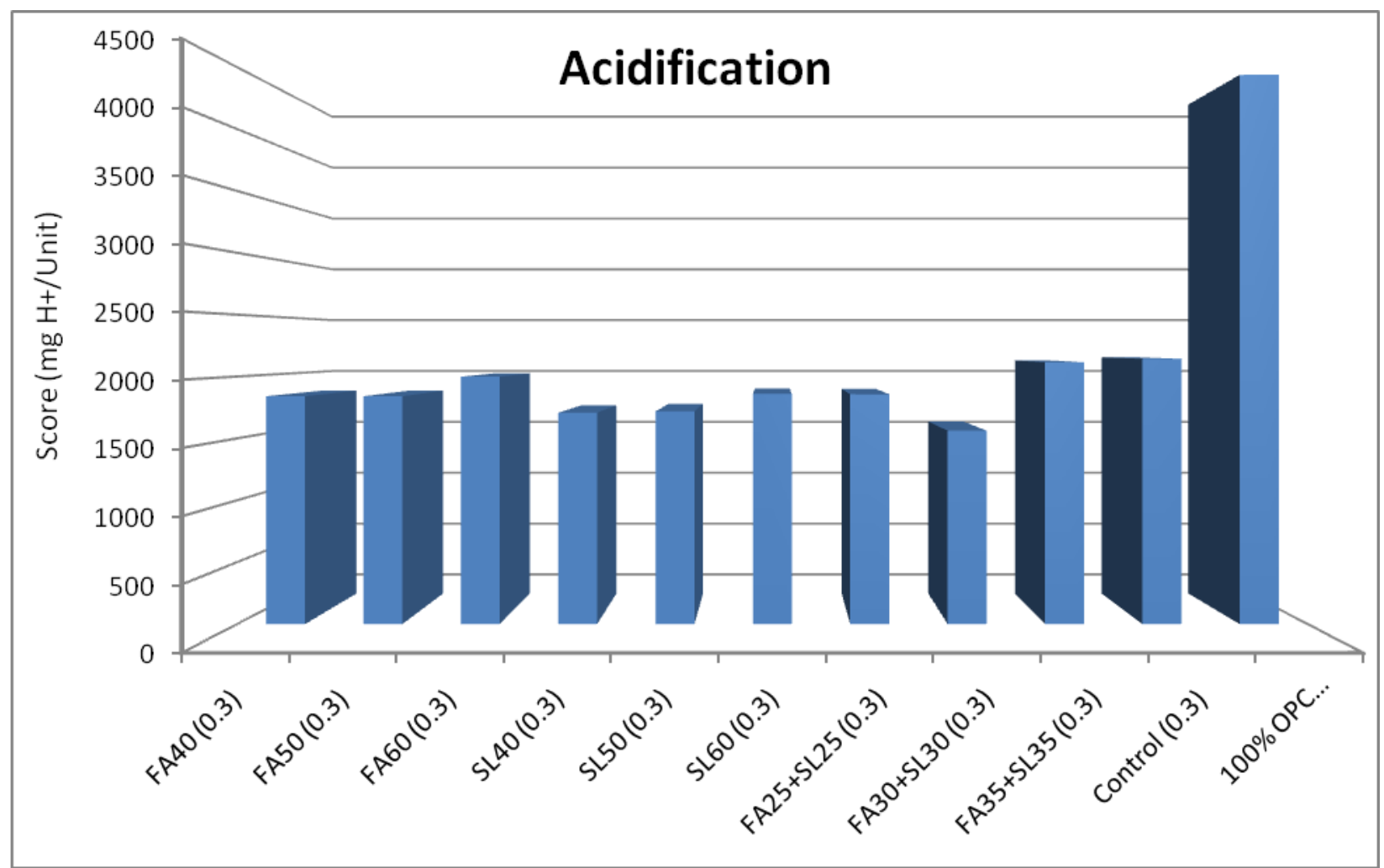

Figure 7-46Acidification (Column)

\subsection{Eutrophication}

The eutrophication potential does not change, when compared with the control mix, but difference with the $100 \%$ OPC (4KSI) is due to the strength factor. Concrete mixes with increasing fly ash replacement, showed increase in eutrophication potential too, whereas the eutrophication potential increases significantly as the amount of slag in mix increases too. Concrete mixes where cement is replaced by the combination of fly ash and/or slag, concrete with $60 \%$ cement replacement showed least eutrophication potential among all. 


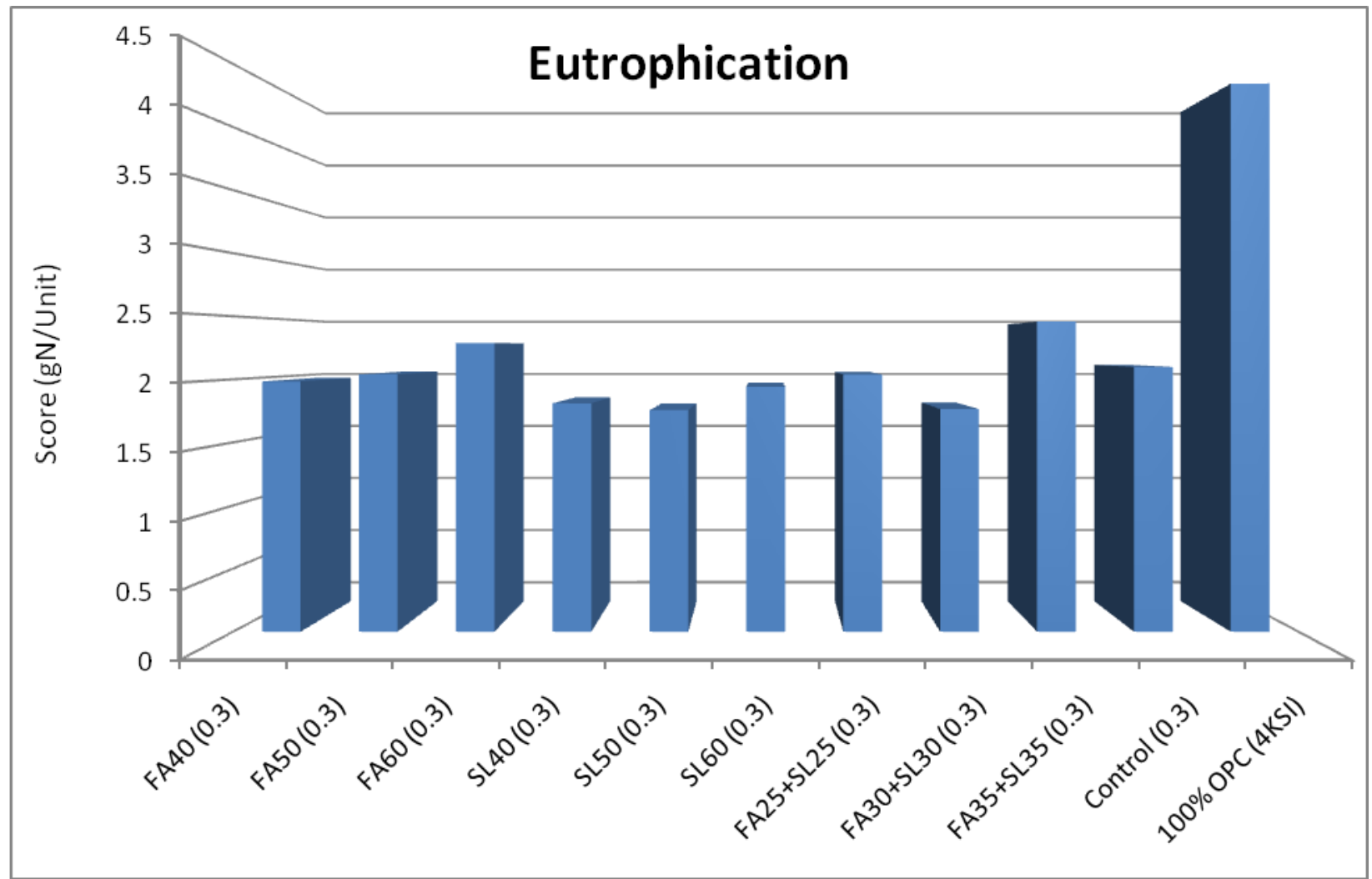

Figure 7-47 Eutrophication (Column)

\subsection{Criteria Air Pollutant}

The criterial air pollutants does not change, when compared with the control mix, but difference with the $100 \%$ OPC (4KSI) is due to the strength factor. Concrete mixes with increasing fly ash replacement, showed increase in criterial air pollutants too, whereas the criterial air pollutants rincreases significantly as the amount of slag in mix increases too. Concrete mixes where cement is replaced by the combination of fly ash and/or slag, concrete with $60 \%$ cement replacement showed least criterial air pollutants among all. 


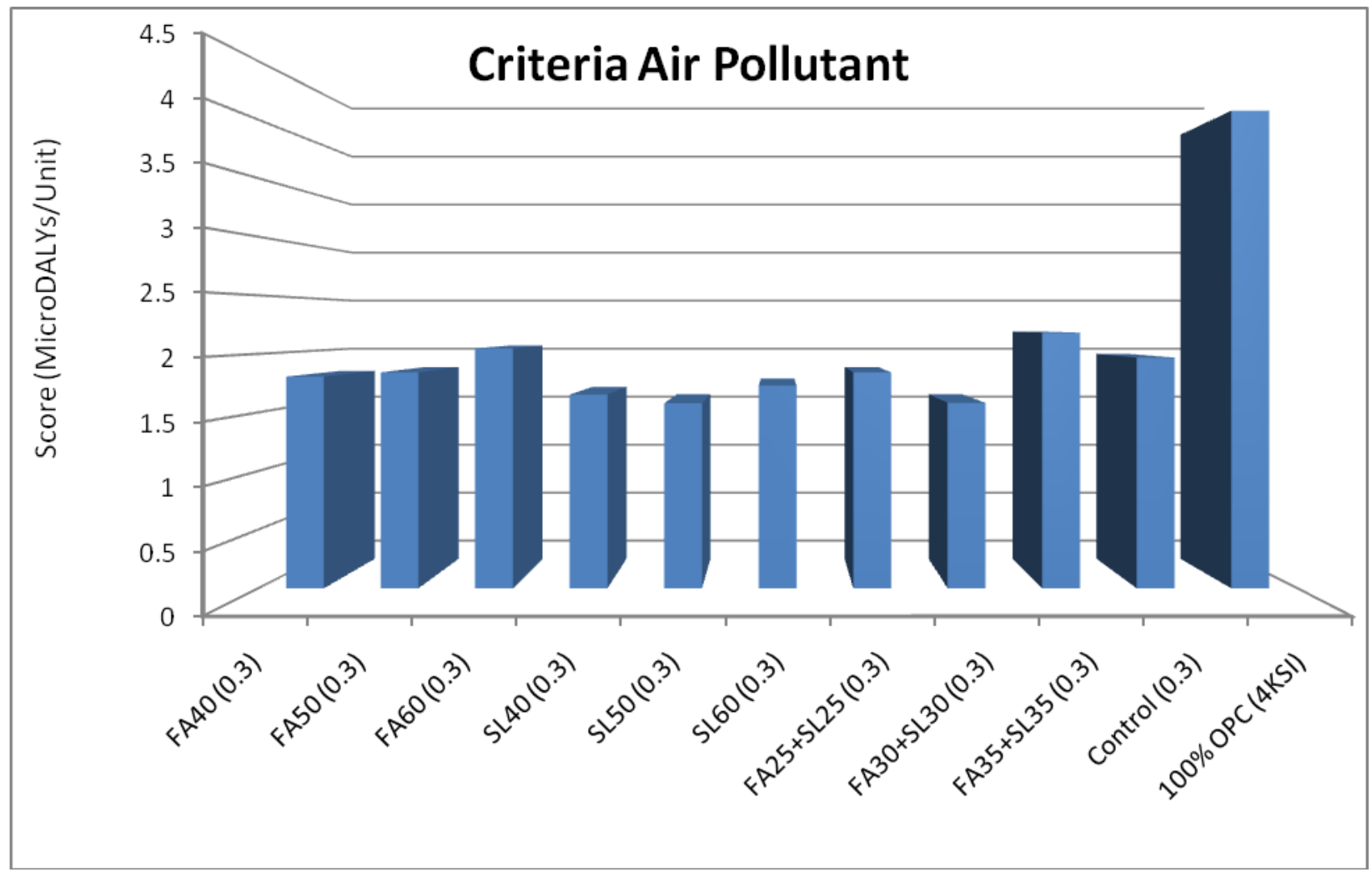

Figure 7-48 Criteria Air Pollutant (Column)

\subsection{Smog Formation}

The smog formation potential does not change, when compared with the control mix, but difference with the $100 \%$ OPC (4KSI) is due to the strength factor. Concrete mixes with increasing fly ash replacement, showed increase in smog formation potential too, whereas the smog formation potential increases significantly as the amount of slag in mix increases too. Concrete mixes where cement is replaced by the combination of fly ash and/or slag, concrete with $60 \%$ cement replacement showed least smog formation potential among all. 


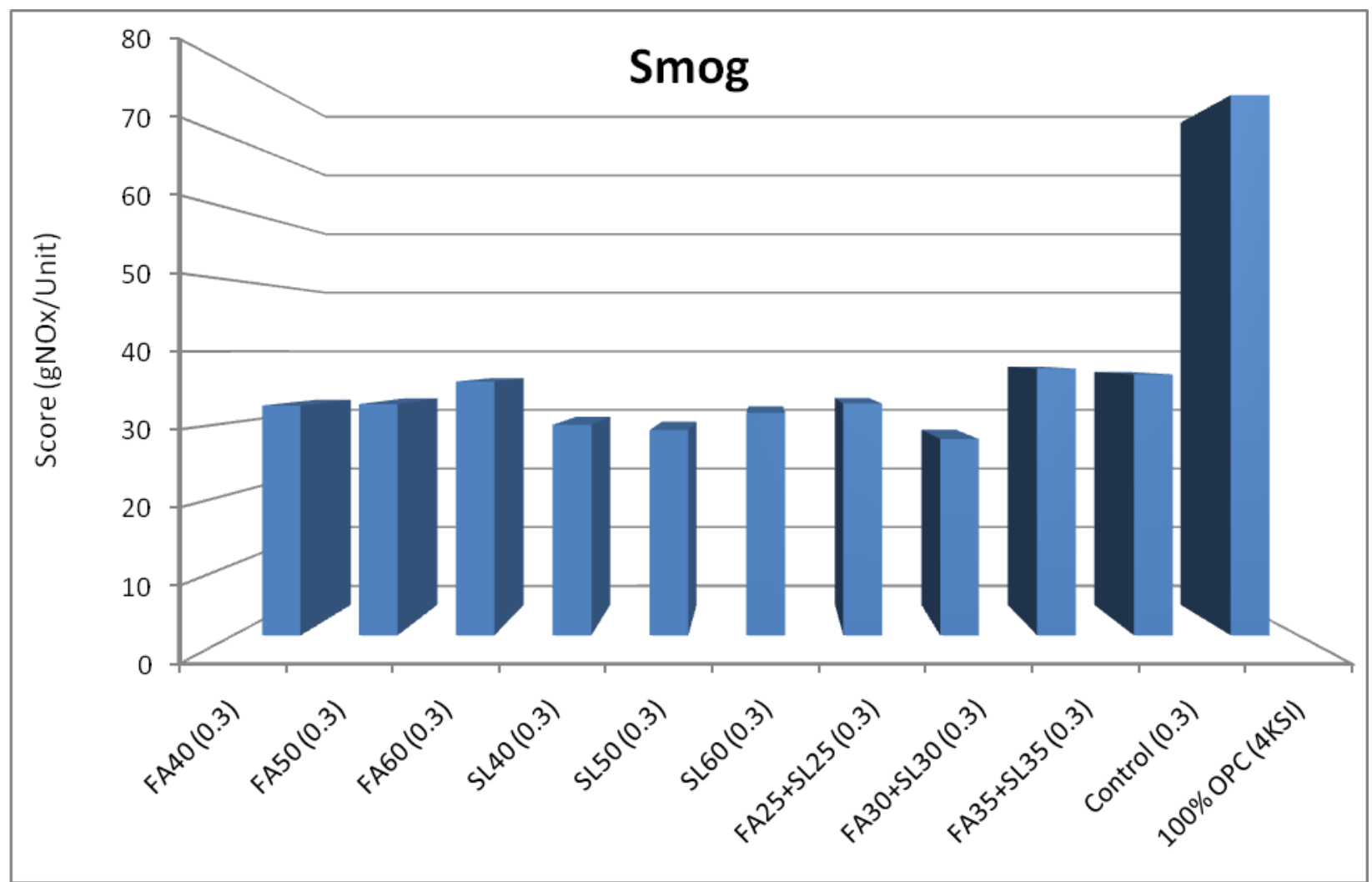

Figure 7-49 Smog (Column)

\subsection{Ozone Depletion}

The ozone depletion potential does not change, when compared with the control mix, but difference with the $100 \%$ OPC (4KSI) is due to the strength factor. Concrete mixes with increasing fly ash replacement, showed increase in ozone depletion potential too, whereas the ozone depletion potential increases significantly as the amount of slag in mix increases too. Concrete mixes where cement is replaced by the combination of fly ash and/or slag, concrete with $60 \%$ cement replacement showed least ozone depletion potential among all. 


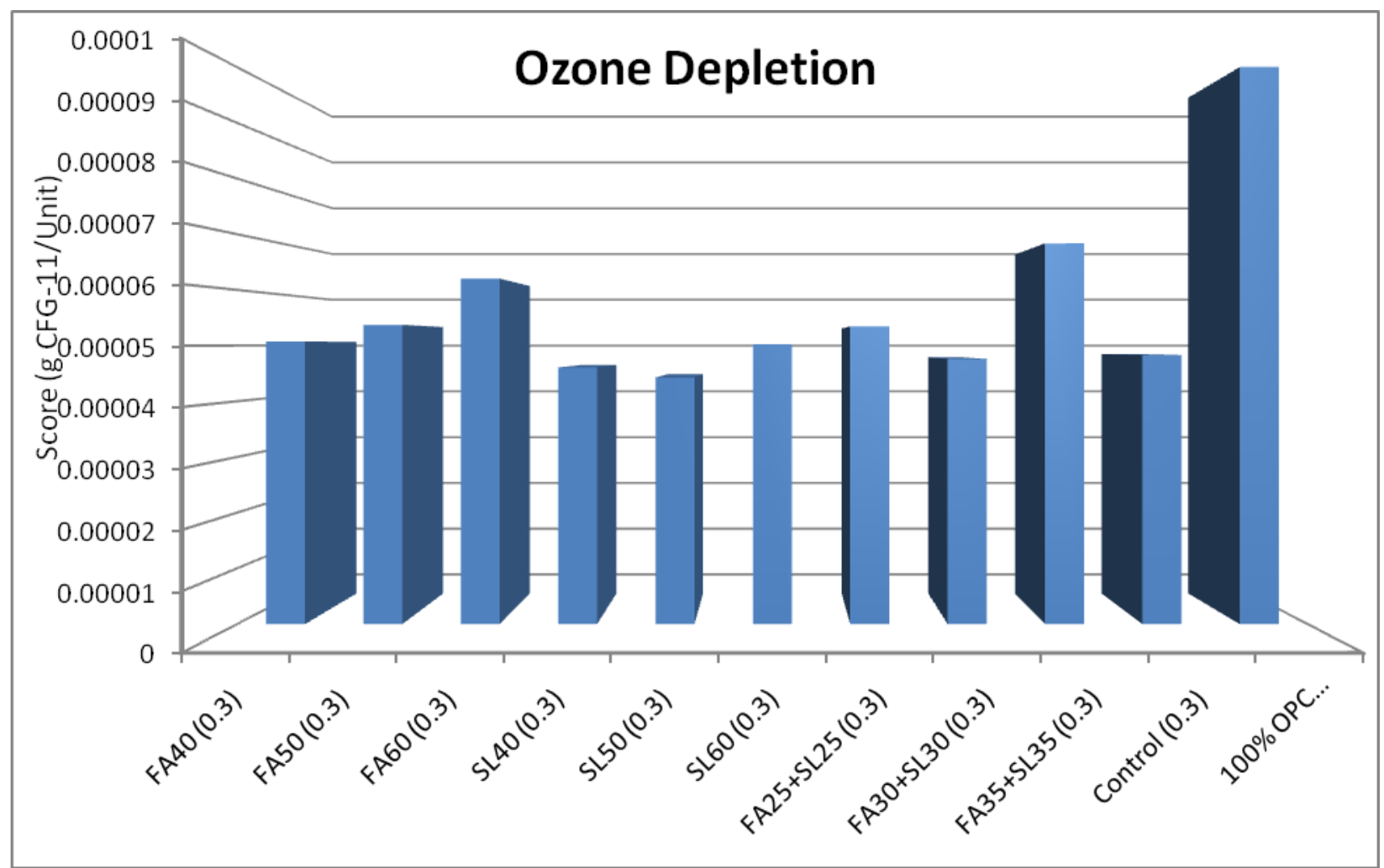

Figure 7-50 Ozone Depletion (Column)

\subsection{Water Intake}

The water intake potential does not change, when compared with the control mix, but difference with the $100 \%$ OPC (4KSI) is due to the strength factor. Concrete mixes with increasing fly ash replacement, showed increase in water intake potential too, whereas the water intake potential increases significantly as the amount of slag in mix increases too. Concrete mixes where cement is replaced by the combination of fly ash and/or slag, concrete with $60 \%$ cement replacement showed least water intake potential among all. 


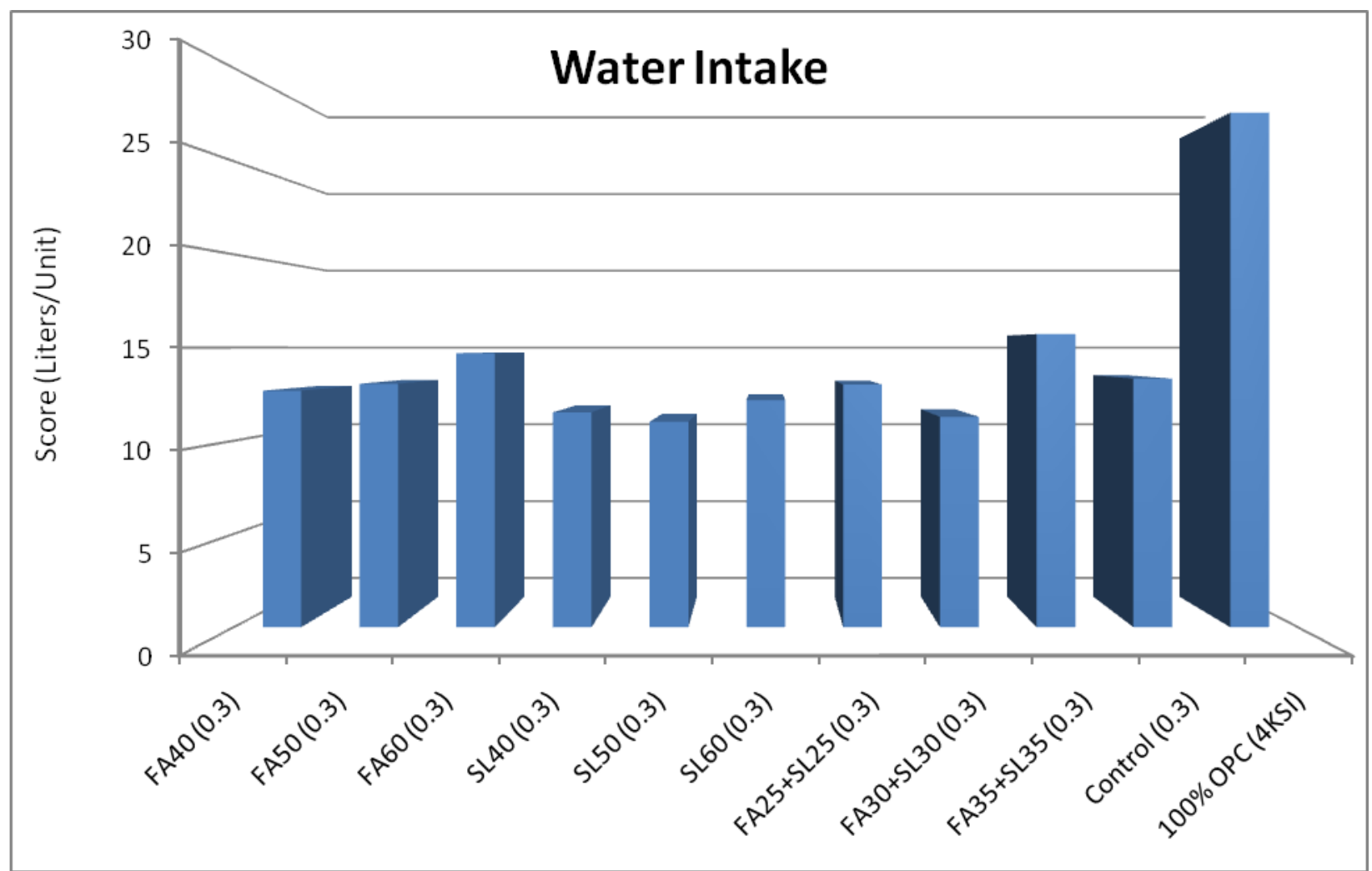

Figure 7-51 Water Intake (Column)

\subsubsection{Overall Performance}

Figure 7.51 showed the global warming potential of our concrete mixes. Global warming potential showed the same trend as the visible difference with control mix. As the replacement increases the potential decreases 


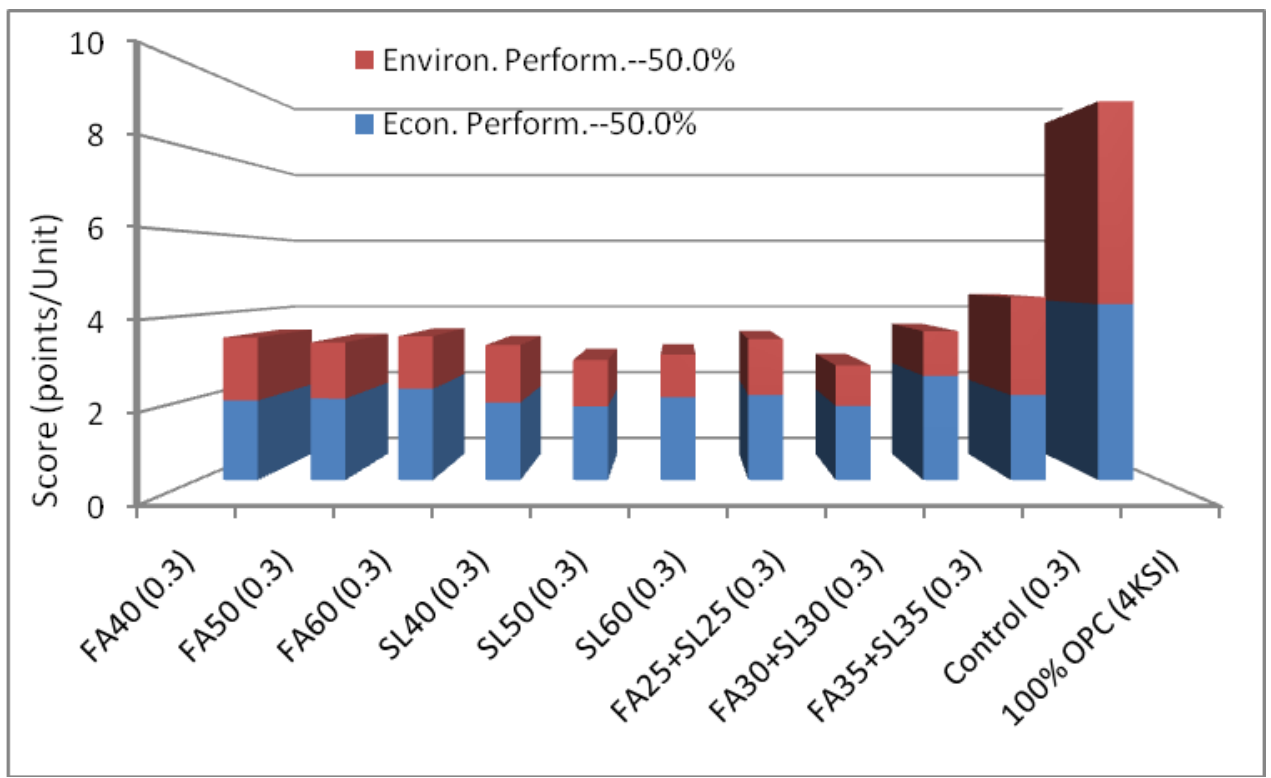

Figure 7-52 Overall Performance (Column)

\subsubsection{Embodied Energy}

Embodied energy graphs are presented and discussed below.

\subsection{Fuel Usage}

The fuel usage perfomance does not change, when compared with the control mix, but difference with the $100 \%$ OPC (4KSI) is due to the strength factor. In fact the concrete mix, where $70 \%$ cement is replaced by fly ash and/or slag combination. Concrete mixes with increasing fly ash replacement, showed increase in fuel usage perfomance too, whereas the fuel usage perfomance increases significantly as the amount of slag in mix increases too. Concrete mixes where cement is replaced by the combination of fly ash and/or slag, concrete with $60 \%$ cement replacement showed best fuel usage perfomance among all. 


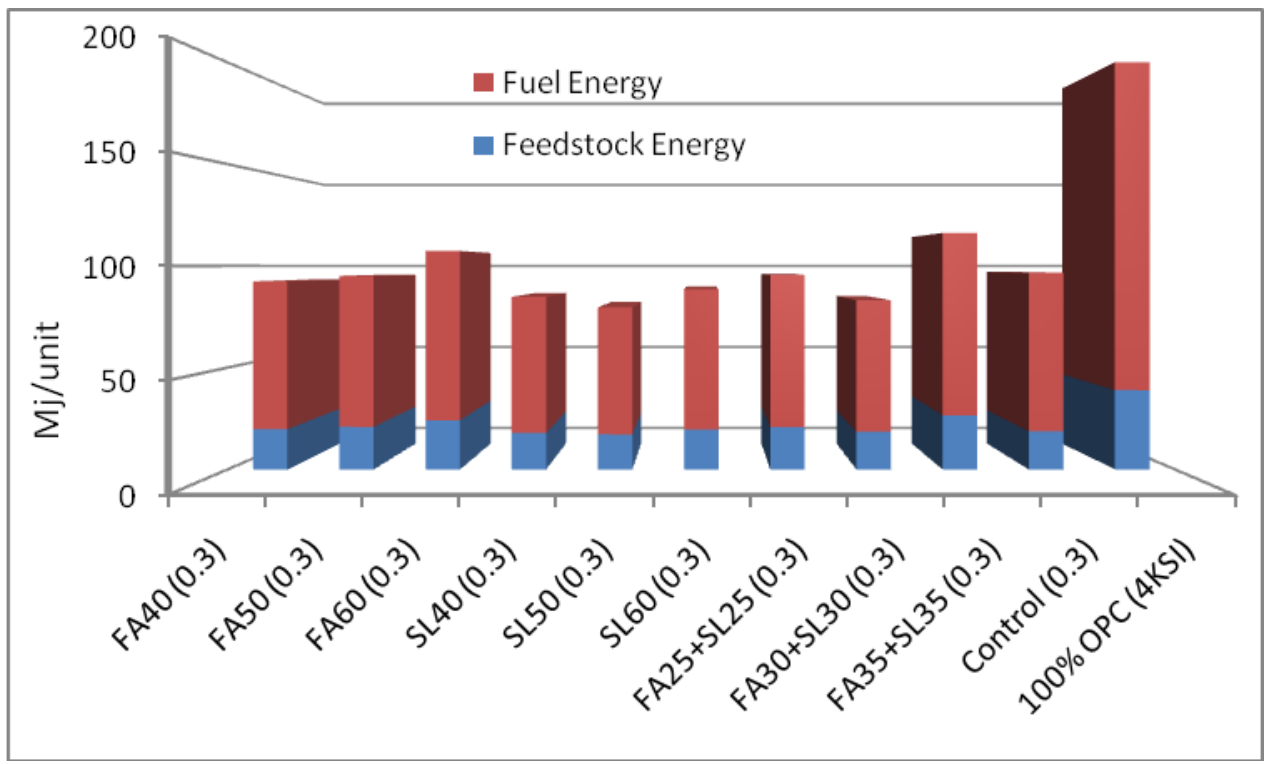

Figure 7-53 Fuel Usage (Column)

\subsection{Fuel Renewability}

The fuel renewability perfomance does not change, when compared with the control mix, but difference with the $100 \%$ OPC (4KSI) is due to the strength factor. In fact the concrete mix, where $70 \%$ cement is replaced by fly ash and/or slag combination. Concrete mixes with increasing fly ash replacement, showed increase in fuel renewability perfomance too, whereas the fuel renewability perfomance increases significantly as the amount of slag in mix increases too. Concrete mixes where cement is replaced by the combination of fly ash and/or slag, concrete with $60 \%$ cement replacement showed best fuel renewability perfomance among all. 


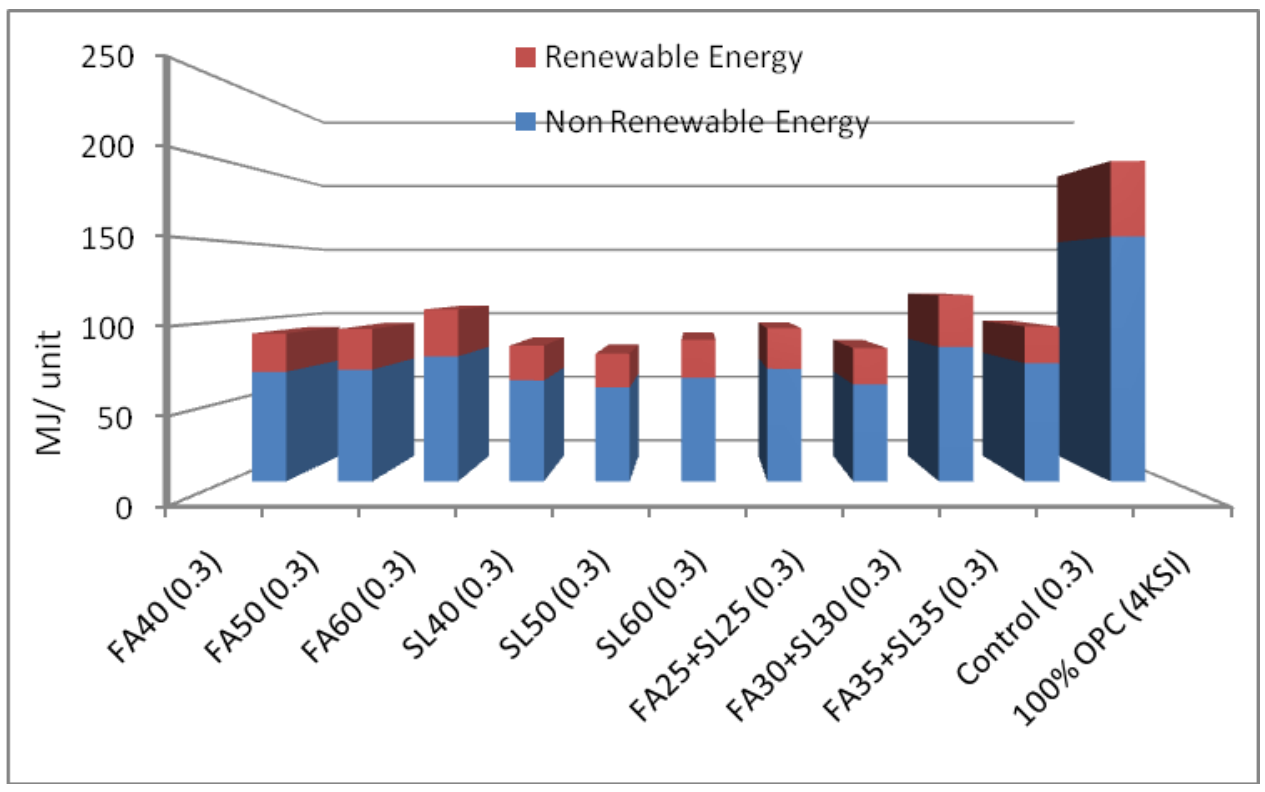

Figure 7-54 Fuel Renewability (Column) 


\section{Chapter 8: Conclusions and Recommendations}

\subsection{Conclusions}

- High volume fly ash and high volume slag modified concrete is viable construction material.

- High volume fly ash concrete has slower strength generation less evolution hydration heat, which means formwork removal can be critical while construction.

- High volume slag modified concrete does not have the same problem like high volume fly ash modified concrete though initial strength gain up 3days is really slow paced.

- As the replacement increases the strength generation as well as strength decreases.

- As the replacement is over $60 \%$ high volume slag concrete or the combination of fly ash and/or slag should be preferred over high volume fly ash concrete especially in case of structural concrete.

- Heating or heat insulation should be provided to fasten the strength generation process.

- Decreasing w/cm may not be an option always to get more strength or durability.

- $\mathrm{W} / \mathrm{cm}$ should be kept at 0.3 for best performance.

- Durability of fly ash and/or slag modified concrete is not an issue.

- Drying shrinkage is reduced as the high volume of fly ash is used.

- Overall the containment of hazardous ions is satisfactory apart from sulfur

- Geopolymer can be another option for viable sustainable construction practice, though feasibility in mass scale production can be an issue.

- Geopolymer concrete cannot be tested for chloride ion penetration; in fact with presently followed procedures can lead to wrong impression.

- Concrete can be used for the containment of hazardous ion coming from industrial byproduct/ wastes 


\subsection{Recommendations}

- New procedures can be designed to check the permeability of high volume fly ash and/or slag modified concrete and geopolymer concrete

- Form of insulation to be provided to the high volume fly ash and/or slag modified concrete to overcome the low early strength generation for faster concrete production

- Finding a process of industrial production of geopolymer Concrete

- Unveiling BEES 4.0 for further sustainability study, may be up gradation

- Leaching study has to be done more extensively

- Sustainability check for geopolymer Concrete, which not possible right now with the resources available

- Full study High volume Fly ash and/or slag modified Concrete and geopolymer

- Setting time of concrete can be measured precisely with P-wave and S-wave penetration and can be correlated to the findings of Isothermal Calorimeter study, by means of forming an empirical equation, which may precisely predict the time of formwork removal 


\section{Bibliography}

- ACI Committee 232. (2003). "Use of Fly Ash in Concrete". ACI Manual of Concrete Practice 232.2R-03.

- American Society for Testing and Materials. (1975). ASTM C 595. "Standard specification for blended hydraulic cements"; ASTM, West Conshohocken, PA, USA.

- American Society for Testing and Materials. (2000). Standards on Disc, Vol. 04.02; "Concrete and Aggregates"; ASTM, West Conshohocken, PA, USA.

- American Society for Testing and Materials. (1999). ASTM C 33 "Standard Specification for Concrete Aggregates"; ASTM, West Conshohocken, PA, USA.

- American Society for Testing and Materials. (1999). ASTM C39/C39M "Standard Test Method for Compressive Strength of Cylindrical Concrete Specimens"; ASTM, West Conshohocken, PA, USA.

- American Society for Testing and Materials. (1998). ASTM C143/C143M "Standard Test Method for Slump of Hydraulic Cement Concrete"; ASTM, West Conshohocken, PA, USA.

- American Society for Testing and Materials. (1998). ASTM C192/C192M "Standard Practice for Making and Curing Concrete Test Specimens in the Laboratory"; ASTM, West Conshohocken, PA, USA.

- American Society for Testing and Materials. (1999). ASTM C403/C403M "Standard Test Method for Time of Setting of Concrete Mixtures by Penetration Resistance"; ASTM, West Conshohocken, PA, USA.

- American Society for Testing and Materials. (1999). ASTM C494/C494M-99a Standard Specification for Chemical Admixtures for Concrete"; ASTM, West Conshohocken, PA, USA.

- American Society for Testing and Materials. (1999). ASTM C618 "Standard Specification for Coal Fly Ash and Raw or Calcined Natural Pozzolan for Use as a Mineral Admixture in Concrete"; ASTM, West Conshohocken, PA, USA.

- American Society for Testing and Materials. (1998). ASTM C672/C672M "Standard Test Method for Scaling Resistance of Concrete Surfaces Exposed to Deicing Chemicals"; ASTM, West Conshohocken, PA, USA.

- American Society for Testing and Materials. (1997). ASTM C1202 "Standard Test Method for Electrical Indication of Concrete's Ability to Resist Chloride Ion Penetration"; ASTM, West Conshohocken, PA, USA.

- Aitcin, P.C, Mehta, P.K., 1990, "Principles Underlying the Production of HighPerformance Concrete." Cement, Concrete and Aggregates Journal 12(2), pp. 70-78.

- Adams, T. H., 1988, "Marketing of fly ash concrete", MSU seminar: Fly ash applications to concrete (January), 1.10, 5.10, East Lansing: Michigan State University.

- American Coal Ash Association, 1995, 'Fly Ash Facts for Highway Engineers', Federal Highway Administration, Report No. FHWA-SA- 94-081, Washington, DC, December.

- ACI Committee 211, 1993, 'Guide for Selecting Proportions for High Strength Concrete with Portland Cement and Fly ash', ACI 211, 4R-93, ACI Materials Journal, Vol.90, No. 3, pp. 272-283. 
- ASTM C595-92a., 1994, "Standard Specification For Blended Hydraulic Cement”, American Society for Testing and Materials, Annual book of ASTM Standars, Volume 04.02, West Conshohocken, Pennsylvania.

- ASTM C311-92, 1994, "Standard Methods of Sampling and Testing Fly Ash or Natural Pozzolans for Use as a Mineral Admixture in Portland Cement Concrete", American Society for Testing and Materials, Annual Book of ASTM Standards, Volume 04.02, West Conshohocken, Pennsylvania.

- Aitcin, P.C, Mehta, P.K., 1990, "Principles Underlying the Production of HighPerformance Concrete." Cement, Concrete and Aggregates Journal 12(2), pp. 70-78.

- ACI 211.4R-93,1996 "Guide for Selecting Properties for High-Strength Concrete with Portland Cement and Fly Ash", ACI Manual of Concrete Practice, Part 1, American Concrete Institute, Detroit, Michigan.

- Atis C. D., 2003, 'Accelerated carbonation and testing of concrete made with fly ash', Construction and Building Materials, Vol. 17, pp.147-152.

- ACI (2010) http://www.concrete.org/flyash/flyash.htm; 38800 Country Club Dr. Farmington Hills, MI 48331 USA

- Aitcin, P. C. (2003) ; "The Art and Science Durable High Performance Concrete"; Proceedings of the Nelu Spiratos Symposium: Committee for Orgnization of CANMET/ACI Conferences; pp. 69-88

- Atis, C. D. (2003); “ High Volume Fly Ash Concrete with High Strength and Low Drying Shrinkage"; Journal of Materials in Civil Engineering; Vol. 15; No. 2; pp. 153-156

- ASTM C 1202 (2010) 'Standard test method for electrical indication of concrete's ability to resist chloride ion penetration', Annual Book of American Society for Testing Materials Standards, Vol. C04.02.

- Alonso, S., Palomo A. Calorimetric study of alkaline activation of calcium hydroxidemetakaolin solid mixtures. Cement and Concrete Research 2001;31:25-30.

- Berry, E.E., and Malhotra, V.M. (1986). "Fly Ash in Concrete". Energy, Mines and Resources Canada, CANMET, Ottawa, Canada.

- Bilodeau, A., Malhotra, V.M., and Seabrook, P.T. (2001). "Use of High - Volume Fly Ash Concrete at the Liu Centre”. Materials Technology Laboratory. January 2001.

- Bilodeau, A., Zhang, M.H., Malhotra, V.M., and Golden, D.M. (1998). "Effects of Curing Methods and Conditions on the Performance of Fly Ash Concrete in De-Icing Salt Scaling". Proceedings, 6th International Conference on Fly Ash, Silica Fume, Slag and Natural Pozzolans in Concrete, ACI SP - 178-20, pp. 361-384, Bangkok, Thailand.

- Bremner, T.W., and Thomas, M.D.A. (2004). "Learning Module on Traditional and NonTraditional Uses of Coal Combustion Products (CCP)".

- Bhanumathidas N. and Kalidas N., Sept-Oct, 2002, 'Prevention is better than cure Concrete is no exception', Master Builder Vol. 4, No. 4.

- Bhattacharjee, U., Kandpal T.C., 2002, 'Potential of fly ash utilization in India', Energy Vol.27,pp.151-166.

- Bilodeau, A., and Malhotra, V. M. (2000) ; "High Volume Fly Ash System: Concrete Solution for Sustainable Development" ACI Materials Journal; Vol. 97; No. 1

- Buchwald A, Kaps C, Hohmann M. Alkali-activated binders and pozzolan cement binders - compete reaction or two sides of the same story? In: Proceedings of the 11th international congress on the chemistry of cement (ICC); 2003. p. 1238-46. 
- Canadian Standards Association (2003). CSA A23.1 - 04, Clause 8.8, "Concrete Made with a High volume of Supplementary Cementing Materials (HVSCM)”, pp. 96-98, 100117, 183-186.

- Cement Association of Canada (2003). "Plastic Shrinkage Cracking". www.cement.ca

- Cement Association of Canada (2005). "Concrete Thinking for a Sustainable Future: Concrete and LEED Canada - New Construction (NC) 1.0”. www.cement.ca, January 13, 2005.

- Crouch, L. K., Hewiit, R., and Byard, B. (2007); "High Volume Fly Ash Concrete"; World of Coal Ash; Tennessee Technological University, Cookeville, TN 38505

- Contenson, H., and Courtois, L. "A propos des vases de chaux". Recherches sur leur fabrication et leur origine. Paleorient 1979;5:177-82.

- Campbell DH, Folk RL. The ancient Egyptian pyramids-concrete or rock. Concrete International

- Criado M, Palomo A, Fernandez-Jimenez A. Alkali activation of fly ashes. Part 1: Effect of curing conditions on the carbonation of the reaction products. Fuel 2005;84:2048-54.

- Chindaprasirt P, Chareerat T, Siricicatnanon V (2007). Workability and strength of coarse high calcium fly ash Geopolymer. Cement and Concrete Composites., 29: 224229.

- Chanh NV, Trung BD, Tuan DV (2008). Recent research Geopolymer concrete. The 3rd ACF International Conference $-\mathrm{ACF} / \mathrm{VCA}$.

- Davis, R.E. (1954). "Pozzolanic materials - with special reference to their use in concrete pipe”. Technical Memo, American Concrete Pipe Association.

- Davis, R,E., R. W. Carlson, J. W. Kelly, and A. G. Davis, 'Properties of cements and concretes containing fly ash', Proceedings, American Concrete Institute 33: pp.577-612.

- De Spot, M. (2003). "The EcoSmart Concrete Project". Presented at the USGBC (United States Green Building Council) Greenbuild conference, Pittsburgh, November 12 - 14, 2003.

- Dhir, R.K. (1989). "Near - Surface Characteristics of Concrete: Prediction of Carbonation Resistance”. Magazine Concrete Research, 1989, 41, No. 148, pp. 137 143.

- Dunn, S. (2001); "Decarbonizing the Energy Economy"; State of the world 2001: A Worldwatch Institute Report on Progress Toward a Sustainable Society; W. W. Norton and Company; pp. 83-102

- Duxson, P., Fernandez-Jimenez, A., Provis, J., Lukey, G., Palomo, A., and Deventer, J. V. (2007); "Geopolymer Concrete with Fly Ash"; Journal Materials Science; Vol. 42; pp. 2917-2933

- Davidovits, J., Courtois L. D.T.A. "Recognition of intra-ceramic Geopolymeric setting in archaeological ceramics and mortars". 21st symposium on archaeometry; 1981. p. 22.

- Davidovits J. Synthesis of new high temperature geo-polymers for reinforced plastics/composites. SPE PACTEC 79 Society of Plastic Engineers, Brookfield Center; 1979. p. 151-4.

- Davidovits J. Ancient and modern concretes: what is the real difference? Concrete International 1987;12:23-5. 
- Davidovits J. Properties of Geopolymers cements. In: Proceedings of the first international conference on alkaline cements and concretes. Kiev, Ukraine: Scientific Research Institute on Binders and Materials; 1994. p. 131-49.

- Davidovits J. Geopolymers: man-made rock geosynthesis and the resulting development of very early high strength cement. Journal Material Education 1994;16:91-139.

- Davidovits J. Geopolymer chemistry and sustainable development. The poly(sialate) terminology: a very useful and simple model for the promotion and understanding of green-chemistry. In: Proceedings of 2005 Geopolymer conference, vol. 1; 2005. p. 9-15.

- Davidovits F. Les Mortiers des pouzzolanes artificielles chez vitruve, evolution historique architecturale. The'se de DEA, Les Cultures des de l' Antiquite' Classique, Universite' Paris X; 1993.

- Davidovits J. Geopolymer chemistry and properties. In: Proceedings of 1988 Geopolymer conference, vol. 1; 1988. p. 25-48.

- Deventer, J. S. J., Provis, J.L., Duxon, P., Lukey, G.C. Reaction mechanismsin the Geopolymeric conversion of inorganic waste to useful products.J Hazard Mater 2007; A139: 506-13.

- Dichtheit von Heißwasser-Langzeitspeichern aus Hochleistungsbeton, Schriftenreihe des IWB, Stuttgart 2001/1, ISBN 3-9805102-3-9

- Estakhri, C.K., and Saylak, D. (2004). "Potential for Reduced Greenhouse Gas Emissions in Texas Through the Use of High Volume Fly Ash Concrete". Transportation Research Board. November 15, 2004.

- EPA Toxicity Characteristic Leaching Procedure 1311

- Fan, A. M., and Alexeeff, G. V. (2001); "Public Health Goal for Nickel In Drinking Water"; Office of Environmental Health and Hazard Assessment; California Environmental Protection Agency

- Ferreira, R. M., Tests for evaluation of concrete durability. Master thesis, University of Minho; 2000 (only in Portuguese).

- Fernandez-Jimenez A, Palomo A, Criado M. Microstructure development of alkaliactivated fly ash cement: a descriptive model. Cement Concrete Research 2004.

- Feret, R., "Slags for the manufacture of cement". Revolutionary Material for Construction. 1939.

- Gebauer, J. (1982). "Some observations on the carbonation of fly ash concrete". Silicates Industriel, 1982, No. 6, pp. 155-159.

- Gillies, V. (2001). "The EcoSmart Concrete Project: Results from the Case Studies". Report prepared by Veronica Gillies of Busby and Associates Architects for the EcoSmart Concrete Project Steering committee. July 2001.

- Green Resource Center (2004); "high Volume Fly Ash Concrete"; http://www.greenresourcecenter.org/MaterialSheetsWord/FlyAshConcrete.pdf

- Gjorv, O. E., "Steel corrosion in concrete structures exposed to Norwegian marine environment". ACI Concrete International 1994:35-9.

- Glukhovsky, V.D., Soil silicates. Kiev, USSR: Gostroiizdat Publish; 1959.

- Granizo ML. Activation alcalina de metacaolin: desarrolllo de nuevos materials cementantes. PhD thesis, University Autonoma of Madrid, 1998 (only in Spanish). 
- Glukhovsky VD, Rostovskaja GS, Rumyna GV. High strength slag alkaline cements. In: Proceedings of the seventh international congress on the chemistry of cement, vol. 3; 1980. p. 164-8.

- Glukhovsky VD. Slag-alkali concretes produced from fine-grained aggregate. Kiev: Vishcha Shkolay; 1981.

- Ho, D.W.S., and Lewis, R.K. "Carbonation of Concrete and its Prediction". Cement Concrete Research, 1987, 17, No. 3, pp. 489 - 504.

- Hobbs, D.W. (1983). "Influence of Fly Ash on the Workability and Early Strength of Concrete". Proceedings, 1st International Conference on the Use of Fly Ash, Silica Fume, Slag and other Mineral By-Products in Concrete. ACI SP - 79, pp. 289-306, Detroit, Michigan.

- Hobbs D.W. (1988). "Carbonation of Concrete Containing PFA". Magazine Concrete Research, 1988, 40, No. 143, pp. 69 - 78.

- Halstead, Woodrow J., 1986, "Use of Fly Ash in Concrete", National Cooperative Highway Research Program Synthesis of Highway Practice No. 127, Transportation Research Board, Washington, DC.

- Helmuth, R. 1987, "Fly ash in cement and concrete", Skokie, III: Portland Cement Association.

- Hawkens, P., Lovins, E., and Lovins, H. (1999) ; Natural Capitalism: Creating the Next Industrial Revolution; Little Brown and Company; pp. 1-369

- Haque, M., Langan, B., and Ward, M. (1984); "High Volume Fly Ash Concrete" ACI Materials Journal; pp.54-60

- Hill, R., and Folliard, K. (2006); “ The Impact of Fly Ash on Air Entrained Concrete”; Bridge View; Vol. 43; pp. 5-6

- Joshi, R.C., and Lohtia, R.P. (1997). "Fly Ash in Concrete - Production, Properties and Uses". Advances in Concrete Technology Volume 2. Gordon and Breach Science Publishers, Printed in India.

- Jerath S. and Hanson N., 2007, 'Effect of fly ash content and aggregate gradation on the durability of concrete pavements', Journal of Materials in Civil Engineering, Vol.19, No.5, pp.367-375.

- Jaarsveld JGS, Deventer JSJ, Lorenzen L. Factors affecting the immobilisation of metals in Geopolymerised fly ash. Metall Mater Trans B 1998;29B:283-91.

- Jaarsveld JGS, Deventer J. The effect of the alkali metal activator on the properties of fly-ash based Geopolymers. Industrial Engineering Research 1999;38:3932-41.

- Jaarsveld JGS, Deventer JSJ, Lukey GC. The effect of composition and temperature on the properties of fly ash and kaolinite based Geopolymers. Chemical Engineering Journal 2002;89:63-73.

- Kohubu, M. 1969, "Fly ash and fly ash cement", Proceedings, Fifth international symposium on the chemistry of cement, Part IV, 75-105. Tokyo: Cement Association of Japan.

- Kumar B., Tike G.K. and Nanda P.K., 2007, 'Evaluation of properties of high volume fly ash concrete for pavements', Journal of Materials in Civil Engineering, Vol.19, No. 10, pp. 906-911. 
- Krauss, P. D., and Rogalla. E. A. (1996) ;'Transverse Cracking in Newly Constructed Bridge Deck"; National Cooperative Highway Research Project 380; Transportation Research Board, Washington D C, USA; pp. 1-126

- Krizan Darko, Zivanovic Branislav. Effects of dosage and modulus of water glass on early hydration of alkali-slag cements. Cement and Concrete Research 2002;32:1181-8.

- Kong DLY, Sanjayan JG (2008). Damage behavior of Geopolymer composites exposed to elevated temperature. Cement and Concrete Composites., 30: 986-991.

- Kong DLY, Sanjayan JG (2010). Effect of elevated temperatures Geopolymer paste, mortar and concrete. Cement and Concrete Research., 40; 334-339.

- Komljenovi'c M, Bascarevic Z, Bradic V (2010). Mechanical and microstructural properties of alkali-activated fly ash Geopolymer. J. Hazardous Matter., 181: 35-42.

- Langley, W.S., and Leaman, G.H. (1998). "Practical Uses for High volume Fly Ash Concrete Utilizing a Low Calcium Fly Ash". Proceedings, 6th International Conference on Fly Ash, Silica Fume, Slag and Natural Pozzolans in Concrete, ACI SP - 178-30, pp. 545-574, Bangkok, Thailand.

- Lewandowski, R. (1983). "Effect of Different Fly-Ash Qualities and Quantities on the Properties of Concrete". Betonwerk and Fetigteil - Technik, 1983, Nos 1 -3.

- Langton, C. A., and Roy, D. M., "Longevity of borehole and shaft sealing materials: characterization of ancient cement-based building materials". Science and Basis of Nuclear Waste Management 1984; Vol. 26 pp. 543-549.

- Lee WKW, Deventer JSJ. The effect of ionic contaminants on the early-age properties of alkali-activated fly ash-based cements. Cement and Concrete Research 2002;32:577-84.

- Lodeiro G, Palomo A, Jiménez F (2007). Alkali-aggregate reaction in activated fly ash system. Cement and Concrete Research., 37: 175-183.

- Malhotra, V.M., and Mehta, P.K. (2002). "High - Performance, High - Volume Fly Ash Concrete". Supplementary Cementing Materials for Sustainable Development Inc., Ottawa, Canada.

- Malhotra, V.M., and Ramezanianpour, A.A. (1994). "Fly Ash in Concrete, Second Edition". Natural Resources Canada, Ottawa, Ontario, CANMET - Canadian Centre for Mineral and Energy Technology.

- Manmohan, D., and Mehta, P.K. (1981). "Influence of Pozzolzinc, Slag, and Chemical Admixtures on Pore Size Distribution and Permeability of Hardened Cement Pastes". Cement, Concrete, and Aggregates, V. 3, No. 1, pp. 63-67.

- Matthews, J.D. (1984). "Carbonation of Ten-Year Old Concretes With and Without PFA". Procedings 2nd International Conference on Fly Ash Technology and Marketing. London, 1984, Ash Marketing, CEGB, 398A.

- Mehta, P.K. (1999). "Concrete Technology for Sustainable Development". Concrete International, V. 21, No, 11, November 1999, pp. 47-53.

- Mehta,P.K., and R.W.Burrows, 2001, "Building Durable Structures in the 21st Century." Concrete International 23(3), pp. 57-63.

- Mehta, P.K. and Gjorv O. E., 1982, ' Properties of Portland Cement Concrete containing Fly ash and Condensed Silica Fume', Cement and concrete Research Journal, Vol. 12, No. 5, pp.587-595. 
- Mehta, P.K. (2004). "High - Performance, High - Volume Fly Ash Concrete for Sustainable Development". Proceedings, International Workshop on Sustainable Development and Concrete Technology, Beijing, May 20-21, 2004.

- Mehta, P.K., 1999, 'Concrete Technology for sustainable development', Concrete International 21 (11), pp. 47-52.

- Mindess, S., Young, J.F., and Darwin, D. (2003). "Concrete, Second Edition”. Prentice Hall, Pearson Education, Inc., Upper Saddle River, NJ.

- Malhotra, V. M., May 1999, 'Making Concrete Greener with Fly Ash', Concrete International, Vol. 21, No. 5, pp.61-66. ISSN: 0975-5462 4476

- Malhotra, V.M., 1986, 'Superplasticised Fly ash Concrete for Structural Applications', Concrete International, Vol. 8, No. 12 pp. 28-31.

- Malhotra V.M. and A.A. Ramezanianpour, 1994, "Fly Ash In Concrete", published by Canadian Centre for mineral and energy technology (CANMET).

- Mehta, P. K. 1983, "Pozzolanic and cementitious by-products as mineral admixtures for concrete: A practical review", ACI special publication SP-79: The use of fly ash, silica fume, slag and other mineral by-products in concrete, ed. V. M. Malhotra, 1-46. Detroit: American Concrete Institute.

- Mehta, P. K.,2001, 'Reducing the Environmental Impact of Concrete', Concrete International Journal, October, 2001,pp.61-66

- Malhotra, V.M., and P.K. Mehta, 2002, 'High-Performance, High volume Fly Ash Concrete', Supplementary Cementing Materials for Sustainable Development, Inc., Ottawa, Canada, 101 pp.

- Mullick, A.K.,2006, 'High Performance Concrete for Bridges and Highway Pavements', Proceedings of National Conference on Advances in Bridge Engineering, pp.51-63.

- Mehta, P. K., 2004, 'High -Performance, High-Volume Fly Ash Concrete for Sustainable Development', International Workshop on Sustainable Development and concrete Technology.

- Mehta, P. K. (2005); “ High-Performance, High volume Fly ash Concrete for Sustainable Development"; International Workshop on Sustainable Development and Concrete Technology; University of California, Berkley, USA; pp. 3-14

- Mehta, P. K. (1999); "Concrete Technology for Sustainable Development"; Concrete International; Vol. 21; No. 11; pp. 47-52

- Mehta, P. K. (1997); "Durability: Critical Issues for Future"; Concrete International; Vol. 19; No. 7; pp. 69-76

- Mehta, P. K., and Burrows. R. W. (2001); "Building Durable Structures in $21^{\text {st }}$ Century" ; Concrete International; Vol. 23; No. 3; pp. 57-63

- Mindess, S., Young, J. F., and Darwin, D. (2002) ; Concrete: $2^{\text {nd }}$ Edition; Pearson Education, Upper saddle River, NJ 07458; pp. 106-111

- Mehta, P. K., Concrete in marine environment. New York, USA: Elsevier Science Publishers; 1991.

- Malinowsky, R. "Concretes and mortars in ancient aqueducts". Concrete International 1979;1:66-76.

- Nagataki, S. (Malhotra, V.M. (Ed.)) (1986). "Effect of Curing Conditions on the Carbonation of Concrete with Fly Ash and the Corrosion of Reinforcement in Long Term 
Tests". Fly Ash, Silica Fume, Slag and Natural Pozzolanas in Concrete. ACI - SP91, Vol. 1, American Concrete Institute, Detroit, 1986, pp. 521 - 540.

- Naik, T. R. and Ramme B.W. 1989, 'High Strength Concrete containing large quantity of fly ash', ACI Material Journal, Vol.86, No.2, pp.111-116.

- Neville AM. Properties of concrete. Fourth and final edition; 1997.

- Naik H.K., Mishra M. K. and Behera B., 2007, 'Laboratory Investigations and characterization of some coal combustion byproducts for effective utilization', Ist International conference on "Managing the social and Environmental consequences of coal mining in India."

- Obla, K., Hill, R., and Martin, R. (2003)) "HVFA Concrete - An Industry Perspective "; Concrete International; Vol. 25; No. 8; pp. 29-34

- Olanrewaju, S., Tempest, B., Ogunro, V., Gergely, J., and Daniel, J. (2009); "Effect of Hydroxyl Ion on Immobilization of Oxy-anions Forming Trace Elements from Fly Ash Based Geopolymer Concrete"; World of Coal Ash; University of Kentucky, Lexington, KY

- Papadakis, V.G., Vayenas, C.G., and Fardis, M.N. (1991). "Fundamental Modeling and Experimental Investigation of Concrete Carbonation". ACI Materials Journal, V. 88, No. 4, July - August 1991.

- Parrott, L.J. (1987). "A Review of Carbonation in Reinforced Concrete". A review carried out by CandCA under a Building Research Establishment contract. July 1987.

- Prasad, P.V. S. and Jha, K., 'High Performance Concrete', Project work for Course No. 624- Sr. Professional Course (Bridges and General), IRICEN, Pune.

- Purdon, A.O., "The action of alkalis on blast furnace slag". Journal of Society of Chemical Industry 1940; pp. 59:191-202.

- Perinet, G., Contenson, H., and Courtois, L., "Etude mineralogique de vaisselles blanches de Ras-Shamra et Tell Ramad (Syrie)". Comptes Rendus Academy of Science 1980:143144 (Paris).

- Pinto, A. T., Alkali-activated metakaolin based binders. PhD thesis, University of Minho; 2004 (only in Portuguese).

- Palomo A, Grutzek MW, Blanco MT. Alkali-activated fly ashes. A cement for the future. Cement and Concrete Research 1999;29:1323-9.

- Palomo A, Alonso S, Fernandez Jimenez A, Sobrados I, Sanz J. Alkaline activation on fly ashes. A Si NMR study of the reaction products. Journal of American Ceramic Society 2004;87:1141-5.

- Provis, J. L., Deventer, J. S. J. Geopolymerisation kinetics. 1. In situ energydispersive Xray diffractometry. Chemical Engineering Science 2007;62:2309-17.

- Provis, J. L., Deventer, J. S. J., Geopolymerisation kinetics in situ energy dispersive Xray diffractometry. Chemical Engineering Science 2007;62:2318-29.(43)

- Provis, J. L., Duxon, P., Deventer, J. S. J., Lukey, G. C., "The role of mathematical modeling and gel chemistry in advancing Geopolymer technology." Chemical Engineering Research and Design 2005; 83:853-60.

- Roberts, M.H. (1981). "Carbonation of Concrete Made with Dense Natural Aggregates". Building Research Establishment Information Paper, April 1981.

- Report No. T(S) 006, January, 2005, 'Use of higher volume fly ash in concrete for building sector', CBRI, Roorkee. 
- Raju, N. K., Ipe, T. V. and Srinath, N., 1994, 'mix Proportioning and strength characteristics of portland cement and pulverized fly ash concrete', ICI Bulletin No. 49, pp.27-32.

- Raju. N.K., 1991, 'Production and Properties of High Strength Concrete Using Superplasticizers', National Seminar on High Strength Structural Concrete, 1991, Indian Concrete Institute, Banglore, pp. 11.32-11.53.

- Rao, B.K. and Kumar Vimal, 1996, 'Fly ash in high strength Concrete', Recent Advances in Civil Engineering, National Seminar, September 28, pp.115-121.

- Roy, D. M. Alkali-activated cements. Opportunities and challenges. Cement and Concrete Research 1999;29:249-54.

- Roy, D. M., and Langton, C. A., Studies of ancient concretes as analogs of cementituos sealing materials for repository in Tuff. LA-11527-MS, Los Alamos National Laboratory; 1989.

- Rangan, B. V. (2007) "Design, Properties, and Application of Low Calcium Fly Ash Based Geopolymer Concrete"; Developments in Porous, Biological, and Geopolymer Ceramics; pp. 347-361

- Siddique, R. (2004). "Performance Characteristics of High - Volume Class F Fly Ash Concrete". Cement and Concrete Research. 34, 2004, pp. 487 - 493.

- Smith, R.L., Raba, C.F., and Mearing, M.A. (1982). "Utilization of Class C Fly Ash in Concrete”. 6th International Fly Ash Utilization Symposium, Reno, Nev., Mar., p.31.

- Swamy, R.N., 1985, 'High Strength Concrete - Material Properties and Structural Behaviour', ACI SP - 87, High strength Concrete, American Concrete Institute, Detroit pp. 119-146.

- Siddique R.,2004, 'Performance characteristics of high volume class F fly ash concrete', Cement and Concrete Research, Vol. 34, pp.487-493.

- Sujjavanich S., Sida V. and Suwanvitaya P.,2005, 'Chloride permeability and corrosion risk of high volume fly ash concrete with midrange water reducer', ACI Materials Journal, Vol.102, No.3,pp. 243-247.

- Sengul O.,Tasdemir C. and Tasdemir M. A.,2005, 'Mechanical properties and rapid chloride permeability of concretes with Ground fly ash', ACI Materials Journal, Vol.102, No.6, pp.474-482.

- Shi Caijun, Day Robert. A calorimetric study of early hydration of alkali-slag cements. Cement and Concrete Research 1995;25:1333-46.

- Sathia R, Babu KG, Santhanam M (2008). Durability study of low calcium fly ash Geopolymer concrete. The 3rd ACF International Coference-ACF/VCA.

- Thomas, M.D.A., and Matthews, J.D. (1992). "Carbonation of Fly Ash Concrete". Magazine of Concrete Research, Vol. 44, No. 160, 1992, pp. 217-228.

- Thomas, M.D.A. (2003). "Use of High volume Fly Ash Concrete in Green Buildings". Proceedings, Annual Conference of the Canadian Society for Civil Engineering, Moncton, New Brunswick, Canada, June 4-7, 2003, pp. ENM - 301 - 1-8.

- Thomas, M.D.A. (2004). "The Effect of Curing and Concrete Quality on the Durability of Concrete with High volumes of Supplementary Cementing Materials". EcoSmart Curing Project Progress Report. March 15, 2004. 
- Tsukayama R. (1980). "Long Term Experiments on the Neutralization of Concrete Mixed with Fly Ash and the Corrosion of Reinforcement". Proceedings 7th International Congressional on the Chemistry of Cement. Paris, 1980, Vol. III, pp. $30-35$.

- Verma, S.,1997, 'Performance Evaluation of High strength Fly ash concrete paving mixes', M.E. Dissertation, Department of Civil Engineering, University of Roorkee, Roorkee, India.

- Vanita Aggarwal et. al. / International Journal of Engineering Science and Technology Vol. 2(9), 2010, 4473-4477

- Varas MJ, Buergo MA, Fort R. Natural cement as the percursor of Portland cement: methodology for its identification. Cement and Concrete Research 2005;35:2055-65.

- Vengata G. K.B., 2009, 'High volume fly ash concrete for pavements', M.E. Dissertation, Department of Civil Engineering, Anna University, Chennai, India.

- World Health Organization (1996); "Guidelines for drinking-water quality"; Health criteria and other supporting information: $2^{\text {nd }}$ Edition; Geneva; Vol. 2

- Xu Hua, Deventer JSJ, Jannie SJ. The effect of alkali metals on the formation of Geopolymeric gels from alkali-feldspars. Colloid Surface 2003;216:27-44.

- Yadava K.P., Tyagi B.S., Pandey K.K. and Singh V. N., January, 1987, 'Fly ash for the treatment of Cd(11) rich effluents', Environmental Technology Journal, Volume 8, Issue $1-12$, pp.225-234.

- Yazic H.,2008, 'The effect of silica fume and high volume class $\mathrm{C}$ fly ash on mechanical properties, chloride penetration and freeze thaw resistance of self-compacting concrete', Construction and building Materials, Vol.22, pp. 456-462.

- Zhang, M.H., Bilodeau, A., Shen, G., and Malhotra, V.M. (1998). "De-Icing Salt Scaling of Concrete Incorporating Different Types and percentages of Fly Ashes". Proceedings, 6th International Conference on Fly Ash, Silica Fume, Slag and Natural Pozzolans in Concrete, ACI SP - 178-28, pp. 493-525, Bangkok, Thailand. 